\title{
Characterization of microcellular plastics for weight reduction in automotive interior parts
}

\author{
Dissertation submitted by: \\ Dipl.-Ing. Javier Gómez Monterde \\ in conformity with the requirements for the degree of \\ Doctor in Materials Science and Engineering
}

Directors (UPC):

Dra. Maria Lluisa Maspoch Rulduà Dr. Miguel Ángel Sánchez Soto
Responsible (SEAT):

Dipl.-Ing. Manfred Schulte

Departament de Ciència dels Materials i Enginyeria Metal·lúrgica

December 2016 

"Real progress is that which puts technology within everyone's reach"

- Henry Ford 



\section{Acknowledgements}

The realization of this project has been possible thanks to the contribution of multitude of persons and institutions. Thus, it has been essential to have the participation of the Universitat Politècnica de Catalunya-BarcelonaTech in cooperation with SEAT under the frame of the Pilot Industrial Doctorate Plan, founded by the Generalitat de Catalunya. The involvement of the Centre Català del Plàstic, Volkswagen and Rücker Lypsa was also crucial for developing the work exposed in the present document.

I would like to start by acknowledging Prof. Dr. Maria Lluisa Maspoch and Jorge Barceló for giving me the opportunity to take part in this project. I would also like to extend special thanks to Prof. Dr. Miguel Sánchez, Ramón Docampo, Manfred Schulte, Stefan Ilijevic, Jörg Hain and Désirée Alcázar for managing this project throughout these three years and encouraging me to keep going. These few words are not enough at all for their efforts made and their valuable advice given over this period.

Most of the experimental work of this thesis has been conducted in the facilities of the Centre Català del Plàstic, so the following words of gratitude are addressed to its entire staff and everybody who, at some time, has gone through there: Dr. Antonio Martínez, Dr. Edgar Franco, Dr. David Arencón, Dr. Jonathan Cailloux, Dr. José Ignacio Velasco, Dr. Liang Wang, Dr. Marcelo Antunes, Dr. Orlando Santana, Dra. Silvia Illescas, Dra. Vera Realinho, Dr. Tobias Abt, Alba Giménez, Anna Carreras, David Loaeza, Raja Hakim, Hooman Abbasi, Kian Habibi, Kiko Romo, María Navarro, Noel León, Pilar Castejón, Ramón Pérez, Susana Ortiz, Valentina Ratmiroff and Víctor Bernabé.

Likewise, I would like to express my appreciation to the personnel of the different departments in the Technical Center of SEAT (EK-3, EK-6 and EG-6) where some tasks of the project were developed, as well as the SEAT Laboratory facilities of the Tecnología de Materiales department (GQ-31), particularly to Blanca Grau, David Patiño, Noemí Rodriguez and Maria Dolores Delgado, for their active interest and their support with the X-Ray scans and aging analysis. And of course, many thanks to the rest of the $\mathrm{PhD}$ candidates of SEAT: Adrián Schiffer, Armand Rius, Carlos Viñolo, Daniel Dorribo, Jorge López, Lluc Canals, Miguel Ángel Galarza, Mireia Gilibert, Pablo Gamonal and Xavier Carod. All of them have contributed to make this a great and enjoyable experience. 
I am also very grateful to the staff of the Konzernforschung $(K-G E R W / K)$ department of Volkswagen, as well as Mr. Till Quabeck and his team in the Ostfalia Hochschule for their help and guidance with the injection molding experiments with IQ Foam ${ }^{\circledR}$ technology in the Institut für Recycling. I would also like to thank Mr. Winfried Kohl and the injection molding technicians of Covestro for their kind hospitality during our stay in Leverkusen and Köln.

It is also important for me to highlight the excellent work carried out by the technicians of the microscopy labs of the $U P C$, Isaac López and Josep Palou, taking pictures and giving me some helpful advice for a proper morphological study of the foamed parts. Additional thanks are given to Dr. Jaime Frigola and Eduardo Barriuso from the CORELAB laboratory of the Universitat de Barcelona, as well as to Dr. Wilco Verbeeten from the CENIEH facilities of the Universidad de Burgos, for their analysis through the Computed Tomography technique.

My gratitude is also extended to the staff of Aida and CoreTech for their support with the simulation experiments with Moldex $3 \mathrm{D} \AA$ software, as well as Borealis and Styron (currently Trinseo) for supplying the materials employed in this work, completely free of charge.

Finally, thanks to my family, parents, brother and sister, for their support always present and the confidence they have shown in me. I would like to make a special mention to Cristina Torre, for her continuous and unconditional support during this period and her immeasurable help with some pictures of this thesis.

Thank you very much!

Vielen Dank!

Moltes gràcies!

¡Muchas gracias a todos! 


\section{Abstract}

The present $\mathrm{PhD}$ thesis is framed within the Industrial Doctorate Plan promoted by the Generalitat de Catalunya and has been developed in cooperation between the Universitat Politècnica de Catalunya-BarcelonaTech, the Centre Català del Plàstic, SEAT SA and Volkswagen AG. The research project has as main objective the characterization of microcellular plastics obtained by injection molding, motivated by a concern to reduce weight, cost and carbon footprint in automotive plastic parts.

First, cylindrical bars and square plates made of Acrylonitrile-Butadiene-Styrene (ABS) and 20\% Glass Fiber reinforced-Polypropylene (PP 20GF) were injection molded and foamed through the MuCell@ technology. Shot volume was found as the most influencing parameter on cell structure and tensile and flexural properties. The effect of mold temperature and injection speed was secondary and not statistically significant for the mechanical performance. Tensile and flexural properties decreased almost linearly with the apparent density, whereas impact resistance was strongly reduced during foaming. Glass fibers contributed to partially overcome the loss of properties due to the reduction in density. Cells act as crack arrestors by blunting the crack tip. However, once the crack is propagating, cells acting as stress concentrators lead to a decrease in fracture toughness. Because of the low amount of blowing agent injected during the foaming process, no significant changes in the thermal properties were determined as compared to that of the solid counterpart.

Simulation of the microcellular injection molding process with Moldex 3D® software and prediction models of the mechanical properties based on the apparent density and morphological characteristics provided a good approach to the experimental results.

On the other hand, the Core Back tool technology was also employed in this study. By pulling the core and increasing the final thickness of the part, the apparent density decreased but the bending stiffness was greatly enhanced. Finally, a new alternative foaming technology, called IQ Foam ${ }^{\circledR}$ and developed by Volkswagen AG, was used to produce rectangular plates and compare their properties to that of the obtained by MuCell@ process. By using a minimum amount of blowing agent, foamed plastic parts through IQ Foam ${ }^{\circledR}$ obtained through this process exhibited thicker solid skins and lower cell densities, but consequently higher mechanical properties. Additional benefits such as cost-effectiveness, easy-to-use and machine-independence are also offered by this new emerging technology. 


\section{Resumen}

La presente tesis doctoral se enmarca dentro del Plan de Doctorats Industrials convocado por la Generalitat de Catalunya y se ha desarrollado como colaboración entre la Universitat Politècnica de Catalunya-BarcelonaTech, el Centre Català del Plàstic, SEAT SA y Volkswagen AG. El proyecto de investigación tiene como principal objetivo la caracterización de plásticos microcelulares, motivado por el interés en reducir peso, coste e impacto ambiental en piezas de plástico de automoción.

En primer lugar, se obtuvieron mediante moldeo por inyección barras cilíndricas y placas cuadradas fabricadas con Acrilonitrilo-Butadieno-Estireno (ABS) y Polipropileno reforzado con un $20 \%$ de fibra de vidrio (PP 20GF), espumadas con la tecnología MuCell®. El volumen de dosificación es el parámetro más influyente sobre la estructura celular y las propiedades a tracción y a flexión. El efecto de la temperatura de molde y velocidad de inyección, en cambio, es secundario y no introduce variaciones estadísticamente significativas sobre el rendimiento mecánico.

Las propiedades a tracción y flexión se reducen de manera prácticamente lineal con la disminución de densidad, mientras que la resistencia a impacto decrece drásticamente debido a la espumación. El efecto reforzante de las fibras de vidrio contribuye a compensar parcialmente la caída de propiedades debido a la reducción de densidad. Las celdas tienden a enromar el frente de grieta, retrasando así el inicio de propagación. Sin embargo, una vez la grieta comienza a propagar, las celdas actúan como concentradores de tensión provocando una disminución en la tenacidad a fractura. El reducido contenido de agente espumante inyectado durante el proceso de espumación no es suficiente para producir cambios en las propiedades térmicas en comparación con las del material macizo.

La simulación del proceso de inyección microcelular con el software Moldex 3D® y los modelos de predicción de propiedades mecánicas basados en la densidad y características morfológicas proporcionaron valores cercanos a los obtenidos experimentalmente.

Por otro lado, en este trabajo también se estudió el efecto de la tecnología de molde Core Back en combinación con el proceso de espumado mediante moldeo por inyección. A través del movimiento de la cavidad y el aumento del espesor final de la pieza inyectada, la densidad aparente se reduce al mismo tiempo que la rigidez a flexión se incrementa 
considerablemente. Finalmente, una nueva tecnología de espumación desarrollada por Volkswagen AG, llamada IQ Foam ${ }^{\circledR}$, se utilizó para la inyección de placas rectangulares y la comparación de sus propiedades con las de placas análogas obtenidas mediante el proceso MuCell®. Mediante la utilización de un contenido mínimo de agente espumante, las placas espumadas con IQ Foam ${ }^{\circledR}$ exhibieron mayores espesores de piel y menores densidades celulares, y por tanto, propiedades mecánicas ligeramente superiores. Esta nueva tecnología ofrece también otras ventajas, como una menor inversión inicial, facilidad de operación y posibilidad de utilización en cualquier máquina de inyección convencional. 


\section{Table of Contents}

Acknowledgements i

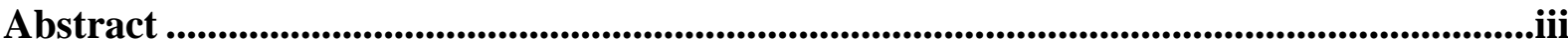

Resumen .. V

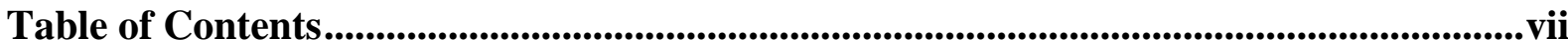

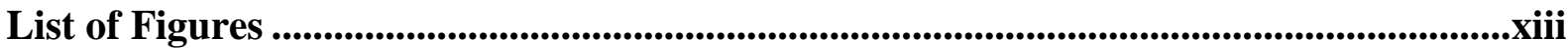

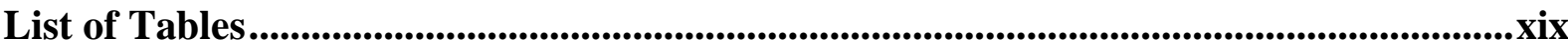

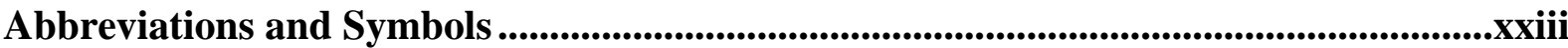

Chapter 1: Introduction ................................................................................................................................ - 1 -

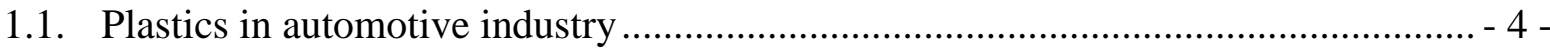

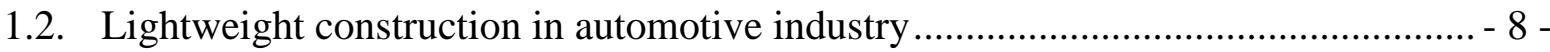

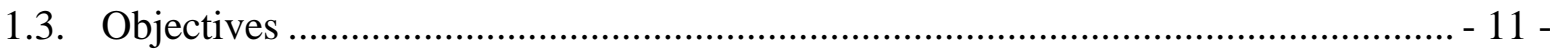

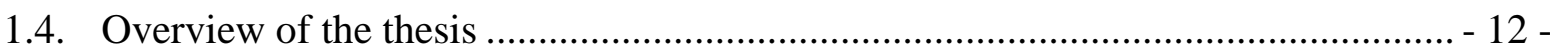

Chapter 2: Theoretical aspects........................................................................................... 13 -

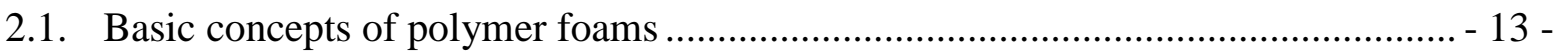

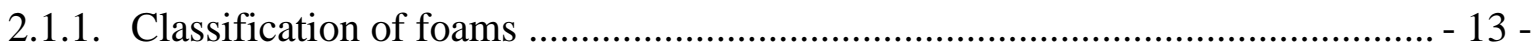

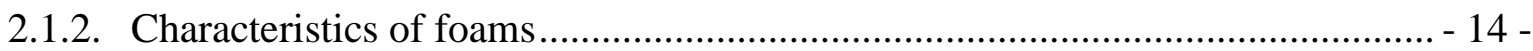

2.1.3. Properties of polymer foams ................................................................... 16 -

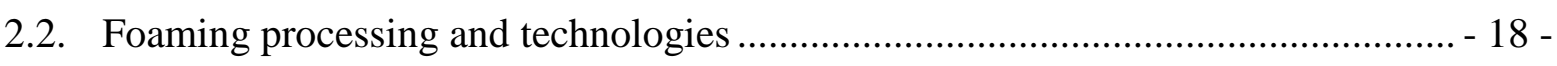

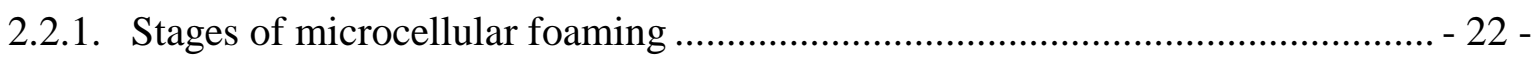

2.2.1.1. Gas dissolution ................................................................................... - 22 -

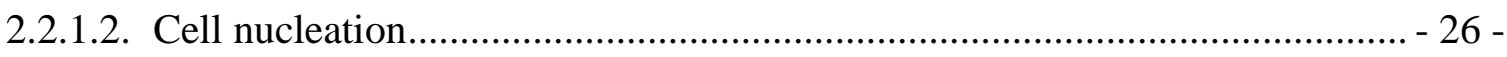

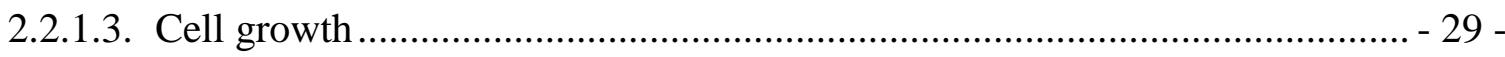


2.2.1.4. Foam stabilization and shaping in the mold ............................................... -31 -

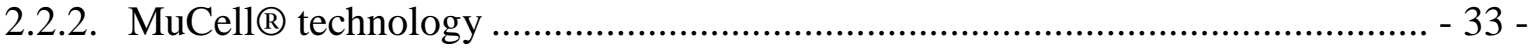

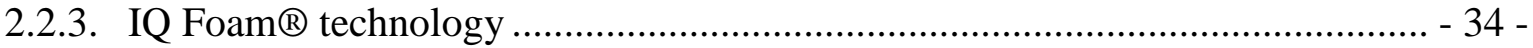

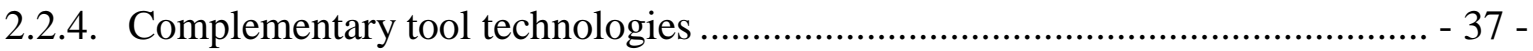

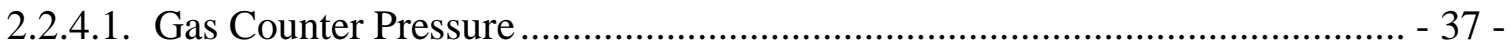

2.2.4.2. Rapid Heating Cycle Molding ....................................................................... - 37 -

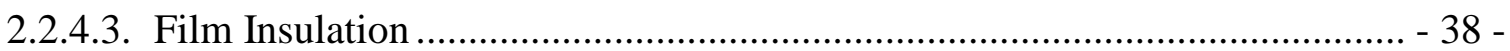

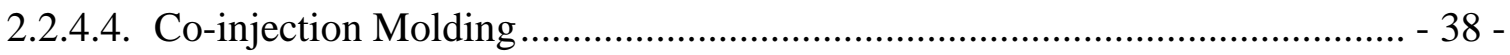

2.2.4.5. Core Back Expansion Molding ................................................................. - 38 -

2.3. State of the art of polymer foaming................................................................. -39 -

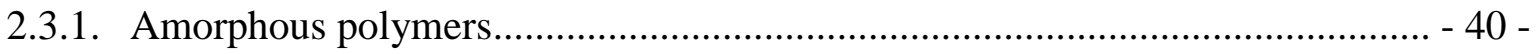

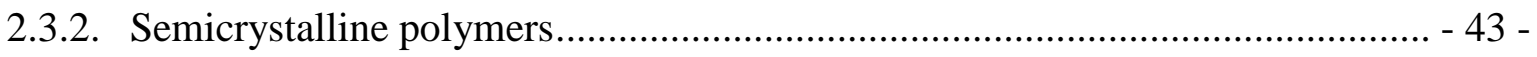

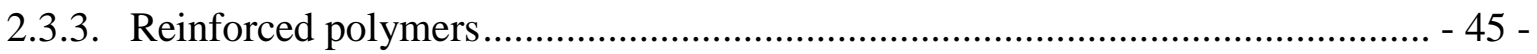

Chapter 3: Materials and methods ........................................................................... - 51 -

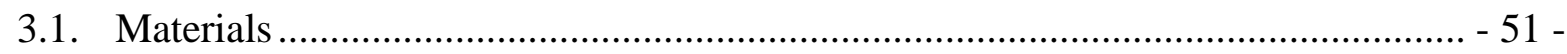

3.1.1. Acrylonitrile-Butadiene-Styrene (ABS) ...................................................... - 51 -

3.1.2. Glass fiber reinforced Polypropylene (PP 20GF) ........................................... - 52 -

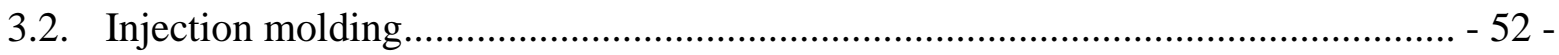

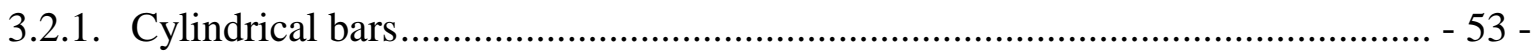

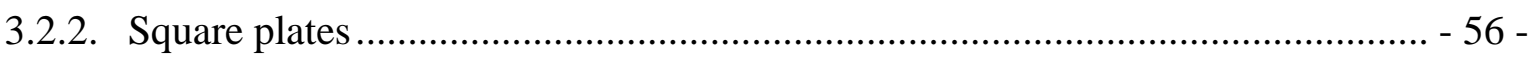

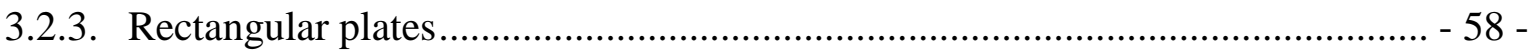

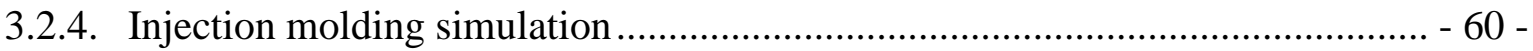

3.3. Apparent density and morphological characterization ....................................... - 60 -

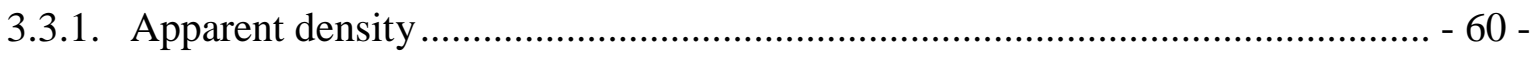

3.3.2. Scanning Electron Microscopy (SEM) ....................................................... - 61 -

3.3.3. X-Ray and Computed Tomography (CT) .................................................. - 63 - 


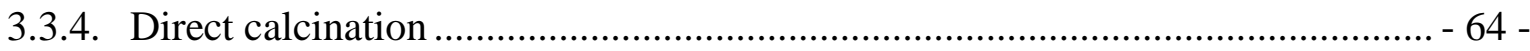

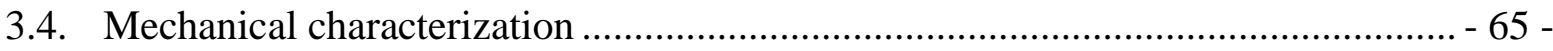

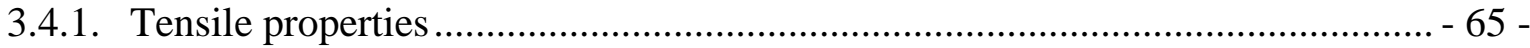

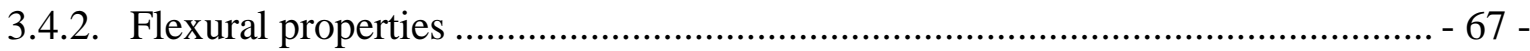

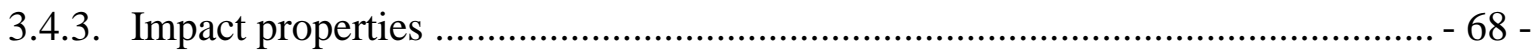

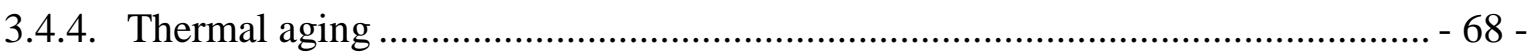

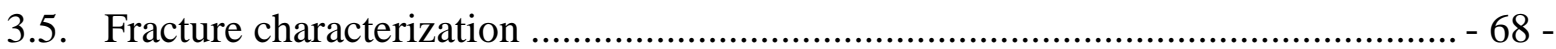

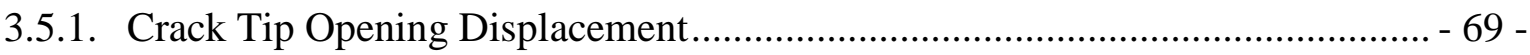

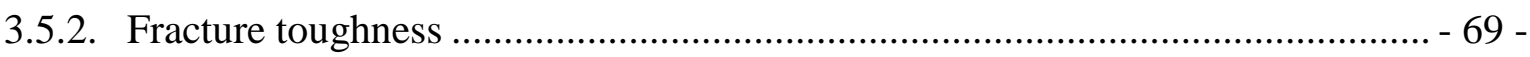

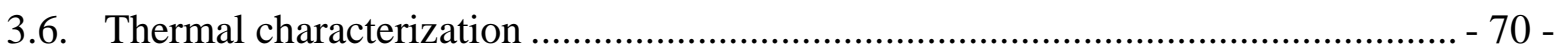

3.6.1. Differential Scanning Calorimetry ........................................................... - 71 -

3.6.2. Heat Deflection Temperature .................................................................... -71 -

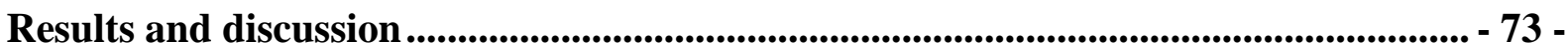

Chapter 4: ABS - MuCell ${ }^{\circledR}$ foams .......................................................................... - 75 -

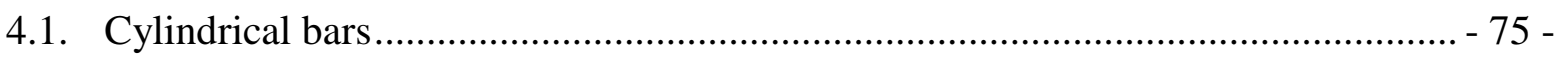

4.1.1. Design of Experiments: Effect of processing conditions ................................ - 76 -

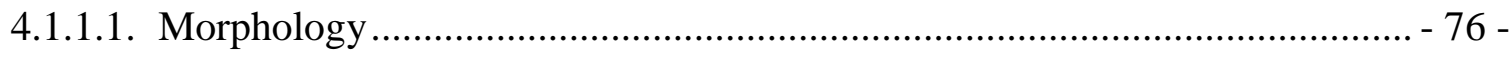

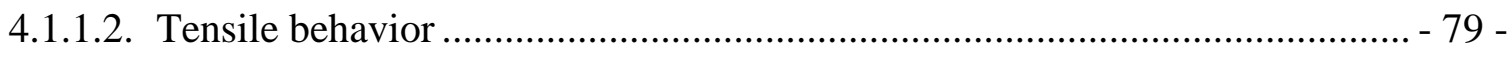

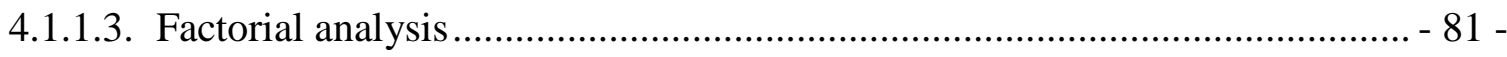

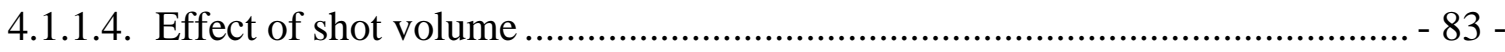

4.1.1.5. Effect of mold temperature …............................................................. 85 -

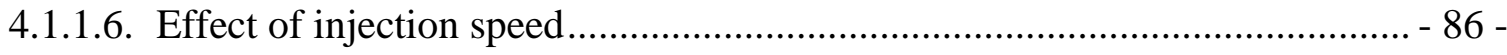

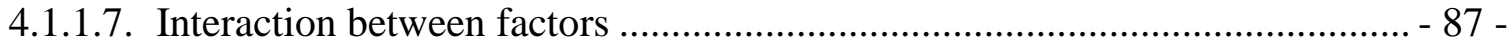

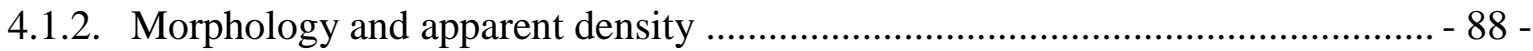

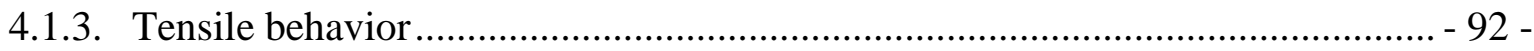

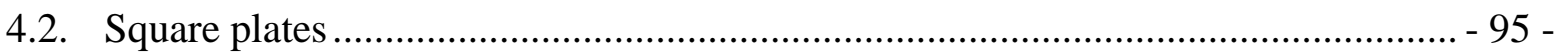




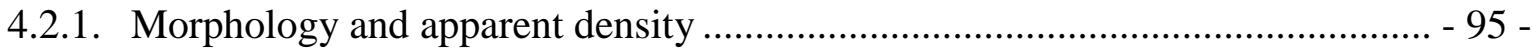

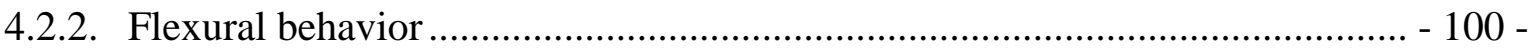

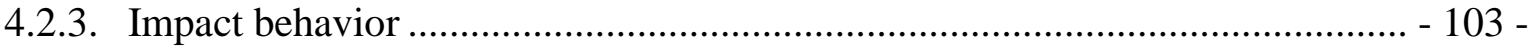

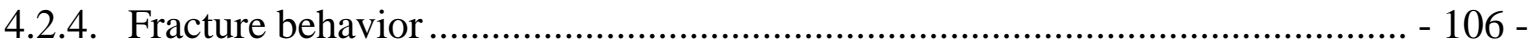

4.2.4.1. Crack Tip Opening Displacement CTOD ................................................. - 106 -

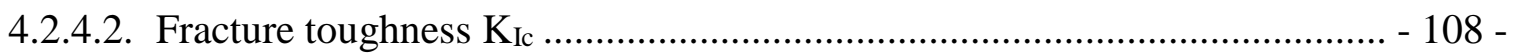

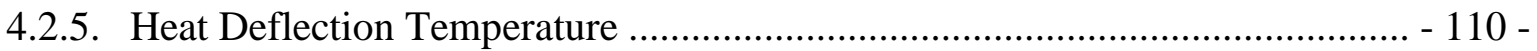

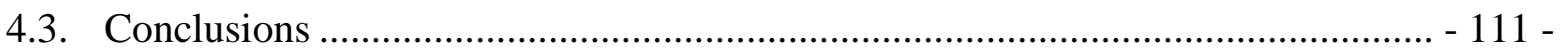

Chapter 5: PP 20GF - MuCell囚 foams............................................................................ - 113 -

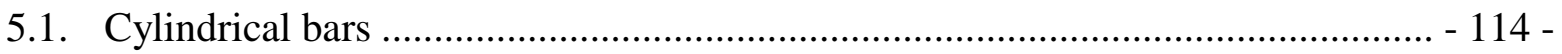

5.1.1. Morphology and apparent density ............................................................ - 114 -

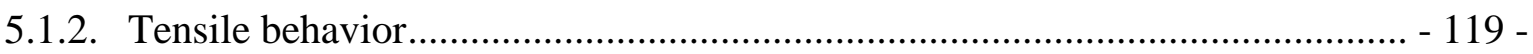

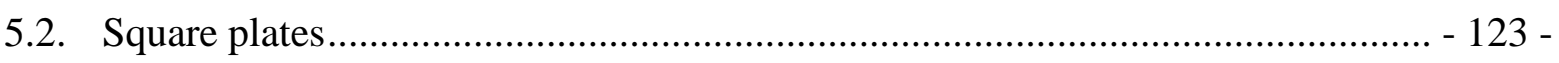

5.2.1. Design of Experiments: Effect of processing conditions …........................... - 123 -

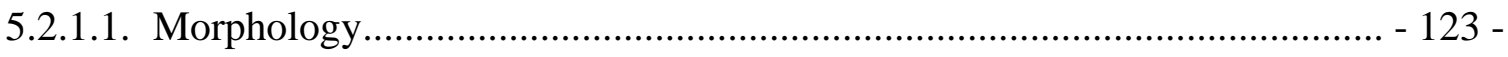

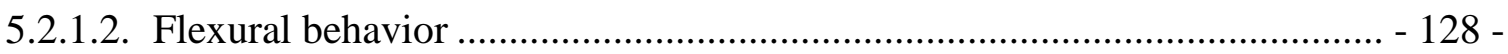

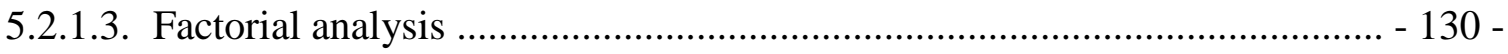

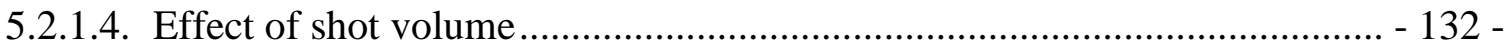

5.2.1.5. Effect of mold temperature .................................................................. - 135 -

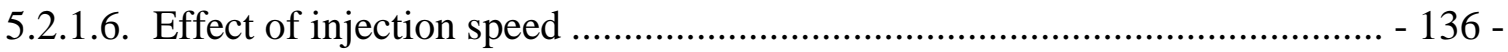

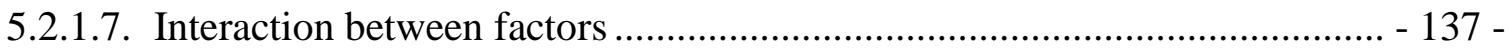

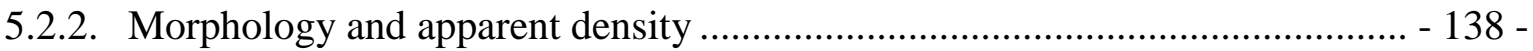

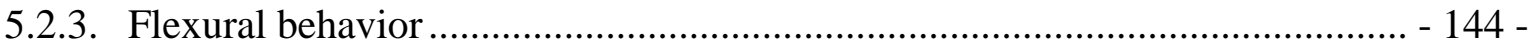

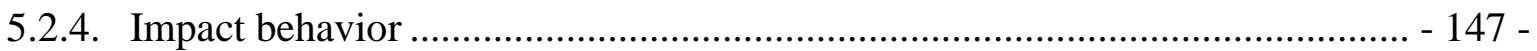

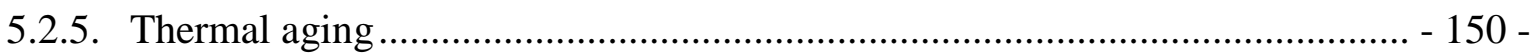

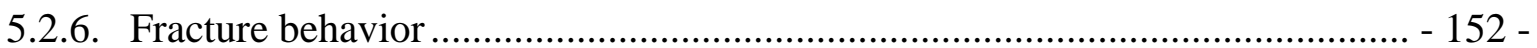


5.2.6.1. Crack Tip Opening Displacement CTOD $-152-$

5.2.6.2. Fracture toughness $\mathrm{K}_{\mathrm{Ic}}$ $-156-$

5.2.7. Differential Scanning Calorimetry..... $-158-$

5.2.8. Heat Deflection Temperature $-160-$

5.3. Conclusions $-161-$

Chapter 6: MuCell® vs IQ Foam ${ }^{\circledR}$ $-165-$

6.1. Morphology and apparent density $-166-$

6.2. Tensile behavior $-175-$

6.3. Flexural behavior $-178-$

6.4. Impact behavior $-182-$

6.5. Conclusions $-184-$

Chapter 7: Conclusions. 187

7.1. Future research works $-189-$

References. $191-$

Appendix A: ANOVA tables for ABS $221-$

Appendix B: ANOVA tables for PP 20GF 225 -

Appendix C: List of publications $237-$

C.1. Publications in journals. $-237-$

C.2. Publications derived from conferences $-240-$

C.3. Conferences $-243-$ 


\section{List of Figures}

Figure 1.1. Evolution of $\mathrm{CO}_{2}$ emissions from new passenger cars per year and fuel type, and emissions targets for 2015 and 2020. Modified from [2] .................................................. 1 -

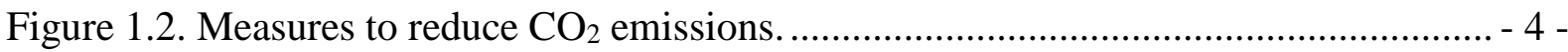

Figure 1.3. Percentages by weight of materials used in vehicles over time. Modified from [20].

Figure 1.4. Plastic materials used in the dashboard of a) SEAT 600 (1960) [23]; b) SEAT

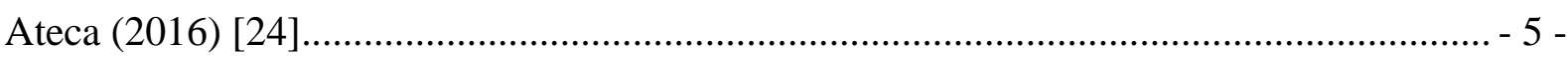

Figure 1.5. Percentages by weight of plastic materials used in cars per a) polymer type; b) vehicle zone. Modified from [18].

Figure 1.6. Representative vehicle energy flows in an urban driving cycle. Modified from [31].

Figure 1.7. Vehicle mass distribution by subsystem. Modified from [32]. $-8-$

Figure 1.8. Lighter car bodies made of a) Aluminum (Audi A8) [38]; b) CFRP (BMW i Concept) [39]

Figure 1.9. Automotive foamed plastic parts manufactured by MuCell@ technology [44].- 11 Figure 2.1. SEM micrographs of Polyurethane foams with a) open-cell [54]; b) closed-cell [55] structures.

Figure 2.2. Three-dimensional polyhedral cells: a) tetrahedron; b) triangular prism; c) rectangular prism; d) hexagonal prism; e) octahedron; f) rhombic dodecahedron; g) pentagonal dodecahedron; h) tetrakaidecahedron; i) icosahedron. Modified from [51].... - 15 Figure 2.3. Schematic compression stress-strain curve for a plastic foam. Modified from [53].17 -

Figure 2.4. Schematic representation of Solid-state microcellular foaming process. Modified from [64] $20-$

Figure 2.5. Schematic representation of foam extrusion on a tandem-line. Modified from [62]. $-21-$

Figure 2.6. Ring-shaped die design for Optifoam ${ }^{\circledR}$ process. Modified from [69].............. - 22 -

Figure 2.7. Stages of microcellular polymer foaming process....................................... - 23 -

Figure 2.8. Diagram of material phases. Modified from [58]. $-24-$

Figure 2.9. Free energy change associated with the homogeneous nucleation of a sphere of

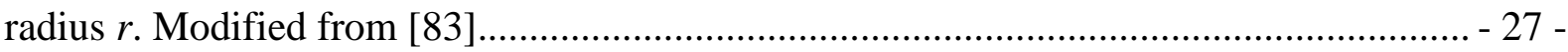

Figure 2.10. Schematic diagram of the unit cell model. Modified from [88]. .................... - 30 - 
Figure 2.11. Typical cycle time reduction of an automotive part with MuCell®. Modified from [98].

Figure 2.12. Plant concept for MuCell@ process. Modified from [103]............................. - 33 -

Figure 2.13. Plant concept for IQ Foam ${ }^{\circledR}$ process. Modified from [103]. ......................... - 35 -

Figure 2.14. Operating steps of IQ Foam® technology. $-36-$

Figure 2.15. Schematic representation of Gas Counter Process effect on foaming. Modified from [109]. - 37 -

Figure 2.16. Schematic representation of Core Back technology. Modified from [115].... - 39 -

Figure 3.1. Schematic representation of injection molded cylindrical bars. ...................... - 53 -

Figure 3.2. Schematic representation of injection molded square plates. .......................... - 56 -

Figure 3.3. Schematic representation of injection molded rectangular plates. $-58-$

Figure 3.4. 3D model for injection molding simulation of the cylindrical bars with Moldex $3 \mathrm{D} \Re$. $-60-$

Figure 3.5. Schematic representation of samples extracted for apparent density measurements, direct calcination tests, CT scans and DSC analysis from a) cylindrical bars; b) square plates; c) rectangular plates. - 61 -

Figure 3.6. Schematic representation of samples extracted for morphology visualizations from a) cylindrical bars; b) square plates; c) rectangular plates. $-62-$

Figure 3.7. Procedure steps for morphological analysis of foamed samples. $-63-$

Figure 3.8. Schematic representation of samples extracted for mechanical characterization and HDT tests from a) cylindrical bars; b) square plates; c) rectangular plates. - 66 Figure 3.9. Schematic representation of SENT samples extracted from square plates for fracture $C T O D$ analysis. $-69-$

Figure 3.10. Schematic representation of SENB samples extracted from square plates for fracture toughness determination. . $-70-$

Figure 4.1. SEM micrographs of C1-C4 conditions. Shot volume: $71 \mathrm{~cm}^{3}(10 \%$ weight reduction). $-76-$

Figure 4.2. SEM micrographs of C5-C8 conditions. Shot volume: $68 \mathrm{~cm}^{3}$ (17\% weight reduction). $-77-$

Figure 4.3. SEM micrograph and morphology areas of C0 condition. $-77-$

Figure 4.4. a) Micro-CT picture of $\emptyset=8 \mathrm{~mm}$ section of C8 condition; b) Longitudinal crosssection through the center point. $-78-$

Figure 4.5. Cell size distribution of a) C1-C4 (10\% weight reduction); b) C5-C8 injection conditions (17\% weight reduction). $-79-$

Figure 4.6. Tensile stress-strain curves of ABS solid and foamed samples (C4, C0 and C8 conditions). $-80-$ 
Figure 4.7. Main effect of shot volume, mold temperature and injection speed on skin thickness.

Figure 4.8. Effect of processing parameters on morphology and tensile properties of ABS foamed bars

Figure 4.9. Effect of processing parameters on morphology and tensile properties of ABS foamed bars

Figure 4.10. Pareto charts of standardized effect of processing parameters on a) skin thickness; b) max cell size.

Figure 4.11. Melt front time of ABS foamed bars (10\% wt. red.) simulated with Moldex 3D® software.

Figure 4.12. SEM micrographs taken from different sections of bar A in C4 and C8 ABS foaming conditions.

Figure 4.13. Cell size distribution in 4, 5 and $8 \mathrm{~mm}$ cross-sections of a) $\mathrm{C} 4$ (10\% weight reduction); b) C8 (17\% weight reduction) injection molding conditions

Figure 4.14. Cell size and cell density results of of ABS foamed bars simulated with Moldex $3 \mathrm{D} \circledR$ software.

Figure 4.15. Tensile stress-strain curves of 4 and $5 \mathrm{~mm}$ diameter sections of ABS solid and

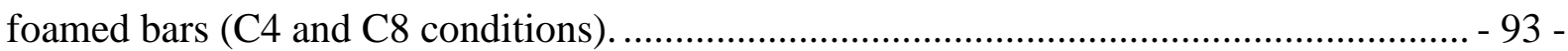

Figure 4.16. SEM micrographs of ABS foamed plates taken in MD direction.................. - 96 -

Figure 4.17. SEM micrographs of ABS foamed plates taken in TD direction.................... - 97 -

Figure 4.18. Cell size distribution of different sections of ABS foamed samples with a) $10 \%$

weight reduction; b) $17 \%$ weight reduction. $-99-$

Figure 4.19. Cell size and cell density results of ABS foamed plates simulated with Moldex $3 \mathrm{D} \circledR$ software. $-100-$

Figure 4.20. Flexural stress-strain curves of ABS solid and foamed samples tested in a) MD; b) TD directions. $-100-$

Figure 4.21. Impact force-displacement curves of ABS samples tested in a) MD; b) TD directions. $-103-$

Figure 4.22. a) Strain field ahead of the crack tip at the crack propagation onset and forcedisplacement curves for solid and foamed samples tested in TD direction at $16 \mathrm{~mm} \mathrm{~min}^{-1} ; \mathrm{b}$ ), e), h) Micrographs taken at the crack propagation onset with the corresponding CTOD value; c) Stable crack propagation of solid samples; f), i) quasi-stable crack propagation of foamed samples with secondary cracks ahead of the main crack front, indicated into the white dashed circles; The stable crack propagation length is indicated in figures d), g), j) for each material investigated before the catastrophic crack propagation. - 106 -

Figure 4.23. Fracture surfaces of solid and foamed samples in MD and TD direction..... - 109 - 
Figure 5.1. Melt front time of PP 20GF foamed bars (10\% wt. red.) simulated with Moldex $3 \mathrm{D} \AA$ software.

Figure 5.2. SEM micrographs taken from different sections of bar A PP 20GF foamed cylindrical bars.

Figure 5.3. Cell size distribution in 4, 5 and $8 \mathrm{~mm}$ cross-sections of PP 20GF foamed bars with a) $10 \%$ weight reduction; b) $20 \%$ weight reduction. $-118-$

Figure 5.4. Cell size and cell density results of of PP 20GF foamed bars simulated with Moldex 3D® software. $-119-$

Figure 5.5. Tensile stress-strain curves of 4 and $5 \mathrm{~mm}$ diameter sections of PP 20GF solid and foamed bars. -120 -

Figure 5.6. SEM micrographs of C1-C4 conditions. Shot volume: $51.2 \mathrm{~cm}^{3}$ (10\% weight reduction).

Figure 5.7. SEM micrographs of C5-C8 conditions. Shot volume: $45.3 \mathrm{~cm}^{3}$ (20\% weight reduction). $-125-$

Figure 5.8. SEM micrographs of C0 condition. Shot volume: $48.3 \mathrm{~cm}^{3}$ (15\% weight reduction).

Figure 5.9. Cell size distribution of a) $\mathrm{C} 1-\mathrm{C} 4$ conditions in $\mathrm{MD}-\mathrm{B}$; b) $\mathrm{C} 1-\mathrm{C} 4$ conditions in $\mathrm{TD}$; c) C5-C8 conditions in MD; d) C5-C8 conditions in TD-B. $-127-$

Figure 5.10. Flexural stress-strain curves of PP 20GF solid and foamed samples (C1, C0 and C5 conditions) in a) MD; b) TD directions. - 128 -

Figure 5.11. Effect of processing parameters on morphology of PP 20GF foamed plates. .- 133

Figure 5.12. Effect of processing parameters on flexural of PP 20GF foamed plates. $-134-$

Figure 5.13. Pareto charts of standardized effect of processing parameters on cell density in MD direction. $-137-$

Figure 5.14. SEM micrographs of PP 20GF foamed plates taken in MD direction. $-138-$

Figure 5.15. SEM micrographs of PP 20GF foamed plates taken in TD direction. $-139-$

Figure 5.16. Cell size distribution of different sections of PP 20GF foamed samples with a) $10 \%$ weight reduction; b) $20 \%$ weight reduction. $-141-$

Figure 5.17. Cell size and cell density results of PP 20GF foamed plates simulated with Moldex 3D® software.

Figure 5.18. Filling flow pattern and Computed Tomography pictures of PP 20GF solid plates.

Figure 5.19. Filling flow pattern and Computed Tomography pictures of PP 20GF foamed plates (10\% wt. red.). -143 -

Figure 5.20. Filling flow pattern and Computed Tomography pictures of PP 20GF foamed plates (20\% wt. red.). - 144 - 
Figure 5.21. Flexural stress-strain curves of PP 20GF solid and foamed samples tested in a) MD; b) TD directions.

Figure 5.22. Impact force-displacement curves of PP 20GF samples tested in a) MD; b) TD directions. -148 -

Figure 5.23. a) Flexural stress-strain curves of non-aged and aged foamed PP 20GF samples (10\% weight reduction); Evolution of flexural properties after different periods of aging time b) Flexural modulus; c) Flexural strength; d) Flexural strain. -150 -

Figure 5.24. a) Impact force-displacement curves of non-aged and aged foamed PP 20GF samples (10\% weight reduction); b) Evolution of impact resistance different periods of aging time.

Figure 5.25. a) Strain field ahead of the crack tip at the crack propagation onset and forcedisplacement curves for solid and foamed samples tested in TD direction at $16 \mathrm{~mm} \mathrm{~min}^{-1}$; b), e), h) Micrographs taken at the crack propagation onset with the corresponding CTOD value; c) Stable crack propagation of solid samples; f), i) quasi-stable crack propagation of foamed samples with secondary cracks ahead of the main crack front, indicated into the white dashed circles; The stable crack propagation length is indicated in figures d), g), j) for each material investigated before the catastrophic crack propagation. $-153-$

Figure 5.26. Failure mechanisms of discontinuous fiber-reinforced thermoplastics. Modified from [298]. $-155-$

Figure 5.27. a) General overview of fracture surface in different ligament regions of a foamed SENT sample with $10 \%$ of weight reduction tested in MD direction; b) Details of different crack propagation modes. - 156 -

Figure 5.28. First and second heating thermograms of solid and foamed samples in a) Skin; b) Core; Cooling cycle thermograms of solid and foamed samples in c) Skin; d) Core layers.......159 -

Figure 6.1. SEM micrographs of MuCell® foamed plates taken in MD direction. CB: Core Back. $-166-$

Figure 6.2. SEM micrographs of MuCell@ foamed plates taken in TD direction. CB: Core Back. $-167-$

Figure 6.3. SEM micrographs of IQ Foam ${ }^{\circledR}$ foamed plates taken in MD direction. CB: Core

Back. $-168-$

Figure 6.4. SEM micrographs of IQ Foam ${ }^{\circledR}$ foamed plates taken in TD direction. CB: Core Back. $-169-$

Figure 6.5. Cell size distribution in MD-B position of PP 20GF foamed plates with a) MuCell®; b) IQ Foam ${ }^{\circledR}$ $-172-$

Figure 6.6. X-Ray scans of PP 20GF foamed plates with IQ Foam® and combined with Core Back technology. -174 - 
Figure 6.7. Cell size and cell density results of PP 20GF rectangular plates simulated with Moldex 3D®.... $-175-$

Figure 6.8. Tensile stress-strain curves of solid, MuCell® and IQ Foam® PP 20GF foamed plates (MD-B). $-175-$

Figure 6.9. Flexural stress-strain curves of solid, MuCell® and IQ Foam ${ }^{\circledR}$ PP 20GF foamed plates (MD-B). $-178-$

Figure 6.10. Relative, specific flexural stiffness $\left(S_{f}\right)$ evolution with density reduction and thickness increase. $-181-$

Figure 6.11. Impact force-displacement curves of solid, MuCell® and IQ Foam® PP 20GF foamed plates.

Figure 6.12. Multivariable plot comparing morphological characteristics and mechanical properties of solid, MuCell ${ }^{\circledR}$ and IQ Foam ${ }^{\circledR}$ foamed specimens. $-185-$ 


\section{List of Tables}

Table 1.1. Emission limits $(\mathrm{g} / \mathrm{km})$ of the Euro emission standards for passenger vehicles [3-8]. - 2 -

Table 1.2. Properties and applications of polymers employed in automotive industry [26]. - 7 -

Table 1.3. Properties and prices of alternative lightweight automotive materials [31]...... - 10 -

Table 2.1. Physical properties of $\mathrm{CO}_{2}$ and $\mathrm{N}_{2}$ blowing agents [58]. $-26-$

Table 2.2. Main research works on foaming injection molding conducted with amorphous polymers.

Table 2.3. Main research works on foaming injection molding conducted with amorphous polymers. $-44-$

Table 2.4. Main research works on foaming injection molding conducted with filled polymers

Table 3.1. Factors and experimental domain for ABS microcellular injection molding. Note that values of 0 level are only employed in intermediate condition $\mathrm{C} 0$ (see Table 3.2) for linearity checking. $-53-$

Table 3.2. Matrix of the Design of Experiments for ABS microcellular injection molding. .- 54

Table 3.3. Processing parameters of solid and foamed ABS cylindrical bars. $-54-$

Table 3.4. Processing parameters of solid and foamed PP 20GF cylindrical bars. $-55-$

Table 3.5. Processing parameters of solid and foamed ABS square plates. $-56-$

Table 3.6. Factors and experimental domain for PP 20GF microcellular injection molding.- 57

Table 3.7. Matrix of the Design of Experiments for PP 20GF microcellular injection molding. - 57 -

Table 3.8. Processing parameters of solid and foamed PP 20GF square plates. $-58-$

Table 3.9. Processing parameters of PP 20GF rectangular plates foamed by MuCell® and IQ Foam ${ }^{\circledR}$ processes. -59 -

Table 4.1. Weight reduction ratio, apparent density and morphological parameters of ABS foamed samples. $-78-$

Table 4.2. Tensile properties of ABS solid and foamed samples. $-80-$

Table 4.3. Regression models derived from factorial design analysis of ABS cylindrical bars. 82 -

Table 4.4. Analysis of variance for skin thickness. $-82-$ 
Table 4.5. Apparent density of ABS cylindrical bars. $88-$

Table 4.6. Apparent density and morphological parameters in different sections of ABS foamed bars. $-90-$

Table 4.7. Tensile properties in different sections of ABS bars. $-94-$

Table 4.8. Morphological parameters in different sections of ABS foamed plates. $-98-$

Table 4.9. Apparent density measured in different sections of the ABS square plates. - 99 -

Table 4.10. Flexural properties in different sections of ABS square plates. $-101-$

Table 4.11. Impact resistance determined in different sections of ABS square plates. .... - 104 -

Table 4.12. CTOD and experimental and predicted $K_{I c}$ of ABS plates. $-107-$

Table 4.13. Heat Deflection Temperature (HDT) of ABS square plates. $-110-$

Table 5.1. Apparent density of PP 20GF cylindrical bars. $-114-$

Table 5.2. Apparent density and morphological parameters in different sections of PP 20GF foamed bars. - 117 -

Table 5.3. Tensile properties in different sections of PP 20GF bars $-121-$

Table 5.4. Weight reduction ratio, apparent density and morphological parameters of PP 20GF foamed samples. $-126-$

Table 5.5. Flexural properties of PP 20GF solid and foamed samples. $-129-$

Table 5.6. Regression models derived from factorial design analysis of PP 20GF square plates. $-131-$

Table 5.7. Analysis of variance for cell density MD-B. $-132-$

Table 5.8. Morphological parameters in different sections of PP 20GF foamed plates. .. - 140 Table 5.9. Apparent density and fiber content measured in different sections of the PP 20GF square plates. -142 -

Table 5.10. Flexural properties in different sections of PP 20GF square plates. $-146-$

Table 5.11. Impact resistance determined in different sections of PP 20GF square plates. - 149

Table 5.12. CTOD and $K_{I c}$ of PP 20GF square plates.

Table 5.13. DSC data of solid and foamed PP 20GF in the surface and core of the injected plates. -160 -

Table 5.14. Heat Deflection Temperature (HDT) of PP 20GF square plates $-161-$

Table 6.1. Morphological parameters in different sections of MuCell® foamed PP 20GF plates. $-170-$

Table 6.2. Morphological parameters in different sections of IQ Foam ${ }^{\circledR}$ foamed PP 20GF plates. 
Table 6.3. Tensile properties of solid and MuCell® foamed PP 20GF plates. $-176-$

Table 6.4. Tensile properties of IQ Foam ${ }^{\circledR}$ foamed PP 20GF plates. - 177 -

Table 6.5. Flexural properties of solid and MuCell® foamed PP 20GF plates $-180-$

Table 6.6. Flexural properties of solid and IQ Foam ${ }^{\circledR}$ foamed PP 20GF plates $-181-$

Table 6.7. Impact resistance of solid and MuCell® foamed PP 20GF plates. $-183-$

Table 6.8. Impact resistance of solid and IQ Foam® foamed PP 20GF plates. $-184-$

Table A.1. Analysis of variance for weight reduction. $-221-$

Table A.2. Analysis of variance for skin thickness. $-221-$

Table A.3. Analysis of variance for cell density. $-222-$

Table A.4. Analysis of variance for maximum cell size. $-222-$

Table A.5. Analysis of variance for $C D I$. $-223-$

Table A.6. Analysis of variance for elastic modulus. $-223-$

Table A.7. Analysis of variance for tensile strength. $-224-$

Table B.1. Analysis of variance for weight reduction. $-225-$

Table B.2. Analysis of variance for skin thickness MD-B........................................... - 225 -

Table B.3. Analysis of variance for cell density MD-B ................................................ - 226 -

Table B.4. Analysis of variance for maximum cell size MD-B. .................................... - 226 -

Table B.5. Analysis of variance for CDI MD-B........................................................ 227 -

Table B.6. Analysis of variance for skin thickness TD-B............................................ - 227 -

Table B.7. Analysis of variance for cell density TD-B................................................ 228 -

Table B.8. Analysis of variance for maximum cell size TD-B. ...................................... 228 -

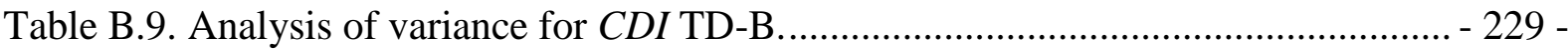

Table B.10. Analysis of variance for flexural modulus MD-A....................................... 229 -

Table B.11. Analysis of variance for flexural modulus MD-B....................................... - 230 -

Table B.12. Analysis of variance for flexural modulus MD-C. ..................................... - 230 -

Table B.13. Analysis of variance for flexural strength MD-A...................................... - 231 -

Table B.14. Analysis of variance for flexural strength MD-B....................................... - 231 -

Table B.15. Analysis of variance for flexural strength MD-C ...................................... - 232 -

Table B.16. Analysis of variance for flexural modulus TD-A........................................ - 232 -

Table B.17. Analysis of variance for flexural modulus TD-B. ....................................... - 233 -

Table B.18. Analysis of variance for flexural modulus TD-C. ….................................. - 233 -

Table B.19. Analysis of variance for flexural strength TD-A...................................... - 234 - 
Table B.20. Analysis of variance for flexural strength TD-B. $-234-$

Table B.21. Analysis of variance for flexural strength TD-C......................................... - 235 - 


\section{Abbreviations and Symbols}

\begin{tabular}{|c|c|}
\hline$A$ & Area \\
\hline$a$ & Notch length \\
\hline$A_{b}$ & Surface area of a bubble nucleus \\
\hline$a_{c U}$ & Impact resistance \\
\hline$b$ & Width of the sample \\
\hline$C$ & Gas concentration \\
\hline$C_{0}$ & Concentration of gas molecules in solution \\
\hline$C_{0}$, & Gas concentration for homogeneous nucleation in presence of fillers \\
\hline$C_{1}$ & Gas concentration in the polymer - filler interface \\
\hline$C B$ & Core Back \\
\hline$C D I$ & Cell Distribution Index \\
\hline$C_{f}$ & Constant for fracture toughness prediction model \\
\hline$C T$ & Computed Tomography \\
\hline CTOD & Crack Tip Opening Displacement \\
\hline$D$ & Diffusion coefficient \\
\hline$D_{0}$ & Diffusion coefficient at infinite temperature \\
\hline$d$ & Cell diameter \\
\hline$D I C$ & Digital Image Correlation \\
\hline displ. & Displacement \\
\hline$\overline{d_{n}}$ & Number average cell diameter \\
\hline$D S C$ & Differential Scanning Calorimetry \\
\hline$\overline{d_{w}}$ & Diameter average cell diameter \\
\hline$E_{c}$ & Impact energy absorbed during impact test \\
\hline$E_{d}$ & Activation energy for diffusion \\
\hline
\end{tabular}


$E_{f} \quad$ Flexural modulus

$E_{f f} \quad$ Flexural modulus of foamed material

$E_{f s} \quad$ Flexural modulus of solid material

$E_{s} \quad$ Activation energy

$E_{t} \quad$ Tensile elastic modulus

$E_{t f} \quad$ Tensile modulus of foamed material

$E_{t s} \quad$ Tensile modulus of solid material

EWF Essential Work of Fracture

$F \quad$ Force

f Geometric function for fracture toughness

$f_{0} \quad$ Frequency factor for homogeneous nucleation

$f_{1} \quad$ Frequency factor for heterogeneous nucleation

$f^{P E} \quad$ Weight fraction of Polyethylene

$f^{P P} \quad$ Weight fraction of Polypropylene

$H \quad$ Henry's law constant

$h \quad$ Thickness of the sample

$H_{0} \quad$ Preexponential constant for Henry's law

HDT Heat Deflection Temperature

I $\quad$ Moment of inertia

$k \quad$ Boltzmann's constant

$K_{I c} \quad$ Fracture toughness

$K_{I c, f} \quad$ Fracture toughness of foamed material

$K_{I c, s} \quad$ Fracture toughness of solid material

$K_{f} \quad$ Constant for fracture toughness prediction model

$L \quad$ Length of the sample

$L_{0} \quad$ Initial gauge length

$M_{0} \quad$ Equilibrium concentration of gas without desorption 
$m_{0} \quad$ Mass of the dried test portion for calcination tests

$m_{1} \quad$ Mass of the ash after calcination tests

MD Melt direction

$m_{f} \quad$ Exponent for fracture toughness prediction model

$M_{t} \quad$ Amount of gas absorbed by the polymer

$N \quad$ Cell density

$n \quad$ Number of cells

$n_{b} \quad$ Number of gas molecules in a bubble nucleus

$n_{f} \quad$ Exponent for fracture toughness prediction model

$N_{h e t} \quad$ Heterogeneous nucleation rate

Nhom Homogeneous nucleation rate

$N_{\text {hom }}^{\prime} \quad$ Homogeneous nucleation rate in presence of heterogeneous nucleation

$N_{\text {tot }} \quad$ Total nucleation rate for mixed homogeneous and heterogeneous modes

$P \quad$ Pressure

$P_{g} \quad$ Gas pressure

$P_{m} \quad$ Molten polymer pressure

$P_{q} \quad$ Force for fracture toughness calculation

$R \quad$ Weight reduction ratio of foamed core

$r \quad$ Radius of the sample

$r^{*} \quad$ Critical radius

$r_{b} \quad$ Radius of a bubble

$r_{c} \quad$ Radial coordinate while cell growing

$R_{g} \quad$ Molar gas constant

$R_{g f} \quad$ Weight reduction ratio of the core material without fillers

$R_{w} \quad$ Weight reduction ratio of the whole microcellular part

S Span length

$s \quad$ Flexural deflection 
$S_{e} \quad$ Radius of the polymer shell

SENB Single Edge Notched Bending

SENT Single Edge Notched Tension

SEM Scanning Electron Microscopy

$S_{h} \quad$ Heterogeneity function for heterogeneous nucleation

SCF Supercritical fluid

$S_{f} \quad$ Flexural stiffness

$T \quad$ Temperature

$t \quad$ Time

$t_{a} \quad$ Time of gas absorption

$t_{b} \quad$ Time of heterogeneous nucleation

$T_{c} \quad$ Crystallization temperature

$T_{c r} \quad$ Critical temperature

TD Transversal direction

$T_{g} \quad$ Glass transition temperature

$T_{m} \quad$ Melting temperature

$T_{m 1} \quad$ Melting temperature during first heating cycle

$T_{m 2} \quad$ Melting temperature during second heating cycle

$T_{\text {poly }} \quad$ Molten polymer temperature

$t_{s} \quad$ Solid skin thickness

$V_{b} \quad$ Volume of a bubble nucleus

$W_{f} \quad$ Weight fraction of Glass fibers

$W_{g f} \quad$ Fiber content ratio

wt. red. Weight reduction

$X_{a} \quad$ Amorphous region degree in a semicrystalline polymer

$X_{c} \quad$ Crystallinity degree

$X_{c 5 \%} \quad$ Crystallinity degree for $5 \%$ content of polyethylene 
$X_{c 15 \%} \quad$ Crystallinity degree for $15 \%$ content of polyethylene

$\Delta G_{h e t} * \quad$ Gibbs energy barrier for heterogeneous nucleation

$\Delta G_{\text {hom }} \quad$ Change in Gibbs free energy for homogeneous nucleation

$\Delta G_{h o m} *$ Gibbs energy barrier required to form a critical nucleus

$\Delta H_{0}^{P E} \quad$ Melting enthalpy for fully perfect crystalline Polyethylene

$\triangle H_{0}^{P P} \quad$ Melting enthalpy for fully perfect crystalline Polypropylene

$\Delta H_{c} \quad$ Crystallization enthalpy

$\Delta H_{m} \quad$ Melting enthalpy

$\Delta H_{m 1} \quad$ Melting enthalpy during first heating cycle

$\Delta H_{m 2} \quad$ Melting enthalpy during second heating cycle

$\Delta L_{0} \quad$ Increment in the gauge length

$\triangle P \quad$ Pressure drop

$\gamma_{b p} \quad$ Surface energy of polymer - bubble interface

$\varepsilon \quad$ Strain

$\varepsilon_{f} \quad$ Flexural strain

$\varepsilon_{f 1} \quad$ Flexural strain of 0.0005 according to ISO 178

$\varepsilon_{f 2} \quad$ Flexural strain of 0.0025 according to ISO 178

Et $\quad$ Tensile strain

$\varepsilon_{t 1} \quad$ Tensile strain of 0.0005 according to ISO 527

$\varepsilon_{t 2} \quad$ Tensile strain of 0.0025 according to ISO 527

$\varepsilon_{u} \quad$ Tensile elongation at break

$\varepsilon_{y} \quad$ Tensile yield strain

$\eta \quad$ Melt viscosity

$\theta \quad$ Wetting angle of polymer - particle - gas interface

$v_{r} \quad$ Gas diffusion velocity

$\rho \quad$ Apparent density

$\rho_{f} \quad$ Apparent density of foamed polymer 


$\begin{array}{ll}\rho_{s} & \text { Apparent density of solid polymer } \\ \rho_{s f} & \text { Apparent density of filled solid material } \\ \sigma & \text { Stress } \\ \sigma_{f} & \text { Flexural strength } \\ \sigma_{f f} & \text { Flexural strength of the foamed material } \\ \sigma_{f s} & \text { Flexural strength of the solid material } \\ \sigma_{f 1} & \text { Flexural stress measured at a strain of } \varepsilon_{f l} \text { according to ISO } 178 \\ \sigma_{f 2} & \text { Flexural stress measured at a strain of } \varepsilon_{f 2} \text { according to ISO } 178 \\ \sigma_{t} & \text { Tensile stress } \\ \sigma_{t f} & \text { Tensile strength of foamed material } \\ \sigma_{t s} & \text { Tensile strength of solid material } \\ \sigma_{t 1} & \text { Tensile stress measured at a strain of } \varepsilon_{t l} \text { according to ISO } 527 \\ \sigma_{t 2} & \text { Tensile stress measured at a strain of } \varepsilon_{t 2} \text { according to ISO } 527 \\ \sigma_{u} & \text { Tensile stress at break } \\ \sigma_{y} & \text { Tensile stress at yielding point } \\ \varnothing & \text { Cross-section diameter } \\ \sigma^{\prime} & \text { Relative density }\end{array}$




\section{Chapter 1:}

\section{Introduction}

Climate change is one of the most important challenges facing the whole planet at present, and it requires the firm commitment of all industrial and service sectors in order to reduce the environmental impact of their activities. The automotive industry is aware of this responsibility, and focuses its efforts on providing more sustainable road transportation systems.

In 2013 , almost one quarter $(24.4 \%)$ of greenhouse gas emissions emitted to the atmosphere in Europe was derived from the transport sector, $43 \%$ of them corresponded to passenger cars [1]. According to data provided by the European Environment Agency (EEA) depicted in Figure 1.1, automobiles in the Europe Union are becoming ever more fuelefficient. In 2014, $\mathrm{CO}_{2}$ mean emissions from new passenger cars were $123.4 \mathrm{~g} \mathrm{CO}_{2} / \mathrm{km}, 3 \%$ less than in the previous year. In Spain, the new sold cars emitted on average $118.6 \mathrm{~g} \mathrm{CO}_{2} / \mathrm{km}$ $[2]$.

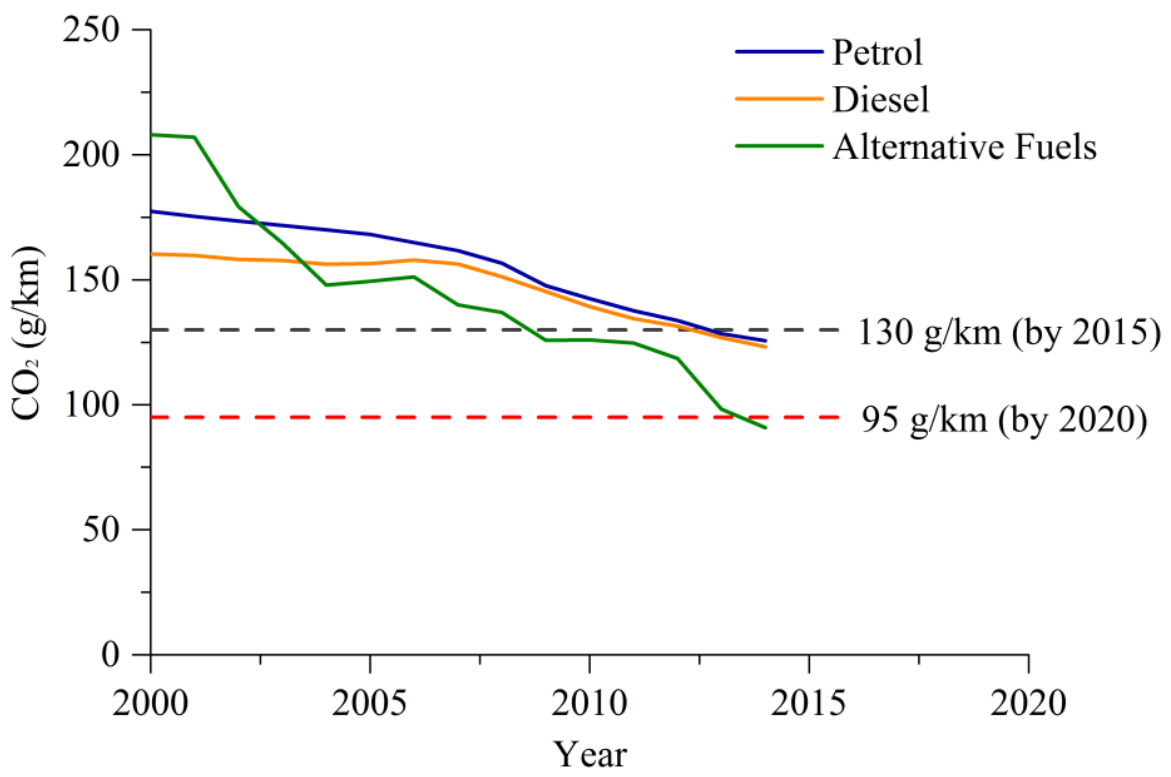

Figure 1.1. Evolution of $\mathrm{CO}_{2}$ emissions from new passenger cars per year and fuel type, and emissions targets for 2015 and 2020. Modified from [2]. 
Since the 1970 s to the present day several directives and regulations have been adopted with a view to control, more and more strictly, the fuel quality, consumption, emissions and environmental impact of the vehicle. Limits in air pollutants, such as carbon monoxide (CO), non-methane hydrocarbons (NMHC), particulate matter (PM) and nitrogen oxides (NOx) have been increasingly and successively constrained over time through the series of directives Euro 1, 2, 3, 4, 5 and 6 [3-8], which are amendments to the first European Council Directive 70/220/EEC introduced in 1970 [9]. The emission levels regulated by these directives are shown in Table 1.1. A particulate number standard (PN) was included in Euro 5b in 2011 for diesel engines and in Euro 6 in 2014 for petrol engines.

Regarding greenhouse gas emissions, in April 2009 the European Union adopted the Regulation No 443/2009 [10] setting average emissions targets for new passenger cars of 130 $\mathrm{g} \mathrm{CO}_{2} / \mathrm{km}$ by 2015 and $95 \mathrm{~g} \mathrm{CO}_{2} / \mathrm{km}$ from 2020 onwards (Figure 1.1). Furthermore, each Member State is claimed to record information for each new passenger car registered in its territory to monitor $\mathrm{CO}_{2}$ emissions reduction, and excess emissions premiums are imposed on car manufacturers that do not meet these specific targets.

The White Paper on Transport [11], approved by the European Commission in 2011, is a roadmap consisting of 40 concrete initiatives aimed at increasing mobility, removing major barriers in key areas, reducing dependence on imported oil and cutting carbon emissions in transport by $60 \%$ by 2050 . The end of life problem of vehicles has also been considered by the Directive 2000/53/EC [12], which establishes measures to prevent and limit waste from car components after their service life and ensure the reuse, recycle and recover of their materials.

Table 1.1. Emission limits $(\mathrm{g} / \mathrm{km})$ of the Euro emission standards for passenger vehicles [3-8].

\begin{tabular}{cccccccc}
\hline Diesel & Date & CO & NMHC & NOx & HC+NOx & PM & PN \\
\hline Euro 1 & $07 / 1992$ & 2.72 & - & - & 0.97 & 0.14 & - \\
Euro 2 & $01 / 1996$ & 1.00 & - & - & 0.70 & 0.08 & - \\
Euro 3 & $01 / 2000$ & 0.64 & - & 0.50 & 0.56 & 0.05 & - \\
Euro 4 & $01 / 2005$ & 0.50 & - & 0.25 & 0.30 & 0.025 & - \\
Euro 5a & $09 / 2009$ & 0.50 & - & 0.18 & 0.23 & 0.005 & - \\
Euro 5b & $09 / 2011$ & 0.50 & - & 0.18 & 0.23 & 0.005 & $6.0 \cdot 10^{11}$ \\
Euro 6 & $09 / 2014$ & 0.50 & - & 0.08 & 0.17 & 0.005 & $6.0 \cdot 10^{11}$ \\
\hline
\end{tabular}


Table 1.1. Continued.

\begin{tabular}{cccccccc}
\hline Petrol & Date & CO & NMHC & NOx & HC+NOx & PM & PN \\
\hline Euro 1 & $07 / 1992$ & 2.72 & - & - & 0.97 & - & - \\
Euro 2 & $01 / 1996$ & 2.20 & - & - & 0.50 & - & - \\
Euro 3 & $01 / 2000$ & 2.30 & - & 0.15 & - & - & - \\
Euro 4 & $01 / 2005$ & 1.00 & - & 0.08 & - & - & - \\
Euro 5 & $09 / 2009$ & 1.00 & 0.068 & 0.06 & - & 0.005 & - \\
Euro 6 & $09 / 2014$ & 1.00 & 0.068 & 0.06 & - & 0.005 & $6.0 \cdot 10^{11}$ \\
\hline
\end{tabular}

As a result of the regulatory constraints and an increase of the environmental awareness, the automotive industry has taken different strategies to reduce greenhouse gas emissions and air pollutants (Figure 1.2). On one hand, major progress has been made in the development of fully electric- and hybrid-drive vehicles [13]. However, the conventional internal combustion engines are still the most widespread powertrain, although its efficiency has been greatly improved and the fuel consumption and emissions have been strongly reduced [14]. Research work has also focus on natural gas, biodiesel, hydrogen, ethanol or propane as alternative fuels derived from resources other than oil [15]. Additionally, some technologies have been developed to improve fuel economy and decrease energy loss, like more efficient transmission systems, regenerative braking techniques or reduced rolling and aerodynamics resistance [16].

On the other hand, the environmental impact can be also diminished by materials selection and part design of automobile components. For example, by employing bio-based and biodegradable polymers [17] and removing additional features. Another strategy to reduce emissions is decreasing the weight of the vehicle, due to lower required tractive efforts and less rolling resistance. Indeed, saving $100 \mathrm{~kg}$ in the bodywork cuts $\mathrm{CO}_{2}$ emissions by $10 \mathrm{~g}$ $\mathrm{CO}_{2} / \mathrm{km}$ [18]. For this reason, conventional materials are being replaced with high performance steels, fiber composites and plastics. In this context, the present $\mathrm{PhD}$ thesis deals with the characterization of microcellular thermoplastic foams obtained by injection molding, as a preliminary approach towards lighter, cheaper and more environmentally friendly automotive interior parts. 


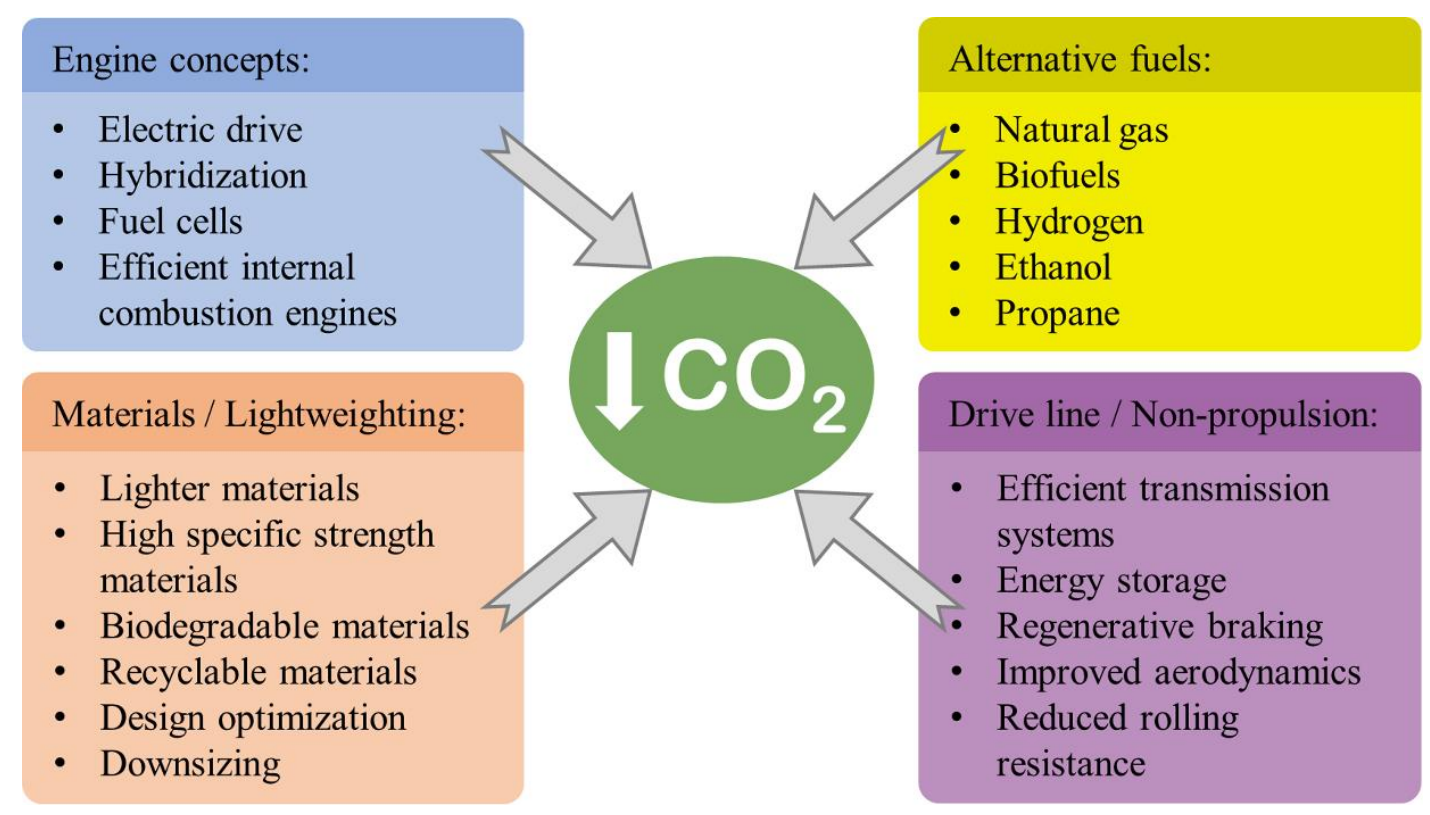

Figure 1.2. Measures to reduce $\mathrm{CO}_{2}$ emissions.

\subsection{Plastics in automotive industry}

The use of plastic materials in cars dates back to the 1950s concurring with the fall of the oil cost and bulk plastic prices after the Second World War [19]. Since then plastics market has only grown and with that the demand for automotive applications [20]. Figure 1.3 illustrates the increase in plastic materials percentage by weight of the overall vehicle mass along the time as well as the continuous growth estimation for 2020. In 2014, automotive industry was the third sector of plastics demand in Europe with a share of 8.6\% [21], resulting in a reduction of 12 million tons in fuel consumption and 30 million tons in $\mathrm{CO}_{2}$ emissions per year [22]. In Figure 1.4 the differences in the amount of plastic materials employed in the dashboard of the SEAT 600 model (1960) as compared to the SEAT Ateca launched in 2016 can be clearly observed [23, 24].

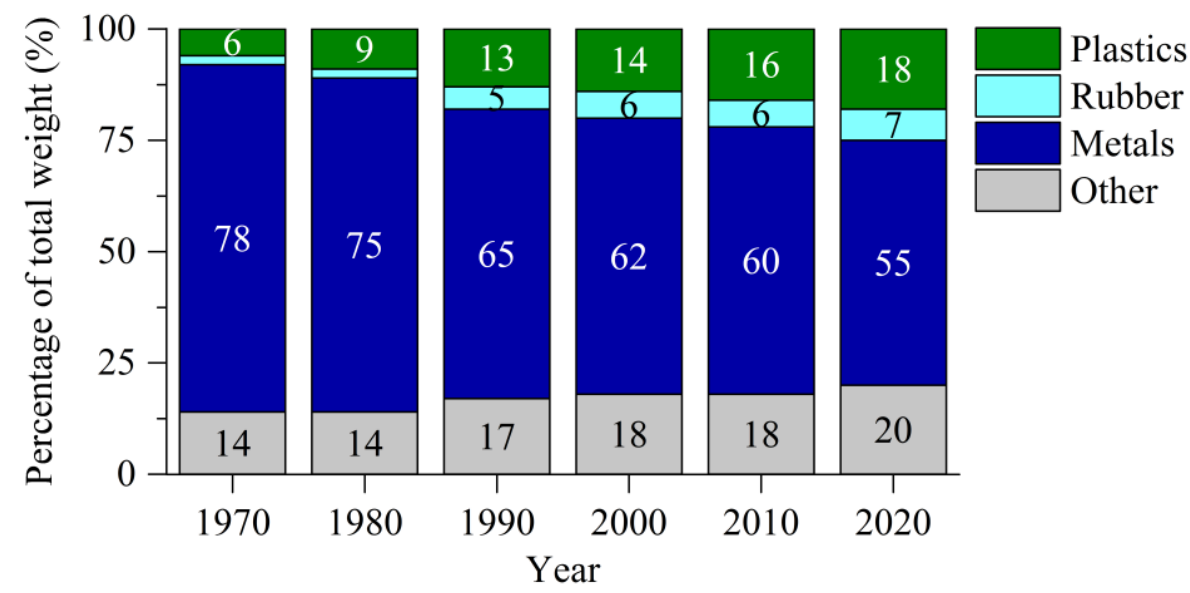

Figure 1.3. Percentages by weight of materials used in vehicles over time. Modified from [20]. 

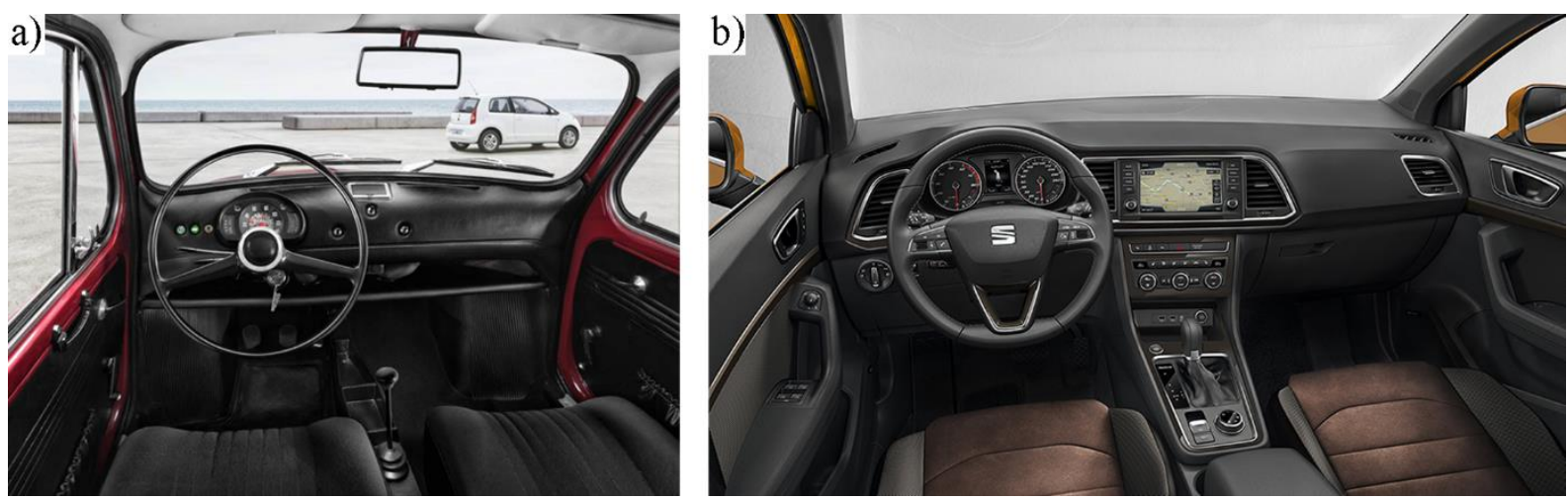

Figure 1.4. Plastic materials used in the dashboard of a) SEAT 600 (1960) [23]; b) SEAT Ateca (2016) [24].

Many reasons make plastics attractive for automotive engineers [25]. To begin with, they have low density and are generally cost effective, providing design freedom to incorporate safety, styling and comfort into vehicles. They can be strong, durable, transparent, translucent or opaque, and resistant to heat, chemicals and corrosion. They can also be formulated in different ways, blended and reinforced with fillers, so that their properties can vary in a wide range of stiffness, softness and hardness. Furthermore, plastics are excellent thermal and electrical insulators, although they can be modified to allow partial conductivity. Finally, this versatility of plastics offers the possibility to be formed into almost any shape, size and color.

Figure 1.5 depicts the use of plastics in a vehicle per polymer type and vehicle area. Polypropylene (PP) is by far the most employed polymer, followed by Polyurethane (PUR), Polyamide (PA) and Acrylonitrile-Butadiene-Styrene (ABS) [18]. The relative good specific mechanical properties and low cost of PP make it suitable for a wide range of applications, such as bumpers, wheel housings or defrost air channels. PUR presents higher flexibility and excellent damping properties and, therefore, it is mainly used as flexible and rigid foams for seat cushions or impact energy absorbers. PA is an engineering polymer with a good combination of mechanical and thermal properties and chemical resistance. It is largely applied to replace metals in engine covers and electrical components. ABS is characterized by reasonable dimensional stability and thermal and impact resistance as well as high gloss, surface quality and possibility to be painted and chromed. Consequently, it is widely used for aesthetic purposes, like interior panels and trims. 
a)

$$
\text { Other engineerings }
$$$$
10.9 \%
$$

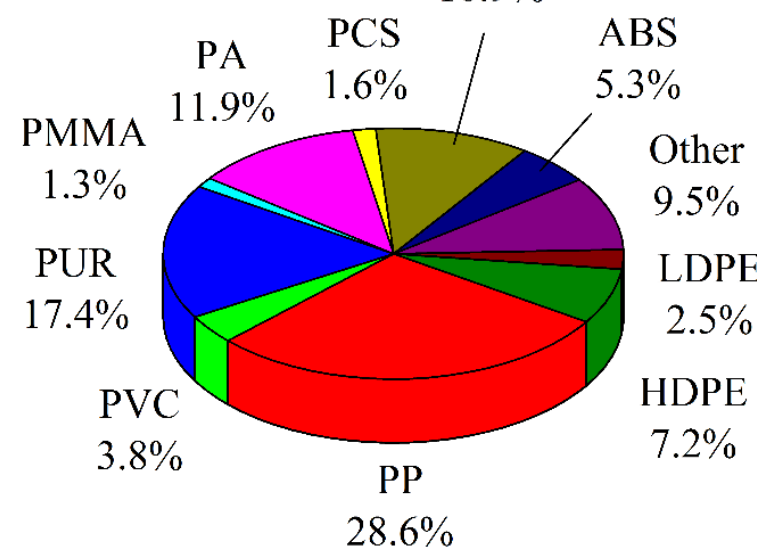

b)

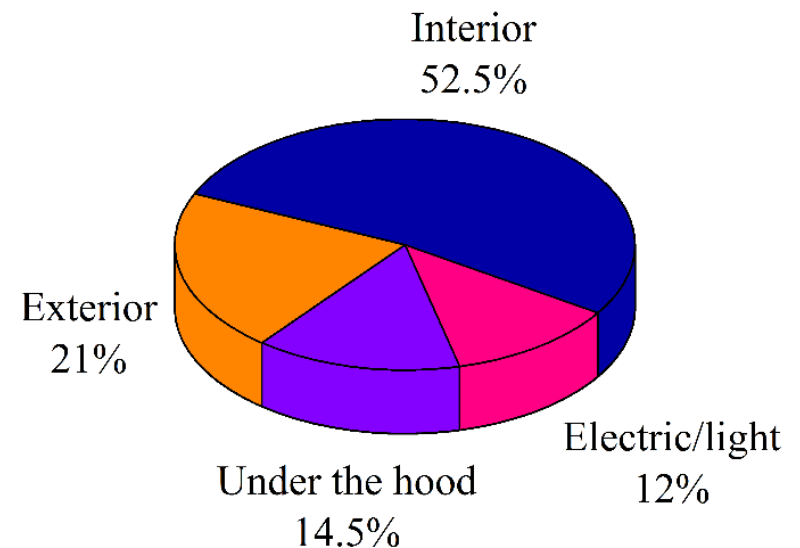

$14.5 \%$

Figure 1.5. Percentages by weight of plastic materials used in cars per a) polymer type; b) vehicle zone.

Modified from [18].

Concerning vehicle areas, plastic materials are predominantly employed in interior parts, where styling, surface quality, passenger comfort and safety are the main aspects that can be easily fulfilled by polymers. ABS individual or blended with Polycarbonate (PC/ABS) are usually employed in parts with aesthetics functions, while reinforced PP with talc particles or glass fibers are mostly present in structural components. Typical exterior parts made of plastics are bumpers (glass fiber reinforced PP), door handles (PC, Polybutylene-terephthalate (PBT), Polyethylene-terephthalate (PET)) or mirror housings (ABS, PC/ABS, Polystyrene (PS)). These parts are subjected to higher mechanical loads and environmental conditions and therefore, their production with thermoplastics is less common. Components under the hood work under high temperature conditions, so only engineering plastics like PA or PBT are used in the surroundings of the engine instead of metals. Finally, transparent PC has replaced glass lenses for lightning applications, as it can resist high levels of heat and shattering and increases design possibilities. Table 1.2 shows a summary of main properties of different plastics and examples of their applications in a vehicle [26].

Automotive plastics parts can be manufactured by different processes, such as extrusion, injection molding, blow molding, thermoforming, rotational molding, casting, compression molding and transfer molding [27]. The possibility of molding almost all thermoplastics and some thermosets in a wide variety of complex geometries and textures, with high manufacturing flexibility and repeatability makes injection molding one of the most common methods for large-scale plastic production [28]. 
Table 1.2. Properties and applications of polymers employed in automotive industry [26].

\begin{tabular}{|c|c|c|c|}
\hline Polymer & Abbreviation & Properties & Applications \\
\hline Polypropylene & $\mathrm{PP}$ & $\begin{array}{l}\text { Low cost, high strength, } \\
\text { chemically resistant }\end{array}$ & $\begin{array}{l}\text { Bumper, wheel } \\
\text { housing, air filter } \\
\text { housing }\end{array}$ \\
\hline Polyethylene & $\mathrm{PE}$ & $\begin{array}{l}\text { Low cost, chemically } \\
\text { resistant, high strength, non- } \\
\text { ageing }\end{array}$ & Fuel tank \\
\hline Polyamide & PA & $\begin{array}{c}\text { Low gas diffusivity, } \\
\text { temperature-stable, high } \\
\text { fatigue strength and stiffness, } \\
\text { non-ageing }\end{array}$ & $\begin{array}{l}\text { Engine cover, plug } \\
\text { connector, air duct }\end{array}$ \\
\hline $\begin{array}{c}\text { Acrylonitrile- } \\
\text { butadiene-styrene }\end{array}$ & ABS & $\begin{array}{l}\text { Dimension-stable, impact- } \\
\text { resistant, high strength }\end{array}$ & $\begin{array}{l}\text { Radiator grill, wheel } \\
\text { flashing, interior } \\
\text { panel }\end{array}$ \\
\hline Polyurethane & PUR & $\begin{array}{l}\text { Good damping behavior, } \\
\text { good electricity, low thermal } \\
\text { conductivity }\end{array}$ & $\begin{array}{l}\text { Seat cushion, } \\
\text { instrument panel } \\
\text { cushion, roof lining }\end{array}$ \\
\hline Polyvinylchloride & PVC & $\begin{array}{l}\text { Low cost, weatherproof, } \\
\text { flame resistant }\end{array}$ & $\begin{array}{c}\text { Underbody skid } \\
\text { plate, wire insulation }\end{array}$ \\
\hline Polyoxymethylene & POM & $\begin{array}{l}\text { Chemically resistant, low } \\
\text { creep, impact-resistant, } \\
\text { temperature-stable, abrasion } \\
\text { resistant }\end{array}$ & $\begin{array}{l}\text { Fastening clip, plug } \\
\text { connector, cog } \\
\text { wheel, bearing } \\
\text { components }\end{array}$ \\
\hline $\begin{array}{l}\text { Poly(methyl- } \\
\text { methacrylate) }\end{array}$ & PMMA & $\begin{array}{l}\text { Transparent, UV-resistant, } \\
\text { stress crack resistant, scratch } \\
\text { resistant }\end{array}$ & Headlight lenses \\
\hline Polycarbonate & $\mathrm{PC}$ & $\begin{array}{c}\text { Transparent, UV-resistant, } \\
\text { impact resistant }\end{array}$ & $\begin{array}{l}\text { Headlight lenses, car } \\
\text { body parts }\end{array}$ \\
\hline $\begin{array}{l}\text { Polyethylene- } \\
\text { terephthalate }\end{array}$ & PET & $\begin{array}{l}\text { High tensile strength and } \\
\text { stiffness, good barrier effect }\end{array}$ & $\begin{array}{l}\text { Textile, safety } \\
\text { seatbelt, airbag }\end{array}$ \\
\hline $\begin{array}{l}\text { Polybutylene- } \\
\text { terephthalate }\end{array}$ & PBT & $\begin{array}{l}\text { High stiffness, high heat } \\
\text { deflection temperature, good } \\
\text { electrical isolation, low } \\
\text { thermal expansion coefficient }\end{array}$ & $\begin{array}{l}\text { Electric housings, } \\
\text { exterior mirror } \\
\text { housing, handgrip }\end{array}$ \\
\hline
\end{tabular}


The continuous development of plastics materials will further increase the demand for automotive components as light, high performance and sustainable solutions [29]. However, improvements in polymers chemistry and behavior understanding as well as advances in recovery and recycling at end of life products are needed for growing plastics market and making an appropriate use of them. By 2030, plastics are expected to be the preferred materials for automotive and other society applications [30].

\subsection{Lightweight construction in automotive industry}

Although the significant progress in powertrain technologies and fuel efficiency reached in the last years, another focus of attention by automotive makers is reducing the overall weight of the vehicle. According to Figure 1.6, the largest loss of the energy supplied to the vehicle corresponds to the fuel combustion in the engine (74\%), and the rest of available energy is mainly consumed in friction with the air and road as well as in braking the vehicle mass (16\%) [31]. Thus, lighter cars have lower inertia and rolling resistance, needing less energy to get moving. Therefore, fuel economy is improved and lower levels of $\mathrm{CO}_{2}$ are emitted into the atmosphere.

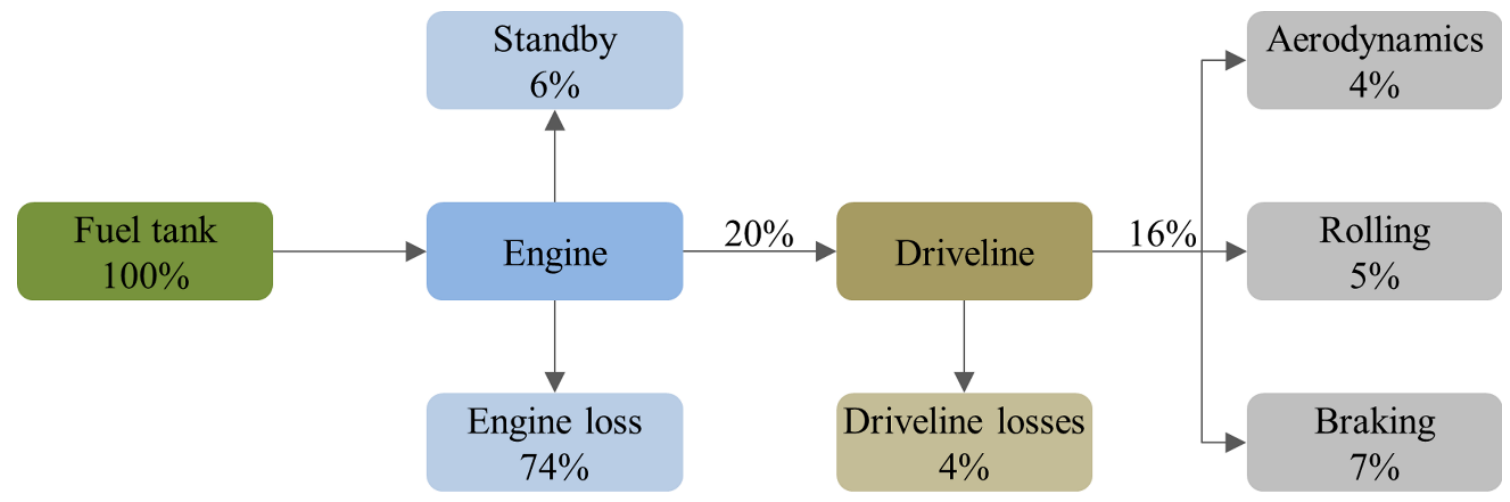

Figure 1.6. Representative vehicle energy flows in an urban driving cycle. Modified from [31].

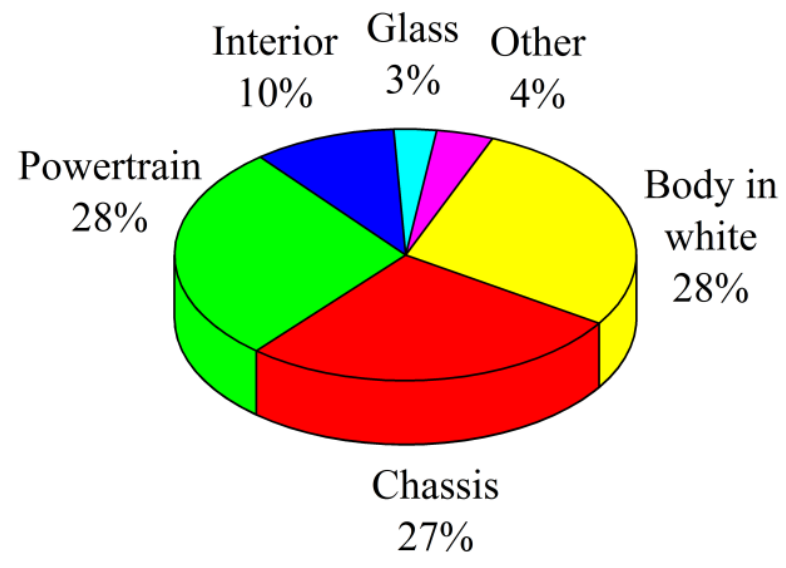

Figure 1.7. Vehicle mass distribution by subsystem. Modified from [32]. 
Figure 1.7 shows the vehicle mass distributed by subsystems [32]. Over $80 \%$ of its weight comes from the chassis, powertrain and body, which are mainly made of ferrous metals like cast iron and steel [33]. The environmental impact can therefore diminished by replacing these materials with lighter alternatives, such as High Strength Steels (HSS), Advanced High Strength Steels (AHSS), Aluminum (Al), Magnesium (Mg) or polymer composites [34].

High Strength Steels (HSS), Advanced High Strength Steels (AHSS) are derived from new alloying and processing combinations to produce unique microstructures with enhanced strength and elongation [35]. Aluminum is a low-density material with a broad range of opportunities to replace mild steel in powertrain, chassis and body structures [36]. Magnesium and its alloys are even lighter than Aluminum with excellent casting behavior and are often employed in body interior parts as well as in fuel tanks. Composite materials, especially Carbon Fiber Reinforced Polymers (CFRP) and Glass Fiber Reinforced Polymers (GFCP), allow great mass savings as compared to metals, and have been also adopted by car manufacturers to reduce weight car structure parts [37]. Figure 1.8 shows examples of lightweight body solutions adopted with aluminum (Audi A8) [38] and carbon fiber (BMW i Concept) [39]. However, the increase in cost involved in manufacturing these lighter materials restricts their widespread use in the competitive automotive market [31]. Table 1.3 summarizes the main mechanical properties of the different alternative materials and the raising cost as compared to the mild steel and iron cast. High performance polymers with increased specific strength and stiffness, polymer sandwich panels or polymer/metal hybrid systems are also considered for metal replacement [40].

a)

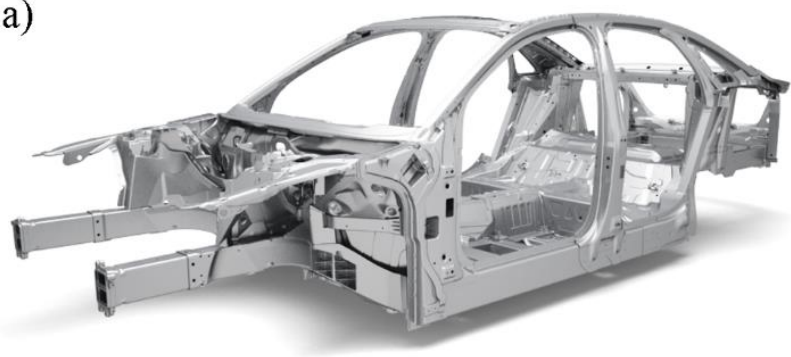

b)

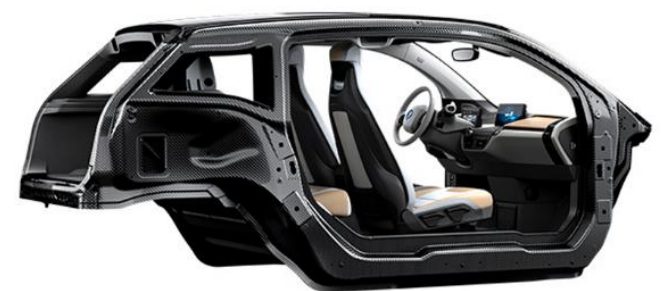

Figure 1.8. Lighter car bodies made of a) Aluminum (Audi A8) [38]; b) CFRP (BMW i Concept) [39]. 
Table 1.3. Properties and prices of alternative lightweight automotive materials [31].

\begin{tabular}{cccccc}
\hline Material & $\begin{array}{c}\text { Density } \\
(\text { relative) } \\
\left(\mathbf{g} / \mathbf{c m}^{\mathbf{3}}\right)\end{array}$ & $\begin{array}{c}\text { Yield } \\
\text { strength } \\
(\mathbf{M P a})\end{array}$ & $\begin{array}{c}\text { Tensile } \\
\text { strength } \\
(\mathbf{M P a})\end{array}$ & $\begin{array}{c}\text { Elastic } \\
\text { modulus } \\
(\mathbf{G P a})\end{array}$ & $\begin{array}{c}\text { Relative cost } \\
\text { per part }\end{array}$ \\
\hline Mild steel & $7.86(1.00)$ & 200 & 300 & 200 & 1.0 \\
Iron & $7.10(0.90)$ & 276 & 414 & 166 & - \\
High Strength Steel & $7.87(1.00)$ & 345 & 483 & 205 & $1.0-1.5$ \\
Aluminum & $2.71(0.34)$ & 275 & 295 & 70 & $1.3-2.0$ \\
Magnesium & $1.77(0.23)$ & 124 & 228 & 45 & $1.5-2.5$ \\
Carbon/Glass fibers & $1.57(0.20)$ & $200($ Flex.) & 810 (Flex.) & 190 (Flex.) & $2.0-10.0$ \\
\hline
\end{tabular}

As the use of plastics in automotive is continuously growing, it seems appropriate to conduct strategies to make them lighter. In this sense, foaming techniques by injection molding arises as one of the most promising methods to reduce weight in plastic components. The microcellular injection molding MuCell@ process, developed by the Massachusetts Institute Technology (MIT) and commercialized by Trexel Inc., consists of dissolving a physical foaming agent in the melted polymer during injection molding in order to create a cellular structure inside the plastic part. Consequently, lighter components with improved dimensional stability are obtained. Unlike the rest of lightweight alternatives previously presented, cost of foamed parts is also decreased, due to saved material and reduced cycle time [41]. Kim and Wallington [42] as well as Elduque et al. [43] found that by microcellular injection molding it is possible not only to lighten industrial components, but also reduce carbon footprint and $\mathrm{CO}_{2}$ emissions.

In 2011, Ford Motor Co. won the Grand Award at the $41^{\text {st }}$ edition of the Society of Plastics Engineers (SPE) Automotive Innovation Awards competition for the foamed instrument panel of Ford Escape/Kuga models as the largest component ever molded with the MuCell® process [44]. Volkswagen AG also manufactures the same foamed part of the VW Golf VII model, and some other automotive components have been produced with MuCell® technology (Figure 1.9), reaching different weight and cost reduction ratios depending on the application [45]. The development of microcellular injection molded bumper systems has also been reported in the literature [46]. 


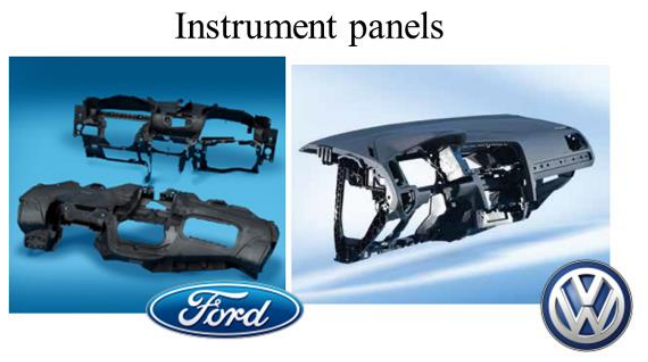

Interior door trim
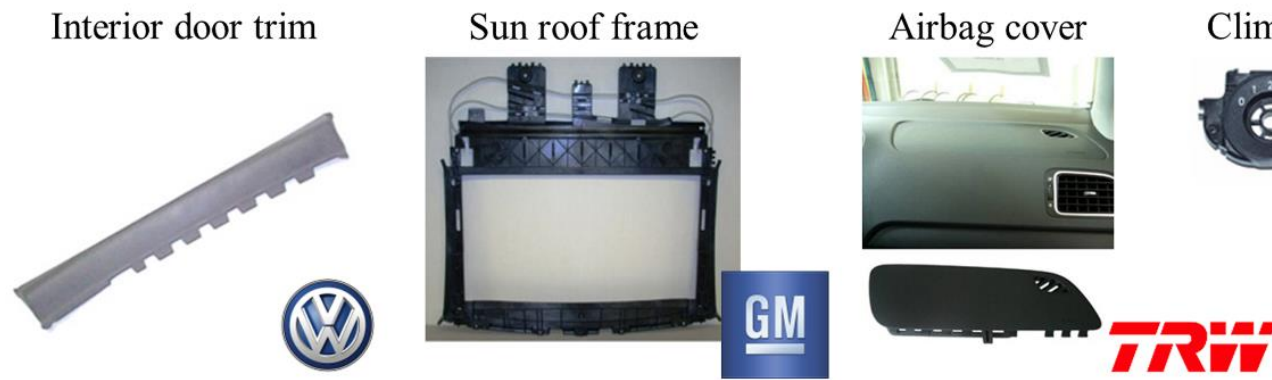

Figure 1.9. Automotive foamed plastic parts manufactured by MuCell® technology [44].

Nevertheless, the application of the MuCell@ foaming technology has not been widely extended in automotive parts due to several factors. For example, the high initial investment to implement the process, the additional complexity in controlling the production and the lower mechanical properties and worse surface qualities of foamed components as compared to the solid counterpart. With the aim of overcoming some of these drawbacks, new foaming injection molding technologies have emerged, such as IQ Foam ${ }^{\circledR}$, developed by Volkswagen AG. Further research on foaming mechanisms and their effect on polymer properties will be essential in order to fully incorporate microcellular plastics in automotive parts.

\subsection{Objectives}

The present thesis has been developed under the frame of the Industrial Doctorates Plan founded by the Generalitat de Catalunya in 2013, aimed to promote company strategic research projects in cooperation with university and technological research centers, which will be carried out as doctoral thesis. This project has been conducted as collaboration between the Universitat Politècnica de Catalunya - BarcelonaTech, by means of the Centre Català del Plàstic, and the Technical Center of SEAT SA with the support of Konzernforschung department of Volkswagen AG.

On one hand, the technological objectives from SEAT and Volkswagen side refer to characterize foamed plastics with the view of exploring potentials and limits in raising the application to real car parts. Besides, it is of great interest to assess a new foaming technology 
recently developed by Volkswagen (IQ Foam®) in comparison to other existing processes in the market (MuCell@).

On the other hand, from a scientific point of view the aims of the Universitat Politècnica de Catalunya and the Centre Català del Plàstic are mainly related to gain deeper knowledge about microcellular plastics and their manufacturing technologies, through studying the influence of processing variables on the cell structure and resulting properties as well as getting insight into their fracture behavior.

The materials selected for this research were commercial grades employed in automotive of an Acrylonitrile-Butadiene-Styrene (ABS) and a Polypropylene reinforced with Glass Fiber (PP GF). Combining both technological and scientific purposes, the following objectives were defined for the present project:

- Morphological, mechanical, thermal and fracture behavior characterization of different plastic foams (ABS and PP GF) obtained by injection molding.

- Analysis of the effect of processing parameters on the cell structure and mechanical performance.

- Comparative study of foaming MuCell® and IQ Foam® technologies in terms of morphology and mechanical properties of PP GF foamed by both processes.

\subsection{Overview of the thesis}

In Chapter 1 the motivation and status of use of plastics and lightweight possibilities in automotive industry and objectives of the thesis have been introduced. Chapter 2 deals with theoretical fundamentals of plastic foams characteristics and microcellular injection molding technologies. Furthermore, relevant literature about research on plastic foams is reviewed. Chapter 3 describes the materials and experimental procedure carried out in this project.

Chapter 4 shows the results of morphology analysis and mechanical, thermal and fracture characterization of ABS foamed material, as well as the influence on them of the injection molding parameters. Chapter 5 replicates a similar study with PP GF polymer. Chapter 6 presents the main conclusions of comparing the properties of PP GF samples foamed by MuCell® and IQ Foam ${ }^{\circledR}$ technologies. Finally, Chapter 7 summarizes the major contributions of this thesis, and suggests proposals for future research works. 


\section{Chapter 2: Theoretical aspects}

Natural foams have been known and employed historically, such as cork, wood, bones or sponges. However, it was not until the 1960s when science and technology were engaged in producing synthetic foams [47]. Plastics foaming enlarged the already wide versatility and property spectrum of polymers, and it was soon extended to different sectors and industries by replacing conventional business.

Thermoplastic foams are characterized by their excellent thermal and acoustic insulation properties, compressibility, cost effectiveness, and, of course, low density. For these reasons, they can be found in many different applications including packaging, building, transportation, shock absorbers, furniture or thermal and sound insulators. Nevertheless, cell sizes of conventional foams, usually over $250 \mu \mathrm{m}$, as well as the non-uniform distribution of them inside the plastic part, gave rise to a dramatic reduction in their mechanical properties, disabling their employment in structural applications. In the last decades several improvements have been made and advanced foaming technologies have been developed with the aim of reducing cell diameter up to the microcellular scale (1-100 $\mu \mathrm{m})$ and homogenizing its distribution, in order to decrease material consumption without sacrificing mechanical properties [48]. There is a constant search for more and more lighter materials. Indeed, polymer foams market is expected only to grow and is estimated to reach US\$ 131.1 billion by 2018 [49].

The main theoretical fundamentals of polymer foams, basic stages and phenomena governing foaming processes as well as technologies for foam manufacturing are introduced in this Chapter.

\subsection{Basic concepts of polymer foams}

\subsubsection{Classification of foams}

Plastic foams or cellular polymers are two phase materials of dispersed gaseous voids dispersed in a continuous polymer matrix. "Foam" and "porous" terms are usually indistinctly 
employed for this kind of materials, but they are different concepts. Foam involves volume expansion, while porous material does not [50].

Regardless of the processing technology, all plastic foams can be categorized according to different criteria. The most common classification of foams is through the connectivity of the cells. Open-cell foams contain cells that are connected by open faces forming an interconnected network, while in closed-cell foams each cell is sealed off from its neighbors (Figure 2.1). Cell struts isolates each cell improving insulation, dimensional stability and compressive strength. And, of course, some foams are partially open and partially closed [51].

Plastic foams can be also divided into rigid and flexible foams [52]. Rigid foams contain the polymer in the crystalline state or, if amorphous, below its glass transition temperature $\left(T_{g}\right)$. On the contrary, the polymer matrix of flexible foams is above its $T_{g}$. The former are usually employed in building, transportation and packaging, and the latter are mostly used in furniture, textiles and shock and sound applications. Finally, depending on the range of cell size, a foam can be said to be macrocellular $(>100 \mu \mathrm{m})$, microcellular $(1-100$ $\mu \mathrm{m})$, nanocellular (1-100 $\mathrm{nm})$ or ultrananocellular $(0.1-1 \mathrm{~nm})$ [52].

\subsubsection{Characteristics of foams}

A polymer foam possesses unique properties which are governed by the polymer matrix, cellular structure, gas composition and foaming technology. Thus, plastic foams can be characterized by the following parameters [53]:
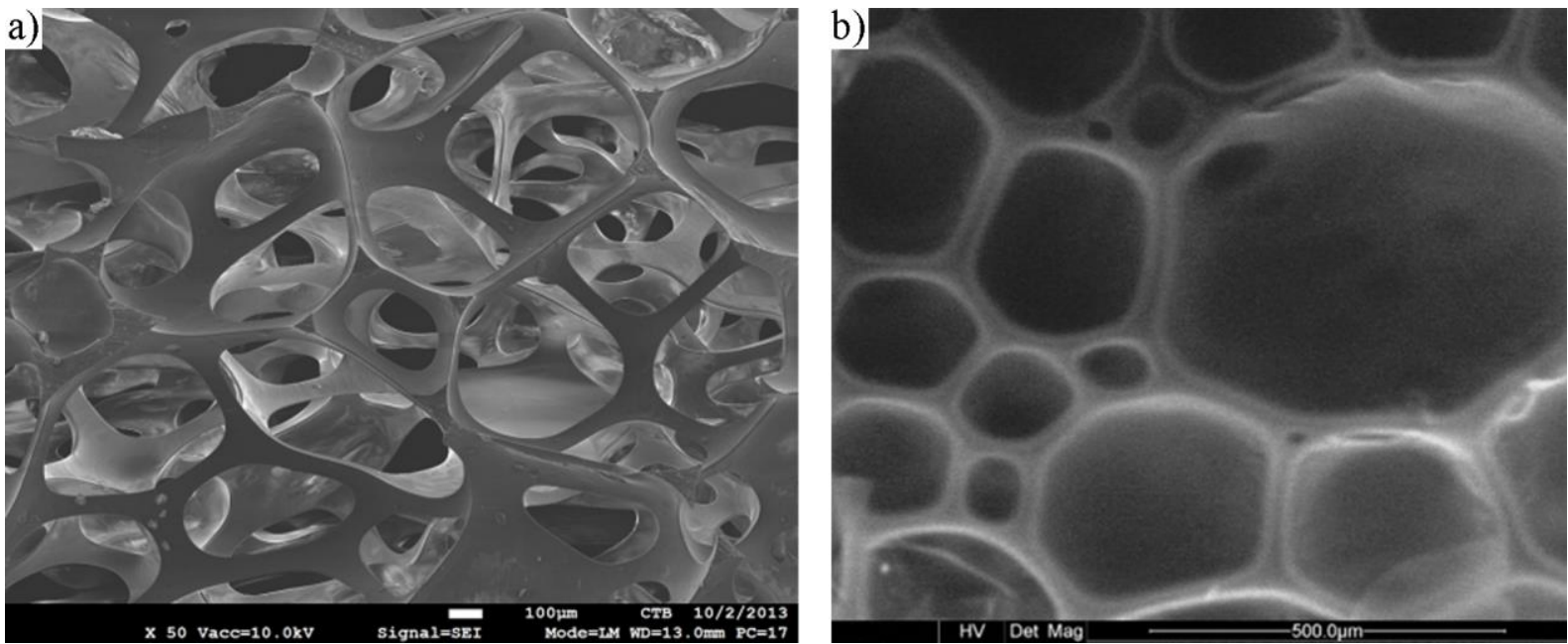

Figure 2.1. SEM micrographs of Polyurethane foams with a) open-cell [54]; b) closed-cell [55] structures. 
- The most important characteristic of a cellular plastic is its relative density $(\phi)$, also known as volume fraction, which measures the density of the foam $\left(\rho_{f}\right)$ as compared to that of the solid polymer $\left(\rho_{s}\right)$ :

$$
\phi=\frac{\rho_{f}}{\rho_{s}}
$$

It is the main characteristic affecting the mechanical and thermal properties [51]. Cellular polymers with relative densities lower than 0.1 are classified as low density foams.

- Cell size is another property resulted from the combination of polymer matrix, type of gas and processing conditions. It can be measured by inspecting a cross-section. Usually there is a distribution of cell sizes. Therefore, although sometimes it is reported as an average cell diameter, cell size is commonly analyzed by range of cell sizes or frequency histograms. Generally, the smaller the cell size, the higher the absorption energy as well as the insulation [56].

- Cell shape. First, small spherical disperse cells are created in the melted matrix. As they grow, cells get distorted forming polyhedral structures. Foam cells consist of three main parts: edges, vertices and faces [57]. Topology of cells and approaches to geometrical forms have been studied extensively, including bidimensional and tridimensional structures [51]. Figure 2.2 shows some polyhedrons employed in the literature to model cell shapes.

a)

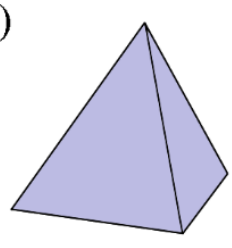

b)

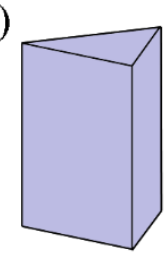

c)

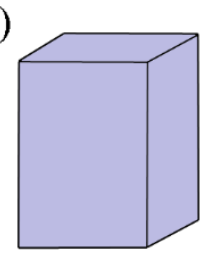

d)

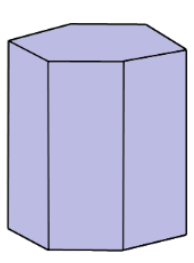

e)

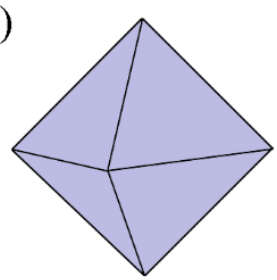

f)

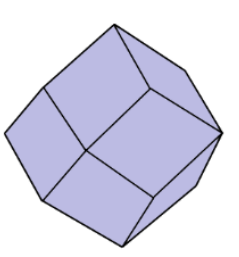

g)

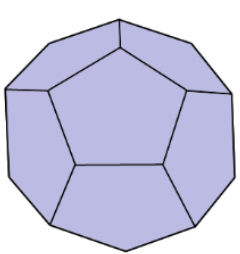

h)

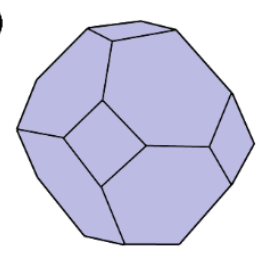

i)

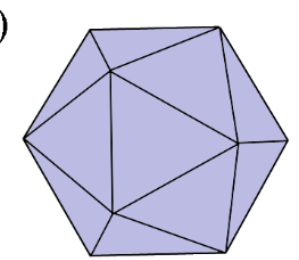

Figure 2.2. Three-dimensional polyhedral cells: a) tetrahedron; b) triangular prism; c) rectangular prism; d) hexagonal prism; e) octahedron; f) rhombic dodecahedron; g) pentagonal dodecahedron; h) tetrakaidecahedron; i) icosahedron. Modified from [51]. 
- Cell density. This property is defined as the number of cells contained in the volume of the foamed part, and it is greatly influenced by the amount of gas mixed with the polymer. Usually, the more gas introduced, the higher the cell density. It is also related with cell size. The gas added to the polymer can be distributed into high number of cells with small sizes, or, if they collapse, low quantities of cells with bigger dimensions.

- Open/close cell ratio. According to the extent of gas expansion and cell grow, cell walls could break and cells would be interconnected, forming open cell structures. This parameter can be determined by water absorption or permeation, and it is especially important in low density foams. At same level of added gas, it can be distributed into high number of small cells, or, if they collapse, low number of bigger cells.

- Cell anisotropy. Plastic foams are hardly made under conditions allowing free cell expansion in three dimensions, for example foams produced by extrusion or injection molding. According to processing parameters, cells could be more or less elongated or flattened. If cells were equiaxed, the mechanical properties would be isotropic, but in any other case the performance of the foamed part would be different in the length and width directions. Then, mechanical properties should be measured in both directions.

\subsubsection{Properties of polymer foams}

Principally, plastic foams stand out for their compressibility, energy absorption capability as well as low thermal conductivity [53], which are strongly influenced by their relative density and cell structure (cell density, size, shape, anisotropy and open/cell ratio).

Under compression load, polymer foams exhibit three main behaviors, corresponding to three clearly differenced regions in the stress-strain curve (Figure 2.3). Region 1 is a linear elastic range governed by cell walls bending and stretching. Then, cells collapse by cell wall buckling or, in case of brittle foams, cell wall crushing and fracturing, and a plateau is observed in Region 2. Finally, in Region 3 the foam density increases, raising the elastic modulus and plateau stresses and reducing the strain. 


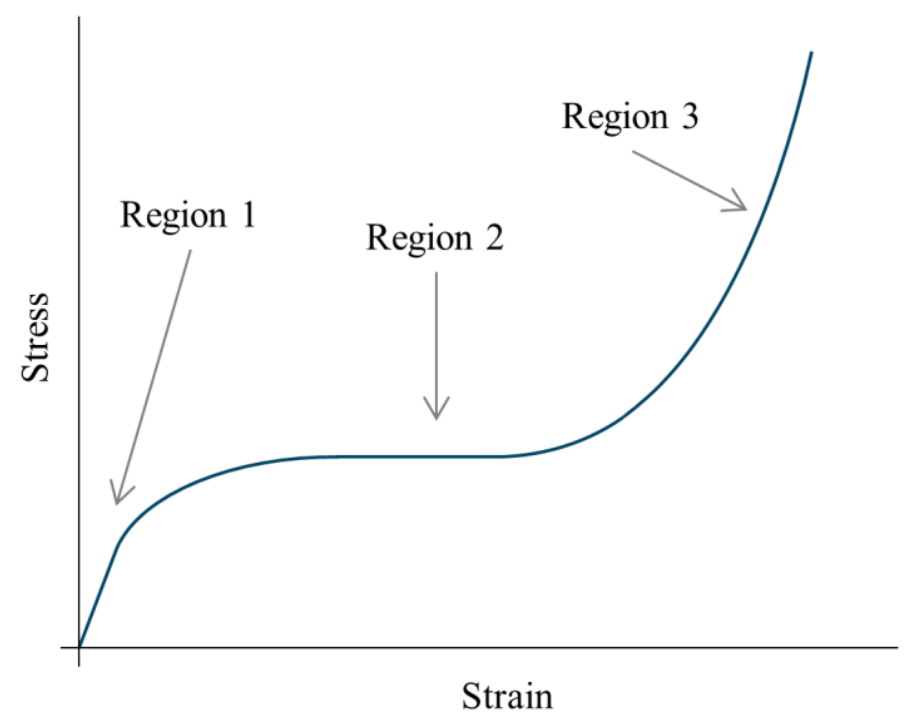

Figure 2.3. Schematic compression stress-strain curve for a plastic foam. Modified from [53].

Some plastic foams are employed in packaging applications because of their better energy absorption performance than the solid counterparts. This improved property is due to the ability of the foamed structure to absorb the energy keeping the maximum peak load below the limit to damage the packaged object. Energy absorption is governed essentially by cell walls deformation through elastic buckling, plastic yielding or brittle crushing in the plateau region. Depending on the polymer matrix material, the energy absorption mechanisms are different. In elastomeric foams, like flexible PUR, elastic cell buckling determines the plateau stress, storing much of external work which is released after the impact. However, there is also an energy component dissipated by hysteresis effects. In thermoplastic foams, such as Polystyrene (PS) or Polyethylene (PE) foams, energy is absorbed by plastic flow of cells or cell fracture and crushing, with very little instant recovery after the application of the load.

Polymer foams are mainly used as thermal insulator in buildings, transportation and appliances, due to the low heat transfer of cellular plastics. Four factors contribute to the thermal conductivity of a foam:

- Heat conduction through the polymer matrix.

- Heat conduction through the gas.

- Heat convention through the cells. It is only significant in extremely large cell sizes (> $10 \mathrm{~mm}$ ). Therefore, convection can be neglected in commercial foams.

- Radiation through cell walls and across voids. 
According to Eaves [53], thermal conductivity, with heat conduction as dominant factor, reduces with the density because of low conduction through the polymer matrix. However, there is a minimum of relative density of around 0.05 , below which radiation increases and with that the thermal conductivity of the foam. The effect of cell size is less pronounced, with a trend of decreasing radiation and conductivity as cells get smaller. Concerning other thermal properties, the author found no significant changes in melting points, specific heat and thermal expansion coefficient of foams as compared to the solid material.

Although they are secondary applications, polymer foams are also used as electrical insulators due to the enhanced electrical resistivity and for transmitting microwaves because their low dielectric constant [51]. Open-cell foams are also able to attenuate acoustic waves and have potential to absorb airbone and contact sounds [47].

Regarding mechanical properties, they are highly dependent on the relative density of the foams, as well as their cell structure. Aimed to create plastic consuming less material minimizing the loss in mechanical properties, especially toughness, the Massachusetts Institute of Technology (MIT) introduced in 1979 the first microcellular foams [58]. From cell morphologies of typical conventional foams, with average cell size of about $250 \mu \mathrm{m}$ and cell densities in the range of $10^{4}-10^{5}$ cells $\cdot \mathrm{cm}^{-3}$, microcellular plastics reduced the cell size below $100 \mu \mathrm{m}$ and increased the cell density up to $10^{6}-10^{9}$ cells $\cdot \mathrm{cm}^{-3}$. The central idea was to replace solid polymers with foamed ones containing a large number of very tiny cells that are smaller than the pre-existing flaws. Thus, cells could act as crazing initiation sites, blunt the crack tip, increase material toughness and maintain essential properties while density decreases.

\subsection{Foaming processing and technologies}

Foaming occurs when the gas is added to a plastic matrix. This gas can be released into the polymer through chemical reactions, or it can be physically introduced without undergoing chemical transformations. Either way, the gas-forming compound is known as blowing agent [52], which is classified into chemical or physical according to these two different methods to incorporate the gas.

Chemical blowing agents are solid substances not stable at higher temperatures and react releasing gas and other decomposition products [59]. They can be endothermic, if they require heat for the decomposition reaction, or exothermic, if they release gas and heat on 
reaching certain temperature. Once started the exothermic reaction, it cannot be influenced, whereas endothermic foaming agents allow to be regulated by heat transfer. Chemical blowing agents can be organic or inorganic materials, such as carbonates, hydrogen phosphates, tartrates, organic acid derivatives, azodicarbonamide (ADC) or benzene sulfonylhydrazide (BSH). The main advantage of using chemical blowing agents is the possibility of foaming almost any thermoplastic without modifications in the processing line (mainly extrusion and injection molding), adding the compounds in masterbach to the polymer in pellets form. Other benefits are broader operating window, self-nucleation and finer cell size [53]. However, the residual byproducts from the chemical reactions could interact with the polymer over time and make difficult recycling after the service life of the part [60].

On the contrary, physical blowing agents provide gas by physical changes. This change includes volatilization of a liquid, or release of a compressed gas. Traditionally, polymers were physically foamed by vaporization of low boiling organic chemicals, like pentane and hydrochlorofluorocarbons (HCFCs), which were dissolved in the polymer. Due to environmental issues related to emissions of HCFCs, inert gases such as carbon dioxide $\left(\mathrm{CO}_{2}\right)$, nitrogen $\left(\mathrm{N}_{2}\right)$ and oxygen $\left(\mathrm{O}_{2}\right)$, has been widely used as environmentally friendly physical blowing agents [61]. Using physical foaming agents eliminates residual byproducts from unreacted substances which may deteriorate the final performance of the foam [52], and their cost is relatively low, although in some cases they may require special equipment for use [53].

Physical microcellular foams can be obtained through different continuous and discontinuous processes. All of them share the same fundamental principles: the polymer is saturated with the bowing agent at high pressure and certain temperatures. Then, a sudden increase in temperature or decrease in pressure induces a thermodynamic instability triggering cell nucleation, followed by cell growth and stabilization and formation of the cell structure [62]. In 1982, Martini et al. [63] presented the solid-state microcellular process, which was a batch technology consisting of three main stages (Figure 2.4). First, the polymer is placed in a vessel with a non-reacting gas at high pressure and usually at room temperature. The gas diffuses into the polymer and is absorbed until an equilibrium gas concentration is reached. Then, the specimen is removed from the vessel and brought to atmospheric pressure. At this point, the sample is supersaturated of gas, that is, it is in a thermodynamically unstable state due to the excessive gas dissolved in the polymer. 


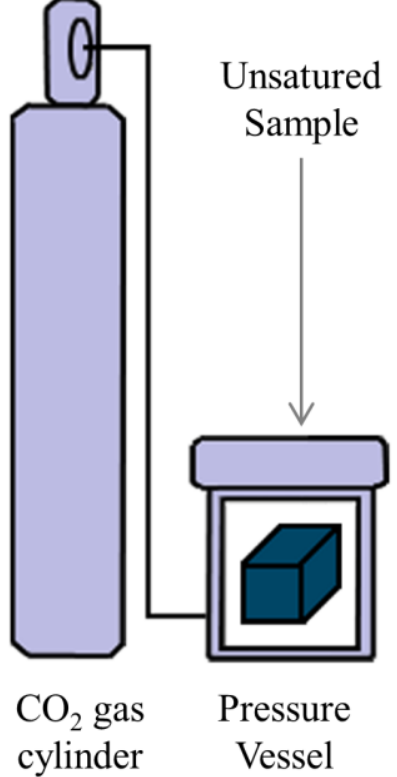

Stage I SATURATION OF SPECIMEN

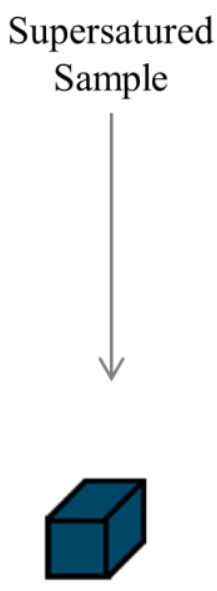

Stage II DESORPTION OF SPECIMEN
Foamed

Sample

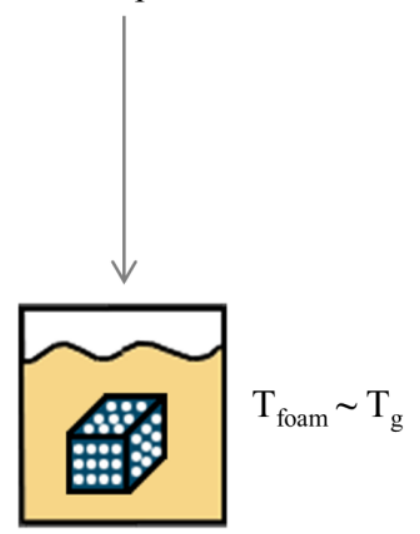

Heated

Bath

Figure 2.4. Schematic representation of Solid-state microcellular foaming process. Modified from [64].

After that, the sample is heated, typically in a hot bath with controlled temperature, to a temperature above the glass transition temperature $\left(T_{g}\right)$ of the polymer-gas mixture, enabling cell nucleation and growth. Finally, the specimen is immersed in a cooling bath to stabilize the resulted foam. The process can be controlled and varied by changing saturation pressure and time as well as foaming temperature [65]. In order to increase productivity of the Solidstate microcellular process, a semi-continuous technology was developed later [66]. However, the gas saturation step takes a long time, hours or even days according to the thickness of the part [65], which makes this technique inappropriate for large-scale production.

In this respect, foaming plastics by extrusion or injection molding seems more timeefficient. In the extrusion process, physical blowing agents are metered into the extruder under high pressure and are dissolved in the melt [67]. The rapid pressure drop generated as the polymer/gas mixture leaves the extruder through the die induces cell nucleation, followed by cell growth and stabilization during cooling. Although working with only one screw is possible, commercial systems often employ a second extruder in tandem with the plasticizing extruder, designed to keep heat and pressure into a range where a satisfactory foam can be formed (Figure 2.5). Several works dealing with the effects of gas content, surface quenching, die geometry, and temperature on foam morphologies with different materials can be found in the literature [68]. 


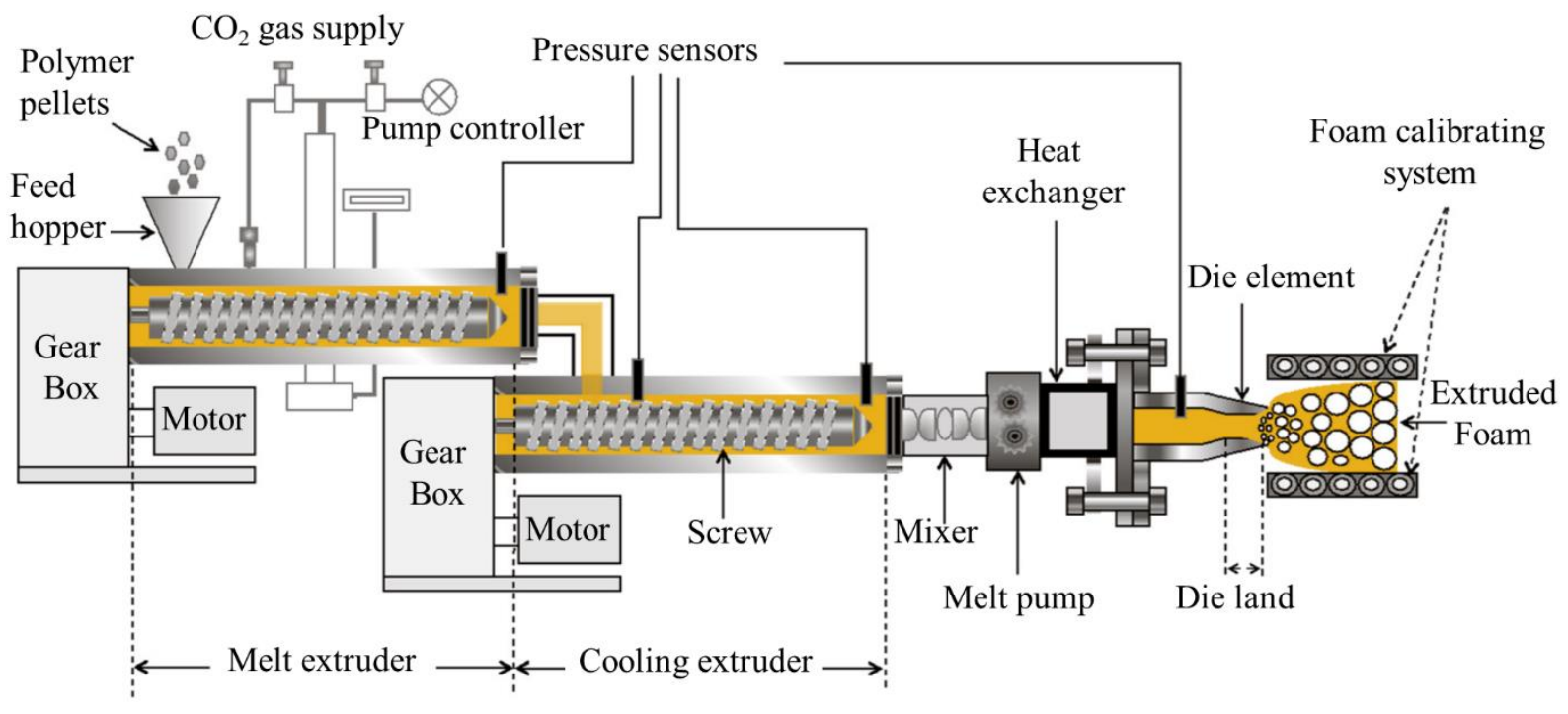

Figure 2.5. Schematic representation of foam extrusion on a tandem-line. Modified from [62].

The major disadvantage of extrusion methods is that only geometries with constant cross-sections can be processed. On this basis, injection molding is put forward as a suitable technique to mass-production of thermoplastic foams with complex geometries. Physical foaming through injection molding comprises the introduction of a gas injector unit and some gas leakage preventive measures such as nozzle shut-off valve or additional external control gate [69]. The gas is dissolved in the melt polymer at high pressure in the plasticizing unit and the injection of the polymer/gas blend through the nozzle into the mold cavity at atmospheric pressure prompts the pressure drop needed to nucleate millions of cells. Cell growth and stabilization take place inside the mold cavity while cooling stage. The temperature gradient from the mold wall to the center of the part gives rise to a structure consisting of two solid surface layers, due to a fast solidification in touch with the tool, and a foamed core, usually with close-cell conformation.

Different technologies for foaming through injection molding have been developed, differing one from each other in the procedure of dissolving the gas in the polymer matrix [58]. Optifoam ${ }^{\circledR}$ was introduced by the Institut für Kunststoffverarbeitung (IKV, Germany) and licensed to Sulzer Chemtech Ltd (Switzerland), and consists of assembling a special nozzle between the plasticizing unit and the shut-off nozzle of a conventional injection molding machine, where the gas is introduced under pressure (Figure 2.6). In Profoam® process, also invented at the IKV Institute for Plastics Processing at RWTH University in Aachen (Germany), plastic pellets are impregnated with blowing agents before they are fed into the barrel. On the other hand, Sumitomo (SHI) Demag Plastics Machinery GmbH (Germany) patented the ErgoCell® technology, based on an external module for gas metering 
and mixing installed upstream of a standard plasticizing unit, as well as a hydraulic shut-off nozzle, full integration of its manipulation into the machine controller and the gas station. However, there are only few applications of both technologies worldwide. MuCell@ process, developed by the Massachusetts Institute Technology (MIT, USA) and commercialized by Trexel Inc. (USA), has had the most industry acceptance and nowadays is the leading microcellular foaming technology. Recently, Volkswagen AG has developed a new physical foaming technique, IQ Foam ${ }^{\circledR}$, which is expected to be integrated in industrial production in forthcoming years. Both MuCell® and IQ Foam ${ }^{\circledR}$ technologies are subject of this study, and their operating principles are described in detail in subsequent sections.

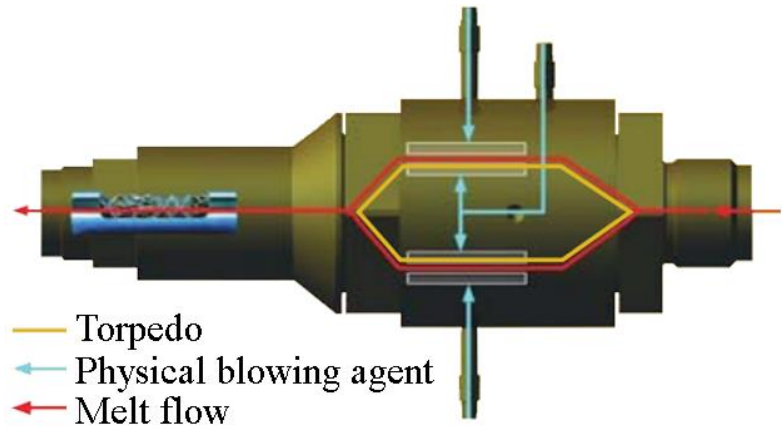

Figure 2.6. Ring-shaped die design for Optifoam ${ }^{\circledR}$ process. Modified from [69].

\subsubsection{Stages of microcellular foaming}

Independently of the different technologies available to foam plastics by injection molding, the foaming process comprises four main steps [58]: dissolution of the gas in the polymer, cell nucleation, cell growth and foam stabilization in the mold (Figure 2.7).

\subsubsection{Gas dissolution}

The first stage of microcellular injection molding is creating the polymer/gas solution. As aforementioned above, every foaming technology differs from the other in the way of introducing the gas into the polymer. MuCell ${ }^{\circledR}$ places its gas injector unit in the dosing zone of the barrel, while IQ Foam ${ }^{\circledR}$ incorporates the gas at the feeding area of the plasticizing unit together with the polymer in pellets form. Thus, in both cases the polymer/gas solution is formed once the polymer is melt inside the barrel. As the gas flows into the molten polymer, big gas droplets are generated, whose size depends on the gas pressure, gas flow rate, viscosity of the plastic and wiping frequency of the flights [58]. 


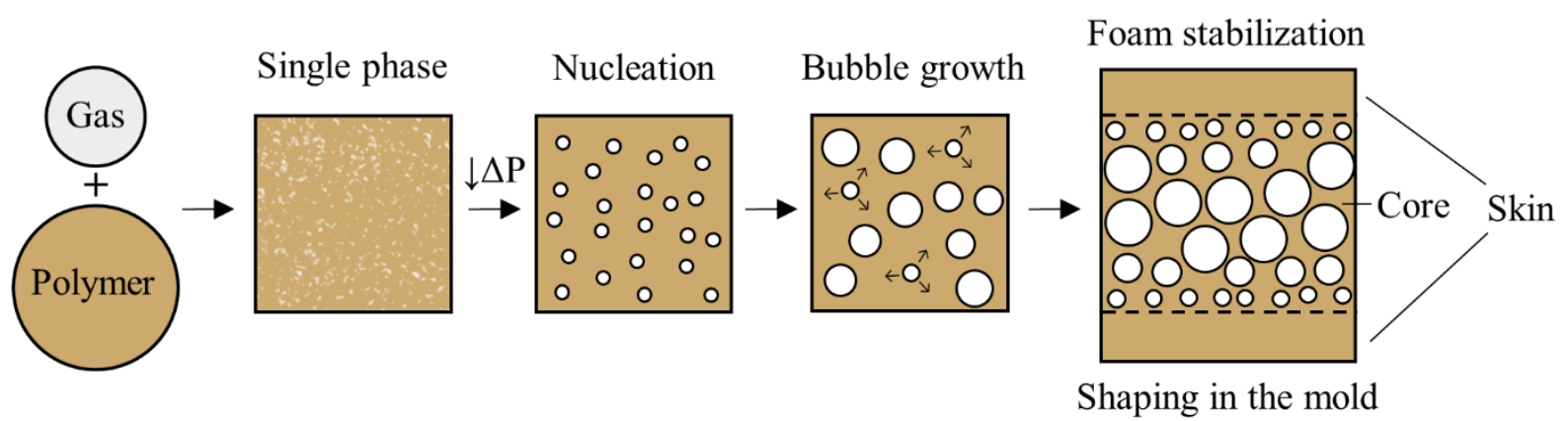

Figure 2.7. Stages of microcellular polymer foaming process.

Then, the screw rotation induces elongation of the gas droplets by shear deformation, until they break up into many small gas droplets. These gas droplet are stabilized in the screw channels to form bubbles which diffuses quickly into the polymer due to shear deformation increasing area-to-volume ratio. As a result, a polymer/gas solution with excellent tiny bubbles distribution is created, which could be ideally considered as a single-phase solution, that is, without separation between gas and polymer phases.

The main difficulty when making a nice single-phase solution is the limited mixing time and short recovery time in the plasticizing unit within the conventional injection molding cycle. For this reason, MuCell ${ }^{\circledR}$ developers leaned towards injecting the gas into the molten polymer at supercritical conditions. In this state, that is, at pressure and temperature above the critical point (Figure 2.8) the blowing agent exhibit some properties that maximize the solubility and dissolution in the polymer [70]. On one hand, the supercritical fluid (SCF) has liquid-like properties, like the density. On the other hand, it keeps some gas-like properties, such as low viscosity and surface tension. Both liquid-like and gas-like properties are essential to precisely meter the SCF and mix with the molten polymer. In case of IQ Foam®, gas does not require to be injected at supercritical conditions, due to the fact that polymer and gas move forward along the barrel from the feeding zone to nozzle, having longer time and space to increase pressure and temperature and form the proper polymer/gas solution. In the view of the above, it may be concluded that solubility and diffusivity are the key factors for achieving foams with the desired fine cell structure. Solubility is the capability of the gas to be dissolved in the molten polymer. Usual techniques for measuring solubility is the increase in mass due to the gas sorption [71]. Thus, the higher the solubility, the more amount of gas is absorbed by the polymer. According to experiments conducted by Sato et al. [72] solubility increases almost linearly with pressure and decreases with increasing temperature. Nevertheless, if energy is absorbed from dissolution process (case of organic solvents like polymers), a "reverse solubility" phenomena occurs and solubility raises with temperature. 


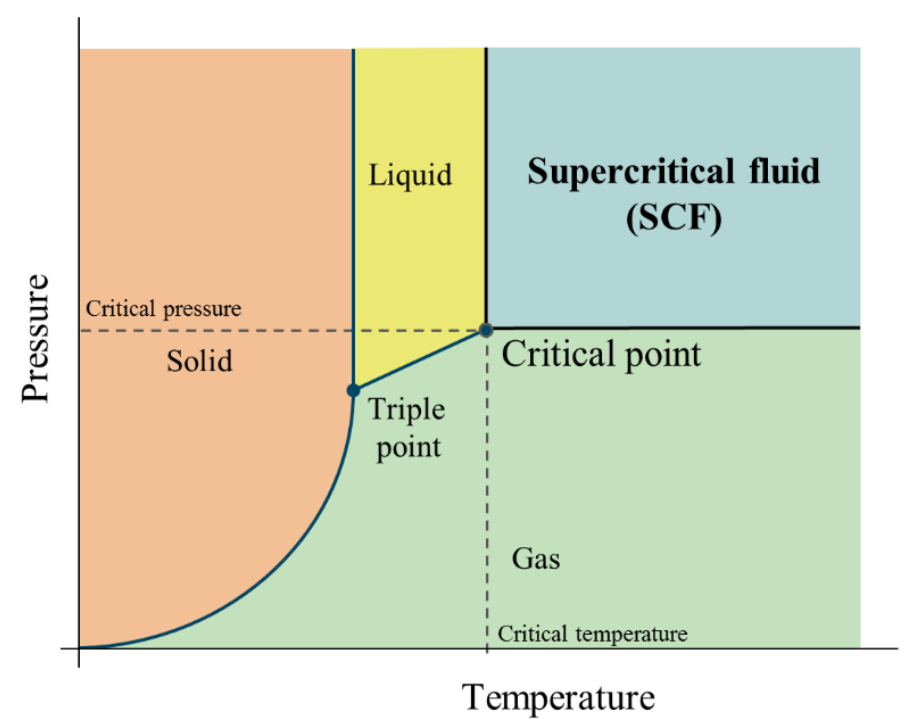

Figure 2.8. Diagram of material phases. Modified from [58].

Either way, solubility changes more quickly with the pressure than with the temperature, so an increase in solubility with the pressure is expected in most cases, being the effect of temperature secondary [58]. At this point, within the plasticizing stage of the injection molding machine, under high pressure and temperature, the solubility of the gas is also high and the polymer becomes saturated with the blowing agent.

The gas concentration $(C)$ can be estimated by the Henry's law [73], as a function of the molten polymer pressure $\left(P_{m}\right)$ and temperature $\left(T_{p o l y}\right)$ in thermodynamic equilibrium:

$$
C=H\left(P_{m}, T_{\text {poly }}\right) P_{m}
$$

Where $H$ is the Henry's law constant. It is constant at low temperatures, but it becomes time-dependent as temperature raises:

$$
H=H_{0} e^{-E_{S} / R_{g} T} \text { poly }
$$

In Equation (2.3), $H_{0}$ is a preexponential constant for Henry's law, $E_{s}$ is the activation energy and $R_{g}$ is the gas constant.

Some Henry's law constants have been determined experimentally, and an experimental relationship for amorphous polymers has been also found [74]:

$$
\ln H=-2.338+2.706\left(T_{c r} / T_{p o l y}\right)^{2}
$$


Here, $T_{c r}$ is the critical temperature of the gas. The gas concentration in semicrystalline plastics depends on the extent of crystallinity $\left(X_{c}\right)$ and the solubility of the gas in an amorphous region of the semicrystalline polymer $\left(X_{a}\right)$ :

$$
C=\left(1-X_{c}\right) X_{a}
$$

On the other hand, diffusivity refers to the rate at which gas molecules move through the molten polymer matrix [58]. It determines the time needed to dissolve the blowing aging in the polymer as well as the kinetics of cell nucleation and growth. The diffusion coefficient $D$ can be determined by sorption/desorption experiments and through the Fick's second law [75]:

$$
\frac{M_{t}}{M_{0}}=4 \cdot(D / \pi)^{1 / 2}\left(t_{a}^{1 / 2} / h\right)
$$

Where $M_{0}$ is the equilibrium concentration of gas without desorption, $M_{t}$ is the amount of gas absorbed by the polymer at time $t_{a}$ and $h$ is the sample thickness. A theoretical diffusion coefficient can be also estimated following an Arrhenius-type temperaturedependence law [56] with a maximum diffusion coefficient $D_{0}$ (at infinite temperature), the activation energy for diffusion $E_{d}$, the molar gas constant $R_{g}$, and the absolute temperature $T$ :

$$
D=D_{0} e^{-E_{d} / R_{g} T}
$$

Diffusivity of gases is low at room temperature, and increases considerably with the temperature. Diffusivity is also dependent on the blowing agent. Gases with lower molecular weight, such as carbon dioxide $\left(\mathrm{CO}_{2}\right)$ and nitrogen $\left(\mathrm{N}_{2}\right)$, present higher diffusivity under same pressure and temperature conditions, resulting in higher cell nucleation and growth. Solubility and diffusivity also varies with the polymer matrix. Lin et al. [76] concluded that amorphous polymers absorbed much more gas and at higher rate than semicrystalline ones. Even in semicrystalline plastics, crystalline regions prevent from gas concentration and the blowing agent is absorbed by amorphous regions [77], giving rise to non-uniform cell distribution in the foam. In reinforced polymers, gas solubility is improved because of gas concentration in the interphase between polymer and fillers [58].

Carbon dioxide $\left(\mathrm{CO}_{2}\right)$ and nitrogen $\left(\mathrm{N}_{2}\right)$ are commonly employed as physical blowing agents because they are chemically inert, inexpensive, non-flammable and non-toxic permanent gases. Additionally, they can be easily processed at supercritical conditions, due to 
their low critical pressure and temperature points. Table 2.1 displays the physical properties of both gases. They have similar diffusion rates, but lower solubility of $\mathrm{N}_{2}$ than that of $\mathrm{CO}_{2}$ has been reported $[78,79]$. However, $\mathrm{N}_{2}$ has been found to be more effective to produce foams with larger cell densities and reduced cell sizes in Polypropylene (PP) and Polyethylene (PE) [80, 81].

Table 2.1. Physical properties of $\mathrm{CO}_{2}$ and $\mathrm{N}_{2}$ blowing agents [58].

\begin{tabular}{ccc}
\hline Property & COO2 & N2 \\
\hline Molecular weight & 44 & 28 \\
Gas density at $21^{\circ} \mathrm{C}\left(\mathrm{g} / \mathrm{cm}^{3}\right)$ & 0.00183 & 0.00116 \\
Thermal conductivity $(\mathrm{W} / \mathrm{m} \cdot \mathrm{K}) /{ }^{\circ} \mathrm{C}$ & $0.0166 / 30$ & $0.0261 / 27$ \\
Boiling point $\left({ }^{\circ} \mathrm{C}\right)$ & -78.5 & - \\
Vapor specific heat $(\mathrm{cal} / \mathrm{g} \cdot \mathrm{K}) /{ }^{\circ} \mathrm{C}$ & $0.204 / 25$ & $-243 / 25$ \\
Heat of vaporization $(\mathrm{cal} / \mathrm{g})$ & 137 & - \\
Global warming potential $(\mathrm{GWP})$ & 0.00025 & - \\
Triple point, temperature $\left({ }^{\circ} \mathrm{C}\right) / \mathrm{pressure}(\mathrm{MPa})$ & $-57 / 0.52$ & -147.0 \\
Critical temperature $\left({ }^{\circ} \mathrm{C}\right)$ & 31.1 & 3.4 \\
Critical pressure $(\mathrm{MPa})$ & 7.22 & 1.146 \\
Density at $25{ }^{\circ} \mathrm{C}\left(\mathrm{g} / \mathrm{cm}{ }^{3}\right)$ & 1.811 & \\
\hline
\end{tabular}

\subsubsection{Cell nucleation}

Once the gas is completely dissolved and the polymer gets saturated of gas within the plasticizing unit, a rapid thermodynamic instability is required to induce cell nucleation. This fast thermodynamic instability can be generated either by a pressure drop or a change in temperature. In injection molding process, a high pressure drop is easily caused when the polymer/gas solution goes through the nozzle orifice or valve gate. At this point, in the gate of the mold, the solubility decreases and the polymer becomes supersaturated of blowing agent, which precipitate out in the form of gas and, hence, foams the polymer [58].

The classical nucleation theory was introduced by Colton and Suh [82] and has been widely employed to model cell nucleation mechanisms. If the material is entirely homogeneous, nucleation takes place in the polymer matrix, where the required activation 
energy is uniform, and the process is called "homogeneous nucleation". The formation of a bubble of gas involves a change in Gibbs free energy $\left(\Delta G_{h o m}\right)$ that can be expressed as:

$$
\Delta G_{\text {hom }}=-V_{b} \Delta P+A_{b} \gamma_{b p}
$$

Where $V_{b}$ is the volume of the bubble nucleus, $\Delta P$ is the pressure difference between inside and the surrounding of the bubble, $A_{b}$ is the surface area of the bubble nucleus, and $\gamma_{b p}$ is the surface energy of polymer - bubble interface. This excess in Gibbs free energy is minimized in perfect spherical bubble with radius $r b$. Accordingly, Equation (2.8) can be rewritten as follows:

$$
\Delta G_{h o m}=-\frac{4}{3} \pi r_{b}^{3} \Delta P+\pi r_{b}^{2} \gamma_{b p}
$$

Note that volume term of energy increases with $r_{b}^{3}$ whereas the interfacial term with $r_{b}^{2}$, as illustrated in Figure 2.9.

A bubble can only be stable and grow if its size exceeds a critical radius $r^{*}$, given by differentiation of Equation (2.9):

$$
r^{*}=\frac{2 \gamma_{b p}}{\Delta P}
$$

Thus, the free energy required to form the critical nucleus is:

$$
\Delta G_{\text {hom }}^{*}=\frac{16 \pi \gamma_{b p}{ }^{3}}{3 \Delta P^{2}}
$$

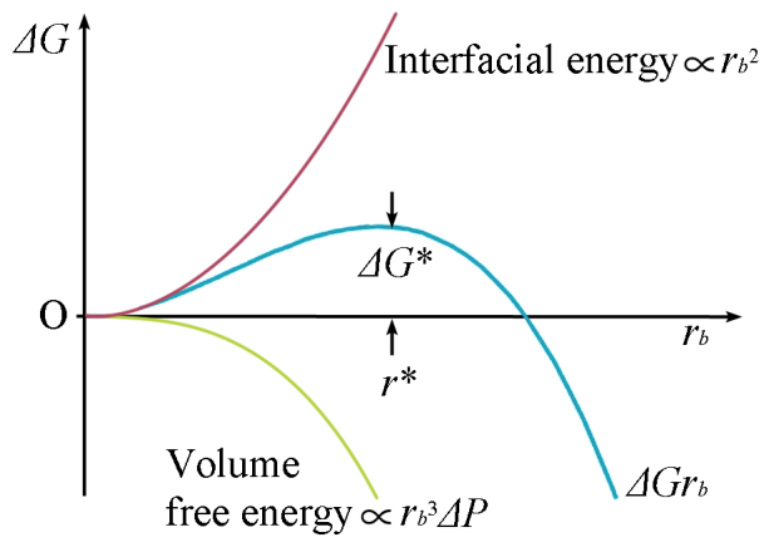

Figure 2.9. Free energy change associated with the homogeneous nucleation of a sphere of radius $r$. Modified from [83]. 
Equation (2.11) determines the energy activation barrier that must be overcome to form a stable nuclei. Generally, it depends on two opposite factors: the energy available in the gas diffused into the nuclei and the surface energy needed to form the cell surface. If this energy barrier is exceeded, the homogeneous nucleation rate $\left(N_{h o m}\right)$, at which gas clusters reach the critical size to form a stable nuclei, can be described by assuming a Boltzmann distribution by the following expression:

$$
N_{\text {hom }}=f_{0} C_{0} e^{-\Delta G_{h o m}^{*} / k T}
$$

Where $f_{0}$ is a frequency factor for homogeneous nucleation, $C_{0}$ is the concentration of gas molecules in solution, $k$ is the Boltzmann's constant and $T$ is the temperature. The major influence of pressure drop on cell morphology can be deduced from Equation (2.12). By increasing pressure drop, the energy barrier decreases, resulting in higher cell nucleation rate.

Nevertheless, most injection molded materials contain additives, so the energy barrier is non-uniform through the entire polymer matrix. Then, cell creation stage is mainly governed by "heterogeneous nucleation" process at interfaces between the two phases [83]. In a solid/liquid interface, the energy barrier is reduced and becomes dependent on the wetting angle of polymer - particle - gas interface $(\theta)$. The equations above are modified by a heterogeneity function $S_{h}(\theta)$ to estimate the heterogeneous energy barrier $\left(\Delta G_{h e t} *\right)$ and heterogeneous nucleation rate $\left(N_{h e t}\right)$ :

$$
\begin{aligned}
& S_{h}(\theta)=\frac{1}{4}(2+\cos \theta)(1-\cos \theta)^{2} \\
& \Delta G_{\text {het }}^{*}=\frac{16 \pi \gamma_{b p^{3}}}{3 \Delta P^{2}} S_{h}(\theta) \\
& N_{\text {het }}=f_{1} C_{1} e^{-\Delta G_{\text {het }}^{*} / k T}
\end{aligned}
$$

With $f_{1}$ as frequency factor for heterogeneous nucleation and $C_{1}$ as gas concentration in the interface. According to the additive type, the energy barrier can be further decreased and cell nucleation improved as a function of the interface angle $\theta$. Different types of particles, like talc, have been used as cell nucleating agents. Leung et al. [84] searched for the ideal filler surface geometry and concluded that nucleating agents with several crevices and small semiconical angles are the most appropriate for polymeric foaming processes. 
According to Colton and Suh [83], homogeneous and heterogeneous nucleation are not exclusive processes, but both mechanisms can occur simultaneously if the energy barriers are exceeded. Therefore, a mixed nucleation mode has been studied. As gas diffusion into bubbles nucleated by heterogeneous nucleation is favored because of a lower energy input required, the gas concentration for homogeneous nucleation $\left(C_{0}{ }^{\prime}\right)$ will be reduced accordingly to the number of gas molecules in a bubble nucleus $\left(n_{b}\right)$ and the time since heterogeneous nucleation occurred $\left(t_{b}\right)$ :

$$
C_{0}^{\prime}=C_{0}-N_{h e t} n_{b} t_{b}
$$

Hence, the homogeneous nucleation rate $\left(N_{h o m}\right)$ in presence of heterogeneous nucleation decreases due to the lowered gas concentration:

$$
N_{\text {hom }}^{\prime}=f_{0} C_{0}^{\prime} e^{-\Delta G_{\text {hom }}^{*} / k T}
$$

The rate of total nucleation for mixed homogeneous and heterogeneous modes can be obtained combining Equations (2.15) and (2.17):

$$
N_{\text {tot }}=N_{\text {hom }}^{\prime}+N_{\text {het }}
$$

Although the classical nucleation theories are considered the basis for studying cell nucleation phenomena, the application of these theories are often limited and barely consistent with experimental results. The reason of these accuracy errors is simplifying assumptions like static thermodynamic equilibrium process and absence of time and pressure drop rate effects, apart from difficulties in precise calculations of the variables. Further research dealt with adjusting the equations above considering reductions in heterogeneous free energy barrier in shear flow fields [85] and continuous changes in critical radius during the foaming process [86]. Shirvan et al. [87] reviewed and discussed the main contributions to nucleation rate theories in thermoplastic foams produced by physical foaming agents through sudden pressure drop.

\subsubsection{Cell growth}

Once enough stable nuclei equal or bigger than the critical radius are created, cells begin to grow up. The polymer/gas system is still warm, the injected short shot volume leaves enough space, and there is also enough blowing agent to supply the required gas. Thus, there are favorable conditions for cell expansion. 


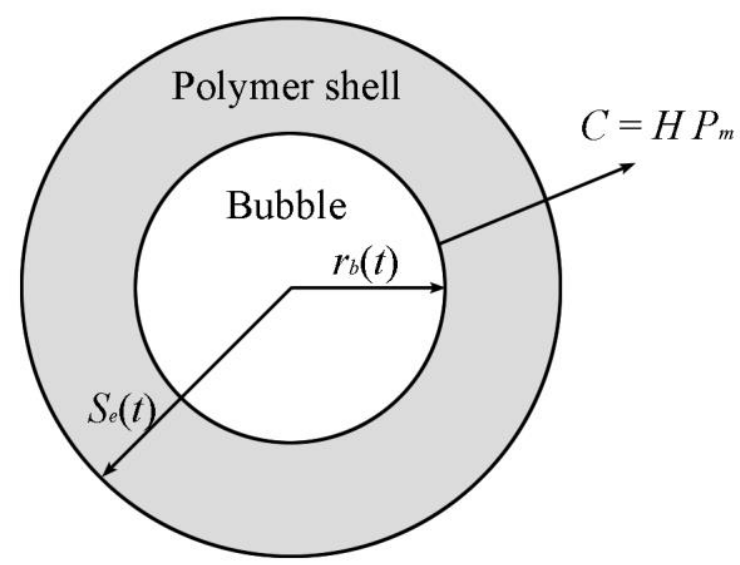

Figure 2.10. Schematic diagram of the unit cell model. Modified from [88].

Cell growth is a complex process governed by pressure and temperature of the system, gas diffusion, hydrodynamic interaction between bubble and molten polymer and rheological properties of the polymer/gas mixture. In amorphous polymers, the blowing agent dissolved in the melt leads to a decrease in the glass transition temperature $\left(T_{g}\right)$ [89], viscosity and elasticity, allowing cells to grow fast. As bubbles become higher, gas diffusion and expansion promote cooling and polymer viscoelasticity increases, reducing the rate of cell growth. Eventually, cells continue to grow until the polymer reaches its $T_{g}$ or its stretching limit [50]. If the second case occurs, a large number of bubbles are growing in close proximity to each other, so thinning and rupturing of the cell walls give rise to cell collapse and coalescence, opening the cell structure [90].

A classical cell growth theory was given by Amon and Denson [88] in 1984. It is a simplified model, assuming absence of gravity and inertia effects, incompressible molten polymer, isothermal cell growth process, ideal gas and no loss of gas to the surroundings. On this basis, a cell unit consisting of a spherical gas bubble of radius $R$ concentrically surrounded by a polymer melt envelop (or shell) with a constant mass and radius $S_{e}$ (Figure 2.10)

Thereby, the change rate of the radius $r_{b}$ over time $\left(d r_{b} / d t\right)$ is determined through the melt viscosity $(\eta)$ and pressure $(P)$, the gas pressure $\left(P_{g}\right)$ inside the bubble and the surface energy of polymer - bubble interface $\left(\gamma_{b p}\right)$ by the following expression:

$$
\frac{d r_{b}}{d t}=\frac{1}{4 \eta}\left[\left(P_{g}-P\right) r_{b}-2 \gamma_{b p}\right]
$$


$P_{g}$ is defined by diffusion, while $P$ is determined by the macroscopic pressure equation governing the molding process [91]. As cell grows, the radius $r_{b}$ increases and the pressure inside the gas $\left(P_{g}\right)$ decreases. The relation between both variables derived from the mass transfer balance in the diffusion process of the gas dissolved in the melt governed by the Fick's law:

$$
\frac{d C}{d t}+v_{r} \frac{d C}{d r_{c}}=D\left[\frac{1}{r_{c}^{2}} \frac{d}{d r_{c}}\left(r_{c}^{2} \frac{d C}{d r_{c}}\right)\right] r_{b}(t) \leq r_{c} \leq S
$$

Where $C$ is the gas concentration, $D$ is the diffusion coefficient, $r_{c}$ is the radial coordinate and $v_{r}$ is the gas diffusion velocity calculated by Equation (2.21):

$$
v_{r}=\frac{r_{b}^{2}}{r_{c}^{2}} \frac{d r_{b}}{d t}
$$

Knowing the gas concentration, the pressure gas can be determined by the Henry's law given in Equation (2.2).

At this point it should be emphasized the fact that gas diffusion occurs from small to large cells, as small bubbles contain gas at a higher pressure than large ones [53]. In the literature there are some works collecting all differential equations derived from the model for numerical computations of cell growth in microcellular injection molding [91, 92].

\subsubsection{Foam stabilization and shaping in the mold}

The cooling step of the injection molding cycle stabilizes the foam, while the foamed structure shapes in the mold. Inherently to the process, a skin/core structure is built up. Due to the fast cooling of the polymer in touch with the mold wall, nucleated cells are not able to grow and two unfoamed skin layers are formed. Dong et al. [93] studied the mechanisms involved in the generation of these surface layers, and concluded that they consist of two regions. The outer one is a thin frozen layer containing deformed and broken cells because of the fountain flow, while the inner region is a solid-like thick layer with no visible cells, but with different structural properties from the solid material due to gas dissolved in it from unstable nucleated cells that cannot grow under high pressure conditions. In the foamed core there is also a variety of cell sizes, cell densities and cell shapes along the thickness because of the temperature gradient, fountain flow and shear stresses during the injection molding filling and after filling stages [94]. Logically, the morphology of the skin layers, as well as the foamed core, is dependent upon the processing parameters. 
However, foamed parts with physical blowing agents present worse surface quality than the conventional non-foamed part. It has limited the scope of application of microcellular injection molding processes. Swirl marks and silver streaks are generated because of gas trapped in the mold, as the melt flow front pushes cells to the surface cavity, where they are stretched and frozen [95]. Other typical surface defects are surface blistering, post-blow and large surface roughness [96]. Some progress in improving surface quality has been made and different solutions based on mold technologies have been successfully applied. These complementary techniques are described below.

Despite these limitations, microcellular injection molding offers several benefits to thermoplastic parts manufacturers [97]. The lower viscosity of the polymer/gas solution facilitates filling the cavity in a shorter time, and with lower pressure and clamp tonnage. It also enables to fill thin-wall sections, which could hardly be injected by means of conventional processes. While conforming the shape of the mold, the residual gas pressure inside the cells pushes the part to the mold walls, improving dimensional stability by reducing or eliminating shrinkage and warpage of the parts. That is, cells provide packing pressure, so the packing and holding phases can be omitted. Finally, the cooling time is also shortened, because of the lower amount of material to cool down and also because cell nucleation and growth are endothermic processes, contributing to cooling down the part faster. As a result, the overall cycle time of the foaming processes is reduced from $20 \%$ up to $50 \%$ as compared to conventional injection molding [96] (Figure 2.11).

Almost every mold without modifications can be employed for microcellular injection molding. However, a careful design focused on improving venting, homogenizing cooling and strengthening welding lines will lead to optimal results of microcellular molded parts [58].

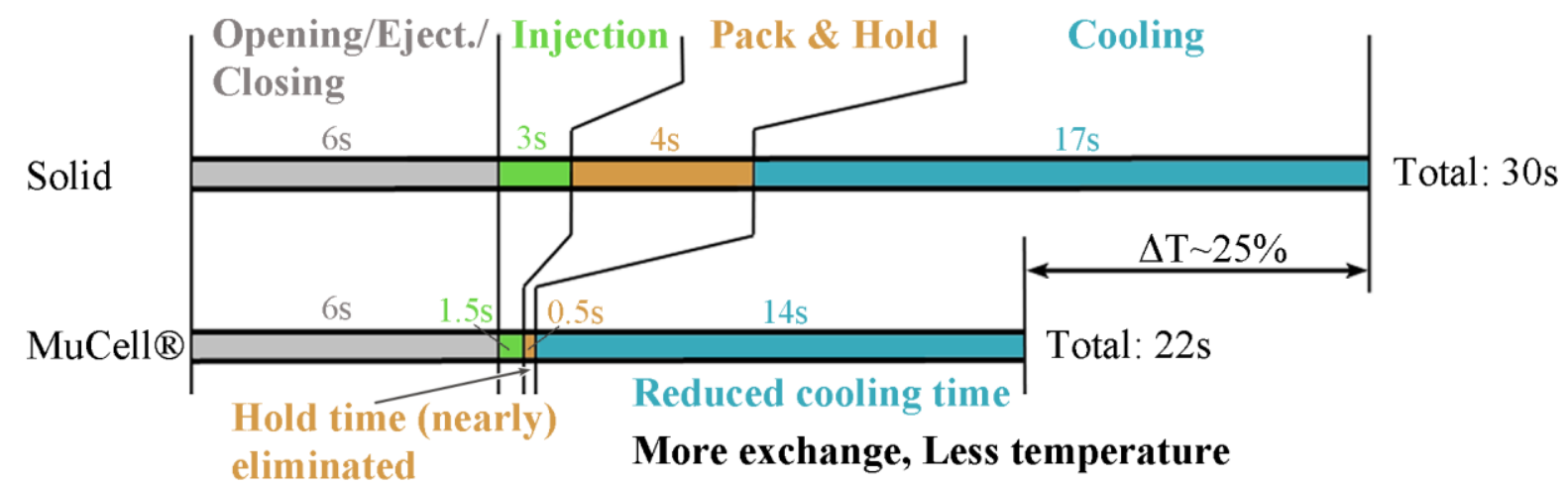

Figure 2.11. Typical cycle time reduction of an automotive part with MuCell®. Modified from [98]. 


\subsubsection{MuCell@ technology}

Microcellular plastics foamed by physical blowing agents were introduced in the Massachusetts Institute Technology (MIT) in the early 1980s with the objective of reducing material consumption but keeping reasonable mechanical properties in packaging applications [73]. Starting research focused on batch processes, later on continuous extrusion, and between 1997 and 1998 the first microcellular injection molding machine was built by Trexel Inc. (USA) and Engel Canada (Canada) [99]. Since then this technology is licensed by Trexel Inc with the registered trademark of MuCell® $[100,101]$.

The fundamentals of MuCell@ process have been summarized previously and consist basically of dissolving the blowing agent under supercritical conditions (SCF) in the molten polymer at the plasticizing unit, forming a single-phase solution. The pressure drops inducing cell nucleation and growth occurs at the entrance of the mold, so foaming takes place inside the mold cavity. As illustrated in Figure 2.12, applying MuCell® involves new equipment and modifications in reference to conventional injection molding [102]. On one hand, gas, usually $\mathrm{N}_{2}$ and $\mathrm{CO}_{2}$, is raised to supercritical conditions in the SCF metering unit and conducted to the interface kit. It regulates the mass flow and provides the blowing agent when required. One or more gas injectors introduce the supercritical fluid in the barrel while plasticizing stage. Opening and closing of gas injectors are controlled by time or screw position signals.

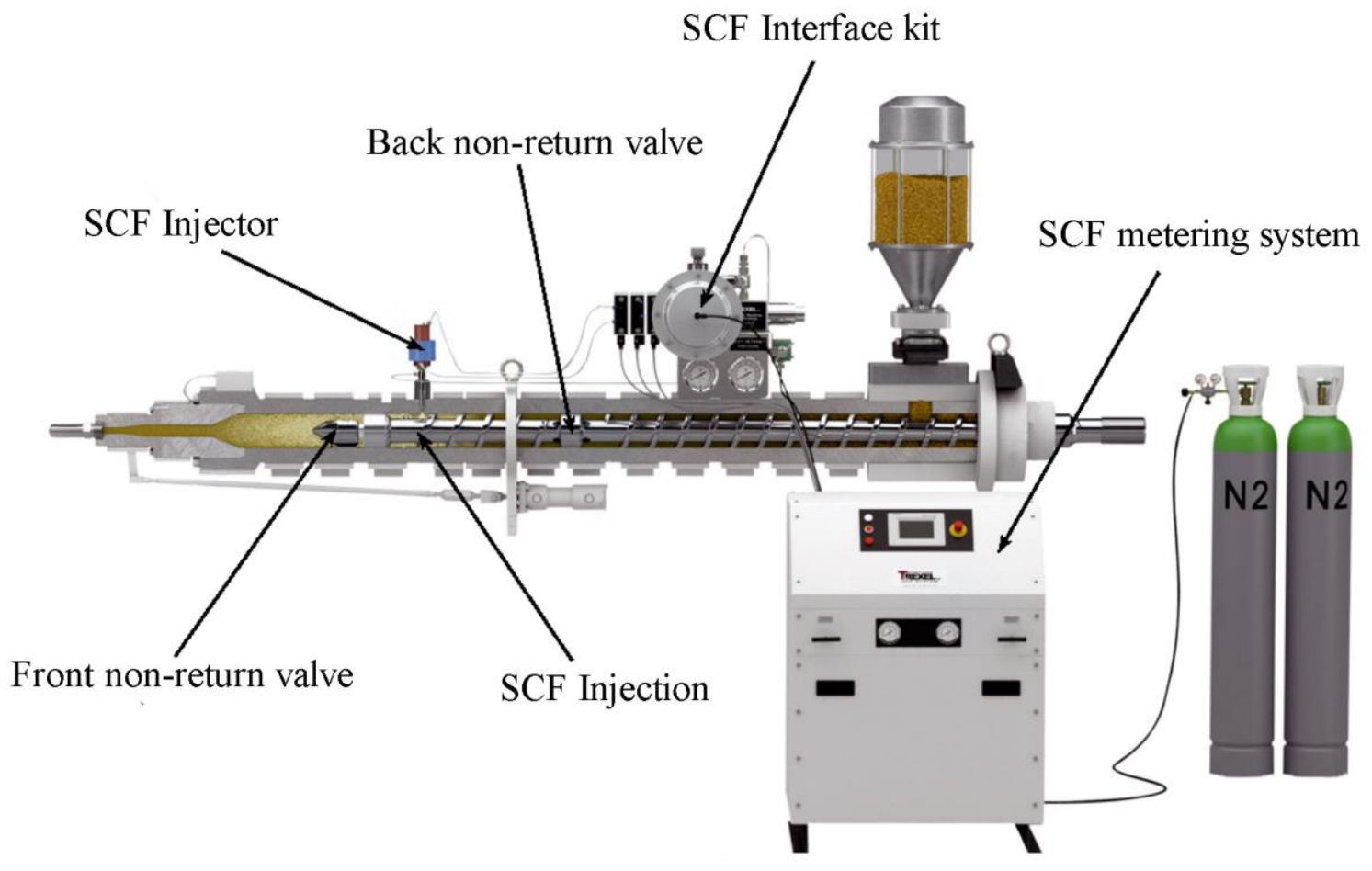

Figure 2.12. Plant concept for MuCell® process. Modified from [103]. 
With the objective of homogenizing and stabilizing the single-phase solution, a special reciprocating screw is required. This screw is longer than a conventional one and equipped with a mixing section specially designed for optimizing the polymer/gas mixture. A back and front check valves prevent from expansion of the mixture towards the feeding zone and the nozzle, respectively. Regarding control of the process, additional aspects must be considered. When the blowing agent is injected in the plasticizing unit, the pressure drops from the supercritical state to the melt pressure. A supplementary variable, named Microcellular Plasticizing Pressure (MPP) measures the pressure of the system in the cylinder. The pressure drop between the gas injector and the MPP has to be limited, in order to avoid foaming inside the barrel.

The advantages offered by MuCell ${ }^{\circledR}$ have been listed before, and include, weight reduction, improved dimensional stability, energy and clamping force decrease and cycle time shortening. All of this lead to reduce cost and environmental impact, and to enhance productivity [104]. However, there are few limitations, like worse surface quality and deterioration of mechanical properties. Furthermore, MuCell® implementation involves a high economic investment to purchase the supercritical fluid supply system, as well as the special reciprocating screw. Besides, a number of additional difficulties are found while running the process, as the opening and closing of gas injectors must be regulated, and the pressure drop to MPP minimized.

\subsubsection{IQ Foam® ${ }^{\circledR}$ technology}

As said above, current foaming technologies involve advanced engineering systems and staff training to make the processes run smoothly. For this reason, Volkswagen conceived a new foaming technology aimed to reduce complexity and cost as compared to other available processes. It has been named IQ Foam ${ }^{\circledR}$, and its main equipment consists of a two-chambered unit assembled between the hopper and the feed of any injection molding machine (Figure 2.13), where polymer is impregnated with gas before melting. This unit was patented in 2014 [105] and contains two gas injectors to introduce the physical blowing agent, valves to regulate the flow of gas and two actuators to allow polymer pellets to pass through the unit and to lock each chamber. 


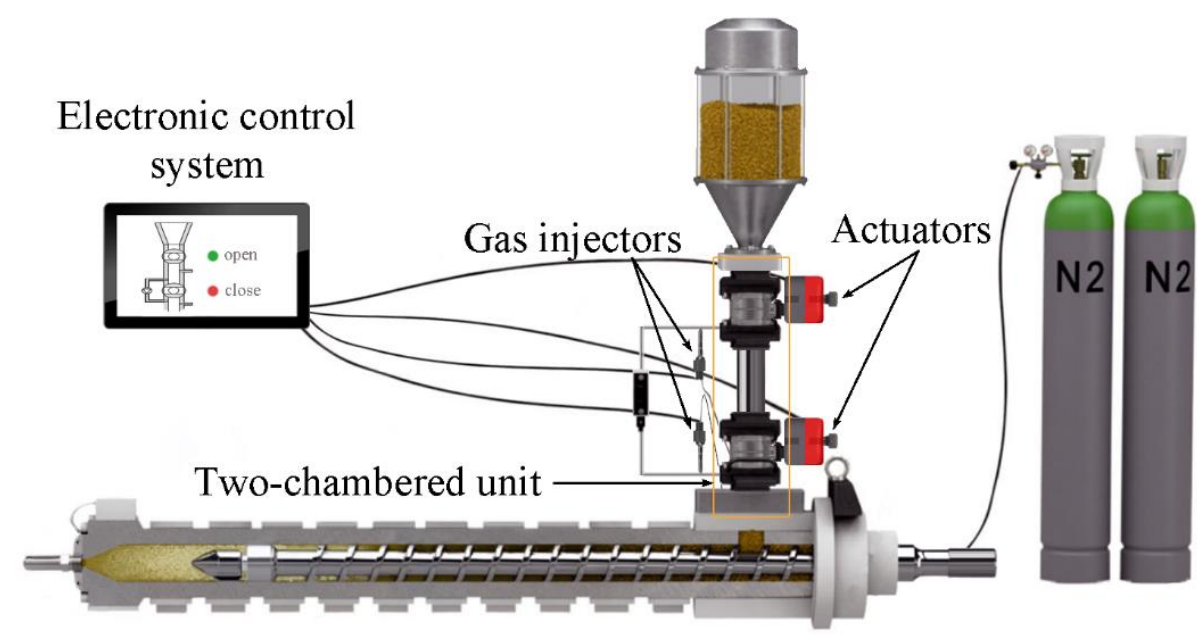

Figure 2.13. Plant concept for IQ Foam ${ }^{\circledR}$ process. Modified from [103].

The operating principle of IQ Foam ${ }^{\circledR}$ is as follows (Figure 2.14):

1. Initially, both actuators close the chamber and there is no communication between the hopper and the feeding zone of the plasticizing unit. Polymer pellets stay in the hopper, and chambers are free of blowing agent.

2. Actuator 1 operates and pellets drop from the hopper to the upper chamber at ambient pressure. Then, the upper chamber is closed again by the actuator 1 .

3. A gas injector introduces the gas into the upper chamber under low pressure. Usually, $\mathrm{N}_{2}$ and $\mathrm{CO}_{2}$ and even normal air are employed, although it can work with any other physical blowing agent.

4. Actuator 2 opens the air lock between both chambers. The polymer falls into the lower chamber, the gas fills all the available space and the lower chamber locks again.

5. Remaining gas in upper chamber is re-routed to the lower one. A second injector adds gas to keep the desired pressure, ensuring gas moving forward with polymer pellets and diffuses during the plasticizing process.

The upper chamber opens and refills again, and the cycle is repeated. It is worth to notice that gas is supplied under moderate-low pressure [106] directly from the bottle, without requiring gas-metering equipment. Re-routing gas from upper to lower chambers prevents from gas leakage and maximizes its use. The only important modification of the injection machine is sealing the back of the screw to avoid gas escaping. 


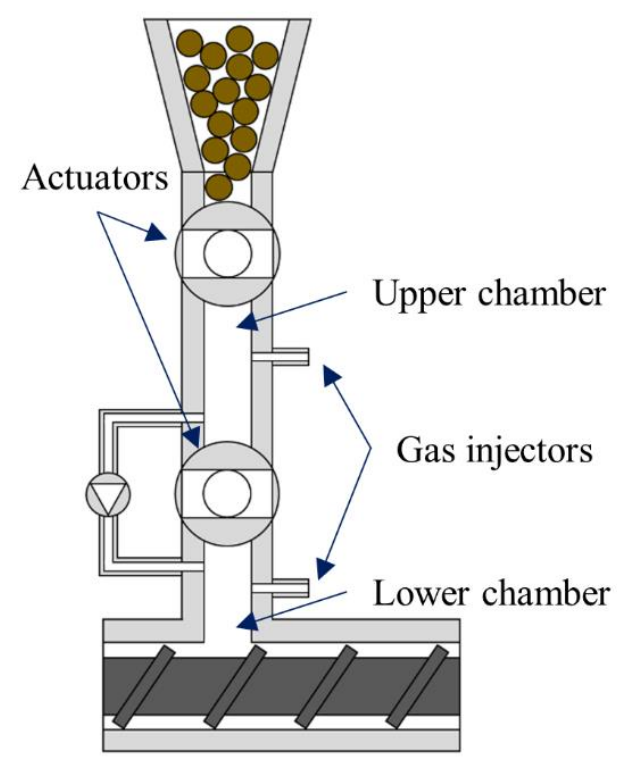

1. Chambers closed. No feeding.

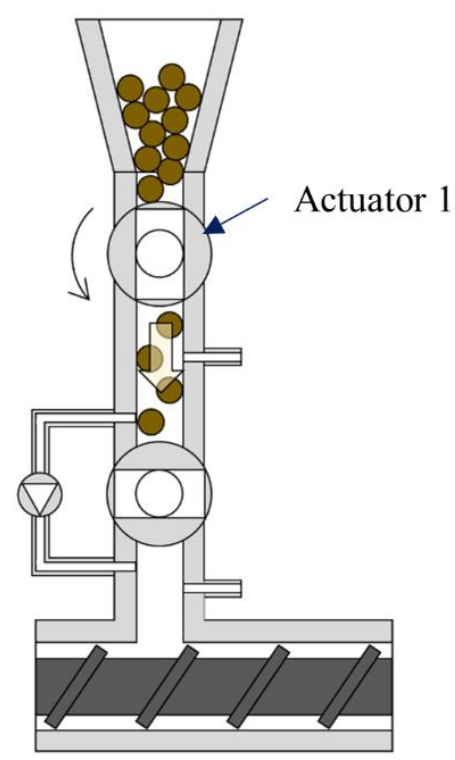

2. Actuator 1 opens and pellets fall into the upper chamber.

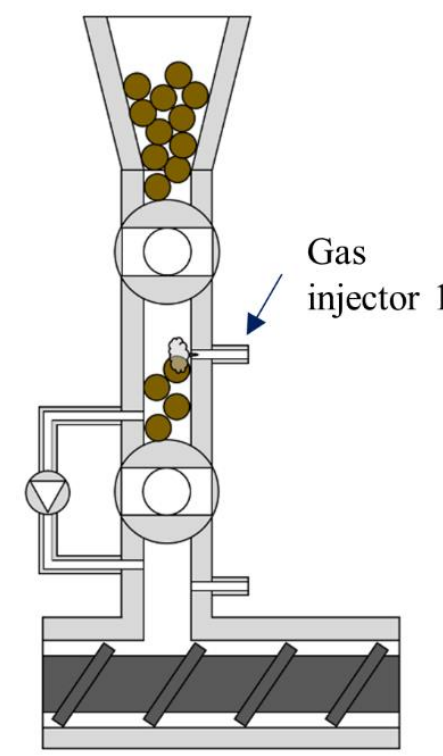

3. Injector 1 introduces gas into the upper chamber.

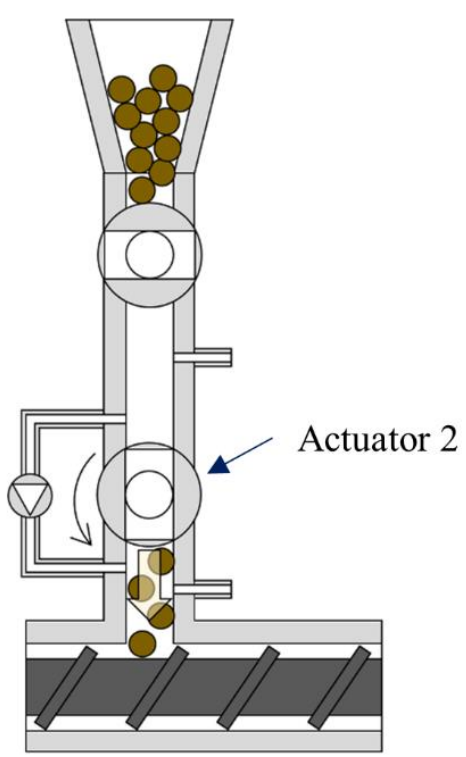

4. Actuator 2 opens and pellets fall into the lower chamber.

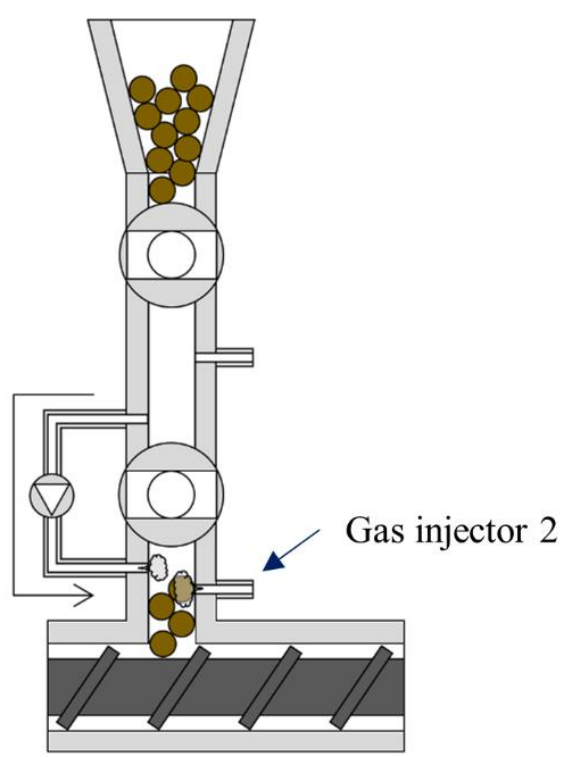

5. Gas is rerouted from upper to lower chambers. Injector 2 introduces gas to keep the pressure.

Figure 2.14. Operating steps of IQ Foam ${ }^{\circledR}$ technology.

On the other hand, the foaming process can be controlled only by the gas pressure, and it can be easily automated and driven by an electronic system managing actuators and gas injectors regardless the original software control of the injection molding machine.

Consequently, IQ Foam ${ }^{\circledR}$ arises as a potentially cost-effective and machine-independent process, easy to start up and reducing both weight and cost of plastic products significantly. 


\subsubsection{Complementary tool technologies}

Despite the many advantages of microcellular plastics listed in this Chapter, it has been also reported some limitations, like mechanical properties deterioration and poor surface quality. The causes of surface defects while foaming have been studied in depth. In fact, attempts to develop numerical simulation models have been made for predicting the surface quality of molded parts [107]. As the surface layer is formed inside the mold cavity, different technologies concerning the tool have been introduced to improve the surface quality of foamed polymers [108]. The most relevant ones are summarized in the next sections.

\subsubsection{Gas Counter Pressure}

Gas Counter Pressure (GCP) technique consists of pressurizing to a high pressure the mold cavity, allowing filling by the polymer/gas system but restricting foaming, as pressure drop does not occur [109]. Thus, fracture cells on the melt flow front is inhibited and swirl marks are eliminated. Once the cavity is completely filled and surface layers cool down, pressure is released from the mold and cells nucleate and grow inside the molded part (Figure 2.15). Due to the low pressure employed in IQ Foam ${ }^{\circledR}$ technology, Gas Counter Pressure is not mandatory with this foaming process.
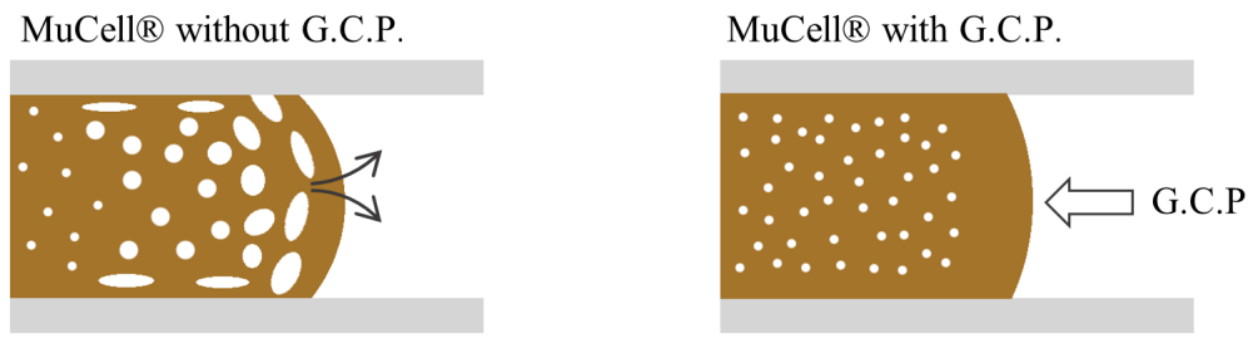

Figure 2.15. Schematic representation of Gas Counter Process effect on foaming. Modified from [109].

\subsubsection{Rapid Heating Cycle Molding}

It is well known that high mold temperatures give rise to better surface qualities. However, it considerably enlarges cooling stage and energy consumption. By Rapid Heating Cycle Molding process (also called as Variotherm technology), mold walls are heated to high temperature, and then the molten polymer/gas solution is injected into the cavity. At this high temperature, any gas escaped from the solution or pushed to the mold wall will be forced to flow to the cavity end and then out through the gas vent, thus removing any swirl marks [110]. Then, the temperature of the mold is rapidly decreased reducing the overall cycle time. 


\subsubsection{Film Insulation}

The last technology presented implies heating equipment and good corrosion resistance and hot strength of the mold, increasing the cost. Derived from this solution, Chen et al. [111] developed a mold temperature control method based on a thermally insulated composite polymer film stick on the surface of mold core to delay heat transfer at the molten polymer mold surface interface during the microcellular injection molding process. The thicker the film, the better the surface quality of the molded part, without significant increase in cycle time.

\subsubsection{Co-injection Molding}

Co-injection Molding has been traditionally employed to improve surface appearance in conventional injection molding, and it also works for foaming technologies [112]. The main principle is a sequential injection of skin and core layers from different injection units. Skin layers serve to overcome the poor surface quality of the core. The resulting surface depends on processing parameters and material combinations. Hain et al. [113] conducted some experiments with a slightly different concept, "In Mold Coating" technology, consisting of applying a PUR coating on the foamed part after molding. They presented an automated process for foaming and coating in the same tool, achieving class A surfaces for automotive components.

\subsubsection{Core Back Expansion Molding}

The Core Back Expansion Molding aims to improve surface quality, but also increase density reduction, stiffness-to-weight ratio and weight saving potential. First, the cavity is volumetrically filled close to solid weight by polymer/gas mixture. The cavity is filled at high injection speed, so as to prevent pressure drop and foaming. After a delay time in which a solid skin is formed, the cavity is expanded and the increase in volume induces a sudden pressure drop, promoting foam generation inside the part [114]. Figure 2.16 illustrates the process. As the thickness increases, lower densities are reached and uniform cell distribution and expansion are obtained. The entire cavity can be expanded, or only partially in determined areas of interest. Either way, precision machinery to move the mold components is required. Furthermore, the partition line must be designed in such a way that cavity expansion is allowed without leaving open areas in the mold. 
Full cavity filling

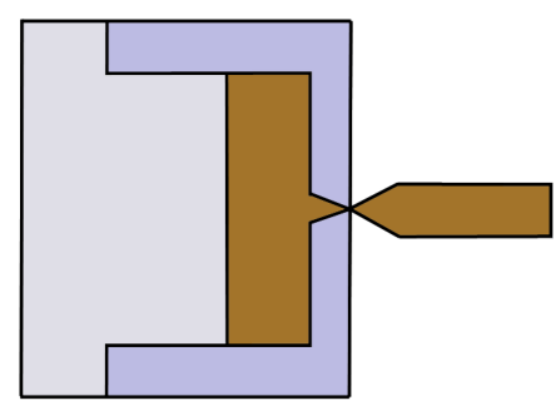

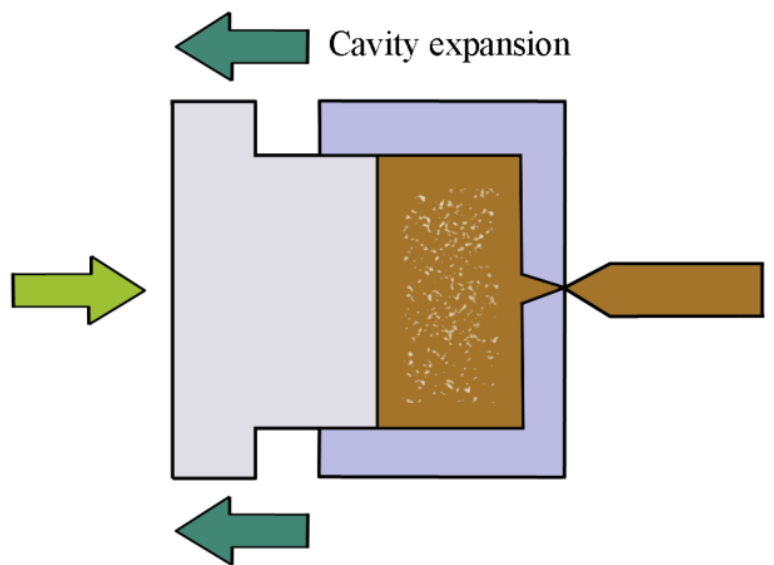

Figure 2.16. Schematic representation of Core Back technology. Modified from [115].

\subsection{State of the art of polymer foaming}

Foaming polymer materials extends the range of their characteristics broadening the scope of possible industrial applications. The variables used during the process influences the formation of the cell structure, which in turn has an impact on the final properties of the foamed material. Traditionally, the work of Gibson and Ashby [51] has been taken as a reference in the investigation about the relationship between the cell structure and the governing parameters of the mechanical, thermal, electric, and acoustic behavior. Since foaming injection molding technologies were developed, several investigations on the cell structure and mechanical properties of a wide range of foamed materials have been carried out. $\mathrm{Xu}$ [58] provided an extensive description of the effect of the processing parameters on the foam morphology and properties, concluding that injection speed, gas dosing and content, mold temperature and shot volume are the most influencing ones. Generally, melt and mold temperatures determine polymer viscosity and dosing speed. Therefore, they affect mostly the solid skin thickness and cell size. Shot volume and foaming agent content control mainly the reduction in apparent density, as well as the number and diameter of nucleated cells. And finally, injection speed promotes a rapid pressure drop and the thermodynamic instability inducing cell nucleation and, thus, affecting primarily cell density.

Regarding material properties, the mechanical behavior deteriorates as the foaming ratio and weight reduction percentage increase. The characteristics of the foam morphology also affect the mechanical properties. Usually, tensile, flexural and impact properties increase with high cell densities, low cell sizes and thick skin thicknesses. Some authors reported a decrease in glass transition and melting temperatures, as a consequence of a weaker attraction forces between molecule chains due to the presence of gas [89], but this reduction is not highly 
significant. The thermal conductivity diminishes with low cell size, while the expansion coefficient and the specific heat do not change as compared to the solid counterpart [53].

Few studies dealt with the comparison between chemical and physical foaming methods. Müller and Ehrenstein [116] made this comparison with impact-modified PP combined with core-back technology. Both foaming processes allowed the same density reduction ratios, although the morphologies obtained by physical methods exhibited thinner solid skins, which turned out slightly lower mechanical properties. In 2013, Gómez-Gómez [117] presented his $\mathrm{PhD}$ dissertation about the comparison of both foaming techniques with an Ethylene-Propylene Block Copolymer (EPBC) and Poly(Ethylene Terephthalate Glycol) (PETG). The former showed more uniform cell structure with chemical foaming, due to the difficulties of gas diffusion through the crystalline regions of EPBC, whereas cell density and cell distribution of the latter material were improved by physical foaming agents. In both cases, the MuCell® process generated lower cell size ranges.

Despite the extensive research on microcellular injection molding and characterization of resulting foams, underlying mechanisms contributing to the cellular structure development are not fully understood yet. Establishing direct relationships between processing parameters, cell structure and mechanical and thermal characteristics is not always satisfactory and sometimes even contradictory, because of dependence on polymer material properties and part geometry [118]. Over the last years, some authors have worked on in situ visual observations of bubble nucleation and growth dynamics in microcellular injection molding, so as to get a better understanding of foaming phenomenon $[119,120]$. The following sections contain the most important findings about the effect of processing parameters on cell structure and properties of amorphous, semicrystalline and reinforced polymers.

\subsubsection{Amorphous polymers}

Within the group of amorphous polymers (Table 2.2), Rizvi and Bhatnagar [121] extensively studied the effect of the injection molding parameters on the physical foaming of Polystyrene (PS) with $\mathrm{N}_{2}$. In general, high injection speed induces a higher pressure drop, resulting in higher cell nucleation and cell density and smaller cell sizes, but also worse surface quality. Fine cell structures were also obtained with high back pressure, due to the increase in gas solubility, as well as with low melt temperature, although the best surface quality was achieved at high melt temperature. Longer residence time of the polymer/gas solution in the plasticizing unit raises also the gas solubility in the molten polymer. However, 
if the residence time is excessive, the gas could escape through the nozzle. Finally, suck back promotes pressure drop and thermodynamic instabilities, with cells nucleating in the plasticizing unit. Consequently, bigger cells and lower cell densities are formed.

Acrylonitrile-Butadiene-Styrene (ABS) is a material widely employed in different industries and has also been studied in this field. Lin et al. [122] reported lower tensile strength but higher impact resistance as the SCF content increased. Both mechanical properties decreased with higher melting temperatures, due to higher average cell diameters. High injection speed induced molecular orientation and, therefore, higher tensile and impact properties. Unlike the conclusions found by Rizvi and Bhatnagar [121] with PS presented before, $\mathrm{Xu}$ [123] found no great influence of the residence time on the single-phase polymer/gas in $\mathrm{ABS} / \mathrm{N}_{2}$ systems. Some other studies have been carried out with Polyetherimide (PEI) and Polyetherimide/Polypropylene (PEI/PP) blends [124]. Liu et al. [125] found better results in cell morphology by polymer blending with PolypropyleneGraftmaleic Anhydride (PPMA), because of binary interface decreasing the nucleation energy barrier and increasing diffusibility of the blowing agent.

One of the amorphous thermoplastics most employed in research works on microcellular polymers is Polycarbonate (PC). In 2005, Hwang et al. [126] increased the tensile strength by injecting at high melting and mold temperatures, high pressure and injection speed as well as shot volume. The same trends were observed for the impact energy absorption capability, except for the mold temperature, which was the opposite. Apart from confirming these results, Chen et al. [127] obtained an increase in the Izod impact resistance with thicker foamed parts. In this case, samples injected at high pressure and speed absorbed less energy during the tests. Foamed specimens presented higher elongation at break as compared to the non-foamed ones. Additionally, the resistance of foamed PC in welding-lines under tensile load has also been analyzed [128]. As in conventional injection molded parts, the tensile strength of PC foams by MuCell ${ }^{\circledR}$ decreased in welding-lines, but it was higher in samples injected at high shot volumes, melt temperature and injection speed. Some other experiments combined physical foaming of PC combined Gas Counter Pressure and Core Back technologies [129-131]. The main findings were the followings: reduction in tensile and flexural properties with high melt and mold temperatures, reduction in tensile modulus and strength but increase in flexural properties with high injection speed and SCF content. The surface quality as well as impact toughness and strain at break enhanced by pressurizing and expanding the mold cavity. 
Table 2.2. Main research works on foaming injection molding conducted with amorphous polymers.

\begin{tabular}{|c|c|c|c|c|}
\hline Author & Polymer & $\begin{array}{l}\text { Blowing } \\
\text { agent }\end{array}$ & Studied parameters & Analyzed properties \\
\hline $\begin{array}{l}\text { Turng and } \\
\text { Kharbas [128] } \\
\quad(2003)\end{array}$ & $\mathrm{PC}$ & $\mathrm{SCF} \mathrm{N}_{2}$ & $\begin{array}{l}\text { Melt temperature, SCF } \\
\text { level, injection speed, shot } \\
\text { volume }\end{array}$ & $\begin{array}{l}\text { Microstructure, } \\
\text { tensile strength in } \\
\text { weld-lines }\end{array}$ \\
\hline $\begin{array}{l}\text { Chen et al. } \\
\text { [127] (2008) }\end{array}$ & $\mathrm{PC}$ & $\mathrm{SCF} \mathrm{N}_{2}$ & $\begin{array}{c}\text { Part thickness, melt } \\
\text { temperature, mold } \\
\text { temperature, SCF level, } \\
\text { injection speed, shot } \\
\text { volume, melt plastizicing } \\
\text { pressure }\end{array}$ & Tensile, impact \\
\hline $\begin{array}{l}\text { Michaeli et al. } \\
\text { [132] (2009) }\end{array}$ & $\mathrm{PC}$ & $\mathrm{SCF} \mathrm{CO}_{2}$ & $\begin{array}{l}\text { Mold temperature, Core } \\
\text { Back opening distance, } \\
\text { rate and delay time }\end{array}$ & $\begin{array}{l}\text { Microstructure, } \\
\text { impact }\end{array}$ \\
\hline $\begin{array}{l}\text { Bledzki et al. } \\
\text { [130] (2010) }\end{array}$ & $\mathrm{PC}$ & $\mathrm{SCF} \mathrm{N}_{2}$ & $\begin{array}{l}\text { Gas Counter Pressure, } \\
\text { Core back opening }\end{array}$ & $\begin{array}{l}\text { Microstructure, } \\
\text { notched impact }\end{array}$ \\
\hline $\begin{array}{l}\text { Bledzki et al. } \\
\text { [131] (2012) }\end{array}$ & $\mathrm{PC}$ & $\mathrm{SCF} \mathrm{N}_{2}$ & $\begin{array}{c}\text { Melt temperature, Gas } \\
\text { Counter Pressure, SCF } \\
\text { level, injection speed, shot } \\
\text { volume, mold temperature }\end{array}$ & $\begin{array}{l}\text { Microstructure, } \\
\text { tensile, flexural }\end{array}$ \\
\hline $\begin{array}{l}\text { Lin et al. }[122] \\
\quad(2005)\end{array}$ & $\mathrm{ABS}$ & $\mathrm{SCF} \mathrm{N}_{2}$ & $\begin{array}{l}\text { SCF dosage, injection } \\
\text { speed, melt temperature }\end{array}$ & $\begin{array}{c}\text { Microstructure, } \\
\text { tensile, impact, } \\
\text { shrinkage, warpage }\end{array}$ \\
\hline $\mathrm{Xu}$ [123] (2006) & $\begin{array}{l}\text { ABS and } \\
\text { GPPS }\end{array}$ & $\mathrm{SCF} \mathrm{N}_{2}$ & $\begin{array}{l}\text { Screw rotation speed, } \\
\text { injection speed }\end{array}$ & $\begin{array}{l}\text { Shearing rate, gas } \\
\text { diffusion time, } \\
\text { pressure drop rate, } \\
\text { viscosity }\end{array}$ \\
\hline $\begin{array}{c}\text { Rizvi and } \\
\text { Bhatnagar [121] } \\
(2009)\end{array}$ & PS & $\mathrm{SCF} \mathrm{N}_{2}$ & $\begin{array}{c}\text { Injection speed, back } \\
\text { pressure, melt temperature, } \\
\text { barrel residence time, suck } \\
\text { back }\end{array}$ & Microstructure \\
\hline $\begin{array}{l}\text { Chen et al. } \\
\text { [133] (2012) }\end{array}$ & PS & $\mathrm{SCF} \mathrm{N}_{2}$ & $\begin{array}{l}\text { Gas Counter Pressure, } \\
\text { mold temperature }\end{array}$ & $\begin{array}{l}\text { Microstructure, } \\
\text { tensile, impact }\end{array}$ \\
\hline $\begin{array}{l}\text { Gómez-Gómez } \\
\text { et al. [134] } \\
\text { (2013) }\end{array}$ & PETG & $\mathrm{SCF} \mathrm{N}_{2}$ & $\begin{array}{l}\text { Shot volume, injection } \\
\text { speed, mold temperature }\end{array}$ & $\begin{array}{l}\text { Microstructure, } \\
\text { dynamic mechanical- } \\
\text { thermal, thermal }\end{array}$ \\
\hline $\begin{array}{l}\text { Liu et al. }[124] \\
\text { (2015) }\end{array}$ & $\begin{array}{l}\text { PEI and } \\
\text { PEI/PP }\end{array}$ & $\mathrm{SCF} \mathrm{CO}_{2}$ & $\begin{array}{l}\text { Shot volume, SCF level, } \\
\text { injection speed }\end{array}$ & Microstructure \\
\hline
\end{tabular}




\subsubsection{Semicrystalline polymers}

Table 2.3 summarizes the research works that have been carried out on the relationship between processing parameters, morphology and foam properties of semicrystalline polymers. Among them, the first studies were conducted with Polypropylene (PP). Kramschuster et al. [135] obtained lower warpage and shrinkage values in foamed samples, with less sensitivity to the injection molding parameters. The content of supercritical fluid agent (SCF), as well as injection speed and melt temperature are the most influencing processing parameters on the dimensional stability of the foamed part, with different effects depending on the studied direction. More recently, Gong et al. [136] concluded that tensile and impact properties of PP cellular samples obtained by chemical foaming improved with low cell sizes and uniform cell size distributions.

Copolymer architectures of PP have been also investigated. Martinez et al. [137] added clarifying and nucleating agents to a PP copolymer during the MuCell@ foaming process with $\mathrm{N}_{2}$, and studied the influence of different processing conditions. On one hand, these clarifying and nucleating agents contributed to increase crystallinity level and tensile strength, improved cell size distribution and reduced the solid skin thickness, whereas the impact resistance decreased due to lower ductility. On the other hand, both tensile and impact resistances were enhanced by injecting at lower melt temperature and injection rate, in contrast to what was concluded by Lin et al. [122] with ABS as earlier aforementioned. Gómez-Gómez et al. [138] determined that low shot volumes gave rise to high cell densities and thicker foamed cores of an Ethylene-Propylene Block Copolymer (EPBC) foamed by MuCell® and $\mathrm{N}_{2}$ as foaming agent. With low mold temperature they achieved smaller cells and more uniform cell structures, whereas injection speed did not affect significantly the foam morphology and properties. The same authors compared the influence of these injection molding parameters on Poly(Ethylene Terephthalate Glycol) PETG [134], an amorphous polymer, having more uniform cell structures with the maximum SCF content. High mold temperatures provided higher void fractions and lower apparent densities of the foamed materials.

Polyethylene (PE) is another semicrystalline polymer widely studied. Chen et al. [139] reported that the rheological properties of Low Density Polyethylene (LDPE) chemically foamed only depend on the matrix material and volume of injected gas. The higher the injection speed, the higher the cell density and the lower the average cell size. Barzegari and Rodrigue [140] found an increase in cell density with the gas content and the melt temperature, because the gas is distributed in a larger number of cells with a smaller size. 
Table 2.3. Main research works on foaming injection molding conducted with amorphous polymers.

\begin{tabular}{|c|c|c|c|c|}
\hline Author & Polymer & $\begin{array}{c}\text { Blowing } \\
\text { agent }\end{array}$ & Studied parameters & Analyzed properties \\
\hline $\begin{array}{l}\text { Edwards et al. } \\
\text { [141] (2004) }\end{array}$ & POM & $\mathrm{SCF} \mathrm{N}_{2}$ & $\begin{array}{c}\text { SCF level, injection time, } \\
\text { melt temperature, mold } \\
\text { temperature }\end{array}$ & $\begin{array}{l}\text { Microstructure, } \\
\text { thermal, } \\
\text { viscoelasticity, } \\
\text { flexural, impact }\end{array}$ \\
\hline $\begin{array}{l}\text { Kramschuster et } \\
\text { al. [135] (2005) }\end{array}$ & $\mathrm{PP}$ & $\mathrm{SCF} \mathrm{N}_{2}$ & $\begin{array}{c}\text { SCF dosage time, shot } \\
\text { volume, melt temperature, } \\
\text { mold temperature, } \\
\text { injection speed, cooling } \\
\text { time }\end{array}$ & Shrinkage, warpage \\
\hline $\begin{array}{l}\text { Spörrer and } \\
\text { Altstädt [142] } \\
\quad(2007)\end{array}$ & $\mathrm{PP}$ & $\mathrm{SCF} \mathrm{N}_{2}$ & $\begin{array}{c}\text { Mold temperature, Core } \\
\text { Back }\end{array}$ & $\begin{array}{l}\text { Microstructure, } \\
\text { flexural, impact }\end{array}$ \\
\hline $\begin{array}{l}\text { Wong et al. } \\
\text { [143] (2008) }\end{array}$ & ТPO & $\mathrm{SCF} \mathrm{N}_{2}$ & $\begin{array}{l}\text { SCF level, Gas Counter } \\
\text { Pressure, Core Back }\end{array}$ & $\begin{array}{l}\text { Microstructure, } \\
\text { tensile, impact }\end{array}$ \\
\hline $\begin{array}{l}\text { Gómez-Gómez } \\
\text { et al. [138] } \\
\text { (2013) }\end{array}$ & $\mathrm{EPBC}$ & $\mathrm{SCF} \mathrm{N}_{2}$ & $\begin{array}{l}\text { Shot volume, injection } \\
\text { speed, mold temperature }\end{array}$ & $\begin{array}{l}\text { Microstructure, } \\
\text { dynamic mechanical- } \\
\text { thermal, thermal }\end{array}$ \\
\hline $\begin{array}{l}\text { Wang et al. } \\
{[144](2015)}\end{array}$ & $\mathrm{PP}$ & $\mathrm{SCF} \mathrm{N}_{2}$ & $\begin{array}{l}\text { Shot volume, injection } \\
\text { speed }\end{array}$ & Microstructure \\
\hline $\begin{array}{l}\text { Barzegari and } \\
\text { Rodrigue [140] } \\
\quad(2009)\end{array}$ & LDPE & Chemical & $\begin{array}{l}\text { Blowing agent content, } \\
\text { mold temperature, melt } \\
\text { temperature, injection } \\
\text { pressure, back pressure }\end{array}$ & Microstructure \\
\hline $\begin{array}{l}\text { Bociaga and } \\
\text { Palutkiewicz } \\
{[145](2012)}\end{array}$ & HDPE & Chemical & $\begin{array}{l}\text { Blowing agent content, } \\
\text { injection speed, melt } \\
\text { temperature, mold } \\
\text { temperature }\end{array}$ & $\begin{array}{c}\text { Microstructure, } \\
\text { tensile, surface gloss } \\
\text { and color }\end{array}$ \\
\hline $\begin{array}{l}\mathrm{Xi} \text { et al. }[146] \\
\text { (2014) }\end{array}$ & PET & $\mathrm{SCF} \mathrm{N}_{2}$ & $\begin{array}{l}\text { SCF level, mold } \\
\text { temperature, injection } \\
\text { speed, shot volume }\end{array}$ & $\begin{array}{l}\text { Microstructure, } \\
\text { tensile, flexural, } \\
\text { impact }\end{array}$ \\
\hline $\begin{array}{l}\text { Seo et al. [147] } \\
\quad(2012)\end{array}$ & PLA & $\begin{array}{l}\mathrm{SCF} \mathrm{N}_{2} / \\
\text { Chemical }\end{array}$ & $\begin{array}{l}\text { Blowing agent content } \\
\text { injection speed }\end{array}$ & Microstructure \\
\hline $\begin{array}{c}\text { Volpe and } \\
\text { Pantani [148] } \\
\quad(2015)\end{array}$ & PLA & $\mathrm{SCF} \mathrm{N}_{2}$ & Back pressure & $\begin{array}{l}\text { Density, tensile, } \\
\text { flexural }\end{array}$ \\
\hline
\end{tabular}


However, an excess in gas content can promote a cell coalescence phenomenon, resulting in the opposite effect. According to Bociaga and Palutkiewicz [145], mold temperature is the most influencing factor in chemical foaming of High Density Polyethylene (HDPE). As it increased, higher weight, density, tensile strength and gloss of the foamed material were obtained.

Regarding biodegradable polymers, low melt strength of Poly(Lactic Acid) (PLA) forces to introduce structural modifications to be processed and foamed. Zhao et al. [149] [37] analyzed the effect of blending PLA with Poly(Hydroxybutyrate-Valerate) (PHBV) on the physical foaming with $\mathrm{N}_{2}$. As compared to the solid material, no differences in thermal properties were found. Nevertheless, the glass transition temperature decreased and the crystallinity fraction increased with the addition of PHBV. Consequently, higher cell densities and lower cell size were determined, but a decrease in tensile strength was found in solid as well as in foamed blends. The elastic modulus was not affected by blending. Jeon et al. [150] and Nofar and Park [151] made an extensive review of the foaming progress achieved with biodegradable polymers.

\subsubsection{Reinforced polymers}

Reinforced polymers are often employed in industrial applications in order to improve the mechanical properties and enable the replacement of heavier metals. Therefore, composite polymers have also been widely studied from the perspective of the relationship between processing parameters and filler content with the resulting morphology and foam properties.

As shown in Table 2.4, several research works have been carried out on clay additives, above all with PA6 as matrix material, as it is one of the most effective filler for this polymer [152]. Yuan and Turng [153] analyzed the effect of different content of montmorillonite (MMT) on the cell structure and crystallinity of microcellular foams, as well as the influence of some injection parameters on the physical foaming with $\mathrm{N}_{2}$ as blowing agent. Fillers act as nucleating agents giving rise to uniform structures, with high cell density and small cells. The filler dispersion is improved due to the expansion of the foaming agent. The crystallinity phase is reduced due to the clay nanoparticles, although the reinforcement effect is predominant and the tensile and impact properties are enhanced as compared to the non-filled material. This effect is clearly evinced as the clay content and shot volume increase, and with a medium level of supercritical fluid (SCF). 
The same filler has been used in experiments with a wide variety of materials. Most of these studies reported the same beneficial effect of clay on cell density, cell size, cell distribution and mechanical properties aforementioned above. Nevertheless, experiments conducted with PLA [154] reported a higher degradation of the polymer with the increase in filler content, reducing cell density, tensile and impact properties. However, in PLA/PHBV blends [155], clay raises the crystallinity levels of PHBV phase, and therefore, the morphology and mechanical properties are improved. Clay particles are polar materials, so compatibilizers like maleic anhydride are needed in order to be employed with polyolefins, such as LDPE [156]. In some investigations with PP [157] was also found that ramified structures lead to more uniform morphologies, with higher cell densities and lower cell size.

Talc and glass fiber are common fillers reinforcing polymers, such as PP in automotive applications. Yetgin et al. [158] reported an increase in cell density and tensile strength and modulus of foamed PP by adding $20 \%$ of talc, but also bigger cells and a decrease in the impact strength and elongation at break. The optimal weight percentage of glass fiber and processing parameters enhancing cell structure and mechanical performance of PP foams was reported by Xi et al. [159].

Rubber particles are effective impact modifier for many polymer systems. According to Xin et al. [160], the content of chemical foaming agent is the most influencing variable on the cell structure and tensile properties of PP foams. Rubber particles act as nucleating agents and increase the viscosity of the melt PP, enabling the formation of fine morphologies with high cell densities and low cell sizes. However, their efficiency as nucleation agents in PA6 resulted lower than nanoclay, as reported by Yuan et al. [152].

Natural fillers offer also many advantages due to environmental issues. Wood fibers are light and stiff and can be processed with microcellular polymers. In different studies [161163], the authors studied the effect of chemical foaming agent, processing variables and fiber types on PP foaming. High weight reduction ratios (up to 30\%) and smoother surfaces than solid parts were obtained with hard wood fibers and exothermic chemical agents. Medium melt temperatures and finer fibers promoted more uniform cell distributions and smaller cell diameters. The most influencing variable was the foaming agent content. The mechanical properties decreased with the apparent density, although an improvement can be obtained with maleic anhydride as compatibilizer agent. 
In some experiments conducted on recycled PP, Xie et al. [164] optimized the processing temperatures and pressures of chemical foaming to achieve fine cell structures, increasing the impact resistance as compared to the non-foamed material. Microcellular wood fiber reinforced polymer composites obtained by different processes (batch, injection molding, extrusion, and compression molding process) and their properties have been reviewed by Faruk et al. [165].

Table 2.4. Main research works on foaming injection molding conducted with filled polymers.

\begin{tabular}{|c|c|c|c|c|}
\hline Author & Filler & Polymer & $\begin{array}{l}\text { Blowing } \\
\text { agent }\end{array}$ & Analyzed properties \\
\hline $\begin{array}{c}\text { Yuan and } \\
\text { Turng [153] } \\
\quad(2005)\end{array}$ & Montmorillonite & PA6 & $\mathrm{SCF} \mathrm{N}_{2}$ & $\begin{array}{l}\text { Microstructure, tensile, } \\
\text { impact, dynamic mechanical, } \\
\text { crystallization }\end{array}$ \\
\hline $\begin{array}{l}\text { Guo et al. } \\
\text { [157] (2007) }\end{array}$ & Nanoclay & $\mathrm{PP}$ & Chemical & $\begin{array}{l}\text { Microstructure, dynamic } \\
\text { mechanical }\end{array}$ \\
\hline $\begin{array}{l}\text { Hwang et al. } \\
{[156](2009)}\end{array}$ & Montmorillonite & LDPE & $\mathrm{SCF} \mathrm{N}_{2}$ & $\begin{array}{l}\text { Microstructure, thermal, } \\
\text { tensile }\end{array}$ \\
\hline $\begin{array}{l}\text { Hwang et al. } \\
\text { [154] (2009) }\end{array}$ & Montmorillonite & PLA & $\mathrm{SCF} \mathrm{CO}_{2}$ & $\begin{array}{l}\text { Microstructure, thermal, } \\
\text { tensile }\end{array}$ \\
\hline $\begin{array}{l}\text { Rizvi and } \\
\text { Bhatnagar } \\
{[166](2011)}\end{array}$ & Montmorillonite & $\mathrm{PP}$ & $\mathrm{SCF} \mathrm{N}_{2}$ & $\begin{array}{l}\text { Microstructure, tensile, } \\
\text { flexural, impact }\end{array}$ \\
\hline $\begin{array}{l}\text { Zhao et al. } \\
\text { [155] (2013) }\end{array}$ & Nanoclay & PLA/PHBV & $\mathrm{SCF} \mathrm{N}_{2}$ & $\begin{array}{l}\text { Microstructure, tensile, } \\
\text { dynamic mechanical }\end{array}$ \\
\hline $\begin{array}{l}\text { Srithep and } \\
\text { Turng [167] } \\
\quad(2014)\end{array}$ & Nanoclay & PET & $\mathrm{SCF} \mathrm{N}_{2}$ & $\begin{array}{l}\text { Microstructure, tensile, } \\
\text { rheology, thermal }\end{array}$ \\
\hline $\begin{array}{l}\text { Wang et al. } \\
\text { [168] (2016) }\end{array}$ & Nanoclay & TPU & $\mathrm{SCF} \mathrm{N}_{2}$ & $\begin{array}{l}\text { Microstructure, thermal, } \\
\text { rheology, filler dispersion, } \\
\text { tensile }\end{array}$ \\
\hline $\begin{array}{l}\text { Michaeli et } \\
\text { al. [132] } \\
\text { (2009) }\end{array}$ & Talc & $\mathrm{PP}$ & $\mathrm{SCF} \mathrm{CO}_{2}$ & Microstructure, impact \\
\hline $\begin{array}{l}\text { Yetgin et al. } \\
\text { [158] (2013) }\end{array}$ & Talc & PP & Chemical & $\begin{array}{l}\text { Microstructure, tensile, } \\
\text { impact }\end{array}$ \\
\hline $\begin{array}{l}\text { Yetkin et al. } \\
\text { [169] (2013) }\end{array}$ & Talc & PP/EPDM & Chemical & $\begin{array}{c}\text { Microstructure, tensile, } \\
\text { impact }\end{array}$ \\
\hline
\end{tabular}


Table 2.4. Continued.

\begin{tabular}{|c|c|c|c|c|}
\hline Author & Filler & Polymer & $\begin{array}{l}\text { Blowing } \\
\text { agent }\end{array}$ & Analyzed properties \\
\hline $\begin{array}{l}\text { Ameli et al. } \\
{[170](2013)}\end{array}$ & Talc & PLA & $\mathrm{SCF} \mathrm{N} \mathrm{N}_{2}$ & $\begin{array}{l}\text { Microstructure, thermal, } \\
\text { tensile }\end{array}$ \\
\hline $\begin{array}{l}\text { Edwards et al. } \\
\text { [141] (2004) }\end{array}$ & Glass Fiber & $\mathrm{PP}$ & $\mathrm{SCF} \mathrm{N}_{2}$ & $\begin{array}{l}\text { Microstructure, thermal, } \\
\text { viscoelasticity, flexural, } \\
\text { impact }\end{array}$ \\
\hline $\begin{array}{l}\text { Bian et al. } \\
\text { [171] (2012) }\end{array}$ & Glass Fiber & $\mathrm{PP}$ & $\mathrm{SCF} \mathrm{N}_{2}$ & Shrinkage, warpage \\
\hline $\begin{array}{l}\text { Xi et al. [159] } \\
\quad \text { (2014) }\end{array}$ & Glass Fiber & $\mathrm{PP}$ & $\mathrm{SCF} \mathrm{N}_{2}$ & $\begin{array}{l}\text { Microstructure, tensile, } \\
\text { flexural, impact }\end{array}$ \\
\hline $\begin{array}{l}\text { Roch et al. } \\
\text { [172] (2014) }\end{array}$ & $\begin{array}{l}\text { Long Glass } \\
\text { Fiber }\end{array}$ & $\mathrm{PP}$ & $\begin{array}{l}\mathrm{SCF} \mathrm{N}_{2} / \\
\text { Chemical }\end{array}$ & Flexural, impact \\
\hline $\begin{array}{l}\text { Roch et al. } \\
{[173](2015)}\end{array}$ & $\begin{array}{l}\text { Long and Short } \\
\text { Glass Fiber }\end{array}$ & PA6 & $\begin{array}{l}\mathrm{SCF} \mathrm{N}_{2} / \\
\text { Chemical }\end{array}$ & $\begin{array}{l}\text { Microstructure, tensile, } \\
\text { flexural, impact }\end{array}$ \\
\hline $\begin{array}{l}\text { Ameli et al. } \\
{[174](2013)}\end{array}$ & Carbon Fiber & $\mathrm{PP}$ & $\mathrm{SCF} \mathrm{N}_{2}$ & $\begin{array}{l}\text { Electrical conductivity, } \\
\text { dielectric permittivity, } \\
\text { electromagnetic interference } \\
\text { shielding effectiveness }\end{array}$ \\
\hline $\begin{array}{l}\text { Hwang et al. } \\
{[175](2014)}\end{array}$ & Carbon Fiber & PBT & $\mathrm{SCF} \mathrm{N}_{2}$ & $\begin{array}{c}\text { Microstructure, tensile, } \\
\text { impact, electrical } \\
\text { conductivity, electromagnetic } \\
\text { interference shielding } \\
\text { effectiveness }\end{array}$ \\
\hline $\begin{array}{l}\text { Pilla et al. } \\
\text { [176] (2007) }\end{array}$ & $\begin{array}{c}\text { Carbon } \\
\text { nanotubes }\end{array}$ & PLA & $\mathrm{SCF} \mathrm{N}_{2}$ & $\begin{array}{l}\text { Microstructure, tensile, } \\
\text { thermal, dynamic } \\
\text { mechanical-thermal }\end{array}$ \\
\hline $\begin{array}{l}\text { Arjmand et } \\
\text { al. }[177] \\
(2014)\end{array}$ & $\begin{array}{c}\text { Carbon } \\
\text { nanotubes }\end{array}$ & PS & Chemical & $\begin{array}{c}\text { Microstructure, electrical } \\
\text { conductivity, dielectric } \\
\text { permittivity }\end{array}$ \\
\hline $\begin{array}{l}\text { Yuan et al. } \\
\text { [152] (2005) }\end{array}$ & $\begin{array}{l}\text { Core Shell } \\
\text { Rubber and } \\
\text { nanoclay }\end{array}$ & PA6 & $\mathrm{SCF} \mathrm{N}_{2}$ & $\begin{array}{l}\text { Microstructure, tensile, } \\
\text { impact }\end{array}$ \\
\hline $\begin{array}{l}\text { Xin et al. } \\
\text { [160] (2010) }\end{array}$ & Rubber powder & $\mathrm{PP}$ & Chemical & Microstructure, tensile \\
\hline $\begin{array}{l}\text { Zhang et al. } \\
\text { [178] (2011) }\end{array}$ & Rubber powder & $\mathrm{PP}$ & Chemical & $\begin{array}{l}\text { Microstructure, rheology, } \\
\text { tensile }\end{array}$ \\
\hline
\end{tabular}


Table 2.4. Continued.

\begin{tabular}{|c|c|c|c|c|}
\hline Author & Filler & Polymer & $\begin{array}{l}\text { Blowing } \\
\text { agent }\end{array}$ & Analyzed properties \\
\hline $\begin{array}{l}\text { Yoon et al. } \\
\text { [179] (2005) }\end{array}$ & $\mathrm{CaCO}_{3}$ & $\mathrm{PP}$ & $\mathrm{SCF} \mathrm{N}_{2}$ & Microstructure \\
\hline $\begin{array}{l}\text { Hwang and } \\
\text { Hsu [180] } \\
\text { (2013) }\end{array}$ & Silica & $\mathrm{PP}$ & $\mathrm{SCF} \mathrm{N}_{2}$ & Microstructure, tensile \\
\hline $\begin{array}{l}\text { Li et al. }[181] \\
\quad(2013)\end{array}$ & $\begin{array}{c}\text { Carbon } \\
\text { nanotube, nano- } \\
\text { montmorillonite, } \\
\text { talc }\end{array}$ & PEI & $\mathrm{SCF} \mathrm{N}_{2}$ & $\begin{array}{l}\text { Microstructure, tensile, } \\
\text { flexural, dielectric constant, } \\
\text { thermal conductivity }\end{array}$ \\
\hline $\begin{array}{l}\text { Bledzki and } \\
\text { Faruk [182] } \\
\quad(2005)\end{array}$ & Wood fiber & $\mathrm{PP}$ & Chemical & $\begin{array}{l}\text { Microstructure, surface } \\
\text { roughness, impact, odor } \\
\text { concentration }\end{array}$ \\
\hline $\begin{array}{l}\text { Gosselin et al. } \\
\text { [183] (2006) }\end{array}$ & Wood fiber & HDPE/PP & Chemical & Microstructure, density \\
\hline $\begin{array}{l}\text { Bledzki and } \\
\text { Faruk [184] } \\
\quad(2006)\end{array}$ & Wood fiber & $\mathrm{PP}$ & Chemical & $\begin{array}{l}\text { Microstructure, tensile, } \\
\text { flexural, odor concentration }\end{array}$ \\
\hline $\begin{array}{l}\text { Bledzki and } \\
\text { Faruk [161] } \\
\quad(2006)\end{array}$ & Wood fiber & $\mathrm{PP}$ & Chemical & $\begin{array}{l}\text { Microstructure, tensile, } \\
\text { flexural, impact }\end{array}$ \\
\hline $\begin{array}{l}\text { Bledzki and } \\
\text { Faruk [162], } \\
{[163](2006)}\end{array}$ & Wood fiber & $\mathrm{PP}$ & Chemical & $\begin{array}{l}\text { Microstructure, density, } \\
\text { tensile, flexural, impact }\end{array}$ \\
\hline $\begin{array}{l}\text { Gwon et al. } \\
\text { [185] (2012) }\end{array}$ & Wood fiber & HDPE & Chemical & $\begin{array}{l}\text { Microstructure, density, } \\
\text { flexural }\end{array}$ \\
\hline $\begin{array}{l}\text { Xie } \text { et al. } \\
\text { [164] (2012) }\end{array}$ & Wood fiber & $\mathrm{PP}$ & Chemical & Microstructure, impact \\
\hline $\begin{array}{l}\text { Kramschuster } \\
\text { et al. }[186] \\
\quad(2007)\end{array}$ & $\begin{array}{l}\text { Recycled paper } \\
\text { fibers }\end{array}$ & PLA & $\mathrm{SCF} \mathrm{N}_{2}$ & $\begin{array}{l}\text { Microstructure, tensile, } \\
\text { thermal, dynamic mechanical }\end{array}$ \\
\hline $\begin{array}{l}\text { Ding et al. } \\
\text { [187] (2016) }\end{array}$ & Cellulosic fiber & PLA & $\mathrm{SCF} \mathrm{N}_{2}$ & $\begin{array}{c}\text { Microstructure, rheology, } \\
\text { thermal }\end{array}$ \\
\hline $\begin{array}{l}\text { Pilla et al. } \\
\text { [188] (2009) }\end{array}$ & Flax fibers & PLA & $\mathrm{SCF} \mathrm{N}_{2}$ & $\begin{array}{l}\text { Microstructure, tensile, } \\
\text { thermal, dynamic mechanical }\end{array}$ \\
\hline
\end{tabular}


Table 2.4. Continued.

\begin{tabular}{ccccc}
\hline Author & Filler & Polymer & $\begin{array}{c}\text { Blowing } \\
\text { agent }\end{array}$ & Analyzed properties \\
\hline $\begin{array}{c}\text { Zafar } \text { et al. } \\
{[189](2016)}\end{array}$ & Willow fiber & PLA & SCF N ${ }_{2}$ & $\begin{array}{c}\text { Microstructure, tensile, } \\
\text { flexural, impact, thermal, } \\
\text { crystallization }\end{array}$ \\
\hline
\end{tabular}




\section{Chapter 3: Materials and methods}

This Chapter describes the materials and techniques employed in this thesis. An amorphous polymer (ABS) and a glass fiber reinforced semicrystalline plastic (PP 20GF) were selected. First, cylindrical bars and square plates were injection molded and foamed by the MuCell@ process. A design of experiments was defined in order to analyze the effect of the injection parameters on the morphology and tensile properties of the cylindrical bars made of ABS. The selected optimal conditions, subject to the criterion of maximum mechanical properties and finest cell structure for each level of weight reduction, were employed and adapted to produce square plates of ABS and cylindrical bars of PP 20GF. An additional design of experiments was performed with square plates and PP 20GF material, in order to determine the influence of the injection parameters on the cell structure, fiber orientation and flexural properties. Impact and fracture behavior as well as thermal characteristics were studied on samples extracted from the square plates too. Then, rectangular plates of PP 20GF were foamed through MuCell ${ }^{\circledR}$ and IQ Foam ${ }^{\circledR}$ processes combined with Core-Back technology. The comparison between both processes was carried out in terms of the morphology and mechanical properties obtained from the resulting foams. The methodology for morphological, mechanical and thermal characterization is also explained in this Chapter.

\subsection{Materials}

\subsubsection{Acrylonitrile-Butadiene-Styrene (ABS)}

Acrylonitrile-Butadiene-Styrene (ABS) is a multiphase polymer with amorphous nature consisting of acrylonitrile, contributing to a better chemical resistance, dimensional stability, surface hardness and resistance to UV radiation; butadiene, enhancing ductility, toughness and impact resistance; and styrene, providing stiffness and easing processing [190]. Because of its good mechanical properties, dimensional stability, chemical resistance, good surface appearance, and easy processing and recycling characteristics, it is widely used in engineering applications, such as electronics, electrics, automotive and aeronautics. 
A commercial grade of ABS (Magnum ${ }^{\mathrm{TM}}$ 8434), supplied by Trinseo Deutschland $\mathrm{GmbH}$ (Germany), was selected for this research. The material has a density of $1.05 \mathrm{~g} \mathrm{~cm}^{-3}$

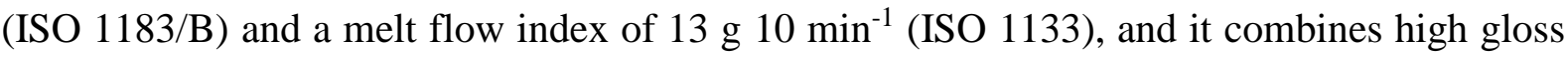
with medium-high heat performance. It is suitable for a wide range of applications, like household appliances, consumer goods, toys and automotive interior trims.

\subsubsection{Glass fiber reinforced Polypropylene (PP 20GF)}

Polypropylene (PP) is a semicrystalline thermoplastic polymer with a quite diverse range of applications due to its relative low cost and density and good physical, mechanical and thermal properties. PP is widely used in automotive parts as homopolymer or copolymer with enhanced impact resistance [191]. Glass fibers (GF) are the most common reinforcement for polymeric matrix composites, having an excellent relationship between low cost, high tensile strength, high chemical resistance, and insulating properties, but with the disadvantages of low tensile modulus, relatively high specific gravity, sensitivity to abrasion during handling, low fatigue resistance and high hardness [192].

In this project a $20 \%$ chemically coupled high performance Glass Fiber reinforced Polypropylene compound (PP 20GF FibremodTM GE277Al) was employed. It is supplied by Borealis AG (Austria) and has been specially developed for demanding applications in the automotive industry, with a density of $1.04 \mathrm{~g} \mathrm{~cm}^{-3}$ (ISO 1183) and a melt flow index of $12 \mathrm{~g}$ $10 \mathrm{~min}^{-1}$ (ISO 1133). It is easy to process and suitable for processing with special foaming technologies. It presents a great balance between impact strength and stiffness, and it is commonly used in structural parts and instrument panel carriers.

\subsection{Injection molding}

Cylindrical bars and square plates (Figure 3.1 and Figure 3.2) made of both materials were injection molded in a Victory 110 injection molding machine (Engel GmbH, Germany), with a clamping force of $1100 \mathrm{kN}$ and equipped with an injection valve II series of $25 \mathrm{~mm}$, the MuCell® (Trexel Inc., USA) supercritical fluid (SCF) supply system and a shut-off nozzle developed for such system, available in the Centre Català del Plàstic (Terrassa, Spain). Prior to the injection experiments, the $\mathrm{ABS}$ material was dried at $80^{\circ} \mathrm{C}$ for a minimum of 4 hours in a DSN560HE dehumidifier (Piovan SPA, Italy) with a dew point of $-40{ }^{\circ} \mathrm{C}$, so as to avoid moisture problems during processing. As recommended by the supplier, the PP 20GF 
compound was also pre-dried at $80{ }^{\circ} \mathrm{C}$ for a minimum of 3 hours. In all cases, $\mathrm{N}_{2}$ gas was employed as blowing agent for foaming.

\subsubsection{Cylindrical bars}

A four-cavity mold was employed to produce cylindrical bars of $300 \mathrm{~mm}$ in length and diameters of 4, 5 and $8 \mathrm{~mm}$ (Figure 3.1). In order to study the effect of shot volume, mold temperature and injection speed on the morphology and tensile properties of the ABS foamed bars, a design of experiments with three variables and two levels was defined (Table 3.1). As a full $2^{3}$ factorial design, 8 different injection molding conditions (C1-C8) outlined in Table 3.2 were used to fabricate the bars. One additional trial, labeled $\mathrm{C} 0$, was conducted at medium levels of experimental settings, in order to check linearity of the effects of the different factors. Preliminary trials were carried out to determine the variation range of injection molding and foaming parameters. It was concluded that the minimum shot volume to ensure a complete filling of the mold cavities when foaming was $68 \mathrm{~cm}^{3}$, which corresponds to a $17 \%$ of weight reduction as compared to the unfoamed counterpart.

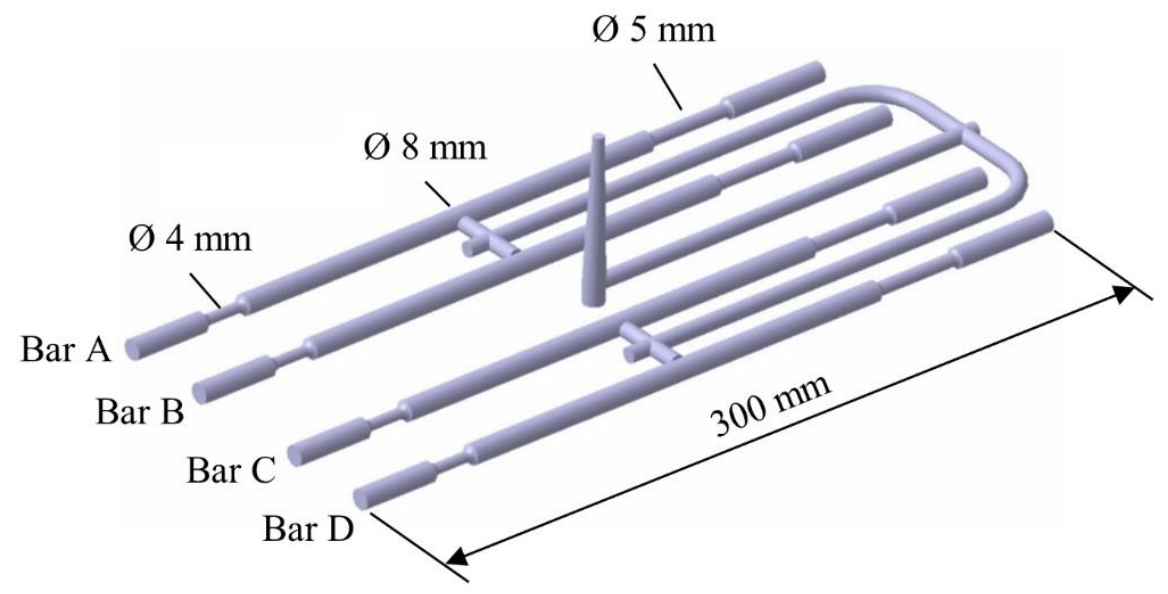

Figure 3.1. Schematic representation of injection molded cylindrical bars.

Table 3.1. Factors and experimental domain for ABS microcellular injection molding. Note that values of 0 level are only employed in intermediate condition C0 (see Table 3.2) for linearity checking.

\begin{tabular}{cccc}
\hline Factor & \multicolumn{3}{c}{ Levels } \\
\cline { 2 - 4 } & $\mathbf{- 1}$ & $\mathbf{0}$ & $\mathbf{1}$ \\
\hline Shot volume $\left(\mathrm{cm}^{3}\right)$ & 68 & 69.5 & 71 \\
Mold temperature $\left({ }^{\circ} \mathrm{C}\right)$ & 35 & 47 & 60 \\
Injection speed $\left(\mathrm{cm}^{3} \mathrm{~s}^{-1}\right)$ & 40 & 70 & 100 \\
\hline
\end{tabular}


Table 3.2. Matrix of the Design of Experiments for ABS microcellular injection molding.

\begin{tabular}{cccc}
\hline $\begin{array}{c}\text { Condition } \\
\text { No. }\end{array}$ & $\begin{array}{c}\text { Shot volume } \\
\left(\mathbf{c m}^{\mathbf{3}}\right)\end{array}$ & $\begin{array}{c}\text { Mold temperature } \\
\left({ }^{\mathbf{o}} \mathbf{C}\right)\end{array}$ & $\begin{array}{c}\text { Injection speed } \\
\left(\mathbf{c m}^{\mathbf{3}} \mathbf{s}^{\mathbf{- 1}}\right)\end{array}$ \\
\hline $\mathrm{C} 1$ & 1 & -1 & -1 \\
$\mathrm{C} 2$ & 1 & -1 & 1 \\
$\mathrm{C} 3$ & 1 & 1 & -1 \\
$\mathrm{C} 4$ & 1 & 1 & 1 \\
$\mathrm{C} 5$ & -1 & -1 & -1 \\
$\mathrm{C} 6$ & -1 & -1 & 1 \\
$\mathrm{C} 7$ & -1 & 1 & -1 \\
$\mathrm{C} 8$ & -1 & 1 & 1 \\
$\mathrm{C} 0$ & 0 & 0 & 0 \\
\hline
\end{tabular}

Table 3.3. Processing parameters of solid and foamed ABS cylindrical bars.

\begin{tabular}{|c|c|c|c|}
\hline Parameter & Solid & $\begin{array}{c}\text { Foamed } \\
(10 \% \text { wt. red.) }\end{array}$ & $\begin{array}{c}\text { Foamed } \\
\text { (17\% wt. red.) }\end{array}$ \\
\hline Melt temperature $\left({ }^{\circ} \mathrm{C}\right)$ & \multicolumn{3}{|c|}{$250-245-230-220-160$} \\
\hline Shot volume $\left(\mathrm{cm}^{3}\right)$ & 85 & 71 & 68 \\
\hline Injection speed $\left(\mathrm{cm}^{3} \mathrm{~s}^{-1}\right)$ & 70 & $40 / 100$ & $40 / 100$ \\
\hline Mold temperature $\left({ }^{\circ} \mathrm{C}\right)$ & 60 & $35 / 60$ & $35 / 60$ \\
\hline Cooling time (s) & 30 & 30 & 30 \\
\hline Holding time (s) & 10 & - & - \\
\hline Holding pressure (bar) & 600 & - & - \\
\hline Gas flow (kg/h) & - & 0.35 & 0.45 \\
\hline Gas dosing time (s) & - & 4 & 4.5 \\
\hline Gas content (\%) & - & 0.60 & 0.93 \\
\hline
\end{tabular}


Then, a lower foaming ratio was set (10\% of weight reduction) in order to adequately study the morphology and tensile properties variations. Thus, both levels (-1 and 1) of the shot volume were adjusted to achieve a $17 \%$ and a $10 \%$ of weight reduction, respectively. The content of the blowing agent $\left(\mathrm{N}_{2}\right)$ was $0.93 \%$ for the former series of foamed bars $(17 \%$ of weight reduction) and $0.60 \%$ for the latter (10\% of weight reduction), and was kept at $0.80 \%$ for the intermediate trial $\mathrm{C} 0$.

In all experiments both the melt temperature profile and cooling time were kept constant. The melt temperature from hopper to nozzle was $160-220-230-245-250{ }^{\circ} \mathrm{C}$. On the other hand, the cooling time was set to 30 seconds, due to the large thickness of the bars $(\varnothing=$ $8 \mathrm{~mm}$ ). The constant processing parameters for solid and foamed bars are listed in Table 3.3.

Regarding the second material (PP 20GF), only solid and two series of foamed bars were produced. This polymer allowed higher reachable ratios of weight reduction, so $10 \%$ and $20 \%$ were set as the levels under study for the foamed bars. The processing parameters are summarized in Table 3.4.

Table 3.4. Processing parameters of solid and foamed PP 20GF cylindrical bars.

Parameter
Solid

Foamed

(10\% wt. red.) $(20 \%$ wt. red.)
Melt temperature $\left({ }^{\circ} \mathrm{C}\right)$

Shot volume $\left(\mathrm{cm}^{3}\right)$

Injection speed $\left(\mathrm{cm}^{3} \mathrm{~s}^{-1}\right)$

Mold temperature $\left({ }^{\circ} \mathrm{C}\right)$

Cooling time (s)

Holding time (s)

Holding pressure (bar)

Gas flow $(\mathrm{kg} / \mathrm{h})$

Gas dosing time (s)

Gas content (\%)
235-225-210-200-190

75

66

100

100

60

60

60

30

30

30

25

500

0.30

0.45

5.5

0.90 


\subsubsection{Square plates}

After analyzing the results from the design of experiments performed with the ABS bars, solid and two groups of foamed square plates of $100 \times 100 \times 5 \mathrm{~mm}^{3}$ (Figure 3.2) were injection molded. With the aim of comparing foaming behavior in different geometries, the same injection molding conditions as the selected optimal ABS bars were tried to keep constant or similar when it was not possible (Table 3.5). The same levels of weight reduction (10\% and $17 \%)$ were also maintained for the foamed bars.

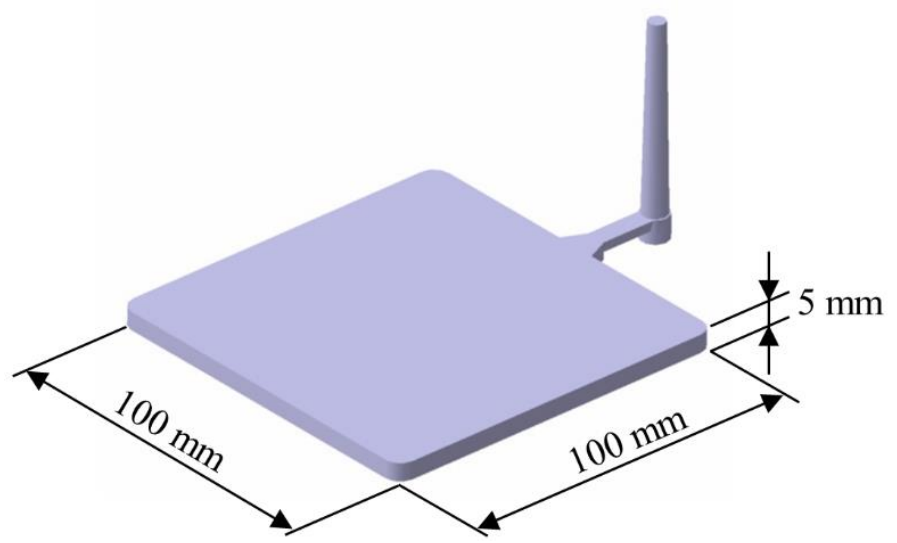

Figure 3.2. Schematic representation of injection molded square plates.

Table 3.5. Processing parameters of solid and foamed ABS square plates.

\begin{tabular}{|c|c|c|c|}
\hline Parameter & Solid & $\begin{array}{c}\text { Foamed } \\
(10 \% \text { wt. red.) }\end{array}$ & $\begin{array}{c}\text { Foamed } \\
(17 \% \text { wt. red. })\end{array}$ \\
\hline Melt temperature $\left({ }^{\circ} \mathrm{C}\right)$ & \multicolumn{3}{|c|}{$250-245-230-220-160$} \\
\hline Shot volume $\left(\mathrm{cm}^{3}\right)$ & 70 & 50.1 & 46.2 \\
\hline Injection speed $\left(\mathrm{cm}^{3} \mathrm{~s}^{-1}\right)$ & 50 & 80 & 80 \\
\hline Mold temperature $\left({ }^{\circ} \mathrm{C}\right)$ & 60 & 60 & 60 \\
\hline Cooling time (s) & 35 & 35 & 35 \\
\hline Holding time (s) & 15 & - & - \\
\hline Holding pressure (bar) & 400 & - & - \\
\hline Gas flow $(\mathrm{kg} / \mathrm{h})$ & - & 0.27 & 0.29 \\
\hline Gas dosing time (s) & - & 3.4 & 3.5 \\
\hline Gas content $(\%)$ & - & 0.53 & 0.58 \\
\hline
\end{tabular}


In case of PP 20GF polymer, a design of experiments was set so as to study the effect of shot volume, mold temperature and injection speed on the morphology and flexural properties. A full $2^{3}$ factorial design was employed again, whose variables and combination array of conditions are defined in Table 3.6 and Table 3.7.

Table 3.6. Factors and experimental domain for PP 20GF microcellular injection molding.

\begin{tabular}{cccc}
\hline Factor & \multicolumn{3}{c}{ Levels } \\
\cline { 2 - 4 } & $\mathbf{- 1}$ & $\mathbf{0}$ & $\mathbf{1}$ \\
\hline Shot volume $\left(\mathrm{cm}^{3}\right)$ & 45.3 & 48.3 & 51.2 \\
Mold temperature $\left({ }^{\circ} \mathrm{C}\right)$ & 35 & 47 & 60 \\
Injection speed $\left(\mathrm{cm}^{3} \mathrm{~s}^{-1}\right)$ & 40 & 60 & 80 \\
\hline
\end{tabular}

Table 3.7. Matrix of the Design of Experiments for PP 20GF microcellular injection molding.

\begin{tabular}{cccc}
\hline $\begin{array}{c}\text { Condition } \\
\text { No. }\end{array}$ & $\begin{array}{c}\text { Shot volume } \\
\left(\mathbf{c m}^{\mathbf{3}}\right)\end{array}$ & $\begin{array}{c}\text { Mold temperature } \\
\left({ }^{\mathbf{o}} \mathbf{C}\right)\end{array}$ & $\begin{array}{c}\text { Injection speed } \\
\left(\mathbf{c m}^{\mathbf{3}} \mathbf{s}^{\mathbf{- 1}}\right)\end{array}$ \\
\hline $\mathrm{C} 1$ & 1 & -1 & -1 \\
$\mathrm{C} 2$ & 1 & -1 & 1 \\
$\mathrm{C} 3$ & 1 & 1 & -1 \\
$\mathrm{C} 4$ & 1 & 1 & 1 \\
$\mathrm{C} 5$ & -1 & -1 & -1 \\
$\mathrm{C} 6$ & -1 & -1 & 1 \\
$\mathrm{C} 7$ & -1 & 1 & -1 \\
$\mathrm{C} 8$ & -1 & 1 & 1 \\
$\mathrm{C} 0$ & 0 & 0 & 0 \\
\hline
\end{tabular}

The remaining processing parameters are summarized in Table 3.8. 
Table 3.8. Processing parameters of solid and foamed PP 20GF square plates.

\begin{tabular}{cccc}
\hline Parameter & Solid & $\begin{array}{c}\text { Foamed } \\
(\mathbf{1 0 \%} \text { wt. red.) }\end{array}$ & $\begin{array}{c}\text { Foamed } \\
\text { (20\% wt. red.) }\end{array}$ \\
\hline Melt temperature $\left({ }^{\circ} \mathrm{C}\right)$ & & $235-225-210-200-190$ & \\
Shot volume $\left(\mathrm{cm}^{3}\right)$ & 70 & 51.2 & 45.3 \\
Injection speed $\left(\mathrm{cm}^{3} \mathrm{~s}^{-1}\right)$ & 45 & $40 / 80$ & $40 / 80$ \\
Mold temperature $\left({ }^{\circ} \mathrm{C}\right)$ & 47 & $35 / 60$ & $35 / 60$ \\
Cooling time (s) & 30 & 30 & 30 \\
Holding time (s) & 15 & - & - \\
Holding pressure (bar) & 200 & - & 0.18 \\
Gas flow (kg/h) & - & 0.18 & 5.5 \\
Gas dosing time (s) & - & 5.5 & 0.86 \\
Gas content (\%) & - & 0.76 & \\
\hline
\end{tabular}

\subsubsection{Rectangular plates}

Rectangular plates of $400 \times 130 \mathrm{~mm}^{2}$ (Figure 3.3) and variable thickness made of PP $20 \mathrm{GF}$ were used to make the comparative study between MuCell® and IQ Foam ${ }^{\circledR}$ processes.

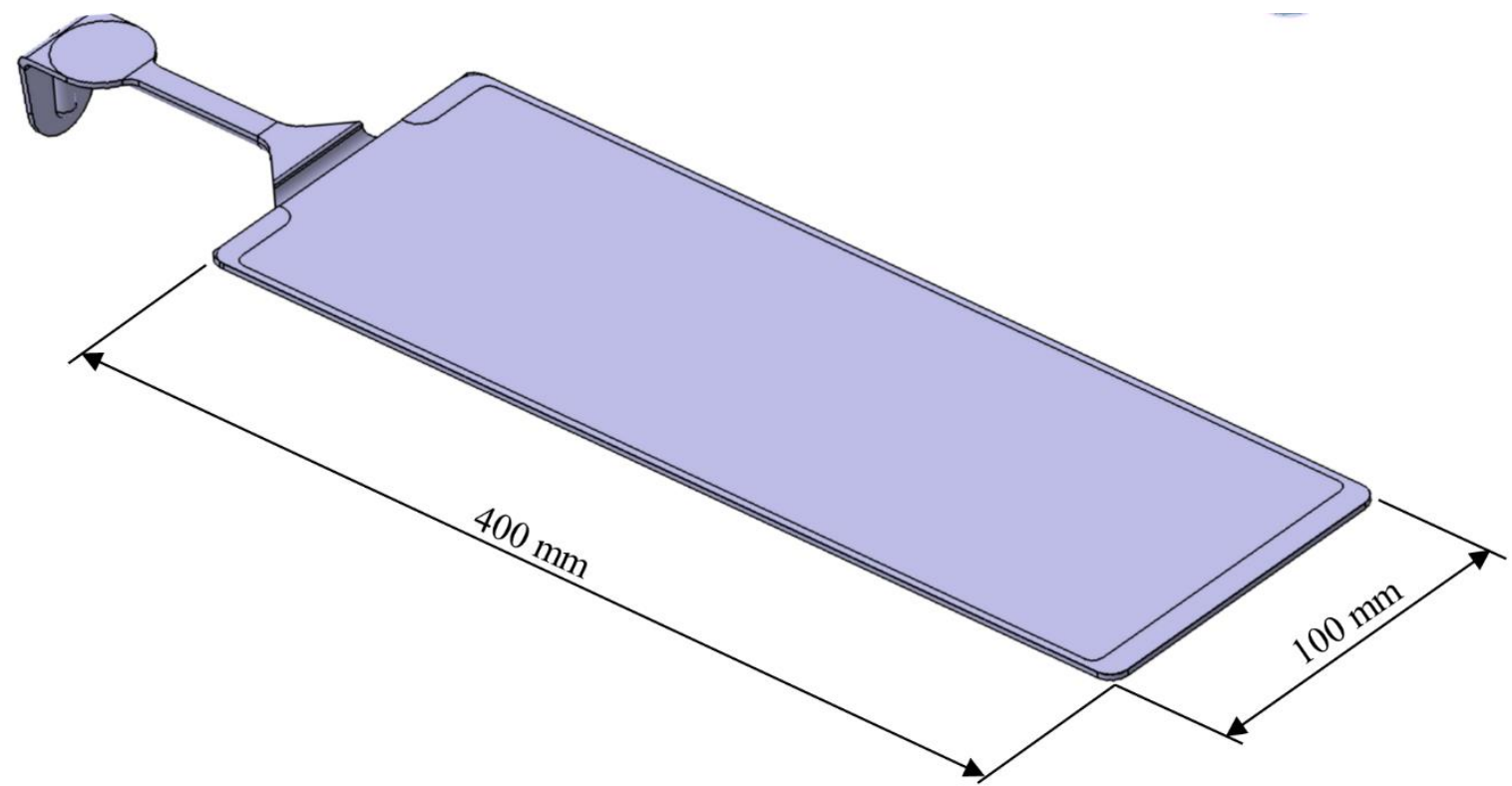

Figure 3.3. Schematic representation of injection molded rectangular plates. 
Table 3.9. Processing parameters of PP $20 \mathrm{GF}$ rectangular plates foamed by MuCell@ and IQ Foam® processes.

\begin{tabular}{|c|c|c|c|}
\hline Parameter & Solid & $\begin{array}{c}\text { MuCell@ } \\
\text { (10\% wt. red.) } \\
\text { + Core Back }\end{array}$ & $\begin{array}{c}\text { IQ Foam® } \\
\text { (10\% wt. red.) } \\
\text { + Core Back }\end{array}$ \\
\hline Melt temperature $\left({ }^{\circ} \mathrm{C}\right)$ & & $240-230-210-40$ & \\
\hline Shot volume $\left(\mathrm{cm}^{3}\right)$ & 190 & 165 & 165 \\
\hline Injection speed $\left(\mathrm{cm}^{3} \mathrm{~s}^{-1}\right)$ & 100 & 100 & 100 \\
\hline Mold temperature $\left({ }^{\circ} \mathrm{C}\right)$ & 30 & 30 & 30 \\
\hline Cooling time (s) & 45 & 45 & 45 \\
\hline Holding time (s) & 10 & - & - \\
\hline Holding pressure (bar) & 300 & - & - \\
\hline Gas flow $(\mathrm{kg} / \mathrm{h})$ & - & 0.18 & - \\
\hline Gas dosing time (s) & - & 11 & - \\
\hline Gas content (\%) & - & 0.50 & - \\
\hline Gas pressure (bar) & - & 34 & 25 \\
\hline
\end{tabular}

This mold was also employed to study the effect of mold cavity expansion by Core Back technology. Previous trials concluded that the shot volume of $165 \mathrm{~cm}^{3}$ and a nitrogen content of $0.5 \%$ were the optimal for achieving a homogeneous and fine cell structure along the whole plate, reducing the weight by $10 \%$ as compared to the unfoamed part. First, solid and foamed $3 \mathrm{~mm}$ thick plates were obtained. After that, two series of foamed samples combined with the Core Back technology were injection molded. A movable core insert located in the lower side of the plate enabled the enlargement of the cavity from a basic wall thickness of $3 \mathrm{~mm}$ up to $3.3 \mathrm{~mm}$ and $3.7 \mathrm{~mm}$, since a starting thickness between 2 and $4 \mathrm{~mm}$ was found to be the optimum for processing with the breathing tool technology [193].

The material was previously dried at $80{ }^{\circ} \mathrm{C}$ for 3 hours. The solid and MuCell@ foamed plates were obtained in an Arburg 570C Allrounder 2000-675 injection machine (Arburg $\mathrm{GmbH}$ (Germany) with a clamping force of $2000 \mathrm{kN}$, located in the Research Lab facilities of Covestro AG (Leverkusen, Germany). The IQ Foam® foamed plates were injection molded in the Institut für Recycling of the Ostfalia University (Wolfsburg, Germany), using a 
KraussMaffei 200-1000/390/CZ Multinject injection molding machine (KraussMaffei Group $\mathrm{GmbH}$, Germany) with $2000 \mathrm{kN}$ of clamping force and equipped with the IQ Foam ${ }^{\circledR}$ foaming devices. As summarized in Table 3.9, the same injection molding parameters were employed to produce all microcellular samples. The pressure of the SCF while foaming with MuCell@ was 34 bar, whereas the gas in IQ Foam ${ }^{\circledR}$ processes was injected at 25 bar. As the IQ Foam® equipment is only controlled by the gas pressure, the rest of foaming parameters (flow and time of gas dosing, weight content of gas introduced within the polymer) were not measured.

\subsubsection{Injection molding simulation}

The injection molding process of the cylindrical bars, square plates and rectangular plates was simulated with the aid of the Moldex 3D® commercial software (CoreTech System Co., Taiwan), in order to compare the results to the experimental ones obtained by the morphological analysis (Figure 3.4).

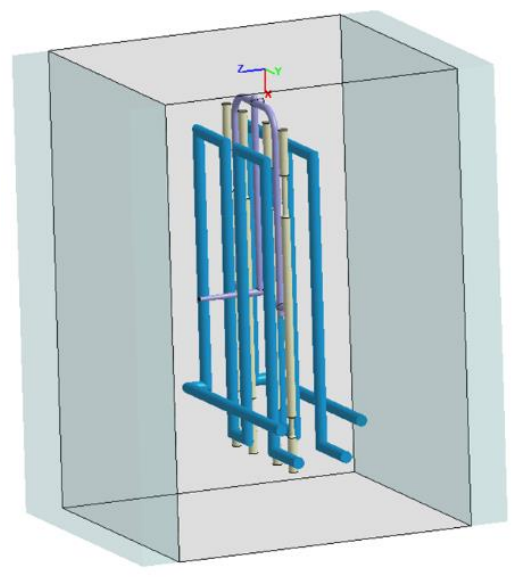

Figure 3.4. 3D model for injection molding simulation of the cylindrical bars with Moldex 3D®.

\subsection{Apparent density and morphological characterization}

\subsubsection{Apparent density}

After the injection procedure, the cylindrical bars and plates were weighed and their volume was measured to calculate the real weight reduction ratio and their apparent density. With the objective of studying variations along the molded parts, the density was also determined in samples taken from different positions of the bars and plates, as illustrated in Figure 3.5. 
a)

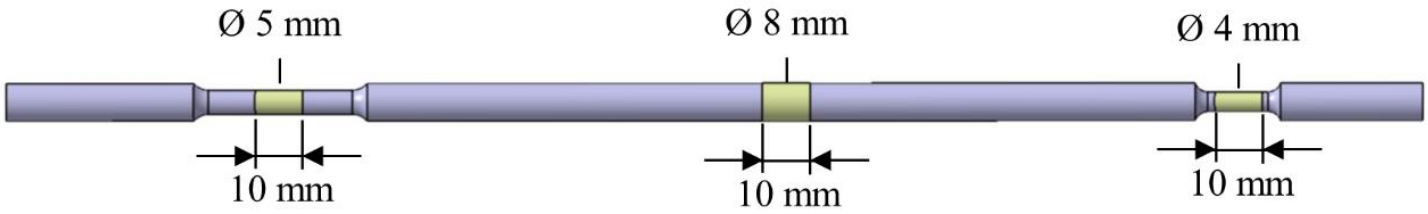

b)

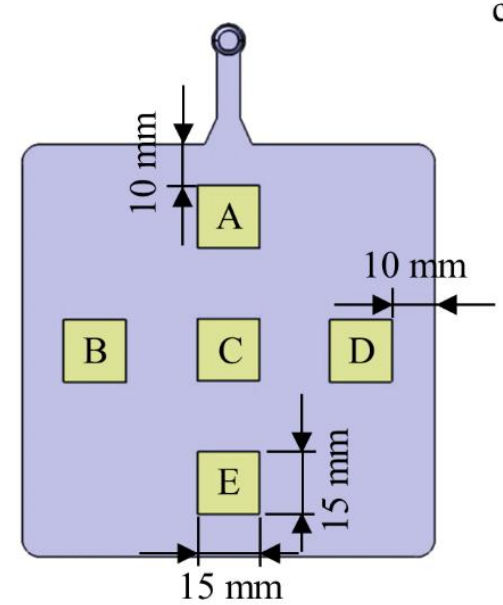

c)

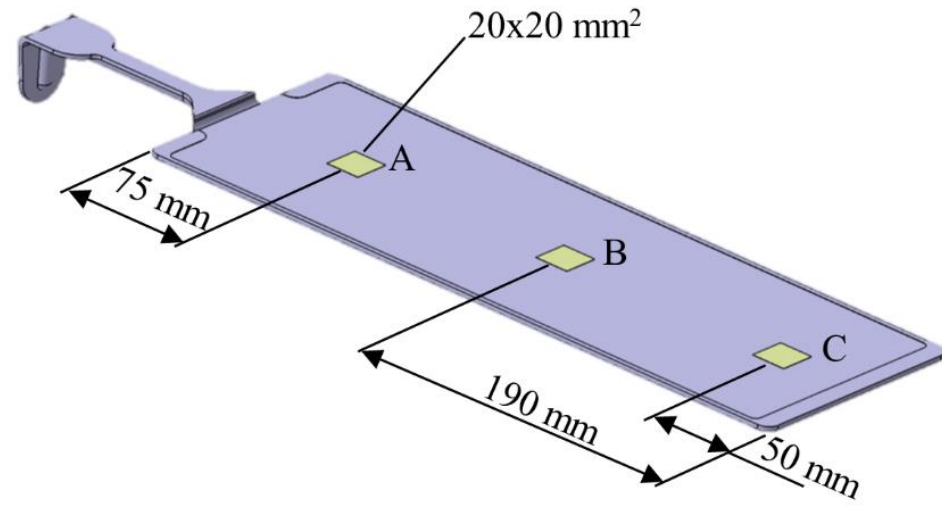

Figure 3.5. Schematic representation of samples extracted for apparent density measurements, direct calcination tests, CT scans and DSC analysis from a) cylindrical bars; b) square plates; c) rectangular plates.

\subsubsection{Scanning Electron Microscopy (SEM)}

The morphology of the foamed specimens was analyzed at the cross-section of $4 \mathrm{~mm}, 5$ $\mathrm{mm}$ and $8 \mathrm{~mm}$ in diameter of the cylindrical bars (Figure 3.6a)). In the square and rectangular plates, the cell structure was examined at $10 \mathrm{~mm}$-width cross sections taken at different distances from the injection gate both in a parallel (MD) and transversal direction (TD) to the injection flow (Figure 3.6b) and Figure 3.6c)). Samples were submitted to cryogenic fracture so as to avoid altering the original morphology, and the resulting fracture surfaces were examined by Scanning Electron Microscopy (SEM) using a JEOL JSM-560 microscope (Jeol Ltd., Japan). Micrographs were adjusted for an appropriate level of contrast and morphological parameters, such as cell size, cell density and skin thickness were determined with the aid of Igor Pro® (Wavemetrics Inc., USA) and Matlab® (The MathWorks Inc., USA) software (Figure 3.7). Cell density $(N)$ represents the number of cells per volume (cells $\mathrm{cm}^{-3}$ ) with respect to the unfoamed solid polymer and it is calculated as follows [62]:

$$
N=\left(\frac{n}{A}\right)^{3 / 2}\left(\frac{\rho_{s}}{\rho_{f}}\right)
$$

where $n$ is the number of cells in the micrograph, $A$ is the analyzed area $\left(\mathrm{cm}^{2}\right)$ and $\rho_{s}$ and $\rho_{f}$ are the density of solid and foamed material, respectively. 
a)

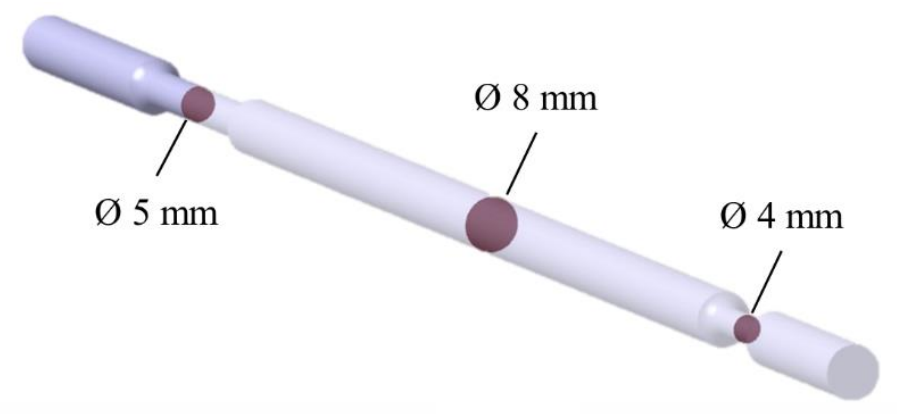

b)
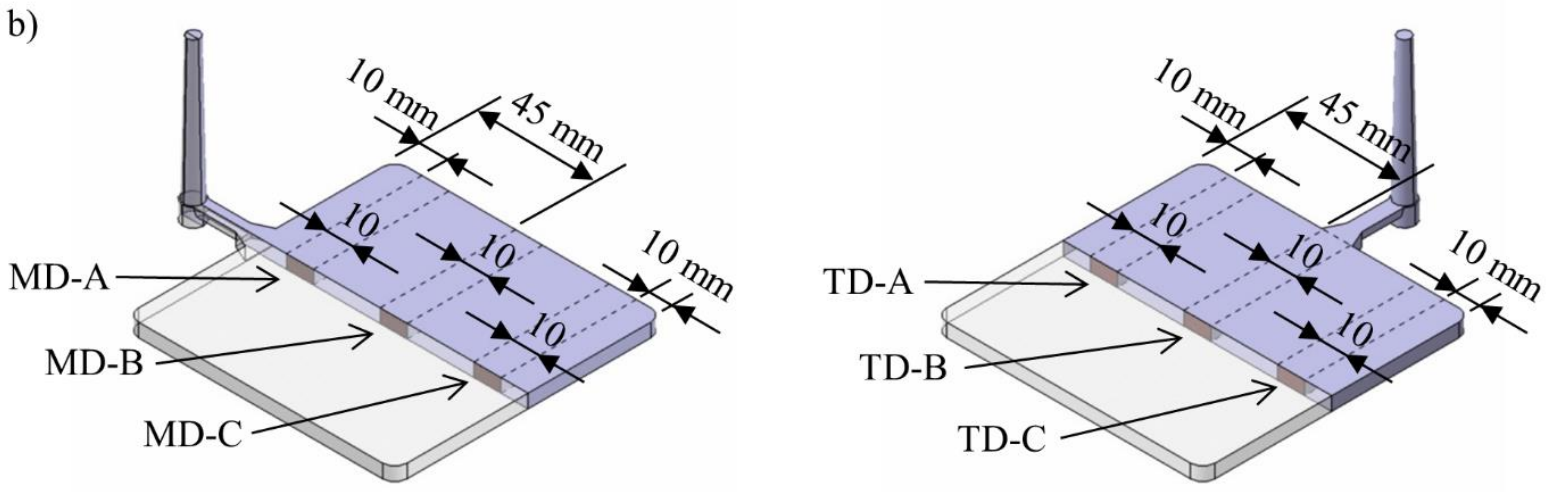

c)

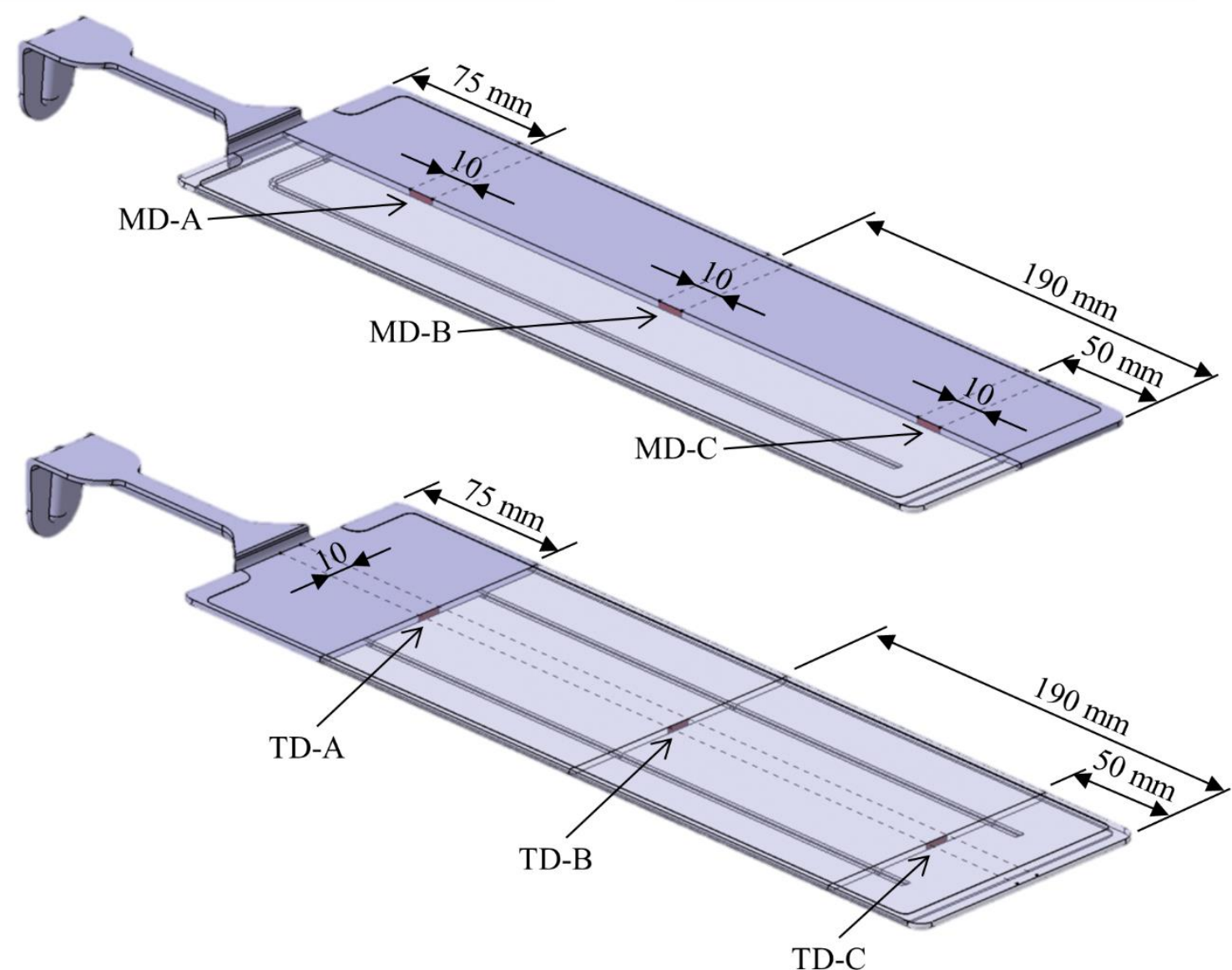

Figure 3.6. Schematic representation of samples extracted for morphology visualizations from a) cylindrical bars; b) square plates; c) rectangular plates. 


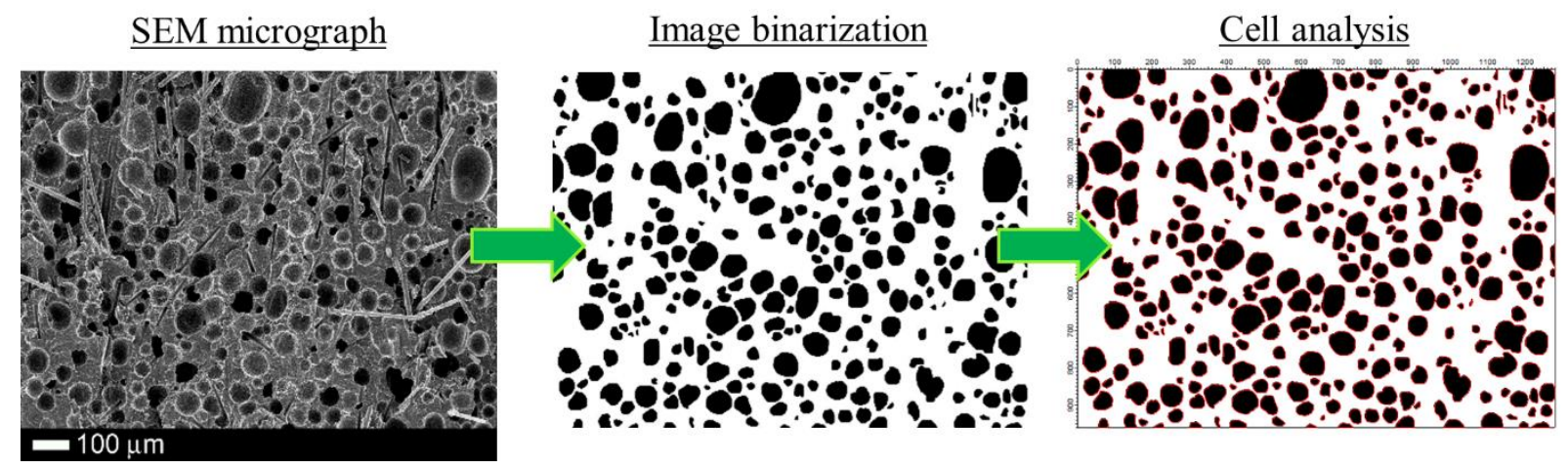

Figure 3.7. Procedure steps for morphological analysis of foamed samples.

The area of each cell of the micrograph was measured and, assuming all of them were completely spherical, an equivalent cell diameter or cell size $(d)$ was determined.

The Cell Distribution Index (CDI) was proposed by Rizvi et al. [194] to assess the uniformity of cell size distribution, and it is defined as:

$$
C D I=\frac{\overline{d_{w}}}{\overline{d_{n}}}
$$

Here, $\overline{d_{w}}$ and $\overline{d_{n}}$ are the diameter average cell diameter and number average cell diameter, respectively, calculated by means of the number of cells $\left(n_{i}\right)$ with the same equivalent diameter $\left(d_{i}\right)$ :

$$
\begin{aligned}
& \overline{d_{w}}=\frac{\sum_{i} n_{i} d_{i}^{2}}{\sum_{i} n_{i} d_{i}} \\
& \overline{d_{n}}=\frac{\sum_{i} n_{i} d_{i}}{\sum_{i} n_{i}}
\end{aligned}
$$

The skin thickness was measured as the distance between the surface and the first cells of the foamed core.

\subsubsection{X-Ray and Computed Tomography (CT)}

In order to get insight into the cell structure in a parallel direction to the injection flow in the ABS cylindrical bars, they were analyzed by the Computed Tomography (CT) technique. The micro-CT scans were conducted using a commercial micro CT scanner system: a General Electric Phoenix v/tome/x s (GE Co., USA) available at the CENIEH facilities (Burgos, Spain), using the 240kV/320 W microfocus direct tube and the multiscan mode. The images were obtained in each scan with the X-ray generation at $80 \mathrm{kV}$ and 290 
$\mu \mathrm{A}$, while acquisition settings were $200 \mathrm{~ms}$ per projection image, averaging of 3 images and skipping of 1 image per position. The total of scans was 9 and the voxel size was $5.38 \mu \mathrm{m}$. These images were then reconstructed using the system-supplied Datos (GE Measurement \& Control, USA) reconstruction software.

The cell morphology and fiber orientation and distribution of the PP 20GF plates were analyzed first at a macroscopic level by X-Ray technique with a GE X-Cube compact equipment (GE Co., USA) available at SEAT Laboratory facilities (Martorell, Spain). The scans were performed at $50 \mathrm{kV}$ and $3.4 \mathrm{~mA}$ using a $0.5 \mathrm{~mm}$-thick filter of cooper and applying a Flash filter on the images. Then, smaller samples were tooled from the plates (Figure 3.5b)) and scanned at the CORELAB laboratory of the University of Barcelona (Barcelona, Spain) with a micro-computerized tomography MultiTom Core system, (XRE bvba, Belgium). The samples were scanned at tube conditions of $90 \mathrm{kV}$ and $10 \mathrm{~W}$, for a total of 2500 projections and an exposure time of $400 \mathrm{~ms}$, resulting in a mean scan duration of 22 minutes and obtaining a voxel size resolution of $6 \mu \mathrm{m}$. All data from each sample was 3D reconstructed and filtered with RECON software from XRE and, finally, segmentation of materials depending on its density, i.e. fibers, polymer and air, was carried out using Avizo software (FEI Company, USA).

\subsubsection{Direct calcination}

The content of glass fiber reinforcement in the PP 20GF samples was carried out by the determination of ash through the direct calcination method, following the guidelines set by the ISO 3451-1 standard [195]. Different portions (around $1 \mathrm{~g}$ ) from the cylindrical bars and square plates (Figure 3.5) were pre-dried at $80^{\circ} \mathrm{C}$ and vacuum conditions for 1 hour in a desiccator Selecta (JP Selecta SA, Spain). The sample in the crucible was weighed and then heated on a burner slowly until volatile products were driven off. After that, the crucible was introduced in a muffle furnace Selecta $367 \mathrm{PE}$ model preheated at $600{ }^{\circ} \mathrm{C}$, and it was calcined until reaching constant mass. Finally, the crucible was placed in the desiccator and cooled until reaching room temperature, and weighed again in an analytical balance with an accuracy of $\pm 1 \mathrm{mg}$. The resulting ash, corresponding to fiber content, is given by the Equation (3.5):

$$
\% \text { Fibers }=\frac{m_{1}}{m_{0}}
$$

Where $m_{0}$ is the mass, in grams, of the dried test portion and $m_{1}$ the mass of the ash obtained after calcination. 


\subsection{Mechanical characterization}

The mechanical properties of solid and foamed samples were assessed through tensile, flexural and impact tests. For all materials and types of tests, the specimens were machined out of the cylindrical bars or plates according to the schemes shown in Figure 3.8, ensuring the correspondence between the tested section and the morphology previously analyzed. At least five samples of solid and foamed materials were tested under room temperature for each position and direction.

\subsubsection{Tensile properties}

Tensile tests were made on samples of 4 and $5 \mathrm{~mm}$ in diameter and a length of 77 and $110 \mathrm{~mm}$ extracted from the cylindrical bars (Figure 3.8a)). The specimens were tested in a universal testing machine Zwick/Roell Amsler HC25/2008 (Zwick GmbH \& Co. KG, Germany) equipped with a $5 \mathrm{kN}$ load cell, at a crosshead speed of $50 \mathrm{~mm} \mathrm{~min}^{-1}$ and an initial distance between clamps of $40 \mathrm{~mm}$ and $50 \mathrm{~mm}$, respectively.

Additionally, type 5A specimens indicated in the ISO 527-2 standard [196] (Figure 3.8c)) and tooled from the rectangular plates were employed to compare the properties of MuCell® and IQ Foam ${ }^{\circledR}$ foams. Tests were carried out on a universal testing machine Zwick/Roell Z010 (Zwick GmbH \& Co. KG, Germany) using a $10 \mathrm{kN}$ load cell, at a crosshead speed of $50 \mathrm{~mm} \mathrm{~min}^{-1}$ and an initial distance between clamps of $72 \mathrm{~mm}$.

Following the recommendations given by the ISO 527-1 standard [197], stresses (yield strength $\sigma_{y}$ and break stress $\sigma_{u}, \mathrm{MPa}$ ) were calculated according to Equation (3.6):

$$
\sigma=\frac{F}{A}
$$

Where $F$ is the measured force $(\mathrm{N})$ and $A$ is the nominal cross-sectional area of the samples $\left(\mathrm{mm}^{2}\right)$.

Strain values (yield strain $\varepsilon_{y}$ and elongation at break $\varepsilon_{u}, \%$ ) were determined by means of the initial gauge length $L_{0}(\mathrm{~mm})$ and the change in the gauge length $\Delta L_{0}(\mathrm{~mm})$ :

$$
\varepsilon=\frac{\Delta L_{0}}{L_{0}} \times 100 \%
$$


a)

Tensile specimens:
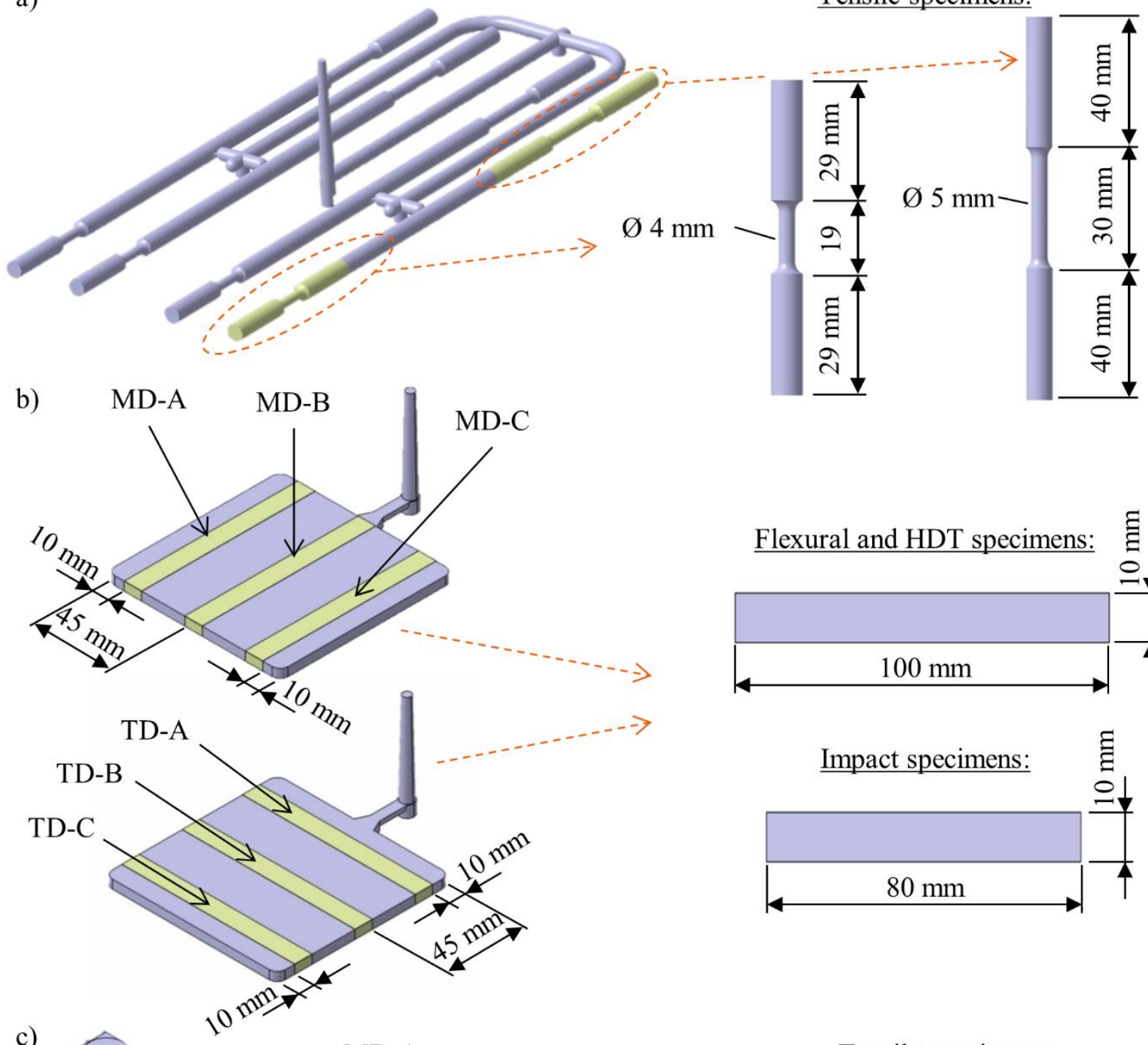

c)
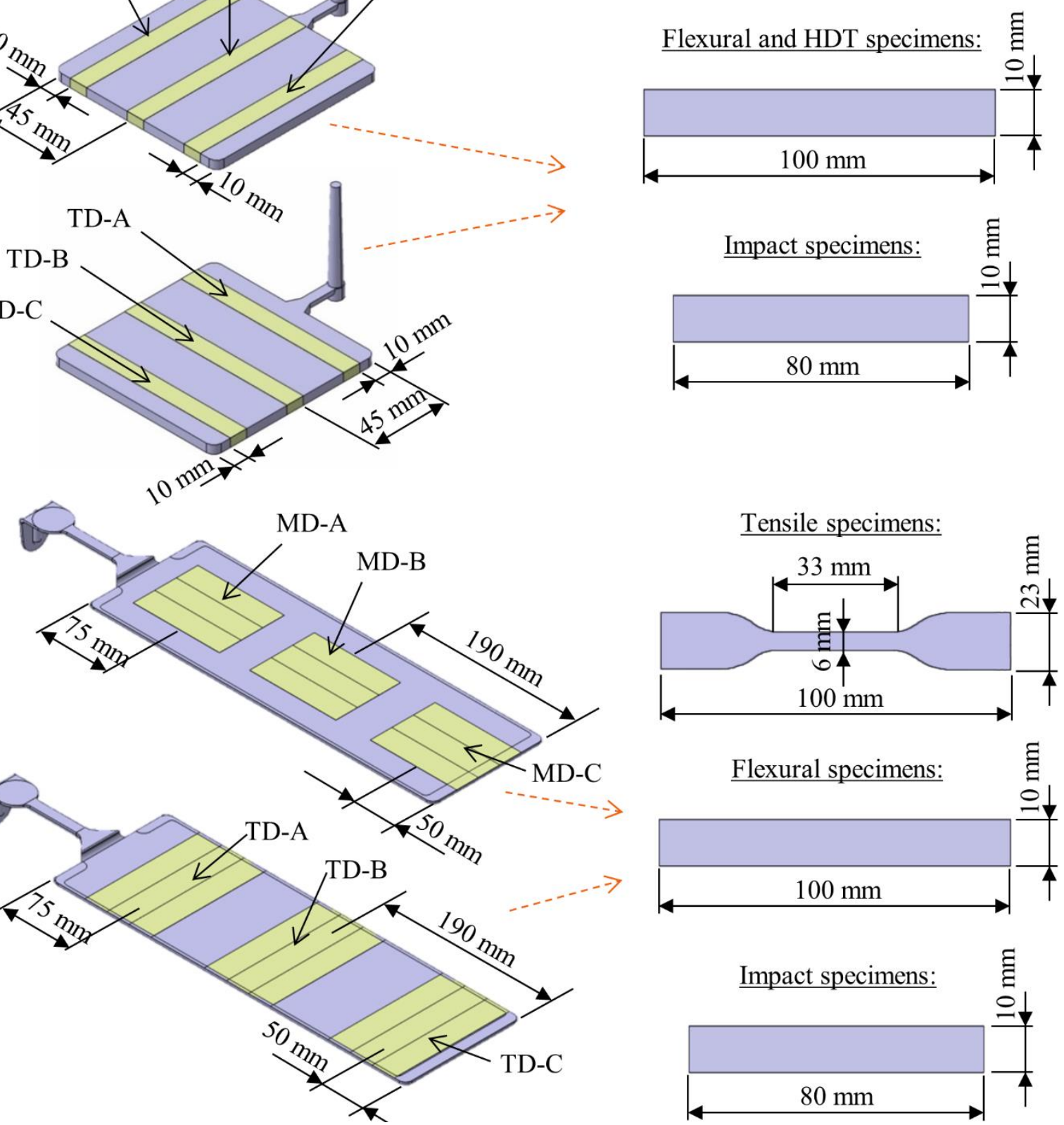

Figure 3.8. Schematic representation of samples extracted for mechanical characterization and HDT tests from a) cylindrical bars; b) square plates; c) rectangular plates. 
Finally, the elastic modulus $\left(E_{t}, \mathrm{MPa}\right)$ was obtained as follows:

$$
E_{t}=\frac{\sigma_{t 2}-\sigma_{t 1}}{\varepsilon_{t 2}-\varepsilon_{t 1}}
$$

Where $\sigma_{t l}$ is the stress measured at a strain of $\varepsilon_{t l}=0.0005$ and $\sigma_{t 2}$ is the stress measured at a strain of $\varepsilon_{t 2}=0.0025$. When this method did not work accurately, the elastic modulus was calculated by linear regression applied to the elastic portion of the stress - strain curve, dividing the difference in stress $(d \sigma)$ corresponding to any segment of section on this straight line by the corresponding difference in strain $(d \varepsilon)$ :

$$
E_{t}=\frac{d \sigma}{d \varepsilon}
$$

\subsubsection{Flexural properties}

Flexural tests were carried out in $100 \times 10 \mathrm{~mm}^{2}$ (length $\mathrm{x}$ width) specimens machined out of the square and rectangular plates (Figure 3.8). Experiments were done following the ISO 178 standard [198], in a Galdabini Sun 2500 (Galdabini SPA, Italy) testing machine equipped with a $5 \mathrm{kN}$ load cell, at a crosshead speed of $10 \mathrm{~mm} \mathrm{~min}^{-1}$. According to the aforementioned standard, the span length $(S)$ was $(16 \pm 1) x h$, where $h$ is the thickness of the samples.

Flexural strength $\left(\sigma_{f}, \mathrm{MPa}\right)$ and flexural strain $(\varepsilon f, \%)$ at failure were calculated as follows:

$$
\begin{aligned}
\sigma_{f} & =\frac{3 F S}{2 b h^{2}} \\
\varepsilon_{f} & =\frac{6 s h}{S^{2}} \times 100 \%
\end{aligned}
$$

Where $F(\mathrm{~N})$ and $s(\mathrm{~mm})$ are the measured force and deflection, $S(\mathrm{~mm})$ is the span length, and $b$ and $h(\mathrm{~mm})$ are the width and thickness of the specimen, respectively.

The flexural modulus $\left(E_{f}, \mathrm{MPa}\right)$ was determined by means of $\sigma_{f 1}$, which is the stress measured at a strain of $\varepsilon_{f 1}=0.0005$, and $\sigma_{f 2}$ as the stress measured at a strain of $\varepsilon_{f 2}=0.0025$ :

$$
E_{f}=\frac{\sigma_{f 2}-\sigma_{f 1}}{\varepsilon_{f 2}-\varepsilon_{f 1}}
$$


The linear regression method (Equation (3.9)) was also employed to calculate $E_{f}$ when the application of this procedure was not possible.

\subsubsection{Impact properties}

Charpy impact tests were made on $80 \times 10 \mathrm{~mm}^{2}$ (length $\mathrm{x}$ width) unnotched samples in flatwise configuration (Figure 3.8). The impact tests were carried out using an instrumented Ceast Resil impactor (Instron Ltd., UK), equipped with a 15J hammer. The pendulum had a length of $0.374 \mathrm{~m}$ and a reduced mass of $3.654 \mathrm{~kg}$. It was impacted at an angle of $99^{\circ}$, resulting in an impact rate of $2.91 \mathrm{~m} \mathrm{~s}^{-1}$. The span length was $62 \mathrm{~mm}$. Force, displacement, energy and time values were recorded by a data acquisition system DAS-1600 from Ceast. According to ISO 179-2 standard [199], the impact resistance $\left(a_{c}, \mathrm{~kJ} / \mathrm{m}^{2}\right)$ was calculated following Equation (3.13):

$$
a_{c U}=\frac{E_{c}}{h b} \times 10^{3}
$$

Where $E_{c}(\mathrm{~J})$ is the energy absorbed during the test, and $b$ and $h(\mathrm{~mm})$ are the width and thickness of the sample, respectively.

\subsubsection{Thermal aging}

Polymer degradation can occur due to different causes, such as atmospheric agents, heat, ultraviolet light or radiant energy absorption. Automotive parts must keep their properties beyond certain limits over the service life of the vehicle. The aging effect was performed by exposing PP 20GF solid and foamed square plates at $150{ }^{\circ} \mathrm{C}$ for periods of 200 , 300, 400 and 500 hours in a TU 60/60 heating and drying oven (Vötsch Industrietechnik $\mathrm{GmbH}$, Germany). The change in properties was assessed by flexural and impact tests, as described in the respective sections above.

\subsection{Fracture characterization}

The fracture behavior of the solid and foamed square plates was characterized at low loading speed by the Crack Tip Opening Displacement (CTOD), as well as at high testing rate by the fracture toughness $\left(K_{I c}\right)$. In order to relate the fracture properties with the cell structure determined by morphology analysis, the same distances from the injection gate and orientations were employed. All fracture tests were performed at room temperature and the 
notch was sharpened by sliding a razor blade. At least five specimens were tested for each material, orientation and loading speed.

\subsubsection{Crack Tip Opening Displacement}

SENT (Single Edge Notched Tension) specimens were employed to determine the CTOD parameter, whose size and dimensions are plotted in Figure 3.9. The notch length/width ratio $(a / b)$ was kept at 0.6 , in order to avoid triaxial stress states at the crack tip [200]. The low speed tests were performed using a Zwick/Roell universal testing machine, Amsler HC25/2008 model (Zwick GmbH \& Co. KG, Germany), at a crosshead rate of $16 \mathrm{~mm}$ $\min ^{-1}$. The tests were recorded by two digital cameras at a frame rate of 10 pictures per second (Xenoplan 1.4/23-0.902, Schneider Optische Werke GmbH, Germany) coupled to a GOM/ARAMIS (GOM mbH, Germany) Digital Image Correlation system (DIC). The CTOD parameter was calculated by measuring the displacement of the notch faces at the crack propagation onset.

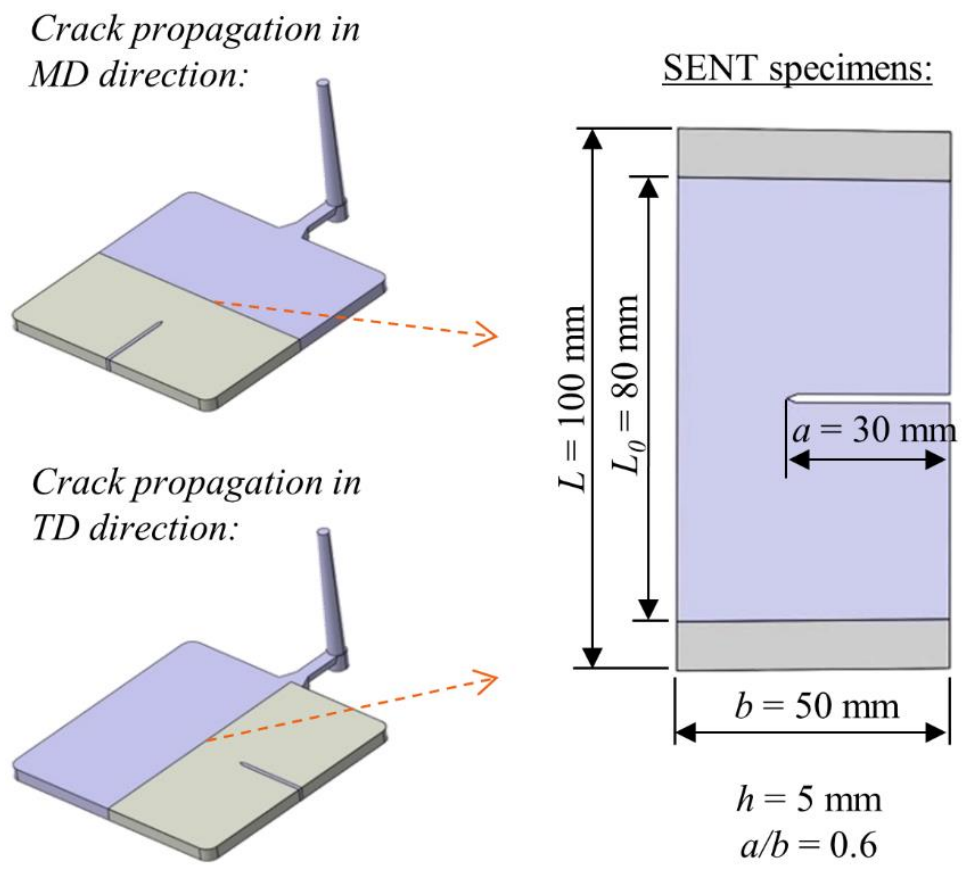

Figure 3.9. Schematic representation of SENT samples extracted from square plates for fracture CTOD analysis.

\subsubsection{Fracture toughness}

The fracture toughness of the solid and foamed ABS was assessed through SENB (Single Edge Notched Bending) specimens, as shown in Figure 3.10. According to the testing protocol for determining fracture toughness at moderately high loading rates [201], the $a / b$ ratio was in the range of $0.45 \leq a / b \leq 0.55$. 


\section{Crack propagation in MD direction:}

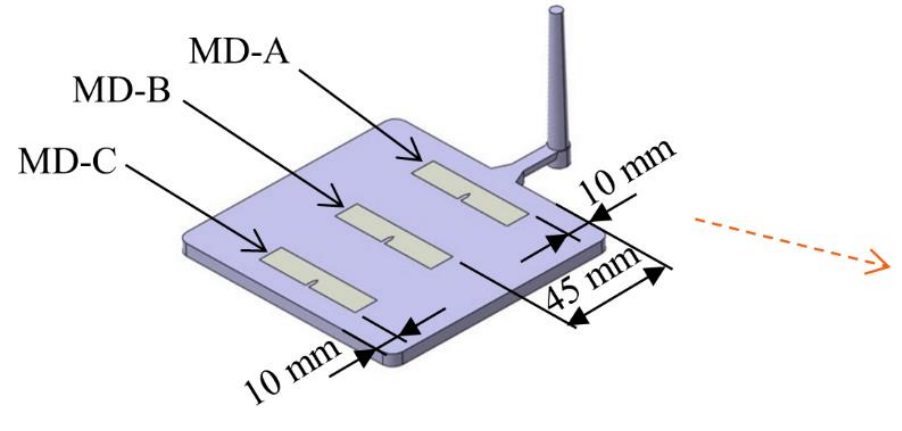

Crack propagation in TD direction:

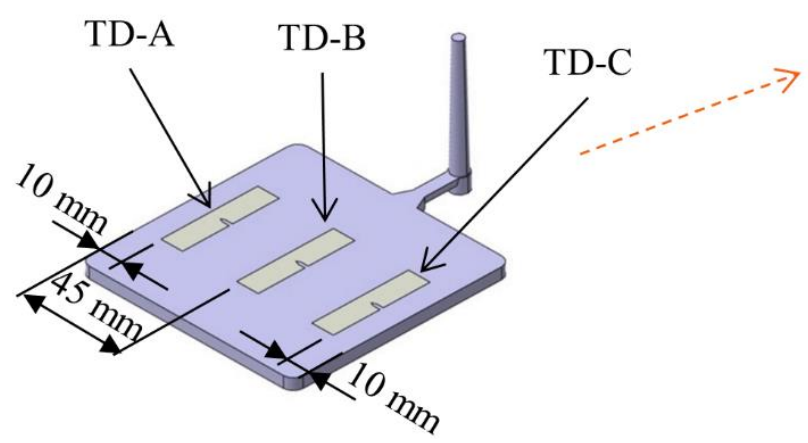

$\underline{\text { SENB specimens: }}$

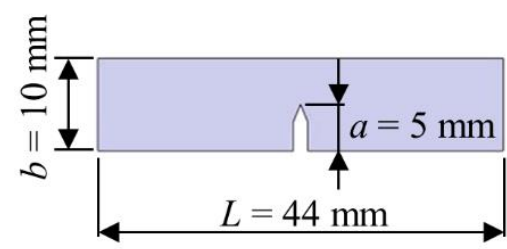

$$
\begin{gathered}
h=5 \mathrm{~mm} \\
S=40 \mathrm{~mm} \\
0.45 \leq a / b \leq 0.55
\end{gathered}
$$

Figure 3.10. Schematic representation of SENB samples extracted from square plates for fracture toughness determination.

The impact tests at $1 \mathrm{~m} \mathrm{~s}^{-1}$ were carried out using an instrumented Ceast Resil impactor (Instron Ltd., UK), equipped with a 15J hammer. The pendulum had a length of $0.374 \mathrm{~m}$ and a reduced mass of $3.654 \mathrm{~kg}$, and it was impacted at an angle of $30^{\circ}$. Force, displacement, energy and time were recorded by a data acquisition system DAS-1600 from Ceast. The fracture toughness $K_{I c}\left(\mathrm{MPa} \mathrm{m}^{1 / 2}\right)$ was calculated as follows:

$$
K_{I c}=f \frac{P_{q}}{h \sqrt{b}}
$$

Where $P_{q}$ is the calculation force $(\mathrm{N}), h$ and $b$ are the part thickness and width $(\mathrm{mm})$ respectively, and $f$ is a geometric function depending on the $a / b$ ratio and determined according to the aforementioned protocol [201].

\subsection{Thermal characterization}

The objective of the thermal characterization is studying possible changes in crystallinity level and melting temperature of foamed plates as compared to solid material, by Differential Scanning Calorimetry (DSC) analysis, as well as variations in softening temperature due to foaming by Heat Deflection Temperature (HDT) tests. 


\subsubsection{Differential Scanning Calorimetry}

The effect of foaming on thermal properties was studied by Differential Scanning Calorimetry (DSC) analysis. PP 20GF samples of around 5-10 mg extracted from the center of the square plates. In order to assess differences between the solid skin and the foamed core, tests were made on samples taken from both areas (Figure 3.5b)). A Perkin Elmer Pyris 1 device, with a Perkin 2P Intracooler (PerkinElmer Inc., USA) system and calibrated with indium and lead, was employed, as well as standard aluminum crucibles. Samples were heated from $-20{ }^{\circ} \mathrm{C}$ to $210^{\circ} \mathrm{C}$ at a heating rate of $10{ }^{\circ} \mathrm{C} \mathrm{min}{ }^{-1}$. Heating and cooling scans allowed the determination of melting and crystallization parameters, following the guidelines given by ISO 11357 standard [202]. The maximum of the exothermic peak obtained during the first cooling corresponds to the crystallization temperature $T_{c}\left({ }^{\circ} \mathrm{C}\right)$, while the melting temperature $T_{m}\left({ }^{\circ} \mathrm{C}\right)$ was taken as the maximum of the endothermic peak from the second heating. By integrating the areas underneath the corresponding peaks, crystallization and melting enthalpies were determined. The crystallinity degree $X_{c}(\%)$ was determined according to Equation (3.15):

$$
X_{c}=\frac{\Delta H_{m}}{\left(\Delta H_{0}^{P P} f^{P P}+\Delta H_{0}^{P E} f^{P E}\right)\left(1-W_{f}\right)}
$$

Where $\Delta H_{m}$ is the measured melting enthalpy $(\mathrm{J} / \mathrm{g})$ and $\Delta H_{0}^{P P}$ and $\Delta H_{0}^{P E}$ are the melting enthalpies for fully perfect crystalline PP and PE, whose values were taken as $207 \mathrm{~J} / \mathrm{g}$ and 296 $\mathrm{J} / \mathrm{g}$, respectively [203]. $f^{P P}$ and $f^{P E}$ are the weight fraction of PP and PE, and $W_{f}$ is the weight fraction of the used reinforcement ( 0.2 in this case).

\subsubsection{Heat Deflection Temperature}

Heat Deflection Temperature tests were performed on 100x10x5 $\mathrm{mm}^{3}$ specimens machined out the square plates following the scheme showed in Figure 3.8b) (only TD-A, TD-B and TD-C samples). Method A described in ISO 75-2 standard [204] specifies a load in the middle of the sample of $1.80 \mathrm{MPa}$. The silicone bath was heated at a rate of $2{ }^{\circ} \mathrm{C} \min ^{-1}$ in a Ceast 6520 HDT/Vicat testing instrument (Instron Ltd., UK). The test standard indicates a normalized deflection of $0.34 \mathrm{~mm}$ for $4 \mathrm{~mm}$ thick specimens. This value was extrapolated to a thickness of $5 \mathrm{~mm}$, and the Heat Deflection Temperature $H D T\left({ }^{\circ} \mathrm{C}\right)$ was taken as the temperature at which specimens reached a deflection of $0.24 \mathrm{~mm}$. 
Results and discussion 


\section{Chapter 4:}

\section{ABS - MuCell@ foams}

The main results obtained from ABS foams processed by MuCell@ technology are presented. The wide range of applications of this material explains the fact that some authors have already researched its foamability. Being an amorphous material, ABS absorbs more gas than crystalline polymers [76], mainly $\mathrm{CO}_{2}$, although a higher diffusion of $\mathrm{N}_{2}$ in $\mathrm{ABS}$ and a reduction in the glass transition temperature due to the gas content have been reported [205]. Many investigations have been made on ABS foamed by batch processes [65, 206, 207], and an enhancement of mechanical properties with glass fibers and mineral fillers have been found [208]. According to Mahmoodi and Behravesh [209], the pressure drop rate in a batch process does not affect the microstructure, despite its effect on cell nucleation. However, the number of research works on foaming by injection molding is limited. Lin et al. [122] studied the effect of blowing agent content, injection rate and melt temperature on the morphology, dimensional stability and tensile and impact properties. Dong et al. [210] employed ABS foams to describe the governing cell forming mechanisms, and an improvement of the cell structure was obtained combining chemical and physical nucleating agents [147].

\subsection{Cylindrical bars}

The study of ABS foamed samples began with the analysis of the influence of processing parameters on their morphology and mechanical properties. To do this, a design of injection experiments with different combinations of shot volume, mold temperature and injection speed was conducted (Table 3.1 and Table 3.2). For comparison purposes, only one extreme bar of all different foamed series was considered (bar A, Figure 3.1) and the morphology and tensile properties were determined in the $\varnothing=5 \mathrm{~mm}$ section. After analyzing statistical data of obtained results, those injection molding condition series for each level of weight reduction that optimized the cell structure and maximized the tensile properties were selected. A broader study of the morphology and mechanical behavior in the different diameter sections and mold cavities was conducted with these selected foamed groups. 


\subsubsection{Design of Experiments: Effect of processing conditions}

\subsubsection{Morphology}

The SEM micrographs corresponding to the cross-sections of the different injected bars are shown in Figure 4.1 and Figure 4.2. The material structure of the foamed samples consists of a solid external layer and a foamed core. As a consequence of the temperature gradient from the surface to the middle of the part, different cell morphologies were developed and therefore this foamed core can be divided into two different areas (Figure 4.3). The high heat concentration and slow cooling in the center of the bars made the polymer viscosity in the region to be insufficient to prevent massive cell coalescence and expansion in the nucleus area, forming bigger bubbles heterogeneously dispersed. Between the nucleus and the solid skin, there is a transition region with cells smaller than $100 \mu \mathrm{m}$ uniformly distributed (microcellular area). A similar structure was reported by Bledzki et al. [131] with microcellular polycarbonate.

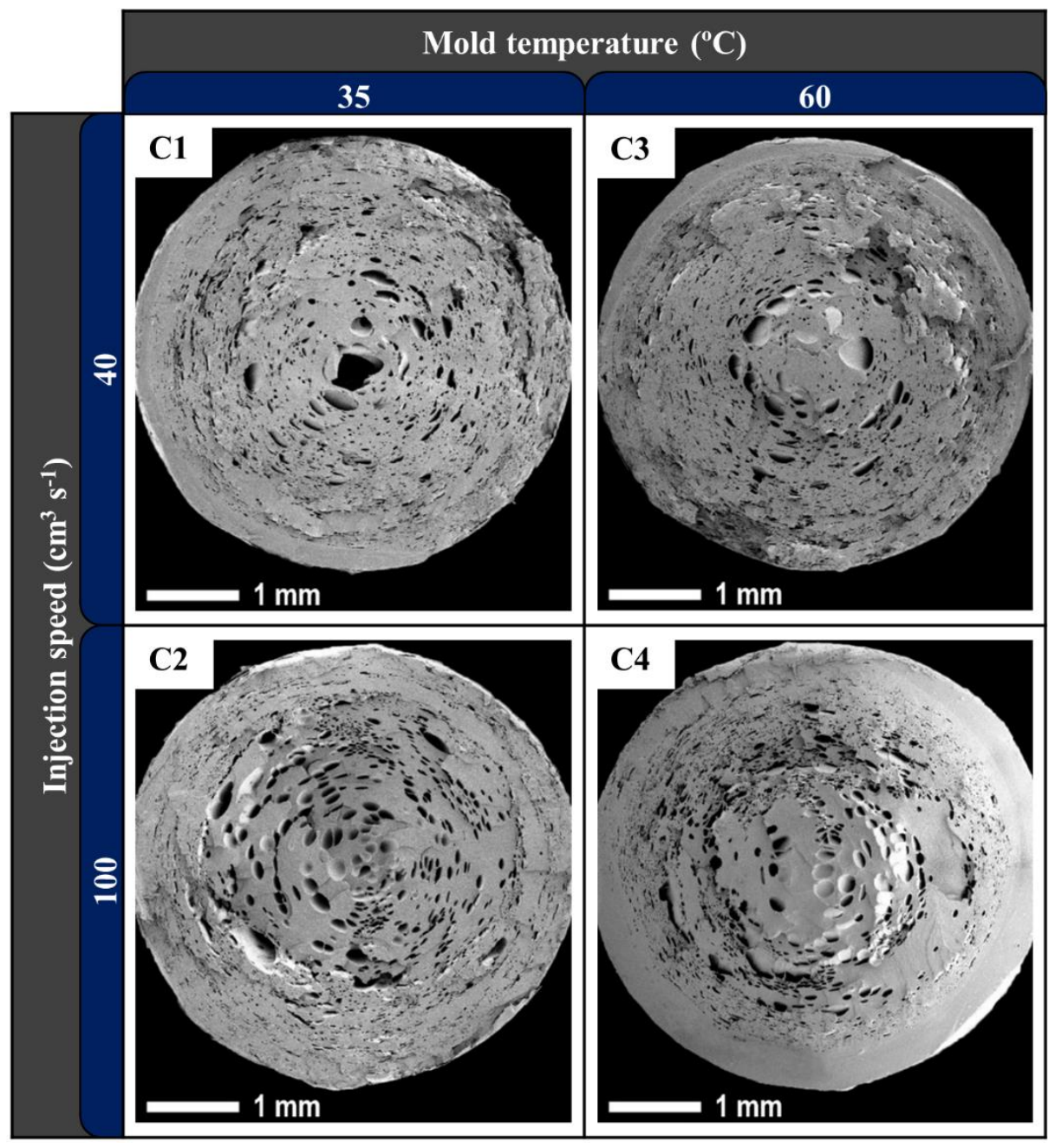

Figure 4.1. SEM micrographs of $\mathrm{C} 1-\mathrm{C} 4$ conditions. Shot volume: $71 \mathrm{~cm}^{3}$ (10\% weight reduction). 


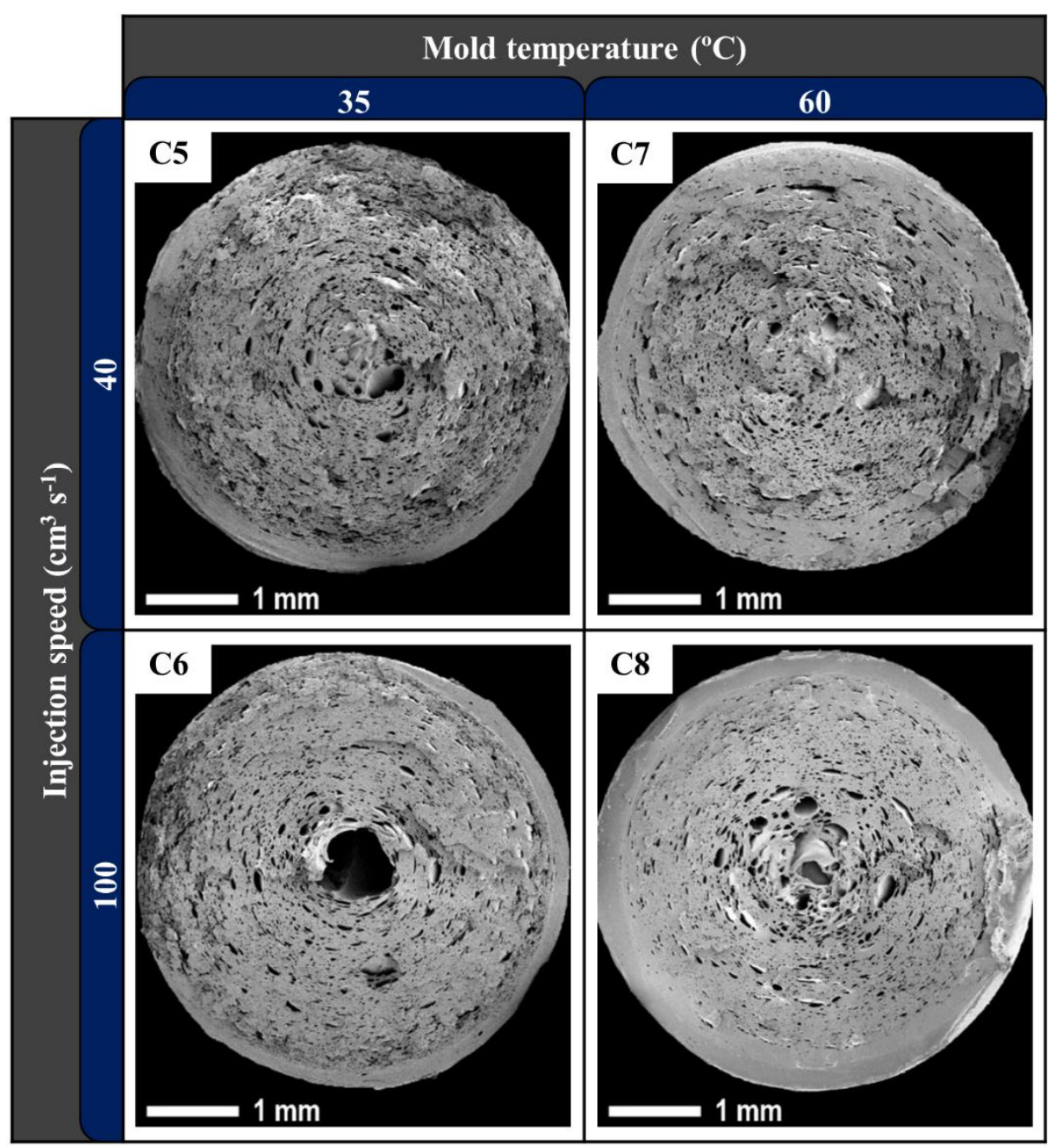

Figure 4.2. SEM micrographs of C5-C8 conditions. Shot volume: $68 \mathrm{~cm}^{3}$ (17\% weight reduction).

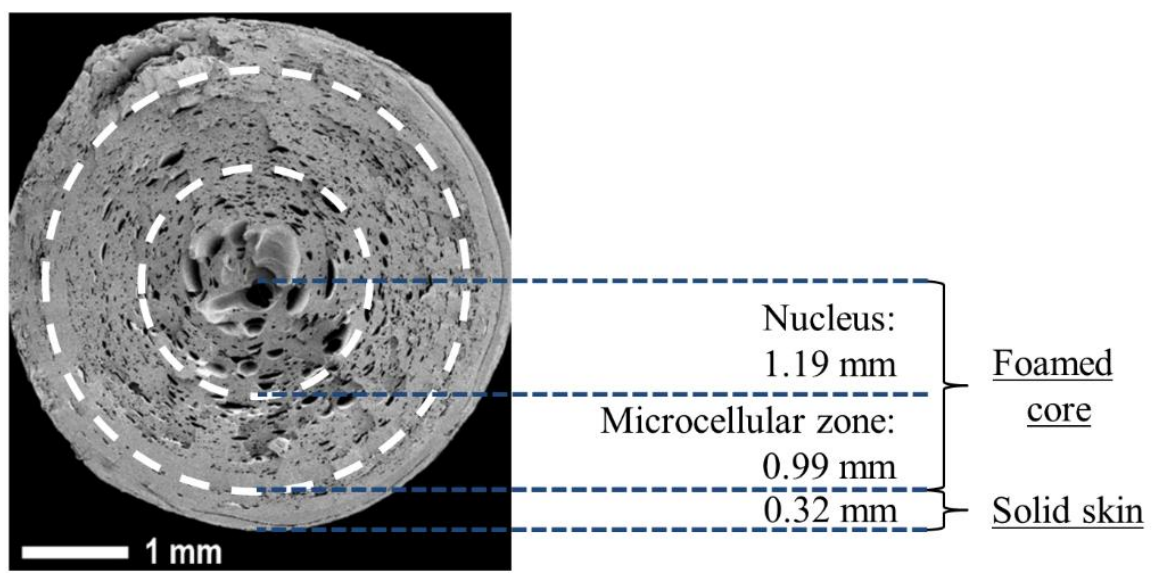

Figure 4.3. SEM micrograph and morphology areas of $\mathrm{C} 0$ condition.

Regarding the shape of the cells, near the surface cells were distorted following the circumferential shape of the cross-section, but they became more spherical as they got closer to the center. However, in the parallel direction to the injection flow, cells near the skins were elongated due to the fountain flow during filling (Figure 4.4), as stated by Wang et al. [94]. 
a)

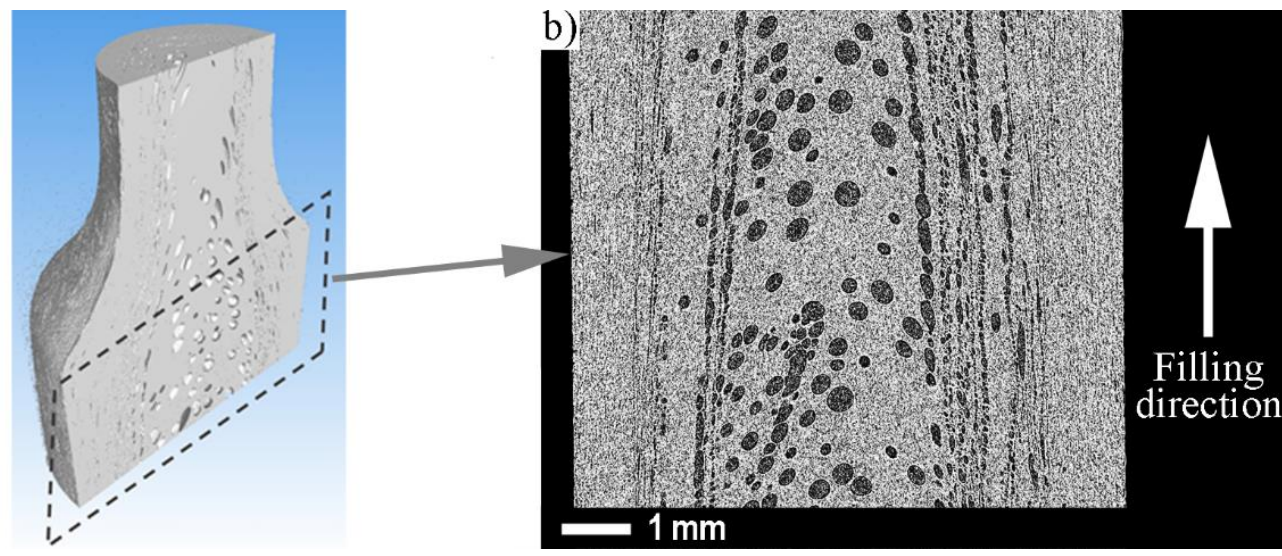

Figure 4.4. a) Micro-CT picture of $\varnothing=8 \mathrm{~mm}$ section of $\mathrm{C} 8$ condition; $\mathbf{b})$ Longitudinal cross-section through the center point.

Qualitatively, samples with $17 \%$ of weight reduction (Figure 4.2) seem to present finer cell structures, with a higher number of smaller cells more homogenously distributed than bars foamed with $10 \%$ of weight reduction (Figure 4.1). These remarks are in agreement with the morphological parameters summarized in Table 4.1. The solid skin thickness varied from 0.25 to $0.36 \mathrm{~mm}$. The cell density was kept in an order of magnitude of $10^{6}$ cells $\mathrm{cm}^{-3}$ in all cases. This can be explained by the high diffusivity of $\mathrm{N}_{2}$ in ABS reported by Hwang and Cha [205]. According to the study carried out by Sorrentino et al. [211] with PET foams, a high diffusivity of the gas in the polymer increases cell density and reduces cell size.

Table 4.1. Weight reduction ratio, apparent density and morphological parameters of ABS foamed samples.

\begin{tabular}{ccccccc}
\hline $\begin{array}{c}\text { Condition } \\
\text { No. }\end{array}$ & $\begin{array}{c}\text { Weight } \\
\text { reduction } \\
(\%)\end{array}$ & $\begin{array}{c}\text { Density } \\
\left(\mathbf{g ~ c m}^{-3}\right)\end{array}$ & $\begin{array}{c}\text { Skin } \\
\text { thickness } \\
(\mathbf{m m})\end{array}$ & $\begin{array}{c}\text { Cell } \\
\mathbf{d e n s i t y} \\
\left(\mathbf{c e l l s ~} \mathbf{c m}^{-3}\right)\end{array}$ & $\begin{array}{c}\text { Cell size } \\
\text { range } \\
(\boldsymbol{\mu m})\end{array}$ & CDI \\
\hline C1 & $11.14 \pm 0.51$ & $0.91 \pm 0.02$ & 0.35 & $3.1 \cdot 10^{6}$ & $8-271$ & 1.87 \\
C2 & $11.12 \pm 0.64$ & $0.91 \pm 0.03$ & 0.27 & $2.7 \cdot 10^{6}$ & $8-262$ & 2.10 \\
C3 & $11.03 \pm 0.59$ & $0.91 \pm 0.02$ & 0.28 & $3.6 \cdot 10^{6}$ & $8-260$ & 1.83 \\
C4 & $9.33 \pm 0.33$ & $0.91 \pm 0.03$ & 0.36 & $4.2 \cdot 10^{6}$ & $8-188$ & 2.04 \\
C5 & $19.09 \pm 0.77$ & $0.83 \pm 0.03$ & 0.31 & $5.4 \cdot 10^{6}$ & $8-147$ & 1.57 \\
C6 & $17.84 \pm 1.12$ & $0.84 \pm 0.04$ & 0.25 & $5.2 \cdot 10^{6}$ & $8-208$ & 1.97 \\
C7 & $18.76 \pm 0.70$ & $0.83 \pm 0.02$ & 0.30 & $5.9 \cdot 10^{6}$ & $8-228$ & 1.52 \\
C8 & $17.32 \pm 0.48$ & $0.83 \pm 0.03$ & 0.31 & $6.0 \cdot 10^{6}$ & $8-163$ & 1.69 \\
C0 & $13.55 \pm 0.76$ & $0.88 \pm 0.03$ & 0.32 & $5.1 \cdot 10^{6}$ & $8-240$ & 1.92 \\
\hline
\end{tabular}



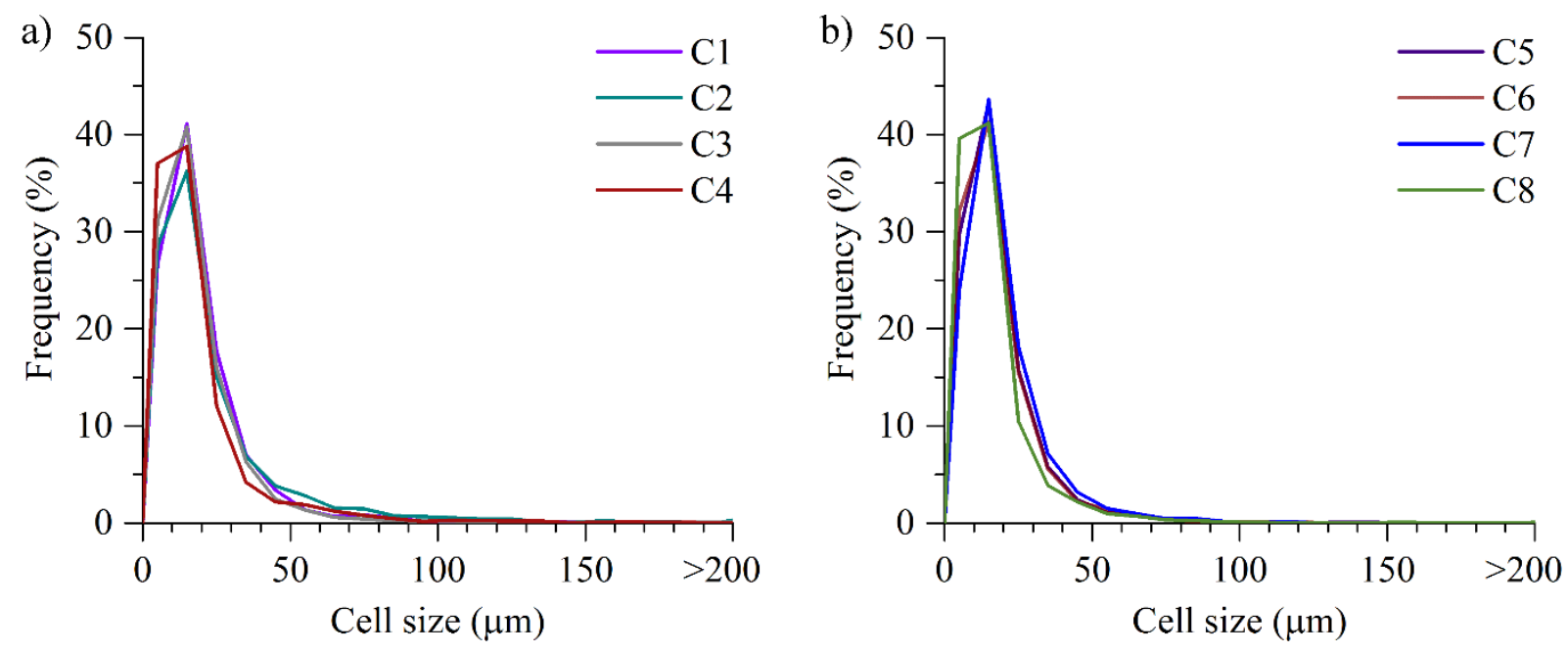

Figure 4.5. Cell size distribution of a) C1-C4 (10\% weight reduction); b) C5-C8 injection conditions (17\% weight reduction).

Figure 4.5 depicts the cell size distribution of samples with both levels of weight reduction. The minimum diameter which was possible to measure due to the resolution of the micrographs was $8 \mu \mathrm{m}$. Despite the wide range of cell size obtained, around $95 \%$ of cells were smaller than $50 \mu \mathrm{m}$, with a center value of $20 \mu \mathrm{m}$.

The extent of uniformity in cell size can be assessed on the basis of the Cell Distribution Index (CDI) parameter, proposed by Rizvi et al. [194]. This parameter is defined as a polydispersity index, and gives an idea about the lowest and highest cell size, as well as the distribution pattern of the intermediate cell sizes. As a polidispersity index, a CDI value close to unity represents monodispersity of cell size, and higher values indicate greater differences in cell sizes. According to the results provided in Table 4.1 and Figure 4.5, the $C D I$ varied from 1.50 to 2.00 , due to the wide cell size range of the foams obtained under the different injection molding conditions.

\subsubsection{Tensile behavior}

The engineering stress-strain curves of solid and foamed samples ( $\mathrm{C} 4, \mathrm{C} 0$ and $\mathrm{C} 8$ ) obtained from tensile tests are shown in Figure 4.6. All specimens reached the yield point followed by necking and plastic deformation prior to breaking. The results of elastic modulus, stress and strain at yield point and ultimate strength of solid and foamed bars at different processing conditions are summarized in Table 4.2. These properties corresponding to the solid material are in accordance to that found in the literature [212-214]. As reported by Beydokhti et al. [208] working on ABS composites, foaming reduces gradually the elastic modulus and tensile strength as the density decreases. 


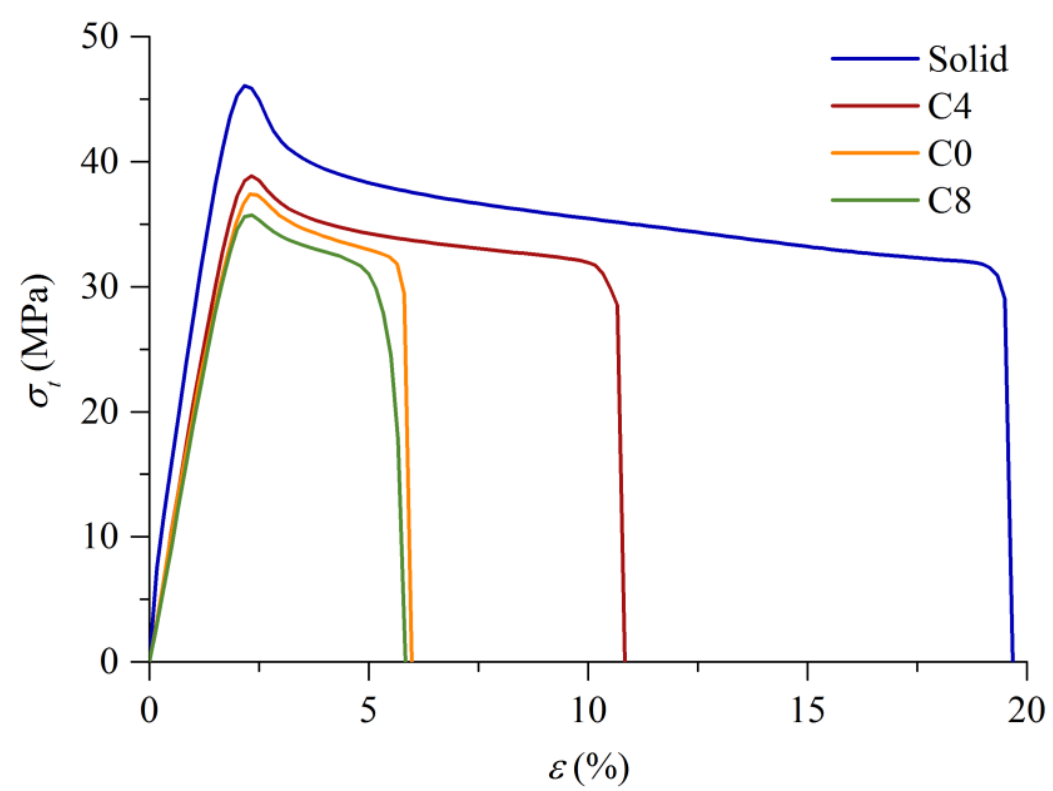

Figure 4.6. Tensile stress-strain curves of ABS solid and foamed samples ( $\mathrm{C} 4, \mathrm{C} 0$ and $\mathrm{C} 8$ conditions).

Table 4.2. Tensile properties of ABS solid and foamed samples.

\begin{tabular}{ccccccc}
\hline $\begin{array}{c}\text { Condition } \\
\text { No. }\end{array}$ & $\begin{array}{c}\boldsymbol{E}_{t} \\
(\mathbf{M P a})\end{array}$ & $\begin{array}{c}\boldsymbol{\sigma}_{\boldsymbol{y}} \\
(\mathbf{M P a})\end{array}$ & $\begin{array}{c}\boldsymbol{E}_{t} / \boldsymbol{\rho} \\
\left(\mathbf{M P a} / \mathbf{g ~ c m}^{-3}\right)\end{array}$ & $\begin{array}{c}\boldsymbol{\sigma}_{y} / \boldsymbol{\rho} \\
\left(\mathbf{M P a} / \mathbf{g ~ c m} \mathbf{~ c m}^{-3}\right)\end{array}$ & $\begin{array}{c}\boldsymbol{\varepsilon}_{y} \\
(\boldsymbol{\%})\end{array}$ & $\begin{array}{c}\boldsymbol{\sigma}_{u} \\
(\mathbf{M P a})\end{array}$ \\
\hline Solid & $2375 \pm 43$ & $46.2 \pm 1.1$ & $2331 \pm 44$ & $45.3 \pm 1.1$ & $2.36 \pm 0.09$ & $28.7 \pm 1.4$ \\
C1 & $1927 \pm 41$ & $37.8 \pm 0.8$ & $2127 \pm 88$ & $41.7 \pm 1.7$ & $2.49 \pm 0.06$ & $33.6 \pm 1.6$ \\
C2 & $1892 \pm 42$ & $37.1 \pm 0.5$ & $2088 \pm 113$ & $40.9 \pm 1.9$ & $2.49 \pm 0.06$ & $31.7 \pm 2.6$ \\
C3 & $1893 \pm 50$ & $37.1 \pm 0.9$ & $2087 \pm 96$ & $40.9 \pm 1.8$ & $2.46 \pm 0.01$ & $32.6 \pm 2.8$ \\
C4 & $1933 \pm 78$ & $37.9 \pm 0.6$ & $2134 \pm 157$ & $41.8 \pm 2.0$ & $2.31 \pm 0.10$ & $30.2 \pm 1.9$ \\
C5 & $1853 \pm 34$ & $35.1 \pm 2.0$ & $2246 \pm 107$ & $42.5 \pm 3.7$ & $2.30 \pm 0.08$ & $31.5 \pm 1.3$ \\
C6 & $1873 \pm 64$ & $35.1 \pm 1.8$ & $2238 \pm 118$ & $41.9 \pm 3.5$ & $2.21 \pm 0.09$ & $30.2 \pm 1.7$ \\
C7 & $1855 \pm 27$ & $35.3 \pm 1.6$ & $2240 \pm 131$ & $42.6 \pm 3.2$ & $2.30 \pm 0.09$ & $31.3 \pm 1.4$ \\
C8 & $1871 \pm 64$ & $34.5 \pm 1.3$ & $2265 \pm 171$ & $41.7 \pm 3.3$ & $2.20 \pm 0.11$ & $29.0 \pm 1.5$ \\
C0 & $1881 \pm 63$ & $36.7 \pm 0.9$ & $2135 \pm 142$ & $41.7 \pm 2.4$ & $2.30 \pm 0.08$ & $30.5 \pm 1.8$ \\
\hline
\end{tabular}

The specific modulus and tensile strength, defined as the ratio between these properties and the apparent density, remained almost constant and at the same order of magnitude as the solid samples. 
It is well known that crazing is the main plastic deformation mechanism of ABS [215217]. Foamed samples were more brittle than the solid counterparts due the presence of cells in the core region, as can be observed in Figure 4.6 by comparing the elongation at break of the different solid and foamed series. The elongation at break was excluded from the studied effects because of the large scatter observed in this parameter. In any case, the stress-strain curves depicted in Figure 4.6 correspond to the average behavior of the samples tested in each plotted condition. Finally, it is worth to notice the same level of yield strain $\left(\varepsilon_{y} \approx 2.40\right)$ and ultimate strength ( $\left.\sigma_{u} \approx 30 \mathrm{MPa}\right)$ obtained in all solid and foamed materials.

\subsubsection{Factorial analysis}

The experimental results obtained from the morphology and mechanical characterizations were collected and underwent statistical analysis. Then, the influence of the processing parameters on the cell structure and mechanical performance was determined. As an example of analysis, Figure 4.7 shows the main effect of shot volume, mold temperature and injection speed on the skin thickness. The results of intermediate condition $\mathrm{C} 0$ are plotted as individual points. As they do not fit the line joining the extreme values, it could seem that there is no perfect linearity between the factors and the response variables. However, it should be noted that the variations in the solid skin thickness range from 0.29 to $0.32 \mathrm{~mm}$ and therefore clear tendencies are difficult to be drawn. Moreover, the addition of central points does not affect the usual effects estimated in the factorial design [218] The analysis of curvature and variance cannot be performed considering all factors included in the model. At least one degree of freedom is required, so the Backward method of regression stepwise technique [219] was employed to remove factors with the smallest contribution to the response. The significance level $\alpha$ for this procedure was taken as 0.05 .

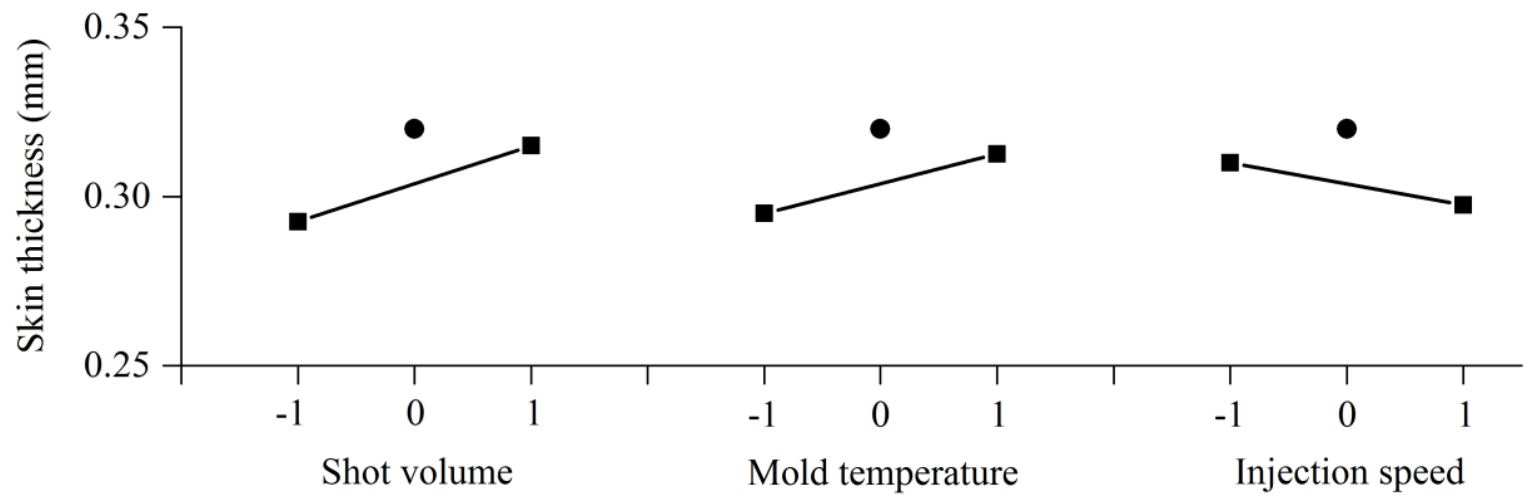

Figure 4.7. Main effect of shot volume, mold temperature and injection speed on skin thickness. 
The simplified regression models for each morphological and tensile parameter are summarized in Table 4.3. Following the example with skin thickness, the analysis of variance (ANOVA) is shown in Table 4.4. The Sum of Squares, Mean Square, F-value and p-value were calculated according to the equations and guidelines given by Montgomery [218]. All factors and interactions with a $p$-value lower than the confidence level $(\alpha=0.05)$ are significant, that is, they have a remarkable effect on the response when moving from one level to another, and cannot be neglected in the regression models of Table 4.3.

Table 4.3. Regression models derived from factorial design analysis of ABS cylindrical bars.

\section{Response}

\section{Regression model}

\section{(A: Shot volume; B: Mold temperature; C: Injection speed)}

Weight reduction Weight reduction $(\%)=14.353-3.799 \mathrm{~A}-0.551 \mathrm{C}$

Skin thickness Skin thickness $(\mathrm{mm})=0.30556+0.00875 \mathrm{~B}-0.00625 \mathrm{C}+0.02875 \mathrm{~B} \cdot \mathrm{C}$

Cell density Cell density $\left(\right.$ cells $\left.\cdot \mathrm{cm}^{-3}\right)=4590851-1122047 \mathrm{~A}+401962 \mathrm{~B}$

Max. cell size $\quad$ Maximum cell size $(\mu \mathrm{m})=218.5+29.5$ A -6.2 B -10.6 C -23.7 B $\cdot C$
$C D I$
$C D I=1.8344+0.1363 \mathrm{~A}+0.1262 \mathrm{C}$
$E_{t}$
$E_{t}(\mathrm{MPa})=1886.44+24.13 \mathrm{~A}$
$\sigma_{y}$
$\sigma_{y}(\mathrm{MPa})=36.289+1.238 \mathrm{~A}$

Table 4.4. Analysis of variance for skin thickness.

\begin{tabular}{|c|c|c|c|c|c|}
\hline Source of variation & \multirow{2}{*}{$\begin{array}{c}\begin{array}{c}\text { Degrees of } \\
\text { freedom }\end{array} \\
3\end{array}$} & \multirow{2}{*}{$\begin{array}{c}\begin{array}{c}\text { Sum of } \\
\text { Squares }\end{array} \\
0.007537\end{array}$} & \multirow{2}{*}{$\begin{array}{c}\begin{array}{c}\text { Mean } \\
\text { Square }\end{array} \\
0.002513\end{array}$} & \multirow{2}{*}{$\begin{array}{c}\boldsymbol{F} \text {-value } \\
4.68\end{array}$} & \multirow{2}{*}{$\begin{array}{c}p \text {-value } \\
0.065\end{array}$} \\
\hline Model & & & & & \\
\hline Mold temperature & 1 & 0.000613 & 0.000613 & 1.14 & 0.334 \\
\hline Injection speed & 1 & 0.000313 & 0.000313 & 0.58 & 0.480 \\
\hline Mold temperature*Injection speed & 1 & 0.006613 & 0.006613 & 12.32 & 0.017 \\
\hline Residual & 5 & 00.2685 & 0.000537 & & \\
\hline Curvature & 1 & 0.000235 & 0.000235 & 0.38 & 0.569 \\
\hline Lack of Fit & 4 & 0.002450 & 0.000612 & & \\
\hline Total & 8 & 0.010222 & & & \\
\hline
\end{tabular}


Through the ANOVA analysis, it can be seen that the curvature is not significant for skin thickness response, as has been already commented above due to the narrow range of variation. However, there is an interaction between parameters which needs to be considered. When interactions occur, the factors cannot be evaluated individually [220]. The presence of interaction between factors is discussed in the corresponding section below. The variance analysis (ANOVA Tables) obtained from the rest of morphological and tensile properties are compiled in Appendix A.

As a general trend, the shot volume was the most influencing factor on the studied morphology and tensile properties. Therefore, for a better visualization of the effect of mold temperature and injection speed on the response variables (weight reduction, solid skin thickness, cell density, maximum cell size, $C D I$, elastic modulus and tensile strength), they are displayed separately in Figure 4.8 and Figure 4.9 for each level of shot volume.

\subsubsection{Effect of shot volume}

As expected, Figure 4.8 and Figure 4.9 evinces that both cell structure and mechanical properties were more dependent on shot volume than upon mold temperature and injection rate. Since this parameter corresponds to the amount of material injected into the cavity mold, it determines the final weight and density of the part. Obviously, a higher shot volume resulted in lower weight reduction ratio, and vice versa.

In order to fill completely the mold cavity, the SCF content was increased as the level of shot volume decreased $(0.93 \%$ for foamed bars with $17 \%$ of weight reduction; $0.60 \%$ for $10 \%$ of weight reduction, and $0.80 \%$ for the intermediate trial $\mathrm{C} 0$ ). Therefore, in this investigation the study of the variation in shot volume is equivalent to analyze the effect of different SCF levels. Barzegari and Rodrigue [140] stated that an increase in the blowing agent content reduces the melt viscosity and, additionally, improves the number of nucleated cells. Thus, cells are created faster than the polymer solidification when it gets in contact with the cold mold wall. Consequently, as indicated in Figure 4.8, the skin thickness decreased and the cell density increased with the blowing agent content (reducing the shot volume). The gas was then distributed into a larger number of cells, reducing the probability of cell coalescence and decreasing their maximum size. Additionally, lower shot size took shorter solidification time and provided less time for cells to grow. As the cells got smaller, the CDI parameter became closer to unity. 

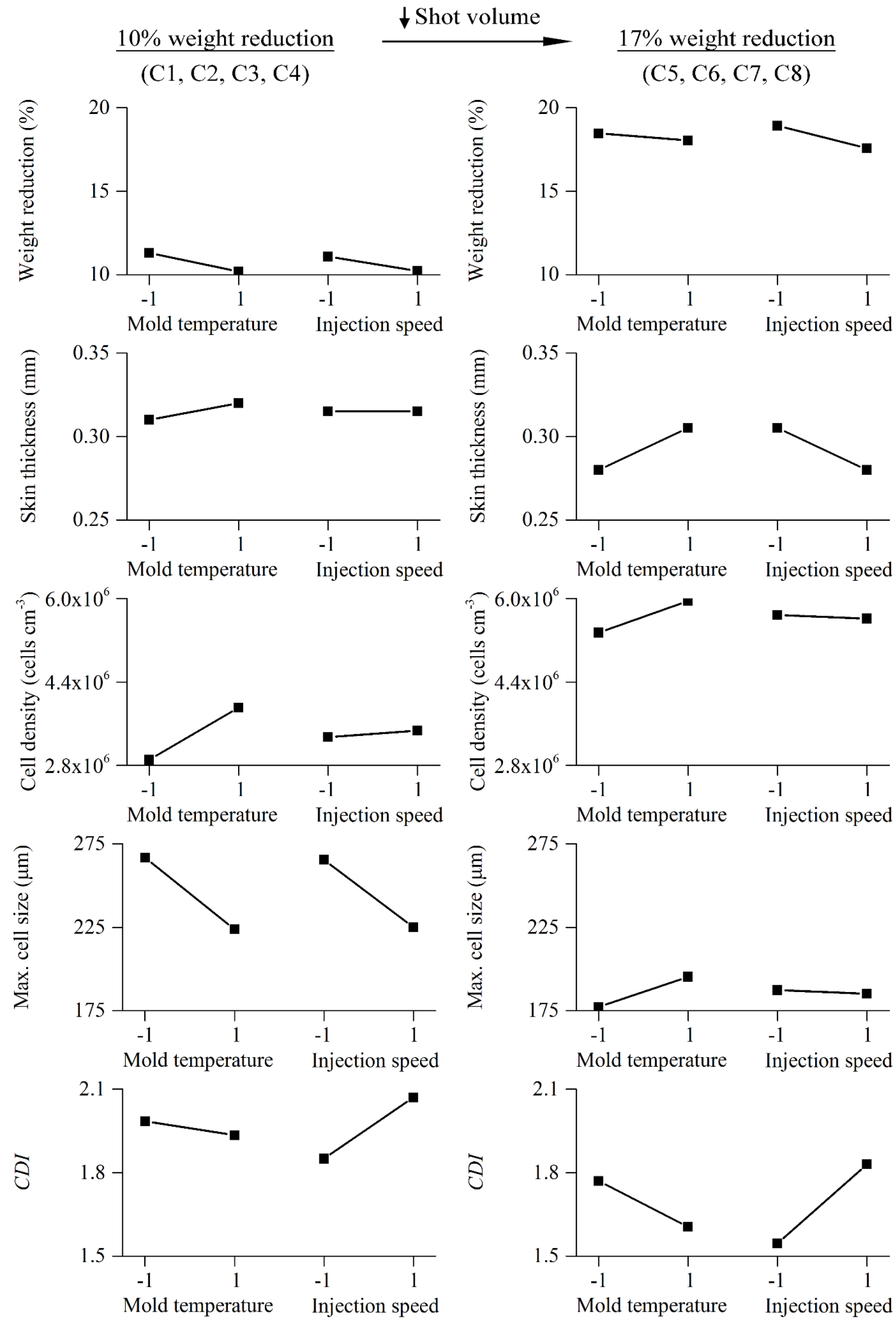

Figure 4.8. Effect of processing parameters on morphology and tensile properties of ABS foamed bars. 


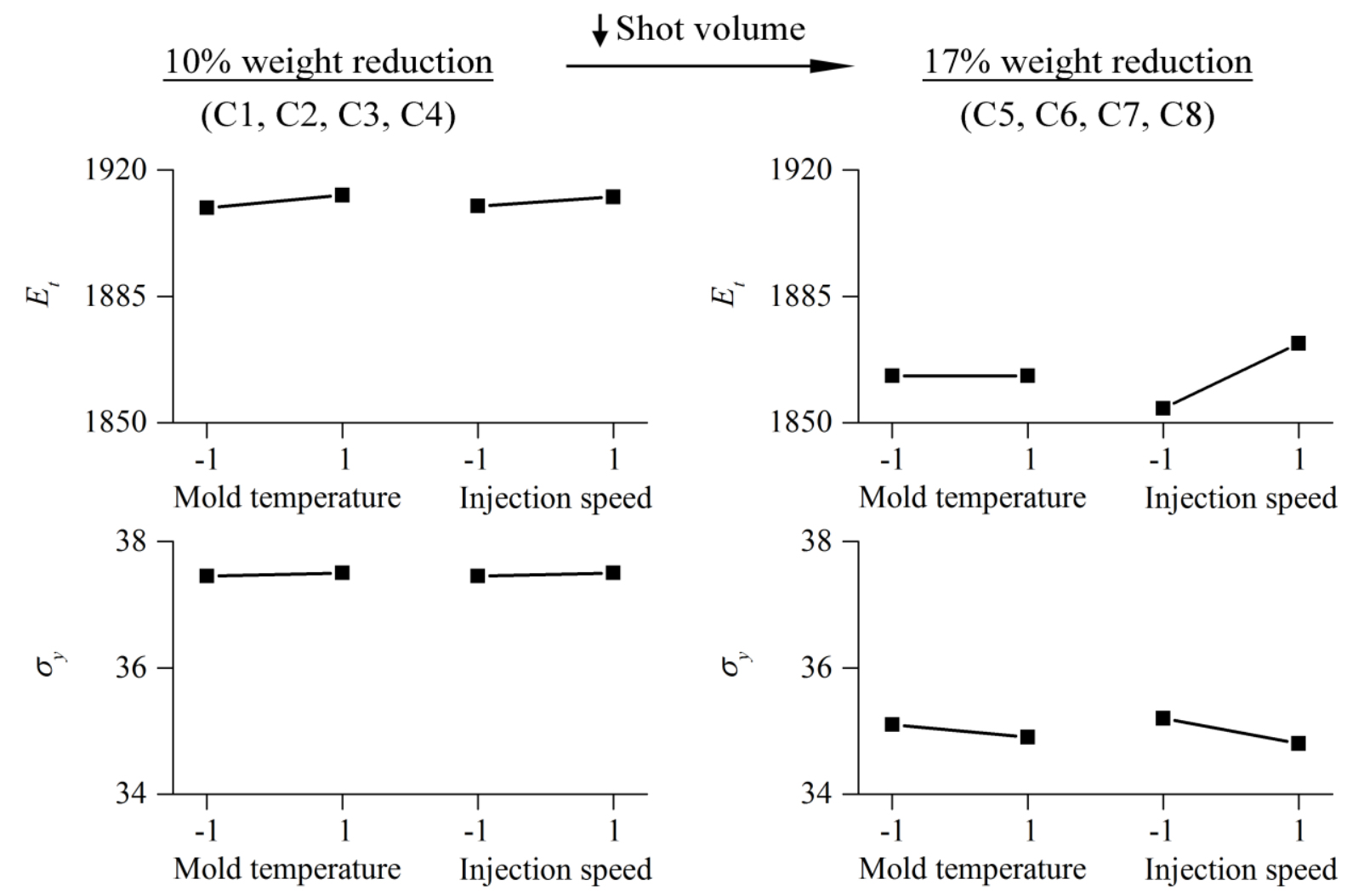

Figure 4.9. Effect of processing parameters on morphology and tensile properties of ABS foamed bars.

Concerning the mechanical properties (Figure 4.9), a higher level of shot volume involves a higher part weight and density, and obviously, a higher polymer fraction which can withstand the applied tensile load. As found by Li et al. [181] in microcellular Polyetherimide (PEI), the elastic modulus as well as the yield strength increased with the shot volume.

\subsubsection{Effect of mold temperature}

The mold temperature had a much lower effect on the weight reduction than the shot volume. As it increased, the weight reduction ratio experimented a slight decrease, but it was closer to the proposed targets of $10 \%$ and $17 \%$. According to some authors such as Spörrer and Altstädt [142], a higher temperature in mold wall gives more time for foaming due to a longer cooling stage. Therefore a thinner solid surface layer is expected. In this study, a reduction in the skin thickness was observed in conditions where the molten polymer was injected at low speed with $10 \%$ of weight reduction ( $\mathrm{C} 1$ and $\mathrm{C} 3)$. However, at higher injection rates, the observed trend was the opposite. This is also the case for the series of $17 \%$ of weight reduction. The combination of high injection rates and low shot sizes led to high shear and gas content levels. The higher injection speed increased the pressure in the mold cavity too, which might cause cell embryos redissolved back into the molten polymer counteracting the effect of mold temperature on the thickness of the surface layer. An increase in skin 
thickness and cell density with the mold temperature is shown in Figure 4.8. The maximum cell diameter decreased at high levels of mold temperature in case of $10 \%$ of weight reduction, but slightly increased in samples with $17 \%$ of weight reduction. Either way, the cell size distribution was constricted at higher temperatures in the mold wall, as indicated by the drop in the CDI parameter. The occurrence of an interaction between processing parameters is clearly evidenced in this analysis, and it is discussed further on in this Chapter.

Bledzki et al. [131] obtained a decrease in the elastic modulus and tensile strength of Polycarbonate (PC) foams as the mold temperature increased from $20^{\circ} \mathrm{C}$ to $108{ }^{\circ} \mathrm{C}$, due to the thinner solid skin, lower cell density and bigger cells formed. However, these trends were not observed in the injected ABS bars of this study, which may be due to the temperature range of the mold and its distance to the glass transition temperature $\left(T_{g}\right)$ of the polymer. Verbeeten $e t$ al. [221] showed that mechanical properties, such as tensile strength, are influenced by the cooling profile of the material below $T_{g}$. The closer the mold temperature is to $T_{g}$, the effect of the mold temperature variations is more significant. In this work, the mold temperature ranged from $30{ }^{\circ} \mathrm{C}$ to $60{ }^{\circ} \mathrm{C}$, while the $T_{g}$ of $\mathrm{ABS}$ is around $100{ }^{\circ} \mathrm{C}$. Since foaming process itself also influences cooling, the mold temperature variations appear not to be enough to significantly change the elastic modulus and tensile strength (Figure 4.9). As a matter of fact, the mold temperature does not appear in the regression models shown in Table 4.3 of any of the tensile properties studied in this section.

\subsubsection{Effect of injection speed}

The increase in the injection rate contributed to a lower ratio of weight reduction, but closer to the objectives of $10 \%$ and $17 \%$. According to Figure 4.8, the solid skin was not affected by the injection rate in foamed bars with $10 \%$ of weight reduction. However, thinner surface layers were formed as the injection rate increased in case of $17 \%$ of weight reduction. Dong et al. [93] reported that when filling at high speed, the effect of cooling is strongly reduced. The material keeps at relatively high temperature to allow the expansion of the foaming core, reducing the thickness of the surface layer. The injection speed has been widely related to the pressure drop of the polymer/gas solution inside the mold cavity. As concluded by Mahmoodi and Behravesh [209], a high pressure drop improves cell nucleation, which turns into higher cell densities. However, it is quite noticeable the insignificant effect of the injection speed on the cell density obtained in this research. The confinement of gas and polymer in a circular geometry could promote cell coalescence having a lower number of 
cells and then, the real influence of the injection rate on cell density could not be determined. Gómez-Gómez et al. [134] reported that the effect of injection speed on the cell density of PETG plates is inconclusive. Rizvi et al. [194] pointed out a decrease in cell diameter and CDI parameter with the injection speed. In the present study, the maximum cell size decreased, however, the $C D I$ increased, that is, the cell size distribution became more heterogeneous. Lin et al. [122] reported an improvement of the tensile properties of ABS foams with the injection speed, due to higher material orientation. In this study, the variation in elastic modulus and tensile strength obtained at the different injection rates were within the experimental accuracy (Figure 4.9), so the effect of the injection rate can be neglected.

\subsubsection{Interaction between factors}

The presence of significant interaction effects between processing parameters can be concluded from the discussion above. An interaction effect between parameters occurred when the influence of one factor depends on the value of the other ones. The Pareto charts illustrated in Figure 4.10 point out the magnitude of the standardized effects (effects divided by their respective standard errors) caused by the different factors. The dashed line drawn on the graphs indicates the minimum magnitude of statistically significance, with a confidence level of $95 \%(\alpha=0.05)$. Thus, the effects extending this reference line are potentially important. It is very clear from Figure 4.10a) that the interaction between mold temperature and injection speed had the highest effect on the solid skin thickness variability and sensitivity. Another response affected by an interaction between factors was the maximum cell size (Figure 4.10b)). It is mainly influenced by shot volume, followed by the combination of mold temperature and injection speed, whose effect on cell diameter was occasionally different depending on the level of each one.

a)

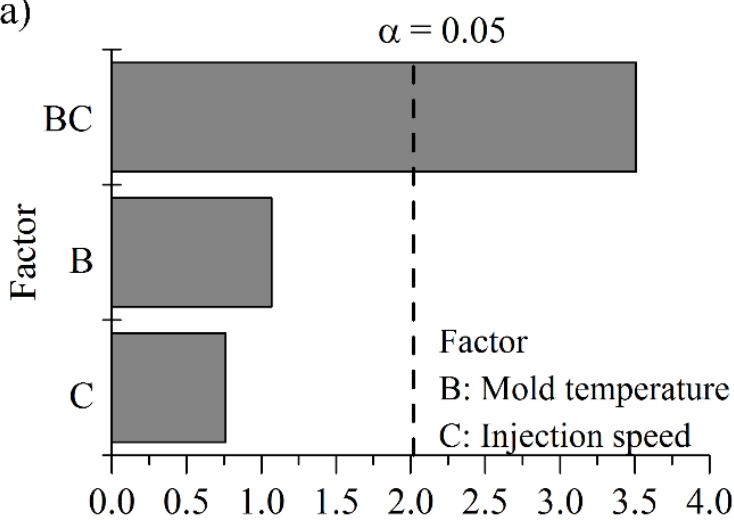

Standardized effect on Skin thickness b)

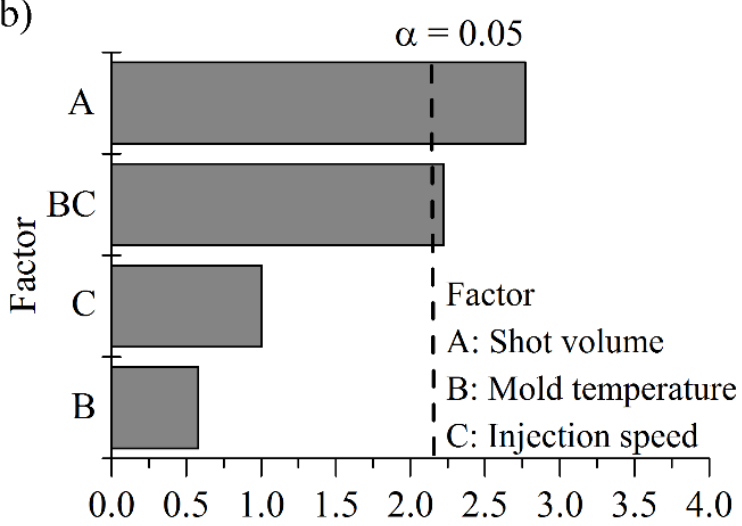

Standardized effect on Max. cell size

Figure 4.10. Pareto charts of standardized effect of processing parameters on a) skin thickness; b) max cell size. 
From the analysis above, predominant influence of shot volume on the cell structure and tensile properties can be determined. The effect of mold temperature and injection speed was secondary. Nevertheless, higher levels of both parameters contributed to improve the morphology of the foamed parts for $10 \%$ and $17 \%$ weight reduction ratios $\left(60{ }^{\circ} \mathrm{C}\right.$ and 100 $\left.\mathrm{cm}^{3} \cdot \mathrm{s}^{-1}\right)$. Therefore, only solid bars and C4 and C8 foamed series were considered for further research of morphology and tensile properties in the following sections.

\subsubsection{Morphology and apparent density}

Table 4.5 shows the apparent density of bars A, C and D, injected in solid and C4 and C8 foamed conditions. During foaming, a lack of filling in cavity B was observed. Therefore, the bars from this cavity were not included in the experimental analysis. Solid bars presented the same density in the different cavities, with a slight standard deviation. However, considering the foamed samples, the outer bars were $5 \%$ and $6 \%$ denser than bar $\mathrm{C}$ in case of $10 \%$ and $17 \%$ of weight reduction, respectively.

Table 4.5. Apparent density of ABS cylindrical bars.

\begin{tabular}{cccc}
\hline Condition No. & $\begin{array}{c}\text { Bar A } \\
\left(\mathbf{g ~ c m}^{-3}\right)\end{array}$ & $\begin{array}{c}\text { Bar C } \\
\left(\mathbf{g ~ c m}^{-3}\right)\end{array}$ & $\begin{array}{c}\text { Bar D } \\
\left(\mathbf{g ~ c m}^{-3}\right)\end{array}$ \\
\hline Solid & $1.02 \pm 0.01$ & $1.02 \pm 0.01$ & $1.02 \pm 0.01$ \\
C4: $10 \%$ wt. red. & $0.92 \pm 0.02$ & $0.88 \pm 0.02$ & $0.93 \pm 0.03$ \\
C8: $17 \%$ wt. red. & $0.84 \pm 0.03$ & $0.79 \pm 0.02$ & $0.85 \pm 0.02$ \\
\hline
\end{tabular}

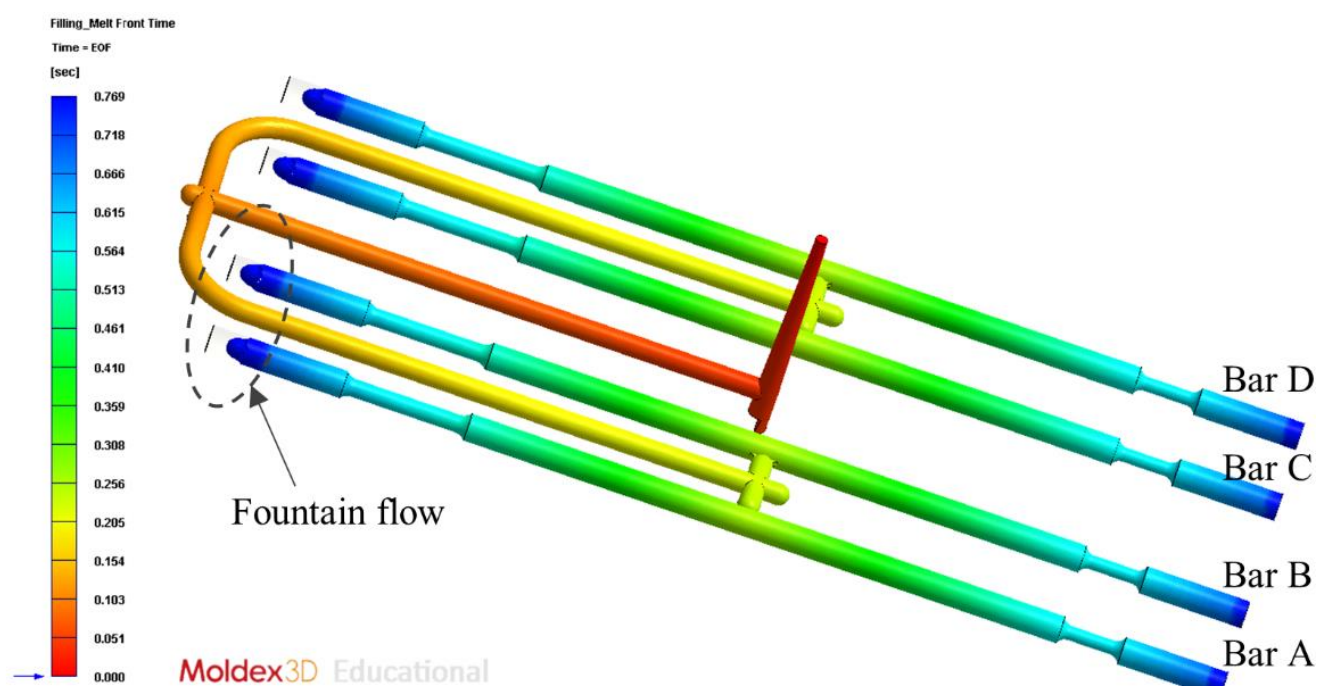

Figure 4.11. Melt front time of ABS foamed bars (10\% wt. red.) simulated with Moldex 3D® software. 
Despite the symmetrical position of the cavities inside the mold, these results of density suggest that cooling of inner and outer bars was different. This could be also the reason of the lack of filling in bar B. As obtained by means of injection process simulation with Moldex $3 \mathrm{D} ®$ software, after the change of section the fountain effect in the melt front becomes more pronounced and the molten polymer in the core reaches the end of the cavity faster than the material located in the skins (Figure 4.11). When solid samples were injected, all cavities were equally filled due to the holding pressure. But during foaming, the holding step was removed and less amount of material was introduced in the mold cavity. Thereby, if for any reason the cooling channels were not symmetrically distributed inside the tool, inner bars may have solidified faster, giving rise to a lower packing of material and lighter or even not fully filled bars.

Figure 4.12 shows SEM micrographs taken in of 4, 5 and $8 \mathrm{~mm}$ cross-sections of bar A for both groups of foamed bars. The morphological parameters are depicted in Table 4.6.

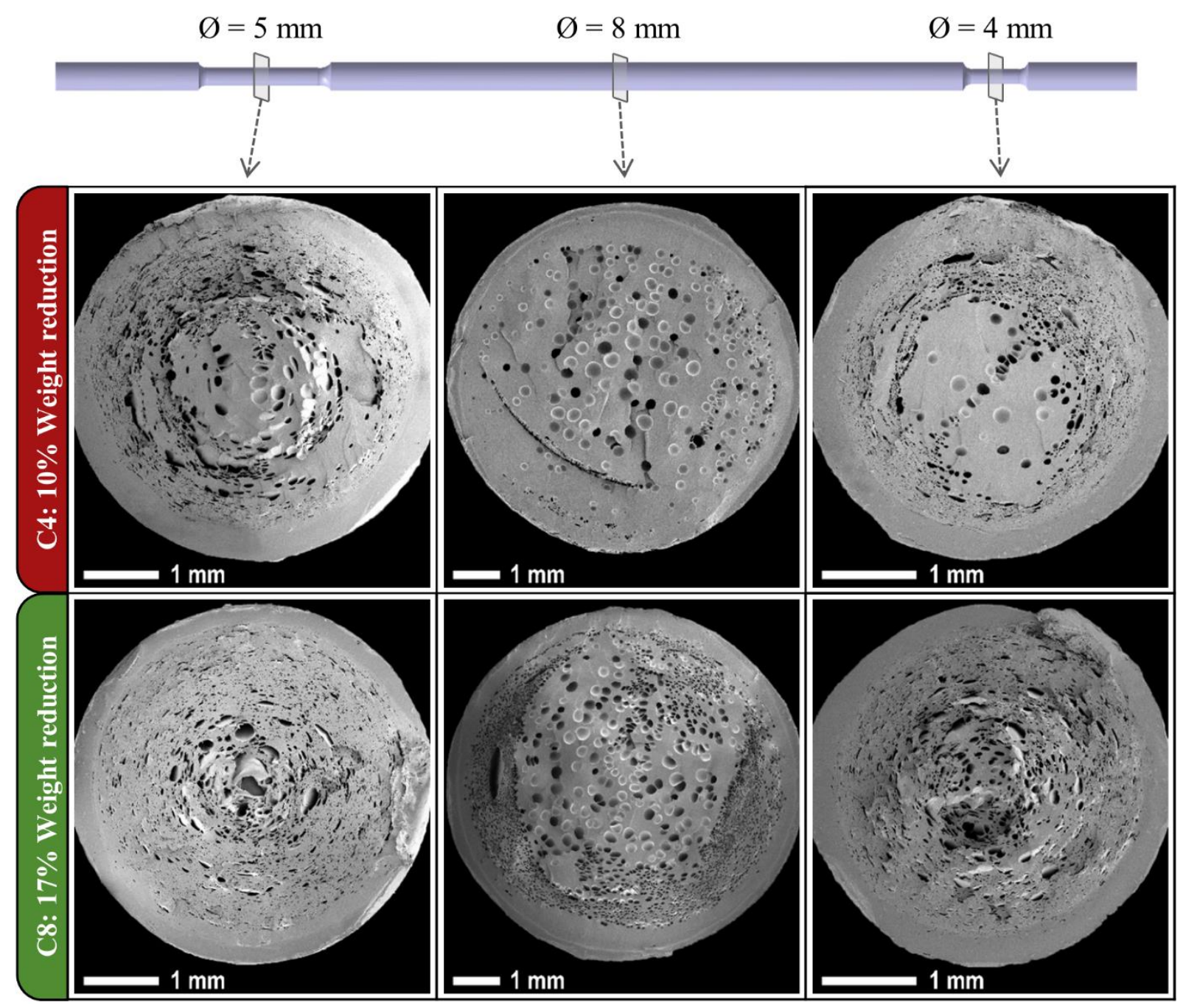

Figure 4.12. SEM micrographs taken from different sections of bar A in C4 and C8 ABS foaming conditions. 
Table 4.6. Apparent density and morphological parameters in different sections of ABS foamed bars.

\begin{tabular}{|c|c|c|c|c|c|c|c|}
\hline $\begin{array}{c}\text { Condition } \\
\text { No. }\end{array}$ & Bar & $\begin{array}{c}\text { Section } \\
\varnothing \\
(\mathbf{m m})\end{array}$ & $\begin{array}{l}\text { Density } \\
\left(\mathrm{g} \mathrm{cm}^{-3}\right)\end{array}$ & $\begin{array}{c}\text { Skin } \\
\text { thickness } \\
(\mathbf{m m})\end{array}$ & $\begin{array}{c}\text { Cell } \\
\text { density } \\
\left(\text { cells } \mathbf{c m}^{-3}\right)\end{array}$ & $\begin{array}{c}\text { Cell size } \\
\text { range } \\
(\boldsymbol{\mu m})\end{array}$ & $C D I$ \\
\hline \multirow[t]{9}{*}{ C4 (10\%) } & A & 4 & $0.92 \pm 0.03$ & 0.30 & $6.9 \cdot 10^{6}$ & $6-177$ & 2.12 \\
\hline & & 5 & $0.89 \pm 0.01$ & 0.36 & $4.2 \cdot 10^{6}$ & $8-188$ & 2.04 \\
\hline & & 8 & $0.92 \pm 0.02$ & 0.49 & $4.4 \cdot 10^{4}$ & $13-388$ & 1.50 \\
\hline & $\mathrm{C}$ & 4 & $0.87 \pm 0.01$ & 0.31 & $5.9 \cdot 10^{6}$ & $6-216$ & 2.15 \\
\hline & & 5 & $0.86 \pm 0.02$ & 0.39 & $3.8 \cdot 10^{6}$ & $8-194$ & 1.93 \\
\hline & & 8 & $0.88 \pm 0.01$ & 0.49 & $5.8 \cdot 10^{4}$ & $13-382$ & 1.44 \\
\hline & $\mathrm{D}$ & 4 & $0.93 \pm 0.02$ & 0.35 & $8.5 \cdot 10^{6}$ & $6-197$ & 2.06 \\
\hline & & 5 & $0.91 \pm 0.03$ & 0.33 & $3.2 \cdot 10^{6}$ & $8-210$ & 2.42 \\
\hline & & 8 & $0.93 \pm 0.01$ & 0.55 & $6.6 \cdot 10^{4}$ & $13-402$ & 1.78 \\
\hline \multirow[t]{9}{*}{ C8 (17\%) } & A & 4 & $0.84 \pm 0.02$ & 0.29 & $9.0 \cdot 10^{6}$ & $6-201$ & 1.91 \\
\hline & & 5 & $0.82 \pm 0.01$ & 0.31 & $6.0 \cdot 10^{6}$ & $8-163$ & 1.69 \\
\hline & & 8 & $0.84 \pm 0.01$ & 0.45 & $6.9 \cdot 10^{5}$ & $13-344$ & 2.04 \\
\hline & $\mathrm{C}$ & 4 & $0.80 \pm 0.01$ & 0.23 & $1.0 \cdot 10^{7}$ & $6-184$ & 1.96 \\
\hline & & 5 & $0.76 \pm 0.02$ & 0.29 & $6.9 \cdot 10^{6}$ & $8-189$ & 1.57 \\
\hline & & 8 & $0.79 \pm 0.02$ & 0.45 & $6.8 \cdot 10^{5}$ & $13-260$ & 1.73 \\
\hline & $\mathrm{D}$ & 4 & $0.84 \pm 0.02$ & 0.27 & $1.2 \cdot 10^{7}$ & $6-204$ & 1.72 \\
\hline & & 5 & $0.82 \pm 0.03$ & 0.25 & $5.9 \cdot 10^{6}$ & $8-240$ & 1.70 \\
\hline & & 8 & $0.85 \pm 0.02$ & 0.47 & $5.6 \cdot 10^{5}$ & $13-314$ & 1.90 \\
\hline
\end{tabular}

Generally, there were no great differences in morphology between cavity positions (bars A, C and D). Trends of morphology characteristics due to gas content variation in foamed bars with $10 \%$ and $17 \%$ of weight reduction have been discussed in the section above. Regarding the effect of cross-section diameter, $\varnothing=4 \mathrm{~mm}$ and $\varnothing=8 \mathrm{~mm}$ were slightly denser than $\varnothing=5 \mathrm{~mm}$, because of higher packing of material in these sections nearer the injection point. The solid skin increased as the bar got thicker, although in all cases it represents around 
$15 \%$ of the overall diameter. The maximum cell density was obtained in the thinner section $(\varnothing=4 \mathrm{~mm})$. It slightly decreased by increasing the diameter up to $5 \mathrm{~mm}$, but it remained at the level of $10^{6}$ cells $\mathrm{cm}^{-3}$. However, it was drastically reduced by one or two orders of magnitude in the section of $\varnothing=8 \mathrm{~mm}$. The opposite tendency was obtained in cell size. As depicted in Figure 4.13 and Table 4.6, cell size ranged from 6 to $200 \mu \mathrm{m}$ in sections of 4 and 5 $\mathrm{mm}$ in diameter, but around $95 \%$ of cells were smaller than $50 \mu \mathrm{m}$, and the cell size distribution was centered in $20 \mu \mathrm{m}$. In both foamed series the $C D I$ parameter was also similar, with slightly lower $C D I$ values in case of specimens with $17 \%$ of weight reduction. In the middle section of the bar, with a thickness of $8 \mathrm{~mm}$, the cell size reached a maximum value of $400 \mu \mathrm{m}$, with a more irregular cell distribution. However, the $C D I$ parameter was similar to that obtained in the other thicknesses. The high temperature in this section enabled higher cell growth and expansion, as well as bubble coalescence. Shrinkage of the part during cooling could also contribute to higher cell sizes, resulting in bigger cells and lower cell densities.
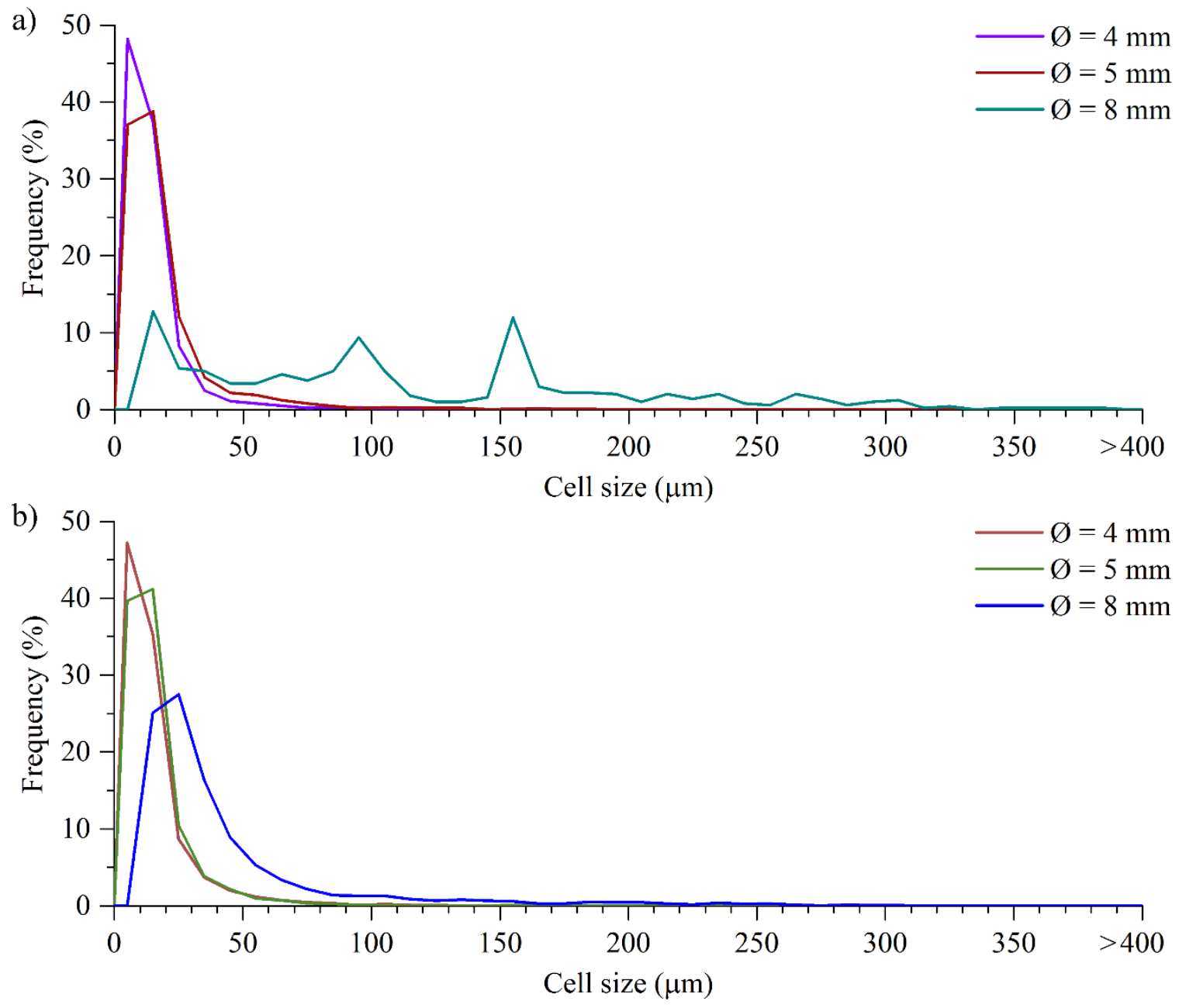

Figure 4.13. Cell size distribution in 4, 5 and $8 \mathrm{~mm}$ cross-sections of a) C4 (10\% weight reduction); b) C8 (17\% weight reduction) injection molding conditions. 


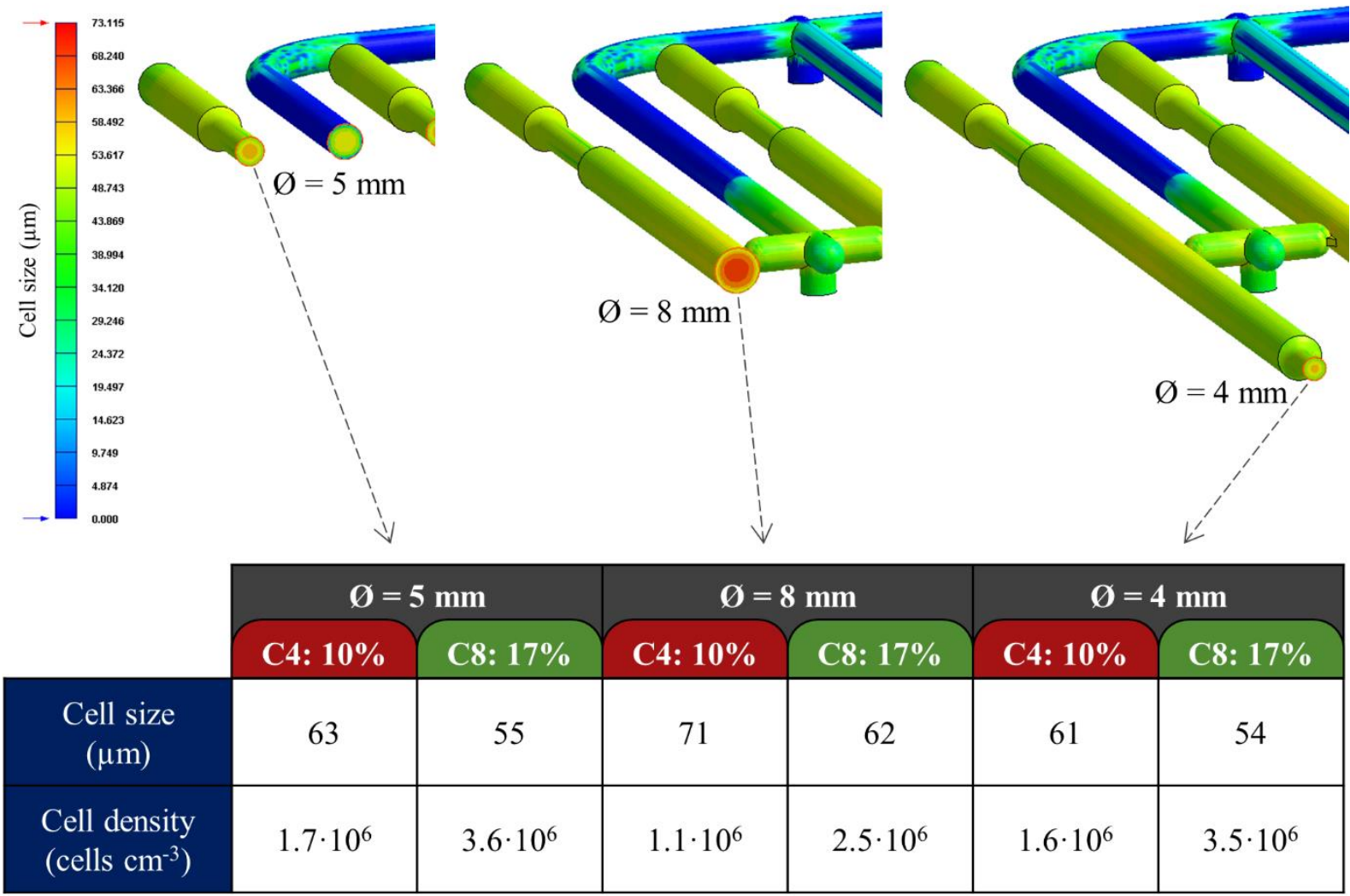

Figure 4.14. Cell size and cell density results of of ABS foamed bars simulated with Moldex 3D® software.

Simulation of injection process by means of Moldex 3D® software provided the results illustrated in Figure 4.14. Comparing these values with data from the experimental analysis, a reasonable agreement can be observed in 4 and $5 \mathrm{~mm}$ sections, while numerical simulation overestimates the cell size and cell density resulted in $\varnothing=8 \mathrm{~mm}$. A reduction in clamping force and viscosity of the material during injection, and an improvement of the dimensional stability in the final part by foaming, are other features that can also be estimated with the aid of the simulation software.

\subsubsection{Tensile behavior}

Figure 4.15 compares tensile stress-strain curves corresponding to solid and foamed cylindrical bars tested in $\varnothing=4 \mathrm{~mm}$ and $\varnothing=5 \mathrm{~mm}$ sections. Absolute and specific values of elastic modulus and yield strength are displayed in Table 4.7. These properties were slightly lower in the inner bar (C) as compared to the outer ones (A and D), because of the reduced density reported in Table 4.5. By decreasing the cross-sectional diameter to $4 \mathrm{~mm}$, the elastic modulus was increased by around $25 \%$ and the yield strength up to $16 \%$, although samples broke at lower elongation. 


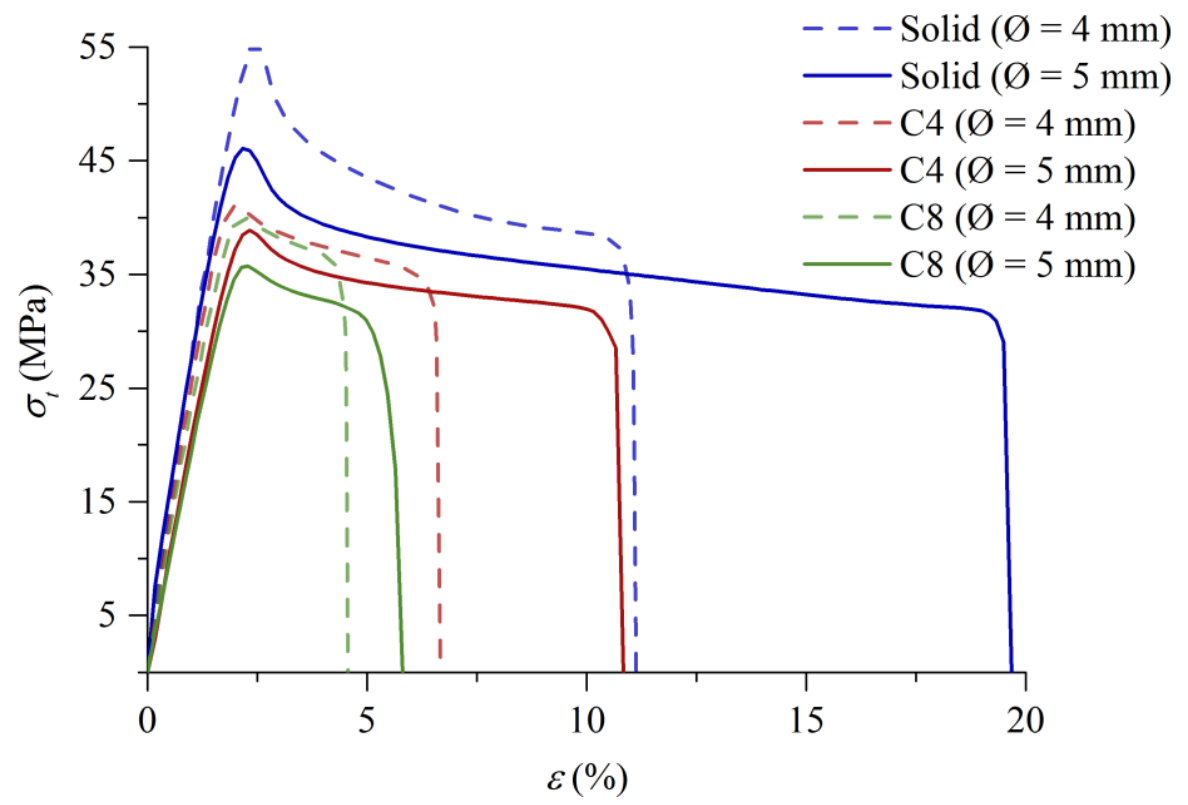

Figure 4.15. Tensile stress-strain curves of 4 and $5 \mathrm{~mm}$ diameter sections of ABS solid and foamed bars (C4 and C8 conditions).

The dependence of the tensile characteristics with the density of the samples has been referred before. Young's modulus was hardly affected in section of $\varnothing=4 \mathrm{~mm}$ and $10 \%$ of weight reduction (C4), whereas it was decreased by $20 \%$ in $5 \mathrm{~mm}$ cross-section and by $15 \%$ and $22 \%$ in samples with $17 \%$ of weight reduction $(\varnothing=4 \mathrm{~mm}$ and $5 \mathrm{~mm}$, respectively). On the other hand, tensile strength was reduced by approximately $20 \%$ and $26 \%$ according to the two levels of weight reduction, for both 4 and $5 \mathrm{~mm}$ diameter sections. This higher decrease ratio in the yield stress could be due to the negative effect of the bigger voids located in the nucleus on the tensile strength [127]. The same trend has been reported by Lin et al. [122]. Regarding specific values, the gap between properties of solid and foamed specimens was strongly reduced. In all cases, the yield strain was contained in the range of $\varepsilon_{y}=2.35 \pm 0.15$ $\%$, and the elongation at break in approximately $\sigma_{u}=33.4 \pm 5.2 \mathrm{MPa}$.

Current theories of conventional foams established a linear dependency of the relative modulus with the relative density (Single Blend model [51, 222]):

$$
\frac{E_{t f}}{E_{t s}}=\frac{\rho_{f}}{\rho_{s}}
$$

Where $E_{t f}, E_{t s}, \rho_{f}$ and $\rho_{s}$ are the elastic modulus and apparent density of foamed and solid material, respectively. 
Table 4.7. Tensile properties in different sections of ABS bars.

\begin{tabular}{|c|c|c|c|c|c|c|}
\hline $\begin{array}{c}\text { Condition } \\
\text { No. }\end{array}$ & Bar & $\begin{array}{c}\text { Section } \varnothing \\
(\mathbf{m m})\end{array}$ & $\begin{array}{c}E_{t} \\
(\mathrm{MPa})\end{array}$ & $\begin{array}{c}\sigma_{y} \\
(\mathrm{MPa})\end{array}$ & $\begin{array}{c}E_{t} / \rho \\
\left(\mathrm{MPa} / \mathrm{g} \mathrm{cm}^{-3}\right)\end{array}$ & $\begin{array}{c}\sigma_{y} / \rho \\
\left(\mathrm{MPa} / \mathrm{g} \mathrm{cm}^{-3}\right)\end{array}$ \\
\hline \multirow[t]{6}{*}{ Solid } & A & 4 & $3086 \pm 40$ & $54.0 \pm 0.9$ & $3028 \pm 43$ & $52.9 \pm 1.0$ \\
\hline & & 5 & $2375 \pm 43$ & $46.2 \pm 1.1$ & $2331 \pm 44$ & $45.3 \pm 1.1$ \\
\hline & $\mathrm{C}$ & 4 & $2938 \pm 55$ & $55.4 \pm 1.2$ & $2884 \pm 56$ & $54.3 \pm 1.2$ \\
\hline & & 5 & $2340 \pm 42$ & $45.9 \pm 0.9$ & $2297 \pm 43$ & $45.0 \pm 0.9$ \\
\hline & $\mathrm{D}$ & 4 & $3130 \pm 68$ & $54.9 \pm 0.7$ & $3072 \pm 69$ & $53.8 \pm 0.8$ \\
\hline & & 5 & $2383 \pm 48$ & $46.3 \pm 1.6$ & $2338 \pm 49$ & $45.4 \pm 1.7$ \\
\hline \multirow[t]{6}{*}{ C4 (10\%) } & A & 4 & $3188 \pm 75$ & $45.3 \pm 0.8$ & $3519 \pm 150$ & $50.0 \pm 1.7$ \\
\hline & & 5 & $1933 \pm 78$ & $37.9 \pm 0.6$ & $2134 \pm 157$ & $41.8 \pm 2.0$ \\
\hline & $\mathrm{C}$ & 4 & $2640 \pm 89$ & $42.0 \pm 0.9$ & $3018 \pm 116$ & $48.0 \pm 2.2$ \\
\hline & & 5 & $1839 \pm 34$ & $36.0 \pm 0.6$ & $2102 \pm 65$ & $41.1 \pm 1.7$ \\
\hline & $\mathrm{D}$ & 4 & $3135 \pm 65$ & $45.3 \pm 0.7$ & $3461 \pm 130$ & $50.0 \pm 1.5$ \\
\hline & & 5 & $1964 \pm 36$ & $37.9 \pm 0.5$ & $2168 \pm 72$ & $41.8 \pm 1.6$ \\
\hline \multirow[t]{6}{*}{ C8 (17\%) } & A & 4 & $2686 \pm 72$ & $40.6 \pm 0.7$ & $3252 \pm 172$ & $49.1 \pm 1.8$ \\
\hline & & 5 & $1871 \pm 64$ & $34.5 \pm 1.3$ & $2265 \pm 171$ & $41.7 \pm 3.3$ \\
\hline & $\mathrm{C}$ & 4 & $2526 \pm 86$ & $38.4 \pm 0.4$ & $3205 \pm 193$ & $48.7 \pm 1.1$ \\
\hline & & 5 & $1835 \pm 70$ & $34.2 \pm 1.1$ & $2329 \pm 181$ & $43.4 \pm 2.7$ \\
\hline & $\mathrm{D}$ & 4 & $2535 \pm 45$ & $40.6 \pm 0.8$ & $2969 \pm 120$ & $47.5 \pm 1.9$ \\
\hline & & 5 & $1893 \pm 13$ & $34.9 \pm 0.5$ & $2216 \pm 35$ & $40.9 \pm 1.3$ \\
\hline
\end{tabular}

Taking average values, the elastic modulus given by Equation (4.1) for foamed bars with $10 \%$ and $17 \%$ of weight reduction was $2722 \mathrm{MPa}$ and $2473 \mathrm{MPa}$, for $\varnothing=4 \mathrm{~mm}$, and $2110 \mathrm{MPa}$ and $1918 \mathrm{MPa}$ for $\varnothing=5 \mathrm{~mm}$. The predicted values are similar to that of obtained by tensile tests, being the maximum deviation from the experimental results $14 \%$. 
On the other hand, Xu and Kishbaugh [223] developed estimation models of the tensile strength ratio for plane specimens based on the solid skin and foamed area structure. Adapting the model to a circular section, the following equations was employed:

$$
\frac{\sigma_{t f}}{\sigma_{t s}}=\frac{\pi r^{2}-\pi\left(r-t_{s}\right)^{2}+(1-R)^{2} \pi\left(r-t_{s}\right)^{2}}{\pi r^{2}}
$$

Where $\sigma_{t f}$ and $\sigma_{t s}$ are the tensile strength of solid and foamed material, $r$ is the radius of the part, $t_{s}$ is the solid skin thickness and $R$ is the ratio of weight reduction for foamed core, determined by means of the weight reduction ratio of the whole microcellular part $R_{w}(0.9$ and 0.83 in this study):

$$
R=\frac{\pi r^{2}\left(1-R_{w}\right)}{\pi\left(r-t_{s}\right)^{2}}
$$

The calculated yield strength for both foamed series (10\% and $17 \%$ of weight reduction) was $44.9 \mathrm{MPa}$ and $37.9 \mathrm{MPa}$ for $\varnothing=4 \mathrm{~mm}$ section, and $38.0 \mathrm{MPa}$ and $32.0 \mathrm{MPa}$ for samples with $5 \mathrm{~mm}$ in diameter. These values are accurately close to the experimental data, having a maximum error of $8 \%$.

Some works have been carried out relating the mechanical properties to the cell morphology, obtaining an improvement of the elastic modulus and tensile strength with higher cell densities and smaller cell sizes [136, 181]. Nevertheless, in this study, specimens with higher cell densities and smaller cells (or lower CDI parameter) corresponded to bars injected at the higher level of weight reduction (17\%) and, therefore, lower density and mechanical properties were determined. Due to similar thicknesses of the solid skin in all specimens, its effect on the tensile performance could not be determined, although a build-up in the modulus and yield strength as the surface layer gets thicker is expected [143].

\subsection{Square plates}

\subsubsection{Morphology and apparent density}

Figure 4.16 and Figure 4.17 show SEM micrographs taken from different sections and directions of both foamed plates groups. The skin/core structure is observed again. Near the injection point (MD-A), cells were spherical and uniformly distributed through the foamed core. However, cells became distorted as the distance away from the injection gate became larger (Figure 4.16 MD-C). 


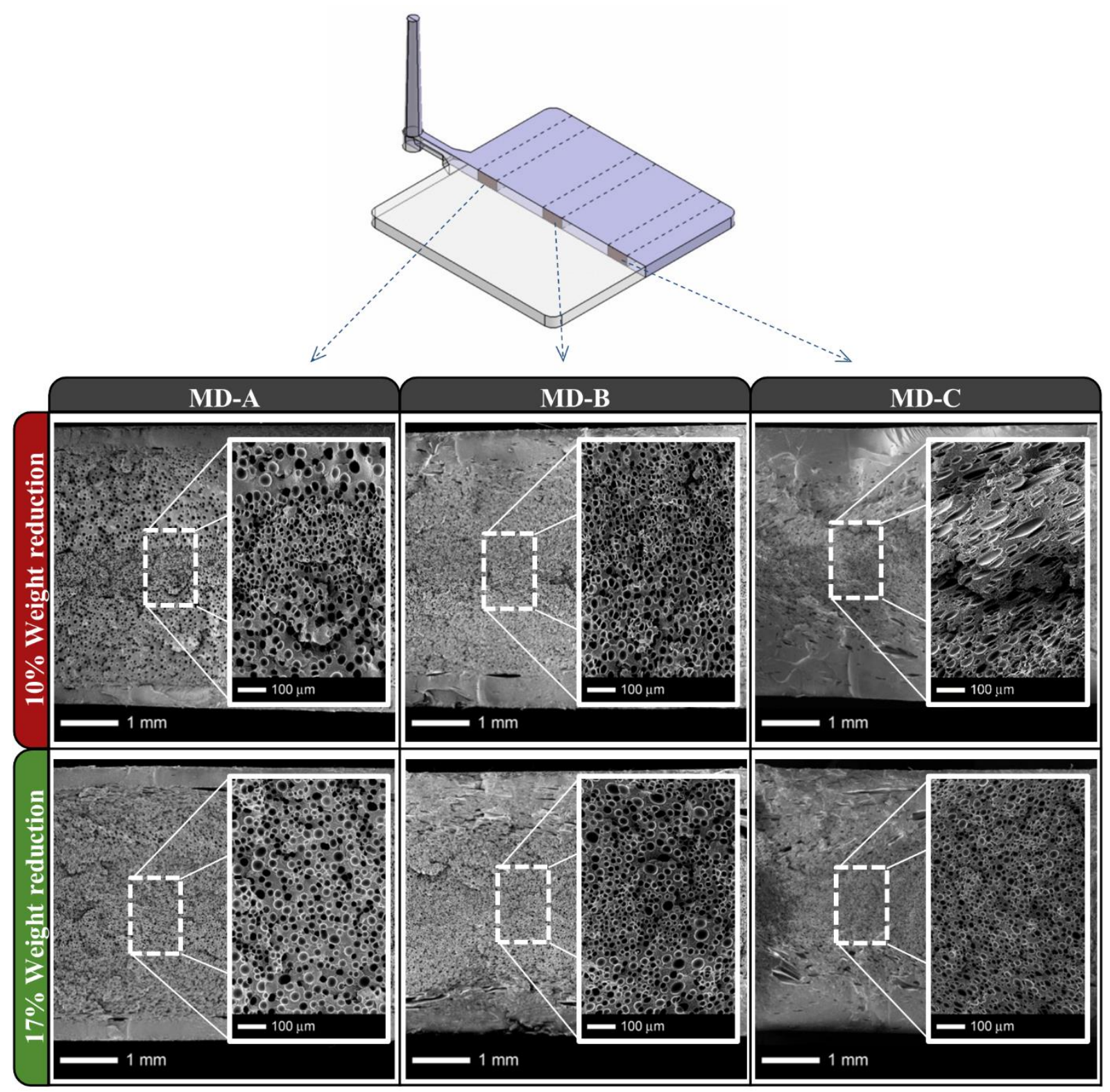

Figure 4.16. SEM micrographs of ABS foamed plates taken in MD direction.

Dong et al. [210] explained this phenomenon as the result of the two mechanisms involved in the cell forming process: foaming during filling and foaming after filling. At the beginning of the filling stage, the fast pressure drop leads to the nucleation of a large number of cells. Cells near the melt front are distorted by the fountain-flow behavior of the melt. This cell forming process is called foaming during filling. As the mold cavity gets filled, the pressure increases up to a critical point at which the polymer melt is just not supersaturated of gas, and foaming does not take place. Finally, once the filling stage is finished, the melt pressure drops again during cooling and spherical cells are formed at the beginning of the part. This second mechanism is known as foaming after filling. In TD direction, however, cells presented a mainly spherical shape along the whole foamed core. 


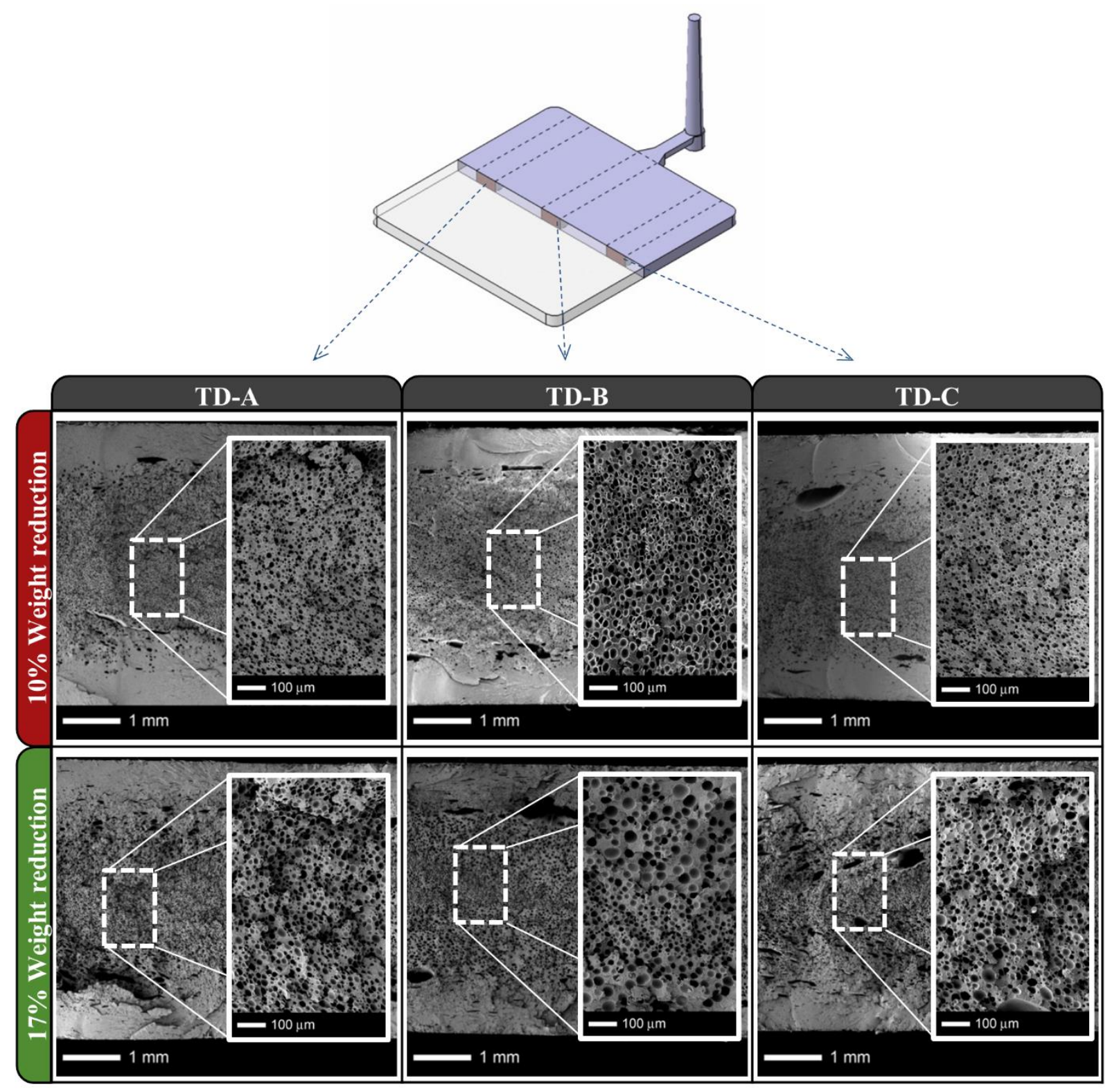

Figure 4.17. SEM micrographs of ABS foamed plates taken in TD direction.

The morphological parameters (solid skin, cell density and cell size range) determined from details of Figure 4.16 and Figure 4.17 are displayed in Table 4.8. In general, there were no significant variances in the morphology parameters between the two levels of weight reduction and between the different analyzed sections, either in parallel (MD) or transversal (TD) direction to the melt front. However, an increase in the solid skin along the flow direction can be noticed. As explained by Dong et al. [93], the solid surface layers formation is also submitted to the different mechanisms during filling and after filling, and it is expected a thinner solid skin near the gate and an increase in thickness with the distance to the injection gate, with a maximum value in the center of the part. 
Table 4.8. Morphological parameters in different sections of ABS foamed plates.

\begin{tabular}{|c|c|c|c|c|c|}
\hline $\begin{array}{c}\text { Condition } \\
\text { No. }\end{array}$ & Section & $\begin{array}{c}\text { Skin thickness } \\
(\mathbf{m m})\end{array}$ & $\begin{array}{l}\text { Cell density } \\
\left(\text { cells } \mathbf{c m}^{-3}\right)\end{array}$ & $\begin{array}{c}\text { Cell size range } \\
\qquad(\mu \mathrm{m})\end{array}$ & CDI \\
\hline \multirow{6}{*}{$\begin{array}{c}\text { Foamed } 10 \% \\
\text { wt. red. }\end{array}$} & MD-A & 0.36 & $1.1 \cdot 10^{7}$ & $17-47$ & 1.22 \\
\hline & MD-B & 0.52 & $6.7 \cdot 10^{7}$ & $8-22$ & 1.23 \\
\hline & MD-C & 0.66 & $7.3 \cdot 10^{7}$ & $9-25$ & 1.34 \\
\hline & TD-A & 0.65 & $6.2 \cdot 10^{7}$ & $7-16$ & 1.19 \\
\hline & TD-B & 0.63 & $1.8 \cdot 10^{7}$ & $12-33$ & 1.26 \\
\hline & TD-C & 0.58 & $6.7 \cdot 10^{7}$ & $7-18$ & 1.22 \\
\hline \multirow{6}{*}{$\begin{array}{c}\text { Foamed } 17 \% \\
\text { wt. red. }\end{array}$} & MD-A & 0.38 & $1.9 \cdot 10^{7}$ & $15-34$ & 1.16 \\
\hline & MD-B & 0.46 & $4.2 \cdot 10^{7}$ & $9-30$ & 1.28 \\
\hline & MD-C & 0.52 & $9.9 \cdot 10^{7}$ & $6-24$ & 1.39 \\
\hline & TD-A & 0.49 & $7.0 \cdot 10^{7}$ & $5-20$ & 1.40 \\
\hline & TD-B & 0.50 & $2.0 \cdot 10^{7}$ & $5-29$ & 1.47 \\
\hline & TD-C & 0.49 & $3.8 \cdot 10^{7}$ & $6-25$ & 1.40 \\
\hline
\end{tabular}

The cell density was kept in an order of magnitude of $10^{7}$ cells $\cdot \mathrm{cm}^{-3}$ in all cases. Tsuchiya et al. [224] stated that the butadiene rubber in ABS acts as foaming nucleus, which justifies the high cell density and the homogeneous cell distribution observed. The cell size was contained in the range of 6-47 $\mu \mathrm{m}$ (Figure 4.18), which is in the same order as the average diameter $(50 \mu \mathrm{m})$ obtained in ABS foams produced by combining chemical and physical foaming processes at the same time [147]. As a general trend, foamed plates with $17 \%$ of weight reduction presented slightly higher cell densities and narrower cell size ranges. The ability of cell nucleation increases with the content of supercritical fluid agent, as has been found in Polyetherimide (PEI) [125] and Polystyrene (PS) foams [225]. Nevertheless, the morphology examination at a macroscopic scale revealed a greater presence of bigger cells $(150-250 \mu \mathrm{m})$ in this group of foamed plates, due to a higher gas content and cell coalescence. As a consequence, the overall apparent density decreased from $1.03 \mathrm{~g} \cdot \mathrm{cm}^{-3}$ of the solid samples to $0.93 \mathrm{~g} \cdot \mathrm{cm}^{-3}$ (10\% of weight reduction) and $\mathrm{g} \cdot \mathrm{cm}^{-3}$ (17\% of weight reduction). 

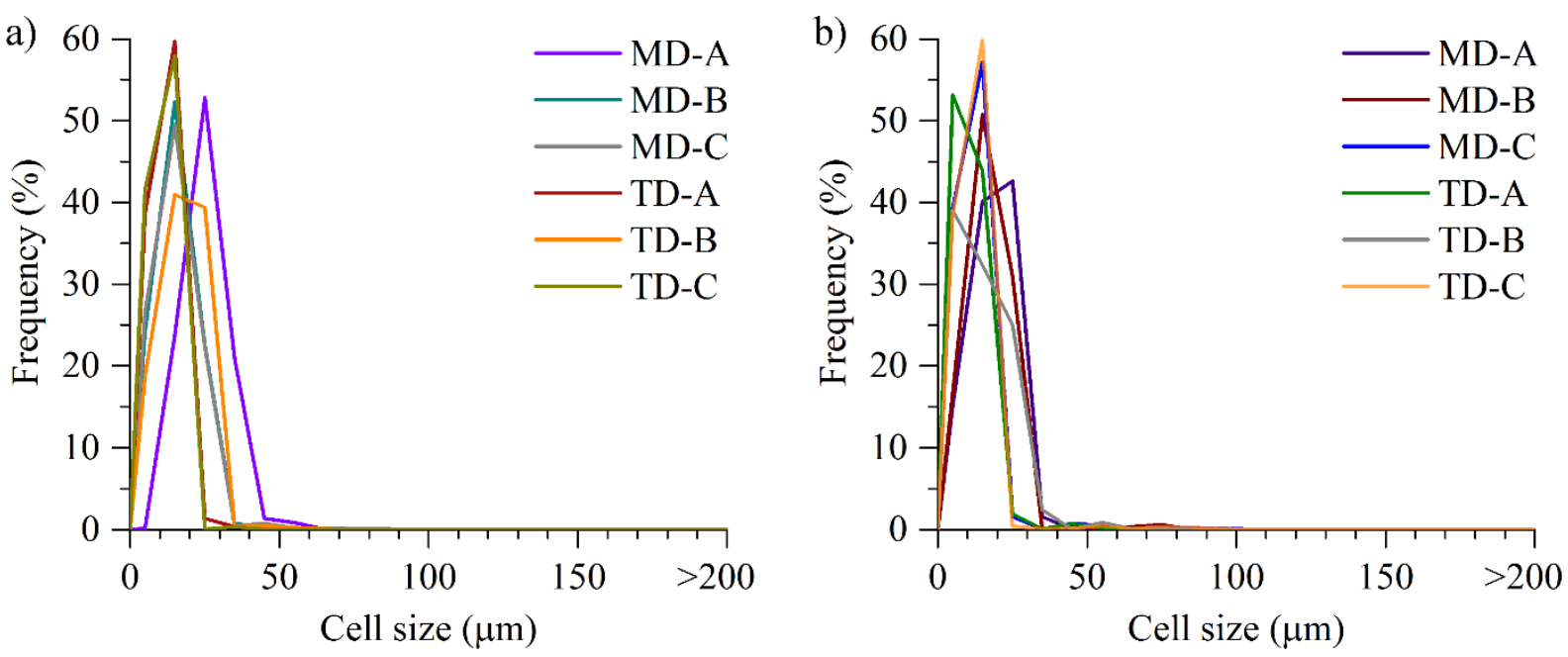

Figure 4.18. Cell size distribution of different sections of ABS foamed samples with a) $10 \%$ weight reduction;

b) $17 \%$ weight reduction.

Table 4.9. Apparent density measured in different sections of the ABS square plates.

\begin{tabular}{|c|c|c|c|c|c|c|}
\hline م & \multirow{2}{*}{$\begin{array}{c}\text { Condition } \\
\text { No. }\end{array}$} & \multicolumn{5}{|c|}{ Apparent density $\left(\mathrm{g} \mathrm{cm}^{-3}\right)$} \\
\hline \multirow{2}{*}{ 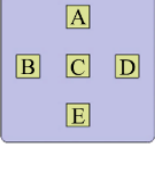 } & & $\mathbf{A}$ & B & C & D & $\mathbf{E}$ \\
\hline & Solid & $0.98 \pm 0.02$ & $1.01 \pm 0.03$ & $1.00 \pm 0.03$ & $1.01 \pm 0.02$ & $0.96 \pm 0.03$ \\
\hline & Foamed 10\% & $0.80 \pm 0.04$ & $0.83 \pm 0.04$ & $0.83 \pm 0.03$ & $0.85 \pm 0.03$ & $0.91 \pm 0.03$ \\
\hline & Foamed 17\% & $0.75 \pm 0.01$ & $0.78 \pm 0.02$ & $0.78 \pm 0.01$ & $0.79 \pm 0.03$ & $0.76 \pm 0.05$ \\
\hline
\end{tabular}

Table 4.9 shows the apparent density measured in different sections of the plates. Positions far from the injection gate (E) of foamed samples were slightly denser than those close to the beginning areas (A), which could be explained because of the higher skin/core ratio. A similar trend has been observed in Ethylene-Propylene Block Copolymer (EPBC) foams [138].

As compared to the morphological parameters previously reported in cylindrical bars, narrower cell size distributions $(6-47 \mu \mathrm{m})$ and higher cell densities $\left(10^{7}\right.$ cells $\left.\cdot \mathrm{cm}^{-3}\right)$ have been obtained in $5 \mathrm{~mm}$-thick plates with similar levels of weight reduction. The influence of the part geometry on the cell structure is then evidenced considering the cellular characteristics of both foamed samples made of the same material. Regarding the simulation results obtained by Moldex 3D®, Figure 4.19 indicates values provided by the software, with slightly higher cell sizes and one order of magnitude lower cell densities than those found experimentally (Table 4.8). 


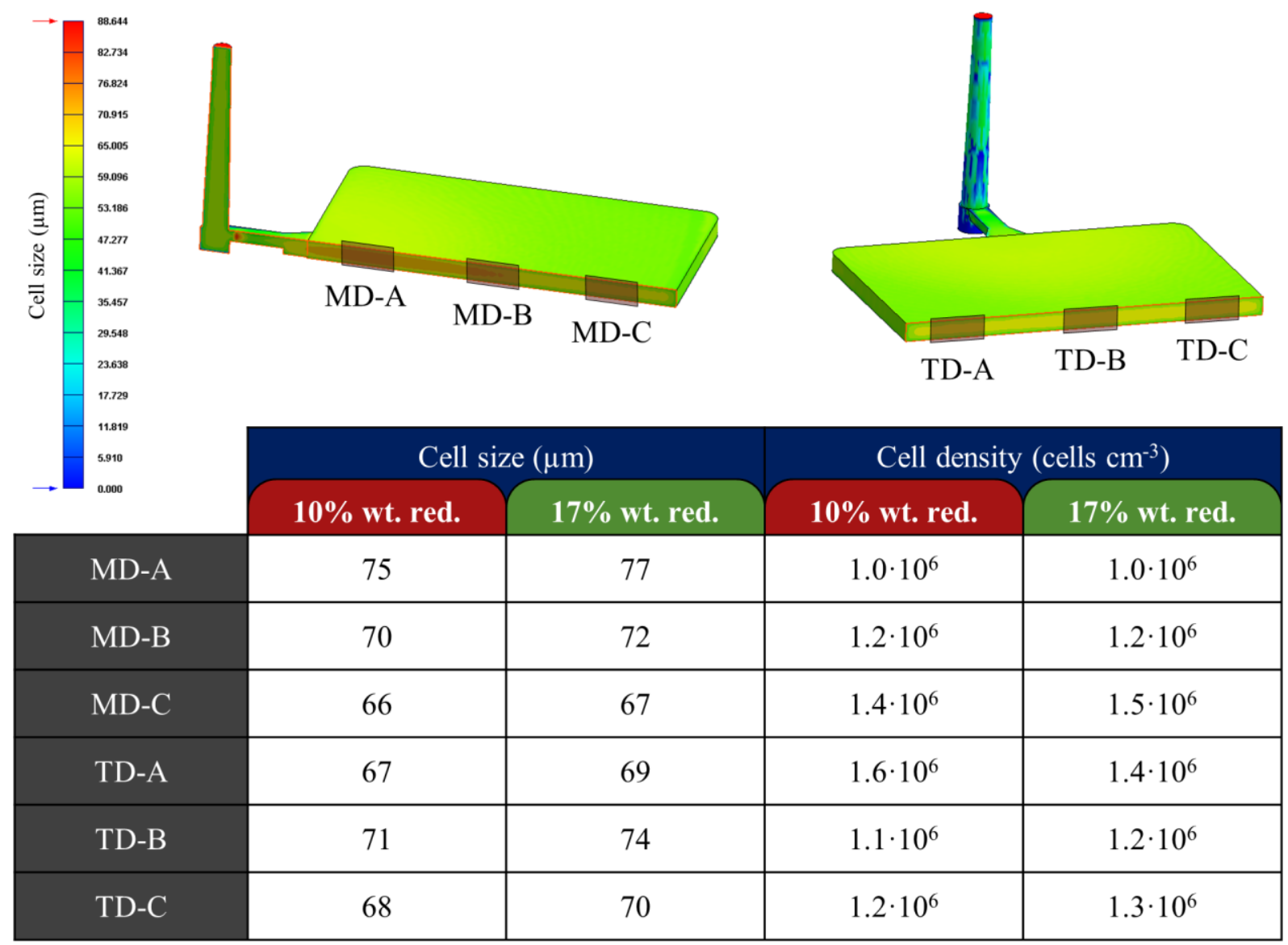

Figure 4.19. Cell size and cell density results of ABS foamed plates simulated with Moldex 3D® software.

\subsubsection{Flexural behavior}

The stress-strain curves obtained from the flexural tests of solid and foamed specimens are illustrated in Figure 4.20. All the specimens reached a maximum stress but did not break before the conventional deflection given by the ISO 178 standard [198].
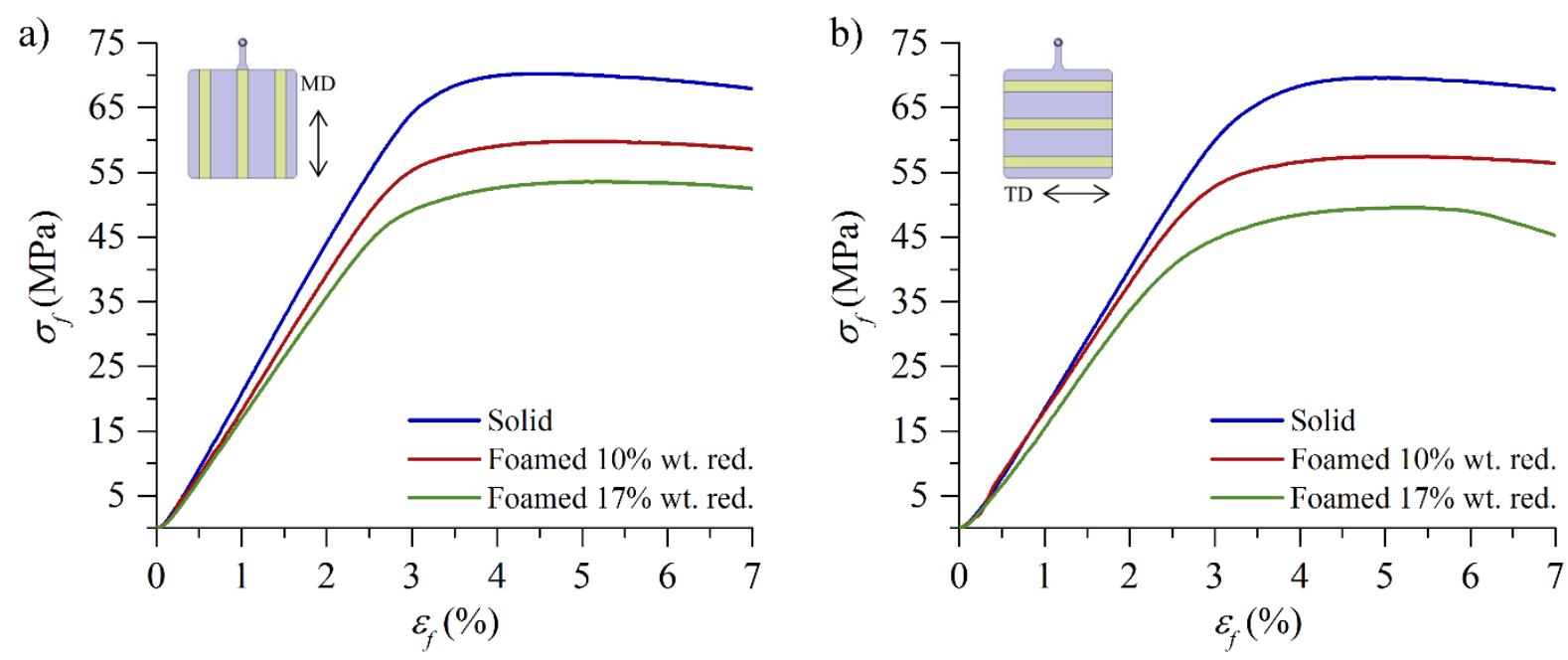

Figure 4.20. Flexural stress-strain curves of ABS solid and foamed samples tested in a) MD; b) TD directions. 
Table 4.10. Flexural properties in different sections of ABS square plates.

\begin{tabular}{|c|c|c|c|c|c|}
\hline $\begin{array}{c}\text { Condition } \\
\text { No. }\end{array}$ & Section & $\begin{array}{c}E_{f} \\
(\mathbf{M P a})\end{array}$ & $\begin{array}{c}\sigma_{f} \\
(\mathbf{M P a})\end{array}$ & $\begin{array}{c}E_{f} / \rho \\
\left(\mathrm{MPa} / \mathrm{g} \mathrm{cm}^{-3}\right)\end{array}$ & $\begin{array}{c}\sigma_{f} / \rho \\
\left(\mathrm{MPa} / \mathrm{g} \mathrm{cm}^{-3}\right)\end{array}$ \\
\hline \multirow[t]{6}{*}{ Solid } & MD-A & $2378 \pm 117$ & $71.0 \pm 2.7$ & $2306 \pm 149$ & $68.9 \pm 3.7$ \\
\hline & MD-B & $2392 \pm 78$ & $71.5 \pm 2.1$ & $2298 \pm 150$ & $68.7 \pm 3.3$ \\
\hline & MD-C & $2345 \pm 61$ & $70.5 \pm 1.2$ & $2288 \pm 91$ & $68.8 \pm 2.1$ \\
\hline & TD-A & $2398 \pm 151$ & $71.0 \pm 1.7$ & $2342 \pm 179$ & $69.3 \pm 2.6$ \\
\hline & TD-B & $2212 \pm 103$ & $68.4 \pm 1.4$ & $2181 \pm 127$ & $67.5 \pm 2.2$ \\
\hline & TD-C & $2206 \pm 58$ & $68.3 \pm 0.8$ & $2182 \pm 72$ & $67.6 \pm 1.3$ \\
\hline \multirow{6}{*}{$\begin{array}{c}\text { Foamed } 10 \% \\
\text { wt. red. }\end{array}$} & MD-A & $2049 \pm 179$ & $56.8 \pm 3.7$ & $2388 \pm 232$ & $66.2 \pm 5.7$ \\
\hline & MD-B & $2066 \pm 152$ & $57.0 \pm 2.8$ & $2492 \pm 216$ & $68.8 \pm 4.0$ \\
\hline & MD-C & $2087 \pm 81$ & $58.1 \pm 1.2$ & $2396 \pm 140$ & $66.7 \pm 2.7$ \\
\hline & TD-A & $1925 \pm 62$ & $52.3 \pm 2.7$ & $2297 \pm 222$ & $62.4 \pm 3.8$ \\
\hline & TD-B & $2070 \pm 34$ & $54.1 \pm 2.7$ & $2424 \pm 170$ & $63.3 \pm 4.5$ \\
\hline & TD-C & $1986 \pm 93$ & $54.4 \pm 2.6$ & $2259 \pm 219$ & $61.9 \pm 3.1$ \\
\hline \multirow{6}{*}{$\begin{array}{c}\text { Foamed } 17 \% \\
\text { wt. red. }\end{array}$} & MD-A & $1925 \pm 53$ & $53.7 \pm 0.9$ & $2333 \pm 84$ & $65.1 \pm 1.6$ \\
\hline & MD-B & $1883 \pm 44$ & $52.4 \pm 1.1$ & $2345 \pm 96$ & $65.3 \pm 2.5$ \\
\hline & MD-C & $1896 \pm 62$ & $53.3 \pm 1.4$ & $2315 \pm 90$ & $65.1 \pm 2.1$ \\
\hline & TD-A & $1653 \pm 97$ & $44.7 \pm 2.8$ & $2108 \pm 107$ & $57.0 \pm 3.8$ \\
\hline & TD-B & $1740 \pm 27$ & $47.7 \pm 1.2$ & $2109 \pm 58$ & $57.8 \pm 2.2$ \\
\hline & TD-C & $1826 \pm 91$ & $48.1 \pm 2.9$ & $2169 \pm 124$ & $57.1 \pm 3.9$ \\
\hline
\end{tabular}

The results of flexural strength and flexural modulus are summarized in Table 4.10. As a consequence of the density reduction, the flexural modulus was diminished by around $13 \%$ and $20 \%$ (10\% and $17 \%$ of weight reduction) in samples extracted in MD direction, whereas it was decreased by $12 \%$ and $23 \%$ in the opposite orientation. Flexural strength, however, experimented a greater reduction ratio, with reductions of $19 \%$ and $25 \%$ in case of specimens tested in MD direction, and $22 \%$ and $32 \%$ in TD samples. In all cases, the gap between 
properties of solid and foamed specimens was strongly reduced when the specific values were calculated. The specific flexural modulus of the $10 \%$ of weight reduction foamed specimens even exceeded the specific modulus of the unfoamed plates.

A slight reduction in the flexural modulus and strength of solid samples can be observed in TD direction, which might be due to a slight decrease in the packing pressure at the end of the cavity. Nevertheless, foamed samples presented the opposite trend, with higher flexural modulus and strength at the end areas, as also reported by Rezavand et al. [226]. This tendency could be due to the thicker skin layers. When samples were taken in MD direction, no great differences were detected in the three tested sections, because of the more homogeneous morphology generated at medium distance from the injection point.

The two levels of foamed samples presented differences in flexural strength of $7 \%$ and $12 \%$, respectively, when MD and TD directions were compared. This variation cannot be only attributed to the material orientation, but also to the influence of the elongation of the cells observed in the morphology analysis.

When load is applied in a bending test, the upper side of the specimen is compressed, while the lower surface is in tension. Therefore, the solid skins play an important role on the flexural performance of foams, as well as the density. Zhang et al. [227] developed the Square-Power law model, simplifying the structural foam as a three-layer sandwich. Hence, the normalized modulus is given as:

$$
\frac{E_{f f}}{E_{f s}}=\left[1-\left(1-\left(\frac{\rho_{f}}{\rho_{s}}\right)^{2}\right)\left(1-\frac{2 t_{s}}{h}\right)^{3}\right]
$$

Where $E_{f f}, E_{f s}, \rho_{f}$ and $\rho_{s}$ are the flexural modulus and apparent density of foamed and solid material, respectively. The variable $t_{s}$ is the skin thickness of the surface layer, and $h$ is the overall part thickness. Taking average values of skin layer, apparent density and flexural properties of the solid material, the predicted flexural modulus was $1913 \mathrm{MPa}$ (10\% of weight reduction) and $1780 \mathrm{MPa}$ (17\% of weight reduction), with a maximum deviation from the experimental results of $8 \%$.

For the flexural strength, $\mathrm{Xu}$ and Kishbaugh [223] proposed a model to estimate the flexural strength of microcellular plastics considering the skin/core complex structure:

$$
\frac{\sigma_{f f}}{\sigma_{f s}}=\frac{2 t_{s}^{3}}{h^{3}}+\frac{6 t\left(h-t_{s}\right)^{3}}{h^{3}}+(1-R)^{2}\left(\frac{h-2 t_{s}}{h}\right)^{3}
$$


In Equation (4.5), $t_{s}$ is the solid skin thickness, $h$ is the overall part thickness, and $R$ is the real weight reduction ratio in the foamed core, calculated as a function of $t$ and $h$ thicknesses and the weight reduction ratio of the whole part $R_{w}(0.9$ and 0.83$)$ :

$$
R=\frac{h\left(1-R_{w}\right)}{h-2 t_{s}}
$$

In this case, the estimated flexural strengths obtained were $61.7 \mathrm{MPa}$ and $57.2 \mathrm{MPa}$ for $10 \%$ and $17 \%$ levels of weight reduction $\left(R_{w}=0.10\right.$ and 0.17$)$. The maximum deviation with regard the experimental results in MD direction is around $8 \%$, and $21 \%$ in TD specimens. This difference in the accuracy of the model is due to the anisotropy induced by the addition of gas, which was not considered in the model. Cell density and size also influence the mechanical properties of the foam. According to Li et al. [181], low cell sizes have a positive effect on the flexural modulus and strength. In the present study, the achieved fine cell structures pointed out towards maximum values of flexural properties.

\subsubsection{Impact behavior}

Load-displacement curves in Figure 4.21 and impact resistance in Table 4.11 show a significant reduction in the impact properties of the foamed samples. Indeed, the impact resistance of the specimens with $10 \%$ and $17 \%$ of weight reduction was around $50 \%$ and $58 \%$ lower than the solid samples in MD, and $63 \%$ and $73 \%$ when TD direction was considered. This is in concordance to the impact properties under falling dart tests of ABS foams reported by Avalle and Scattina [228], as well as other studies found in the literature with Polyetherimide (PEI) and their composites [181].
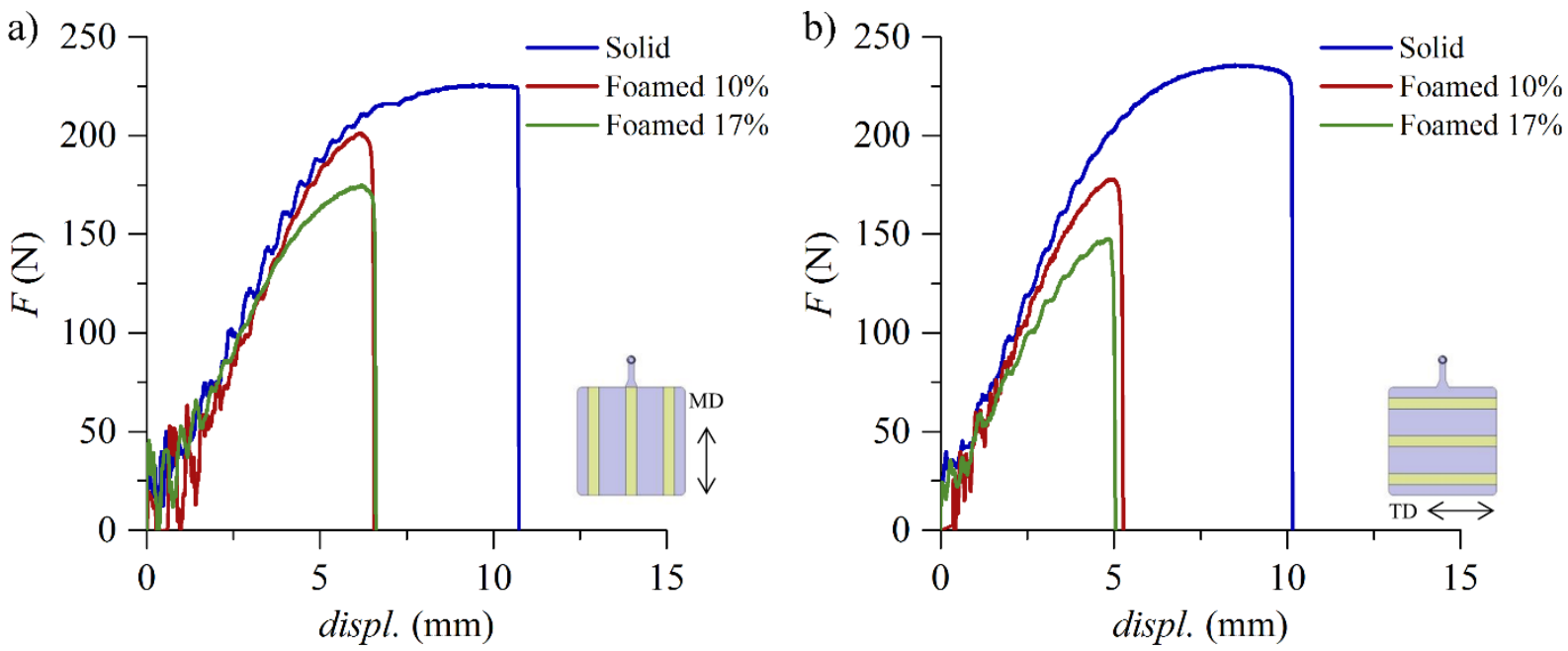

Figure 4.21. Impact force-displacement curves of ABS samples tested in a) MD; b) TD directions. 
Table 4.11. Impact resistance determined in different sections of ABS square plates.

\begin{tabular}{|c|c|c|c|}
\hline $\begin{array}{c}\text { Condition } \\
\text { No. }\end{array}$ & Section & 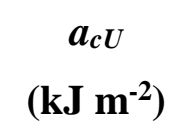 & $\begin{array}{c}a_{c U} / \rho \\
\left(\mathrm{kJ} \mathrm{m}^{-2} / \mathrm{g} \mathrm{cm}^{-3}\right)\end{array}$ \\
\hline \multirow[t]{6}{*}{ Solid } & MD-A & $28.1 \pm 1.0$ & $27.4 \pm 1.2$ \\
\hline & MD-B & $27.9 \pm 0.9$ & $27.5 \pm 1.2$ \\
\hline & MD-C & $28.3 \pm 0.3$ & $27.8 \pm 0.5$ \\
\hline & TD-A & $26.7 \pm 2.2$ & $26.6 \pm 2.8$ \\
\hline & TD-B & $30.7 \pm 2.1$ & $31.1 \pm 2.6$ \\
\hline & TD-C & $28.2 \pm 1.6$ & $27.9 \pm 1.8$ \\
\hline \multirow{6}{*}{$\begin{array}{c}\text { Foamed } 10 \% \\
\text { wt. red. }\end{array}$} & MD-A & $13.9 \pm 1.2$ & $16.1 \pm 1.7$ \\
\hline & MD-B & $13.5 \pm 1.0$ & $16.0 \pm 1.5$ \\
\hline & MD-C & $15.0 \pm 1.4$ & $17.7 \pm 1.9$ \\
\hline & TD-A & $10.1 \pm 0.5$ & $12.2 \pm 0.9$ \\
\hline & TD-B & $9.6 \pm 0.4$ & $11.6 \pm 0.8$ \\
\hline & TD-C & $11.4 \pm 1.0$ & $12.8 \pm 1.3$ \\
\hline \multirow{6}{*}{$\begin{array}{c}\text { Foamed } 17 \% \\
\text { wt. red. }\end{array}$} & MD-A & $11.4 \pm 1.1$ & $14.0 \pm 1.5$ \\
\hline & MD-B & $12.5 \pm 1.1$ & $16.0 \pm 1.6$ \\
\hline & MD-C & $11.6 \pm 1.1$ & $14.3 \pm 1.5$ \\
\hline & TD-A & $7.9 \pm 0.2$ & $10.1 \pm 0.5$ \\
\hline & TD-B & $7.0 \pm 0.3$ & $9.0 \pm 0.5$ \\
\hline & TD-C & $7.6 \pm 0.6$ & $9.1 \pm 0.9$ \\
\hline
\end{tabular}

However, it is in disagreement with the increase in the energy absorbed by the microcellular materials as compared to the neat polymer obtained in Polycarbonate (PC) [127, 129]. According to Li et al. [229], the impact resistance of microcellular foams depends on the material toughness itself and on the effect of foaming. And this effect results from the combination of two opposite mechanisms that exist simultaneously. On one hand, cells can passivate the stress of crack tips, dissipate impact energy and then increase impact strength. 
On the other hand, the reduction of the effective sectional area and cells collapse decrease the impact resistance. The presence of butadiene phase makes ABS a tough material. However, the predominant mechanism of foaming effect seems to be the reduction in resistant area and cells collapse acting as intern defects, thus decreasing the impact resistance.

Specific properties provided still lower values than the calculated in the solid specimens (Table 4.11), which leads to the conclusion that impact behavior is much more sensitive to the apparent density than tensile and flexural properties [143]. The lower content in butadiene particles due to the less amount of material injected during foaming could also contribute to the reduction in ductility and energy absorption of the foamed samples. The dependency of the impact resistance with the solid skin, cell size and cell density has been also studied [130]. Some authors showed the convenience of higher solid skin $[132,230]$ and fine cell structures (higher cell density and lower cell sizes) in order to improve the impact performance of the foamed part [132, 136, 142, 231]. However, opposite results were obtained in further investigations. Hwang et al. [126] reported better impact properties of Polycarbonate (PC) foams with higher cell sizes, a bi-modal cellular structure of Polystyrene (PS) consisting of two main different cell sizes was found more favorable to impact energy absorption by Bao et al. [232], and Chen et al. [133] obtained higher impact resistance with thinner solid skins in Polystyrene (PS).

As observed in the flexural tests results, the impact resistance in foamed samples slightly increased at the end areas of the injected plates, and kept similar in the three specimens tooled in MD direction. It can be explained in the same terms of density and morphology as mentioned before. Some solid samples tooled in MD direction exhibited yielding followed by plastic deformation before breaking. The effect of molecular orientation in this case is evidenced. However, in order to reduce the scatter in the impact resistance and be compared to the foamed specimens, only the energy absorbed until reaching the maximum load was considered. This is the reason why no differences between impact resistance in MD and TD directions of solid samples are observed in Table 4.11. In case of foamed materials, a clear effect of orientation and cell elongation was detected comparing the impact resistance obtained in both directions (differences of $26 \%$ and $36 \%$ for $10 \%$ and $17 \%$ foamed specimens respectively). The same anisotropy phenomenon was reported in microcellular ABS panels [122] and PS [233]. 


\subsubsection{Fracture behavior}

\subsubsection{Crack Tip Opening Displacement CTOD}

Figure 4.22a) shows the force versus displacement plots obtained with SENT solid and foamed specimens tested in TD direction. In all materials, crack propagation initiated before reaching the maximum force, and before undergoing full ligament yielding.
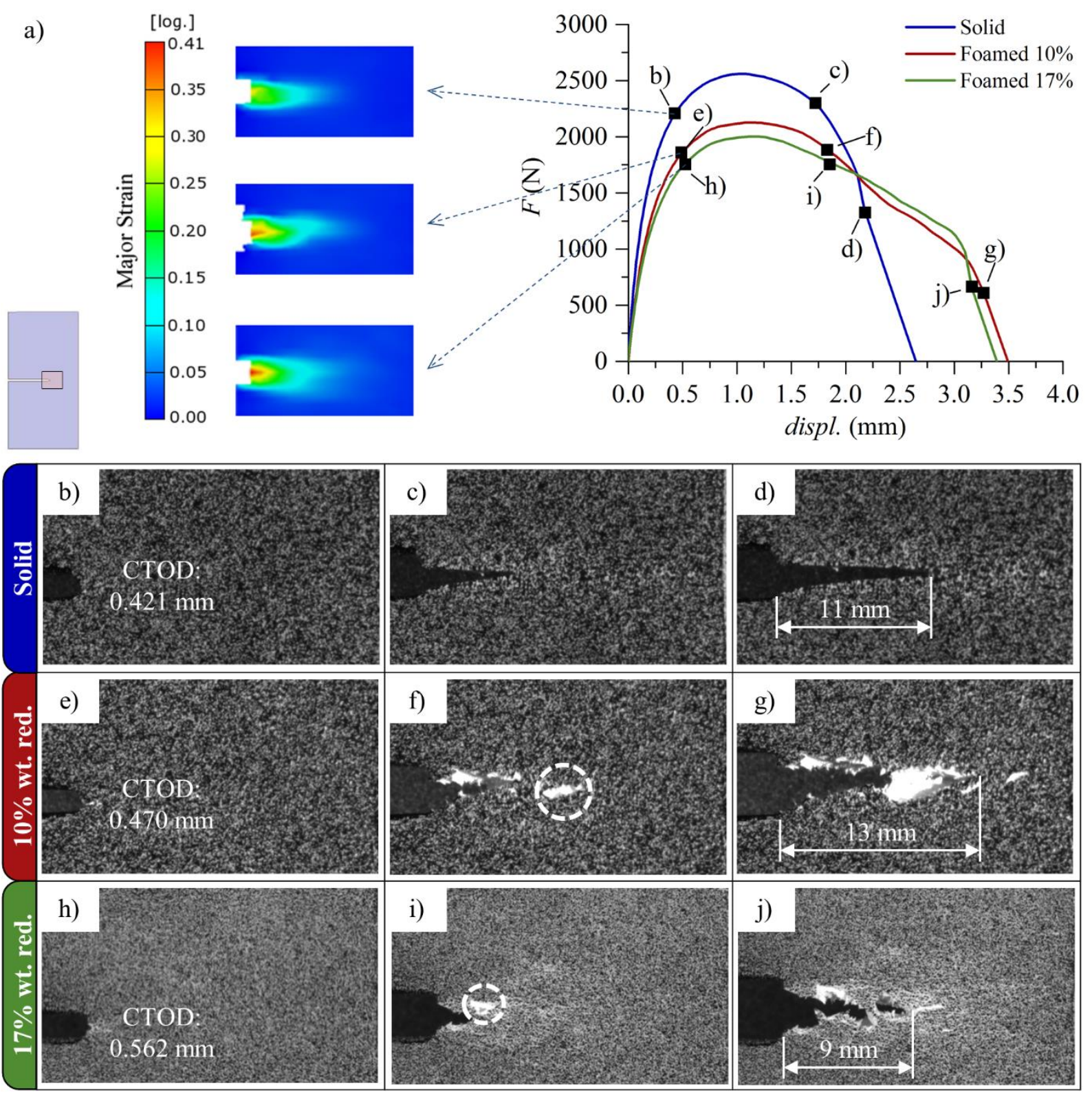

Figure 4.22. a) Strain field ahead of the crack tip at the crack propagation onset and force-displacement curves for solid and foamed samples tested in TD direction at $\left.\left.\left.16 \mathrm{~mm} \mathrm{~min}^{-1} ; \mathbf{b}\right), \mathbf{e}\right), \mathbf{h}\right)$ Micrographs taken at the crack propagation onset with the corresponding $C T O D$ value; c) Stable crack propagation of solid samples; f), i) quasistable crack propagation of foamed samples with secondary cracks ahead of the main crack front, indicated into the white dashed circles; The stable crack propagation length is indicated in figures $\mathbf{d}$ ), $\mathbf{g}$ ), j) for each material investigated before the catastrophic crack propagation. 
Additionally, crack propagation was not stable along the whole ligament. This behavior suggests that the stress state ahead of the crack tip was possibly not pure plane stress due to the relative large sample thickness (i.e. $5 \mathrm{~mm}$ ); probably leading to unstable crack propagation. Therefore, the application of the Essential Work of Fracture (EWF) method was not fully accurate for characterizing the fracture behavior of these solid and foamed ABS samples. On this basis, the Crack Tip Opening Displacement (CTOD) concept was used in the current work in order to evaluate the fracture behavior of these materials.

Table 4.12 summarizes the results determined from the low loading speed tests. The $C T O D$ value of both foamed samples was higher than the solid ones and increased with the gas content (i.e. $12 \%$ and $30 \%$ in case of $10 \%$ and $17 \%$ of weight reduction levels, respectively). As expected, cells acted as crack arrestors by blunting the crack tip. Thus, the crack propagation onset was delayed and a higher $C T O D$ value was obtained. The strain field ahead of the crack tip was determined at the crack propagation onset using Digital Image Correlation (DIC) technique. As shown in Figure 4.22a), the size of the plastic zone cannot be neglected as compared to the ligament length, due to the ductile behavior of the ABS material. In the foamed samples, the higher $C T O D$ values gave rise to an increase in the maximum strain levels. In case of the solid samples, no significant differences between the $C T O D$ values obtained in MD and TD directions were detected. However, in the foamed specimens the CTOD determined in TD direction was slightly higher than in $\mathrm{MD}$, due to the increased anisotropy caused by the gas introduction.

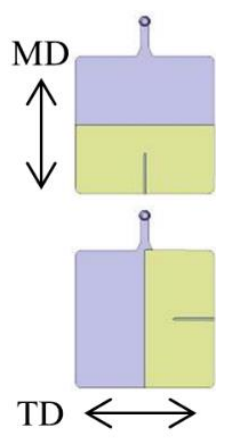

Table 4.12. $C T O D$ and experimental and predicted $K_{I c}$ of ABS plates.

\begin{tabular}{cccc}
\hline $\begin{array}{c}\text { Condition } \\
\text { No. }\end{array}$ & $\begin{array}{c}\text { Direction } \\
(\mathbf{m m})\end{array}$ & $\begin{array}{c}\text { CTOD } \\
(\mathbf{m m})\end{array}$ & $\begin{array}{c}\boldsymbol{K}_{\text {Ic }} \\
\left(\mathbf{M P a ~ m}^{-\mathbf{1} / 2}\right)\end{array}$ \\
\hline Solid & MD & $0.434 \pm 0.014$ & $3.34 \pm 0.30$ \\
& TD & $0.444 \pm 0.015$ & $3.36 \pm 0.16$ \\
\hline $\begin{array}{c}\text { Foamed } \\
\text { 10\% wt. red. }\end{array}$ & MD & $0.481 \pm 0.032$ & $1.94 \pm 0.18$ \\
\hline $\begin{array}{c}\text { Foamed } \\
17 \% \text { wt. red. }\end{array}$ & TD & $0.497 \pm 0.028$ & $2.23 \pm 0.19$ \\
& TD & $0.504 \pm 0.021$ & $1.68 \pm 0.14$ \\
\hline
\end{tabular}


Regarding crack propagation process, in solid specimens the crack tended to propagate in a stable manner along a straight line up to a ligament length of around $10 \mathrm{~mm}$, when catastrophic failure took place (Figure 4.22c)-d)). In the foamed samples, however, the crack propagation can be considered quasi-stable, due to the subsequent processes of deformation, rupture and cell coalescence. In the foam structure, the crack tended to surround the cells prior to propagation. Therefore the crack path was certainly not a straight line. In addition, once the crack started to propagate, secondary cracks arose ahead of the main crack front which grow and coalesce, triggering a faster crack propagation process (Figure 4.22f)-i)). The same phenomenon has been reported in Polyvinyl Chloride (PVC) and Polyethersulfone (PES) foams although under fatigue cycle load conditions [234]. All of the above justifies the quasistable character of the crack propagation in different planes observed in the foamed specimens. The maximum extension of this quasi-stable crack propagation before unstable failure was similar to that of the solid material $(10 \mathrm{~mm})$.

\subsubsection{Fracture toughness $K_{I c}$}

The fracture toughness $K_{I c}$ results of the high speed tests are outlined in Table 4.12. The values obtained in the solid material are consistent with those provided by the European Structural Integrity Society (ESIS) for ABS [201] and slightly lower than the obtained at slow loading speed on $10 \mathrm{~mm}$ thick samples [235] According to Bureau and Kumar [236], cells act as stress concentrators at the crack tip due to stress triaxiality, thus a reduction in the fracture toughness is expected in foamed materials. Table 4.12 points out a decrease in the fracture toughness of $42 \%$ and $50 \%$ in MD direction with the weight reduction ratio, as a consequence of lower density, resistance and energy absorption capability. In the transverse direction (TD), fracture toughness was reduced by $33 \%$ and $42 \%$, respectively. The same trend has been reported for Polyvinyl Chloride (PVC) and Polyethersulfone (PES) foams [237].

As observed in the CTOD parameter, foaming promoted a higher anisotropic material behavior, with higher fracture toughness when the crack propagated in TD direction. In order to get a better insight into the different behavior of the foams according to the crack propagation orientation, the fracture surfaces were examined using Scanning Electron Microscopy (SEM). It is well known that ABS failure is governed by rubber particles cavitation and shear-yielding. However, in the presence of a sharpened notch, the notch itself dominates the crack propagation and the fracture process. The fracture surfaces of the solid samples and 10\% weight reduction foams are illustrated in Figure 4.23. 


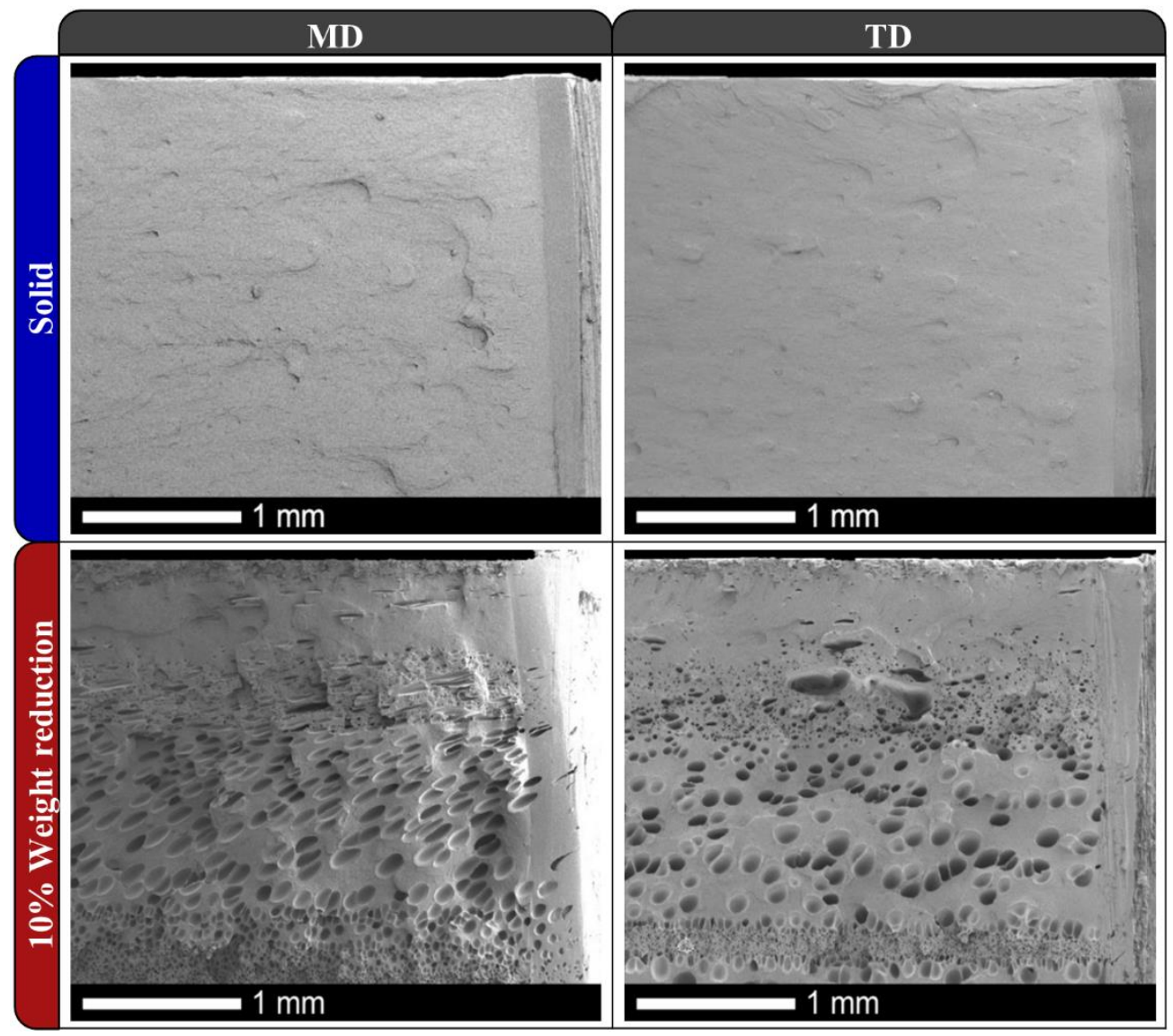

Figure 4.23. Fracture surfaces of solid and foamed samples in MD and TD direction.

It can be seen that there is not significant differences between the fracture surfaces of solid specimens. In case of the cellular material, the surfaces shown in Figure 4.23 present similar solid thicknesses and a smooth surface, which evidences a brittle failure. Moreover, the notches spread over the whole part thickness. However, in the surface obtained when the crack propagated in MD direction, cells are elongated and distorted as discussed in the morphology analysis, while fracture surfaces corresponding to TD direction exhibit more spherical cells. This difference in the cell shape could explain the differences in the fracture behavior according to the crack propagation direction.

Finally, two estimation models for predicting the $K_{I c}$ parameter were applied. The Model 1 was used by Kabir et al. [238], and relates the relative fracture toughness to the relative foam density through a power law as described in Equation (4.7):

$$
\frac{K_{I c, f}}{K_{I c, S}}=C_{f}\left(\frac{\rho_{f}}{\rho_{S}}\right)^{n_{f}}
$$

Taking the values of $C_{f}=1$ and $n_{f}=2$, the resulting model is analog to the equations to predict the tensile and flexural properties of the cellular materials reported by Gibson and 
Ashby [51]. The estimated $K_{I c}$ values were $2.24 \mathrm{MPa} \mathrm{m}^{-1 / 2}$ and $1.99 \mathrm{MPa} \mathrm{m}^{-1 / 2}$ for foamed series with $10 \%$ and $17 \%$ of weight reduction. Thus, the model fitted well to the experimental $K_{I c}$ obtained in TD direction of crack propagation, but the error was around $15 \%-20 \%$ compared to that of MD direction.

The Model 2 was suggested by Maiti et al. [239], and it considers additional parameters such as the strength of the cell walls in bending $\sigma_{f s}$ and the average cell size $d$ :

$$
\frac{K_{I c, f}}{K_{I c, s}}=K_{f} \sigma_{f s} \sqrt{\pi d}\left(\frac{\rho_{f}}{\rho_{s}}\right)^{m_{f}}
$$

In this case, the best fitting value for the $K_{f}$ constant was 2 , the average flexural strength of the solid ABS $\sigma_{f s}$ was $70 \mathrm{MPa}$, and the average cell size $d$ was $16 \mu \mathrm{m}$. The exponent $m_{f}$ took a value of 2 , as proposed by the authors for closed cell structures. The predicted fracture toughness obtained applying this second model was $2.22 \mathrm{MPa} \mathrm{m}^{-1 / 2}$ for $10 \%$ of weight reduction, and $1.98 \mathrm{MPa} \mathrm{m} \mathrm{m}^{-1 / 2}$ for $17 \%$. Again, the model was quite accurate for the experimental values in TD direction, but the error when the MD results were considered was similar to that of the Model 1. In conclusion, these two models are well adjusted with foams having perfect spherical cell shapes, but they deviate from the experimental results when cells are elongated and distorted.

\subsubsection{Heat Deflection Temperature}

Heat Deflection Temperature tests were conducted on samples extracted from the middle of the injected plates (MD-B position). As summarized in Table 4.13, the temperature at which the specimen reached a deflection of $0.24 \mathrm{~mm}$ decreased from $92.4 \pm 3.1^{\circ} \mathrm{C}$ of solid samples to $88.2 \pm 2.6{ }^{\circ} \mathrm{C}$ and $84.8 \pm 1.2{ }^{\circ} \mathrm{C}$ (10\% and $17 \%$ foamed materials). Weal [240] related the $H D T$ temperature to the glass-transition temperature $\left(T_{g}\right)$ of amorphous polymers. If this statement is accurate, it can be assumed that the $T_{g}$ of the foamed ABS must be around $85-90{ }^{\circ} \mathrm{C}$.

Table 4.13. Heat Deflection Temperature (HDT) of ABS square plates.

\begin{tabular}{ccc}
\hline Condition No. & Section & $\boldsymbol{H D T}\left({ }^{\mathbf{o}} \mathbf{C}\right)$ \\
\hline Solid & TD-B & $92.4 \pm 3.1$ \\
Foamed 10\% wt. red. & TD-B & $88.2 \pm 2.6$ \\
Foamed 17\% wt. red. & TD-B & $84.8 \pm 1.2$ \\
\hline
\end{tabular}


Some authors, such as Krause et al. [241], Ma et al. [242] or Li et al. [243], stated a decrease in $H D T$ and $T_{g}$ temperatures due to foaming. By dissolving gas into the polymer, the attraction between molecules gets weakened and the entanglement changes, promoting molecular movements more active and causing a drop in $T_{g}$ [89]. Nevertheless, other materials like Polyethylene Therephtalate Glicol (PETG) [134] and Poly(Lactic Acid) (PLA) [149] keep the $T_{g}$ invariant while foaming, because the low gas saturation levels were not enough to produce changes in polymer chains. The HDT temperatures resulted in this research with both series of ABS foams diminished by $5 \%$ and $8 \%$ as compared to that of the solid counterpart. As discussed above, the flexural modulus decreased around $12 \%$ and $23 \%$ when foaming. Therefore, the lower $H D T$ values obtained in the ABS foamed specimens seems to be due to a lower stiffness of these materials, rather than changes in the chemical structure because of the gas.

\subsection{Conclusions}

The solid skin/foamed core structure of ABS cylindrical bars and square plates has been analyzed, and their mechanical properties have been tested. From the results presented above, the following conclusions can be drawn:

- The most influencing parameter on cell structure and mechanical properties was the shot volume and, indirectly, the SCF content. As the shot size decreased and the gas content increased, finer and more uniform cell structures were created, with higher cell densities and narrower cell size ranges. However, enhanced mechanical properties were obtained by increasing the shot volume.

- The effect of mold temperature and injection speed was secondary. They are related to the cooling rate and pressure drop induced inside the mold cavity and, in general terms, higher levels of both parameters contributed to improve the morphology of the foamed parts. Nevertheless, they were not statistically relevant to the mechanical properties. Interactions between processing parameters were found and in some cases had a greater effect than each factor independently.

- Thicker parts $(\varnothing=8 \mathrm{~mm}$ of cylindrical bars $)$ gave rise to high cell size, low cell densities and irregular cell distributions. The morphology was significantly improved by reducing the diameter to 4 and $5 \mathrm{~mm}$ and with the square plate geometry. Traditionally, physical injection molding foaming processes has been recommended to parts thinner than $4 \mathrm{~mm}[58]$. 
- The different foam morphologies obtained in this study do not seem to have a determinant influence on the mechanical properties, which were mainly dependent on the apparent density. Tensile and flexural characteristics decreased gradually with the apparent density, whereas impact resistance was greatly impaired by foaming, with reductions up to $70 \%$ with ratios of $17 \%$ of weight reduction. Prediction models available in the literature to estimate the evolution of the relative tensile and flexural properties fitted accurately to the experimental data.

- Moldex 3D® can be employed successfully for simulations of microcellular injection molding process as reasonable approach to foaming behavior and resulting cell density and size in the material.

- Cells act as crack arrestors by blunting the crack tip and, thus, increasing the Crack Tip Opening Displacement CTOD value as compared to the solid counterpart. However, the fracture toughness $K_{I c}$ decreased with the density of the samples. The fracture toughness $K_{I c}$ has been well described by a simple power law equation as well as by a more complex model considering flexural properties and cell size.

- Foaming increased the anisotropic behavior of the material, obtaining higher flexural properties, $C T O D$ and fracture toughness $K_{I c}$ in the cross direction to the melt flow. The cell elongation due to the fountain flow in the injection direction seems to be the most likely reason for this different performance.

- The introduction of gas during the foaming process did not change the thermal behavior significantly. The slight decrease in HDT temperature determined in ABS foamed samples can be due to the starting lower stiffness as compared to the solid injection molded specimens. 


\section{Chapter 5: \\ PP 20GF - MuCell® foams}

The relative low material density and cost, easy processing and good mechanical properties of Polypropylene (PP) make it suitable for a wide range of applications. Therefore, PP foams are potentially interesting for products like food packages, cosmetic or electric devices, and are strongly suggested to replace polystyrene and polyethylene in industry [244].

Foamability of PP has been extensively studied by the way of batch methods [245-250], extrusion [68, 251-254] and injection molding processes [135, 144, 157, 171, 255, 256]. Unfortunately, the low melt strength of PP and its crystalline nature results in poor cell structure [257]. Low solubility and diffusivity of blowing agents in PP have been determined [258, 259], leading to inhomogeneous morphology along the part. On the other hand, the weak melt strength promotes cell walls breakage under elongational forces while processing, causing cell coalescence and open-cell structures and decreasing mechanical properties [260].

Different methods have been conducted aimed to improve cell nucleation behavior and melt strength of PP, such as long-chain branching [261, 262], ramified molecular structures $[157,260]$ and blending with other polymer [125, 263-266]. Furthermore, it has been reported that inorganic fillers dramatically enhance cell structure of foamed polymers acting as nucleating agents. Leung et al. [84] showed that additives with many crevices of small semiconical angles lead to higher quality polymer foams, with a high cell density, a smaller cell size and narrower cell size distribution. Some of the most common fillers, namely talc, calcium carbonate, mica and carbon fibers have been successfully employed to the formation of fine and uniform cell morphologies [179, 180, 182, 267-271], as well as wood fibers, clay and rubber particles $[162,163,165,178,182,184,272-274]$. Glass fibers (GF) have been traditionally utilized in many industrial applications due to the increase in stiffness and strength of reinforced thermoplastics, creep resistance and service temperature [275]. Regarding foaming experiments with PP/GF composites, $\mathrm{Xi}$ et al. [159] determined an optimum fiber content of $11.8 \%$ for improving cell morphology and mechanical properties. 
Few other works have focused on physical foaming of PP/GF through injection molding [141, $171,172]$.

This Chapter outlines the results obtained from characterizing PP 20GF foams processed by MuCell® technology. First, the analysis of morphology and tensile properties of cylindrical bars is discussed. Unlike the approach followed in Chapter 4, the experiments carried out to determine the effect of injection molding parameters on the cell structure and mechanical properties of PP 20GF foams were made on the square plates. Once selected those conditions optimizing the flexural properties, a more extensive study on morphology and other mechanical and thermal properties was developed.

\subsection{Cylindrical bars}

\subsubsection{Morphology and apparent density}

The apparent density obtained in the solid and foamed cylindrical bars is summarized in Table 5.1. Although in PP 20GF all four cavities were completely filled, differences in density between outer and inner bars were still found, as has also been reported with ABS in the previous section. While the apparent density of solid bars remained constant for all four cavities, in case of foamed samples the outer bars were slightly denser than the inner bars, being bar B the lightest one, and bar D the heaviest. Different cooling rates between the four cavities seems to be the most likely cause for the diverse apparent densities obtained in ABS as well as in PP 20GF. As illustrated in Figure 5.1, the parabolic fountain flow generated under the injection molding conditions selected for foaming these samples was less prominent than that of reported with ABS in the previous Chapter (Figure 4.11) That is, the molten flow moved forward practically at once on the surfaces and the core leading to the complete filling of the PP 20GF bars.

Table 5.1. Apparent density of PP 20GF cylindrical bars.

\begin{tabular}{ccccc}
\hline Condition No. & $\begin{array}{c}\text { Bar A } \\
\left(\mathbf{g ~ c m}^{-3}\right)\end{array}$ & $\begin{array}{c}\text { Bar B } \\
\left(\mathbf{g ~ c m}^{-3}\right)\end{array}$ & $\begin{array}{c}\text { Bar C } \\
\left(\mathbf{g ~ c m}^{-3}\right)\end{array}$ & $\begin{array}{c}\text { Bar D } \\
\left(\mathbf{g ~ c m}^{-3}\right)\end{array}$ \\
\hline Solid & $1.04 \pm 0.01$ & $1.04 \pm 0.01$ & $1.04 \pm 0.01$ & $1.04 \pm 0.01$ \\
Foamed 10\% wt. red. & $0.94 \pm 0.01$ & $0.92 \pm 0.02$ & $0.94 \pm 0.01$ & $0.95 \pm 0.01$ \\
Foamed 20\% wt. red. & $0.84 \pm 0.01$ & $0.82 \pm 0.01$ & $0.84 \pm 0.02$ & $0.85 \pm 0.01$ \\
\hline
\end{tabular}




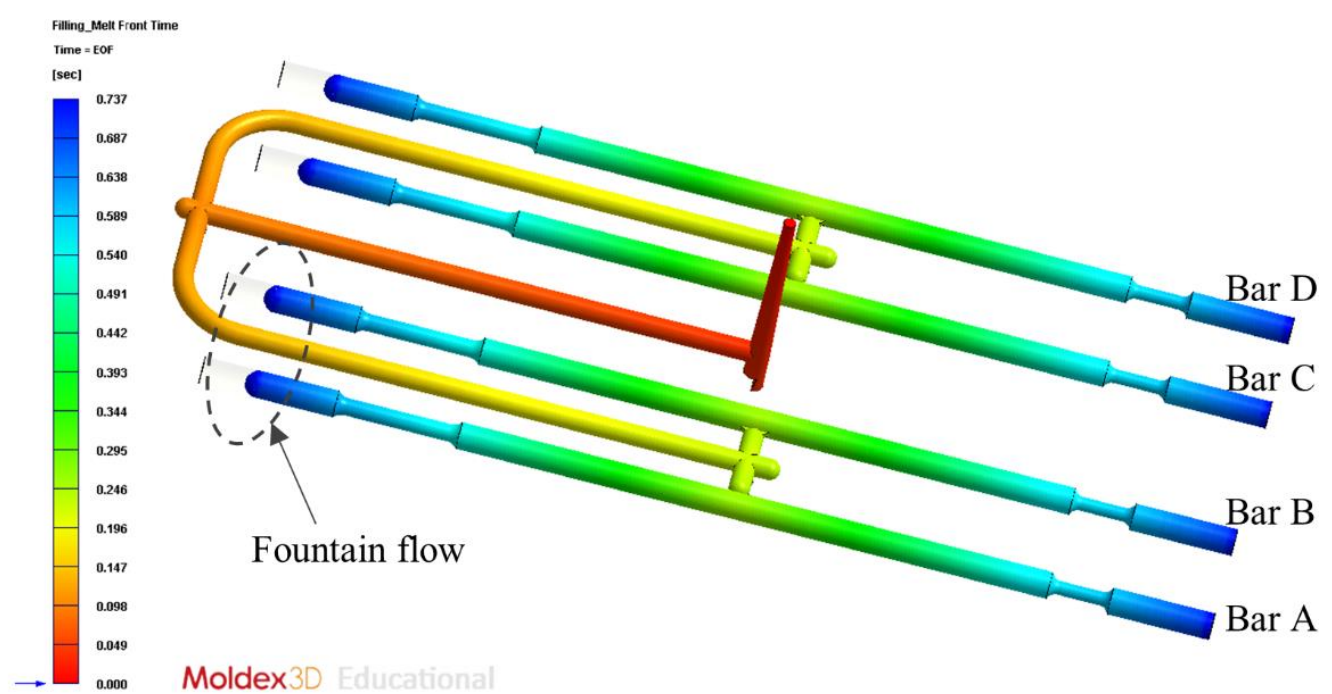

Figure 5.1. Melt front time of PP 20GF foamed bars (10\% wt. red.) simulated with Moldex 3D® software.

Figure 5.2 illustrates the morphology obtained in different diameter sections $(\varnothing=4,5$ and $8 \mathrm{~mm}$ ) of the two series of foamed bars. All SEM pictures show a solid skin/foamed core structure, with cell shape mainly spherical. Transition regions throughout the thickness of the part due to shear stress and temperature gradients wre not observed in this case. Small circular holes correspond to fiber pullout while breaking the specimen criogenically for examination.

The morphological parameters are displayed in Table 5.2. As can be observed, the skin thickness was in the range of $0.3-0.4 \mathrm{~mm}$, with a slight increase as the diameter rises. Only the $\varnothing=8 \mathrm{~mm}$ cross-section exceeded the $0.5 \mathrm{~mm}$ of skin thickness. In all cases, there was a very slight decrease in solid skin with the weight reduction ratio. As obtained with ABS, the solid skin depicts around the $15 \%-17 \%$ of the overall thickness for all diameter sections and both levels of weight reduction. Regarding cell size and cell density, it can be noted in Figure 5.2 that morphologies formed with $10 \%$ of weight reduction were characterized by few cells with bigger diameters, while bars with $20 \%$ of weight reduction exhibited a higher number of smaller cells. The relationship between shot volume (or gas content), cell size and cell density was discussed in the previous section with ABS results and are confirmed with PP 20GF. The increase in gas content led to high cell nucleation and cell density. Thus, creating more cells resulted in a faster depletion of the gas and less time for them to grow through gas diffusion. With $20 \%$ of weight reduction, the cell density reached the value of $10^{7}$ cells cm $\mathrm{cm}^{-3}$, one order of magnitude higher than that of $10 \%$ of weight reduction, but the effect on cell size was not so evident. It can be concluded from Figure 5.3 that in all diameter sections and foamed series, around $95 \%$ of cells were smaller than $60 \mu \mathrm{m}$. The $C D I$ values close to unity demonstrate the uniformity in the morphology obtained with PP 20GF. 


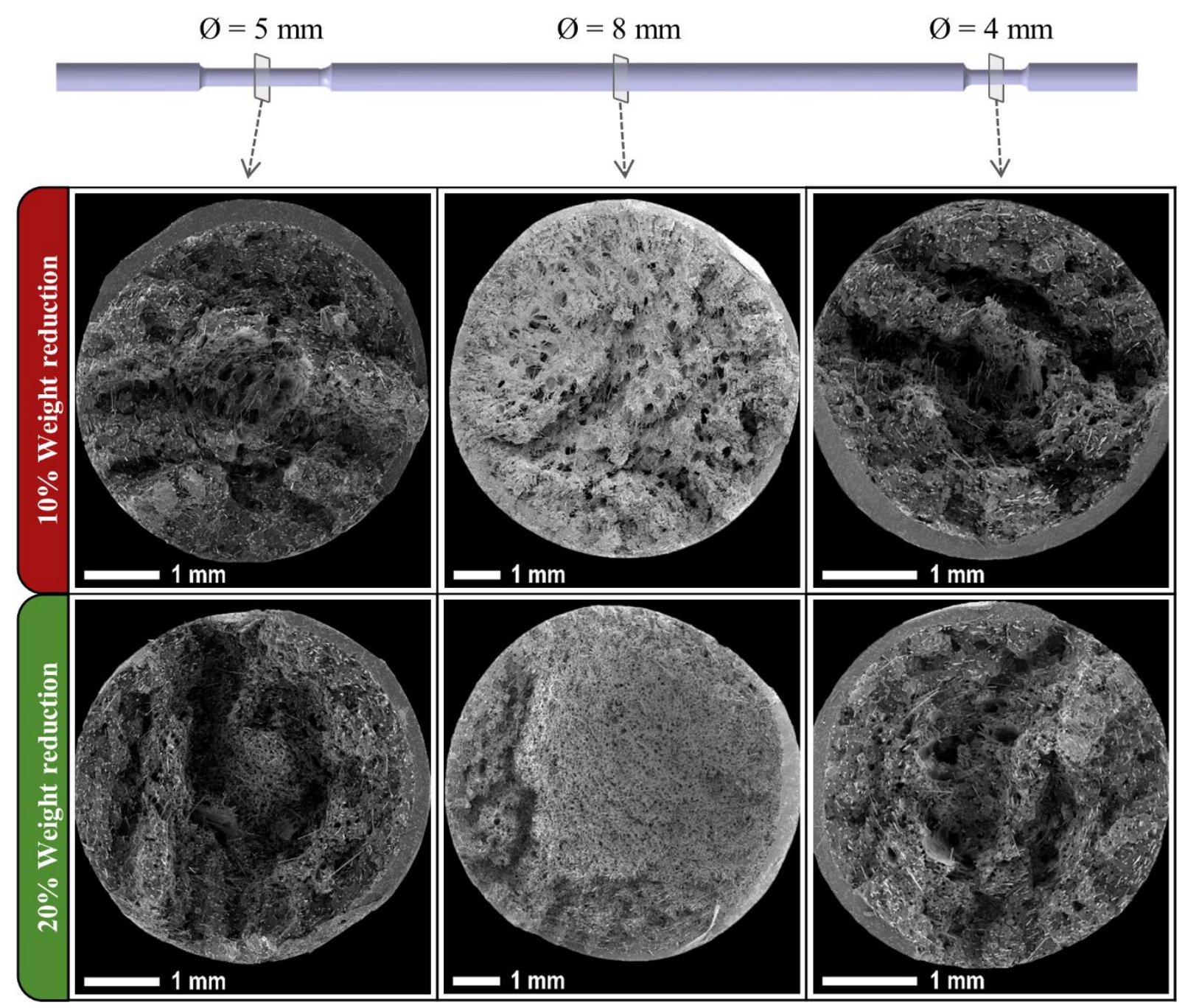

Figure 5.2. SEM micrographs taken from different sections of bar A PP 20GF foamed cylindrical bars.

It has been reported that foaming PP is very difficult because of its low melt strength and crystalline regions [276]. According to Jiang et al. [277], cells nucleate at the centers, boundaries and interlamellar amorphous regions of spherulites of pure PP, resulting in inhomogeneous cell distribution. However, SEM pictures shown in Figure 5.2 exhibit uniform cell structure and parameters given in Table 5.2 provide cell densities and sizes comparable to those obtained with ABS in the previous Chapter, and even better in case of $\varnothing=8 \mathrm{~mm}$. Hence, it is clear that the governing mechanism for cell nucleation was heterogeneous nucleation induced by glass fiber. According to the classical nucleation theory explained in Chapter 2 [83], undissolved gas trapped at the filled/polymer interface promotes the occurrence of multitude of sites for cell formation requiring much lower activation energy for bubble nucleation, accelerating cell nucleation and the development of a large number of cells with small cell size. Moreover, the added fillers increase melt strength of the material [267], contributing to prevent cell coalescence and improving its foaming behavior. 
Table 5.2. Apparent density and morphological parameters in different sections of PP 20GF foamed bars.

\begin{tabular}{|c|c|c|c|c|c|c|c|c|}
\hline $\begin{array}{c}\text { Condition } \\
\text { No. }\end{array}$ & Bar & $\begin{array}{c}\text { Section } \\
\varnothing \\
(\mathbf{m m})\end{array}$ & $\begin{array}{l}\text { Density } \\
\left(\mathrm{g} \mathrm{cm}^{-3}\right)\end{array}$ & $\begin{array}{c}\text { Fiber } \\
\text { content } \\
(\%)\end{array}$ & $\begin{array}{c}\text { Skin } \\
\text { thickness } \\
(\mathbf{m m})\end{array}$ & $\begin{array}{c}\text { Cell } \\
\text { density } \\
\left(\text { cells } \mathbf{c m}^{-3}\right)\end{array}$ & $\begin{array}{c}\text { Cell size } \\
\text { range } \\
(\mu \mathrm{m})\end{array}$ & CDI \\
\hline \multirow{12}{*}{$\begin{array}{l}\text { Foamed } \\
10 \% \mathrm{wt} . \\
\text { red. }\end{array}$} & \multirow[t]{3}{*}{ A } & 4 & $0.93 \pm 0.01$ & 23.2 & 0.35 & $4.4 \cdot 10^{6}$ & $7-214$ & 2.45 \\
\hline & & 5 & $0.93 \pm 0.01$ & 21.5 & 0.43 & $1.7 \cdot 10^{6}$ & $7-197$ & 2.43 \\
\hline & & 8 & $0.93 \pm 0.01$ & 20.3 & 0.64 & $1.3 \cdot 10^{5}$ & $7-290$ & 3.21 \\
\hline & \multirow[t]{3}{*}{ B } & 4 & $0.92 \pm 0.02$ & 22.5 & 0.34 & $4.4 \cdot 10^{6}$ & $7-174$ & 1.84 \\
\hline & & 5 & $0.92 \pm 0.01$ & 21.7 & 0.32 & $3.1 \cdot 10^{6}$ & $7-198$ & 2.46 \\
\hline & & 8 & $0.92 \pm 0.02$ & 20.3 & 0.65 & $1.9 \cdot 10^{5}$ & $7-325$ & 2.07 \\
\hline & \multirow[t]{3}{*}{$\mathrm{C}$} & 4 & $0.93 \pm 0.01$ & 22.7 & 0.36 & $1.7 \cdot 10^{6}$ & $7-187$ & 1.84 \\
\hline & & 5 & $0.92 \pm 0.01$ & 21.6 & 0.48 & $1.0 \cdot 10^{6}$ & $7-206$ & 2.35 \\
\hline & & 8 & $0.93 \pm 0.01$ & 20.3 & 0.62 & $1.2 \cdot 10^{5}$ & $33-336$ & 1.56 \\
\hline & \multirow[t]{3}{*}{$\mathrm{D}$} & 4 & $0.94 \pm 0.01$ & 22.9 & 0.34 & $4.2 \cdot 10^{6}$ & $7-185$ & 2.04 \\
\hline & & 5 & $0.93 \pm 0.01$ & 21.7 & 0.42 & $2.1 \cdot 10^{6}$ & $7-173$ & 2.27 \\
\hline & & 8 & $0.94 \pm 0.01$ & 20.4 & 0.58 & $2.9 \cdot 10^{5}$ & $11-322$ & 1.99 \\
\hline \multirow{12}{*}{$\begin{array}{l}\text { Foamed } \\
20 \% \text { wt. } \\
\text { red. }\end{array}$} & \multirow[t]{3}{*}{ A } & 4 & $0.83 \pm 0.01$ & 20.7 & 0.31 & $1.2 \cdot 10^{7}$ & $7-216$ & 1.68 \\
\hline & & 5 & $0.83 \pm 0.01$ & 20.4 & 0.39 & $1.2 \cdot 10^{7}$ & $7-218$ & 1.69 \\
\hline & & 8 & $0.83 \pm 0.01$ & 20.7 & 0.55 & $4.8 \cdot 10^{6}$ & $13-152$ & 1.36 \\
\hline & \multirow[t]{3}{*}{ B } & 4 & $0.82 \pm 0.01$ & 20.9 & 0.29 & $1.4 \cdot 10^{7}$ & $7-209$ & 1.58 \\
\hline & & 5 & $0.82 \pm 0.01$ & 20.0 & 0.35 & $1.1 \cdot 10^{7}$ & $7-234$ & 1.55 \\
\hline & & 8 & $0.82 \pm 0.01$ & 20.5 & 0.52 & $5.0 \cdot 10^{6}$ & $13-138$ & 1.27 \\
\hline & \multirow[t]{3}{*}{$\mathrm{C}$} & 4 & $0.83 \pm 0.02$ & 20.6 & 0.34 & $1.1 \cdot 10^{7}$ & $7-224$ & 1.58 \\
\hline & & 5 & $0.83 \pm 0.01$ & 20.5 & 0.42 & $1.2 \cdot 10^{7}$ & $7-168$ & 1.49 \\
\hline & & 8 & $0.83 \pm 0.01$ & 20.5 & 0.54 & $5.3 \cdot 10^{6}$ & $8-163$ & 1.39 \\
\hline & \multirow[t]{3}{*}{$\mathrm{D}$} & 4 & $0.85 \pm 0.01$ & 20.7 & 0.32 & $1.2 \cdot 10^{7}$ & $7-160$ & 1.50 \\
\hline & & 5 & $0.84 \pm 0.01$ & 20.3 & 0.44 & $1.2 \cdot 10^{7}$ & $7-197$ & 1.55 \\
\hline & & 8 & $0.85 \pm 0.01$ & 20.6 & 0.53 & $8.2 \cdot 10^{6}$ & $12-146$ & 1.24 \\
\hline
\end{tabular}


Table 5.2 shows the fiber content determined in the different diameter sections. As a reference, the fiber content was previously measured in the raw material in pellet form, obtaining an average of $20.5 \pm 0.1 \%$. Similar results were found in the $8 \mathrm{~mm}$ diameter section located in the middle of the solid and foamed injection-molded bars. However, at the ends of the cavity and in thinner diameters the fiber content slightly increased, especially in solid and $10 \%$ foamed bars (mean values of around $21 \%$ of fiber content). Gas expansion during foaming pushed fibers toward polymeric matrix and the surface layers. As seen before, the skin layer represents between $15 \%$ (for $\varnothing=8 \mathrm{~mm}$ ) and $17 \%(\varnothing=4$ and $5 \mathrm{~mm}$ ) of the overall cross-section thickness. Thereby, this slightly higher relative solid skin area contributed to a higher confinement of the fiber content in the thinner sections. Finally, as the shot volume decreased, the cell structure became more uniform (20\% of weight reduction), with smaller cell sizes and homogeneous cell distribution (and indeed, uniform gas expansion through the whole cross-section), the differences in fiber content were less pronounced either negligible.
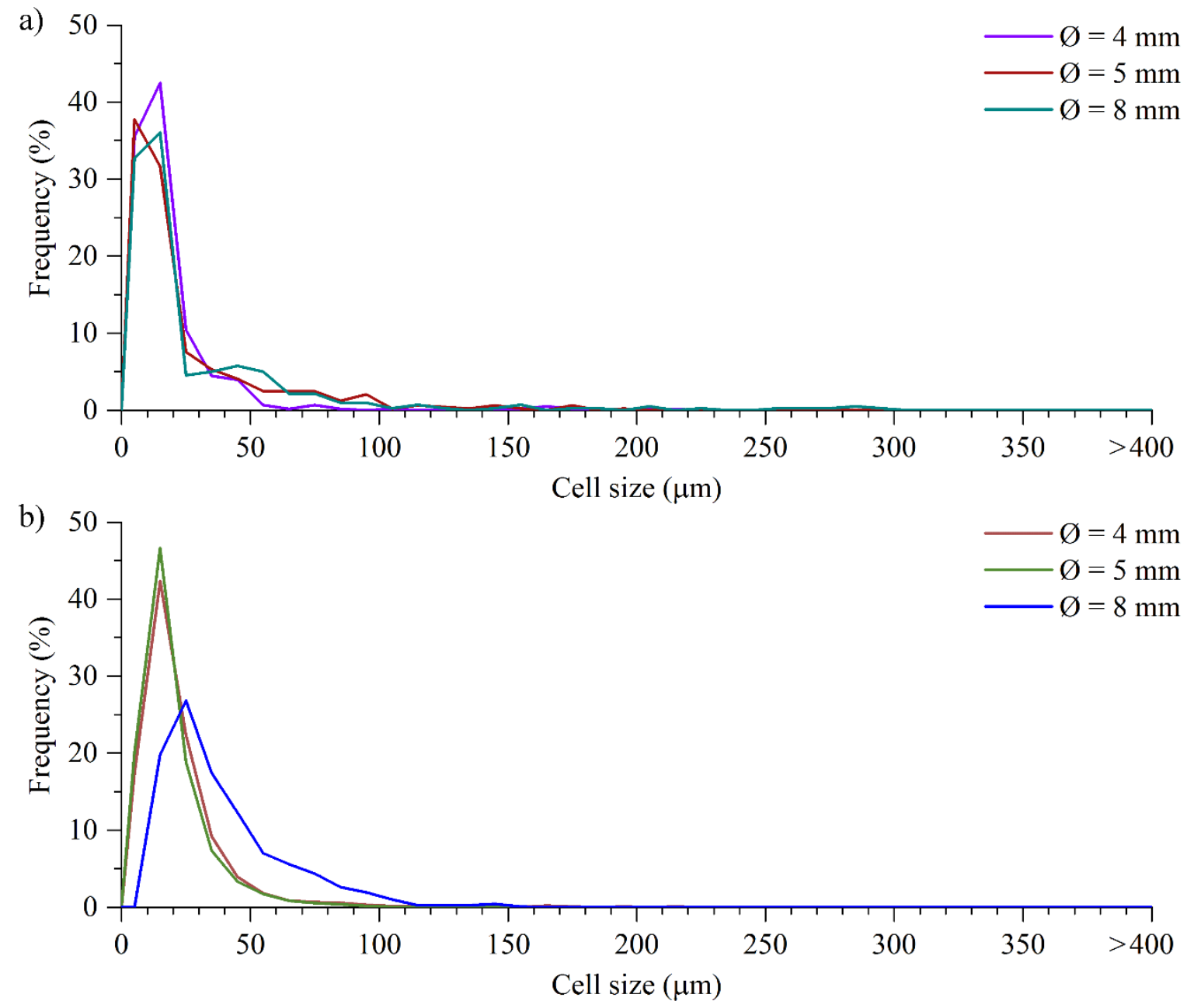

Figure 5.3. Cell size distribution in 4,5 and $8 \mathrm{~mm}$ cross-sections of PP 20GF foamed bars with a) $10 \%$ weight reduction; b) $20 \%$ weight reduction. 


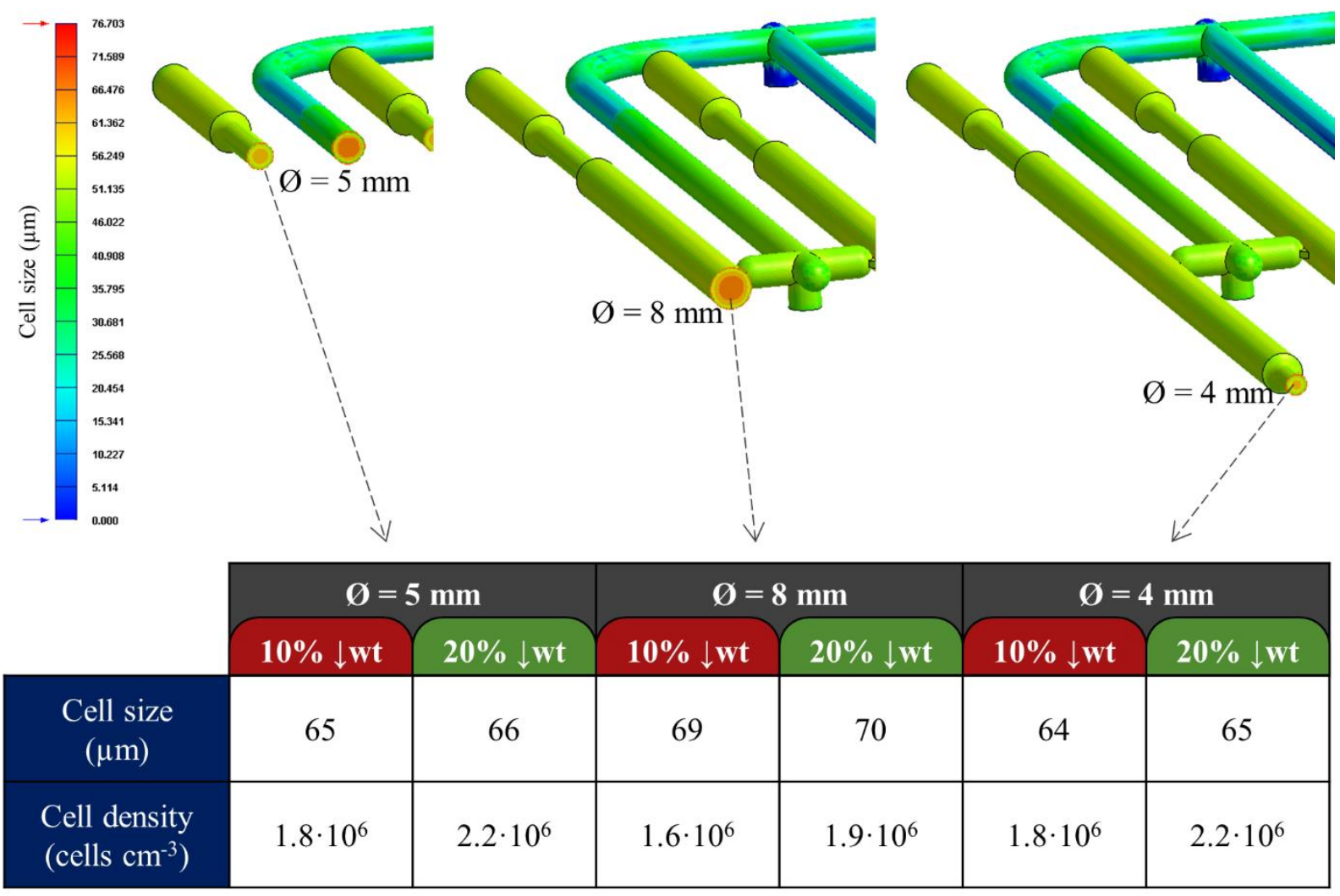

Figure 5.4. Cell size and cell density results of of PP 20GF foamed bars simulated with Moldex 3D® software.

Results obtained from Moldex 3D® simulation experiments are summarized in Figure 5.4. As previously stated with ABS cylindrical bars, numerical simulation provided comparable results of cell density and cell size to the experimental analysis for all studied sections, in this case also for $\varnothing=8 \mathrm{~mm}$.

\subsubsection{Tensile behavior}

Stress-strain curves of solid and foamed bars tested in $\varnothing=4 \mathrm{~mm}$ and $\varnothing=5 \mathrm{~mm}$ are shown in Figure 5.5. All specimens experimented brittle fracture, before reaching the yielding point and without necking. This behavior is usual in PP polymer reinforced with glass fiber due to two main reasons: on one hand, fibers restrict matrix movement and deformation [278, 279] and, on the other hand, stress concentrates at the fiber ends and the matrix cannot support the increased local load [280]. It is worth to notice in this section that most samples broke at areas near the ends of the cylindrical bars, which may be caused due to lower material packing in this zones and, in case of foamed bars, due to higher or distorted cells formed at the thickness transition region. 


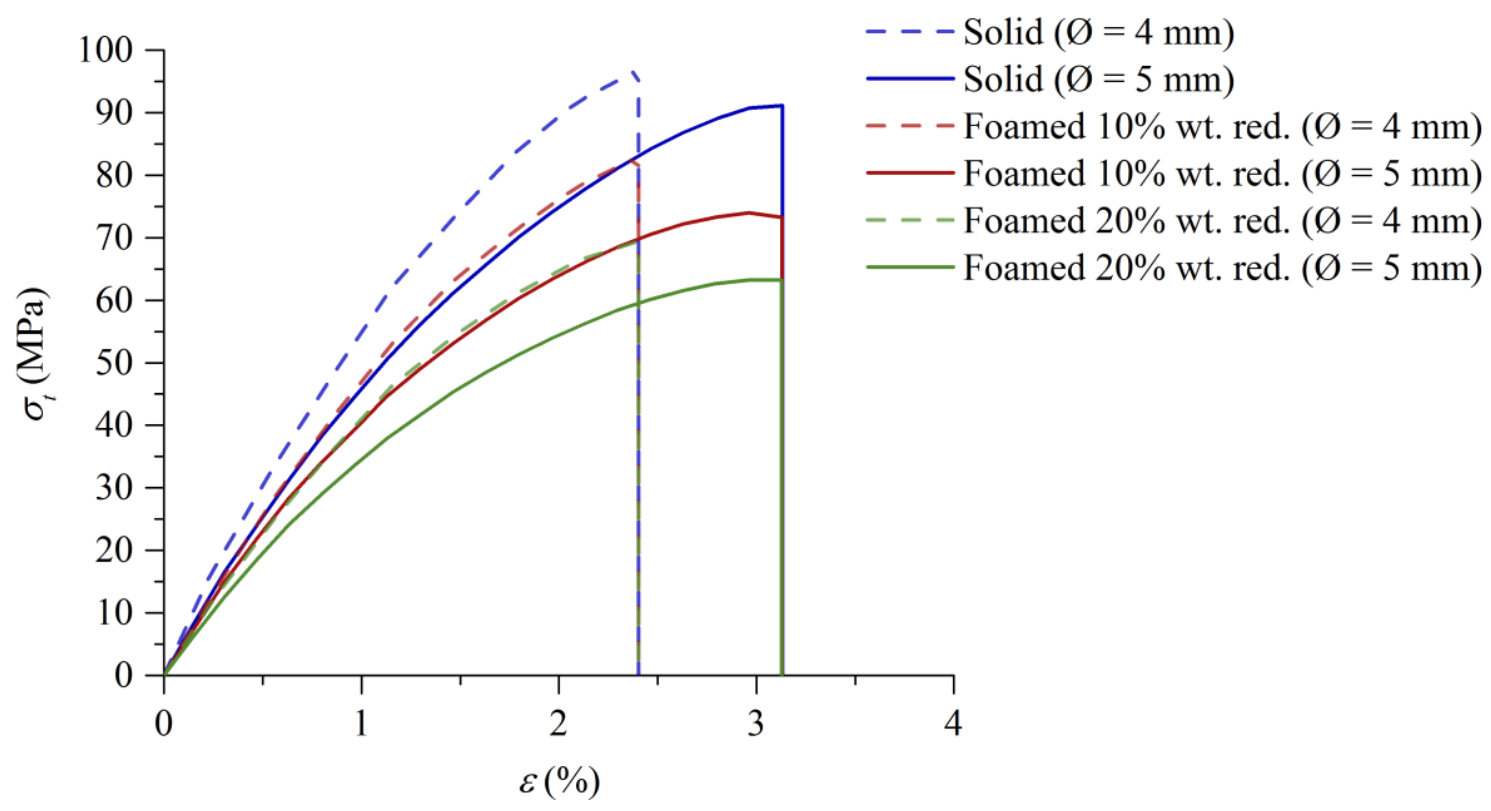

Figure 5.5. Tensile stress-strain curves of 4 and $5 \mathrm{~mm}$ diameter sections of PP 20GF solid and foamed bars.

From the stress-strain curve, it is clearly observed that foamed samples showed a lower modulus and stress values than the solid counterparts, because cells in the center effectively led to a decrease in density and effective cross-sectional area. The reduction in solid skin with increasing gas content also contributed to diminish these properties [160]. The same lowering effect of tensile properties with the foaming ratio has been found with neat PP [281] and reinforced with other kind of fillers, such as talc [158] and nanoclay [166]. The elastic modulus, ultimate strength and elongation at break values are summarized in Table 5.3. Tension load was applied in the direction of filling, where preferential fiber orientation is expected, mainly in the surface layers [282]. Thus, the morphology created in the injection molded bars of this work pointed toward maximum values of tensile properties. The elastic modulus decreased by $13 \%$ and $24 \%$ (10\% and $20 \%$ weight reduction, respectively) in samples with $\varnothing=4 \mathrm{~mm}$ and $\varnothing=5 \mathrm{~mm}$. The ultimate strength was reduced by $11 \%$ and $29 \%$ in thinner specimens, and by $19 \%$ and $30 \%$ in the thicker ones. As reported in $\mathrm{ABS}$ previously, the tensile strength experimented a greater reduction with foaming ratio than the elastic modulus. In case of PP 20GF foamed samples, glass fibers enhanced the mechanical properties because of their reinforcing effect but also by optimizing cell structure. The specific properties of elastic modulus and ultimate strength show constant values between solid and foamed samples. Considering the standard deviation obtained in yield strain, it can be assumed that the variations of this parameter at solid and foamed materials lie within the experimental accuracy for each specimen diameter (around $2.2 \%$ for $\emptyset=4 \mathrm{~mm}$, and $3.0 \%$ for $\varnothing=5 \mathrm{~mm})$. 
Table 5.3. Tensile properties in different sections of PP 20GF bars.

\begin{tabular}{|c|c|c|c|c|c|c|c|}
\hline $\begin{array}{c}\text { Condition } \\
\text { No. }\end{array}$ & Bar & $\begin{array}{c}\text { Section } \varnothing \\
(\mathbf{m m})\end{array}$ & $\begin{array}{c}E_{t} \\
(\mathbf{M P a})\end{array}$ & $\begin{array}{c}\sigma_{u} \\
(\mathbf{M P a})\end{array}$ & $\begin{array}{c}E_{t} / \rho \\
\left(\mathrm{MPa} / \mathrm{g} \mathrm{cm}^{-3}\right)\end{array}$ & $\begin{array}{c}\sigma_{u} / \rho \\
\left(\mathrm{MPa} / \mathrm{g} \mathrm{cm}^{-3}\right)\end{array}$ & $\begin{array}{c}\varepsilon_{u} \\
(\%)\end{array}$ \\
\hline \multirow[t]{8}{*}{ Solid } & \multirow[t]{2}{*}{ A } & 4 & $5049 \pm 97$ & $91.5 \pm 2.8$ & $4885 \pm 121$ & $88.5 \pm 3.2$ & $2.24 \pm 0.19$ \\
\hline & & 5 & $4717 \pm 77$ & $91.3 \pm 0.5$ & $4661 \pm 104$ & $90.2 \pm 1.0$ & $3.23 \pm 0.09$ \\
\hline & \multirow[t]{2}{*}{ B } & 4 & $4956 \pm 74$ & $92.9 \pm 2.9$ & $4809 \pm 111$ & $90.1 \pm 3.6$ & $2.27 \pm 0.17$ \\
\hline & & 5 & $4878 \pm 95$ & $91.7 \pm 1.8$ & $4793 \pm 136$ & $90.1 \pm 2.6$ & $3.08 \pm 0.21$ \\
\hline & \multirow[t]{2}{*}{$\mathrm{C}$} & 4 & $5020 \pm 89$ & $91.5 \pm 2.7$ & $4839 \pm 124$ & $88.2 \pm 3.3$ & $2.21 \pm 0.16$ \\
\hline & & 5 & $4943 \pm 89$ & $92.3 \pm 1.8$ & $4855 \pm 134$ & $90.7 \pm 2.6$ & $3.13 \pm 0.17$ \\
\hline & \multirow[t]{2}{*}{$\mathrm{D}$} & 4 & $5100 \pm 98$ & $92.5 \pm 2.7$ & $4871 \pm 126$ & $88.4 \pm 3.2$ & $2.22 \pm 0.16$ \\
\hline & & 5 & $4822 \pm 92$ & $91.9 \pm 2.8$ & $4725 \pm 116$ & $90.0 \pm 3.2$ & $3.26 \pm 0.15$ \\
\hline \multirow{8}{*}{$\begin{array}{c}\text { Foamed } \\
10 \% \mathrm{wt} . \\
\text { red. }\end{array}$} & \multirow[t]{2}{*}{$\mathrm{A}$} & 4 & $4384 \pm 99$ & $81.3 \pm 2.9$ & $4718 \pm 146$ & $87.5 \pm 3.8$ & $2.34 \pm 0.15$ \\
\hline & & 5 & $4196 \pm 99$ & $74.4 \pm 1.8$ & $4527 \pm 118$ & $80.3 \pm 2.1$ & $3.00 \pm 0.16$ \\
\hline & \multirow[t]{2}{*}{ B } & 4 & $4422 \pm 94$ & $82.0 \pm 2.3$ & $4792 \pm 183$ & $88.8 \pm 4.0$ & $2.52 \pm 0.17$ \\
\hline & & 5 & $4179 \pm 78$ & $73.5 \pm 0.8$ & $4559 \pm 102$ & $80.2 \pm 1.2$ & $3.09 \pm 0.15$ \\
\hline & \multirow[t]{2}{*}{$\mathrm{C}$} & 4 & $4280 \pm 94$ & $81.2 \pm 2.6$ & $4611 \pm 144$ & $87.5 \pm 3.6$ & $2.42 \pm 0.19$ \\
\hline & & 5 & $4222 \pm 83$ & $73.0 \pm 0.9$ & $4584 \pm 116$ & $79.3 \pm 1.4$ & $2.97 \pm 0.09$ \\
\hline & \multirow[t]{2}{*}{$\mathrm{D}$} & 4 & $4318 \pm 98$ & $81.2 \pm 1.2$ & $4613 \pm 144$ & $86.7 \pm 2.0$ & $2.59 \pm 0.18$ \\
\hline & & 5 & $4240 \pm 82$ & $73.8 \pm 0.2$ & $4558 \pm 121$ & $79.4 \pm 0.8$ & $2.90 \pm 0.12$ \\
\hline \multirow{8}{*}{$\begin{array}{c}\text { Foamed } \\
20 \% \text { wt. } \\
\text { red. }\end{array}$} & \multirow[t]{2}{*}{ A } & 4 & $3815 \pm 70$ & $64.8 \pm 2.6$ & $4617 \pm 134$ & $78.4 \pm 4.0$ & $2.09 \pm 0.12$ \\
\hline & & 5 & $3609 \pm 85$ & $62.6 \pm 1.9$ & $4352 \pm 141$ & $75.5 \pm 2.9$ & $2.83 \pm 0.14$ \\
\hline & \multirow[t]{2}{*}{ B } & 4 & $3734 \pm 50$ & $65.1 \pm 2.1$ & $4529 \pm 109$ & $78.9 \pm 3.4$ & $2.22 \pm 0.17$ \\
\hline & & 5 & $3627 \pm 99$ & $63.9 \pm 1.0$ & $4422 \pm 173$ & $77.9 \pm 2.2$ & $3.06 \pm 0.09$ \\
\hline & \multirow[t]{2}{*}{$\mathrm{C}$} & 4 & $3834 \pm 83$ & $65.5 \pm 2.4$ & $4625 \pm 170$ & $79.0 \pm 4.0$ & $2.09 \pm 0.10$ \\
\hline & & 5 & $3627 \pm 73$ & $62.9 \pm 1.7$ & $4399 \pm 118$ & $76.0 \pm 2.5$ & $2.92 \pm 0.09$ \\
\hline & \multirow[t]{2}{*}{$\mathrm{D}$} & 4 & $3830 \pm 94$ & $64.9 \pm 2.1$ & $4507 \pm 142$ & $76.4 \pm 3.1$ & $2.10 \pm 0.11$ \\
\hline & & 5 & $3643 \pm 95$ & $64.1 \pm 1.3$ & $4330 \pm 160$ & $76.2 \pm 2.4$ & $3.06 \pm 0.12$ \\
\hline
\end{tabular}


The elastic modulus, as well as the ultimate strength, was higher in samples with $\varnothing=4$ $\mathrm{mm}$ than specimens with $\emptyset=5 \mathrm{~mm}$. In the morphology results section it has been pointed out the slightly higher fiber content in the smaller diameter section. Moreover, it was demonstrated that thinner sections promote a higher alignment of the fibers in the longitudinal direction [283]. Both effects could lead to the better modulus and stress properties but lower elongation at break obtained in the $4 \mathrm{~mm}$ diameter section.

Applying the Single Blend model of Equation (4.1) [51, 222] with average values of density and tensile properties, the estimated elastic modulus of foamed samples with $10 \%$ and $20 \%$ for $\varnothing=4 \mathrm{~mm}$ were $4547 \mathrm{MPa}$ and $4063 \mathrm{MPa}$, respectively. Although both values overestimate the ones obtained from experimental tests, the maximum deviation was lower than $7 \%$. In case of $\varnothing=5 \mathrm{~mm}$, the elastic modulus values provided by the model were 4374 MPa and 3909 MPa for both levels of weight reduction, which are equally accurate with regard to the experimental data.

Concerning tensile strength, $\mathrm{Xu}$ and Kishbaugh [223] modified the model presented in Equations (4.2) and (4.3) for filled polymers. The tensile strength of foamed PP 20GF can be estimated through the addition of a new variable, the real weight reduction ratio of the core material without fillers $R_{g f}$, calculated as follows:

$$
R_{g f}=\frac{\rho_{s}-(1-R) \rho_{s f}\left(1-W_{g f} R_{w}\right)}{\rho_{s}}
$$

Where $\rho_{s}$ and $\rho_{s f}$ are the apparent density of neat and filled solid material, respectively, $R$ is the ratio of weight reduction for foamed core given by Equation (4.3), $W_{g f}$ is the fiber content ratio (0.2) and $R_{w}$ weight reduction ratio of the whole microcellular part (0.9 and 0.8 in this study). Then, Equation (4.2) is derived to determine the tensile strength of foamed filled polymers $\left(\sigma_{t f}\right)$ from the tensile strength of the solid one $\left(\sigma_{t s}\right)$ :

$$
\frac{\sigma_{t f}}{\sigma_{t s}}=\frac{\pi r^{2}-\pi\left(r-t_{s}\right)^{2}+\left(1-R_{g f}\right)^{1.2} \pi\left(r-t_{s}\right)^{2}}{\pi r^{2}}
$$

Taking average values of skin thickness $\left(t_{s}\right)$, the resulted tensile strength of foamed bars with $10 \%$ and $20 \%$ ratios of weight reduction and $\varnothing=4 \mathrm{~mm}$ was $67.7 \mathrm{MPa}$ and $61.5 \mathrm{MPa}$, while it was $68.4 \mathrm{MPa}$ and $62.4 \mathrm{MPa}$ for $\varnothing=5 \mathrm{~mm}$. These values are closer to experimental data for foamed series of $20 \%$ of weight reduction, but slightly less accurate in case of $10 \%$, with a maximum error of $16 \%$. In composite materials, the mechanical performance depends 
on additional factors like fiber length and orientation distributions and stress transfer from material matrix to fillers, so implementation of estimation models for predicting mechanical properties is complex and is subject to certain margins of error. Therefore, equations employed before can be considered valid as an approach to assess the tensile strength of microcellular injection molded composites.

\subsection{Square plates}

\subsubsection{Design of Experiments: Effect of processing conditions}

The effect of shot size, mold temperature and injection speed on PP 20GF foams was assessed by analyzing the morphology and flexural properties of the molded square plates, both in the parallel (MD) and transversal (TD) directions to the injection flow.

\subsubsection{Morphology}

Figure 5.6, Figure 5.7 and Figure 5.8, illustrate SEM pictures taken from the center position of the square plates in $\mathrm{MD}$ and $\mathrm{TD}$ directions for all injection molding series (sections MD-B and TD-B, respectively). All surfaces exhibit the solid skin/foamed core structure, which is inherent to the molding process. Fibers contained in the solid surface layers seemed to be highly aligned in the horizontal plane, while fibers in the foamed core appeared randomly oriented due to fountain flow and gas expansion [159]. On the other hand, cells near the skins in MD direction were slightly elongated because of shear stress induced by melt flow during the filling along the mold cavity, whereas they kept a mainly spherical shape in the opposite direction (TD), although C0, C5 and C7 conditions contained some bigger and distorted cells which might be caused by cell coalescence.

In contrast to that previously reported with ABS, samples molded under high shot volume and low gas content seem to present finer cell size. The morphological parameters contained in Table 5.4 support this observation. While cell density remained in the same order for all foamed conditions $\left(10^{6}\right.$ cells $\left.\mathrm{cm}^{-3}\right)$, maximum cell size was higher in those with $20 \%$ of weight reduction. Consequently, lower uniformities in cell distribution and higher CDI values were determined. Despite the fact that fibers increased melt strength and viscosity of the system [284], it could be not enough to bear extensional forces promoted by gas expansion, restrict cell growth and prevent cell coalescence with the increase in gas content levels. Nonetheless, the presence of larger cells was occasional because cell size distributions show very similar curves for all foamed series, as depicted in Figure 5.9. 


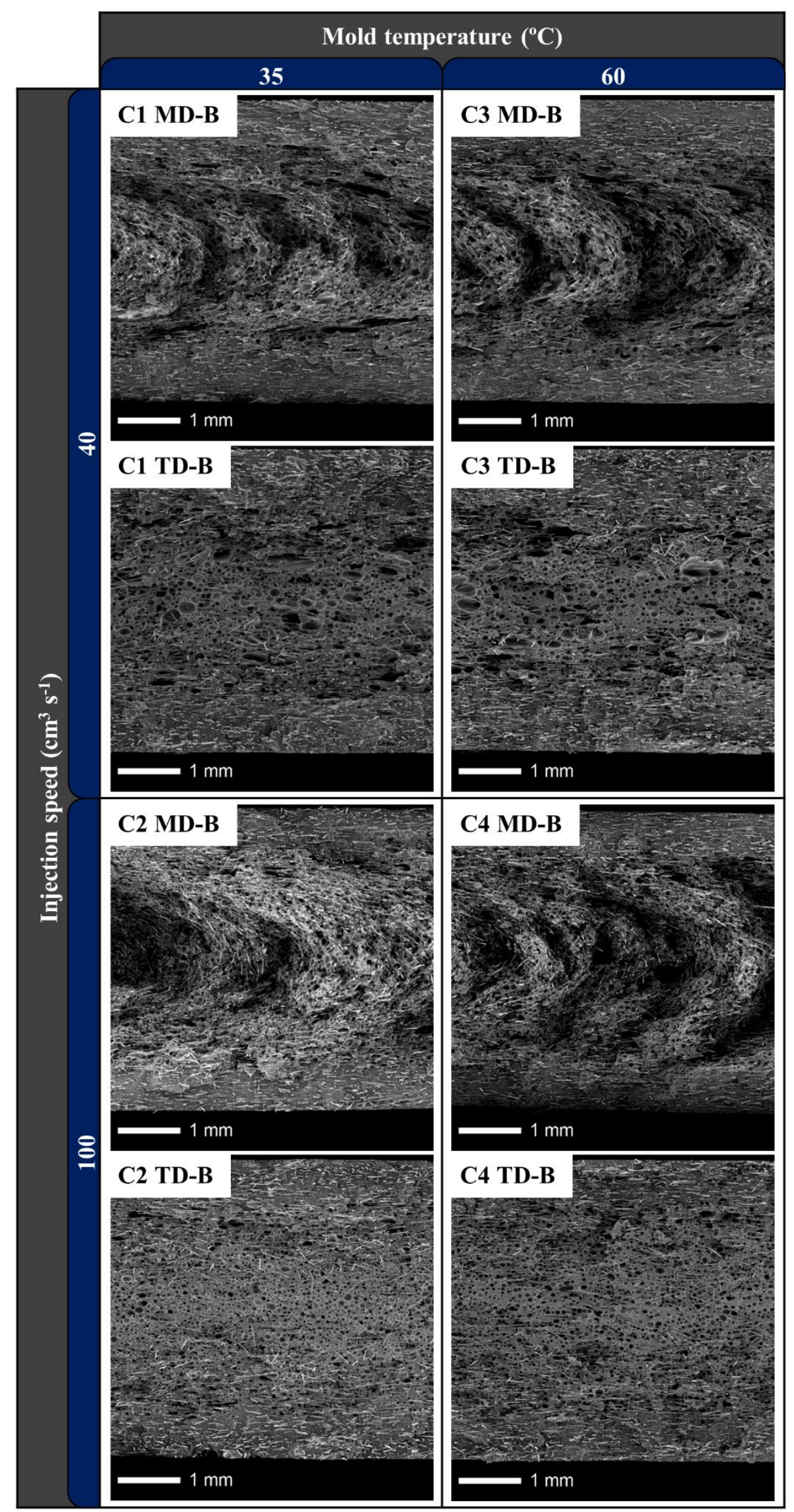

Figure 5.6. SEM micrographs of $\mathrm{C} 1-\mathrm{C} 4$ conditions. Shot volume: $51.2 \mathrm{~cm}^{3}$ (10\% weight reduction). 


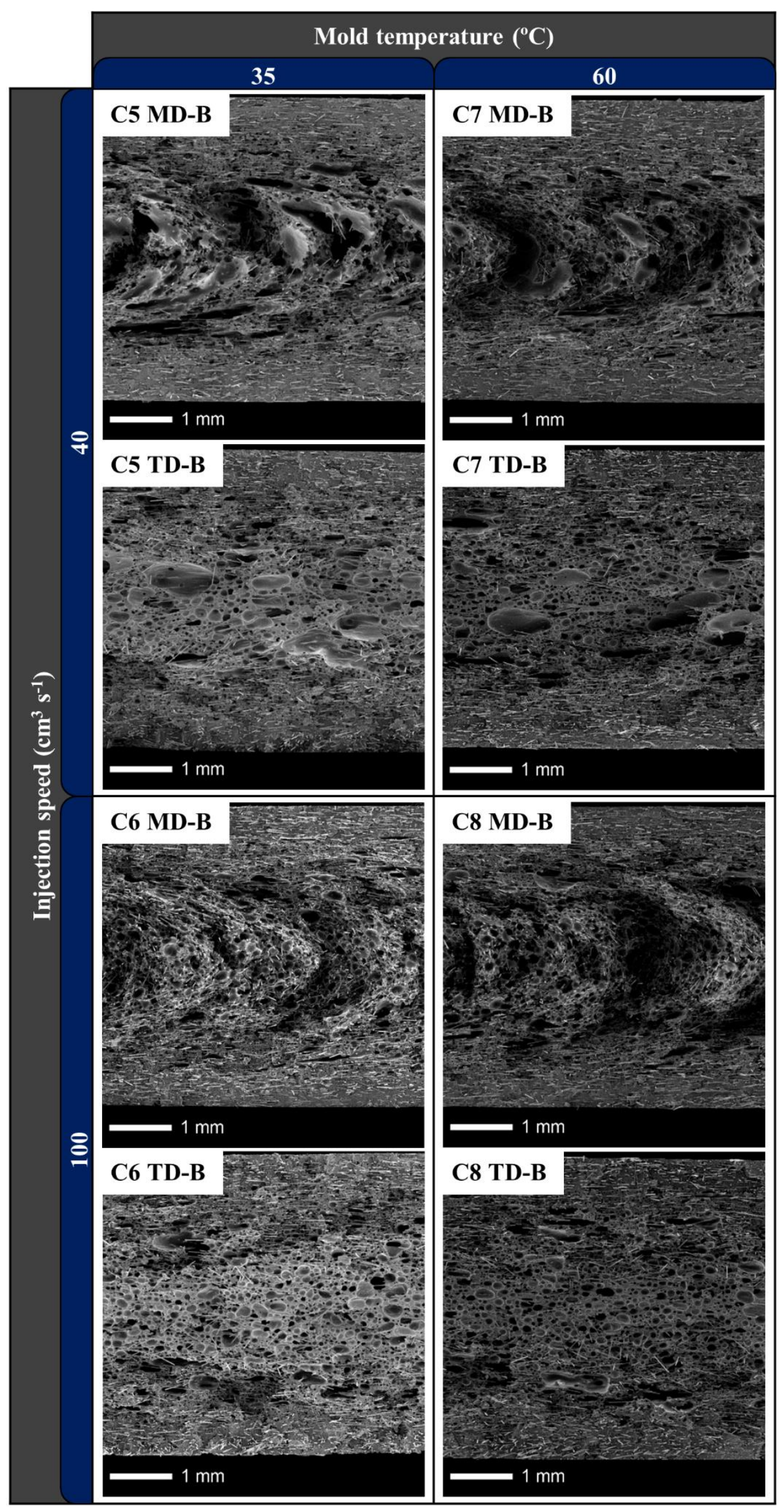

Figure 5.7. SEM micrographs of $\mathrm{C} 5-\mathrm{C} 8$ conditions. Shot volume: $45.3 \mathrm{~cm}^{3}$ ( $20 \%$ weight reduction). 
Table 5.4. Weight reduction ratio, apparent density and morphological parameters of PP 20GF foamed samples.

\begin{tabular}{|c|c|c|c|c|c|c|c|}
\hline $\begin{array}{c}\text { Condition } \\
\text { No. }\end{array}$ & Section & $\begin{array}{c}\text { Weight } \\
\text { reduction } \\
(\%)\end{array}$ & $\begin{array}{l}\text { Density } \\
\left(\mathrm{g} \mathrm{cm}^{-3}\right)\end{array}$ & $\begin{array}{c}\text { Skin } \\
\text { thickness } \\
(\mathbf{m m})\end{array}$ & $\begin{array}{c}\text { Cell } \\
\text { density } \\
\left(\text { cells } \mathbf{c m}^{-3}\right)\end{array}$ & $\begin{array}{c}\text { Cell size } \\
\text { range } \\
(\mu \mathrm{m})\end{array}$ & CDI \\
\hline \multirow[t]{2}{*}{$\mathrm{C} 1$} & MD-B & $10.16 \pm 0.23$ & $0.88 \pm 0.01$ & 0.71 & $3.1 \cdot 10^{6}$ & $8-188$ & 1.63 \\
\hline & TD-B & & & 0.76 & $3.5 \cdot 10^{6}$ & $6-135$ & 1.36 \\
\hline \multirow[t]{2}{*}{$\mathrm{C} 2$} & MD-B & $10.49 \pm 0.24$ & $0.88 \pm 0.01$ & 0.64 & $8.1 \cdot 10^{6}$ & $5-132$ & 1.39 \\
\hline & TD-B & & & 0.66 & $4.4 \cdot 10^{6}$ & $10-138$ & 1.25 \\
\hline \multirow[t]{2}{*}{$\mathrm{C} 3$} & MD-B & $10.34 \pm 0.38$ & $0.88 \pm 0.01$ & 0.73 & $3.4 \cdot 10^{6}$ & $7-155$ & 1.49 \\
\hline & TD-B & & & 0.72 & $2.9 \cdot 10^{6}$ & $10-171$ & 1.34 \\
\hline \multirow[t]{2}{*}{$\mathrm{C} 4$} & MD-B & $10.42 \pm 0.25$ & $0.88 \pm 0.01$ & 0.57 & $1.3 \cdot 10^{7}$ & $5-84$ & 1.41 \\
\hline & TD-B & & & 0.58 & $3.7 \cdot 10^{6}$ & $8-118$ & 1.29 \\
\hline \multirow[t]{2}{*}{$\mathrm{C} 5$} & MD-B & $19.70 \pm 0.27$ & $0.79 \pm 0.01$ & 0.59 & $3.4 \cdot 10^{6}$ & $4-240$ & 1.89 \\
\hline & TD-B & & & 0.58 & $1.6 \cdot 10^{6}$ & $2-248$ & 1.80 \\
\hline \multirow[t]{2}{*}{ C6 } & MD-B & $19.99 \pm 0.34$ & $0.78 \pm 0.01$ & 0.50 & $4.9 \cdot 10^{6}$ & $7-161$ & 1.65 \\
\hline & TD-B & & & 0.51 & $3.8 \cdot 10^{6}$ & $9-200$ & 1.57 \\
\hline \multirow[t]{2}{*}{$\mathrm{C} 7$} & MD-B & $19.69 \pm 0.19$ & $0.79 \pm 0.01$ & 0.55 & $4.8 \cdot 10^{6}$ & $7-175$ & 1.65 \\
\hline & TD-B & & & 0.56 & $4.8 \cdot 10^{6}$ & $7-254$ & 1.56 \\
\hline \multirow[t]{2}{*}{$\mathrm{C} 8$} & MD-B & $20.25 \pm 0.41$ & $0.78 \pm 0.01$ & 0.53 & $5.0 \cdot 10^{6}$ & $7-152$ & 1.54 \\
\hline & TD-B & & & 0.52 & $2.8 \cdot 10^{6}$ & $8-178$ & 1.53 \\
\hline \multirow[t]{2}{*}{$\mathrm{C} 0$} & MD-B & $14.99 \pm 0.26$ & $0.83 \pm 0.01$ & 0.59 & $5.5 \cdot 10^{6}$ & $7-216$ & 1.77 \\
\hline & TD-B & & & 0.56 & $4.4 \cdot 10^{6}$ & $7-251$ & 1.64 \\
\hline
\end{tabular}

Here, narrower curves are observed in MD direction and wider distributions in TD, although $90 \%$ of cells were contained in the microcellular range in all cases (cells smaller than $100 \mu \mathrm{m})$. Skin thickness decreased with decreasing shot volume and increasing supercritical fluid concentrations (Table 5.4), as was observed with ABS.

Additional differences in morphology due to injection molding parameters are discussed below. It must be noticed that quantitative morphological parameters have been calculated 
from the examination of "good" local regions of the samples with uniform cell structures at x50 magnification. Moreover, fibers might hide cells and difficult image analysis to measure number and area of bubbles. Therefore, they should be handled with care for comparison purposes.
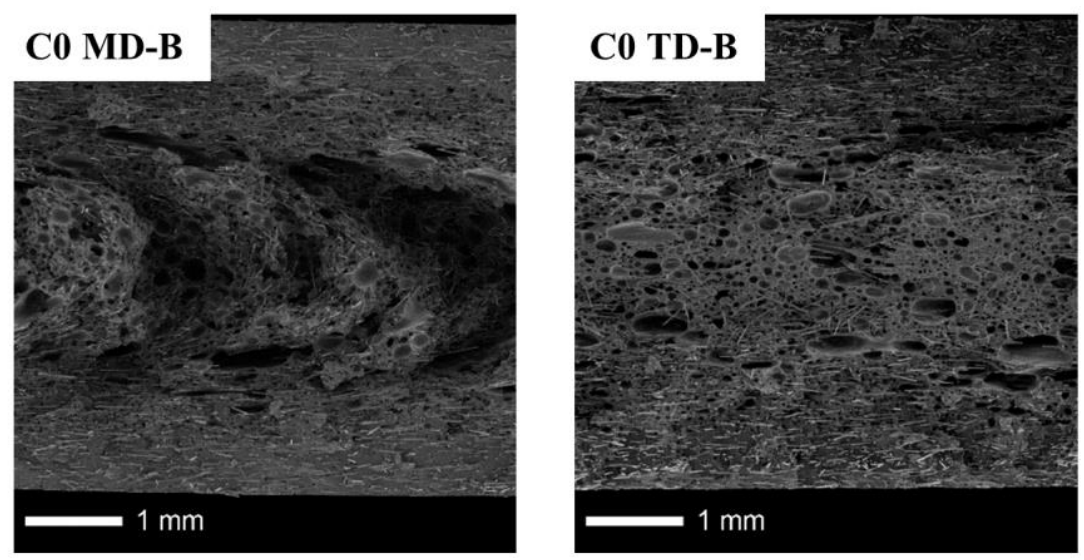

Figure 5.8. SEM micrographs of $\mathrm{C} 0$ condition. Shot volume: $48.3 \mathrm{~cm}^{3}$ (15\% weight reduction).
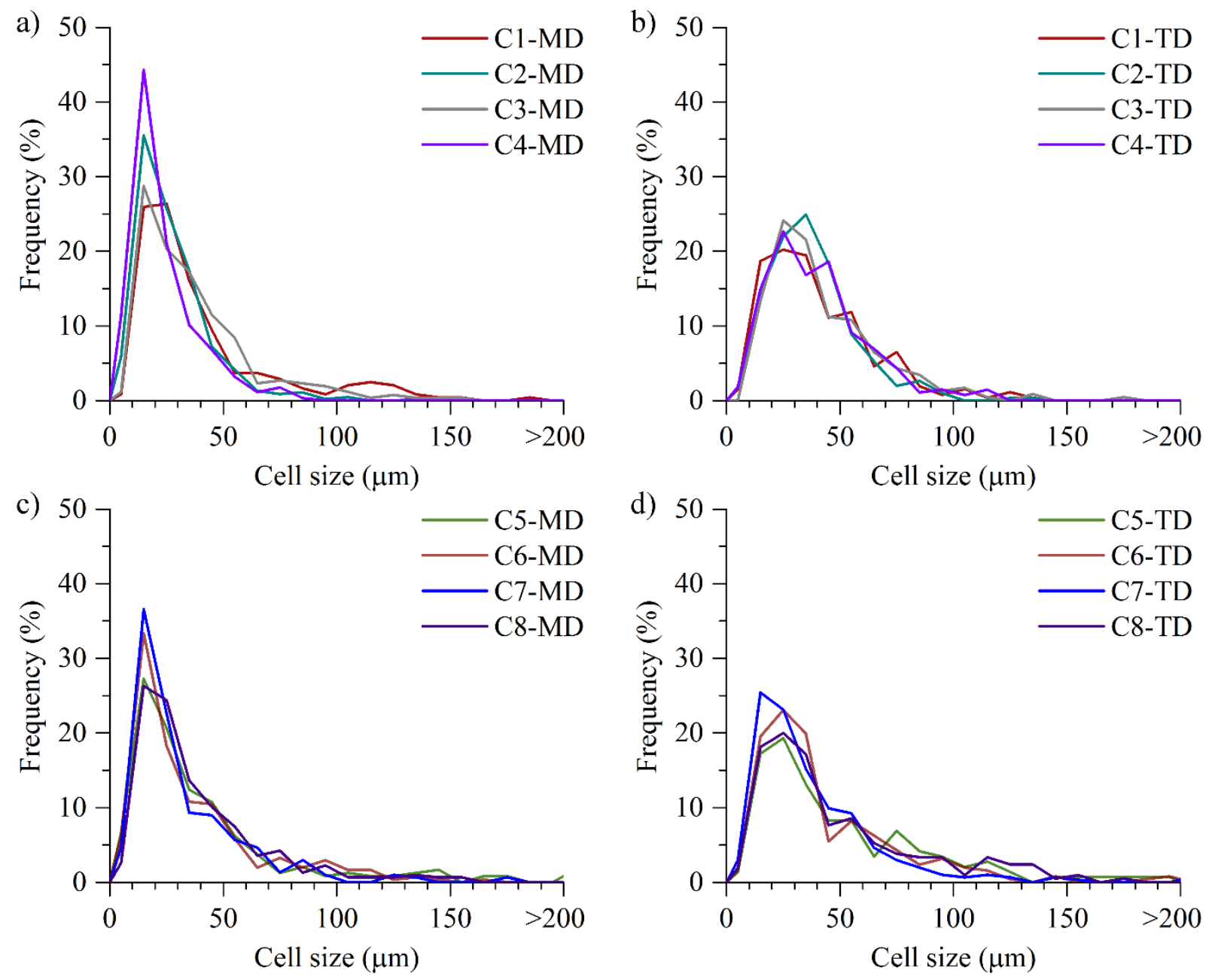

Figure 5.9. Cell size distribution of a) C1-C4 conditions in MD-B; b) C1-C4 conditions in TD; c) C5-C8 conditions in MD; d) C5-C8 conditions in TD-B. 


\subsubsection{Flexural behavior}

Figure 5.10 outlines flexural stress-strain curves of solid and foamed samples in MD and TD directions. All samples broke after reaching the maximum load. Table 5.5 shows the flexural modulus and strength obtained from testing specimens in different positions and orientations of the square plates. As expected, the highest flexural properties were achieved at the highest shot size corresponding to less weight reduction. From these values it can be seen that samples tooled in MD direction and from the extreme positions of the plates (MD-A and MD-C) were the stiffest and strongest, while the specimen of the middle sections (MD-B) indicated a flexural modulus and strength closer to the ones determined in the transversal orientation (TD-A, TD-B and TD-C). This statement could be related to the fiber orientation pattern reported in early studies [285], which attributes a preferential alignment of fibers in the filling direction at side positions and in the transverse direction in the middle location. Further study on fiber orientation is developed in the extended morphology analysis of the next sections.

Fiber filled composites are characterized by a remarked anisotropy in the mechanical properties [172]. The average values of flexural modulus and strength in the extreme positions (MD-A and MD-C) of solid samples differed from that of the opposite orientation (average results of TD-A, TD-B and TD-C specimens) in around 20\%. In case of foamed samples, these differences were increased up to $30 \%$. Therefore, microcellular square plates processed in this study presented a slightly increase in the anisotropic behavior. It is also related to fiber orientation due to the injection process, so differences in flexural properties according to sample position and orientation will be discussed in detail later on in this work.
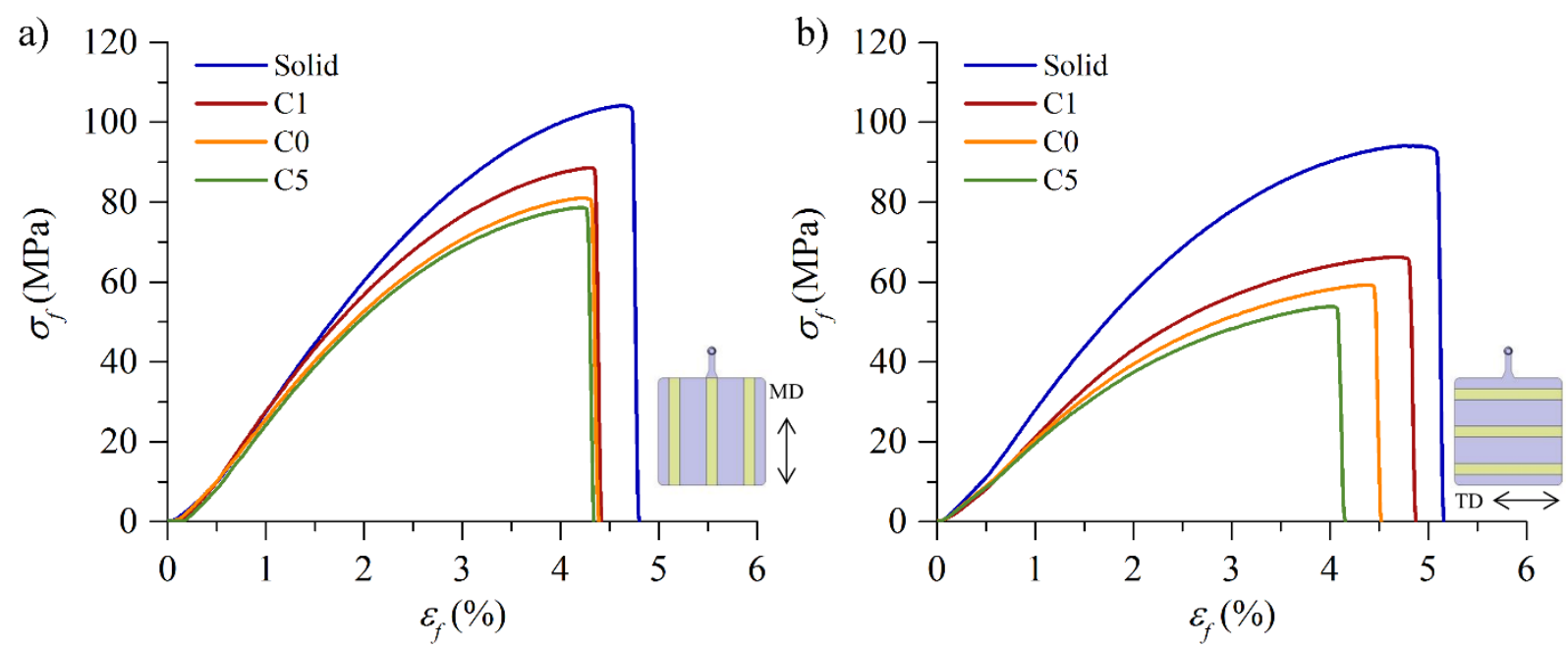

Figure 5.10. Flexural stress-strain curves of PP 20GF solid and foamed samples (C1, C0 and C5 conditions) in a) $\mathrm{MD}$; b) TD directions. 
Table 5.5. Flexural properties of PP 20GF solid and foamed samples.

\begin{tabular}{|c|c|c|c|c|c|c|c|}
\hline $\begin{array}{c}\text { Condition } \\
\text { No. }\end{array}$ & Section & $\begin{array}{c}E_{f} \\
(\mathrm{MPa})\end{array}$ & $\begin{array}{c}\sigma_{f} \\
(\mathbf{M P a})\end{array}$ & $\begin{array}{c}\text { Condition } \\
\text { No. }\end{array}$ & Section & $\begin{array}{c}E_{f} \\
(\mathbf{M P a})\end{array}$ & $\begin{array}{c}\sigma_{f} \\
(\mathbf{M P a})\end{array}$ \\
\hline \multirow[t]{6}{*}{ Solid } & MD-A & $3851 \pm 41$ & $87.0 \pm 2.4$ & $\mathrm{CO}$ & MD-A & $3340 \pm 61$ & $79.2 \pm 1.4$ \\
\hline & MD-B & $3267 \pm 52$ & $86.6 \pm 1.0$ & & MD-B & $2595 \pm 54$ & $60.7 \pm 1.1$ \\
\hline & MD-C & $3903 \pm 61$ & $91.6 \pm 2.2$ & & MD-C & $3314 \pm 80$ & $78.6 \pm 1.8$ \\
\hline & TD-A & $3138 \pm 88$ & $102.0 \pm 1.6$ & & TD-A & $2256 \pm 74$ & $57.5 \pm 1.1$ \\
\hline & TD-B & $3002 \pm 76$ & $79.4 \pm 2.4$ & & TD-B & $2307 \pm 96$ & $55.3 \pm 1.5$ \\
\hline & TD-C & $3196 \pm 90$ & $102.8 \pm 2.0$ & & TD-C & $2357 \pm 92$ & $59.1 \pm 2.4$ \\
\hline \multirow[t]{6}{*}{$\mathrm{C} 1$} & MD-A & $3702 \pm 59$ & $88.8 \pm 1.0$ & $\mathrm{C} 2$ & MD-A & $3482 \pm 86$ & $83.2 \pm 1.6$ \\
\hline & MD-B & $2888 \pm 68$ & $66.6 \pm 0.6$ & & MD-B & $2553 \pm 39$ & $60.7 \pm 1.1$ \\
\hline & MD-C & $3614 \pm 91$ & $87.8 \pm 2.6$ & & MD-C & $3347 \pm 54$ & $81.3 \pm 1.9$ \\
\hline & TD-A & $2500 \pm 81$ & $65.5 \pm 0.4$ & & TD-A & $2437 \pm 34$ & $65.4 \pm 0.7$ \\
\hline & TD-B & $2333 \pm 85$ & $60.9 \pm 0.9$ & & TD-B & $2364 \pm 35$ & $61.8 \pm 1.2$ \\
\hline & TD-C & $2595 \pm 83$ & $66.3 \pm 1.1$ & & TD-C & $2567 \pm 29$ & $65.5 \pm 0.9$ \\
\hline \multirow[t]{6}{*}{ C3 } & MD-A & $3550 \pm 94$ & $85.3 \pm 2.9$ & $\mathrm{C} 4$ & MD-A & $3507 \pm 30$ & $84.3 \pm 1.3$ \\
\hline & MD-B & $2732 \pm 40$ & $64.1 \pm 1.0$ & & MD-B & $2583 \pm 58$ & $61.4 \pm 0.7$ \\
\hline & MD-C & $3450 \pm 92$ & $82.0 \pm 1.0$ & & MD-C & $3430 \pm 53$ & $82.9 \pm 1.4$ \\
\hline & TD-A & $2382 \pm 38$ & $61.5 \pm 0.7$ & & TD-A & $2480 \pm 54$ & $65.9 \pm 0.6$ \\
\hline & TD-B & $2306 \pm 60$ & $58.1 \pm 2.5$ & & TD-B & $2432 \pm 61$ & $63.6 \pm 1.4$ \\
\hline & TD-C & $2556 \pm 53$ & $63.7 \pm 2.2$ & & TD-C & $2627 \pm 64$ & $65.6 \pm 1.4$ \\
\hline \multirow[t]{6}{*}{$\mathrm{C} 5$} & MD-A & $3287 \pm 56$ & $78.8 \pm 1.0$ & C6 & MD-A & $3207 \pm 65$ & $74.8 \pm 2.7$ \\
\hline & MD-B & $2530 \pm 47$ & $59.0 \pm 0.7$ & & MD-B & $2365 \pm 58$ & $55.0 \pm 0.9$ \\
\hline & MD-C & $3205 \pm 33$ & $76.8 \pm 1.1$ & & MD-C & $3231 \pm 66$ & $75.9 \pm 0.3$ \\
\hline & TD-A & $2062 \pm 41$ & $52.2 \pm 0.9$ & & TD-A & $2037 \pm 28$ & $48.7 \pm 1.5$ \\
\hline & TD-B & $2038 \pm 88$ & $50.6 \pm 2.3$ & & TD-B & $2049 \pm 67$ & $52.3 \pm 0.9$ \\
\hline & TD-C & $2266 \pm 49$ & $55.6 \pm 2.4$ & & TD-C & $2180 \pm 62$ & $55.4 \pm 2.2$ \\
\hline
\end{tabular}


Table 5.5. Continued.

\begin{tabular}{cccccccc}
\hline $\begin{array}{c}\text { Condition } \\
\text { No. }\end{array}$ & Section & $\begin{array}{c}\boldsymbol{E}_{f} \\
(\mathbf{M P a})\end{array}$ & $\begin{array}{c}\boldsymbol{\sigma}_{f} \\
(\mathbf{M P a})\end{array}$ & $\begin{array}{c}\text { Condition } \\
\text { No. }\end{array}$ & Section & $\begin{array}{c}\boldsymbol{E}_{f} \\
(\mathbf{M P a})\end{array}$ & $\begin{array}{c}\boldsymbol{\sigma}_{f} \\
(\mathbf{M P a})\end{array}$ \\
\hline C7 & MD-A & $3156 \pm 91$ & $76.4 \pm 1.0$ & C8 & MD-A & $3190 \pm 20$ & $76.5 \pm 1.1$ \\
& MD-B & $2524 \pm 45$ & $59.9 \pm 0.8$ & & MD-B & $2375 \pm 44$ & $55.5 \pm 0.9$ \\
& MD-C & $3082 \pm 99$ & $75.9 \pm 2.9$ & & MD-C & $3152 \pm 13$ & $75.2 \pm 1.1$ \\
& TD-A & $1984 \pm 44$ & $49.1 \pm 1.6$ & & TD-A & $1981 \pm 34$ & $51.2 \pm 0.5$ \\
& TD-B & $2034 \pm 27$ & $51.0 \pm 1.1$ & & TD-B & $2015 \pm 23$ & $51.3 \pm 1.8$ \\
& TD-C & $2181 \pm 53$ & $52.6 \pm 1.1$ & & TD-C & $2089 \pm 89$ & $52.5 \pm 3.0$ \\
\hline
\end{tabular}

\subsubsection{Factorial analysis}

Data collected from morphological analysis and flexural tests was analyzed with Minitab® software according to the design of experiments. This method allows the identification of the effect of several factors on different responses simultaneously. As conducted with ABS previously, regression models, ANOVA tables, main effects and interactions between factors were determined and analyzed. First, the Backward method of regression stepwise technique was applied so as to release degrees of freedom from the models, with a significance level of $\alpha=0.05$. Table 5.6 display the regression models derived from testing microcellular square plates. Factors with the smallest contribution of each response were removed.

Variance analysis was carried out through the ANOVA statistical tool. By comparing $F$ value and p-value parameters it is possible to analyze how much the factors influence the responses. Table 5.7 shows the ANOVA results for cell density in MD direction. There, high value of $F$-value of injection speed indicates large influence of it on cell density, and a $p$ value lower than the confidence level points out a significant interaction between shot volume and injection speed. The irrelevance of curvature effect of the factors could be also confirmed by ANOVA analysis. The ANOVA tables obtained for the rest of response variables can be found in Appendix B. 
Table 5.6. Regression models derived from factorial design analysis of PP 20GF square plates.

\section{Response}

\section{Regression model}

\section{(A: Shot volume; B: Mold temperature; C: Injection speed)}

Weight reduction Weight reduction $(\%)=15.1144-4.7775 \mathrm{~A}+0.1575 \mathrm{C}$

Skin thickness Skin thickness MD-B $(\mathrm{mm})=0.6025+0.0604 \mathrm{~A}-0.0424 \mathrm{C}$

Skin thickness TD-B $(\mathrm{mm})=0.6037+0.0667 \mathrm{~A}-0.0444 \mathrm{C}$

Cell density Cell density MD-B $\left(\right.$ cells $\left.\cdot \mathrm{cm}^{-3}\right)=5691430+1191342 \mathrm{~A}+2026106 \mathrm{C}+$ $1608256 \mathrm{~A} \cdot \mathrm{C}$

Cell density TD-B $\left(\right.$ cells $\left.\cdot \mathrm{cm}^{-3}\right)=5540518+130596 \mathrm{~A}+233494 \mathrm{C}-$ $1327201 \mathrm{~A} \cdot \mathrm{C}$

Max. cell size $\quad$ Max. cell size MD-B $(\mu \mathrm{m})=160.82-20.97 \mathrm{~A}-19.44 \mathrm{~B}-28.66 \mathrm{C}$

Max. cell size TD-B $(\mu \mathrm{m})=180.45-39.81 \mathrm{~A}+0.01 \mathrm{~B}-21.92 \mathrm{C}$

CDI $\quad C D I \mathrm{MD}-\mathrm{B}=1.58-0.10 \mathrm{~A}-0.06 \mathrm{~B}-0.082 \mathrm{~B}+0.028 \mathrm{~A} \cdot \mathrm{B}+0.036 \mathrm{~B} \cdot \mathrm{C}$

CDI TD-B $=1.4826-0.1538 \mathrm{~A}$

$E_{f} \quad E_{f} \mathrm{MD}-\mathrm{A}(\mathrm{MPa})=3380.1+175.1 \mathrm{~A}$

$E_{f} \mathrm{MD}-\mathrm{B}(\mathrm{MPa})=2571.1+120.3 \mathrm{~A}-99.7 \mathrm{C}$

$E_{f} \mathrm{MD}-\mathrm{C}(\mathrm{MPa})=3313.8+146 \mathrm{~A}$

$E_{f} \mathrm{TD}-\mathrm{A}(\mathrm{MPa})=2235.4+216.9 \mathrm{~A}$

$E_{f} \mathrm{TD}-\mathrm{B}(\mathrm{MPa})=2208.7+162.4 \mathrm{~A}$

$E_{f} \mathrm{TD}-\mathrm{C}(\mathrm{MPa})=2379.8+203.6 \mathrm{~A}$

$\sigma_{f}$

$\sigma_{f} \mathrm{MD}-\mathrm{A}(\mathrm{MPa})=80.811+4.388 \mathrm{~A}-0.387 \mathrm{~B}-1.313 \mathrm{~B}+1.087 \mathrm{~B} \cdot \mathrm{C}$

$\sigma_{f} \mathrm{MD}-\mathrm{B}(\mathrm{MPa})=60.322+2.825 \mathrm{~A}-2.125 \mathrm{C}$

$\sigma_{f} \mathrm{MD}-\mathrm{C}(\mathrm{MPa})=79.600+3.775 \mathrm{~A}$

$\sigma_{f}$ TD-A $(\mathrm{MPa})=57.444+7.138 \mathrm{~A}-0.513 \mathrm{~B}$

$\sigma_{f} \mathrm{TD}-\mathrm{B}(\mathrm{MPa})=56.100+4.900 \mathrm{~A}$

$\sigma_{f} \mathrm{TD}-\mathrm{C}(\mathrm{MPa})=59.589+5.625 \mathrm{~A}-1.050 \mathrm{~B}$

As with ABS, a predominant effect of shot volume on the morphology and mechanical properties of PP 20GF injection molded samples was determined. Figure 5.11 and Figure 5.12 illustrate the main effect of mold temperature and injection speed on cell structure parameters and flexural modulus and strength separately for each level of weight reduction. 
Table 5.7. Analysis of variance for cell density MD-B.

\begin{tabular}{|c|c|c|c|c|c|}
\hline Source of variation & \multirow{2}{*}{$\begin{array}{c}\begin{array}{c}\text { Degrees of } \\
\text { freedom }\end{array} \\
3\end{array}$} & \multirow{2}{*}{$\begin{array}{c}\begin{array}{c}\text { Sum of } \\
\text { Squares }\end{array} \\
6.49 \cdot 10^{13}\end{array}$} & \multirow{2}{*}{$\begin{array}{c}\begin{array}{c}\text { Mean } \\
\text { Square }\end{array} \\
2.16 \cdot 10^{13}\end{array}$} & \multirow{2}{*}{$\begin{array}{c}\boldsymbol{F} \text {-value } \\
8.14\end{array}$} & \multirow{2}{*}{$\begin{array}{c}\boldsymbol{p} \text {-value } \\
0.023\end{array}$} \\
\hline Model & & & & & \\
\hline Shot volume & 1 & $1.14 \cdot 10^{13}$ & $1.14 \cdot 10^{13}$ & 4.28 & 0.094 \\
\hline Injection speed & 1 & $3.29 \cdot 10^{13}$ & $3.29 \cdot 10^{13}$ & 12.37 & 0.017 \\
\hline Shot volume*Injection speed & 1 & $2.07 \cdot 10^{13}$ & $2.07 \cdot 10^{13}$ & 7.79 & 0.038 \\
\hline Residual & 5 & $1.33 \cdot 10^{13}$ & $2.66 \cdot 10^{12}$ & & \\
\hline Curvature & 1 & $4.76 \cdot 10^{10}$ & $4.76 \cdot 10^{10}$ & 0.01 & 0.910 \\
\hline Lack of Fit & 4 & $1.32 \cdot 10^{13}$ & $3.31 \cdot 10^{12}$ & & \\
\hline Total & 8 & $7.82 \cdot 10^{13}$ & & & \\
\hline
\end{tabular}

\subsubsection{Effect of shot volume}

As resulted in ABS material, the shot volume was the most influencing factor on the final weight, morphology and mechanical properties of the injected plates. In case of the weight, all conditions presented values very close to the theoretical ones set as targets $(10 \%$, $15 \%$ and $20 \%$ ), according to the different levels of shot volume employed.

In the previous Chapter was pointed out that the study of the shot volume in this work is analogue to analyze the effect of different SCF contents $(0.76 \%$ for the highest shot size and $0.86 \%$ for the lowest). This variation in blowing agent content also affected the cellular structure of PP 20GF foams. First, the higher amount of SCF gas injected into the melt polymer to get a $20 \%$ of weight reduction led to higher expansion of the foamed core and thinner surface layers $[158,160]$. Nevertheless, the effect on cell density and size w contrary to that observed in cylindrical bars previously. Theoretically, the increase in blowing agent content should promote a higher nucleation of cells, which result in lower size [157, 185]. However, from Table 5.4 no variation in cell density and bigger cells with higher amounts of gas is determined. The reduction in weight involved a smaller metered amount of plastic but higher space for foaming, that is, gas expansion. 

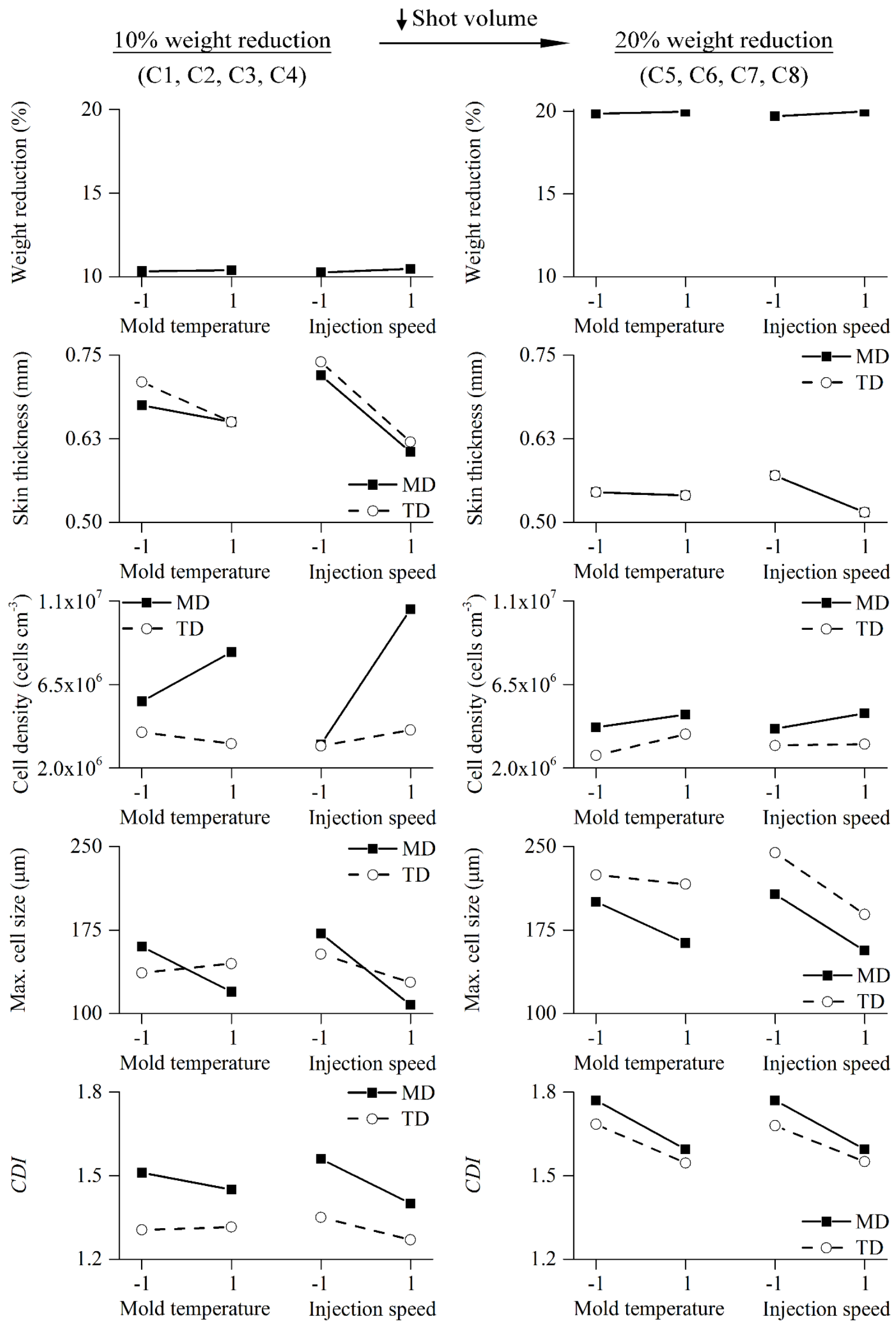

Figure 5.11. Effect of processing parameters on morphology of PP 20GF foamed plates. 


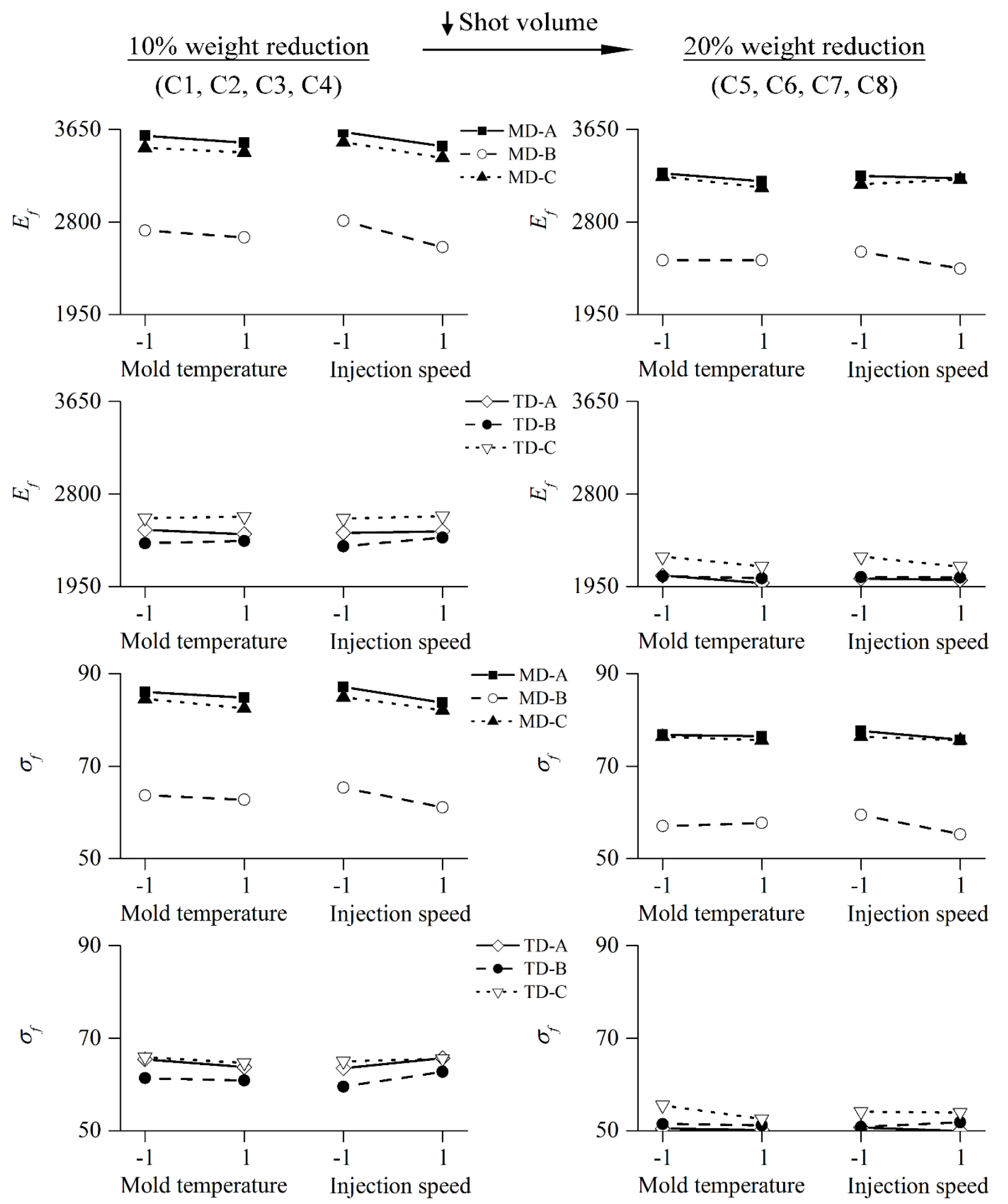

Figure 5.12. Effect of processing parameters on flexural of PP 20GF foamed plates.

Hence, cell walls were thinner and higher proliferation of coarsening and/or coalescence phenomena could easily take place [179] under the stretching force imposed onto the cell wall during the bubble growth. Moreover, the increased amount of gas migrated preferentially to the already existing bubbles rather than nucleating new cells [178], resulting in bigger and irregular bubbles. According Zhu et al. [286], coalescence of small cells interacting with 
bigger ones is inevitably. Consequently, foamed series with $20 \%$ of weight reduction presented bigger cells but keeping the cell density similar to that of microcellular plates with $10 \%$ of weight reduction, in contrast to that found with ABS in the previous Chapter. Thus, the maximum cell sizes as well as CDI increased with decreasing shot volume. Due to this coalescence phenomenon, cell density was not well controlled and clear trends of the variation with shot volume cannot be determined. The same effect has been also reported in PP reinforced with wood fiber [287] and waste ground rubber tire powder [274].

Concerning the flexural properties, the decrease in shot volume involved a reduction in the flexural modulus and strength in all foamed series and different sections studied, which can be explained by the decrease in density and solid skin with the foaming ratio [153, 288]. Differences in flexural properties between MD and TD directions were about $30 \%$ in all foamed series, which suggests that shot volume and gas content have small effect on fiber orientation and anisotropy behavior.

\subsubsection{Effect of mold temperature}

The similar weight of the plates injected with the same levels of shot volume highlights that mold temperature was not influential on it. Regarding the morphology, variations in mold temperature promoted a slight decrease in the surface layer thickness, as expected because of a longer cooling stage and more time for gas expansion [93]. Little effect was also determined on cell density. In this case, cell density leaned towards increasing with raising the temperature of the mold wall, although at high shot size the opposite trend was observed in TD direction. The reason of this discrepancy might lie in fibers hindering cells and altering bubble counting, as well as in the selection of magnification area for morphology analysis in $\mathrm{C} 1$ and $\mathrm{C} 3$ conditions. In general, the main effect of mold temperature seems to be increasing cell density, which is contrary to that expected and reported by other authors [289]. It could be explained in terms of crystallization kinetics of the PP matrix. It is well-known that high mold temperatures enlarge cooling times and allows higher degree of crystallinity [290]. According to Wang et al. [144], crystallization can promote cell nucleation by, on one hand, releasing dissolved gas out of the crystalline regions and, on the other, crystals acting as nucleating agents. Conversely, the maximum cell diameter got smaller and the uniformity of the cell size distribution, represented by the $C D I$ parameter, was slightly enhanced.

The influence of mold temperature on the flexural properties seems to be statistically insignificant, as found by Edwards et al. [141]. A slight decrease with increasing the mold 
temperature could be distinguished, but these variations are in the range of the experimental error and it could be due to the decrease in skin thickness. Regarding the anisotropy of the material, the mold temperature did not contribute to increase nor decrease the difference in flexural properties between samples tested in the parallel or transversal direction to the injection flow (MD or TD), since no effect on fiber orientation has been found [275].

\subsubsection{Effect of injection speed}

As discussed before with mold temperature, no significant effect of injection rate on the weight of samples can be concluded.

The main effect of injection speed on the morphology of the foamed plates illustrated in Figure 5.11 follows the same trends as reported by other authors and explained in Chapter 4 . The fast filling of the mold cavity implies higher temperatures and expansion of the foamed core, resulting in thinner solid skins by increasing the injection rate [291]. This effect was more evidenced at higher shot volumes (conditions C1 and C2). Additionally, the higher pressure drop caused by the increase in injection speed promotes the nucleation of a higher amount of cells [169]. As a consequence, at same levels of SCF contents, the gas was distributed into smaller cells, with lower cell diameter and more uniform cell size distribution, that is, lower values of $C D I$. However, it should be noted that the improvement effect of injection speed on cell density was higher at large shot volume and limited at low filling ratio. On the basis of the low melt strength of PP above aforementioned, maintaining nucleated cells in cell growth stage is much more critical than achieving high cell nucleation ratios [144]. Despite increasing cell nucleation sites by rising injection speed, the increased shear field favors cell stretching and coalescence. If cell coalescence induced by increasing injection velocity is dominant than the cell nucleation enhancement, the final cell density will be barely improved by the increase in the injection rate.

Another effect of injection speed on the cell structure can be noted. Among the SEM pictures illustrated in Figures 6.6 and Figure 6.7, it can be observed that those taking in MD direction corresponding to high injection speeds ( $\mathrm{C} 2, \mathrm{C} 4, \mathrm{C} 7$ and $\mathrm{C} 8$ conditions) exhibited lower levels of cells elongated than that of fabricated at low injection rates $(\mathrm{C} 1, \mathrm{C} 3, \mathrm{C} 5$ and C7 series). This is because different nucleation mechanisms of foaming governed by the injection pressure [120]. At low levels of injection speed, pressure during filling is also low and cells nucleate at the gate, which get elongated and coalesce due to shear stresses. 
However, faster injection molding implies higher pressure in the cavity and the pressure drop that origin cells takes place after filling, remaining a main spherical shape.

The flexural modulus and strength depended very little on the speed at which the plates were injected. It has been reported that higher injection speed causes a preferential orientation of fibers transverse to the flow direction [292]. Hence, the increase in injection speed tends to improve the flexural properties in TD direction, whereas they are deteriorated in the opposite one (MD). That is, the injection speed contributes to equalize the flexural parameters of specimens tested in MD and TD direction, and thus, to a more isotropic behavior of the foamed materials. However, the reduced slope of the lines represented in Figure 5.12 points out a limited effect of injection speed on the flexural properties.

\subsubsection{Interaction between factors}

As occurred with ABS in the last Chapter, interactions between processing parameters have been found. In this case, rather than triggering opposite effects of the factors accordingly to the levels of the other parameters, the consequence of the interactions determined with PP 20GF samples are related to changes in the magnitude of the influence of factors on the responses. For instance, the effect of the injection speed on cell density was higher at high shot sizes and it was diminished while reducing the shot size, as can be clearly observed in Figure 5.11. Statistically, the presence of this interaction is evident in the regression model of Table 5.6 and in Figure 5.13, showing the standardized effects on cell density in MD with a confidence level of $95 \%(\alpha=0.05)$.

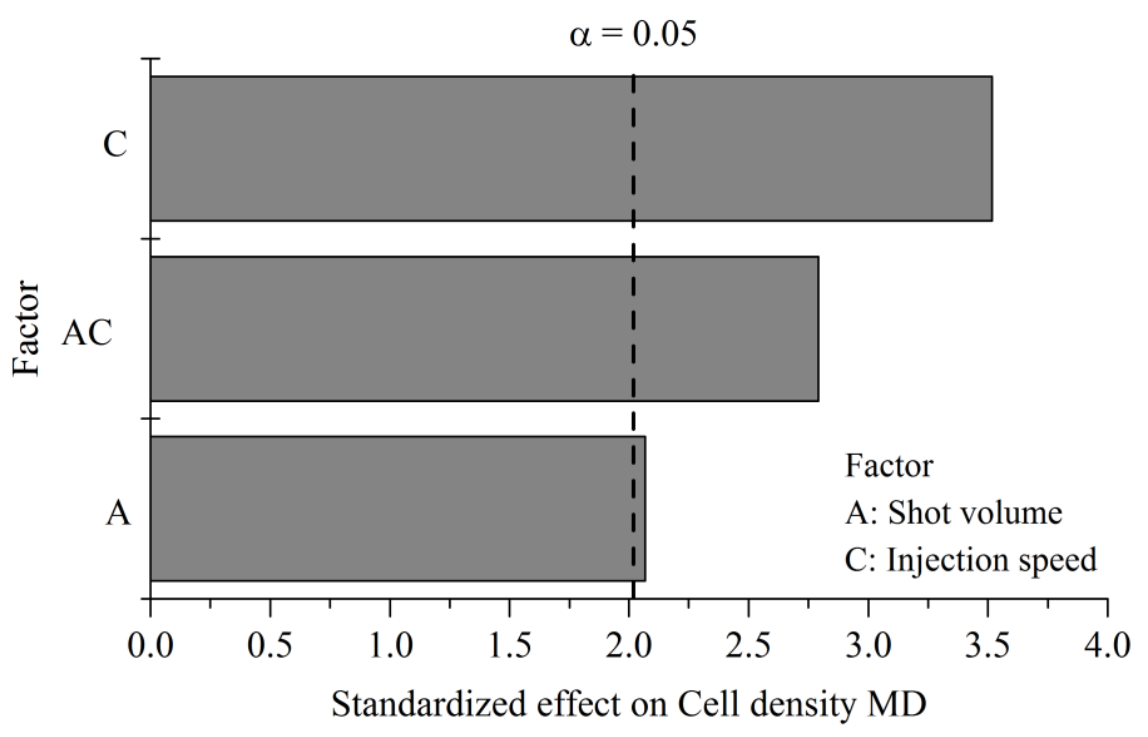

Figure 5.13. Pareto charts of standardized effect of processing parameters on cell density in MD direction. 
From the above discussion, it can be concluded that shot size dominated cell morphology and flexural properties. Despite high levels of mold temperature and injection speed gave rise to finer cell characteristics, their lower values led to increase the overall flexural modulus and strength and reduce differences between testing directions. Hence, foamed series molded under low mold temperature and injection speed of each level of weight reduction ( $\mathrm{C} 1$ and $\mathrm{C} 5$ conditions) were selected for extended analysis.

\subsubsection{Morphology and apparent density}

SEM micrographs showing solid skin/foamed core taken from different sections and directions of the selected conditions are outlined in Figure 5.14 and Figure 5.15.

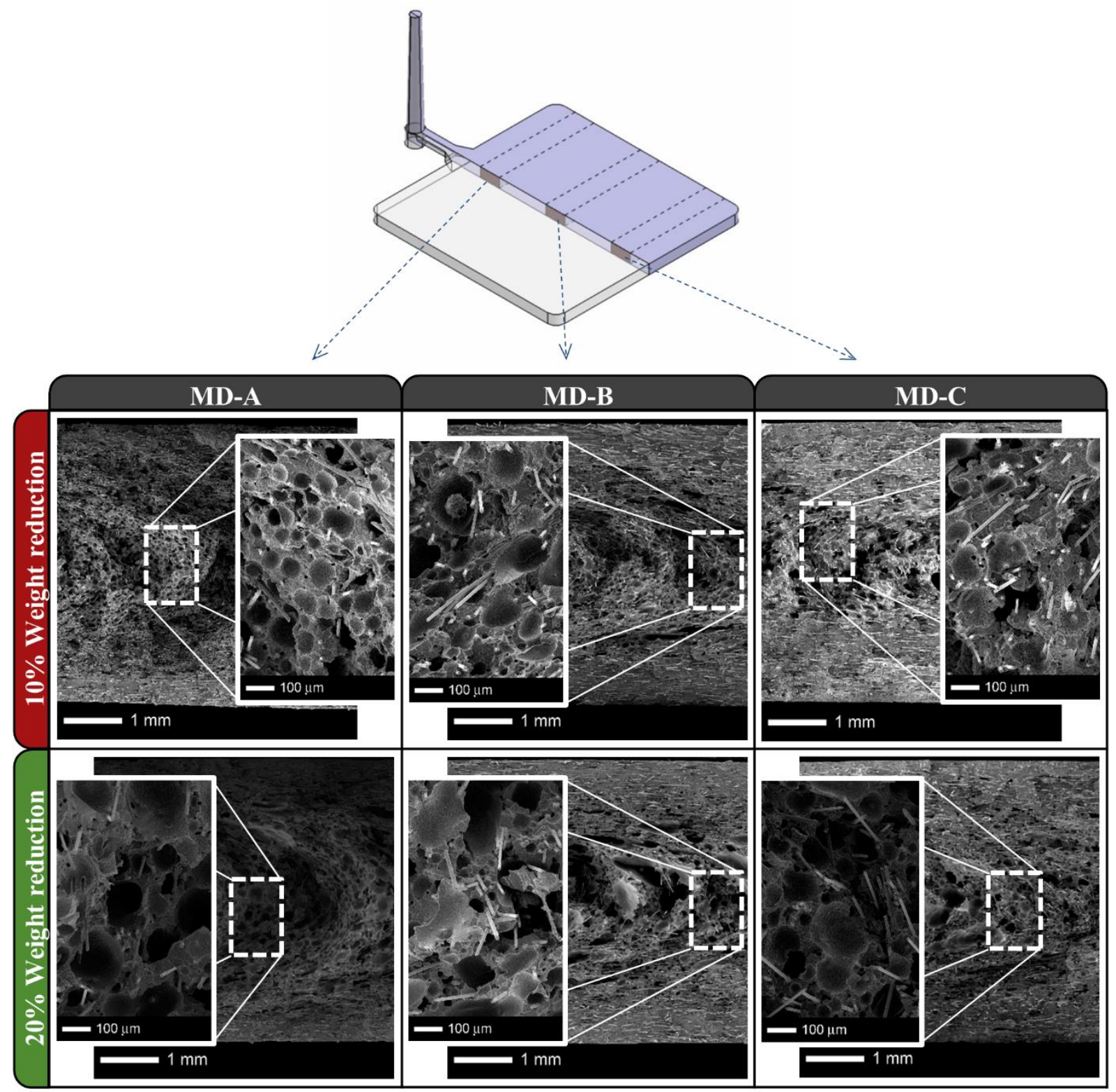

Figure 5.14. SEM micrographs of PP 20GF foamed plates taken in MD direction. 


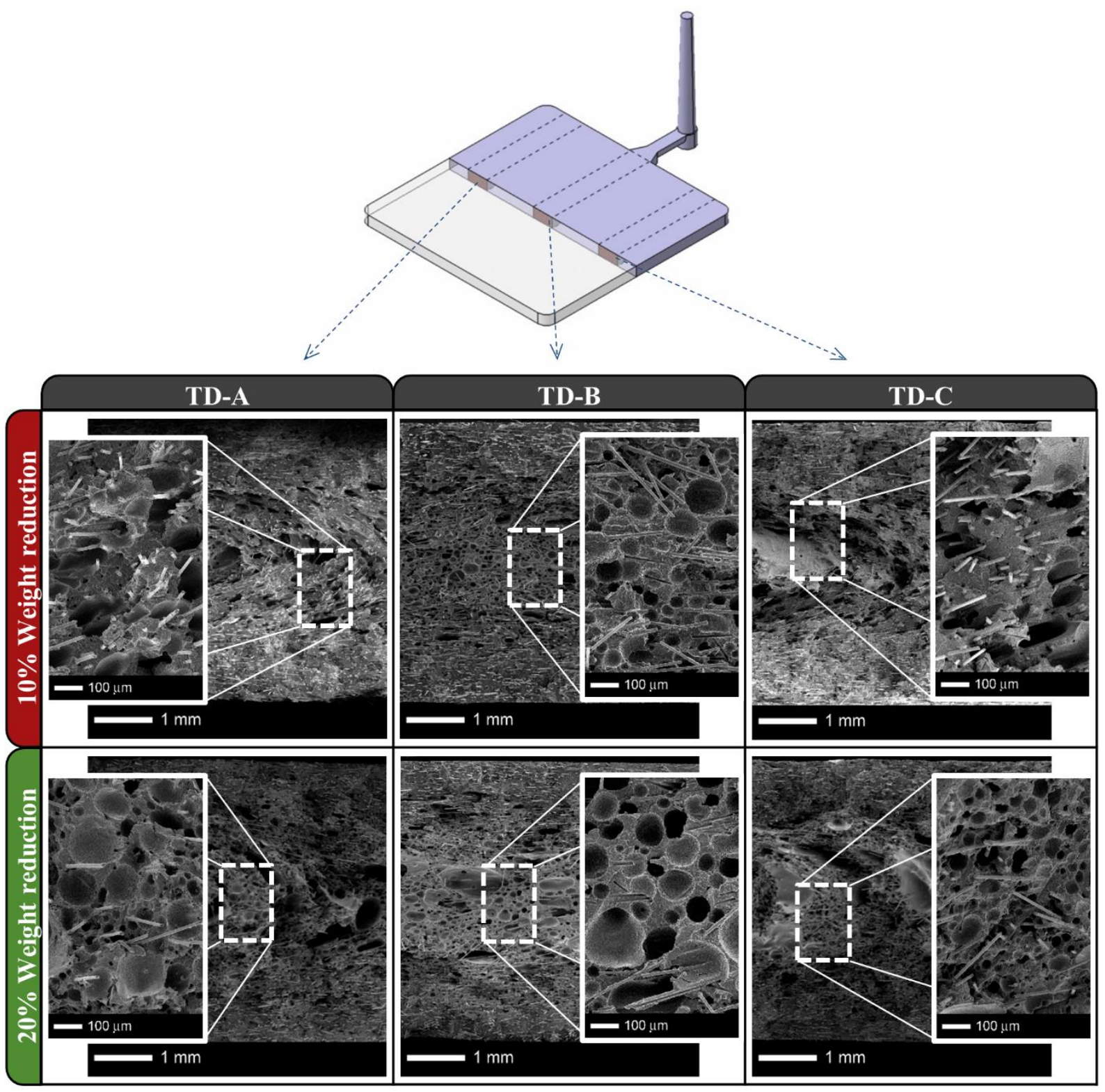

Figure 5.15. SEM micrographs of PP 20GF foamed plates taken in TD direction.

Fibers in surface layers seem to be contained in a parallel plane to the main surface of the plates, whereas in the foamed core follow the pattern of the fountain flow [293]. Cells near the skin are elliptical and oriented in the filling direction and circular in TD direction, as previously stated, indicating that they were nucleated during the filling stage and deformed by shear flow.

Once again, bubbles distributed around glass fibers indicate that heterogeneous nucleation was the predominant mechanism of PP 20GF foaming. The morphological parameters are summarized in Table 5.8. As seen with ABS before, the solid skin became thicker as the distance from the injection gate increased (MD-A, MD-B and MD-C), because molten polymer reached the cavity ends at lower temperatures and solidified faster. Due to 
this build-up in the solid skin thickness, sections at the end of the cavity were denser than those near the injection gate (Table 5.9). In TD direction, however, the solid skin thickness remained practically constant in all different studied sections (TD-A, TD-B and TD-C) for each condition. Furthermore, this surface layer was thicker in foamed samples with $10 \%$ of weight reduction, as compared to that of $20 \%$-reduced weight foams, because of higher expansion of the foamed core with higher contents of blowing agent.

Cell density was kept in an order of magnitude of $10^{6}$ cells $\mathrm{cm}^{-3}$ in all cases. Previously, it has been already discussed that, the higher gas content introduced to get a $20 \%$ of weight reduction would increase cell nucleation. However, if growing force of cells is larger than the strength of cell walls, cell coalescence occurs and results in larger bubbles but similar cell density to that of foamed samples with $10 \%$ of weight reduction. As a consequence, CDI parameter increased in the lighter foamed series. However, Figure 5.16 points out analogous cell size distributions in every analyzed sample with $90 \%$ of them smaller than $100 \mu \mathrm{m}$, despite C5 foamed series contained some bigger cells.

Table 5.8. Morphological parameters in different sections of PP 20GF foamed plates.

\begin{tabular}{|c|c|c|c|c|c|}
\hline $\begin{array}{c}\text { Condition } \\
\text { No. }\end{array}$ & Section & $\begin{array}{l}\text { Skin thickness } \\
(\mathbf{m m})\end{array}$ & $\begin{array}{l}\text { Cell density } \\
\left(\text { cells } \mathbf{c m}^{-3} \text { ) }\right.\end{array}$ & $\begin{array}{c}\text { Cell size range } \\
\qquad(\mu \mathrm{m})\end{array}$ & CDI \\
\hline \multirow[t]{6}{*}{ C1 $(10 \%)$} & MD-A & 0.52 & $4.8 \cdot 10^{6}$ & $2-100$ & 1.28 \\
\hline & MD-B & 0.71 & $3.1 \cdot 10^{6}$ & 8-188 & 1.63 \\
\hline & MD-C & 0.81 & $2.5 \cdot 10^{6}$ & $6-180$ & 1.94 \\
\hline & TD-A & 0.77 & $1.0 \cdot 10^{6}$ & $9-147$ & 1.39 \\
\hline & TD-B & 0.76 & $3.5 \cdot 10^{6}$ & $6-135$ & 1.36 \\
\hline & TD-C & 0.77 & $1.8 \cdot 10^{6}$ & $3-145$ & 1.57 \\
\hline \multirow[t]{6}{*}{ C5 (20\%) } & MD-A & 0.42 & $2.9 \cdot 10^{6}$ & $7-252$ & 2.08 \\
\hline & MD-B & 0.59 & $3.4 \cdot 10^{6}$ & $4-240$ & 1.89 \\
\hline & MD-C & 0.71 & $5.5 \cdot 10^{6}$ & $7-203$ & 1.82 \\
\hline & TD-A & 0.59 & $4.7 \cdot 10^{6}$ & $7-243$ & 1.96 \\
\hline & TD-B & 0.58 & $1.6 \cdot 10^{6}$ & $2-248$ & 1.80 \\
\hline & TD-C & 0.59 & $7.0 \cdot 10^{6}$ & $6-215$ & 1.79 \\
\hline
\end{tabular}



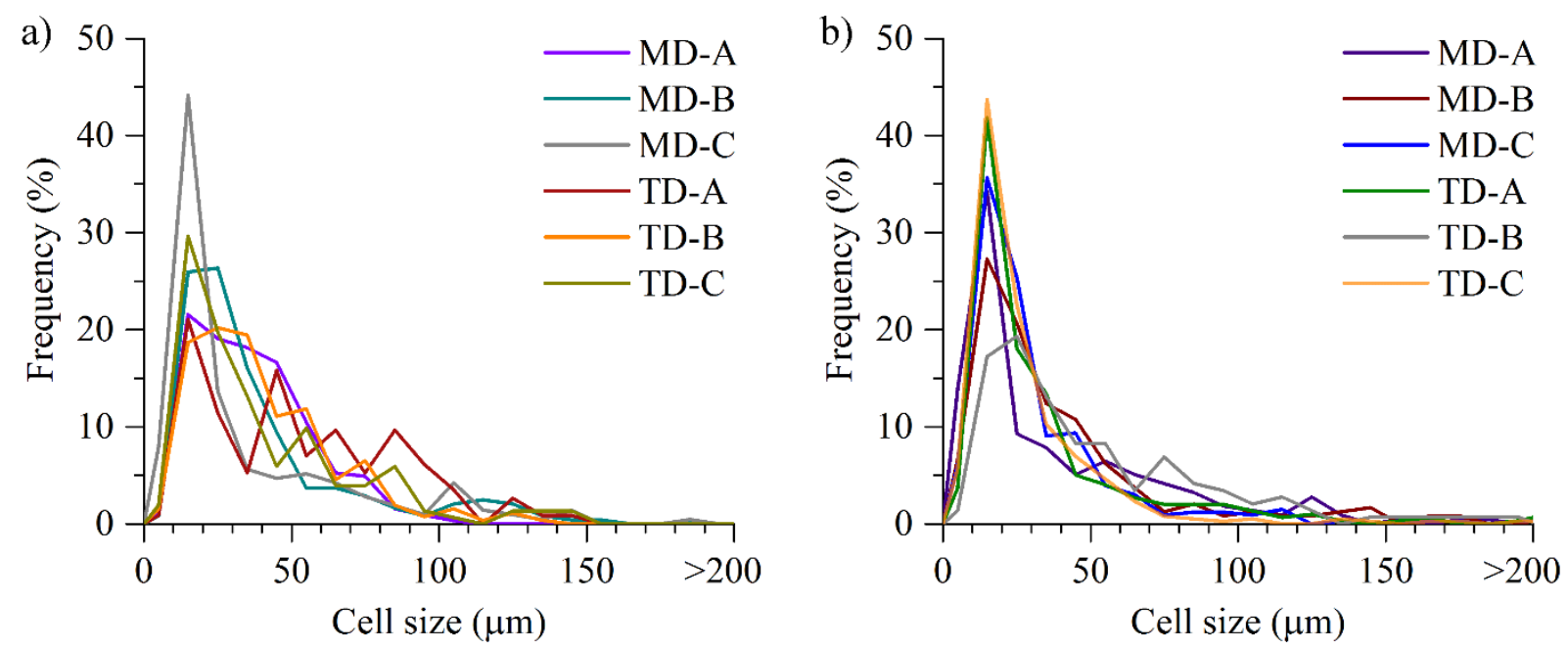

Figure 5.16. Cell size distribution of different sections of PP 20GF foamed samples with a) $10 \%$ weight reduction; b) $20 \%$ weight reduction.
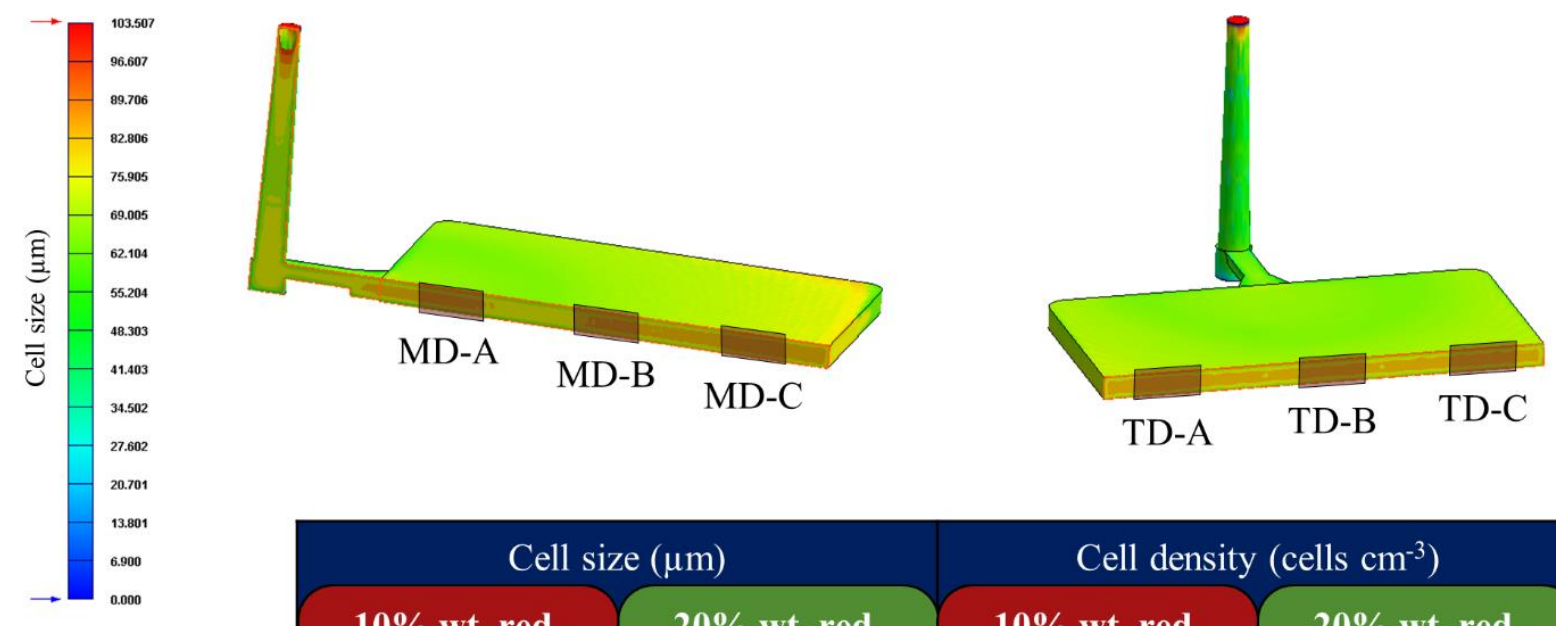

\begin{tabular}{|c|c|c|c|c|}
\cline { 3 - 5 } & $\mathbf{1 0} \%$ wt. red. & $\mathbf{2 0} \%$ wt. red. & $\mathbf{1 0} \%$ wt. red. & $\mathbf{2 0} \%$ wt. red. \\
\hline MD-A & 82 & 82 & $1.3 \cdot 10^{6}$ & $1.5 \cdot 10^{6}$ \\
\hline MD-B & 84 & 80 & $1.4 \cdot 10^{6}$ & $1.6 \cdot 10^{6}$ \\
\hline MD-C & 86 & 79 & $1.3 \cdot 10^{6}$ & $1.6 \cdot 10^{6}$ \\
\hline TD-A & 87 & 79 & $1.3 \cdot 10^{6}$ & $1.6 \cdot 10^{6}$ \\
\hline TD-B & 83 & 77 & $1.3 \cdot 10^{6}$ & $1.7 \cdot 10^{6}$ \\
\hline TD-C & 85 & 79 & $1.3 \cdot 10^{6}$ & $1.6 \cdot 10^{6}$ \\
\hline
\end{tabular}

Figure 5.17. Cell size and cell density results of PP 20GF foamed plates simulated with Moldex 3D® software.

Figure 5.17 collects the results of cell size and cell density obtained with Moldex 3D® simulation software. Although the increase in the amount of blowing agent for foaming with $20 \%$ of weight reduction, the software predicted no changes in cell density and slightly lower cell sizes, concurring with the range of bubble diameter that contains around $85 \%$ of cells. 
Table 5.9. Apparent density and fiber content measured in different sections of the PP 20GF square plates.

\begin{tabular}{|c|c|c|c|c|c|c|}
\hline & \multirow{2}{*}{$\begin{array}{c}\text { Condition } \\
\text { No. }\end{array}$} & \multicolumn{5}{|c|}{ Apparent density $\left(\mathrm{g} \mathrm{cm}^{-3}\right)$} \\
\hline 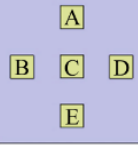 & & A & B & C & D & $\mathbf{E}$ \\
\hline & Solid & $1.03 \pm 0.01$ & $1.03 \pm 0.01$ & $1.03 \pm 0.01$ & $1.03 \pm 0.01$ & $1.02 \pm 0.01$ \\
\hline & C1 $(10 \%)$ & $0.79 \pm 0.01$ & $0.86 \pm 0.01$ & $0.82 \pm 0.01$ & $0.86 \pm 0.01$ & $0.88 \pm 0.01$ \\
\hline & C5 (20\%) & $0.67 \pm 0.01$ & $0.78 \pm 0.01$ & $0.73 \pm 0.01$ & $0.78 \pm 0.01$ & $0.80 \pm 0.01$ \\
\hline & Condition & & & er content & & \\
\hline & No. & $\mathbf{A}$ & B & $\mathrm{C}$ & D & $\mathbf{E}$ \\
\hline & Solid & $20.5 \pm 0.1$ & $20.4 \pm 0.1$ & $20.3 \pm 0.2$ & $20.3 \pm 0.1$ & $20.1 \pm 0.3$ \\
\hline & C1 (10\%) & $20.3 \pm 0.2$ & $20.6 \pm 0.1$ & $20.6 \pm 0.1$ & $20.4 \pm 0.1$ & $20.6 \pm 0.1$ \\
\hline & C5 (20\%) & $20.5 \pm 0.3$ & $20.2 \pm 0.4$ & $20.3 \pm 0.3$ & $20.2 \pm 0.2$ & $20.5 \pm 0.1$ \\
\hline
\end{tabular}

On the other hand, Table 5.9 points out that fiber content is in the range of $20.4 \pm 0.2 \%$, being the fiber concentration in solid plates of $20.3 \pm 0.2 \%$ and $20.5 \pm 0.1 \%$ in the polymer in pellets form, as previously aforementioned. That is, the filler content remained invariant despite the decrease in apparent density from $1.03 \pm 0.03 \mathrm{~g} \mathrm{~cm}^{-3}$ (solid plates) to $0.88 \pm 0.01 \mathrm{~g}$ $\mathrm{cm}^{-3}$ and $0.79 \pm 0.01 \mathrm{~g} \mathrm{~cm}^{-3}$ (10\% and $20 \%$ of weight reduction, respectively) due to foaming process.

Another important morphological feature of fiber-filled composites is the orientation and distribution of the fibers. In these materials, the orientation of the fibers has more effect on the mechanical response than the molecular orientation [294]. Additionally, it can influence shrinkage and warpage of the part and compromise its dimensional stability. Fiber orientation is mainly dependent on the processing conditions [275]. Pictures of fiber orientation in the surface and in the middle plane of molded samples taken from Computed Tomography technique are illustrated in Figure 5.18, Figure 5.19 and Figure 5.20. To better understand this phenomenon, the flow pattern obtained from simulation is included. In the center plane of the plates, flow was diverging and induced transverse alignment of fibers to filling direction [295] as can be observed in section C-Core of Figure 5.18. Only near the walls, at surfaces and sides of the samples, shear stress caused a higher orientation in the flow direction or, as in this case, no obvious preferential alignment in the surface layers. 

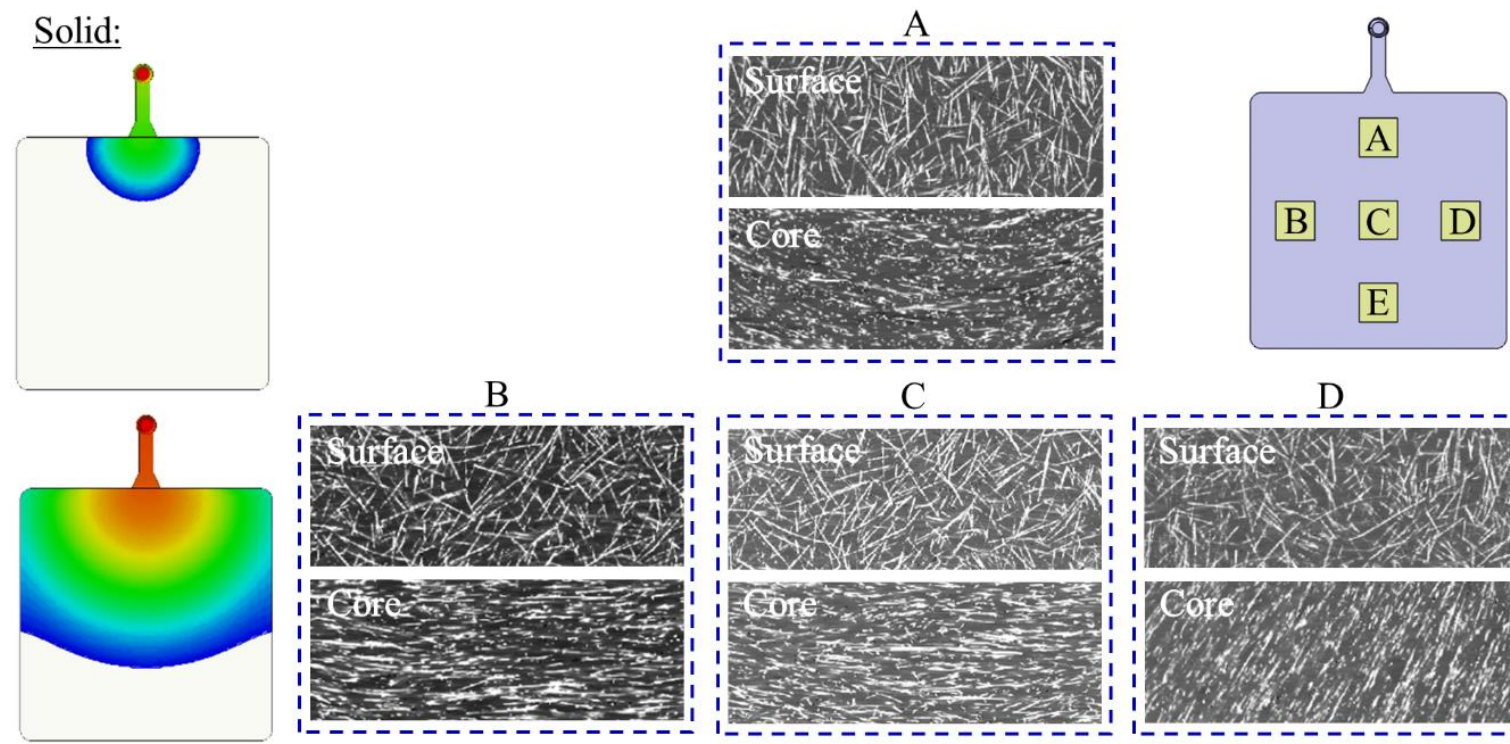

$\mathrm{B}$

C
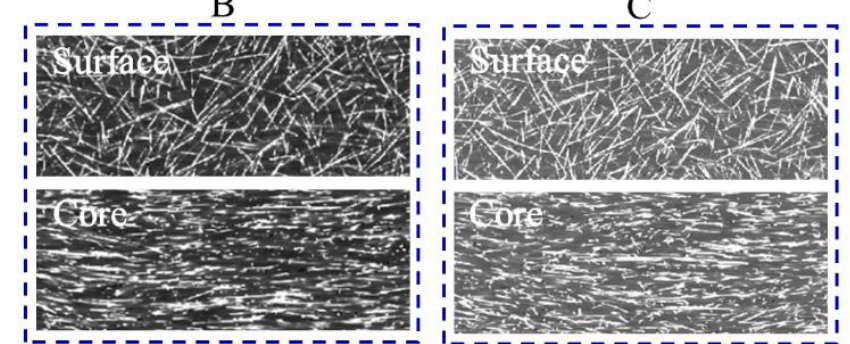

D

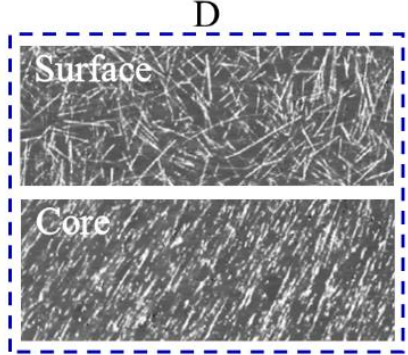

$\mathrm{E}$
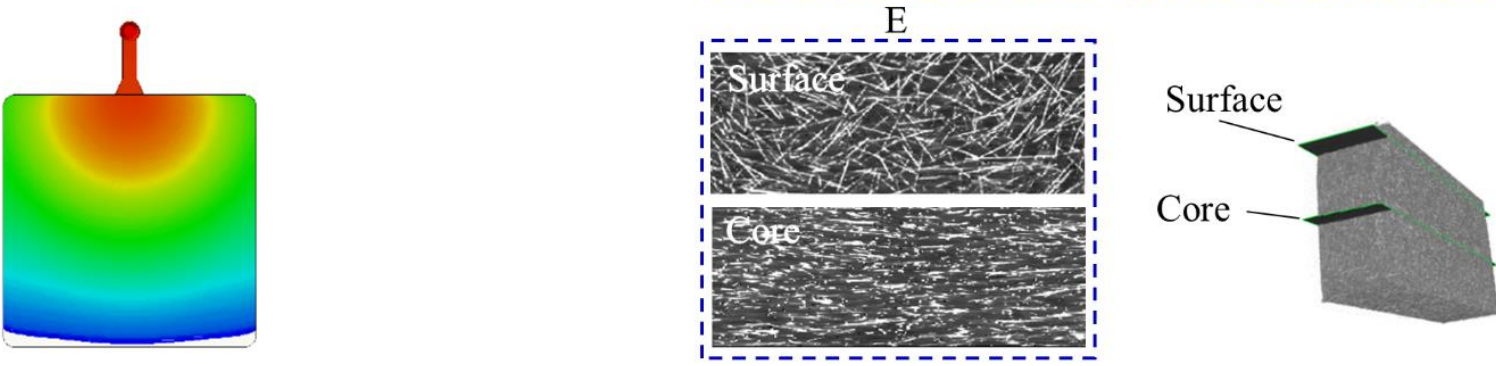

Figure 5.18. Filling flow pattern and Computed Tomography pictures of PP 20GF solid plates.

\section{C1: $10 \%$ weight reduction}
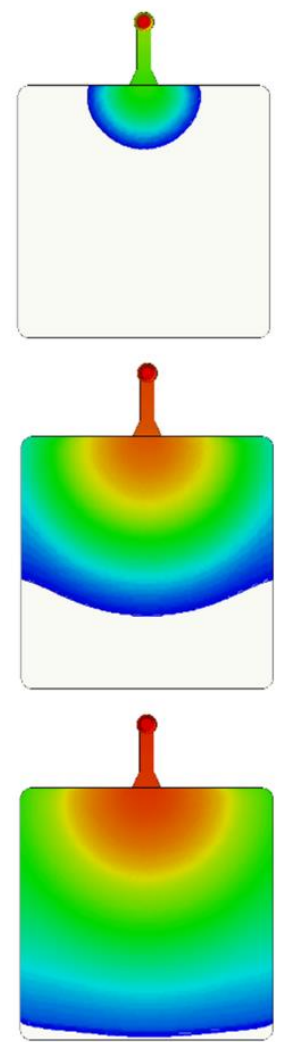

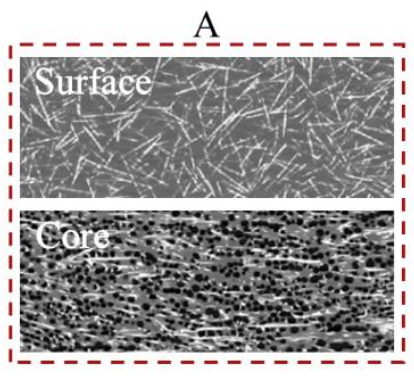

C
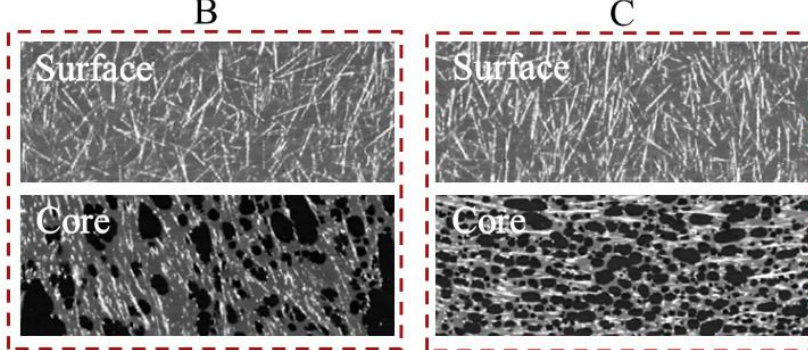

$\mathrm{E}$
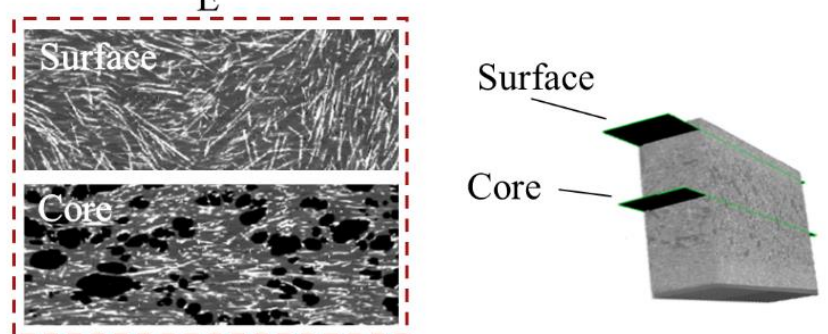

Figure 5.19. Filling flow pattern and Computed Tomography pictures of PP $20 \mathrm{GF}$ foamed plates (10\% wt. red.). 


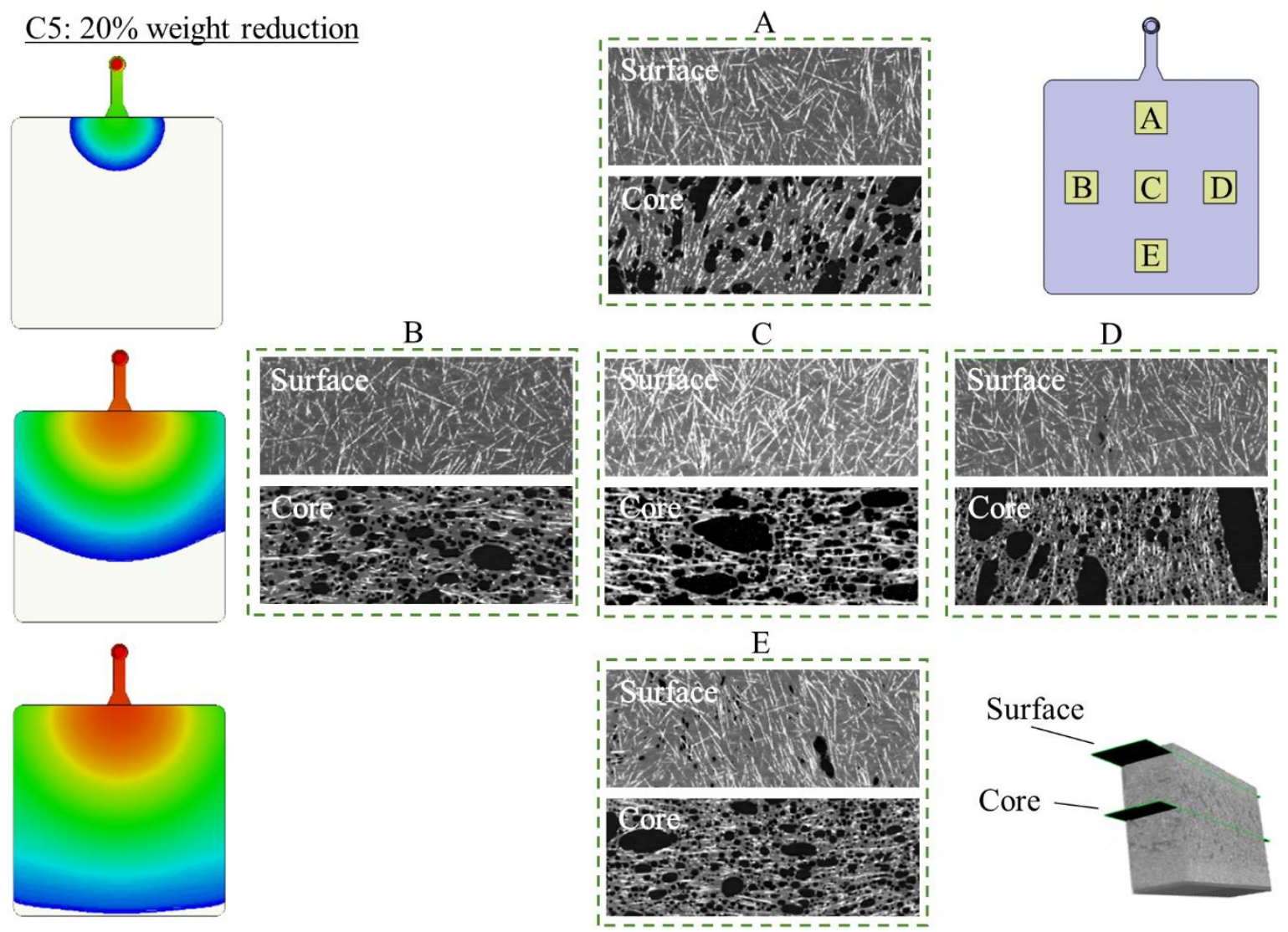

Figure 5.20. Filling flow pattern and Computed Tomography pictures of PP 20GF foamed plates (20\% wt. red.).

These fiber orientation and distribution patterns work are in agreement to the first researches carried out by several authors [296-299]. According to the type of load and ratios of skin/core of the different positions in the molded plates, the mechanical response will be higher or lower in magnitude. Gong et al. [300] discussed about a minimum length of the glass fiber in order to effectively bear stress in foamed PP. From the CT analysis carried out in this work, an average length of $740 \pm 150 \mu \mathrm{m}$ of the glass fibers for all solid and foamed samples was calculated. Since the maximum cell size was about $250 \mu \mathrm{m}$, these fibers were long enough to pass through the cells and reinforce the polymer matrix.

\subsubsection{Flexural behavior}

The stress-strain curves and flexural properties obtained in solid and all foamed samples are plotted on Figure 5.21 and Table 5.10. Flexural strength and modulus decreased accordingly with the increase in microvoid content and reduction in density, as reported in PP with flax and wood fibers [301]. By reducing $10 \%$ the weight of the injected plates, the flexural modulus and strength was reduced by around $6 \%$ and $14 \%$ in MD, respectively, whereas it was diminished by $20 \%$ and $27 \%$ in the opposite orientation. 

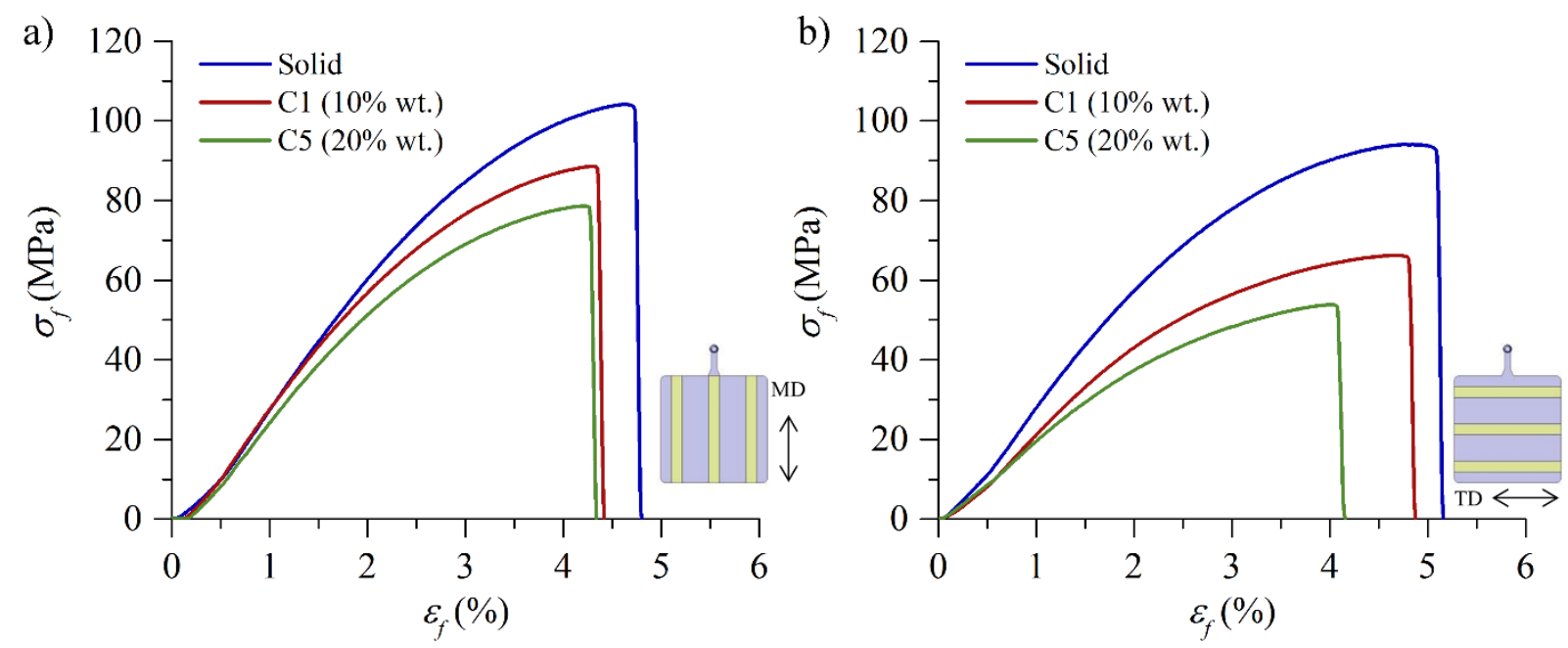

Figure 5.21. Flexural stress-strain curves of PP 20GF solid and foamed samples tested in a) MD; b) TD directions.

In case of series with $20 \%$ of weight reduction, flexural modulus and strength decreased by $16 \%$ and $24 \%$ in $\mathrm{MD}$, and by $32 \%$ and $40 \%$ in TD direction. Notwithstanding a preferential fiber orientation in the surface layers could not be clearly determined from the CT pictures of Figure 5.18, Figure 5.19 and Figure 5.20, the values of Table 5.10 evidence a reinforcing effect of fibers favored in the direction of flow at the extreme locations of the plates in the direction of filling (MD-A and MD-C). This allowed keeping enough stiffness to response mechanical requirements and overcome the loss in flexural properties due to density reduction. Other works also reported a better response of PP foams under bending loads than in tension configurations [302]. The inexistence of open cells also contributed to enhance the flexural properties of foamed samples. In the transversal direction (TD), the highest elastic modulus and strength were determined at the furthest location from the injection gate (TD-C), which could be explained by the thicker solid skin and apparent density obtained at the end of the cavity. The dependency of the flexural properties with the apparent density can be observed in the specific values summarized in Table 5.10, where results of solid and foamed specimens were equated or even exceeded.

Regarding anisotropy, in the analysis of the effect of processing parameters on flexural properties it has been reported that differences in modulus and strength of solid samples between MD and TD directions were about 20\%, whereas they were about $30 \%$ in foamed specimens. However, it must be noticed that solid square plates were injection molded at higher speed and mold temperature than the studied foamed series. It is known that higher fiber orientation in filling direction is resulted when injecting at lower speed [275]. Therefore, direct conclusions about anisotropy changes due to foaming cannot be drawn from this study. 
Table 5.10. Flexural properties in different sections of PP 20GF square plates.

\begin{tabular}{|c|c|c|c|c|c|}
\hline $\begin{array}{c}\text { Condition } \\
\text { No. }\end{array}$ & Section & $\begin{array}{c}E_{f} \\
(\mathrm{MPa})\end{array}$ & $\begin{array}{c}\sigma_{f} \\
(\mathbf{M P a})\end{array}$ & $\begin{array}{c}E_{f} / \rho \\
\left(\mathrm{MPa} / \mathrm{g} \mathrm{cm}^{-3}\right)\end{array}$ & $\begin{array}{c}\sigma_{f} / \rho \\
\left(\mathrm{MPa} / \mathrm{g} \mathrm{cm}^{-3}\right)\end{array}$ \\
\hline \multirow[t]{6}{*}{ Solid } & MD-A & $3851 \pm 41$ & $102.0 \pm 1.6$ & $3739 \pm 52$ & $99.1 \pm 1.0$ \\
\hline & MD-B & $3267 \pm 52$ & $79.4 \pm 2.4$ & $3194 \pm 50$ & $77.6 \pm 1.5$ \\
\hline & MD-C & $3903 \pm 61$ & $102.8 \pm 2.0$ & $3834 \pm 99$ & $100.9 \pm 1.2$ \\
\hline & TD-A & $3138 \pm 88$ & $87.0 \pm 2.4$ & $3049 \pm 54$ & $84.5 \pm 1.9$ \\
\hline & TD-B & $3002 \pm 76$ & $86.6 \pm 1.0$ & $2870 \pm 88$ & $82.9 \pm 1.3$ \\
\hline & TD-C & $3196 \pm 90$ & $91.6 \pm 2.2$ & $3084 \pm 62$ & $88.4 \pm 1.3$ \\
\hline \multirow[t]{6}{*}{ C1 $(10 \%)$} & MD-A & $3702 \pm 59$ & $88.8 \pm 1.0$ & $4181 \pm 59$ & $100.3 \pm 1.3$ \\
\hline & MD-B & $2888 \pm 68$ & $66.6 \pm 0.6$ & $3469 \pm 50$ & $80.0 \pm 0.5$ \\
\hline & MD-C & $3614 \pm 91$ & $87.8 \pm 2.6$ & $4062 \pm 68$ & $98.6 \pm 2.2$ \\
\hline & TD-A & $2500 \pm 81$ & $65.5 \pm 0.4$ & $3002 \pm 100$ & $78.7 \pm 1.1$ \\
\hline & TD-B & $2333 \pm 85$ & $60.9 \pm 0.9$ & $2699 \pm 90$ & $70.5 \pm 0.8$ \\
\hline & TD-C & $2595 \pm 83$ & $66.3 \pm 1.1$ & $2806 \pm 75$ & $71.7 \pm 0.4$ \\
\hline \multirow[t]{6}{*}{ C5 (20\%) } & MD-A & $3287 \pm 56$ & $78.8 \pm 1.0$ & $4151 \pm 70$ & $99.5 \pm 1.7$ \\
\hline & MD-B & $2530 \pm 47$ & $59.0 \pm 0.7$ & $3441 \pm 58$ & $80.2 \pm 0.9$ \\
\hline & MD-C & $3205 \pm 33$ & $76.8 \pm 1.1$ & $4030 \pm 55$ & $96.6 \pm 1.5$ \\
\hline & TD-A & $2062 \pm 41$ & $52.2 \pm 0.9$ & $2810 \pm 58$ & $71.1 \pm 1.2$ \\
\hline & TD-B & $2038 \pm 88$ & $50.6 \pm 2.3$ & $2572 \pm 99$ & $63.8 \pm 2.5$ \\
\hline & TD-C & $2266 \pm 49$ & $55.6 \pm 2.4$ & $2762 \pm 65$ & $67.8 \pm 2.9$ \\
\hline
\end{tabular}

A higher isotropic behavior was found in the middle of the injected plates, where flexural properties of both directions (MD-B and TD-B) were closer. Therefore, a more random fiber orientation in this region is suggested.

Concerning theoretical models for predicting flexural properties of foams, the Square Power law model [227] given by Equation (4.4) was employed to estimate the flexural modulus of the microcellular samples. The anisotropy of the foamed materials was also 
considered, so predicted properties were determined with average values of main fiber orientation locations on one hand (MD-A and MD-C), and with the transverse direction (TDA, TD-B and TD-C), on the other hand. In the former case, theoretical values of flexural values were $3488 \mathrm{MPa}$ and $3140 \mathrm{MPa}$ for $10 \%$ and $20 \%$ levels of weight reduction, respectively, with less than $5 \%$ of difference from the experimental data. In the second case, taking average results of TD direction, the determined flexural modulus was $2797 \mathrm{MPa}$ and $2545 \mathrm{MPa}$, which deviated from the experimental values in around 13\%-19\%.

The prediction model of flexural strength modified by $\mathrm{Xu}$ and Kishbaugh [223] for filled polymers was also used for the materials of this work. On the basis of Equation (4.5), the modified model determines the flexural strength of the foam $\sigma_{f f}$ by employing the flexural strength of the solid counterpart $\sigma_{f s}$, the solid skin thickness $t_{s}$, the overall sample thickness $h$ and the real weight reduction ratio of the core material without fillers $R_{g f}$ (Equation (5.1)) as follows:

$$
\frac{\sigma_{f f}}{\sigma_{f s}}=\frac{2 t_{s}^{3}}{h^{3}}+\frac{6 t\left(h-t_{s}\right)^{3}}{h^{3}}+\left(1-R_{g f}\right)\left(\frac{h-2 t_{s}}{h}\right)^{3}
$$

Taking average values in both testing directions, the predicted flexural strength in TD direction was 84.2 $\mathrm{MPa}$ and $74.8 \mathrm{MPa}$ for both levels of both reduction and a maximum error of $4 \%$, whereas it resulted in 69.3 $\mathrm{MPa}$ and $63.1 \mathrm{MPa}$ in $\mathrm{MD}$ direction, whose deviation from the experimental data is up to $20 \%$. In this case, this theoretical approach of the mechanical properties of foamed polymers was highly accurate in the direction of filling, where maximum fiber orientation is expected. Nevertheless, the models lost precision in the transverse direction due to more random fiber orientation, which cannot be easily measured.

\subsubsection{Impact behavior}

Force-displacement curves of solid and foamed specimens are illustrated in Figure 5.22. It has been reported in the literature that PP becomes brittle with the addition of glass fibers [303]. Thus, the capability of energy absorption becomes lower. According to Thomason [304], the effect of fiber on PP matrix is contradictory. On one hand, regions from fibermatrix debonding act as critical flaw and reduce the energy required to initiate a crack. On the other, reinforced material is both stiffer and stronger than unfilled material, so the resistance to crack propagation is significantly increased. 

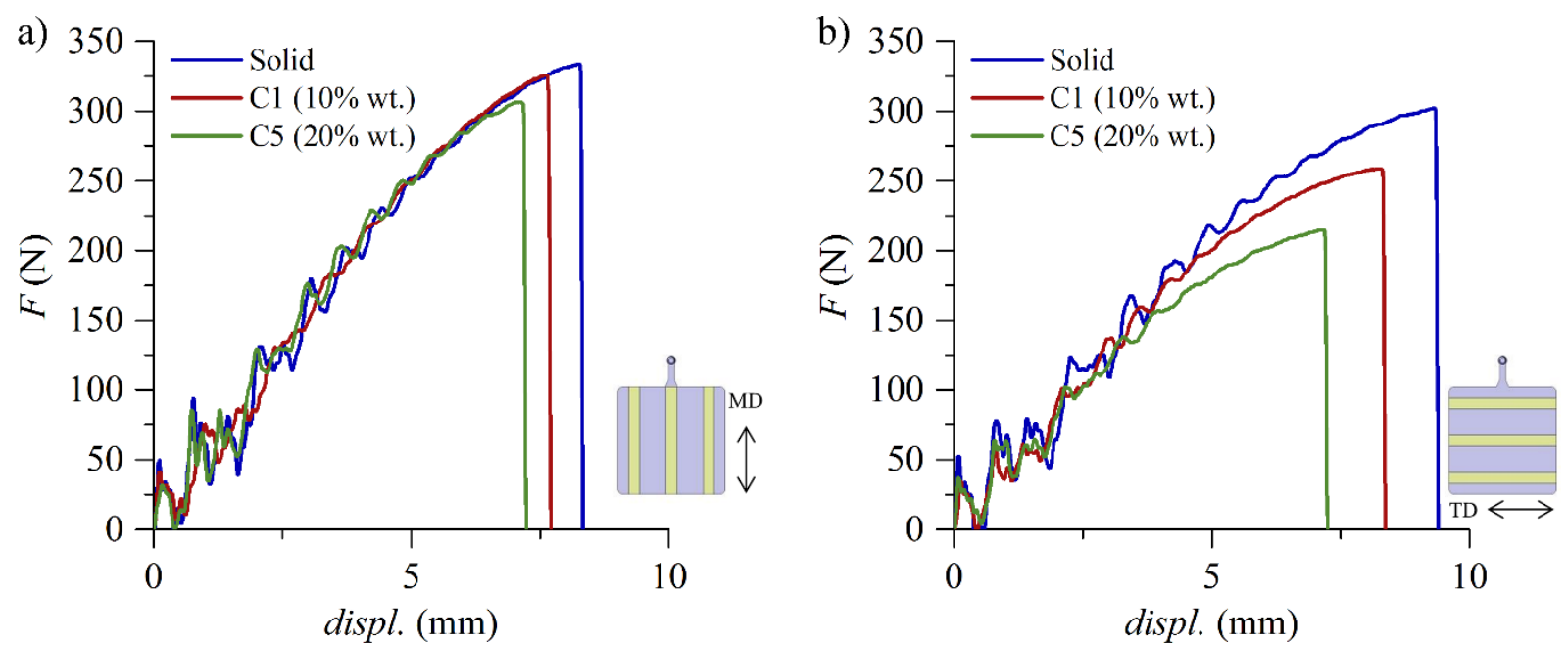

Figure 5.22. Impact force-displacement curves of PP 20GF samples tested in a) MD; b) TD directions.

Impact resistance values are summarized in Table 5.11. In case of solid samples, this parameter was very similar in all specimens tested through the whole plate, so fiber orientation seems not to be greatly influent on the impact resistance, as it has been found in other studies [305]. A slight decrease in impact resistance as the distance from the injection gate rises was observed (samples TD-A, TD-B, TD-C), which might be attributed to a lower material packing at the end of the cavity. However, it is noticeable the reduction in impact resistance in samples tested in TD direction in the middle of the plate (MD-B), which has been also observed in flexural properties and could be explained by an increased random fiber orientation in that location.

Regarding foamed specimens, impact resistance was lowered with decreasing density and solid skin thickness $[158,166]$. From results of Table 5.11, impact resistance decreased by $18 \%$ and $27 \%$ (10\% and $20 \%$ of weight reduction) when samples were tested in MD direction, whereas it was reduced by $29 \%$ and $47 \%$ in the opposite direction. As reported in ABS previously, the main consequence of foaming here was also diminishing the resistant area which can withstand the impact load. Nevertheless, drop ratios in impact resistance were significantly lowered in PP 20GF as compared to ABS, due to the reinforcing effect of fibers.

As said above, processing parameters could led to higher preferential fiber orientation parallel to filling direction in microcellular parts. That is the reason why higher anisotropic behavior was found in foamed specimens. The impact resistance kept almost constant or slightly increased at the end of the cavities (comparing TD-A, TD-B and TD-C), also due to the slight increase in skin thickness far away from the injection gate. 
Table 5.11. Impact resistance determined in different sections of PP 20GF square plates.

\begin{tabular}{|c|c|c|c|}
\hline $\begin{array}{c}\text { Condition } \\
\text { No. }\end{array}$ & Section & 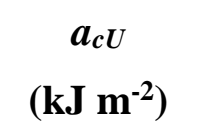 & $\begin{array}{c}a_{c U} / \rho \\
\left(\mathrm{kJ} \mathrm{m}^{-2} / \mathrm{g} \mathrm{cm}^{-3}\right)\end{array}$ \\
\hline \multirow[t]{6}{*}{ Solid } & MD-A & $31.0 \pm 2.7$ & $30.4 \pm 2.8$ \\
\hline & MD-B & $24.0 \pm 2.2$ & $23.5 \pm 2.5$ \\
\hline & MD-C & $29.9 \pm 1.8$ & $29.2 \pm 2.0$ \\
\hline & TD-A & $32.3 \pm 1.9$ & $31.8 \pm 2.3$ \\
\hline & TD-B & $30.6 \pm 0.3$ & $30.1 \pm 0.6$ \\
\hline & TD-C & $28.2 \pm 1.8$ & $27.8 \pm 2.1$ \\
\hline \multirow[t]{6}{*}{ C1 (10\%) } & MD-A & $25.9 \pm 1.3$ & $29.5 \pm 1.7$ \\
\hline & MD-B & $18.5 \pm 0.7$ & $22.4 \pm 1.1$ \\
\hline & MD-C & $25.4 \pm 1.7$ & $29.0 \pm 2.1$ \\
\hline & TD-A & $21.1 \pm 1.8$ & $26.4 \pm 2.5$ \\
\hline & TD-B & $20.9 \pm 1.5$ & $24.8 \pm 2.0$ \\
\hline & TD-C & $21.9 \pm 1.3$ & $24.1 \pm 1.7$ \\
\hline \multirow[t]{6}{*}{ C5 (20\%) } & MD-A & $23.2 \pm 0.8$ & $29.7 \pm 1.2$ \\
\hline & MD-B & $15.5 \pm 1.0$ & $21.3 \pm 1.5$ \\
\hline & MD-C & $23.0 \pm 1.2$ & $28.9 \pm 1.8$ \\
\hline & TD-A & $16.2 \pm 1.2$ & $21.4 \pm 1.7$ \\
\hline & TD-B & $14.7 \pm 0.3$ & $21.1 \pm 0.6$ \\
\hline & TD-C & $16.2 \pm 1.4$ & $20.2 \pm 2.0$ \\
\hline
\end{tabular}

However, higher impact resistance values were found in samples tested in MD direction located at the extreme positions (MD-A and MD-C).Once again, the more random fiber orientation at the middle of the part made the impact resistance obtained in MD-B specimen equal to the average values resulted in the transversal direction (TD-B). By controlling a proper solid skin thickness and fiber orientation, it would be possible to produce lightweight products without sacrificing largely the impact properties. 


\subsubsection{Thermal aging}

After completing the mechanical characterization with non-aged specimens, additional flexural and impact tests were carried out in order to assess the evolution of these properties after different periods of time of exposure at $150{ }^{\circ} \mathrm{C}$. As the anisotropic mechanical behavior due to cell structure and fiber orientation has been already analyzed and discussed, only samples tooled in the extreme positions in MD-A and MD-C of the plates were employed for the aging study.

Several works have dealt with aging and degradation processes in polymers. At elevated temperatures, chemical and physical processes occur affecting the mechanical properties of the material. The most important degradation mechanism related to aging is oxidation [306]. It is initiated by free radicals on a polymer chain reacting with oxygen molecules.
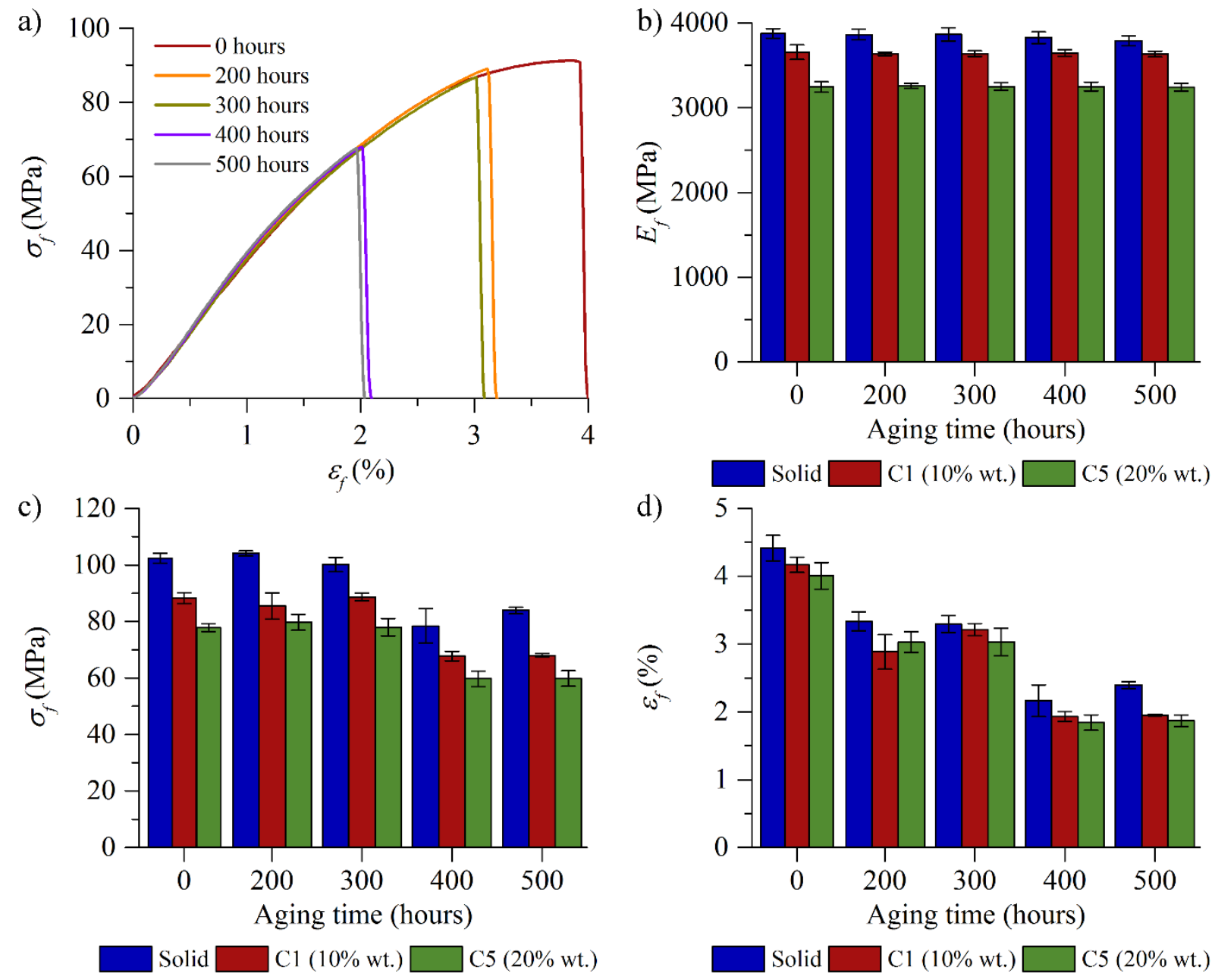

Figure 5.23. a) Flexural stress-strain curves of non-aged and aged foamed PP 20GF samples (10\% weight reduction); Evolution of flexural properties after different periods of aging time b) Flexural modulus; c) Flexural strength; d) Flexural strain. 
Once formed the peroxide radicals, slower propagation reactions undergo and result in chain scissions. Consequences of thermal aging are usually reductions in molecular weight distribution, surface contractions and embrittlement [307]. In PP GF composites, phase separation between matrix and filler has been also observed after certain aging induction time [308].

No changes in density nor deformations and visible surface degradations were seen after the different periods of aging time. Figure 5.23 shows representative stress-strain curves obtained from flexural tests of non-aged and aged foamed samples with $10 \%$ of weight reduction, as well as the flexural parameters resulting after the different periods of aging time. From them it can be concluded that all solid and foamed specimens followed the same degradation pattern. The elastic modulus remained unaltered after aging. The force, and therefore the flexural stress were kept constant after 400 hours of high temperature exposure, when they dropped by around $22 \%$, and remained equal for 100 more hours of aging. The flexural strain (and displacement) presented a more sensitive behavior to aging, with a decrease of around 25\% after 200 hours and an additional loss of $25 \%$ in strain after 400 hours. Wyzgoski [309] obtained a catastrophic drop in tensile elongation at break of PP after 400 hours exposed at $90^{\circ} \mathrm{C}$ in an oven, mainly caused by microcracks and crazes appeared in the surface and oxidative attack. However, in this work the temperature in the oven was higher $\left(150^{\circ} \mathrm{C}\right)$, which could accelerate the degradation process and anticipate the effect of aging on the flexural strain.

Similar conclusions can be drawn from the impact tests (Figure 5.24). Solid and foamed materials presented the same evolution of impact resistance loss due to foaming.
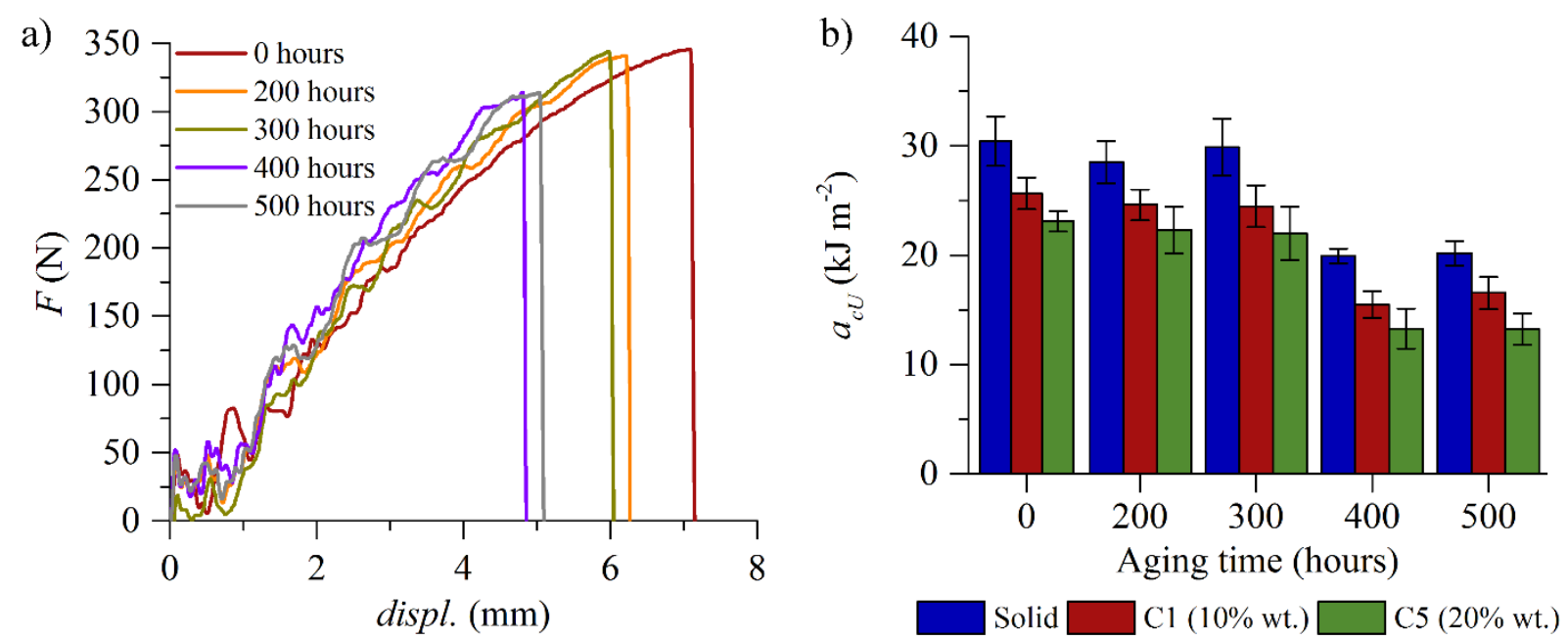

Figure 5.24. a) Impact force-displacement curves of non-aged and aged foamed PP 20GF samples (10\% weight reduction); b) Evolution of impact resistance different periods of aging time. 
The displacement at break decreased after 200 and 400 hours of aging. However, the maximum force did not change after 200 hours, but it decreased after 400 hours at high temperature exposure. Consequently, only a significant reduction of $40 \%$ in impact resistance was found after 400 hours.

\subsubsection{Fracture behavior}

\subsubsection{Crack Tip Opening Displacement CTOD}

Force-displacement curves obtained with SENT specimens and tested in TD directions are shown in Figure 5.25. As occurred with ABS material, conditions of crack propagation onset after full ligament collapse, crack propagation stability and curves parallelism were not fulfilled and therefore the Essential Work of Fracture method could not be applied for fracture characterization. The size of the plastic zone in the strain fields plotted in Figure 5.25 does not allow the application of the Linear Elastic Fracture Mechanics theories, either. Instead, the CTOD parameter was determined by Digital Image Correlation (DIC) technique, whose results are displayed in Table 5.12. Cells acting as crack arrestors by blunting the crack tip gave rise to an increase in $C T O D$ values with the foaming ratio (up to $15 \%$ in foamed samples with $10 \%$ of weight reduction and $10 \%$ in $20 \%$ of weight reduction when crack propagated in MD direction, and about $10 \%$ in the opposite direction).

In case of solid specimens, higher CTOD values were obtained in TD direction, which might be due to the preferential fiber orientation in the filling direction opposing crack propagation. However, the effect of fiber orientation became less influential while foaming, with more balanced CTOD values between MD and TD directions. In foamed SENT specimens with $20 \%$ of weight reduction, no great differences from both orientations were determined. As seen before, similar cell structure was examined in both directions, and more randomly fiber orientation is suggested in that region. Thus, the diminished solid skin thickness in this second series of foamed materials could have led to this more isotropic behavior, reaching similar CTOD values to that of foamed samples with $10 \%$ of weight reduction tested in TD direction.

Failure mechanisms of fiber-filled polymers can be classified into matrix-related (crazing, voiding, fracture, shear yielding) and fiber-related (debonding, bridging, pull-out and fracture) (Figure 5.26) [310]. Stress is concentrated at the fiber ends within the damage zone, prompting the occurrence of crazing in PP matrix, and debonding along the fiber surfaces. Then, crack propagates by connection of the different craze planes due to fiber 
debonding, pull-out and fracture together with matrix deformation (shear yielding and plastic deformation) [298]. Thus, fiber orientation has a remarked effect on crack propagation. Fiber aligned transversal to the crack path tends to restrict propagation and forces to follow a zigzag path, resulting in ductile failure, whereas fiber parallel to crack propagation direction enables brittle fracture. The occurrence of crazes degenerating in unstable crack propagation is the quasi-exclusive failure mechanisms for composites [311].
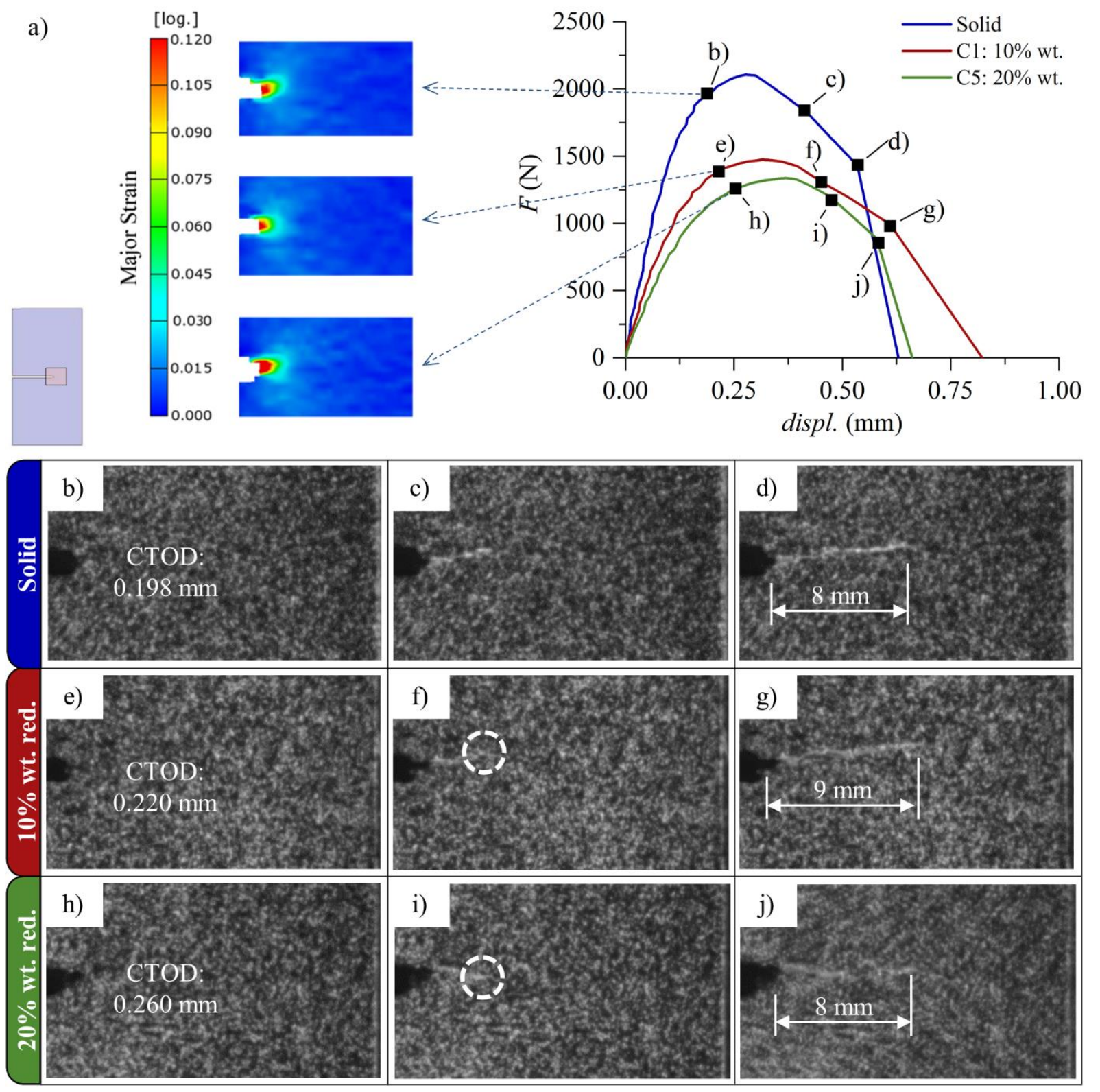

Figure 5.25. a) Strain field ahead of the crack tip at the crack propagation onset and force-displacement curves for solid and foamed samples tested in TD direction at $\left.\left.16 \mathrm{~mm} \mathrm{~min}^{-1} ; \mathbf{b}\right), \mathbf{e}\right), \mathbf{h}$ ) Micrographs taken at the crack propagation onset with the corresponding CTOD value; c) Stable crack propagation of solid samples; f), i) quasistable crack propagation of foamed samples with secondary cracks ahead of the main crack front, indicated into the white dashed circles; The stable crack propagation length is indicated in figures $\mathbf{d}$ ), $\mathbf{g}$ ), $\mathbf{j}$ ) for each material investigated before the catastrophic crack propagation. 


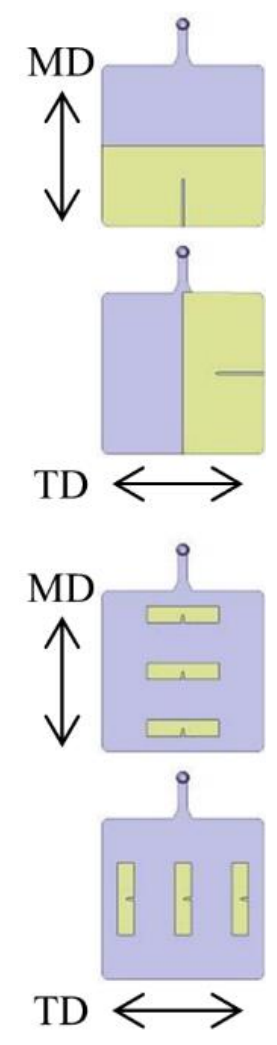

Table 5.12. CTOD and $K_{I c}$ of PP $20 \mathrm{GF}$ square plates.

\begin{tabular}{|c|c|c|c|}
\hline $\begin{array}{c}\text { Condition } \\
\text { No. }\end{array}$ & Section & $\begin{array}{c}C T O D \\
(\mathrm{~mm})\end{array}$ & $\begin{array}{c}K_{I c} \\
\left(\mathrm{MPa} \mathrm{m}^{-1 / 2}\right)\end{array}$ \\
\hline \multirow[t]{6}{*}{ Solid } & MD-A & - & $3.52 \pm 0.14$ \\
\hline & MD-B & $0.194 \pm 0.011$ & $3.95 \pm 0.15$ \\
\hline & MD-C & - & $4.44 \pm 0.13$ \\
\hline & TD-A & - & $4.02 \pm 0.19$ \\
\hline & TD-B & $0.226 \pm 0.020$ & $3.06 \pm 0.14$ \\
\hline & TD-C & - & $3.47 \pm 0.22$ \\
\hline \multirow[t]{6}{*}{ C1 (10\%) } & MD-A & - & $2.80 \pm 0.16$ \\
\hline & MD-B & $0.229 \pm 0.008$ & $2.41 \pm 0.18$ \\
\hline & MD-C & - & $2.88 \pm 0.13$ \\
\hline & TD-A & - & $2.86 \pm 0.15$ \\
\hline & TD-B & $0.249 \pm 0.020$ & $2.32 \pm 0.18$ \\
\hline & TD-C & - & $2.54 \pm 0.16$ \\
\hline \multirow[t]{6}{*}{ C5 $(20 \%)$} & MD-A & - & $1.84 \pm 0.18$ \\
\hline & MD-B & $0.254 \pm 0.014$ & $1.84 \pm 0.18$ \\
\hline & MD-C & - & $1.92 \pm 0.05$ \\
\hline & TD-A & - & $2.84 \pm 0.16$ \\
\hline & TD-B & $0.251 \pm 0.020$ & $1.59 \pm 0.12$ \\
\hline & TD-C & - & $2.41 \pm 0.07$ \\
\hline
\end{tabular}




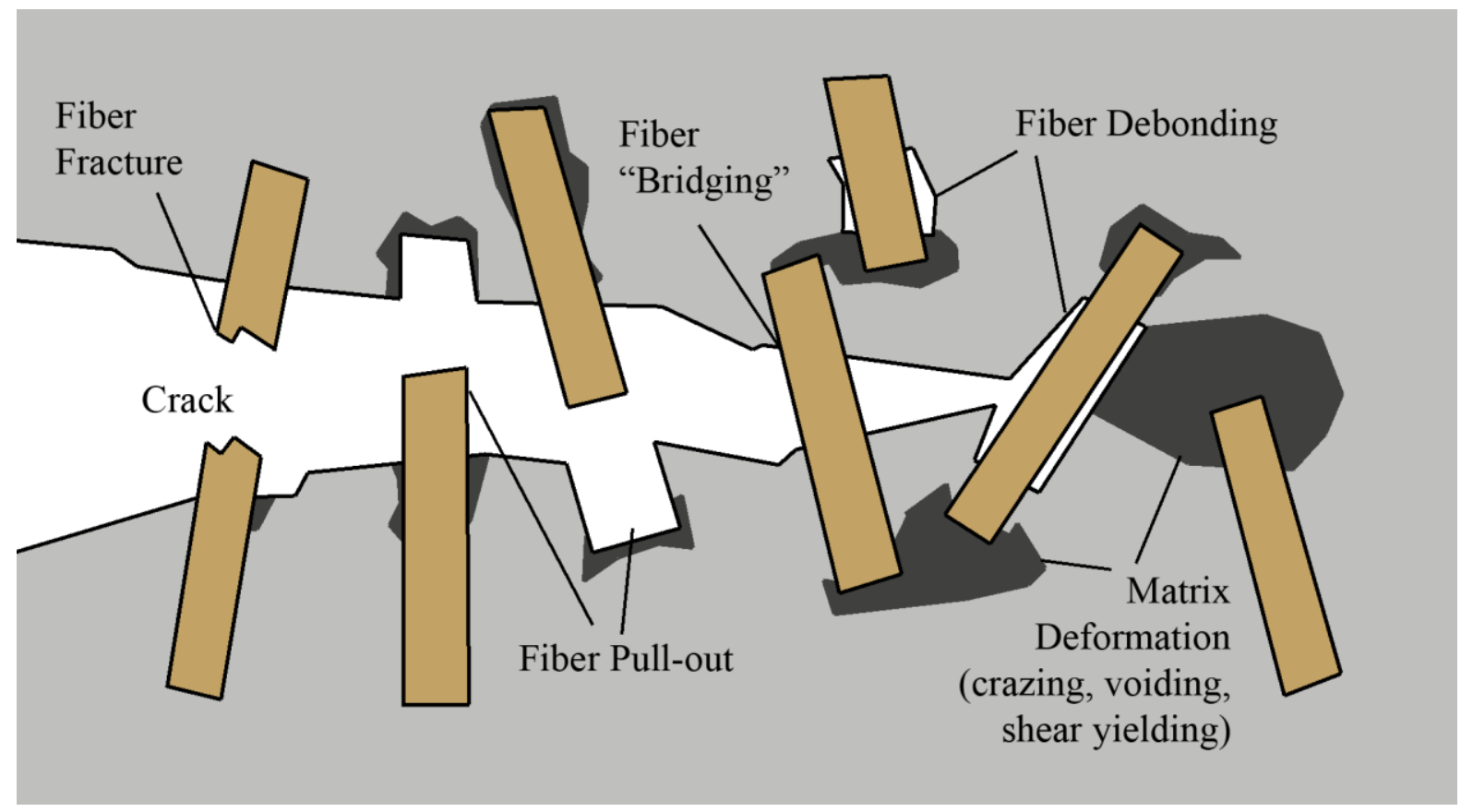

Figure 5.26. Failure mechanisms of discontinuous fiber-reinforced thermoplastics. Modified from [298].

Fiber "bridging" kept both crack faces fairly close to each other, so the analysis of the crack propagation was not an easy task with this material. As a matter of fact, values of CTOD of PP 20GF were half the ones measured with ABS previously.

The same quasi-stable crack propagation feature and the occurrence of secondary cracks ahead of the main crack tip reported in ABS foamed specimens was obtained with PP 20GF. To get a better insight into the crack propagation phenomena, fracture surfaces were analyzed by Scanning Electron Microscopy (Figure 5.27). The areas near the notch with quasi-stable crack propagation showed typical ductile rough fracture surface, characterized by ridges and peaks due to material tearing. When unstable failure takes place, the corresponding areas exhibited smooth surfaces due to the brittle fracture.

As highlighted in Figure 5.27, the ductile-brittle behavior transition was not performed uniformly along the whole thickness of the sample, but the ductile region was more extended in the foamed core than in the solid skin. That is, the crack in the core propagated ahead of the main crack tip in the compact surface layers and triggered the emergence of the secondary cracks highlighted in Figure 5.25f) and Figure 5.25i). In all cases, the ligament length of stable or quasi-stable crack propagation was around 8-9 $\mathrm{mm}$. 
a)
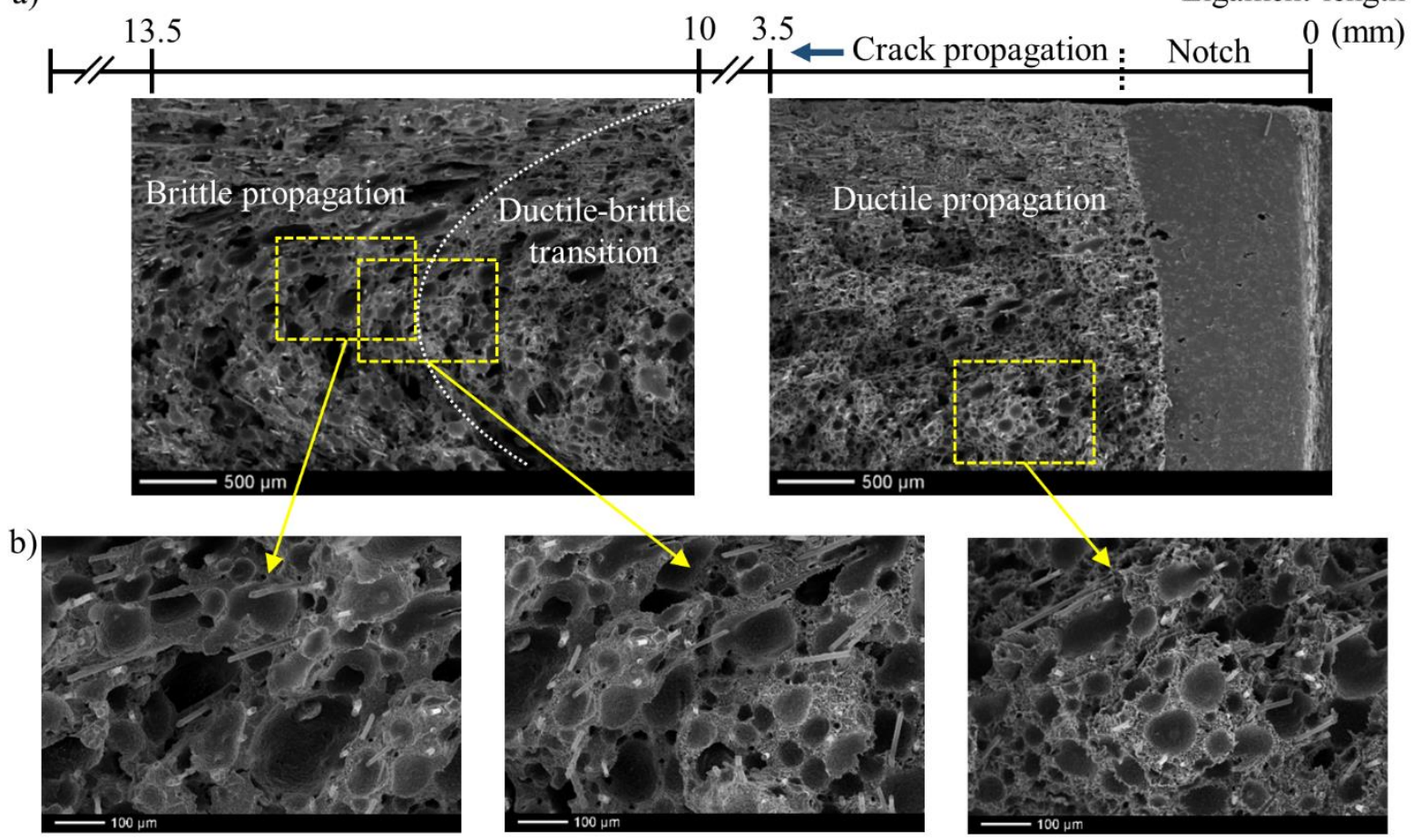

Figure 5.27. a) General overview of fracture surface in different ligament regions of a foamed SENT sample with $10 \%$ of weight reduction tested in MD direction; b) Details of different crack propagation modes.

\subsubsection{Fracture toughness $K_{\text {Ic }}$}

The fracture toughness obtained in solid and foamed samples from high speed tests are summarized in Table 5.12. Early studies on the effect of glass fiber on the fracture behavior of polymers showed an increase in fracture toughness for brittle matrix materials, but a decrease for initially ductile ones [312]. For thick samples under high loading speed, the crack tips are under plane-strain condition and brittle fracture of cell walls around crack tip is promoted [313]. Examination of fracture surfaces revealed that brittle matrix failure and fiber bridging and pull-out were the main fracture mechanisms, although fiber breakage was expected at high loading rates, decreasing toughness [275].

Due to stress concentration on cell walls, lower density and energy absorption capability, the fracture toughness decreased by around $20 \%$ and $40 \%$ with the foaming ratio (10\% and $20 \%$ of weight reduction, respectively). In TD direction, solid and foamed samples taken from the extreme areas (TD-A and TD-C) presented higher $K_{I c}$ than the central section (TD-B). From all the analysis above it was observed that the middle of the plate is a region with scarcely dependence on fiber orientation, where properties in both transversal directions were almost equal (TD-B and MD-B). Similar conclusions were found by [Hartl et al. [314]] with notched samples tooled from the center area of PP/GF plates under Charpy impact tests. 
Fiber orientation plays a relevant role on fracture toughness at high impact loads. Table 5.12 points out an increase in values of $K_{I c}$ in solid samples tested in MD direction as the distance from the injection gate increases, even higher than that obtained in TD direction. This might be due to the alignment of fibers in the transverse direction to filling in the core region, opposing to crack propagation. Differences in fracture toughness of foamed samples between extreme and central samples (TD-A, TD-B and TD-C) were small. In the opposite direction, lower and similar values of $K_{I c}$ were determined in all tested specimens (MD-A, MD-B and MD-C) for each foaming condition.

In neat polymers, density arises as the main factor influencing the mechanical and fracture properties. Nevertheless, fillers play an important role on this mechanical and fracture behavior, and contribute to overcome the loss in properties due to foaming and density reduction. It can be observed in highly fiber oriented specimens (such as TD-A and TD-C), where similar fracture toughness was obtained for foamed samples with $10 \%$ and $20 \%$ of weight reduction levels.

The same models presented in Chapter 4 were employed to assess their accuracy with foamed composite materials. Average values in TD-A and TD-C, and in MD-A, MD-B and MD-C were taken for the calculations in both directions. The simplest model presented by Kabir et al. [238] (Equation (4.7)) provided estimated fracture toughness values of $2.58 \mathrm{MPa}$ $\mathrm{m}^{-1 / 2}$ and $1.99 \mathrm{MPa} \mathrm{m}^{-1 / 2}$ for both levels of weight reduction in MD direction, and 2.61 MPa $\mathrm{m}^{-1 / 2}$ and $2.15 \mathrm{MPa} \mathrm{m} \mathrm{m}^{-1 / 2}$ in the opposite orientation. Deviation of these results from experimental data was less than $10 \%$, except for the case of $20 \%$ of weight reduction and crack propagation in TD direction, where the maximum error reached $24 \%$.

The second model used in this work was suggested by Maiti et al. [239] (Equation (4.8)) and involves additional features of the foamed material like cell walls strength in bending and the average cell size. Due to the wide range of cell size measured in the samples of this study, the cell diameter with most frequency (approximately $18 \mu \mathrm{m}$ ) was taken, instead of the average value. Thus, the predicted values from this model for MD direction were 3.15 $\mathrm{MPa} \mathrm{m}^{-1 / 2}$ and $2.43 \mathrm{MPa} \mathrm{m}^{-1 / 2}$ (10\% and $20 \%$ of weight reduction) whereas they resulted in 3.67 $\mathrm{MPa} \mathrm{m}^{-1 / 2}$ and 3.02 $\mathrm{MPa} \mathrm{m}^{-1 / 2}$ in the transverse direction. It can be seen that the fracture toughness estimated by this model were higher than that of the first one and they deviate from the experimental data in around 15\%-20\%. The less accuracy of these models for PP 20GF as compared to that determined with ABS might be explained by the wider cell size distribution, as well as the effect of fiber orientation, since they are not considered in the equations. 


\subsubsection{Differential Scanning Calorimetry}

Differential Scanning Calorimetry tests were performed on samples tooled from the center of the injected plates (section C, Figure 3.5). For semicrystalline polymers, such as PP, crystallization behavior is crucial on the final performance of the polymeric products. For instance, it has been demonstrated that plastic deformation is governed by the amorphous phase [315], while impact strength is contributed by crystalline regions [166]. Some studies also found that crystalline phase improves the mechanical properties of microcellular PP [316]. Therefore, knowing the degree of crystallinity and possible variations due to foaming is essential so as to predict changes in ductile/brittle behavior.

Fillers, such as glass fibers, have been found to act as nucleating agents increasing crystallinity [317] and promoting molecular orientation [318]. Inside an injection molded part, Djoumaliisky et al. [319] determined a greater crystallinity in the surface layers than in the core, due to crystallization induced by shear stress. Therefore, while not being the main objective of this research the characterization of both areas separately, samples for DSC tests were taken from sections near the surface and in the middle plane of the plates, in order to determine possible differences in thermal properties between skin and core regions. The resulted thermograms are plotted in Figure 5.28.

Despite heating from $-20{ }^{\circ} \mathrm{C}$ to $210^{\circ} \mathrm{C}$, no changes in the curves corresponding to glass transition temperature $\left(T_{g}\right)$ were observed. In the fusion region, two peaks were detected (Figure 5.28a)). The lower one occurred at around $122^{\circ} \mathrm{C}$ and corresponds to a small ethylene fraction [117] present in the copolymer with the aim of improving impact resistance of automotive parts. The ethylene content in copolymers used for industrial components usually ranges from $5 \%$ to $15 \%$ [320]. Since it was unknown for this commercial grade, crystallinity degree was calculated for both limits (Table 5.13). The larger peak corresponds to the PP, and it took place at around $163{ }^{\circ} \mathrm{C}$ during the first heating cycle, similar to that reported in the literature [193].

Some authors observed plasticization effect of gases on polymer matrix reducing viscosity, crystallization rate, crystallization temperature, crystallinity, glass transition temperature and melting temperature [246, 321]. Contrarily, Pilla et al. [176] with Poly(Lactic Acid) (PLA) nanocomposites and Srithep and Turng [167] with recycled Poly(Ethylene Terephthalate Glycol) (PETG) reported higher degree of crystallinity of microcellular polymers as compared to the solid counterpart. 
a)

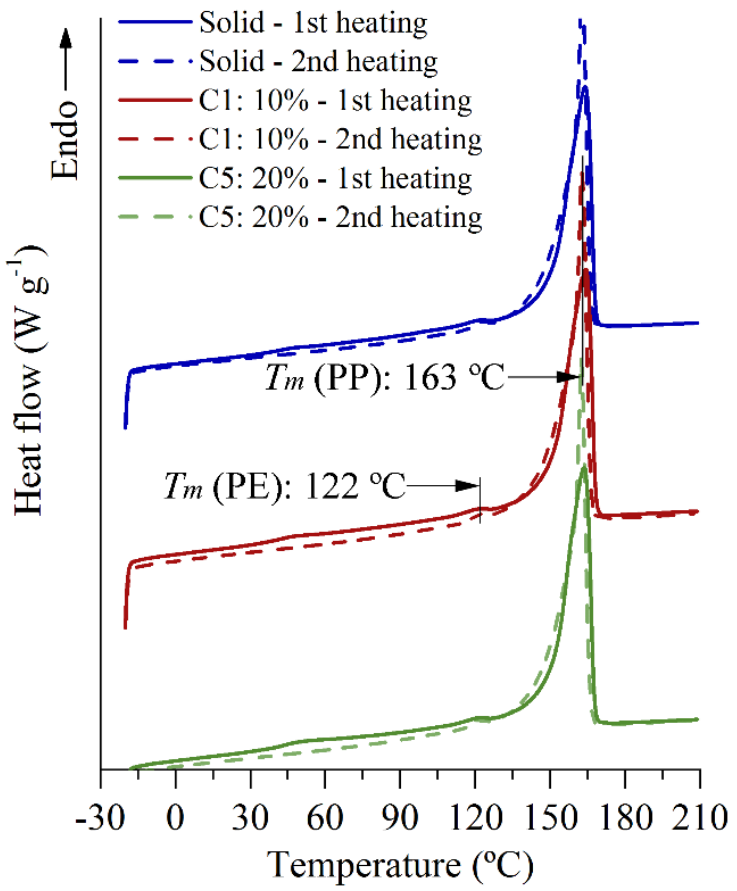

c)

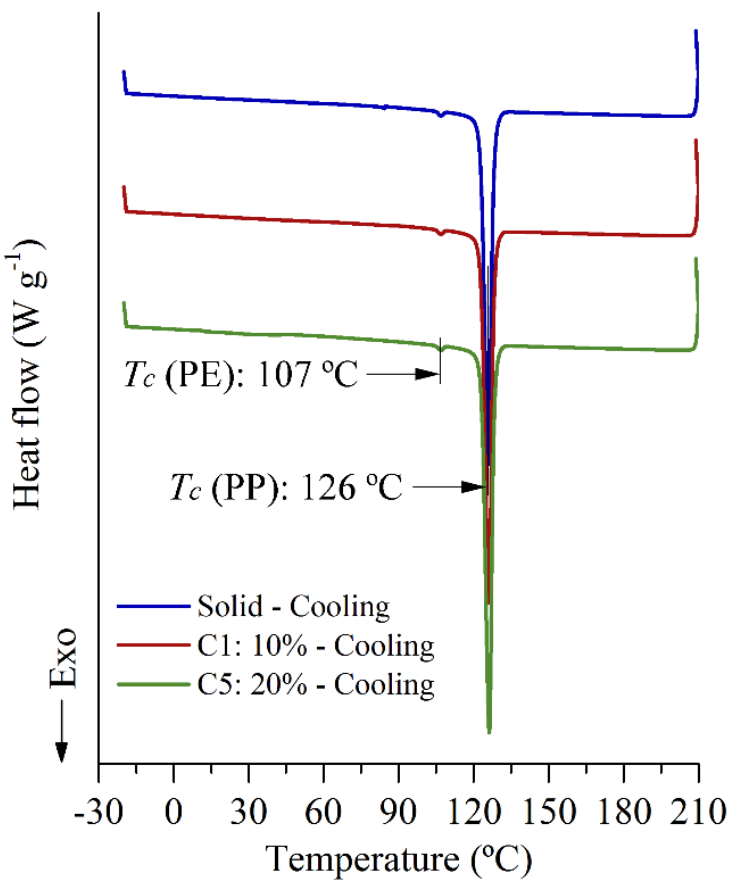

b)

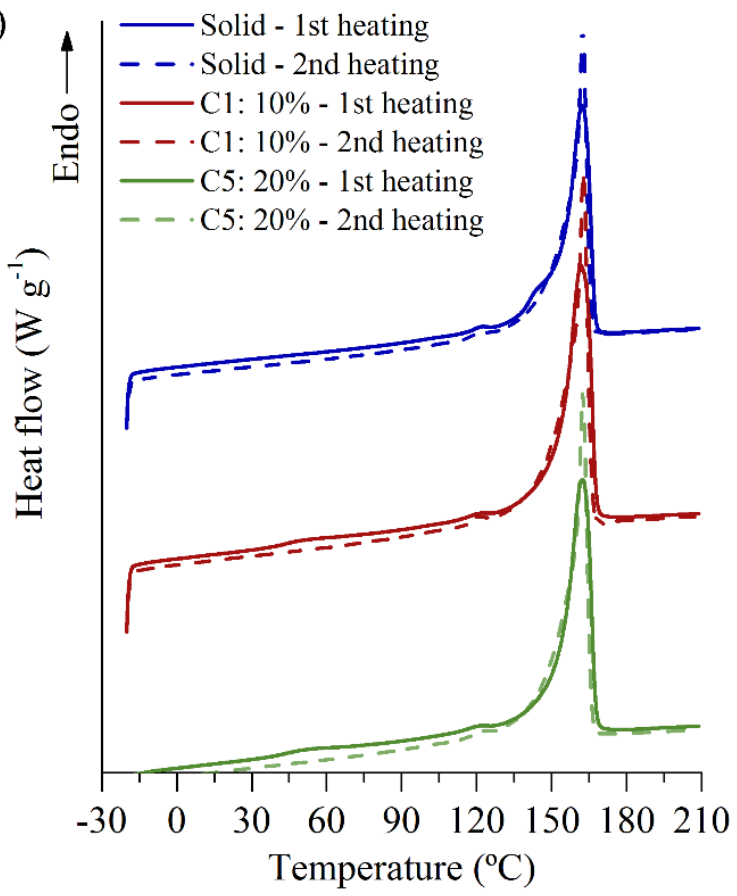

d)

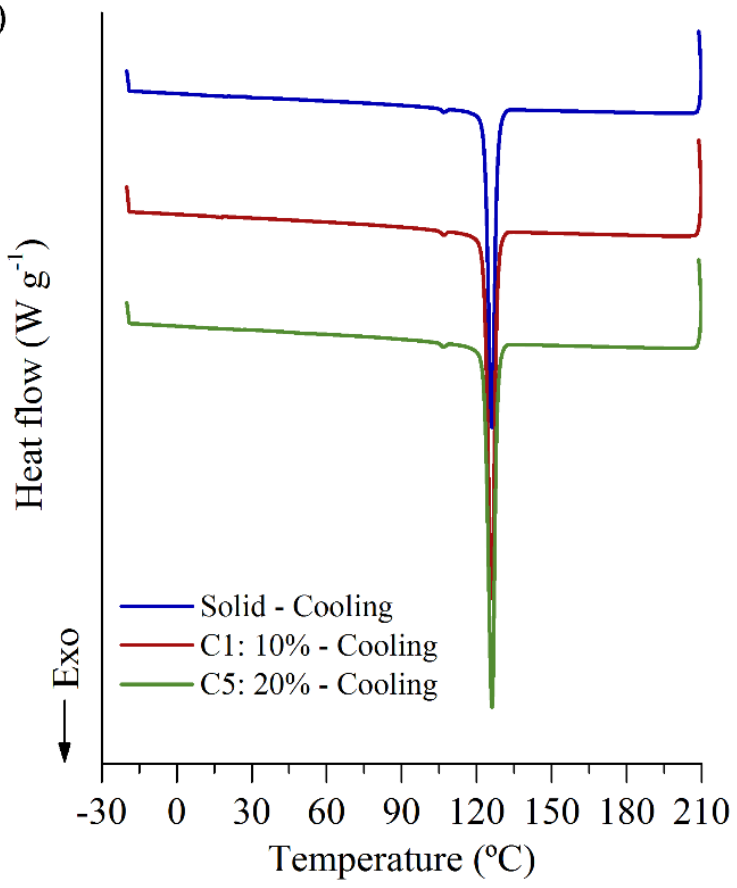

Figure 5.28. First and second heating thermograms of solid and foamed samples in a) Skin; b) Core; Cooling cycle thermograms of solid and foamed samples in c) Skin; d) Core layers.

In contrast to all these studies, the samples tested in this work did not experience significant changes in the enthalpy, melting and crystallization temperature and crystallinity levels reported in Table 5.13. According to Edwards et al. [141], this results suggest that either the microcellular injection molding process did not influence crystallinity, because the low gas content introduced into the melt polymer and the short time of dissolution were not enough to penetrate into the space between polymer chains and alter the chain mobility and 
free volume characteristics, or that cells were formed in amorphous regions of the matrix. During the first heating, melting was at $163{ }^{\circ} \mathrm{C}$ and the exothermic enthalpy was measured as around $65 \mathrm{~J} / \mathrm{g}$. The crystallization peak of PP was observed at a temperature of around $126^{\circ} \mathrm{C}$, with and endothermic enthalpy of $70 \mathrm{~J} / \mathrm{g}$. A second crystallization peak at $107{ }^{\circ} \mathrm{C}$ was also detected, which corresponds to the phase of PE (Figure 5.28c)). After second heating scan, prior thermal history of the injection molded plates was deleted and direct comparison of the crystallization of solid and foamed materials can be conducted. A slight increase in melting enthalpy was obtained (around $69 \mathrm{~J} / \mathrm{g}$ ), which results in crystallinity levels between $40.7 \%$ and $38.6 \%$. However, the fusion process of PP occurred at the same temperature of $163{ }^{\circ} \mathrm{C}$. In conclusion, the addition of gas while foaming had no remarkable effects on the thermal properties of PP 20GF.

Table 5.13. DSC data of solid and foamed PP 20GF in the surface and core of the injected plates.

\begin{tabular}{|c|c|c|c|c|c|c|c|c|c|}
\hline \multirow{2}{*}{$\begin{array}{c}\text { Condition } \\
\text { No. }\end{array}$} & \multirow[t]{2}{*}{ Section } & \multicolumn{2}{|c|}{$1^{\text {st }}$ heating } & \multicolumn{2}{|c|}{ Cooling } & \multicolumn{2}{|c|}{$2^{\text {nd }}$ heating } & \multicolumn{2}{|c|}{ Crystallinity* } \\
\hline & & $\begin{array}{l}T_{m 1} \\
\left({ }^{\circ} \mathrm{C}\right)\end{array}$ & $\begin{array}{r}\Delta H_{m 1} \\
(\mathrm{~J} / \mathrm{g})\end{array}$ & $\begin{array}{c}T_{c} \\
\left({ }^{\circ} \mathbf{C}\right)\end{array}$ & $\begin{array}{l}\Delta H_{c} \\
(\mathrm{~J} / \mathrm{g})\end{array}$ & $\begin{array}{l}T_{m 2} \\
\left({ }^{\circ} \mathrm{C}\right)\end{array}$ & $\begin{array}{c}\Delta H_{m 2} \\
\left({ }^{\circ} \mathrm{C}\right)\end{array}$ & $\begin{array}{l}X_{c 5 \%} \\
(\%)\end{array}$ & $\begin{array}{c}X_{c 15 \%} \\
(\%)\end{array}$ \\
\hline \multirow[t]{2}{*}{ Solid } & Surface & 163.9 & 64.8 & 125.9 & 69.1 & 162.8 & 68.6 & 40.5 & 38.9 \\
\hline & Core & 162.1 & 62.2 & 126.1 & 69.9 & 162.4 & 68.9 & 40.7 & 39.1 \\
\hline \multirow[t]{2}{*}{ C1 $(10 \%)$} & Surface & 165.3 & 67.8 & 128.1 & 70.5 & 162.7 & 70.1 & 41.4 & 39.8 \\
\hline & Core & 161.6 & 67.3 & 126.1 & 70.4 & 162.7 & 70.3 & 41.5 & 39.9 \\
\hline \multirow[t]{2}{*}{ C5 (20\%) } & Surface & 163.5 & 67.9 & 128.2 & 70.3 & 162.5 & 69.4 & 41.0 & 39.4 \\
\hline & Core & 162.3 & 64.4 & 126.1 & 68.7 & 162.6 & 68.0 & 40.2 & 38.6 \\
\hline
\end{tabular}

$* X_{c 5 \%}$ and $X_{c 15 \%}$ calculated from second heating melting enthalpy for 5\% and $15 \%$ of ethylene weight fraction.

\subsubsection{Heat Deflection Temperature}

Heat Deflection Temperature tests were made on specimens tooled from the injected plates in MD direction. The obtained results are illustrated in Table 5.14. A deflection of 0.24 mm was reached by solid samples of the extreme positions at about $152{ }^{\circ} \mathrm{C}$, similar to that obtained with PP reinforced with long glass fiber [322], while foamed samples did it at around $145^{\circ} \mathrm{C}$, that is, $5 \%$ less of temperature. 
Table 5.14. Heat Deflection Temperature (HDT) of PP 20GF square plates.

\begin{tabular}{ccc}
\hline Condition No. & Section & $\boldsymbol{H D T}\left({ }^{\circ} \mathbf{C}\right)$ \\
\hline Solid & MD-A & $151.8 \pm 0.4$ \\
& MD-B & $140.7 \pm 1.6$ \\
& MD-C & $152.2 \pm 1.1$ \\
C1 $(10 \%)$ & MD-A & $144.9 \pm 3.0$ \\
& MD-B & $131.9 \pm 1.9$ \\
& MD-C & $146.0 \pm 0.4$ \\
C5 (20\%) & MD-A & $145.3 \pm 0.8$ \\
& MD-B & $125.6 \pm 2.3$ \\
& MD-C & $145.2 \pm 2.1$ \\
\hline
\end{tabular}

It is noticeable the same HDT values obtained in both foamed series in MD-A and MDC specimens, which came from locations with maximum fiber orientation. Due to a lower stiffness in the middle position (MD-B), solid samples reached that deflection at $140.7^{\circ} \mathrm{C}$, and this temperature was reduced up to $131.9^{\circ} \mathrm{C}$ and $125.6^{\circ} \mathrm{C}$ with foamed specimens, which represents a decrease of $6 \%$ and $11 \%$, respectively. As the flexural modulus of foamed samples diminished around $6 \%$ and $14 \%$ with the foaming ratio, and since no changes in crystallinity and melting temperature have been determined through DSC tests, the reduction in $H D T$ values cannot be attributed to changes in the chemical structure of these plates, but to the lower stiffness of the foamed materials.

\subsection{Conclusions}

Glass fiber-reinforced Polypropylene was injection molded into cylindrical bars and square plates under solid and foaming conditions. Their morphology, mechanical and thermal characteristics were analyzed and related to processing parameters. The main conclusions obtained from this study can be summarized as follows:

- Heterogeneous nucleation induced by glass fibers was the main cell forming mechanism of the studied material. Despite the weak melt strength and semicrystalline nature of PP, the incorporation of the filler decreases the energy 
barrier leading to uniform cell distribution along the part and cell densities comparable to that reported with ABS in the previous Chapter.

- Among the different analyzed processing parameters, shot volume and gas content level were found as the most influencing ones. However, their effect on morphology was contrary to that observed in ABS. Generally, the decrease in shot size and increase in the amount of blowing agent remained cell density unchanged but increased cell size. It could be due to the lower melt strength of PP as compared to ABS, which might lead to massive cell coalescence with increasing the gas content. By increasing shot volume, the higher effective sectional area enhanced the mechanical performance of the parts.

- Although mold temperature and injection speed produced some variations in cell morphology, none of them seemed to effect significantly flexural modulus and strength of microcellular materials.

- Together with apparent density, fiber orientation arose as a dominant factor on mechanical properties. From Computed Tomography analysis, a preferential alignment of fibers in the transverse direction to filling in the core was observed, as well as more random and oriented fibers in the filling direction in the surface layers and extreme positions. This led to an anisotropic behavior of the mechanical performance of the injection molded part depending on the location and testing direction, which was not hampered by foaming.

- Those locations with preferential fiber orientation tended to increase mechanical properties in the concurrent loading direction overcoming partially the loss of properties due to foaming and density reduction. It has been observed in flexural, impact and HDT tests. In case of fracture, fibers oriented perpendicular to crack direction opposed to its propagation and increased fracture toughness.

- Accelerated thermal aging tests showed the same degradation mechanisms and deterioration of flexural and impact properties between solid and foamed samples after different periods of time of exposure at high temperature. Likewise, the small amount of gas incorporated during foaming and the short time of dissolution prevented from changes in crystallinity levels, enthalpies and crystallization and melting temperatures due to foaming. 
- As with ABS, Moldex 3D® provided valid data to well predict the distribution cell density and cell size during the microcellular injection molding process. Prediction models of tensile and flexural properties and fracture toughness of plastic foams were employed and fitted accurately with experimental data when values in locations with most fiber orientation were used for validation. In other instances estimated results further deviated from the ones obtained from experimental methods. None of these models considered fiber length and orientation as input parameter for predicting the different properties. 
- 164 - 


\section{Chapter 6:}

\section{MuCell@ vs IQ Foam®}

In Chapter 4 and Chapter 5 microcellular ABS and PP 20GF samples have been characterized. From these analysis and literature review it can be concluded that the reduction in weight due to foaming is achieved with the detriment in some other properties of the material, such as surface quality and mechanical performance.

In section 2.2.4 of Chapter 2 different tool technologies to overcome some of these drawbacks were described. Particularly, the Core Back expansion molding has been employed in this study. Different strategies lie behind this technology consisting of expanding the cavity volume after it is completely filled by the polymer/gas system. On one hand, increasing pressure at the beginning stages of injection and preventing foam generation until the complete filling and solidification of the skin layers, thus improving surface quality [114]. On the other hand, two approaches can be taken concerning mechanical properties. It is possible either to keep the weight but enhance stiffness by increasing the thickness, or maintaining stiffness while reducing the weight of the part [193].

Alternative techniques of foaming through injection molding in order to decrease economical investment and processing difficulties have been also presented in Chapter 2. In this study, MuCell® is compared to a new technology, IQ Foam®, developed by Volkswagen Konzernforschung. MuCell® introduces the gas at supercritical conditions into the molten polymer in the barrel of the injection machine, whereas IQ Foam ${ }^{\circledR}$ injects the gas at lower pressure with the polymer in pellets form in a chamber unit between the hopper and the feed zone of the machine. Hence, differences in the quality of the final products could occur due to the different operating principles of both foaming technologies.

In the present Chapter the effect of mold cavity expansion through the Core Back tool technology on the foaming behavior of PP 20GF injection molded plates is studied. Moreover, a comparison between MuCell@ and IQ Foam ${ }^{\circledR}$ technologies is presented, in terms of morphology and tensile, flexural and impact properties of microcellular PP 20GF resulted from both foaming processes. 


\subsection{Morphology and apparent density}

SEM micrographs taken from MuCell® and IQ Foam® microcellular samples are plotted on Figure 6.1, Figure 6.2, Figure 6.3 and Figure 6.4. For the investigation of the effect of Core Back technique as well as foaming technology, the cell structure was investigated at the beginning (A), the middle (B) and the end of the flow path (C), in both parallel (MD) and transversal (TD) directions.
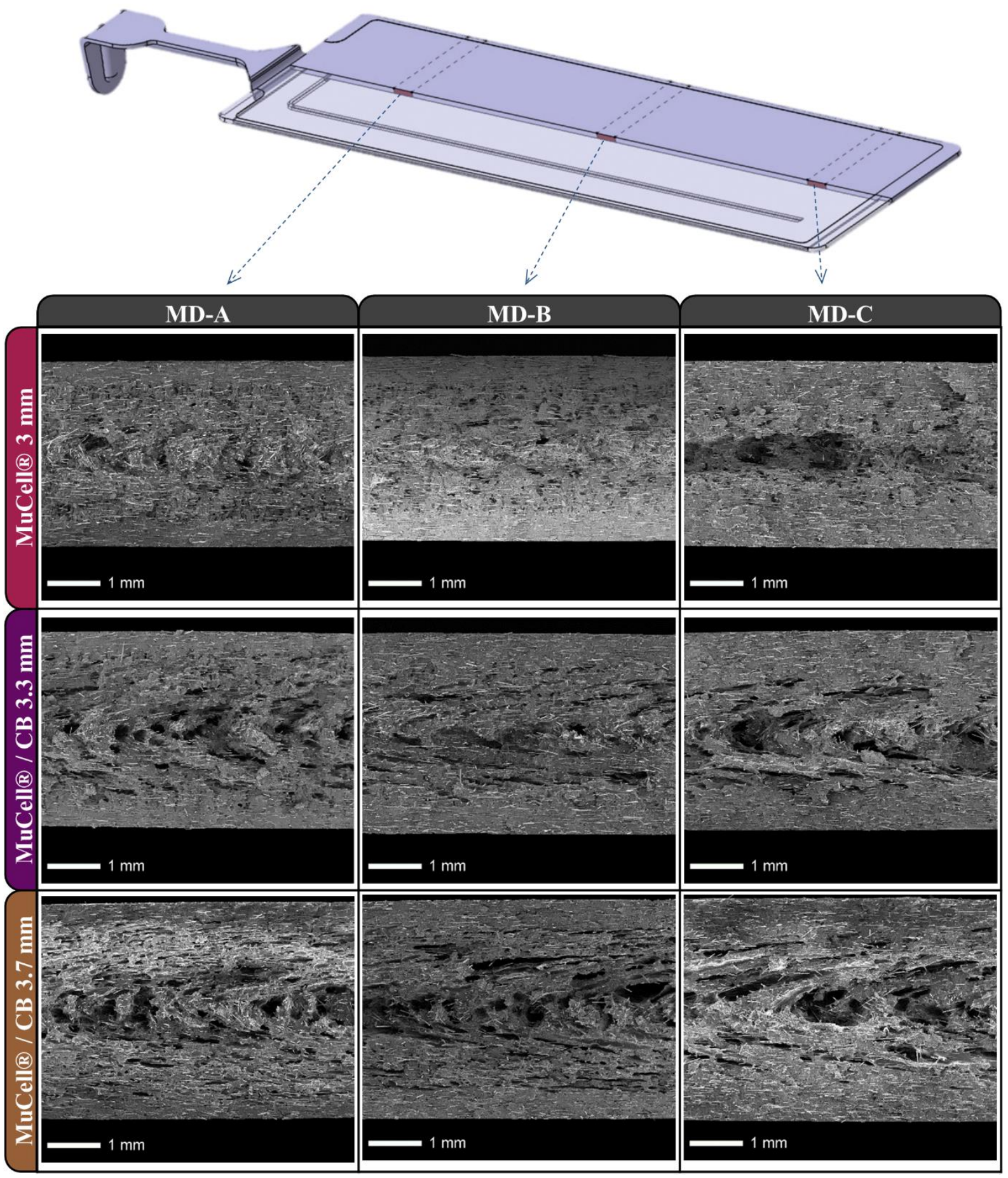

Figure 6.1. SEM micrographs of MuCell@ foamed plates taken in MD direction. CB: Core Back. 


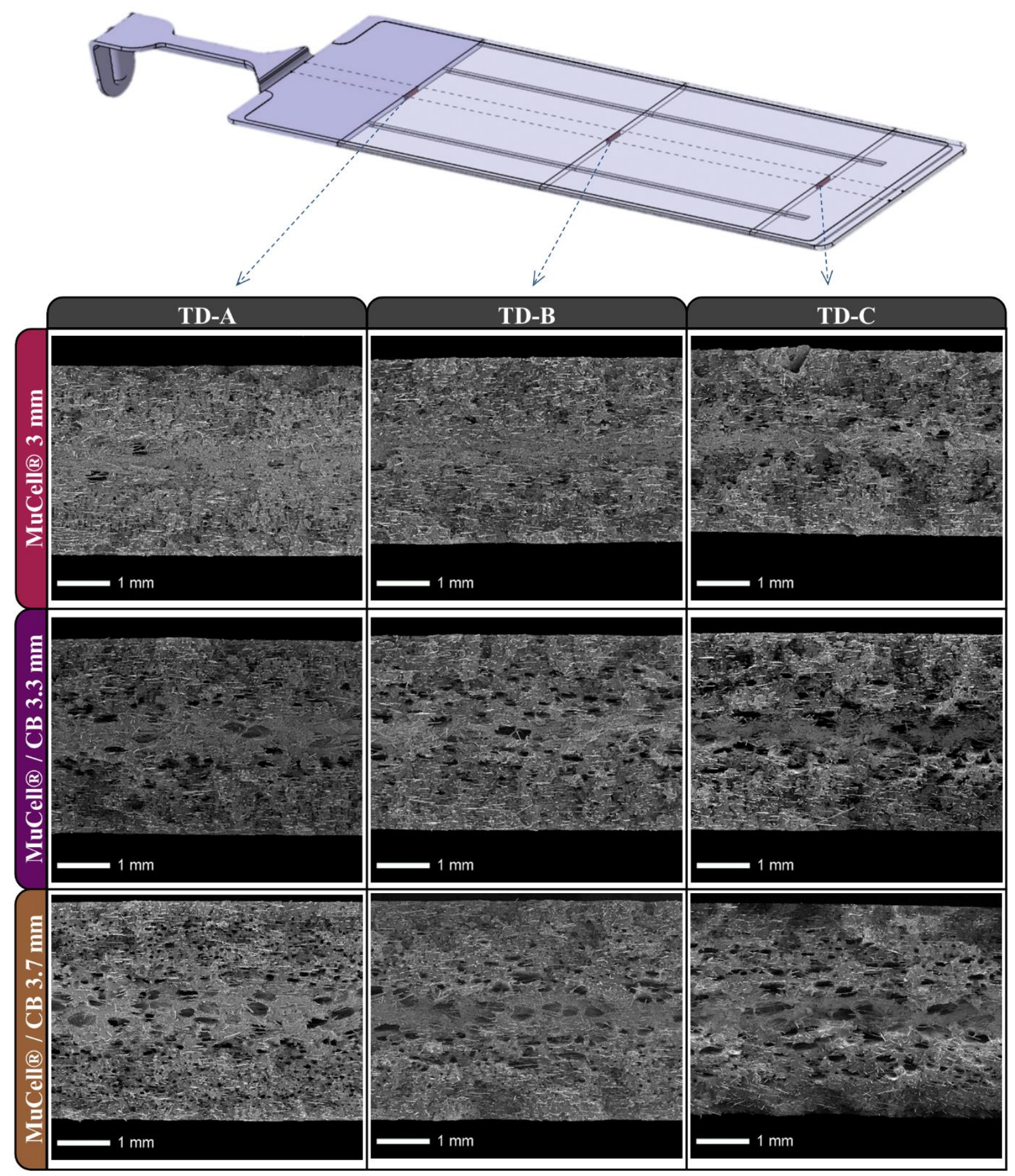

Figure 6.2. SEM micrographs of MuCell® foamed plates taken in TD direction. CB: Core Back.

In MD direction, mostly spherical cells can be observed at the starting thickness of 3 $\mathrm{mm}$ without using Core Back expansion. By increasing the thickness up to $3.3 \mathrm{~mm}$ and 3.7 $\mathrm{mm}$, cells became distorted and elongated, and higher diameters were determined. In the Core Back method, the cavity was volumetrically filled with the polymer/gas system, then the thickness of the mold cavity was quickly increased to a predefined extent reducing the pressure and thus enhancing cell nucleation. According to experiments carried out by Heim 
and Tromm [114], bubble nucleation occurred once the cavity is fully filled and the pressure drops due to the mold plate movement. Ahmadzai et al. [119] explained two opposite mechanisms governing the foaming behavior in the Core-Back technology. On one hand, the increased volume provides more space for foam expansion. On the other hand, the reduced pressure also induces the scape of a higher amount of gas from the polymer to the environment, lowering the portion of blowing agent for cell nucleation and growth.

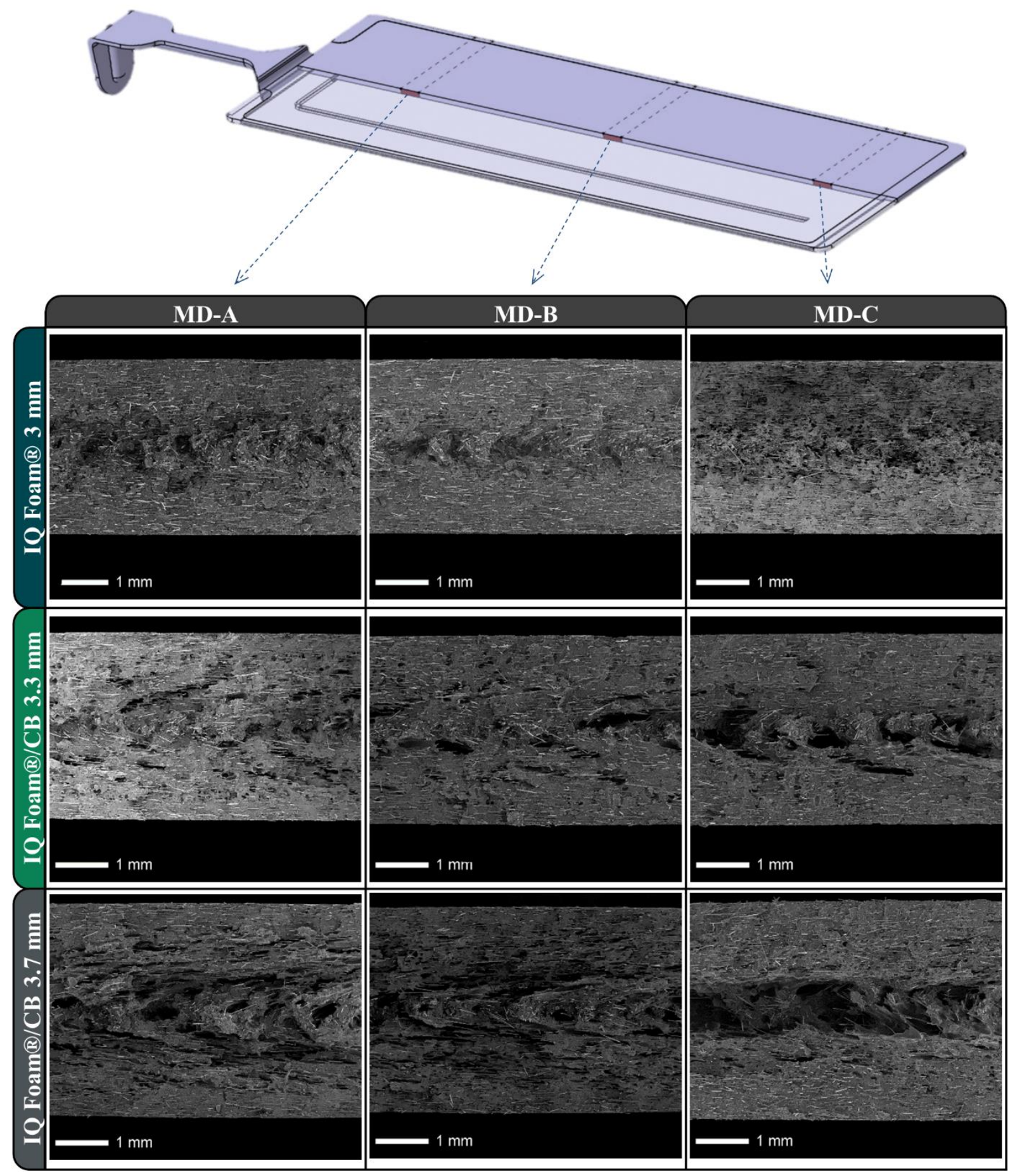

Figure 6.3. SEM micrographs of IQ Foam ${ }^{\circledR}$ foamed plates taken in MD direction. CB: Core Back. 

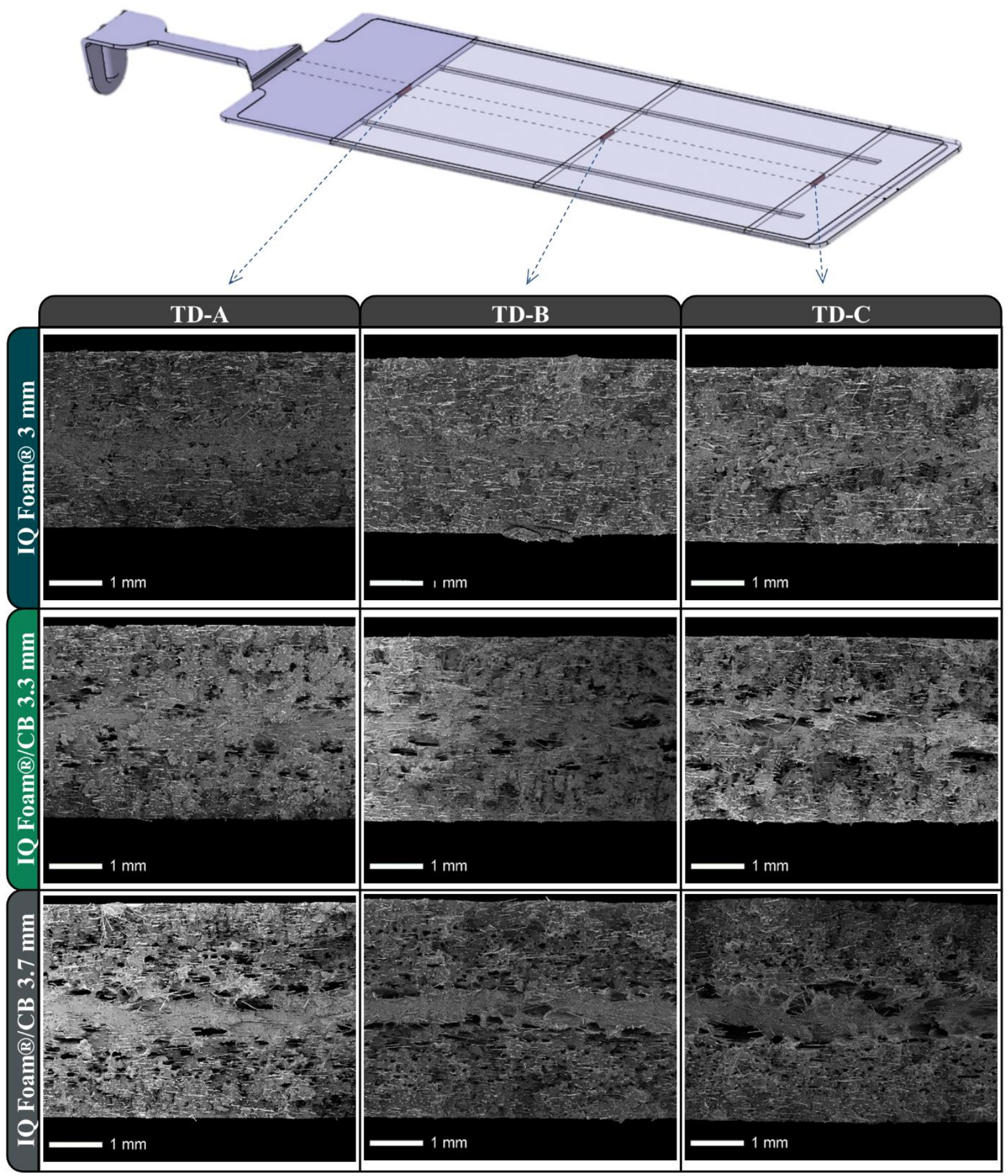

Figure 6.4. SEM micrographs of IQ Foam® foamed plates taken in TD direction. CB: Core Back.

According to the previous Figures, the former mechanism seems to be the predominant in the foamed plates of this work. Stretching forces caused by the mold opening could cause cell elongation, also accompanied by shrinkage of cell walls while polymer cooling [323, 324]. That is why bigger and distorted cells can be observed, as have been also reported by Spörrer and Altstädt [142] and Heim and Tromm [325]. Ruiz et al. [326] also observed that cell growth continues after the Core Back movement, but most of the process is due to 
depressurization and mold opening. Some research works also indicated a slightly increase in the solid skin thickness with increasing the pulling core distance $[142,325]$. Nevertheless, qualitative and quantitative analysis in this study pointed out to unchanged or thinner layers while cavity expansion. As the thickness increased, the core region remained at the molten state for a longer time leading to thinner solid skin layers [119, 324].

Table 6.1. Morphological parameters in different sections of MuCell® foamed PP 20GF plates.

\begin{tabular}{|c|c|c|c|c|c|c|}
\hline $\begin{array}{c}\text { Condition } \\
\text { No. }\end{array}$ & Section & $\begin{array}{l}\text { Density } \\
\left(\mathrm{g} \mathrm{cm}^{-3}\right)\end{array}$ & $\begin{array}{c}\text { Skin } \\
\text { thickness } \\
(\mathbf{m m})\end{array}$ & $\begin{array}{c}\text { Cell } \\
\text { density } \\
\left(\text { cells } \mathbf{c m}^{-3}\right)\end{array}$ & $\begin{array}{c}\text { Cell size } \\
\text { range } \\
(\boldsymbol{\mu m})\end{array}$ & CDI \\
\hline \multirow[t]{6}{*}{ MuCell@ 3 mm } & MD-A & $0.94 \pm 0.01$ & 0.37 & $9.5 \cdot 10^{5}$ & $9-162$ & 1.26 \\
\hline & MD-B & $0.94 \pm 0.01$ & 0.41 & $7.1 \cdot 10^{5}$ & $9-165$ & 1.40 \\
\hline & MD-C & $0.94 \pm 0.02$ & 0.51 & $8.5 \cdot 10^{5}$ & $6-158$ & 1.31 \\
\hline & TD-A & $0.94 \pm 0.01$ & 0.37 & $9.7 \cdot 10^{5}$ & $8-163$ & 1.31 \\
\hline & TD-B & $0.94 \pm 0.01$ & 0.42 & $8.5 \cdot 10^{5}$ & $9-125$ & 1.28 \\
\hline & TD-C & $0.94 \pm 0.02$ & 0.48 & $7.8 \cdot 10^{5}$ & $8-158$ & 1.33 \\
\hline \multirow{6}{*}{$\begin{array}{c}\text { MuCell@ / Core } \\
\text { Back } 3.3 \mathrm{~mm}\end{array}$} & MD-A & $0.90 \pm 0.01$ & 0.31 & $7.1 \cdot 10^{5}$ & $9-226$ & 1.70 \\
\hline & MD-B & $0.90 \pm 0.01$ & 0.46 & $8.4 \cdot 10^{5}$ & $9-263$ & 1.99 \\
\hline & MD-C & $0.90 \pm 0.01$ & 0.52 & $7.1 \cdot 10^{5}$ & $3-268$ & 1.93 \\
\hline & TD-A & $0.90 \pm 0.01$ & 0.23 & $7.5 \cdot 10^{5}$ & $7-273$ & 1.91 \\
\hline & TD-B & $0.90 \pm 0.01$ & 0.38 & $8.2 \cdot 10^{5}$ & $9-223$ & 1.76 \\
\hline & TD-C & $0.90 \pm 0.01$ & 0.39 & $7.4 \cdot 10^{5}$ & $7-268$ & 2.04 \\
\hline \multirow{6}{*}{$\begin{array}{l}\text { MuCell@ / Core } \\
\text { Back } 3.7 \text { mm }\end{array}$} & MD-A & $0.81 \pm 0.01$ & 0.25 & $7.5 \cdot 10^{5}$ & $6-292$ & 1.80 \\
\hline & MD-B & $0.82 \pm 0.01$ & 0.41 & $6.1 \cdot 10^{5}$ & $4-286$ & 2.45 \\
\hline & MD-C & $0.82 \pm 0.01$ & 0.52 & $7.2 \cdot 10^{5}$ & $4-250$ & 2.22 \\
\hline & TD-A & $0.81 \pm 0.01$ & 0.22 & $7.9 \cdot 10^{5}$ & $8-297$ & 1.94 \\
\hline & TD-B & $0.82 \pm 0.01$ & 0.31 & $6.8 \cdot 10^{5}$ & $3-280$ & 2.09 \\
\hline & TD-C & $0.82 \pm 0.01$ & 0.47 & $7.2 \cdot 10^{5}$ & $4-289$ & 2.22 \\
\hline
\end{tabular}


The morphological parameters and apparent density results are contained in Table 6.1 and Table 6.2. The apparent density measured in different regions of the solid plates ranged around $1.04 \pm 0.01 \mathrm{~g} \mathrm{~cm}^{-3}$. By foaming, it was decreased by $10 \%$ without using Core Back technology. As the final thickness and overall volume increased by mold opening, apparent density decreased up to $14 \%$ and $21 \%$ for the final thickness of $3.3 \mathrm{~mm}$ and $3.7 \mathrm{~mm}$ respectively.

Table 6.2. Morphological parameters in different sections of IQ Foam® foamed PP 20GF plates.

\begin{tabular}{|c|c|c|c|c|c|c|}
\hline $\begin{array}{l}\text { Condition } \\
\text { No. }\end{array}$ & Section & $\begin{array}{l}\text { Density } \\
\left(\mathrm{g} \mathrm{cm}^{-3}\right)\end{array}$ & $\begin{array}{c}\text { Skin } \\
\text { thickness } \\
(\mathbf{m m})\end{array}$ & $\begin{array}{c}\text { Cell } \\
\text { density } \\
\left(\text { cells } \mathbf{c m}^{-3}\right)\end{array}$ & $\begin{array}{c}\text { Cell size } \\
\text { range } \\
(\mu \mathrm{m})\end{array}$ & $C D I$ \\
\hline \multirow[t]{6}{*}{ IQ Foam $® 3$ mm } & MD-A & $0.94 \pm 0.01$ & 0.60 & $5.3 \cdot 10^{5}$ & $9-131$ & 1.74 \\
\hline & MD-B & $0.94 \pm 0.01$ & 0.70 & $4.4 \cdot 10^{5}$ & $6-195$ & 1.76 \\
\hline & MD-C & $0.94 \pm 0.01$ & 0.75 & $5.7 \cdot 10^{5}$ & $7-112$ & 1.41 \\
\hline & TD-A & $0.94 \pm 0.01$ & 0.54 & $6.9 \cdot 10^{5}$ & $6-101$ & 1.33 \\
\hline & TD-B & $0.94 \pm 0.01$ & 0.67 & $4.3 \cdot 10^{5}$ & $9-128$ & 1.36 \\
\hline & TD-C & $0.94 \pm 0.01$ & 0.77 & $5.8 \cdot 10^{5}$ & $7-243$ & 1.57 \\
\hline \multirow{6}{*}{$\begin{array}{l}\text { IQ Foam }{ }^{\circledR} / \text { Core } \\
\text { Back } 3.3 \mathrm{~mm}\end{array}$} & MD-A & $0.90 \pm 0.01$ & 0.29 & $4.6 \cdot 10^{5}$ & $6-239$ & 2.06 \\
\hline & MD-B & $0.90 \pm 0.01$ & 0.41 & $4.5 \cdot 10^{5}$ & $4-234$ & 1.84 \\
\hline & MD-C & $0.90 \pm 0.01$ & 0.59 & $4.8 \cdot 10^{5}$ & $7-240$ & 2.54 \\
\hline & TD-A & $0.90 \pm 0.01$ & 0.25 & $5.8 \cdot 10^{5}$ & $5-244$ & 1.86 \\
\hline & TD-B & $0.90 \pm 0.01$ & 0.42 & $5.8 \cdot 10^{5}$ & $7-222$ & 1.92 \\
\hline & TD-C & $0.90 \pm 0.01$ & 0.57 & $5.7 \cdot 10^{5}$ & $6-287$ & 1.96 \\
\hline \multirow{6}{*}{$\begin{array}{l}\text { IQ Foam }{ }^{\circledR} \text { / Core } \\
\text { Back } 3.7 \mathrm{~mm}\end{array}$} & MD-A & $0.81 \pm 0.01$ & 0.33 & $5.9 \cdot 10^{5}$ & $6-255$ & 2.03 \\
\hline & MD-B & $0.82 \pm 0.01$ & 0.40 & $5.5 \cdot 10^{5}$ & $3-276$ & 2.14 \\
\hline & MD-C & $0.82 \pm 0.01$ & 0.50 & $5.9 \cdot 10^{5}$ & 4-292 & 2.14 \\
\hline & TD-A & $0.81 \pm 0.01$ & 0.26 & $6.5 \cdot 10^{5}$ & $3-278$ & 2.43 \\
\hline & TD-B & $0.81 \pm 0.01$ & 0.32 & $6.8 \cdot 10^{5}$ & $3-288$ & 1.78 \\
\hline & TD-C & $0.82 \pm 0.01$ & 0.43 & $6.6 \cdot 10^{5}$ & $4-280$ & 2.30 \\
\hline
\end{tabular}



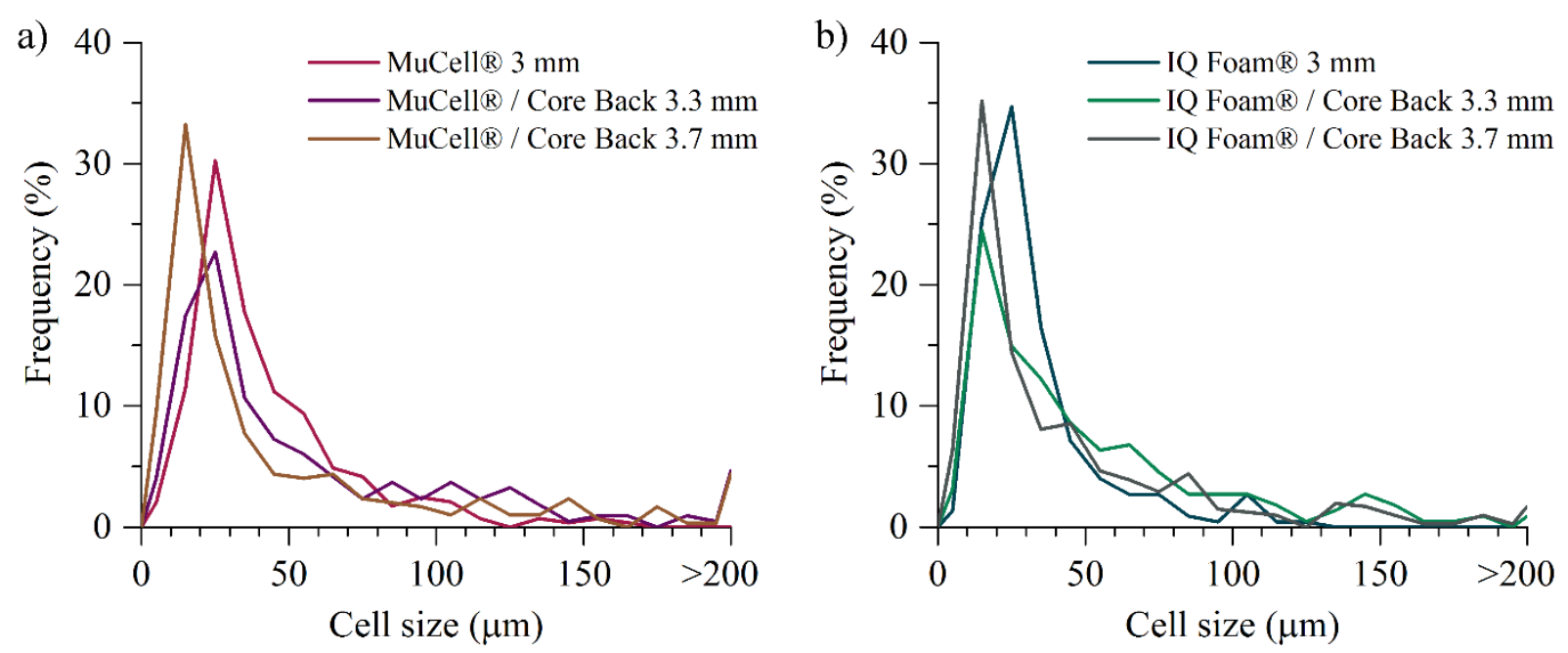

Figure 6.5. Cell size distribution in MD-B position of PP 20GF foamed plates with a) MuCell@; b) IQ Foam®.

Despite the fact that the optimum $\mathrm{N}_{2}$ concentration of $0.5 \%$ for mixing with crystalline materials suggested by Okamoto [104] was employed, cell density determined in these rectangular plates were one order of magnitude lower than that of presented in the previous Chapter with square plates and the same material, because of the reduced amount of blowing agent utilized in this case. The low mold temperature used for processing the rectangular plates $\left(30^{\circ} \mathrm{C}\right.$, Table 3.9$)$ together with the thin wall thickness could have accelerated the cooling of the polymer and hampered the nucleation and growth of a higher number of cells.

Regarding the comparison between MuCell® and IQ Foam® resulted parts, well defined and uniform cell structures can be observed from the micrographs of Figure 6.1, Figure 6.2, Figure 6.3 and Figure 6.4, which indicate that foam formation was governed by heterogeneous nucleation and that microcellular reinforced thermoplastics can be successfully developed by both foaming technologies. Slightly thicker solid skins of IQ Foam ${ }^{\circledR}$ without Core Back expansion can be determined from Table 6.1 and Table 6.2. Despite the cell density measured in all samples was in the order of $10^{5}$ cells $\mathrm{cm}^{-3}$, those obtained by IQ Foam ${ }^{\circledR}$ process were slightly lower. Since the same injection molding parameters were employed for processing with both methods, differences in the amount of blowing agent used for each foaming process arises as the main reason for these morphological differences.

Contrary to MuCell® technology, IQ Foam ${ }^{\circledR}$ consists of a two chambered unit assembled below the hopper where the gas is incorporated into the polymer in pellets form. The key parameter controlling the process is the gas pressure, so the gas content injected into the polymer was not measured, Nevertheless, a lower amount of blowing agent in the IQ Foam ${ }^{\circledR}$ molded parts is expected due to the low solubility of the gas in the solid pellets, 
which would explain the increased solid layer determined in the $3 \mathrm{~mm}$-thick specimens, as well as the decrease in cell density. However, no differences in cell size between both processing technologies were reported, neither in Table 6.1 and Table 6.2 nor in Figure 6.5. From this chart it can be concluded that regardless the foaming method and combination with Core Back technology, around $90 \%$ of cells were concentrated in the range of $1-120 \mu \mathrm{m}$.

Of particular interest could be the analysis of fiber length from the comparison between both foaming technologies. As described in Chapter 2, MuCell@ equipment requires a special design of the screw for optimizing the polymer/gas mixture. Increased shear stresses in this zone could result in higher fiber breakage. Contrarily, the blowing agent in IQ Foam® process is introduced in the feeding region of a conventional injection machine, which means that fibers are no longer subject to additional shear efforts. Nevertheless, measurements of fiber length provided values contained in the range of $748 \pm 174 \mu \mathrm{m}$ for all solid, MuCell® and IQ Foam ${ }^{\circledR}$ derived samples, which suggests that special machinery designed for MuCell ${ }^{\circledR}$ does not affect fiber length in case of short fiber reinforced thermoplastics. Indeed, Zhang and Thompson [327] found that the presence of a dissolved gas into the molten polymer dramatically reduces the occurrence of fiber breakage during processing. Fiber content remained in all specimens in the range of $20.1 \pm 0.2 \%$.

From data reported in Table 6.1 and Table 6.2 the evolution of morphology along the part can be also analyzed. Generally, similar values were obtained in MD and TD direction for each sample location. Solid skin tended to increase with the distance from the injection gate, whereas cell density decreased. Tendency of cell size was inconclusive with the results obtained by analyzing SEM pictures. Hence, the molded plates were examined through X-Ray technique so as to get insight into variations through the whole parts (Figure 6.6). Both MuCell® and IQ Foam ${ }^{\circledR}$ plates showed similar morphologies. While $3 \mathrm{~mm}$-thick plates evidenced no changes along the flow path, those with increased thickness exhibited larger cells at the end of the cavity, which became more evident with increasing the pulling core distance.

The explanation for this observation could be as follows. Near the gate the pressure of this system is high and cell nucleation and growth is restricted. However, pressure drop is experienced at the flow front, creating a pressure gradient from this point to the gate [119]. At the end of the cavity, the lower pressure enables cell growth and coalescence. The higher degree in mold opening stroke provides even lower pressure and adds more space for cell growth [324]. 
IQ Foam ${ }^{\circledR} 3 \mathrm{~mm}$ :

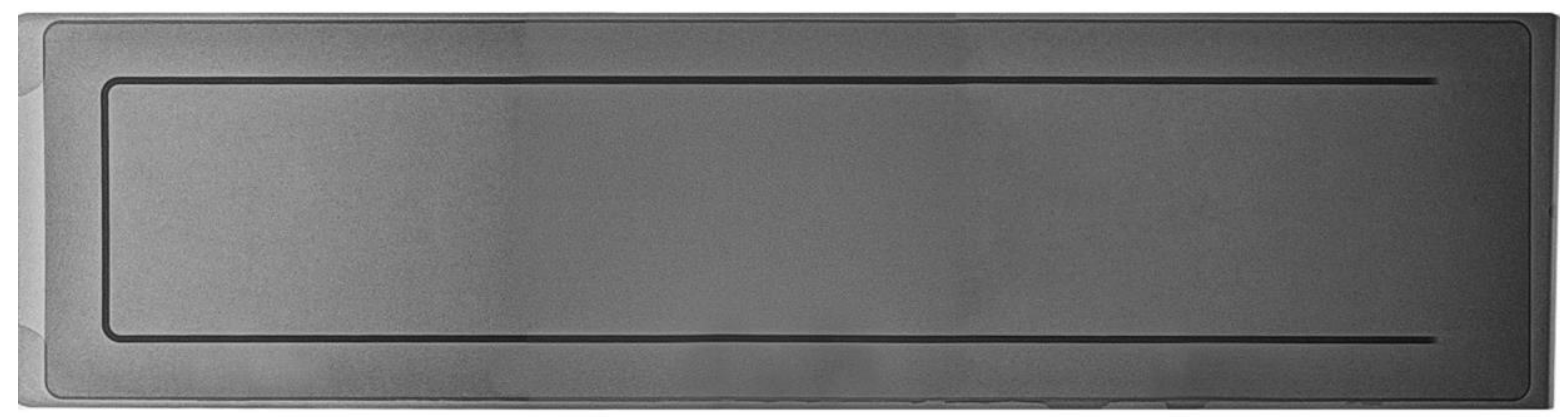

$\underline{\text { IQ Foam }}{ }^{\circledR} /$ Core Back $3.3 \mathrm{~mm}$ :

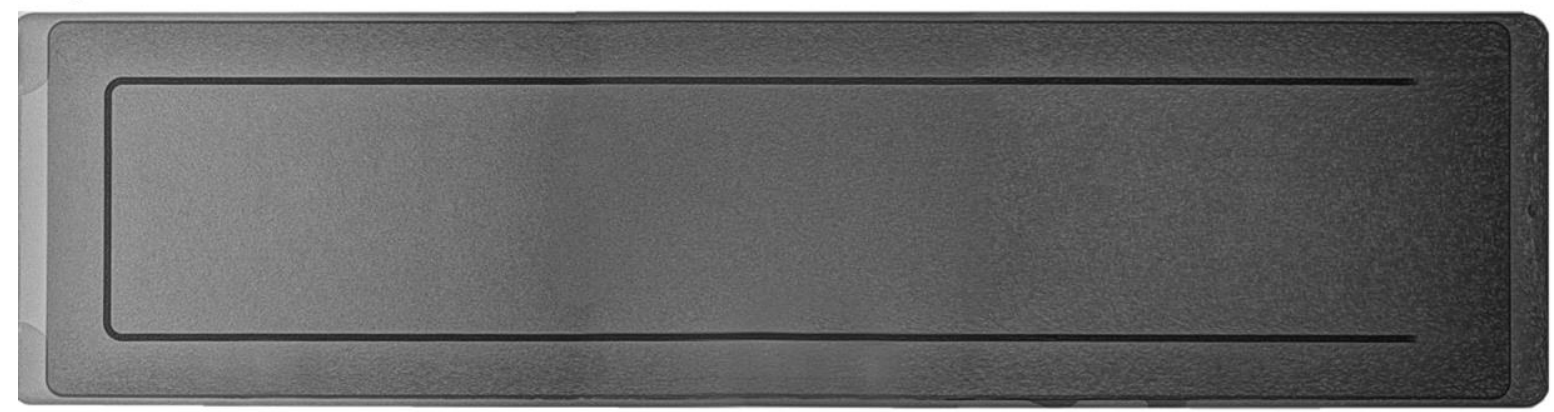

IQ Foam ${ }^{\circledR} /$ Core Back $3.7 \mathrm{~mm}$ :

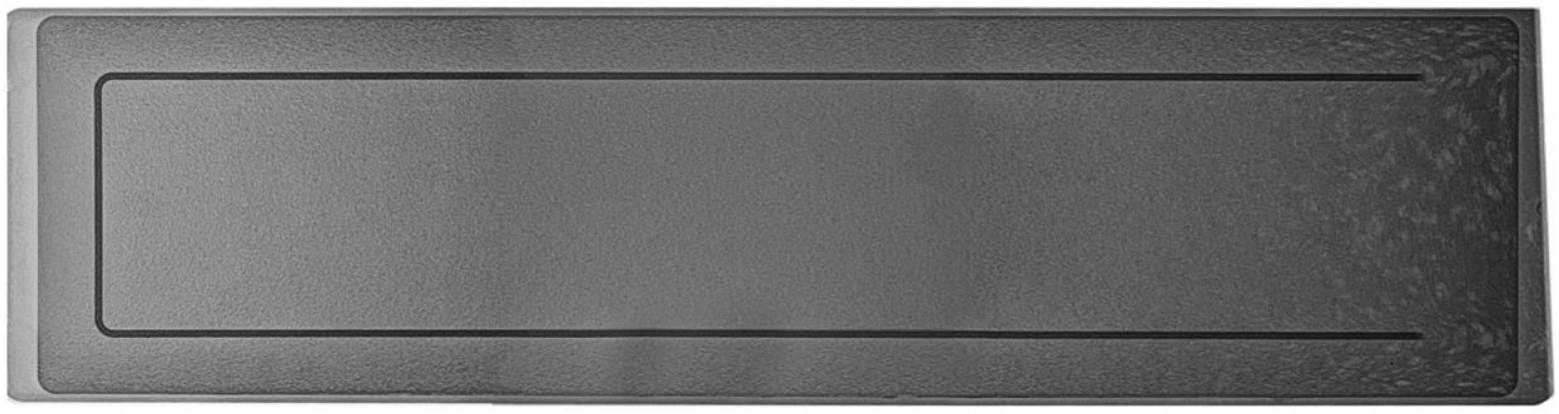

Figure 6.6. X-Ray scans of PP $20 \mathrm{GF}$ foamed plates with IQ Foam® and combined with Core Back technology.

Mueller et al. [267] also observed bigger cells and wider cell size distribution at the end of the flow direction, because of the reduced fraction of the plastic core that can expand by foaming to the end of the flow path as the material solidifies at the cold cavity wall resulting in cell coalescence.

From Figure 6.7 good agreement between experimental and simulated results with Moldex 3D® can be observed. Other authors also validated the capability of the simulation software to predict the microcellular injection molding of Polypropylene with supercritical $\mathrm{N}_{2}$ [289, 328, 329]. Furthermore, the simulation of MuCell@ technique has been also validated for combinations with Core Back technology $[330,331]$ and even with real large automotive parts [332]. 


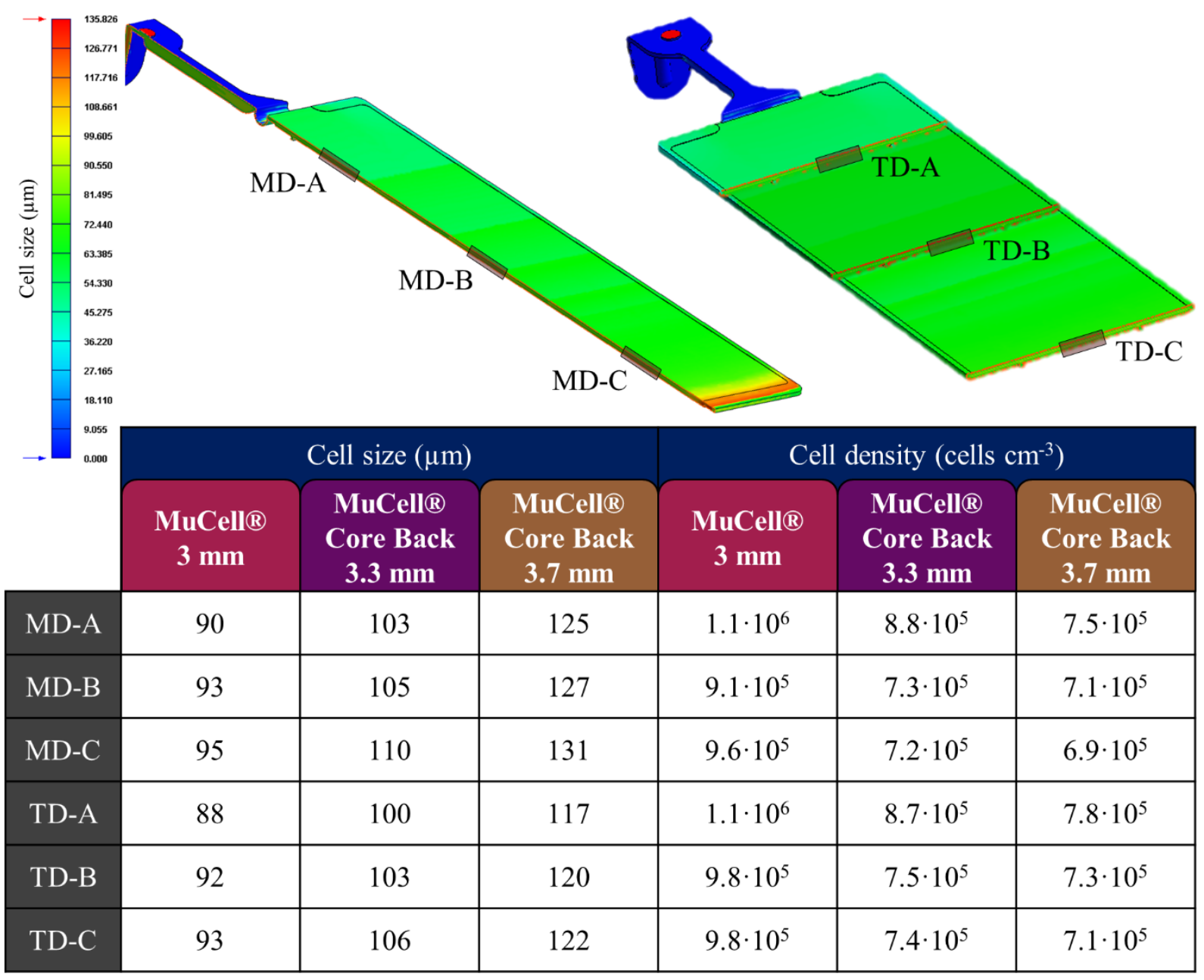

Figure 6.7. Cell size and cell density results of PP 20GF rectangular plates simulated with Moldex 3D®.

\subsection{Tensile behavior}

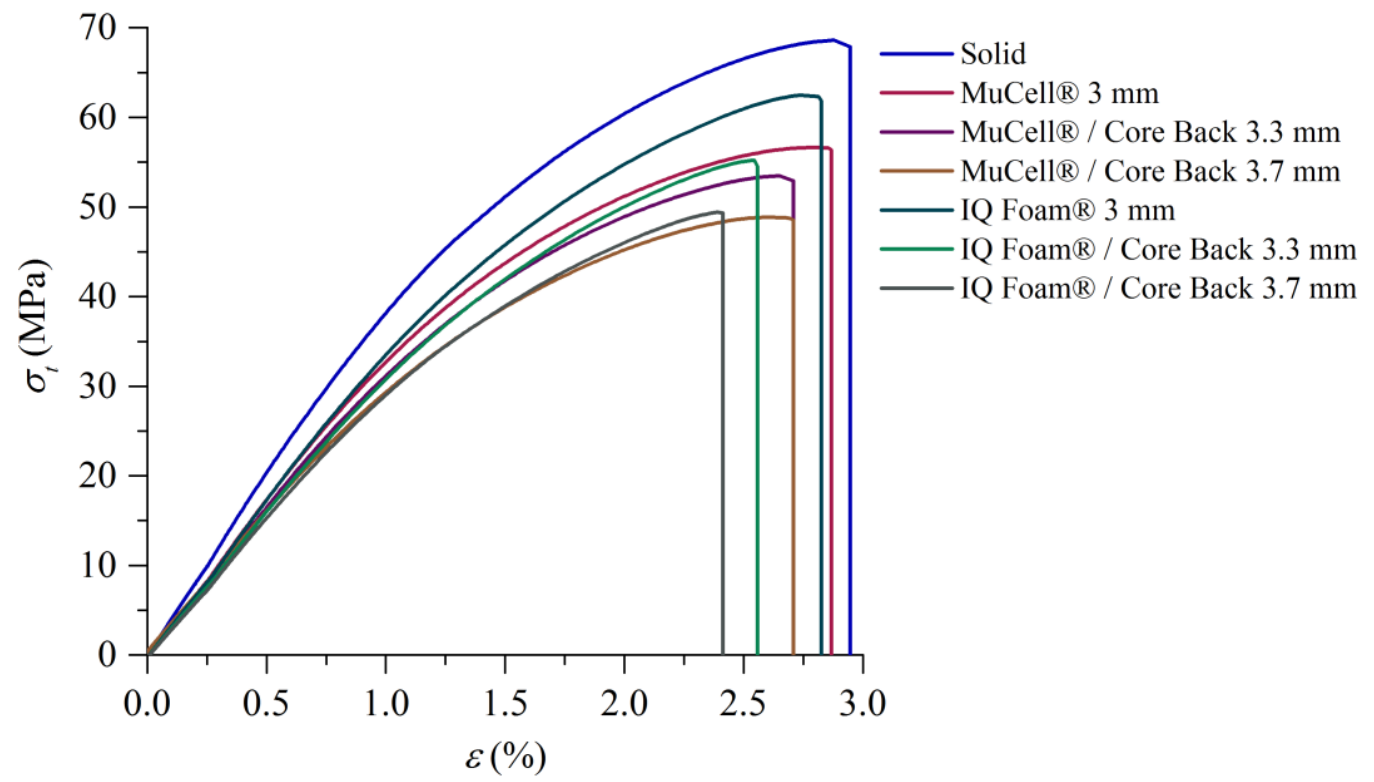

Figure 6.8. Tensile stress-strain curves of solid, MuCell® and IQ Foam® PP 20GF foamed plates (MD-B). 
Table 6.3. Tensile properties of solid and MuCell@ foamed PP 20GF plates.

\begin{tabular}{|c|c|c|c|c|c|}
\hline $\begin{array}{c}\text { Condition } \\
\text { No. }\end{array}$ & Section & $\begin{array}{c}E_{t} \\
(\mathrm{MPa})\end{array}$ & $\begin{array}{c}\sigma_{u} \\
(\mathbf{M P a})\end{array}$ & $\begin{array}{c}E_{t} / \rho \\
\left(\mathrm{MPa} / \mathrm{g} \mathrm{cm}^{-3}\right)\end{array}$ & $\begin{array}{c}\sigma_{u} / \rho \\
\left(\mathrm{MPa} / \mathrm{g} \mathrm{cm}^{-3}\right)\end{array}$ \\
\hline \multirow[t]{6}{*}{ Solid } & MD-A & $3606 \pm 99$ & $60.9 \pm 2.0$ & $3461 \pm 122$ & $58.5 \pm 2.4$ \\
\hline & MD-B & $3870 \pm 99$ & $66.5 \pm 1.6$ & $3712 \pm 138$ & $63.8 \pm 2.3$ \\
\hline & MD-C & $3889 \pm 84$ & $66.7 \pm 1.2$ & $3828 \pm 167$ & $65.7 \pm 2.7$ \\
\hline & TD-A & $2908 \pm 88$ & $48.2 \pm 1.7$ & $2791 \pm 107$ & $46.3 \pm 2.0$ \\
\hline & TD-B & $2671 \pm 24$ & $44.1 \pm 0.6$ & $2562 \pm 53$ & $42.3 \pm 1.0$ \\
\hline & TD-C & $2655 \pm 17$ & $44.6 \pm 0.2$ & $2614 \pm 75$ & $43.9 \pm 1.2$ \\
\hline \multirow{6}{*}{$\begin{array}{c}\text { MuCell }{ }^{\circledR} 3 \\
\text { mm }\end{array}$} & MD-A & $2881 \pm 89$ & $51.2 \pm 2.0$ & $3063 \pm 132$ & $54.4 \pm 2.8$ \\
\hline & MD-B & $3346 \pm 70$ & $56.1 \pm 0.9$ & $3545 \pm 100$ & $59.4 \pm 1.4$ \\
\hline & MD-C & $3510 \pm 81$ & $59.5 \pm 1.6$ & $3740 \pm 153$ & $63.4 \pm 2.8$ \\
\hline & TD-A & $2593 \pm 53$ & $43.6 \pm 1.6$ & $2757 \pm 89$ & $46.3 \pm 2.3$ \\
\hline & TD-B & $2320 \pm 40$ & $37.6 \pm 0.4$ & $2459 \pm 60$ & $39.9 \pm 0.7$ \\
\hline & TD-C & $2317 \pm 97$ & $36.3 \pm 1.1$ & $2470 \pm 147$ & $38.7 \pm 1.8$ \\
\hline \multirow{6}{*}{$\begin{array}{c}\text { MuCell@ / } \\
\text { Core Back } \\
3.3 \mathrm{~mm}\end{array}$} & MD-A & $2798 \pm 44$ & $46.4 \pm 1.5$ & $3125 \pm 88$ & $51.8 \pm 2.4$ \\
\hline & MD-B & $3208 \pm 35$ & $53.2 \pm 0.7$ & $3568 \pm 66$ & $59.2 \pm 1.3$ \\
\hline & MD-C & $3378 \pm 63$ & $56.4 \pm 1.3$ & $3746 \pm 119$ & $62.5 \pm 2.2$ \\
\hline & TD-A & $2262 \pm 78$ & $38.3 \pm 1.0$ & $2526 \pm 118$ & $42.8 \pm 1.6$ \\
\hline & TD-B & $2045 \pm 96$ & $34.1 \pm 0.5$ & $2274 \pm 125$ & $38.0 \pm 0.8$ \\
\hline & TD-C & $2217 \pm 94$ & $34.4 \pm 0.9$ & $2459 \pm 137$ & $38.2 \pm 1.5$ \\
\hline \multirow{6}{*}{$\begin{array}{c}\text { MuCell@ / } \\
\text { Core Back } \\
3.7 \mathrm{~mm}\end{array}$} & MD-A & $2643 \pm 43$ & $42.3 \pm 1.1$ & $3247 \pm 103$ & $51.9 \pm 2.1$ \\
\hline & MD-B & $3002 \pm 52$ & $48.7 \pm 0.5$ & $3661 \pm 103$ & $59.4 \pm 1.3$ \\
\hline & MD-C & $3090 \pm 65$ & $50.1 \pm 1.1$ & $3752 \pm 128$ & $60.8 \pm 2.1$ \\
\hline & TD-A & $1838 \pm 56$ & $31.7 \pm 1.3$ & $2258 \pm 103$ & $39.0 \pm 2.2$ \\
\hline & TD-B & $1790 \pm 23$ & $28.1 \pm 0.2$ & $2183 \pm 51$ & $34.3 \pm 0.6$ \\
\hline & TD-C & $1853 \pm 94$ & $29.7 \pm 1.2$ & $2250 \pm 144$ & $36.0 \pm 1.9$ \\
\hline
\end{tabular}


Representative stress-strain curves obtained from tensile testing of MD-B samples at solid, MuCell® and IQ Foam ${ }^{\circledR}$ conditions are illustrated in Figure 6.8. Absolute and specific values of elastic modulus and tensile strength are summarized in Table 6.3 and Table 6.4. With increasing density reduction by foaming and Core Back expansion, the reduction of both tensile modulus and strength was nearly linear, as indicated by the closed specific values to those of solid specimens. As observed in Chapter 4 and Chapter 5, foamed samples tended to behave more brittle, so the strain at failure slightly decreased in the foamed samples.

Table 6.4. Tensile properties of IQ Foam® foamed PP 20GF plates.

\begin{tabular}{|c|c|c|c|c|c|}
\hline $\begin{array}{c}\text { Condition } \\
\text { No. }\end{array}$ & Section & $\begin{array}{c}E_{t} \\
(\mathbf{M P a})\end{array}$ & $\begin{array}{c}\sigma_{u} \\
(\mathbf{M P a})\end{array}$ & $\begin{array}{c}E_{t} / \rho \\
\left(\mathrm{MPa} / \mathrm{g} \mathrm{cm}^{-3}\right)\end{array}$ & $\begin{array}{c}\sigma_{u} / \rho \\
\left(\mathrm{MPa} / \mathrm{g} \mathrm{cm}^{-3}\right)\end{array}$ \\
\hline \multirow{6}{*}{$\begin{array}{c}\text { IQ Foam }{ }^{\circledR} 3 \\
\text { mm }\end{array}$} & MD-A & $3264 \pm 88$ & $55.9 \pm 1.8$ & $3470 \pm 118$ & $59.4 \pm 2.3$ \\
\hline & MD-B & $3682 \pm 65$ & $63.4 \pm 1.8$ & $3901 \pm 101$ & $67.2 \pm 2.5$ \\
\hline & MD-C & $3818 \pm 92$ & $66.3 \pm 1.9$ & $4069 \pm 137$ & $70.7 \pm 2.7$ \\
\hline & TD-A & $2779 \pm 39$ & $47.7 \pm 2.1$ & $2955 \pm 62$ & $50.7 \pm 2.6$ \\
\hline & TD-B & $2511 \pm 55$ & $42.0 \pm 1.3$ & $2660 \pm 80$ & $44.5 \pm 1.8$ \\
\hline & TD-C & $2528 \pm 46$ & $40.5 \pm 0.9$ & $2694 \pm 75$ & $43.2 \pm 1.4$ \\
\hline \multirow{6}{*}{$\begin{array}{c}\text { IQ Foam® / } \\
\text { Core Back } \\
3.3 \mathrm{~mm}\end{array}$} & MD-A & $3026 \pm 99$ & $48.7 \pm 2.1$ & $3380 \pm 144$ & $54.4 \pm 2.9$ \\
\hline & MD-B & $3436 \pm 94$ & $55.8 \pm 1.6$ & $3822 \pm 127$ & $62.1 \pm 2.1$ \\
\hline & MD-C & $3541 \pm 98$ & $57.6 \pm 2.2$ & $3927 \pm 140$ & $63.9 \pm 2.9$ \\
\hline & TD-A & $2405 \pm 21$ & $39.2 \pm 0.8$ & $2686 \pm 51$ & $43.8 \pm 1.4$ \\
\hline & TD-B & $2161 \pm 52$ & $35.4 \pm 1.1$ & $2404 \pm 72$ & $39.3 \pm 1.5$ \\
\hline & TD-C & $2164 \pm 63$ & $35.3 \pm 1.5$ & $2511 \pm 89$ & $39.1 \pm 2.0$ \\
\hline \multirow{6}{*}{$\begin{array}{c}\text { IQ Foam® / } \\
\text { Core Back } \\
3.7 \mathrm{~mm}\end{array}$} & MD-A & $2755 \pm 91$ & $43.4 \pm 1.5$ & $3385 \pm 138$ & $53.3 \pm 2.3$ \\
\hline & MD-B & $3057 \pm 75$ & $49.4 \pm 2.3$ & $3774 \pm 131$ & $60.9 \pm 3.5$ \\
\hline & MD-C & $3217 \pm 85$ & $50.4 \pm 1.9$ & $3906 \pm 137$ & $61.2 \pm 2.8$ \\
\hline & TD-A & $1946 \pm 83$ & $33.7 \pm 2.0$ & $2391 \pm 121$ & $41.4 \pm 2.8$ \\
\hline & TD-B & $1904 \pm 68$ & $29.6 \pm 1.1$ & $2350 \pm 108$ & $36.5 \pm 1.7$ \\
\hline & TD-C & $1878 \pm 96$ & $31.0 \pm 1.5$ & $2280 \pm 137$ & $37.6 \pm 2.1$ \\
\hline
\end{tabular}


Concerning variations in tensile properties along the part, both tensile modulus and strength increased with the distance from the injection gate (MD-C > MD-B > MD-A), which could be due to the thicker solid skin formed at the end areas. The opposite trend was found in the transverse direction (TD-A > TD-B > TD-C). As results in samples taken in MD direction were higher than in TD direction, a preferential orientation of fibers in the filling direction is suggested. In all unfoamed and foamed samples through MuCell® and IQ Foam® technologies, differences of mean values obtained in MD and TD directions were in all cases about $30 \%$, so no effect of foaming nor Core Back expansion in anisotropic behavior can be determined as compared to the conventional injection molded solid plates.

Comparing tensile properties between samples manufactured by both foaming processes, those obtained by IQ Foam ${ }^{\circledR}$ technology without Core Back expansion were about $10 \%$ higher than the ones corresponding to MuCell® technique. The thicker solid skins seems to be the most likely reason for this results. On the basis of the lower blowing agent incorporated in the IQ Foam ${ }^{\circledR}$ plates, the consequent reduction in cell density led to wider cell struts [333] and higher cross-sectional resistant area, which also contributed to withstand higher tensile loads. These differences in tensile properties between foamed samples through both processes were lowered when Core Back was applied and the volume cavity was increased, suggesting that, as the part gets thicker, tensile properties become more dependent on apparent density and the overall thickness than upon skin thickness or cell density.

\subsection{Flexural behavior}

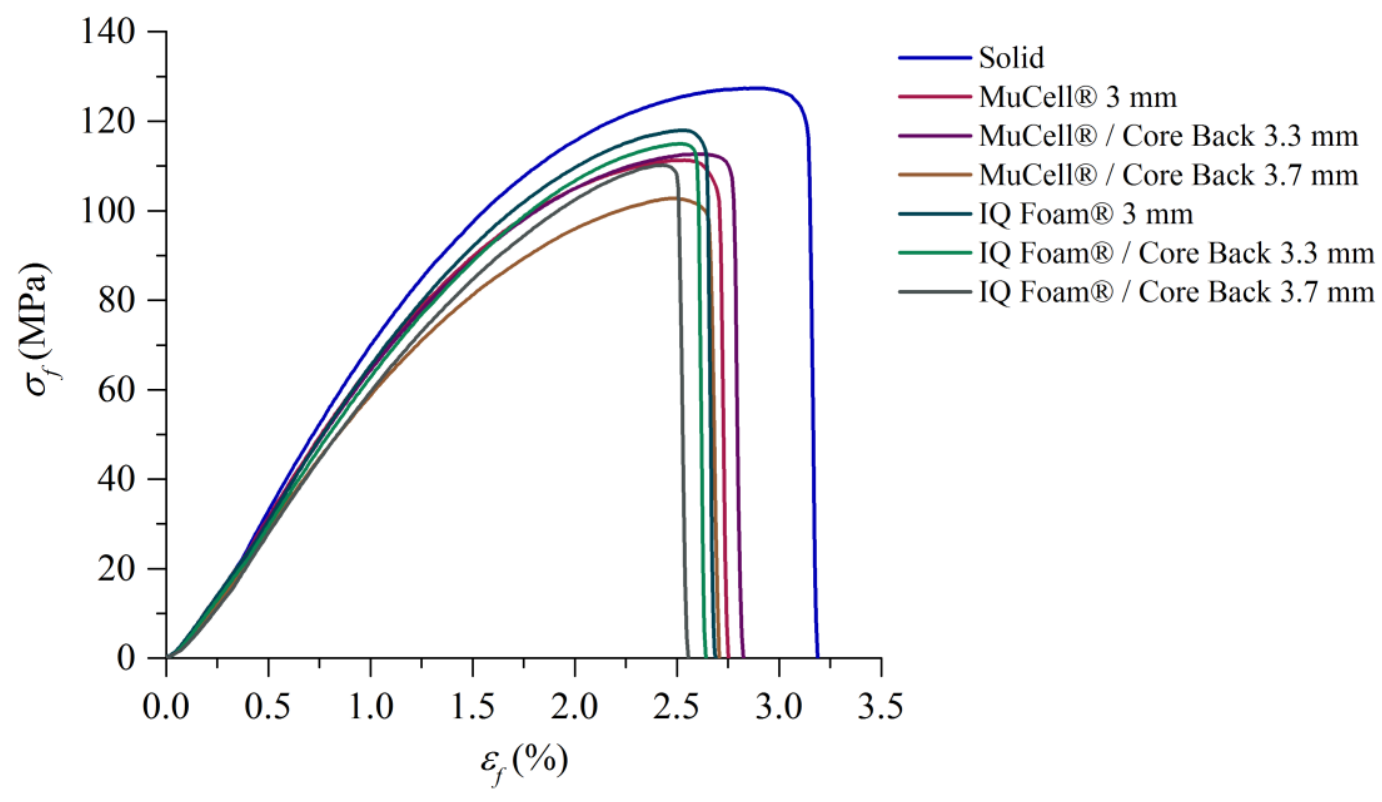

Figure 6.9. Flexural stress-strain curves of solid, MuCell® and IQ Foam® PP 20GF foamed plates (MD-B). 
Flexural stress-strain curves corresponding to MD-B solid, MuCell® and IQ Foam ${ }^{\circledR}$ foamed samples are depicted in Figure 6.9, and the experimental results are depicted in Table 6.5 and Table 6.6. As stated in the previous analysis of tensile behavior, flexural properties decreased gradually with the density of foamed and enlarged samples. Nevertheless, specific values were practically equaled. Similarly, both flexural modulus and strength increased in positions far from the injection gate when samples were tested in the filling direction (MD), and decreased in the opposite orientation (TD). This tendency can be again attributed to the thicker skin thickness in that locations and preferential fiber orientation. Particularly in this case, flexural modulus as well as strength determined in MD direction of all solid and foamed samples were about $45 \%$ higher than that of in the transverse direction (TD). This value is higher than that reported with the tensile properties before, which remarks the more effective reinforcing effect of glass fiber under bending loads.

In reference to the comparison between foaming technologies, flexural properties of samples obtained by IQ Foam ${ }^{\circledR}$ process were higher and differed from the corresponding ones of MuCell@ in approximately 10\%. The thicker compact skin layer and effective bearing area were crucial for improving the flexural performance of the foamed parts, as occurred with tensile properties. Once more, these differences were blurred while employing Core Back technology, because apparent density and overall thickness act as dominant factors of the mechanical performance.

Most of the works dealing with Core Back expansion molding process focus on the flexural properties of the resulted foams $[142,172,323,333,334]$. This is due to, for engineering purposes, design criteria is based on the flexural stiffness rather than on the flexural modulus. This parameter involves the geometry of the part by means of the moment of inertia. For flat panel geometries, the flexural stiffness $\left(S_{f}\right)$ is calculated as follows[335]:

$$
S_{f}=E_{f} I=E_{f} \frac{b h^{3}}{12}
$$

Where $I$ is the moment of inertia, $E_{f}$ is the flexural modulus and $b$ and $h$ the part width and thickness, respectively. Thus, flexural stiffness is significantly increased by the third power of the thickness. Figure 6.10 illustrates the evolution of the relative, specific flexural strength by foaming and increasing the thickness with Core Back technology. It should be noted that despite the drop in flexural modulus, the stiffness can be improved up to $200 \%$ as compared to that of the solid counterpart by increasing the thickness to $3.7 \mathrm{~mm}$. 
Table 6.5. Flexural properties of solid and MuCell® foamed PP 20GF plates.

\begin{tabular}{|c|c|c|c|c|c|}
\hline $\begin{array}{c}\text { Condition } \\
\text { No. }\end{array}$ & Section & $\begin{array}{c}E_{f} \\
(\mathrm{MPa})\end{array}$ & $\begin{array}{c}\sigma_{f} \\
(\mathbf{M P a})\end{array}$ & $\begin{array}{c}E_{f} l \rho \\
\left(\mathrm{MPa} / \mathrm{g} \mathrm{cm}^{-3}\right)\end{array}$ & $\begin{array}{c}\sigma_{f} l \rho \\
\left(\mathrm{MPa} / \mathrm{g} \mathrm{cm}^{-3}\right)\end{array}$ \\
\hline \multirow[t]{6}{*}{ Solid } & MD-A & $7164 \pm 82$ & $118.9 \pm 1.1$ & $6878 \pm 133$ & $114.2 \pm 2.0$ \\
\hline & MD-B & $7669 \pm 76$ & $127.6 \pm 2.2$ & $7355 \pm 159$ & $122.4 \pm 3.5$ \\
\hline & MD-C & $7463 \pm 84$ & $127.0 \pm 1.8$ & $7347 \pm 246$ & $125.1 \pm 4.5$ \\
\hline & TD-A & $4275 \pm 44$ & $80.4 \pm 0.4$ & $4104 \pm 75$ & $77.2 \pm 1.0$ \\
\hline & TD-B & $3823 \pm 60$ & $72.2 \pm 0.8$ & $3666 \pm 100$ & $69.3 \pm 1.6$ \\
\hline & TD-C & $3744 \pm 91$ & $70.3 \pm 0.8$ & $3686 \pm 172$ & $69.2 \pm 2.3$ \\
\hline \multirow{6}{*}{$\begin{array}{c}\text { MuCell@ } 3 \\
\mathrm{~mm}\end{array}$} & MD-A & $5948 \pm 88$ & $96.0 \pm 1.2$ & $6324 \pm 170$ & $102.1 \pm 2.6$ \\
\hline & MD-B & $6515 \pm 78$ & $111.7 \pm 0.6$ & $6903 \pm 133$ & $118.4 \pm 1.5$ \\
\hline & MD-C & $6702 \pm 97$ & $115.1 \pm 1.8$ & $7143 \pm 231$ & $122.7 \pm 4.1$ \\
\hline & TD-A & $3506 \pm 92$ & $68.0 \pm 2.0$ & $3728 \pm 143$ & $72.3 \pm 3.0$ \\
\hline & TD-B & $3181 \pm 95$ & $57.7 \pm 1.2$ & $3371 \pm 125$ & $61.1 \pm 1.7$ \\
\hline & TD-C & $3150 \pm 99$ & $61.2 \pm 2.9$ & $3357 \pm 165$ & $65.2 \pm 4.2$ \\
\hline \multirow{6}{*}{$\begin{array}{c}\text { MuCell@ / } \\
\text { Core Back } \\
3.3 \mathrm{~mm}\end{array}$} & MD-A & $6108 \pm 80$ & $98.2 \pm 1.0$ & $6822 \pm 174$ & $109.7 \pm 2.5$ \\
\hline & MD-B & $6510 \pm 95$ & $112.7 \pm 1.6$ & $7240 \pm 161$ & $125.3 \pm 2.8$ \\
\hline & MD-C & $6634 \pm 99$ & $117.5 \pm 1.9$ & $7358 \pm 208$ & $130.3 \pm 3.8$ \\
\hline & TD-A & $3387 \pm 46$ & $64.8 \pm 0.5$ & $3783 \pm 99$ & $72.7 \pm 1.5$ \\
\hline & TD-B & $3273 \pm 81$ & $61.0 \pm 2.9$ & $3640 \pm 118$ & $67.9 \pm 3.7$ \\
\hline & TD-C & $3582 \pm 77$ & $66.2 \pm 1.9$ & $3973 \pm 138$ & $73.4 \pm 3.1$ \\
\hline \multirow{6}{*}{$\begin{array}{c}\text { MuCell@ / } \\
\text { Core Back } \\
3.7 \mathrm{~mm}\end{array}$} & MD-A & $5744 \pm 60$ & $90.9 \pm 0.6$ & $7056 \pm 183$ & $111.7 \pm 2.5$ \\
\hline & MD-B & $6420 \pm 98$ & $102.6 \pm 1.6$ & $7829 \pm 203$ & $125.1 \pm 3.3$ \\
\hline & MD-C & $6630 \pm 68$ & $104.1 \pm 2.0$ & $8048 \pm 187$ & $126.3 \pm 4.1$ \\
\hline & TD-A & $3193 \pm 93$ & $57.8 \pm 1.1$ & $3922 \pm 174$ & $71.0 \pm 2.5$ \\
\hline & TD-B & $2997 \pm 30$ & $55.1 \pm 0.3$ & $3655 \pm 76$ & $67.2 \pm 1.1$ \\
\hline & TD-C & $3203 \pm 77$ & $59.9 \pm 1.8$ & $3888 \pm 144$ & $72.7 \pm 3.2$ \\
\hline
\end{tabular}


Table 6.6. Flexural properties of solid and IQ Foam® foamed PP 20GF plates.

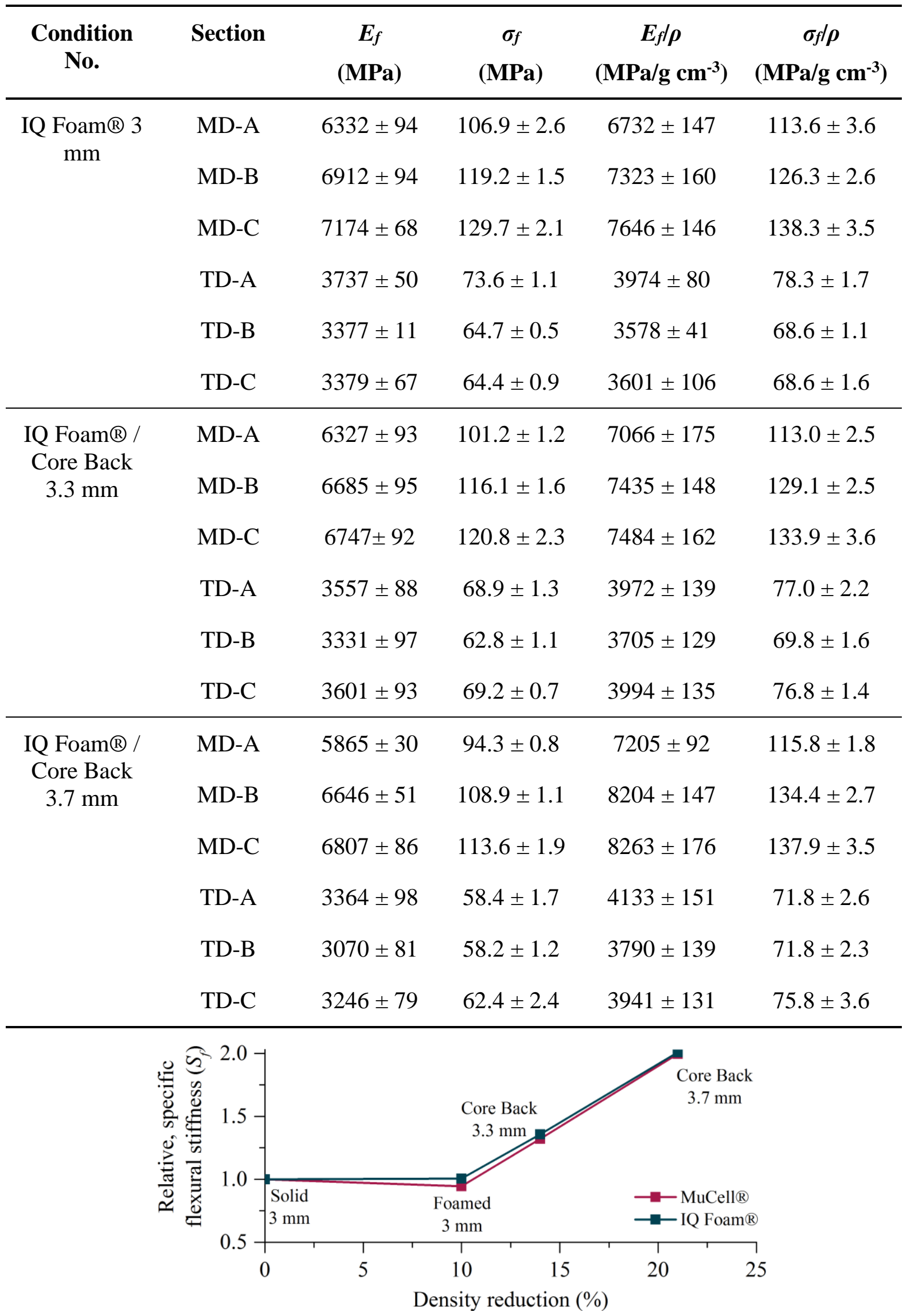

Figure 6.10. Relative, specific flexural stiffness $\left(S_{f}\right)$ evolution with density reduction and thickness increase. 


\subsection{Impact behavior}

Curves force-deflection obtained from impact tests of solid and foamed samples are illustrated in Figure 6.11. The impact resistance calculated by the integral of the curves are shown in Table 6.7 and Table 6.8. As discussed in the previous Chapters, foamed material is more sensitive to impact loads and the impact resistance decreases in higher ratios than the reduction in density. Thus, it decreased by around $15 \%$ when foaming without core expansion, and by $22 \%$ and $35 \%$ while increasing the thickness to $3.3 \mathrm{~mm}$ and $3.7 \mathrm{~mm}$.

Since the testing method consists of an impact bending load, thickness of the solid skins plays a crucial role on the performance of the part [142, 172]. Indeed, the impact resistance increased with the distance from the injection point, due to the thicker skin layer. However, unlike the observed in tensile and flexural behavior analysis, this increase at the end areas of the cavity occurred for both testing directions (MD and TD), suggesting that there is a greater dependency on the surface layer than upon fiber orientation. Additionally, differences in MD and TD values of solid samples were around $28 \%$, but they were significantly reduced by foaming and Core Back expansion molding, reaching a deviation between both directions of $5 \%$ when the thickness was raised up to $3.7 \mathrm{~mm}$. The impact resistance was also the property with less differences between both foaming technologies. Due to the higher skin thickness, the impact resistance of samples obtained through IQ Foam® was $7 \%$ higher than that of the MuCell ${ }^{\circledR}$ foamed specimens. As occurred with the other mechanical properties, these differences decreased with the thickness expansion of the Core Back process.

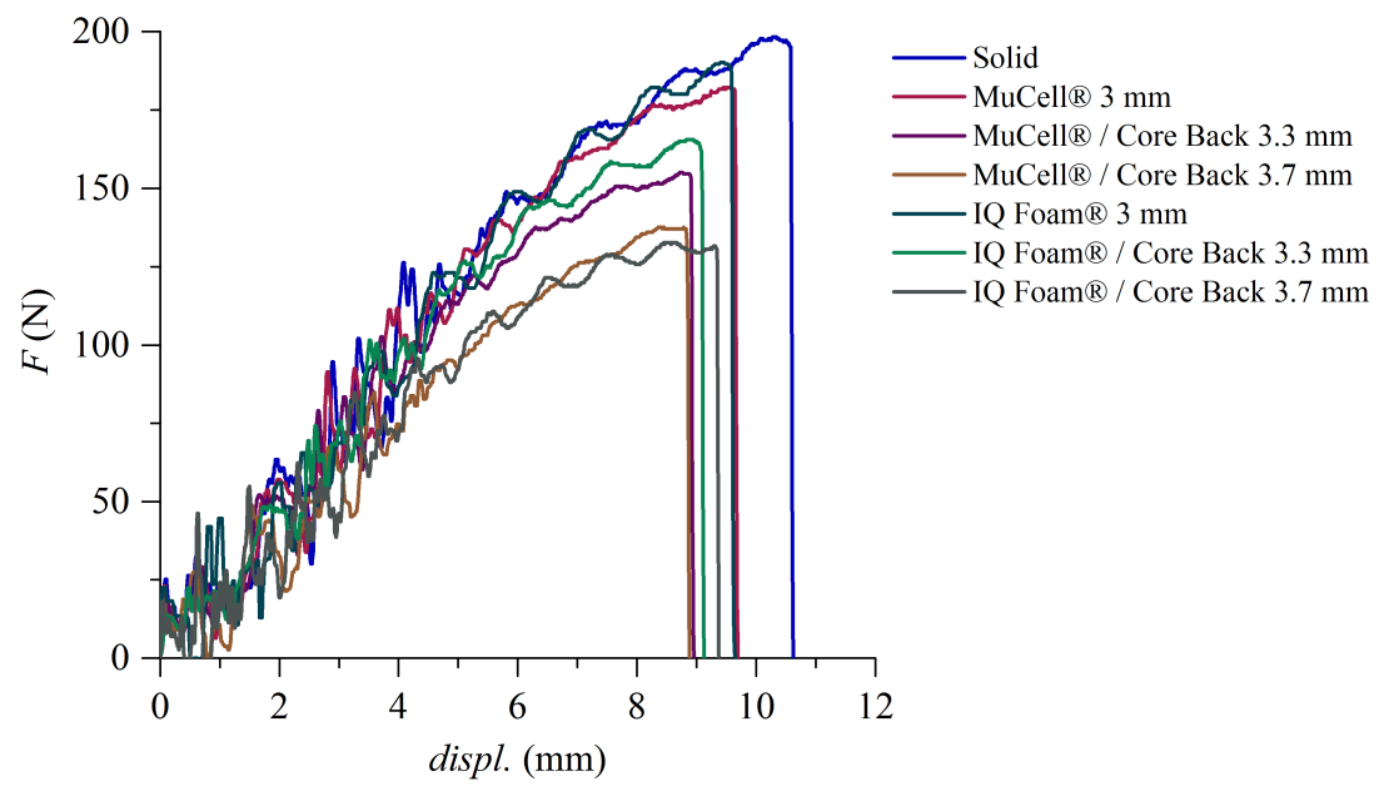

Figure 6.11. Impact force-displacement curves of solid, MuCell® and IQ Foam ${ }^{\circledR}$ PP 20GF foamed plates. 
Table 6.7. Impact resistance of solid and MuCell® foamed PP 20GF plates.

\begin{tabular}{|c|c|c|c|}
\hline $\begin{array}{c}\text { Condition } \\
\text { No. }\end{array}$ & Section & 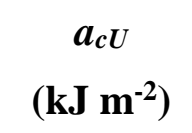 & $\begin{array}{c}a_{c U} / \rho \\
\left(\mathrm{kJ} \mathrm{m}^{-2} / \mathrm{g} \mathrm{cm}^{-3}\right)\end{array}$ \\
\hline \multirow[t]{6}{*}{ Solid } & MD-A & $31.4 \pm 1.6$ & $30.2 \pm 1.8$ \\
\hline & MD-B & $34.4 \pm 1.2$ & $33.0 \pm 1.6$ \\
\hline & MD-C & $37.5 \pm 2.2$ & $36.9 \pm 3.0$ \\
\hline & TD-A & $40.9 \pm 1.9$ & $39.3 \pm 2.2$ \\
\hline & TD-B & $44.7 \pm 3.0$ & $42.9 \pm 3.4$ \\
\hline & TD-C & $46.9 \pm 1.8$ & $46.2 \pm 2.8$ \\
\hline \multirow{6}{*}{$\begin{array}{c}\text { MuCell@ } 3 \\
\text { mm }\end{array}$} & MD-A & $26.1 \pm 1.9$ & $27.8 \pm 2.3$ \\
\hline & MD-B & $28.5 \pm 1.9$ & $30.2 \pm 2.2$ \\
\hline & MD-C & $30.9 \pm 2.3$ & $33.0 \pm 3.1$ \\
\hline & TD-A & $31.0 \pm 2.1$ & $33.0 \pm 2.6$ \\
\hline & TD-B & $35.2 \pm 1.3$ & $37.3 \pm 1.7$ \\
\hline & TD-C & $35.8 \pm 2.2$ & $38.1 \pm 3.0$ \\
\hline \multirow{6}{*}{$\begin{array}{c}\text { MuCell@ / } \\
\text { Core Back } \\
3.3 \mathrm{~mm}\end{array}$} & MD-A & $25.6 \pm 1.6$ & $28.6 \pm 2.1$ \\
\hline & MD-B & $27.2 \pm 1.7$ & $30.3 \pm 2.1$ \\
\hline & MD-C & $28.1 \pm 2.5$ & $31.2 \pm 3.1$ \\
\hline & TD-A & $27.5 \pm 2.0$ & $30.7 \pm 2.6$ \\
\hline & TD-B & $28.2 \pm 2.7$ & $31.4 \pm 3.2$ \\
\hline & TD-C & $29.9 \pm 2.5$ & $33.2 \pm 3.2$ \\
\hline \multirow{6}{*}{$\begin{array}{c}\text { MuCell@ / } \\
\text { Core Back } \\
3.7 \mathrm{~mm}\end{array}$} & MD-A & $23.8 \pm 1.5$ & $29.3 \pm 2.3$ \\
\hline & MD-B & $26.6 \pm 1.9$ & $32.5 \pm 2.7$ \\
\hline & MD-C & $28.8 \pm 2.0$ & $34.9 \pm 2.9$ \\
\hline & TD-A & $25.3 \pm 2.0$ & $31.0 \pm 2.9$ \\
\hline & TD-B & $28.1 \pm 2.0$ & $34.3 \pm 2.9$ \\
\hline & TD-C & $29.6 \pm 2.5$ & $35.9 \pm 3.5$ \\
\hline
\end{tabular}


Table 6.8. Impact resistance of solid and IQ Foam® foamed PP 20GF plates.

\begin{tabular}{|c|c|c|c|}
\hline $\begin{array}{c}\text { Condition } \\
\text { No. }\end{array}$ & Section & 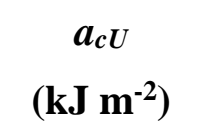 & $\begin{array}{c}a_{c v} / \rho \\
\left(\mathrm{kJ} \mathrm{m}^{-2} / \mathrm{g} \mathrm{cm}^{-3}\right)\end{array}$ \\
\hline \multirow{6}{*}{$\begin{array}{c}\text { IQ Foam }{ }^{\circledR} 3 \\
\text { mm }\end{array}$} & MD-A & $27.7 \pm 2.4$ & $29.5 \pm 2.7$ \\
\hline & MD-B & $30.4 \pm 2.6$ & $32.2 \pm 3.1$ \\
\hline & MD-C & $33.1 \pm 1.4$ & $35.3 \pm 1.9$ \\
\hline & TD-A & $32.7 \pm 2.4$ & $34.7 \pm 2.8$ \\
\hline & TD-B & $35.8 \pm 1.6$ & $37.9 \pm 2.0$ \\
\hline & TD-C & $36.7 \pm 1.9$ & $39.1 \pm 2.4$ \\
\hline \multirow{6}{*}{$\begin{array}{c}\text { IQ Foam® / } \\
\text { Core Back } \\
3.3 \mathrm{~mm}\end{array}$} & MD-A & $27.2 \pm 1.0$ & $30.4 \pm 1.4$ \\
\hline & MD-B & $28.5 \pm 1.5$ & $31.7 \pm 1.8$ \\
\hline & MD-C & $28.8 \pm 1.7$ & $31.9 \pm 2.2$ \\
\hline & TD-A & $28.2 \pm 1.2$ & $31.5 \pm 1.6$ \\
\hline & TD-B & $29.6 \pm 1.9$ & $33.0 \pm 2.3$ \\
\hline & TD-C & $30.2 \pm 1.9$ & $33.5 \pm 2.4$ \\
\hline \multirow{6}{*}{$\begin{array}{c}\text { IQ Foam® / } \\
\text { Core Back } \\
3.7 \mathrm{~mm}\end{array}$} & MD-A & $24.1 \pm 1.7$ & $26.9 \pm 2.3$ \\
\hline & MD-B & $26.9 \pm 1.1$ & $33.2 \pm 1.7$ \\
\hline & MD-C & $29.5 \pm 1.5$ & $35.8 \pm 2.1$ \\
\hline & TD-A & $27.0 \pm 0.8$ & $33.1 \pm 1.3$ \\
\hline & TD-B & $28.7 \pm 1.6$ & $35.4 \pm 2.3$ \\
\hline & TD-C & $30.6 \pm 1.1$ & $37.2 \pm 1.7$ \\
\hline
\end{tabular}

\subsection{Conclusions}

In this Chapter the complementary tool Core Back technology and a new foaming injection molding process named IQ Foam ${ }^{\circledR}$ have been evaluated and compared to the already known MuCell®. The analysis of the morphology and mechanical properties of injection molded plates through both technologies and with two expansion ratios of the thickness by the Core Back technique led to the following conclusions: 
- The Core Back technology allowed greater reductions in density than with the conventional foaming process. Cells became bigger, elongated and distorted due to the cavity wall movement. This was particularly relevant at the end areas of the molded part, where lower pressure gave rise to higher expansion of the blowing agent. Additionally, thinner solid skin layers were formed because of longer time at the molten state of the core region.

- The mechanical properties decreased with the density of the Core Back foamed samples. In case of properties assessed at low load speeds (tensile and flexural), the mechanical performance was mainly dependent on the density and fiber orientation. Parameters for design criteria, such as bending stiffness, increased greatly by increasing the thickness, despite the reduction in weight and density while foaming. For impact tests, the mechanical response was governed by the thickness of the solid skin layers.

- IQ Foam® arises as an alternative foaming technology able to produce microcellular parts with comparable properties to those manufactured by MuCell® process (Figure 6.12). By using a minimum content of blowing agent, the number of nucleated cells was reduced and a thicker solid skin was formed, which led to higher mechanical properties. Some other advantages are the possibility to be used in any conventional injection molding machine, easy operation and low economical investment required.

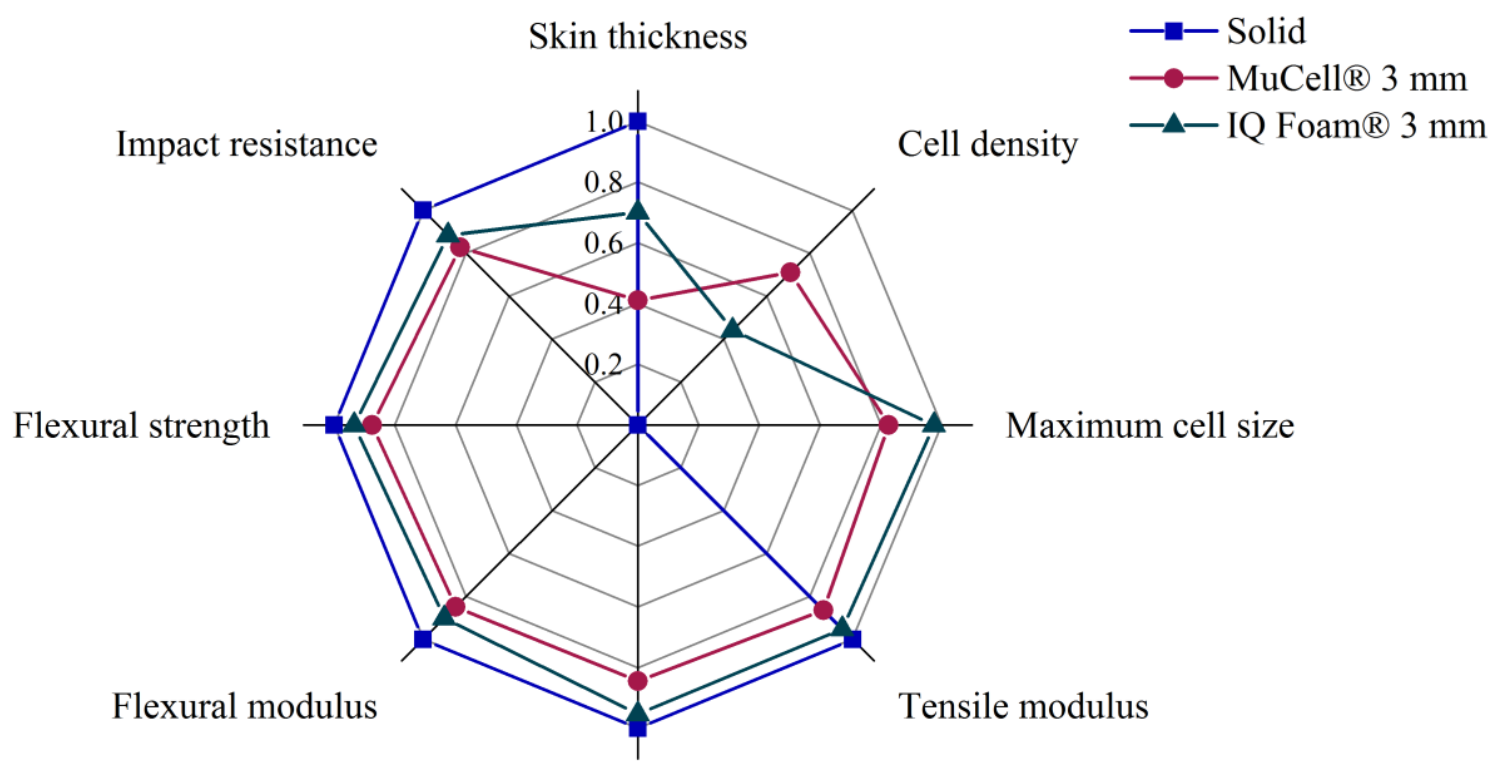

Tensile strength

Figure 6.12. Multivariable plot comparing morphological characteristics and mechanical properties of solid, MuCell® and IQ Foam® foamed specimens. 
- 186 - 


\section{Chapter 7:}

\section{Conclusions}

The research work carried out in this project deals with the characterization of microcellular plastics obtained by injection molding, as a response to the challenge in the automotive industry of achieving lightweight constructions and therefore reductions in fuel consumption as well as in greenhouse gas emissions.

An amorphous polymer (ABS) and a semicrystalline one reinforced with glass fiber (PP 20GF) were selected for this study and injection molded into different cavity geometries. In a first step, the effect of shot volume, mold temperature and injection speed of the MuCell® foaming process on the morphology and mechanical properties was analyzed. After choosing those that optimized their properties, an extended study of additional characteristics was performed.

The morphological structure of these microcellular plastics consists of two compact surface layers and a foamed core. By decreasing shot volume and increasing the content of the blowing agent, a higher nucleation rate is promoted, so the gas is distributed into a high number of cells with smaller diameters. However, if the melt strength of the material is low (as in PP) and insufficient to bear the expansion forces of cells while growing, coalescence phenomena between cells occurs and the result is a lower cell density with bigger bubble size. The optimum content of blowing agent thus depends on the nature and rheological characteristics of each polymer. The main foaming mechanism in neat polymer is homogenous nucleation, while heterogeneous nucleation predominates in the presence of glass fibers. Similar uniform cell distributions are obtained through both mechanisms. The mold temperature and injection speed involve changes in the cooling rate and pressure drop and, in general, high levels of both parameters contribute to obtain finer morphologies (higher cell density and lower cell size).

The mechanical performance is mainly dependent on the reduction in the apparent density. Therefore, the shot size is the most influential processing parameter. Differences in the morphology induced by variations in mold temperature and injection speed do not seem to 
be enough to introduce statistically significant changes in the mechanical properties of the foamed parts. This means that there is no additional restrictions in the window process because of foaming, representing a benefit for structural purposes.

Tensile and flexural properties decrease almost linearly with the apparent density as the foaming ratio increases, whereas impact resistance is strongly reduced because of the reduction in the effective sectional area and cells acting as stress concentrators. Glass fibers contribute to partially overcome the property loss due to density reduction, so reinforcing and redesigning strategies can be successfully conducted for parts subject to impact loads. Cell elongation as well as fiber orientation introduce a higher degree of anisotropy, although it has been observed how impact properties are more influenced by solid skin thickness than on fiber orientation.

Concerning the fracture behavior of the foamed materials, cells blunt the crack tip and thus delay the onset of crack propagation. However, once the crack is propagating, cells acting as stress concentrators lead to a decrease in fracture toughness. Examination of the fracture surfaces revealed that crack in the core propagates ahead of the main crack tip on the solid surface layers, because of subsequent processes of deformation, rupture and cell coalescence.

By comparing it with the experimental data, it has been demonstrated that Moldex $3 \mathrm{D} ®$ simulation software can be employed to properly predict the foaming behavior of both materials economically. Despite the fact that cell structure could be more complex in the actual molded part, simulation results can be used as good approach. Likewise, different models employed to predict tensile and flexural properties, as well as fracture toughness of foamed samples based on the density and morphological characteristics, provide estimated values close to those obtained experimentally. Higher accuracy might be achieved if factors considering cell shape and size distribution and fiber orientation are included in the models.

The low amount of gas introduced during the foaming process does not produce significant changes in the thermal properties of the foamed samples as compared to that of the solid counterpart. Indeed, melting and crystallization temperatures, as well as enthalpies, remain invariant while foaming, and the Heat Deflection Temperature slightly decreases because of a lower flexural modulus of the foamed specimens.

Although thermoplastic foams have been used in different structural applications for a long time, their potential capabilities are still far from being exhausted. The increasing 
demand for lightweight, optimized and economized automotive products calls for new solutions in the injection molding industry. On one hand, the complementary Core Back tool technology has been assessed in combination with the microcellular injection molding techniques for PP 20GF material. By pulling the core and increasing the final thickness of the part, the apparent density decreases, solid skins get thinner but cells become bigger and distorted. Absolute mechanical properties decrease with the apparent density, but specific ones remain close to that of the solid material, and design criteria parameters, such as the bending stiffness, are greatly enhanced due to the build-up in the overall thickness.

On the other hand, a new foaming technology, called IQ Foam® and developed by Volkswagen AG, has been employed in this work. Unlike the MuCell® process, this new system mixes a blowing agent with polymer granulates in a two-chambered unit assembled between the hopper and the feeder of a conventional injection molding machine. Hence, no special design of the screw geometry is required. By using a minimum amount of blowing agent, foamed plastic parts obtained through this process exhibit thicker solid skins and lower cell densities, but consequently higher mechanical properties. Additional benefits such as cost-effectiveness, machine-independence and easy operation enable IQ Foam ${ }^{\circledR}$ to produce lightweight parts with comparable properties to that of the already known MuCell® technology, but also with a reduced economic investment and a simplified control.

\subsection{Future research works}

Aimed to extend the use of foamed materials through the injection molding process to a wider range of application, further research is needed. The following topics are suggested in order to obtain deeper knowledge on microcellular plastics:

- Extension of the analysis of the effect of processing parameters to other variables, such as melt temperature, residence time in the barrel or melt plasticizing pressure (MPP).

- Study on the strain field, stress state and triaxility degree in the crack tips through the Digital Image Correlation (DIC) technique.

- Evaluation of alternative solutions to enhance the surface quality of the foamed parts, like painting, co-injection molding, Gas Counter Pressure or Rapid Heating Cycle Molding. 
- Extension of the investigation of IQ Foam® technology with other polymers, as well as composites filled with long glass fibers, so as to determine differences in fiber breakage between MuCell® and IQ Foam® systems.

- Due to the increased trend in the development of environmentally friendly materials to replace the petroleum-based polymers, study on the foamability of bio-based polymers, like PLA, is also proposed.

- Application and validation of the findings obtained in this thesis to actual car parts, and completion of the materials characterization to introduce this kind of materials into numerical simulations. 


\section{References}

[1] European Environment Agency (EEA). Greenhouse gas emissions from transport. EEA Indicator Assessment - Data and maps, 2015.

[2] European Environment Agency (EEA). Monitoring CO2 emissions from new passenger cars and vans in 2014. EEA Technical report - No 16/2015, 2015.

[3] Council Directive 91/441/EEC of 26 June 1991 amending Directive 70/220/EEC on the approximation of the laws of the Member States relating to measures to be taken against air pollution by emissions from motor vehicles.

[4] Directive 96/69/EC of the European Parliament and of the Council of 8 October 1996 amending Directive 70/220/EEC on the approximation of the laws of the Member States relating to measures to be taken against air pollution by emissions from motor vehicles.

[5] Directive 98/69/EC of the European Parliament and of the Council of 13 October 1998 relating to measures to be taken against air pollution by emissions from motor vehicles and amending Council Directive 70/220/EEC.

[6] Commission Directive 2002/80/EC of 3 October 2002 adapting to technical progress Council Directive 70/220/EEC relating to measures to be taken against air pollution by emissions from motor vehicles.

[7] Regulation (EC) No 715/2007 of the European Parliament and of the Council of 20 June 2007 on type approval of motor vehicles with respect to emissions from light passenger and commercial vehicles (Euro 5 and Euro 6) and on access to vehicle repair and maintenance information.

[8] Commission Regulation (EU) No 459/2012 of 29 May 2012 amending Regulation (EC) No 715/2007 of the European Parliament and of the Council and Commission Regulation (EC) No 692/2008 as regards emissions from light passenger and commercial vehicles (Euro $6)$. 
[9] Council Directive 70/220/EEC of 20 March 1970 on the approximation of the laws of the Member States relating to measures to be taken against air pollution by gases from positiveignition engines of motor vehicles.

[10] Regulation (EC) No 443/2009 of the European Parliament and of the Council of 23 April 2009 setting emission performance standards for new passenger cars as part of the Community's integrated approach to reduce $\mathrm{CO} 2$ emissions from light-duty vehicles.

[11] White Paper. Roadmap to a Single European Transport Area - Towards a competitive and resource efficient transport system. European Commission, Brussels, 28/03/2011.

[12] Directive 2000/53/EC of the European Parliament and of the Council of 18 September 2000 on end-of-life vehicles - Commission Statements.

[13] S.A. Shaheen and T.E. Lipman. Reducing greenhouse emissions and fuel consumption: Sustainable Approaches for Surface Transportation. IATSS Res, 2007, 31: 6-20.

[14] European Automobile Manufacturers Association (ACEA) - About the Automobile Industry - Passenger Cars, http://www.acea.be/automobile-industry/passenger-cars.

[15] US Department of Energy - Energy Efficiency \& Renewable Energy - Alternative Fuels Data Center, http://www.afdc.energy.gov/fuels/index.html.

[16] K. Gadesmann and F. Kuhnert. The automotive industry and climate change. Framework and dynamics of the CO2 (r)evolution. PricewaterhouseCoopers AG, 2007.

[17] A. Chauhan. Environment-friendly biodegradable polymers and their applications. Malaysian Polym J, 2012, 7: 62-67.

[18] Plastics Europe. Automotive. The world moves with plastics. Plastics Europe Publications, 2013.

[19] J. Maxwell. Plastics in the Automotive Industry, 1st ed., Woodhead Publishing, Cambridge, 1994, pp. 192.

[20] G. Klink, O. Wadivkar, G. Rouilloux and B. Znojek. Plastics. The future for automakers and chemical companies. A.T. Kearny Inc, 2012.

[21] Plastics Europe. Plastics - the Facts 2015. Plastics Europe Publications, 2015.

[22] Centro Español de Plásticos - Entrevista a Ángel Lozano, director del Centro Español de Plásticos, http://www.cep-plasticos.com/es/contenido/entrevista-director-del-centro-espanolde-plasticos-el-plastico-en-la-automocion-fuente-continua-de-mejoras. 
[23] Autofacil - Seat 600 vs Seat Mii, http://www.autofacil.es/seat/mii/2013/07/10/seat-600vs-seat-mii-cambian-tiempos-venancio/14979.html.

[24] Motorgiga - Galería de fotos Seat Ateca 2016, http://motorgiga.com/seat/fotos/fotosalpicadero-seat-ateca-suv-todocamino-2016/415539?lightbox=1.

[25] K. Sehanobish. Engineering plastics and plastic composites in automotive applications, 1st ed., SAE International, Warrendale, 2009, pp. 56.

[26] J. Rowe. Advanced materials in automotive engineering, 1st ed., Woodhead Publishing, Cambridge, 2012, pp. 352.

[27] A.B. Strong. Plastics: materials and processing, 3rd ed., Pearson Prentice Hall, New Jersey, 2006, pp. 917.

[28] D.V. Rosato, D.V. Rosato and M.G. Rosato. Injection molding handbook, 3rd ed., Springer Science, New York, 2000, pp. 1457.

[29] Plastics News Research. Plastics in Automotive. Trends Report, 2016.

[30] American Chemistry Council - Plastics Division. Plastics and Polymer Composites Technology Roadmap for Automotive Markets. American Chemistry Council, 2014.

[31] A. Bandivadekar, K. Bodek, L. Cheah, C. Evans, T. Groode, J. Heywood, E. Kasseris, M. Kromer and M. Weiss. On the road in 2035: Reducing transportation petroleum consumption and GHG emissions. Laboratory for Energy and the Environment, Massachusetts Institute of Technology, 2008.

[32] F. Stodolsky, A. Vyas and R. Cuenca. Lightweight materials in the light-duty passenger vehicle market: Their market penetration potential and impacts. The Second World Car Conference, Riverside, California (USA), 1995.

[33] L. Morello, L.R. Rossini, G. Pia and A. Tonoli. The Automotive Body, 1st ed., Springer Science, New York, 2011, pp. 668.

[34] J.C. Kelly, J.L. Sullivan, A. Burnham and A. Elgowainy. Impacts of Vehicle Weight Reduction via Material Substitution on Life-Cycle Greenhouse Gas Emissions. Environ Sci Technol, 2015, 49: 12535-12542.

[35] A.I. Taub and A.A. Luo. Advanced lightweight materials and manufacturing processes for automotive applications. MRS Bulletin, 2015, 40: 1045-1053. 
[36] E. Ghassemieh. Materials in Automotive Application, State of the Art and Prospects. In: New Trends and Developments in Automotive Industry. InTech, Janeza, 2011, pp. 365-394.

[37] D. Scuccimarra. Vehicle lightening with composite materials: Objective performance comparison of material-systems for structural applications. $\mathrm{PhD}$ Thesis, University of Windsor, Windsor, 2012.

[38] Audi-Technology Portal, http://www.audi-technology-portal.de/en/body/.

[39] BMW Insights - The future of urban mobility. BMW i Concept, http://www.bmw.com/com/en/insights/corporation/bmwi/concept.html.

[40] M.-Y. Lyu and T.G. Choi. Research trends in polymer materials for use in lightweight vehicles. Int J Precis Eng Manuf, 2015, 16: 213-220.

[41] A. Handschke and J. Mitzler. Physical Foaming Made Very Easy. Kunststoffe, 2012, 10/2012: 151-156.

[42] H.C. Kim and T.J. Wallington. Life-Cycle Energy and Greenhouse Gas Emission Benefits of Lightweighting in Automobiles: Review and Harmonization. Environ Sci Technol, 2013, 47: 6089-6097.

[43] D. Elduque, I. Claveria, A. Fernandez, C. Javierre, C. Pina and J. Santolaria. Analysis of the Influence of Microcellular Injection Molding on the Environmental Impact of an Industrial Component. Adv Mech Eng, 2014, 6: 793269.

[44] Society of Plastics Enginners. 2011 SPE Automotive Division Grand Award Winner "Most Innovative Use of Plastics". SPE Automotive Plastic News, December 2011 - Volume 41, Issue 2, Page 6.

[45] Trexel - Automotive, http://www.trexel.com/en/industries/automotive.

[46] K.S. Lee, P.J. Jeong, H. Lee, S.-J. Lee and S.W. Cha. Conceptual Design of Microcellular Plastics Bumper Parts Using Axiomatic Approach. Polym-Plast Technol, 2009, 48: 1101-1106.

[47] S.-T. Lee and D.P.K. Scholz. Polymeric Foams: Technology and Developments in Regulation, Process, and Products, 1st ed., CRC Press, Boca Raton, 2008, pp. 302.

[48] N.P. Suh. Impact of microcellular plastics on industrial practice and academic research. Macromol Symp, 2003, 201: 187-202. 
[49] Plastemart - Global polymer foam market poised to surpass US $\$ 131$ bln by 2018, http://www.plastemart.com/Plastic-Technical-Article.asp?LiteratureID=2010\&Paper=globalpolymer-foam-market-surpass-US\$131-billion-2018\#.

[50] J. Wang. Rheology of Foaming Polymers and Its Influence on Microcellular Processing. PhD Thesis, University of Toronto, Toronto, 2009.

[51] L.J. Gibson and M.F. Ashby. Cellular Solids: Structure and Properties, 2nd ed., Cambridge University Press, Cambridge, 1999, pp. 532.

[52] X. Hu, E.M. Wouterson and M. Liu. Polymer Foam Technology. In: Handbook of Manufacturing Engineering and Technology. Springer London, London, 2015, pp. 125-168.

[53] D. Eaves. Handbook of Polymer Foams, 1st ed., Rapra Technology Limited, Shawbury, 2004, pp. 274.

[54] Centexbel - Activities - Image of the month (December 2013), http://www.centexbel.be/image-of-the-month.

[55] A.A. Beltrán and L.A. Boyacá. Production of rigid polyurethane foams from soy-based polyols. Latin Am Appl Res, 2011, 41: 75-80.

[56] S.-T. Lee, C.B. Park and N.S. Ramesh. Polymeric Foams: Science and Technology, 1st ed., CRC Press, Boca Raton, 2007, pp. 220.

[57] N. Mills. Polymer Foams Handbook, 1st ed., Butterworth-Heinemann, Oxford, 2007, pp. 535.

[58] J. Xu. Microcellular Injection Molding, 1st ed., John Wiley \& Sons, Hoboken, 2010, pp. 618.

[59] T. Mergenhagen. Chemical foaming agents in thermoplastics and thermosets. Blowing Agents and Foaming Processes, Mainz (Germany), 2013.

[60] M. Kutz. Applied Plastics Engineering Handbook, 1st ed., William Andrew Publishing, Oxford, 2011, pp. 664.

[61] E. Aram and S. Mehdipour-Ataei. A review on the micro- and nanoporous polymeric foams: Preparation and properties. Int J Polym Mater, 2016, 65: 358-375.

[62] C. Okolieocha, D. Raps, K. Subramaniam and V. Altstädt. Microcellular to nanocellular polymer foams: Progress (2004-2015) and future directions - A review. Eur Polym J, 2015, 73: 500-519. 
[63] J. Martini, F. Waldman and N.P. Suh. The production and analysis of microcellular thermoplastic foams. Annual Technical Conference - ANTEC: Society of Plastics Engineers (SPE), San Francisco Hilton (USA), 1982.

[64] Microcellular Plastics Lab (University of Washington) - The Solid-State Batch Process, http://faculty.washington.edu/vkumar/microcel/solidstate.html.

[65] K. Nadella, V. Kumar and L. Wei. Constrained solid-state foaming of microcellular panels. Cell Polym, 2005, 24: 71-90.

[66] Microcellular Plastics Lab (University of Washington) - The Semi-Continuous Process, http://faculty.washington.edu/vkumar/microcel/semicontinuous.html.

[67] S.-T. Lee and C.B. Park. Foam Extrusion: Principles and Practice, 2nd ed., CRC Press, Boca Raton, 2014, pp. 624.

[68] M. Sauceau, J. Fages, A. Common, C. Nikitine and E. Rodier. New challenges in polymer foaming: A review of extrusion processes assisted by supercritical carbon dioxide. Prog Polym Sci, 2011, 36: 749-766.

[69] A.K. Bledzki, O. Faruk, H. Kirschling, J. Kuehn and A. Jaszkiewicz. Microcellular polymers and composites Part I. Types of foaming agents and technologies of microcellular processing. Polimery-W, 2006, 51: 696-703.

[70] Ž. Knez, E. Markočič, M. Leitgeb, M. Primožič, M. Knez Hrnčič and M. Škerget. Industrial applications of supercritical fluids: A review. Energy, 2014, 77: 235-243.

[71] J.-P.E. Grolier and S.L. Randzio. Simple gases to replace non-environmentally friendly polymer foaming agents. A thermodynamic investigation. J Chem Thermodyn, 2012, 46: 4256.

[72] Y. Sato, K. Fujiwara, T. Takikawa, Sumarno, S. Takishima and H. Masuoka. Solubilities and diffusion coefficients of carbon dioxide and nitrogen in polypropylene, high-density polyethylene, and polystyrene under high pressures and temperatures. Fluid Phase Equilibr, 1999, 162: 261-276.

[73] J.F. Stevenson. Innovation in Polymer Processing: Molding (SPE Books), 1st ed., Hanser Publishers, Cincinnati, 1996, pp. 600.

[74] J.L. Throne Thermoplastic foams, 1st ed., Sherwood Publishers, Hertford, 1996, pp. 693. 
[75] D. Hu, J. Chen, S. Sun, T. Liu and L. Zhao. Solubility and Diffusivity of CO2 in Isotactic Polypropylene/Nanomontmorillonite Composites in Melt and Solid States. Ind Eng Chem Res, 2014, 53: 2673-2683.

[76] G.-G. Lin, D.-J. Lin, L.-J. Wang and T.-W. Kuo. Absorption and foaming of plastics using carbon dioxide. Res Chem Intermediat, 2014, 40: 2259-2268.

[77] S. Kanehashi, A. Kusakabe, S. Sato and K. Nagai. Analysis of permeability; solubility and diffusivity of carbon dioxide; oxygen; and nitrogen in crystalline and liquid crystalline polymers. J Membrane Sci, 2010, 365: 40-51.

[78] Y. Sato, M. Yurugi, K. Fujiwara, S. Takishima and H. Masuoka. Solubilities of carbon dioxide and nitrogen in polystyrene under high temperature and pressure. Fluid Phase Equilibr, 1996, 125: 129-138.

[79] P. Tremblay, M.M. Savard, J. Vermette and R. Paquin. Gas permeability, diffusivity and solubility of nitrogen, helium, methane, carbon dioxide and formaldehyde in dense polymeric membranes using a new on-line permeation apparatus. J Membrane Sci, 2006, 282: 245-256.

[80] T. Ishikawa, K. Taki and M. Ohshima. Visual observation and numerical studies of N2 vs. CO2 foaming behavior in core-back foam injection molding. Polym Eng Sci, 2012, 52: 875-883.

[81] J.W.S. Lee and C.B. Park. Use of Nitrogen as a Blowing Agent for the Production of Fine-Celled High-Density Polyethylene Foams. Macromol Mater Eng, 2006, 291: 1233-1244.

[82] J.S. Colton and N.P. Suh. Nucleation of microcellular foam: Theory and practice. Polym Eng Sci, 1987, 27: 500-503.

[83] J.S. Colton and N.P. Suh. The nucleation of microcellular thermoplastic foam with additives: Part I: Theoretical considerations. Polym Eng Sci, 1987, 27: 485-492.

[84] S.N. Leung, A. Wong, C.B. Park and J.H. Zong. Ideal surface geometries of nucleating agents to enhance cell nucleation in polymeric foaming processes. J Appl Polym Sci, 2008, 108: 3997-4003.

[85] M.-C. Guo, Y.-C. Peng, Y.-B. Cai and W.-G. Zhou. Effect of shear energy upon bubble nucleation under shear flow field. J Mater Sci, 2004, 39: 3805-3807. 
[86] S.N. Leung, A. Wong, Q. Guo, C.B. Park and J.H. Zong. Change in the critical nucleation radius and its impact on cell stability during polymeric foaming processes. Chem Eng Sci, 2009, 64: 4899-4907.

[87] M.M.M. Shirvan, M.H.N. Famili and A. Golbang. A Review on the Application of Nucleation Theories in Thermoplastic Foams. Plast Polym Technol, 2016, 4: 11-32.

[88] M. Amon and C.D. Denson. A study of the dynamics of foam growth: Analysis of the growth of closely spaced spherical bubbles. Polym Eng Sci, 1984, 24: 1026-1034.

[89] J.D. Yoon and S.W. Cha. Change of glass transition temperature of polymers containing gas. Polym Test, 2001, 20: 287-293.

[90] K. Taki, K. Tabata, S.-I. Kihara and M. Ohshima. Bubble coalescence in foaming process of polymers. Polym Eng Sci, 2006, 46: 680-690.

[91] S. Han, P. Kennedy, R. Zheng, J. Xu and L. Kishbaugh. Numerical Analysis of Microcellular Injection Molding. J Cell Plast, 2003, 39: 475-485.

[92] Y. Moon, K.-S. Lee and S.W. Cha. Bubble growth in mold cavities during microcellular injection molding processes. J Mech Sci Technol, 2009, 23: 3349-3356.

[93] G. Dong, G. Zhao, Y. Guan, S. Li and X. Wang. Formation mechanism and structural characteristics of unfoamed skin layer in microcellular injection-molded parts. J Cell Plast, 2015, 52: 419-439.

[94] G.-L. Wang, G.-Q. Zhao, J.-C. Wang and L. Zhang. Research on formation mechanisms and control of external and inner bubble morphology in microcellular injection molding. Polym Eng Sci, 2015, 55: 807-835.

[95] S.W. Cha and J.D. Yoon. The Relationship of Mold Temperatures and Swirl Marks on the Surface of Microcellular Plastics. Polym-Plast Technol, 2005, 44: 795-803.

[96] H. Guanghong and W. Yue. Microcellular Foam Injection Molding Process. In: Some Critical Issues for Injection Molding. InTech, Rijeka, 2012, pp. 175-202.

[97] D. Pierick and K. Jacobsen. Injection molding innovation: The microcellular foam process. Plastics Engineering - Society of Plastics Engineers (SPE), 2001, 57: 46-51.

[98] Trexel Inc. MuCell® - Proven lightweighting technology for automotive applications. Automotive brochure, 2014. 
[99] J. Xu and D. Pierick. Microcellular foam processing in reciprocating-screw injection molding machines. J Injection Molding Technol, 2001, 5: 152-159.

[100] D.E. Pierick, J.R. Anderson, W.C. Sung, J.F. Stevenson and D.E. Laing. European Patent No 0952908: Injection molding of microcellular material, 1998.

[101] D.E. Pierick, J.R. Anderson, W.C. Sung, L. Chen, J.F. Stevenson and D.E. Laing. US Patent No 6884823: Injection molding of microcellular material, 1999.

[102] Trexel - Implementing MuCell®, http://www.trexel.com/en/mucell-injectionmolding/implementation.

[103] Plastic Portal - Thermoplastic Foam Injection Molding, http://www.plasticportal.eu/en/thermoplastic-foam-injection-molding/c/2416.

[104] K.T. Okamoto. Microcellular Processing, 1st ed., Hanser Publishers, Cincinnati, 2003, pp. 186.

[105] C. Schütz, J. Hain and M. Müller. German Patent No 102014212048: System zum Schleusen, Dosieren und Spritzgiessen von Material, 2014.

[106] J. Hain. Thermoplastschaum-Spritzguss - neue Möglichkeiten durch IQ-Foam. Kunstofftrends im Automobil, Wolfsburg (Germany), 2015.

[107] L. Zhang, G. Zhao, G. Dong, S. Li and G. Wang. Bubble morphological evolution and surface defect formation mechanism in the microcellular foam injection molding process. RSC Adv, 2015, 5: 70032-70050.

[108] Y. Wang and G.H. Hu. Research progress of improving surface quality of microcellular foam injection parts. Appl Mech Mater, 2011, 66: 2010-2016.

[109] S.C. Chen, P.S. Hsu and Y.W. Lin. Establishment of Gas Counter Pressure Technology and Its Application to Improve the Surface Quality of Microcellular Injection Molded Parts. Int Polym Proc, 2011, 26: 275-282.

[110] S.-C. Chen, Y.-W. Lin, R.-D. Chien and H.-M. Li. Variable mold temperature to improve surface quality of microcellular injection molded parts using induction heating technology. Adv Polym Tech, 2008, 27: 224-232.

[111] H.-L. Chen, R.-D. Chien and S.-C. Chen. Using thermally insulated polymer film for mold temperature control to improve surface quality of microcellular injection molded parts. Int Commun Heat Mass, 2008, 35: 991-994. 
[112] L.S. Turng and H. Kharbas. Development of a Hybrid Solid-Microcellular Co-injection Molding Process. Int Polym Proc, 2004, 19: 77-86.

[113] J. Hain, A. Schmiemann and P. Bersch. Material Concept for Large-Scale Production of Finished Colored External Body Panels in Automobile. Annual Technical Conference ANTEC: Society of Plastics Engineers (SPE), Las Vegas (USA), 2014.

[114] H.-P. Heim and M. Tromm. General aspects of foam injection molding using local precision mold opening technology. Polymer, 2015, 56: 111-118.

[115] ENGEL North America. ENGEL Provides Technology Solutions With MuCell® Core Back Expansion Molding. Press Release, 2009.

[116] N. Müller and G.W. Ehrenstein. Constancy of Properties Resulting from Foam Injection-Molding Techniques. Annual Technical Conference - ANTEC: Society of Plastics Engineers (SPE), Boston (USA), 2005.

[117] J.F. Gómez-Gómez. Caracterización y estudio comparativo de materiales celulares poliméricos obtenidos mediante moldeo por inyección con espumación física o química. $\mathrm{PhD}$ Thesis, Universitat Politècnica de Catalunya-BarcelonaTech, Barcelona, 2013.

[118] H. Wu, E. Wintermantel and H.J. Haugen. The Effects of Mold Design on the Pore Morphology of Polymers Produced with MuCell® Technology. J Cell Plast, 2010, 46: 519530.

[119] A. Ahmadzai, A.H. Behravesh, M.T. Sarabi and P. Shahi. Visualization of foaming phenomena in thermoplastic injection molding process. J Cell Plast, 2014, 50: 279-300.

[120] V. Shaayegan, L.H. Mark, A. Tabatabaei and C.B. Park. A new insight into foaming mechanisms in injection molding via a novel visualization mold. eXPRESS Polym Lett, 2016, 10: 462-469.

[121] S.J.A. Rizvi and N. Bhatnagar. Optimization of Microcellular Injection Molding Parameters. Int Polym Proc, 2009, 24: 399-405.

[122] C.-K. Lin, S.-H. Chen, H.-Y. Liou and C.-C. Tian. Study on Mechanical Properties of ABS Parts in Microcellular Injection Molding Process. Annual Technical Conference ANTEC: Society of Plastics Engineers (SPE), Boston (USA), 2005. 
[123] J. Xu. Effect of Injection Molding Process Parameters on the Morphology and Quality of Microcellular Foams. Annual Technical Conference - ANTEC: Society of Plastics Engineers (SPE), North Carolina (USA), 2006.

[124] T. Liu, Y. Lei, Z. Chen, X. Wang and S. Luo. Effects of processing conditions on foaming behaviors of polyetherimide (PEI) and PEI/polypropylene blends in microcellular injection molding process. J Appl Polym Sci, 2015, 132: 41443.

[125] T. Liu, Z. Chen, Y. Lei, X. Wang and S. Luo. Foaming behaviors of polyetherimide/ polypropylene-graft-maleic anhydride blends in the microcellular injection molding process. J Cell Plast, 2015, 51: 387-400.

[126] S.-S. Hwang, S.-C. Chen and M.-H. Chung. Study on the mechanical properties of microcellular injection molded parts. Annual Technical Conference - ANTEC: Society of Plastics Engineers (SPE), Boston (USA), 2005.

[127] S.-C. Chen, J.-P. Yang, J.S. Hwang and M.-S. Chung. Effects of Process Conditions on the Mechanical Properties of Microcellular Injection Molded Polycarbonate Parts. J Reinf Plast Compos, 2008, 27: 153-165.

[128] L.-S. Turng and H. Kharbas. Effect of process conditions on the weld-line strength and microstructure of microcellular injection molded parts. Polym Eng Sci, 2003, 43: 157-168.

[129] A.K. Bledzki, H. Kirschling, G. Steinbichler and P. Egger. Polycarbonate Microfoams with a Smooth Surface and Higher Notched Impact Strength. J Cell Plast, 2004, 40: 489-496.

[130] A.K. Bledzki, M. Rohleder, H. Kirschling and A. Chate. Correlation Between Morphology and Notched Impact Strength of Microcellular Foamed Polycarbonate. J Cell Plast, 2010, 46: 415-440.

[131] A.K. Bledzki, H. Kirschling, M. Rohleder and A. Chate. Correlation between injection moulding processing parameters and mechanical properties of microcellular polycarbonate. $\mathrm{J}$ Cell Plast, 2012, 48: 301-340.

[132] W. Michaeli, L. Florez, D. Obeloer and M. Brinkmann. Analysis of the Impact Properties of Structural Foams. J Cell Plast, 2009, 45: 321-351.

[133] S.-C. Chen, W.-H. Liao and R.-D. Chien. Structure and mechanical properties of polystyrene foams made through microcellular injection molding via control mechanisms of gas counter pressure and mold temperature. Int Commun Heat Mass, 2012, 39: 1125-1131. 
[134] J.F. Gómez-Gómez, D. Arencón, M.Á. Sánchez-Soto and A.B. Martínez. Influence of the injection moulding parameters on the microstructure and thermal properties of microcellular polyethylene terephthalate glycol foams. J Cell Plast, 2013, 49: 47-63.

[135] A. Kramschuster, R. Cavitt, D. Ermer, Z. Chen and L.-S. Turng. Quantitative study of shrinkage and warpage behavior for microcellular and conventional injection molding. Polym Eng Sci, 2005, 45: 1408-1418.

[136] W. Gong, J. Gao, M. Jiang, L. He, J. Yu and J. Zhu. Influence of cell structure parameters on the mechanical properties of microcellular polypropylene materials. J Appl Polym Sci, 2011, 122: 2907-2914.

[137] K. Martinez, L.-S. Turng, A. Kramschuster and J. Lee. Microcellular injection molding of polypropylene with nucleating and clarifying agents. Annual Technical Conference ANTEC: Society of Plastics Engineers (SPE), Milwaukee (USA), 2008.

[138] J.F. Gómez-Gómez, D. Arencón, M.A. Sánchez-soto and A.B. Martínez. Influence of the Injection-Molding Parameters on the Cellular Structure and Thermo-Mechanical Properties of Ethylene-Propylene Block Copolymer Foams. Adv Polym Tech, 2013, 32: E692-E704.

[139] X. Chen, M.-C. Heuzey and P.J. Carreau. Rheological properties of injection molded LDPE and mPE foams. Polym Eng Sci, 2004, 44: 2158-2164.

[140] M.R. Barzegari and D. Rodrigue. The effect of injection molding conditions on the morphology of polymer structural foams. Polym Eng Sci, 2009, 49: 949-959.

[141] S.A. Edwards, J. Kennedy, J. Nicholson, N.R. Choudhury and M. Provatas. An Investigation of Microcellular Injection Moulding on the Structure-Property Relationships of Engineering Thermoplastics Used in Exterior Automotive Applications. Annual Technical Conference - ANTEC: Society of Plastics Engineers (SPE), Chicago (USA), 2004.

[142] A.N.J. Spörrer and V. Altstädt. Controlling Morphology of Injection Molded Structural Foams by Mold Design and Processing Parameters. J Cell Plast, 2007, 43: 313-330.

[143] S. Wong, J.W.S. Lee, H.E. Naguib and C.B. Park. Effect of Processing Parameters on the Mechanical Properties of Injection Molded Thermoplastic Polyolefin (TPO) Cellular Foams. Macromol Mater Eng, 2008, 293: 605-613. 
[144] G. Wang, L.H. Mark, V. Shaayegan and C.B. Park. Foaming Behavior and Control of Polypropylene/Nitrogen System in Microcellular Foam Injection Molding. Annual Technical Conference - ANTEC: Society of Plastics Engineers (SPE), Orlando (USA), 2015.

[145] E. Bociaga and P. Palutkiewicz. The influence of injection molding parameters and blowing agent addition on selected properties, surface state, and structure of HDPE parts. Polym Eng Sci, 2013, 53: 780-791.

[146] Z. Xi, F. Zhang, H. Zhong, T. Liu, L. Zhao and L.-S. Turng. Microcellular injection molding of in situ modified poly(ethylene terephthalate) with supercritical nitrogen. Polym Eng Sci, 2014, 54: 2739-2745.

[147] J.-H. Seo, J. Han, K.S. Lee and S.W. Cha. Combined Effects of Chemical and Microcellular Foaming on Foaming Characteristics of PLA (Poly Lactic Acid) in Injection Molding Process. Polym-Plast Technol, 2012, 51: 455-460.

[148] V. Volpe and R. Pantani. Foam injection molding of poly(lactic) acid: Effect of back pressure on morphology and mechanical properties. J Appl Polym Sci, 2015, 132: 42612.

[149] H. Zhao, Z. Cui, X. Sun, L.-S. Turng and X. Peng. Morphology and Properties of Injection Molded Solid and Microcellular Polylactic Acid/Polyhydroxybutyrate-Valerate (PLA/PHBV) Blends. Ind Eng Chem Res, 2013, 52: 2569-2581.

[150] B. Jeon, H.K. Kim, S.W. Cha, S.J. Lee, M.-S. Han and K.S. Lee. Microcellular foam processing of biodegradable polymers - review. Int J Precis Eng Manuf, 2013, 14: 679-690.

[151] M. Nofar and C.B. Park. Poly (lactic acid) foaming. Prog Polym Sci, 2014, 39: 17211741.

[152] M. Yuan, A. Winardi, S. Gong and L.-S. Turng. Effects of nano- and micro-fillers and processing parameters on injection-molded microcellular composites. Polym Eng Sci, 2005, 45: 773-788.

[153] M. Yuan and L.-S. Turng. Microstructure and mechanical properties of microcellular injection molded polyamide-6 nanocomposites. Polymer, 2005, 46: 7273-7292.

[154] S.-S. Hwang, P.P. Hsu, J.-M. Yeh, K.-C. Chang and Y.-Z. Lai. The mechanical/thermal properties of microcellular injection-molded poly-lactic-acid nanocomposites. Polym Composite, 2009, 30: 1625-1630. 
[155] H. Zhao, Z. Cui, X. Wang, L.-S. Turng and X. Peng. Processing and characterization of solid and microcellular poly(lactic acid)/polyhydroxybutyrate-valerate (PLA/PHBV) blends and PLA/PHBV/Clay nanocomposites. Compos Part B-Eng, 2013, 51: 79-91.

[156] S.-S. Hwang, P.P. Hsu, J.-M. Yeh, J.-P. Yang, K.-C. Chang and Y.-Z. Lai. Effect of clay and compatibilizer on the mechanical/thermal properties of microcellular injection molded low density polyethylene nanocomposites. Int Commun Heat Mass, 2009, 36: 471-479.

[157] M.-C. Guo, M.-C. Heuzey and P.J. Carreau. Cell structure and dynamic properties of injection molded polypropylene foams. Polym Eng Sci, 2007, 47: 1070-1081.

[158] S. Yetgin, H. Unal and A. Mimaroglu. Influence of foam agent content and talc filler on the microcellular and mechanical properties of injection molded polypropylene and talc filled polypropylene composite foams. J Cell Plast, 2014, 50: 563-576.

[159] Z. Xi, X. Sha, T. Liu and L. Zhao. Microcellular injection molding of polypropylene and glass fiber composites with supercritical nitrogen. J Cell Plast, 2014, 50: 489-505.

[160] Z.X. Xin, Z.X. Zhang, K. Pal, J.U. Byeon, S.H. Lee and J.K. Kim. Study of microcellular injection-molded polypropylene/waste ground rubber tire powder blend. Mater Design, 2010, 31: 589-593.

[161] A.K. Bledzki and O. Faruk. Influence of Processing Temperature on Microcellular Injection-Moulded Wood-Polypropylene Composites. Macromol Mater Eng, 2006, 291: 1226-1232.

[162] A.K. Bledzki and O. Faruk. Microcellular Injection Molded Wood Fiber-PP Composites: Part I - Effect of Chemical Foaming Agent Content on Cell Morphology and Physico-mechanical Properties. J Cell Plast, 2006, 42: 63-76.

[163] A.K. Bledzki and O. Faruk. Microcellular Injection Molded Wood Fiber-PP Composites: Part II - Effect of Wood Fiber Length and Content on Cell Morphology and Physico-mechanical Properties. J Cell Plast, 2006, 42: 77-88.

[164] B. Xie, Y.-H. Cui, J. Xu, X.-X. Wang, H.-H. Zhang and Z.-D. Zhang. Investigation on microstructure and properties of foamed (wood fiber)/(recycled polypropylene) composites. $\mathbf{J}$ Vinyl Addit Techn, 2012, 18: 105-112.

[165] O. Faruk, A.K. Bledzki and L.M. Matuana. Microcellular Foamed Wood-Plastic Composites by Different Processes: a Review. Macromol Mater Eng, 2007, 292: 113-127. 
[166] S.J.A. Rizvi and N. Bhatnagar. Microcellular PP vs. Microcellular PP/MMT Nanocomposites: A Comparative Study of Their Mechanical Behavior. Int Polym Proc, 2011, 26: $375-382$.

[167] Y. Srithep and L.-S. Turng. Microcellular injection molding of recycled poly(ethylene terephthalate) blends with chain extenders and nanoclay. J Polym Eng, 2014, 34: 5-13.

[168] X.-C. Wang, X. Jing, Y.-Y. Peng, Z.-K. Ma, C.-T. Liu, L.-S. Turng and C.-Y. Shen. The effect of nanoclay on the crystallization behavior, microcellular structure, and mechanical properties of thermoplastic polyurethane nanocomposite foams. Polym Eng Sci, 2016, 56: 319-327.

[169] S.H. Yetkin, H. Unal, A. Mimaroglu and F. Findik. Influence of Process Parameters on the Mechanical and Foaming Properties of PP Polymer and PP/TALC/EPDM Composites. Polym-Plast Technol, 2013, 52: 433-439.

[170] A. Ameli, D. Jahani, M. Nofar, P.U. Jung and C.B. Park. Processing and characterization of solid and foamed injection-molded polylactide with talc. J Cell Plast, 2013, 49: 351-374.

[171] Z. Bian, P.C. Xie, Y.M. Ding and W.M. Yang. Effect of Processing Conditions on the Shrinkage and Warpage of Glass Fiber Reinforced PP Using Microcellular Injection Molding. Key Eng Mater, 2012, 501: 294-299.

[172] A. Roch, T. Huber, F. Henning and P. Elsner. LFT foam - Lightweight potential for semi-structural components through the use of long-glass-fiber-reinforced thermoplastic foams. AIP Conf Proc, 2014, 1593: 471-476.

[173] A. Roch, L. Kehret, T. Huber, F. Henning and P. Elsner. Investigations on injection molded, glass-fiber reinforced polyamide 6 integral foams using breathing mold technology. AIP Conf Proc, 2015, 1664: 110013.

[174] A. Ameli, P.U. Jung and C.B. Park. Electrical properties and electromagnetic interference shielding effectiveness of polypropylene/carbon fiber composite foams. Carbon, 2013, 60: 379-391.

[175] S.-S. Hwang, P.-M. Hsu, J.-P. Yang and C.-H. Hu. Effects of Carbon Fiber Loading on the Conductive, Mechanical, EMI Shielding Effectiveness Properties of Microcellular Foams of PBT/Carbon Fiber Composites. Annual Technical Conference - ANTEC: Society of Plastics Engineers (SPE), Las Vegas (USA), 2014. 
[176] S. Pilla, A. Kramschuster, S. Gong, A. Chandra and L.S. Turng. Solid and Microcellular Polylactide-Carbon Nanotube Nanocomposites. Int Polym Proc, 2007, 22: 418428.

[177] M. Arjmand, M. Mahmoodi, S. Park and U. Sundararaj. Impact of foaming on the broadband dielectric properties of multi-walled carbon nanotube/polystyrene composites. $\mathbf{J}$ Cell Plast, 2014, 50: 551-562.

[178] Z.-X. Zhang, J.-L. Fan, K. Pal, J.K. Kim and Z.-X. Xin. Influence of compatibilizers and processing temperature on microcellular injection-molded polypropylene/(waste tire powder) composites. J Vinyl Addit Techn, 2011, 17: 254-259.

[179] J.D. Yoon, J.H. Kim and S.W. Cha. The Effect of Control Factors and the Effect of CaCO3 on the Microcellular Foam Morphology. Polym-Plast Technol, 2005, 44: 805-814.

[180] S.-S. Hwang and P.P. Hsu. Effects of silica particle size on the structure and properties of polypropylene/silica composites foams. J Ind Eng Chem, 2013, 19: 1377-1383.

[181] J. Li, Z. Chen, X. Wang, T. Liu, Y. Zhou and S. Luo. Cell morphology and mechanical properties of microcellular mucell ${ }^{\circledR}$ injection molded polyetherimide and polyetherimide/fillers composite foams. J Appl Polym Sci, 2013, 130: 4171-4181.

[182] A.K. Bledzki and O. Faruk. Microcellular Wood Fiber Reinforced PP Composites: Cell Morphology, Surface Roughness, Impact, and Odor Properties. J Cell Plast, 2005, 41: 539550.

[183] R. Gosselin, D. Rodrigue and B. Riedl. Injection Molding of Postconsumer WoodPlastic Composites I: Morphology. J Thermoplast Compos, 2006, 19: 639-657.

[184] A.K. Bledzki and O. Faruk. Microcellular Wood Fibre Reinforced PP Composites. Int Polym Proc, 2006, 21: 256-262.

[185] J.G. Gwon, S.Y. Lee, H. Kang and J.H. Kim. Effects of sizes and contents of exothermic foaming agent on physical properties of injection foamed wood fiber/HDPE composites. Int $\mathbf{J}$ Precis Eng Manuf, 2012, 13: 1003-1007.

[186] A. Kramschuster, S. Pilla, S. Gong, A. Chandra and L.S. Turng. Injection Molded Solid and Microcellular Polylactide Compounded with Recycled Paper Shopping Bag Fibers. Int Polym Proc, 2007, 22: 436-445. 
[187] W. Ding, D. Jahani, E. Chang, A. Alemdar, C.B. Park and M. Sain. Development of PLA/cellulosic fiber composite foams using injection molding: Crystallization and foaming behaviors. Compos Part A-Appl S, 2016, 83: 130-139.

[188] S. Pilla, A. Kramschuster, J. Lee, G.K. Auer, S. Gong and L.-S. Turng. Microcellular and Solid Polylactide-Flax Fiber Composites. Compos Interface, 2009, 16: 869-890.

[189] M.T. Zafar, N. Zarrinbakhsh, A.K. Mohanty, M. Misra, S.N. Maiti and A.K. Ghosh. Biocomposites based on poly(lactic acid)/willow-fiber and their injection moulded microcellular foams. eXPRESS Polym Lett, 2016, 10: 176-186.

[190] T. Boronat, V.J. Segui, M.A. Peydro and M.J. Reig. Influence of temperature and shear rate on the rheology and processability of reprocessed ABS in injection molding process. $\mathbf{J}$ Mater Process Technol, 2009, 209: 2735-2745.

[191] H. Karian. Handbook of Polypropylene and Polypropylene Composites, Revised and Expanded, 2nd ed., CRC Press, Boca Raton, 2003, pp. 576.

[192] M. Etcheverry and S.E. Barbosa. Glass Fiber Reinforced Polypropylene Mechanical Properties Enhancement by Adhesion Improvement. Materials, 2012, 5: 1084.

[193] N. Müller and G.W. Ehrenstein. Evaluation and Modeling of Injection-Molded Rigid Polypropylene Integral Foam. J Cell Plast, 2004, 40: 45-59.

[194] S. Rizvi, M. Alaei, A. Yadav and N. Bhatnagar. Quantitative analysis of cell distribution in injection molded microcellular foam. J Cell Plast, 2014, 50: 199-219.

[195] ISO 3451-1: Plastics - Determination of ash - Part 1: General methods. International Organization for Standardization, 2008.

[196] ISO 527-2: Plastics - Determination of tensile properties - Part 2: Test conditions for moulding and extrusion plastics. International Organization for Standardization, 2012.

[197] ISO 527-1: Plastics - Determination of tensile properties - Part 1: General principles. International Organization for Standardization, 2012.

[198] ISO 178: Plastics - Determination of flexural properties. International Organization for Standardization, 2010.

[199] ISO 179-2: Plastics - Determination of Charpy impact properties - Part 2: Instrumented impact test. International Organization for Standardization, 1997. 
[200] T.L. Anderson. Fracture mechanics: fundamentals and applications, 3rd ed., CRC press, Boca Raton (USA), 2005, pp. 640.

[201] D.R. Moore, J.G. Williams and A. Pavan. Fracture mechanics testing methods for polymers, adhesives and composites, 1st ed., Elsevier, ESIS Publication, Oxford, 2001, pp. 388.

[202] ISO 11357-1: Plastics - Differential scanning calorimetry (DSC) - Part 1: General principles. International Organization for Standardization, 2010.

[203] B. Monasse and J.M. Haudin. Growth transition and morphology change in polypropylene. Colloid Polym Sci, 1985, 263: 822-831.

[204] ISO 75-2: Plastics - Determination of temperature of deflection under load - Part 2: Plastics and ebonite. International Organization for Standardization, 2013.

[205] Y.D. Hwang and S.W. Cha. The relationship between gas absorption and the glass transition temperature in a batch microcellular foaming process. Polym Test, 2002, 21: 269275.

[206] R.E. Murray, J.E. Weller and V. Kumar. Solid-state microcellular acrylonitrilebutadiene-styrene foams. Cell Polym, 2000, 19: 413-425.

[207] K. Nadella and V. Kumar. Tensile and Flexural Properties of Solid-State Microcellular ABS Panels. In: Experimental Analysis of Nano and Engineering Materials and Structures. Springer Netherlands, Dordrecht, 2007, pp. 765-766.

[208] K.K. Beydokhti, A.H. Behravesh and T. Azdast. An experimental study on mechanical and microstructural properties of microcellular foams of ABS composites. Iran Polym J, 2006, 15: 555-567.

[209] M. Mahmoodi and A.H. Behravesh. The Effect of Pressure Drop Rate on Microstructures of Unfilled and Glass-filled ABS Microcellular Foams. Iran Polym J, 2007, 16: 839-849.

[210] G.W. Dong, G.Q. Zhao, Y.J. Guan, G.L. Wang and X.X. Wang. The Cell Forming Process of Microcellular Injection-Molded Parts. J Appl Polym Sci, 2014, 131: 40365.

[211] L. Sorrentino, E. Di Maio and S. Iannace. Poly(ethylene terephthalate) foams: Correlation between the polymer properties and the foaming process. J Appl Polym Sci, 2010, 116: 27-35. 
[212] R.W. Truss and G.A. Chadwick. Tensile deformation behaviour of ABS polymers. J Mater Sci, 1976, 11: 111-117.

[213] S. Hashemi. Tensile and flexural properties of injection-moulded short glass fibre and glass bead ABS composites in the presence of weldlines. J Mater Sci, 2008, 43: 721-731.

[214] M. Rahimi, M. Esfahanian and M. Moradi. Effect of reprocessing on shrinkage and mechanical properties of $A B S$ and investigating the proper blend of virgin and recycled $A B S$ in injection molding. J Mater Process Technol, 2014, 214: 2359-2365.

[215] C.B. Bucknall and R.R. Smith. Stress-whitening in high-impact polystyrenes. Polymer, 1965, 6: 437-446.

[216] R.W. Truss and G.A. Chadwick. The tensile deformation behaviour of a transparent ABS polymer. J Mater Sci, 1976, 11: 1385-1392.

[217] Z.-N. Yin and T.-J. Wang. Investigation of tensile deformation behavior of PC, ABS, and PC/ABS blends from low to high strain rates. Appl Math Mech - Engl Ed, 2012, 33: 455464.

[218] D.C. Montgomery. Design and analysis of experiments, 7th ed., John Wiley \& Sons, Hoboken, New Jersey, 2008, pp. 684.

[219] C.M. Judd, G.H. McClelland and C.S. Ryan. Data analysis: A model comparison approach, 2nd ed., Routledge, Abingdon, Oxon, 2011, pp. 344.

[220] R.L. Mason, R.F. Gunst and J.L. Hess. Statistical design and analysis of experiments: with applications to engineering and science, 2nd ed., John Wiley \& Sons, Hoboken, New Jersey, 2003, pp. 760.

[221] W.M.H. Verbeeten, M.J.W. Kanters, T.A.P. Engels and L.E. Govaert. Yield stress distribution in injection-moulded glassy polymers. Polym Int, 2015, 64: 1527-1536.

[222] H. Sun and J.E. Mark. Preparation, characterization, and mechanical properties of some microcellular polysulfone foams. J Appl Polym Sci, 2002, 86: 1692-1701.

[223] J. Xu and L. Kishbaugh. Simple Modeling of the Mechanical Properties with Part Weight Reduction for Microcellular Foam Plastic. J Cell Plast, 2003, 39: 29-47.

[224] A. Tsuchiya, H. Tateyama, T. Kikuchi, T. Takahashi and K. Koyama. Influence of Filler Types and Contents on Foaming Structures in ABS Microcellular Foams. Polym J, 2007, 39: 514-523. 
[225] S.C. Chen, P.S. Hsu and S.S. Hwang. The effects of gas counter pressure and mold temperature variation on the surface quality and morphology of the microcellular polystyrene foams. J Appl Polym Sci, 2013, 127: 4769-4776.

[226] S.A.M. Rezavand, A.H. Behravesh, M. Mahmoodi and P. Shahi. Experimental study on the surface hardness and flexural strength of microcellular injection molded parts. 25th Annual Meeting of the Polymer Processing Society, Goa (India), 2009.

[227] Y. Zhang, D. Rodrigue and A. Ait-Kadi. High density polyethylene foams. IV. Flexural and tensile moduli of structural foams. J Appl Polym Sci, 2003, 90: 2139-2149.

[228] M. Avalle and A. Scattina. Mechanical properties and impact behavior of a microcellular structural foam. Lat Am J Solids Struct, 2014, 11: 200-222.

[229] M. Li, X. Cao and Y. Luo. Cell structure and impact properties of foamed polystyrene in constrained conditions using supercritical carbon dioxide. Iran Polym J, 2014, 23: 775781.

[230] R.P. Juntunen, V. Kumar, J.E. Weller and W.P. Bezubic. Impact strength of high density microcellular poly(vinyl chloride) foams. J Vinyl Addit Techn, 2000, 6: 93-99.

[231] P. Rachtanapun, S.E.M. Selke and L.M. Matuana. Relationship between cell morphology and impact strength of microcellular foamed high-density polyethylene/polypropylene blends. Polym Eng Sci, 2004, 44: 1551-1560.

[232] J.-B. Bao, G.-S. Weng, L. Zhao, Z.-F. Liu and Z.-R. Chen. Tensile and impact behavior of polystyrene microcellular foams with bi-modal cell morphology. J Cell Plast, 2014, 50: 381-393.

[233] J.-B. Bao, T. Liu, L. Zhao, G.-H. Hu, X. Miao and X. Li. Oriented foaming of polystyrene with supercritical carbon dioxide for toughening. Polymer, 2012, 53: 5982-5993.

[234] E.E. Saenz, L.A. Carlsson and A.M. Karlsson. In situ analysis of fatigue crack propagation in polymer foams. Eng Fract Mech, 2013, 101: 23-32.

[235] A.E. Oskui, N. Choupani and E. Haddadi. Experimental and Numerical Investigation of Fracture of ABS Polymeric Material for Different Sample's Thickness Using a New Loading Device. Polym. Eng. Sci., 2014, 54: 2086-2096.

[236] M.N. Bureau and V. Kumar. Fracture toughness of high density polycarbonate microcellular foams. J Cell Plast, 2006, 42: 229-240. 
[237] E.E. Saenz, L.A. Carlsson and A. Karlsson. Characterization of fracture toughness (Gc) of PVC and PES foams. J Mater Sci, 2011, 46: 3207-3215.

[238] M.E. Kabir, M.C. Saha and S. Jeelani. Tensile and fracture behavior of polymer foams. Mat Sci Eng a-Struct, 2006, 429: 225-235.

[239] S.K. Maiti, M.F. Ashby and L.J. Gibson. Fracture toughness of brittle cellular solids. Scr Metall Mater, 1984, 18: 213-217.

[240] S. Weal. Heat Stability of Polylactic Acid - Based Foams and its Measurement. Biofoams 2011 Conference: 3rd International conference on biofoams, Capri (Italy), 2011.

[241] B. Krause, R. Mettinkhof, N.F.A. van der Vegt and M. Wessling. Microcellular Foaming of Amorphous High-Tg Polymers Using Carbon Dioxide. Macromolecules, 2001, 34: 874-884.

[242] Z. Ma, G. Zhang, Q. Yang, X. Shi and A. Shi. Fabrication of microcellular polycarbonate foams with unimodal or bimodal cell-size distributions using supercritical carbon dioxide as a blowing agent. J Cell Plast, 2014, 50: 55-79.

[243] R. Li, Z. Zhang and T. Fang. Experimental research on swelling and glass transition behavior of poly(methyl methacrylate) in supercritical carbon dioxide. J Supercrit Fluids, 2016, 110: 110-116.

[244] P. Zhang, N. Zhou and B. Li. Effects of Process Variables on Microcellular Structure and Crystallization of Polypropylene Foams with Supercritical CO2 as the Foaming AgentA Study of Microcellular Foaming of Polypropylene. Polym-Plast Technol, 2007, 46: 885891.

[245] Q. Guo, J. Wang and C.B. Park. Visualization of PP Foaming with Nitrogen. Annual Technical Conference - ANTEC: Society of Plastics Engineers (SPE), North Carolina (USA), 2006.

[246] Z.-M. Xu, X.-L. Jiang, T. Liu, G.-H. Hu, L. Zhao, Z.-N. Zhu and W.-K. Yuan. Foaming of polypropylene with supercritical carbon dioxide. J Supercrit Fluids, 2007, 41: 299-310.

[247] J.I. Velasco, M. Antunes, V. Realinho and M. Ardanuy. Characterization of rigid polypropylene-based microcellular foams produced by batch foaming processes. Polym Eng Sci, 2011, 51: 2120-2128. 
[248] A. Maani, H.E. Naguib, M.-C. Heuzey and P.J. Carreau. Foaming behavior of microcellular thermoplastic olefin blends. J Cell Plast, 2013, 49: 223-244.

[249] A. Wong, Y. Guo and C.B. Park. Fundamental mechanisms of cell nucleation in polypropylene foaming with supercritical carbon dioxide-Effects of extensional stresses and crystals. J Supercrit Fluids, 2013, 79: 142-151.

[250] D. Fu, F. Chen, T. Kuang, D. Li, X. Peng, D.Y. Chiu, C.S. Lin and L.J. Lee. Supercritical CO2 foaming of pressure-induced-flow processed linear polypropylene. Mater Design, 2016, 93: 509-513.

[251] C.B. Park and L.K. Cheung. A study of cell nucleation in the extrusion of polypropylene foams. Polym Eng Sci, 1997, 37: 1-10.

[252] A.P. Ranade, A. Hiltner, E. Baer and D.G. Bland. Structure-Property Relationships in Coextruded Foam/Film Microlayers. J Cell Plast, 2004, 40: 497-507.

[253] H.E. Naguib, C.B. Park and N. Reichelt. Fundamental foaming mechanisms governing the volume expansion of extruded polypropylene foams. J Appl Polym Sci, 2004, 91: 26612668.

[254] P.C. Lee, W. Kaewmesri, J. Wang, C.B. Park, J. Pumchusak, R. Folland and A. Praller. Effect of die geometry on foaming behaviors of high-melt-strength polypropylene with CO2. J Appl Polym Sci, 2008, 109: 3122-3132.

[255] F. Gunkel, A.N.J. Spörrer, G.T. Lim, D.S. Bangarusampath and V. Altstädt. Understanding Melt Rheology and Foamability of Polypropylene-based TPO Blends. J Cell Plast, 2008, 44: 307-325.

[256] A. Fernandez and M. Muniesa. Influence of Packing Phase Parameters in the Optimization of Mechanical, Weight Reduction and Dimensional Properties of Microcellular Foaming Injection Molding of Polypropilene. Adv Mat Res, 2012, 445: 319-324.

[257] A.K. Bledzki, O. Faruk, H. Kirschling, J. Kühn and A. Jaszkiewicz. Microcellular polymer and composites. Part II. Properties of different types of microcellular materials. Polimery-W, 2007, 52: 3-12.

[258] S. Doroudiani, C.B. Park and M.T. Kortschot. Effect of the crystallinity and morphology on the microcellular foam structure of semicrystalline polymers. Polym Eng Sci, 1996, 36: 2645-2662. 
[259] G. Li, F. Gunkel, J. Wang, C.B. Park and V. Altstädt. Solubility measurements of N2 and CO2 in polypropylene and etheneloctene copolymer. J Appl Polym Sci, 2007, 103: 29452953.

[260] R. Demori, A.P. de Azeredo, S.A. Liberman and R.S. Mauler. Evaluation of foaming polypropylene modified with ramified polymer. AIP Conf Proc, 2015, 1664: 040004.

[261] J.-H. Seo, S.W. Cha, K.S. Lee and Y. Moon. The Effect of Comonomers on the Foaming Characteristics of Polypropylene. Polym-Plast Technol, 2008, 47: 1122-1126.

[262] L. Wang, D. Wan, J. Qiu and T. Tang. Effects of long chain branches on the crystallization and foaming behaviors of polypropylene-g-poly(ethylene-co-1-butene) graft copolymers with well-defined molecular structures. Polymer, 2012, 53: 4737-4757.

[263] S. Doroudiani, C.B. Park and M.T. Kortschot. Processing and characterization of microcellular foamed high-density polythylene/isotactic polypropylene blends. Polym Eng Sci, 1998, 38: 1205-1215.

[264] E.H. Tejeda, C.Z. Sahagún, R. González-Núñez and D. Rodrigue. Morphology and Mechanical Properties of Foamed Polyethylene-Polypropylene Blends. J Cell Plast, 2005, 41: 417-435.

[265] P. Zhang, N.Q. Zhou, Q.F. Wu, M.Y. Wang and X.F. Peng. Microcellular foaming of PE/PP blends. J Appl Polym Sci, 2007, 104: 4149-4159.

[266] H.-X. Huang, J.-K. Wang and X.-H. Sun. Improving of Cell Structure of Microcellular Foams Based on Polypropylene/High-density Polyethylene Blends. J Cell Plast, 2008, 44: 6985 .

[267] J. Mueller, A. Spoerrer and V. Altstaedt. Foam injection moulding of a TPO/TPC-blend and the effect of different nucleating agents on the resulting foam structure. AIP Conf Proc, 2014, 1593: 367-373.

[268] G. Meli, C. Abler, F. Jouffret, M. Antunes, G. Gedler, D. Arencón and J.I. Velasco. Nucleation Efficiency of Talc in the Foaming Behavior and Cellular Structure of PolyolefinBased Foams: New Perspectives for Optimized Lightweight Materials. Annual Technical Conference - ANTEC: Society of Plastics Engineers (SPE), Orlando (USA), 2012.

[269] H.-X. Huang and J.-K. Wang. Improving polypropylene microcellular foaming through blending and the addition of nano-calcium carbonate. J Appl Polym Sci, 2007, 106: 505-513. 
[270] W. Gong, K.J. Liu, C. Zhang, J.H. Zhu and L. He. Foaming Behavior and Mechanical Properties of Microcellular PP/SiO2 Composites. Int Polym Proc, 2012, 27: 181-186.

[271] C. Wang, S. Ying and Z. Xiao. Preparation of short carbon fiber/polypropylene finecelled foams in supercritical CO2. J Cell Plast, 2013, 49: 65-82.

[272] L.J. Lee, C. Zeng, X. Cao, X. Han, J. Shen and G. Xu. Polymer nanocomposite foams. Compos Sci Technol, 2005, 65: 2344-2363.

[273] M. Jiang, H. Li, D. Fang, L. Liu, Q. Tai, L. Li, L. Dong, H. Xie and C. Xiong. Structure-Property Relationship in Injection-Molded Polypropylene/Clay Composite Foams. Mater Manuf Processes, 2014, 29: 160-165.

[274] Z.X. Zhang, V. Sridhar and J.K. Kim. Polypropylene-waste ground rubber tire powder microcellular composites: Effect of processing variables on morphology and physicomechanical properties. Polym Composite, 2008, 29: 1276-1284.

[275] S.K. De and J.R. White. Short Fibre-Polymer Composites, 1st ed., Woodhead Publishing, Cambridge, 1996, pp. 272.

[276] C. Saiz-Arroyo, J.A. de Saja, J.I. Velasco and M.Á. Rodríguez-Pérez. Moulded polypropylene foams produced using chemical or physical blowing agents: structureproperties relationship. J Mater Sci, 2012, 47: 5680-5692.

[277] X.-L. Jiang, T. Liu, Z.-M. Xu, L. Zhao, G.-H. Hu and W.-K. Yuan. Effects of crystal structure on the foaming of isotactic polypropylene using supercritical carbon dioxide as a foaming agent. J Supercrit Fluids, 2009, 48: 167-175.

[278] K.S. Kumar, N. Bhatnagar and A.K. Ghosh. Development of Long Glass Fiber Reinforced Polypropylene Composites: Mechanical and Morphological Characteristics. J Reinf Plast Compos, 2007, 26: 239-249.

[279] N. Abd. Rahman, A. Hassan, R. Yahya, R.A. Lafia-Araga and P.R. Hornsby. MicroStructural, Thermal and Mechanical Properties of Injection-Molded GlassFiber/Nanoclay/Polypropylene Composites. J Reinf Plast Compos, 2012, 31: 269-281.

[280] J.L. Thomason, M.A. Vlug, G. Schipper and H.G.L.T. Krikor. Influence of fibre length and concentration on the properties of glass fibre-reinforced polypropylene: Part 3. Strength and strain at failure. Compos Part A-Appl S, 1996, 27: 1075-1084. 
[281] S.-S. Hwang, J.-P. Yang, C.-H. Hu and P. Hsu. Effects of Gas Counter Pressure and Dynamic Mold Temperature Control on the Mechanical/Foaming/Surface Roughness Properties of Microcellular Injection Molded PP Parts. Annual Technical Conference ANTEC: Society of Plastics Engineers (SPE), Orlando (USA), 2015.

[282] M. Gupta and K.K. Wang. Fiber orientation and mechanical properties of short-fiberreinforced injection-molded composites: Simulated and experimental results. Polym Composite, 1993, 14: 367-382.

[283] M. Sanou, B. Chung and C. Cohen. Glass fiber-filled thermoplastics. II. Cavity filling and fiber orientation in injection molding. Polym Eng Sci, 1985, 25: 1008-1016.

[284] B. Chung and C. Cohen. Glass fiber-filled thermoplastics. I. Wall and processing effects on rheological properties. Polym Eng Sci, 1985, 25: 1001-1007.

[285] T. Matsuoka, J.-I. Takabatake, Y. Inoue and H. Takahashi. Prediction of fiber orientation in injection molded parts of short-fiber-reinforced thermoplastics. Polym Eng Sci, 1990, 30: 957-966.

[286] Z. Zhu, C.B. Park and J.H. Zong. Challenges to the Formation of Nano-cells in Foaming Processes. Int Polym Proc, 2008, 23: 270-276.

[287] A.K. Bledzki and O. Faruk. Injection moulded microcellular wood fibre-polypropylene composites. Compos Part A-Appl S, 2006, 37: 1358-1367.

[288] A.K. Bledzki and O. Faruk. Effects of the chemical foaming agents, injection parameters, and melt-flow index on the microstructure and mechanical properties of microcellular injection-molded wood-fiber/polypropylene composites. J Appl Polym Sci, 2005, 97: 1090-1096.

[289] Z. Xi, J. Chen, T. Liu, L. Zhao and L.-S. Turng. Experiment and simulation of foaming injection molding of polypropylene/nano-calcium carbonate composites by supercritical carbon dioxide. Chin J Chem Eng, 2016, 24: 180-189.

[290] W. Wang, G. Zhao, Y. Guan, X. Wu and Y. Hui. Effect of rapid heating cycle injection mold temperature on crystal structures, morphology of polypropylene and surface quality of plastic parts. J Polym Res, 2015, 22: 84.

[291] J.J. Lee and S.W. Cha. Characteristics of the Skin Layers of Microcellular Injection Molded Parts. Polym-Plast Technol, 2006, 45: 871-877. 
[292] P.F. Bright, R.J. Crowson and M.J. Folkes. A study of the effect of injection speed on fibre orientation in simple mouldings of short glass fibre-filled polypropylene. J Mater Sci, 1978, 13: 2497-2506.

[293] A. Ameli, P.U. Jung and C.B. Park. Through-plane electrical conductivity of injectionmolded polypropylene/carbon-fiber composite foams. Compos Sci Technol, 2013, 76: 37-44.

[294] M. Huszar, F. Belblidia, H.M. Davies, C. Arnold, D. Bould and J. Sienz. Sustainable injection moulding: The impact of materials selection and gate location on part warpage and injection pressure. Sustainable Mater Technol, 2015, 5: 1-8.

[295] R.J. Crowson, M.J. Folkes and P.F. Bright. Rheology of short glass fiber-reinforced thermoplastics and its application to injection molding I. Fiber motion and viscosity measurement. Polym Eng Sci, 1980, 20: 925-933.

[296] M.R. Kamal, L. Song and P. Singh. Measurement of fiber and matrix orientations in fiber reinforced composites. Polym Composite, 1986, 7: 323-329.

[297] S. Kenig. Fiber orientation development in molding of polymer composites. Polym Composite, 1986, 7: 50-55.

[298] J. Karger-Kocsis. Polypropylene: Structure, Blends and Composites. Volume 3: Composites, 1st ed., Springer Netherlands, Dordrecht, 1994, pp. 390.

[299] E.G. Kim, J.K. Park and S.H. Jo. A study on fiber orientation during the injection molding of fiber-reinforced polymeric composites: (Comparison between image processing results and numerical simulation). J Mater Process Technol, 2001, 111: 225-232.

[300] W. Gong, Y. He, C. Zhang, J.H. Zhu and L. He. Effects of Process Conditions on Mechanics Properties of Micro-Foaming PP/GF Composites. Appl Mech Mater, 2012, 117119: 256-261.

[301] A.K. Bledzki, W. Zhang and O. Faruk. Microfoaming of flax and wood fibre reinforced polypropylene composites. Holz Roh Werkst, 2005, 63: 30-37.

[302] A. Lopez-Gil, C. Saiz-Arroyo, J. Tirado and M.A. Rodriguez-Perez. Production of noncrosslinked thermoplastic foams with a controlled density and a wide range of cellular structures. J Appl Polym Sci, 2015, 132: 42324. 
[303] C.W. Lou, C.W. Lin, W.H. Hsing, J.M. Chen, C.Y. Ke and J.H. Lin. Manufacturing Technique and Property Evaluation of Impact-Resistant Polypropylene/Glass Fiber Composites. Adv Mat Res, 2011, 239-242: 1976-1979.

[304] J.L. Thomason. The influence of fibre length and concentration on the properties of glass fibre reinforced polypropylene: 5. Injection moulded long and short fibre PP. Compos Part A-Appl S, 2002, 33: 1641-1652.

[305] M. Akay and D. Barkley. Processing-structure-property interaction in injection moulded glass-fibre reinforced polypropylene. Compos Struct, 1985, 3: 269-293.

[306] D.C. Wright. Failure of Plastics and Rubber Products: Causes, Effects and Case Studies Involving Degradation, 1st ed., Smithers Rapra Press, Shawbury, 2001, pp. 410.

[307] W.L. Oliani, D.F. Parra, L.F.C.P. Lima and A.B. Lugão. Effects of thermal ageing on HMS-PP crystallinity. International Nuclear Atlantic Conference (INAC), Rio de Janeiro (Brazil), 2009.

[308] T.N. Novotortzeva, O.B. Kulachinckaya, M.B. Andreeva, E.B. Kalugina, I.L. Aizinson, A.S. Lunin, V.A. Tochin, Y.G. Urman, I.G. Kalinina, K.Z. Gumargalieva and G.E. Zaikov. The ageing of modified glass-reinforced polypropylene in air and in antifreeze. Polym Degrad Stab, 2000, 69: 17-22.

[309] M.G. Wyzgoski. Effect of oven aging on polypropylene. J Appl Polym Sci, 1981, 26: 1689-1704.

[310] S.R. Reid and G. Zhou. Impact Behaviour of Fibre-Reinforced Composite Materials and Structures, 1st ed., CRC Press, Boca Raton, 2000, pp. 280.

[311] J.-P. Tancrez, J. Pabiot and F. Rietsch. Damage and fracture mechanisms in thermoplastic-matrix composites in relation to processing and structural parameters. Compos Sci Technol, 1996, 56: 725-731.

[312] S.-Y. Fu, B. Lauke and Y.-W. Mai. Science and Engineering of Short Fibre Reinforced Polymer Composites, 1st ed., Woodhead Publishing, Cambridge, 2009, pp. 338.

[313] P. Poapongsakorn and C. Kanchanomai. Effects of time and stress state on fracture of closed-cell PVC foam. J Sandw Struct Mater, 2012, 14: 557-571. 
[314] A.M. Hartl, M. Jerabek and R.W. Lang. Effect of fiber orientation, stress state and notch radius on the impact properties of short glass fiber reinforced polypropylene. Polym Test, 2015, 43: 1-9.

[315] R. Gosselin, D. Rodrigue and B. Riedl. Injection Molding of Postconsumer WoodPlastic Composites II: Mechanical Properties. J Thermoplast Compos, 2006, 19: 659-669.

[316] M. Shimbo, I. Higashitani and Y. Miyano. Mechanism of Strength Improvement of Foamed Plastics Having Fine Cell. J Cell Plast, 2007, 43: 157-167.

[317] N. Sombatsompop and A. Tangsongcharoen. Effects of glass-fiber content and coolant temperature on temperature and crystallinity profiles of PP melt during cooling. J Appl Polym Sci, 2001, 82: 2087-2097.

[318] M.J. Folkes and D.A.M. Russell. Orientation effects during the flow of short-fibre reinforced thermoplastics. Polymer, 1980, 21: 1252-1258.

[319] S. Djoumaliisky, D. Christova, N. Touleshkov and E. Nedkov. Morphology and Orientation of PP-Structural Foam Moldings. J Macromol Sci A, 1998, 35: 1147-1158.

[320] D. Ferrer-Balas, M.L. Maspoch, A.B. Martinez and O.O. Santana. Influence of annealing on the microstructural, tensile and fracture properties of polypropylene films. Polymer, 2001, 42: 1697-1705.

[321] R. Li, D. Zeng, Q. Liu, Z. Jiang and T. Fang. Glass Transition Temperature in Microcellular Foaming Process with Supercritical Carbon Dioxide: A Review. Polym-Plast Technol, 2015, 54: 119-127.

[322] J.L. Thomason. The influence of fibre length and concentration on the properties of glass fibre reinforced polypropylene. 6. The properties of injection moulded long fibre PP at high fibre content. Compos Part A-Appl S, 2005, 36: 995-1003.

[323] D. Jahani, A. Ameli, M. Saniei, W. Ding, C.B. Park and H.E. Naguib. Characterization of the Structure, Acoustic Property, Thermal Conductivity, and Mechanical Property of Highly Expanded Open-Cell Polycarbonate Foams. Macromol Mater Eng, 2015, 300: 48-56.

[324] H.-P. Heim and M. Tromm. Injection molded components with functionally graded foam structures - Procedure and essential results. J Cell Plast, 2016, 52: 299-319. 
[325] H.-P. Heim and M. Tromm. Pull and Foam - Method: Partially Foamed Components First Investigations With Chemical and Physical Blowing Agents. Annual Technical Conference - ANTEC: Society of Plastics Engineers (SPE), Orlando (USA), 2012.

[326] J.A.R. Ruiz, M. Vincent and J.F. Agassant. Numerical Modeling of Bubble Growth in Microcellular Polypropylene Produced in a Core-Back Injection Process Using Chemical Blowing Agents. Int Polym Proc, 2016, 31: 26-36.

[327] G. Zhang and M.R. Thompson. Reduced fibre breakage in a glass-fibre reinforced thermoplastic through foaming. Compos Sci Technol, 2005, 65: 2240-2249.

[328] T.-Y. Shiu, Y.-J. Chang, C.-T. Huang, C.-H. Hsu, R.-Y. Chang and S.-S. Hwang. Foaming Morphology of Microcellular Injection Molded Parts - Simulation and Experimental Characterization. Annual Technical Conference - ANTEC: Society of Plastics Engineers (SPE), Cincinnati (USA), 2013.

[329] L.-Y. Chang, Y.-J. Chang, C.-H. Hsu, S.-S. Hwang and W.-H. Yang. Simulation and Experimental Characterization of Foam Injection Molding. Annual Technical Conference ANTEC: Society of Plastics Engineers (SPE), Las Vegas (USA), 2014.

[330] S. Yasuhara, S. Ishihara and M. Ohshima. Experiments and Computer Simulations of Microcellular Foam Injection Molding with Coreback Operation for Polypropylene. Annual Technical Conference - ANTEC: Society of Plastics Engineers (SPE), Las Vegas (USA), 2014.

[331] L.-Y. Chang, Y.-J. Chang, C.-H. Hsu, H. Tanaka and M. Ohshima. Numerical Simulation and Experimental Verification in Cell Nucleation and Growth with Core-Back Foam Injection Molding. Annual Technical Conference - ANTEC: Society of Plastics Engineers (SPE), Orlando (USA), 2015.

[332] L. Qi and J. Webb. 3D Simulation of Mucell Microcellular Foam Process in Large Automotive Application. Annual Technical Conference - ANTEC: Society of Plastics Engineers (SPE), Cincinnati (USA), 2013.

[333] M. Stumpf, A. Spörrer, H.-W. Schmidt and V. Altstädt. Influence of supramolecular additives on foam morphology of injection-molded i-PP. J Cell Plast, 2011, 47: 519-534.

[334] T. Ishikawa and M. Ohshima. Visual observation and numerical studies of polymer foaming behavior of polypropylene/carbon dioxide system in a core-back injection molding process. Polym Eng Sci, 2011, 51: 1617-1625. 
[335] J.M. Gere. Timoshenko. Resistencia de materiales, 5th ed., Ediciones Paraninfo, Madrid (Spain), 2002, pp. 946. 


\section{Appendix A:}

\section{ANOVA tables for ABS}

Table A.1. Analysis of variance for weight reduction.

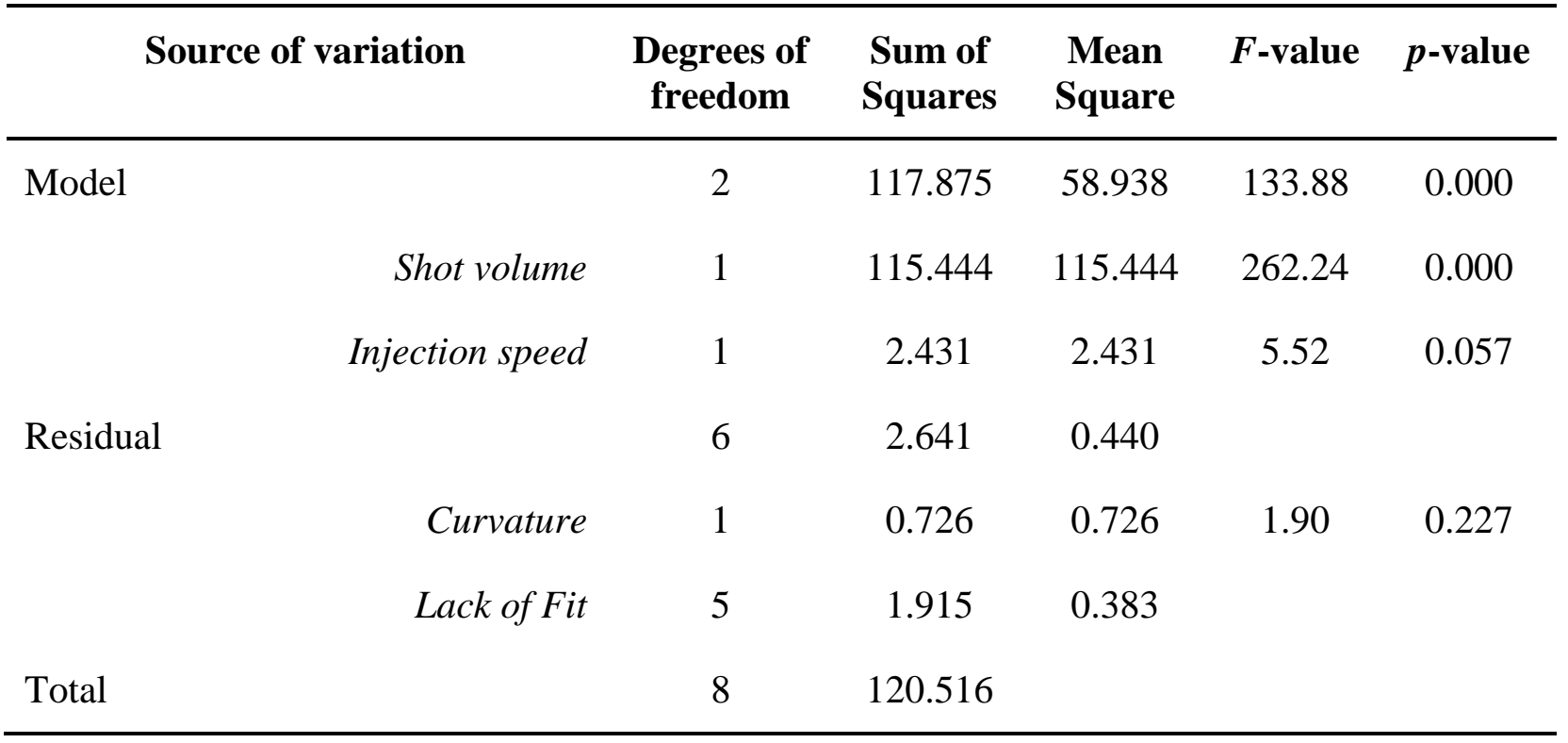

Table A.2. Analysis of variance for skin thickness.

\begin{tabular}{|c|c|c|c|c|c|}
\hline Source of variation & \multirow{2}{*}{$\begin{array}{c}\begin{array}{c}\text { Degrees of } \\
\text { freedom }\end{array} \\
3\end{array}$} & \multirow{2}{*}{$\begin{array}{c}\begin{array}{c}\text { Sum of } \\
\text { Squares }\end{array} \\
0.007537\end{array}$} & \multirow{2}{*}{$\begin{array}{c}\begin{array}{c}\text { Mean } \\
\text { Square }\end{array} \\
0.002513\end{array}$} & \multirow{2}{*}{$\begin{array}{c}\boldsymbol{F} \text {-value } \\
4.68\end{array}$} & \multirow{2}{*}{$\begin{array}{c}\boldsymbol{p} \text {-value } \\
0.065\end{array}$} \\
\hline Model & & & & & \\
\hline Mold temperature & 1 & 0.000613 & 0.000613 & 1.14 & 0.334 \\
\hline Injection speed & 1 & 0.000313 & 0.000313 & 0.58 & 0.480 \\
\hline Mold temperature $*$ Injection speed & 1 & 0.006613 & 0.006613 & 12.32 & 0.017 \\
\hline Residual & 5 & 0.002685 & 0.000537 & & \\
\hline Curvature & 1 & 0.000235 & 0.000235 & 0.38 & 0.569 \\
\hline Lack of Fit & 4 & 0.002450 & 0.000612 & & \\
\hline Total & 8 & 0.010222 & & & \\
\hline
\end{tabular}


Table A.3. Analysis of variance for cell density.

\begin{tabular}{|c|c|c|c|c|c|c|}
\hline \multicolumn{2}{|c|}{ Source of variation } & \multirow{2}{*}{$\begin{array}{c}\begin{array}{c}\text { Degrees of } \\
\text { freedom }\end{array} \\
2\end{array}$} & \multirow{2}{*}{$\begin{array}{c}\begin{array}{c}\text { Sum of } \\
\text { Squares }\end{array} \\
1.14 \cdot 10^{13}\end{array}$} & \multirow{2}{*}{$\begin{array}{c}\begin{array}{c}\text { Mean } \\
\text { Square }\end{array} \\
5.68 \cdot 10^{12}\end{array}$} & \multirow{2}{*}{$\begin{array}{c}\boldsymbol{F} \text {-value } \\
47.95\end{array}$} & \multirow{2}{*}{$\begin{array}{c}\boldsymbol{p} \text {-value } \\
0.000\end{array}$} \\
\hline Model & & & & & & \\
\hline & Shot volume & 1 & $1.01 \cdot 10^{13}$ & $1.01 \cdot 10^{13}$ & 84.99 & 0.000 \\
\hline & Mold temperature & 1 & $1.29 \cdot 10^{12}$ & $1.29 \cdot 10^{12}$ & 10.91 & 0.016 \\
\hline \multirow[t]{3}{*}{ Residual } & & 6 & $7.11 \cdot 10^{11}$ & $1.19 \cdot 10^{11}$ & & \\
\hline & Curvature & 1 & $2.96 \cdot 10^{11}$ & $2.96 \cdot 10^{11}$ & 3.57 & 0.117 \\
\hline & Lack of Fit & 5 & $4.15 \cdot 10^{11}$ & $8.29 \cdot 10^{10}$ & & \\
\hline Total & & 8 & $1.21 \cdot 10^{13}$ & & & \\
\hline
\end{tabular}

Table A.4. Analysis of variance for maximum cell size.

\begin{tabular}{|c|c|c|c|c|c|}
\hline Source of variation & \multirow{2}{*}{$\begin{array}{c}\text { Degrees of } \\
\text { freedom }\end{array}$} & \multirow{2}{*}{$\begin{array}{c}\begin{array}{c}\text { Sum of } \\
\text { Squares }\end{array} \\
12640.2\end{array}$} & \multirow{2}{*}{$\begin{array}{c}\begin{array}{c}\text { Mean } \\
\text { Square }\end{array} \\
3160.1\end{array}$} & \multirow{2}{*}{$\begin{array}{c}\boldsymbol{F} \text {-value } \\
3.48\end{array}$} & \multirow{2}{*}{$\begin{array}{c}\boldsymbol{p} \text {-value } \\
0.127\end{array}$} \\
\hline Model & & & & & \\
\hline Shot volume & 1 & 6951.4 & 6951.4 & 7.67 & 0.050 \\
\hline Mold temperature & 1 & 304.1 & 304.1 & 0.34 & 0.594 \\
\hline Injection speed & 1 & 907.4 & 907.4 & 1.00 & 0.374 \\
\hline Mold temperature*Injection speed & 1 & 4477.4 & 4477.4 & 4.94 & 0.090 \\
\hline Residual & 4 & 3627.4 & 906.8 & & \\
\hline Curvature & 1 & 528.7 & 528.7 & 0.51 & 0.526 \\
\hline Lack of Fit & 3 & 3098.7 & 1032.9 & & \\
\hline Total & 8 & 16267.6 & & & \\
\hline
\end{tabular}


Table A.5. Analysis of variance for $C D I$.

\begin{tabular}{|c|c|c|c|c|c|c|}
\hline \multicolumn{2}{|c|}{ Source of variation } & \multirow{2}{*}{$\begin{array}{c}\begin{array}{c}\text { Degrees of } \\
\text { freedom }\end{array} \\
2\end{array}$} & \multirow{2}{*}{$\begin{array}{c}\begin{array}{c}\text { Sum of } \\
\text { Squares }\end{array} \\
0.276025\end{array}$} & \multirow{2}{*}{$\begin{array}{c}\begin{array}{c}\text { Mean } \\
\text { Square }\end{array} \\
0.138013\end{array}$} & \multirow{2}{*}{$\begin{array}{c}\boldsymbol{F} \text {-value } \\
15.51\end{array}$} & \multirow{2}{*}{$\begin{array}{c}\boldsymbol{p} \text {-value } \\
0.004\end{array}$} \\
\hline Model & & & & & & \\
\hline & Shot volume & 1 & 0.148513 & 0.148513 & 16.69 & 0.006 \\
\hline & Injection speed & 1 & 0.127512 & 0.127512 & 14.33 & 0.009 \\
\hline \multirow[t]{3}{*}{ Residual } & & 6 & 0.053397 & 0.008900 & & \\
\hline & Curvature & 1 & 0.008235 & 0.008235 & 0.91 & 0.384 \\
\hline & Lack of Fit & 5 & 0.045163 & 0.009033 & & \\
\hline Total & & 8 & 0.329422 & & & \\
\hline
\end{tabular}

Table A.6. Analysis of variance for elastic modulus.

\begin{tabular}{|c|c|c|c|c|c|c|}
\hline \multicolumn{2}{|c|}{ Source of variation } & \multirow{2}{*}{$\begin{array}{c}\begin{array}{c}\text { Degrees of } \\
\text { freedom }\end{array} \\
1\end{array}$} & \multirow{2}{*}{$\begin{array}{c}\begin{array}{c}\text { Sum of } \\
\text { Squares }\end{array} \\
4656.13\end{array}$} & \multirow{2}{*}{$\begin{array}{c}\text { Mean } \\
\text { Square }\end{array}$} & \multirow{2}{*}{$\begin{array}{c}\boldsymbol{F} \text {-value } \\
18.25\end{array}$} & \multirow{2}{*}{$\begin{array}{c}\boldsymbol{p} \text {-value } \\
0.004\end{array}$} \\
\hline Model & & & & & & \\
\hline & Shot volume & 1 & 4656.13 & 4656.13 & 18.25 & 0.004 \\
\hline \multirow[t]{3}{*}{ Residual } & & 7 & 1786.10 & 255.16 & & \\
\hline & Curvature & 1 & 33.35 & 33.35 & 0.11 & 0.747 \\
\hline & Lack of Fit & 6 & 1752.75 & 292.13 & & \\
\hline Total & & 8 & 6442.22 & & & \\
\hline
\end{tabular}


Table A.7. Analysis of variance for tensile strength.

\begin{tabular}{|c|c|c|c|c|c|c|}
\hline \multicolumn{2}{|c|}{ Source of variation } & \multirow{2}{*}{$\begin{array}{c}\text { Degrees of } \\
\text { freedom }\end{array}$} & \multirow{2}{*}{$\begin{array}{c}\begin{array}{c}\text { Sum of } \\
\text { Squares }\end{array} \\
12.2512\end{array}$} & \multirow{2}{*}{$\begin{array}{c}\begin{array}{c}\text { Mean } \\
\text { Square }\end{array} \\
12.2512\end{array}$} & \multirow{2}{*}{$\begin{array}{c}\boldsymbol{F} \text {-value } \\
76.73\end{array}$} & \multirow{2}{*}{$\begin{array}{c}\boldsymbol{p} \text {-value } \\
0.000\end{array}$} \\
\hline Model & & & & & & \\
\hline & Shot volume & 1 & 12.2512 & 12.2512 & 76.73 & 0.000 \\
\hline \multirow[t]{3}{*}{ Residual } & & 7 & 1.1176 & 0.1597 & & \\
\hline & Curvature & 1 & 0.1901 & 0.1901 & 1.23 & 0.310 \\
\hline & Lack of Fit & 6 & 0.9275 & 0.1546 & & \\
\hline Total & & 8 & 13.3689 & & & \\
\hline
\end{tabular}




\section{Appendix B:}

\section{ANOVA tables for PP 20GF}

Table B.1. Analysis of variance for weight reduction.

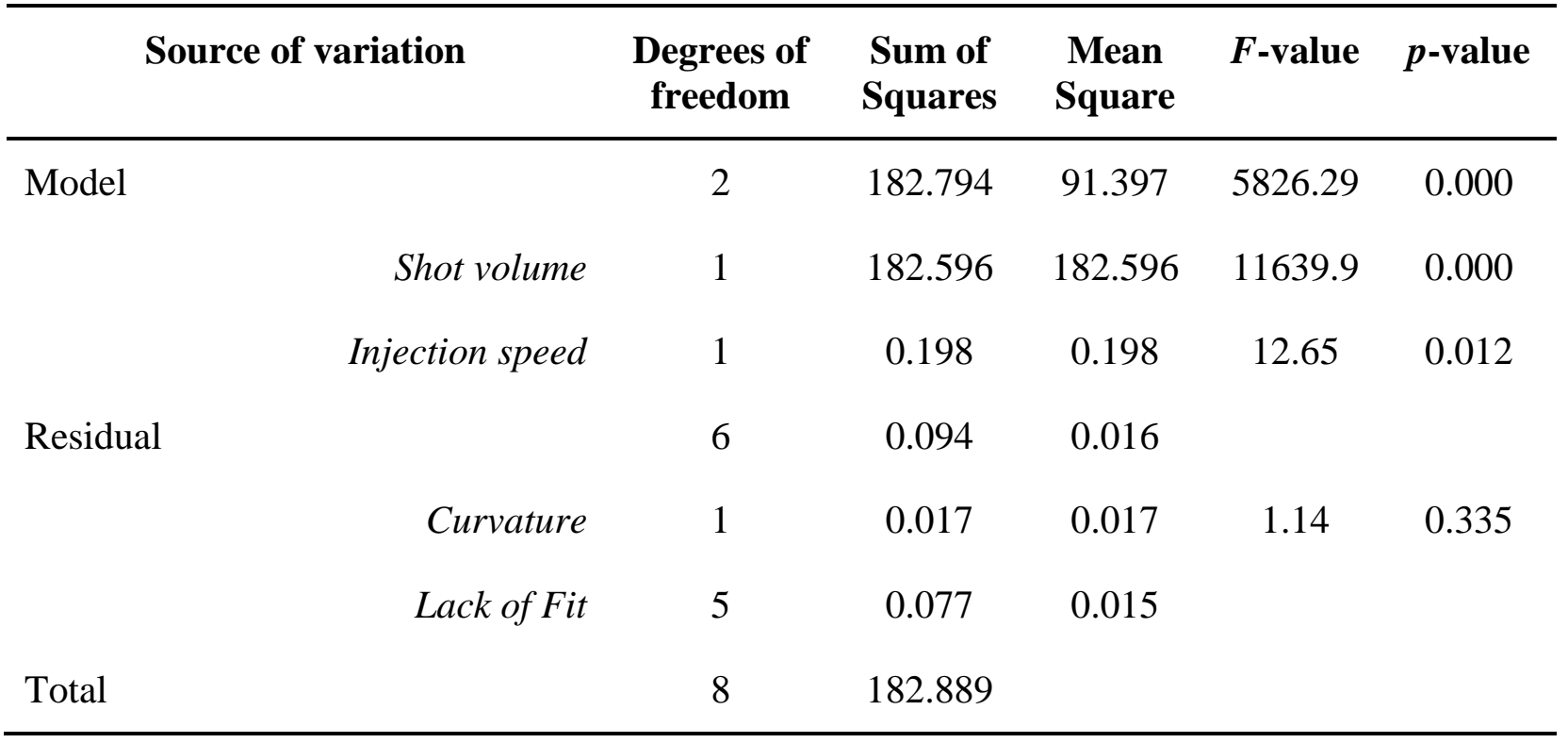

Table B.2. Analysis of variance for skin thickness MD-B.

\begin{tabular}{|c|c|c|c|c|c|c|}
\hline \multicolumn{2}{|c|}{ Source of variation } & \multirow{2}{*}{$\begin{array}{c}\begin{array}{c}\text { Degrees of } \\
\text { freedom }\end{array} \\
2\end{array}$} & \multirow{2}{*}{$\begin{array}{c}\begin{array}{c}\text { Sum of } \\
\text { Squares }\end{array} \\
0.043557\end{array}$} & \multirow{2}{*}{$\begin{array}{c}\begin{array}{c}\text { Mean } \\
\text { Square }\end{array} \\
0.021779\end{array}$} & \multirow{2}{*}{$\begin{array}{c}F \text {-value } \\
22.40\end{array}$} & \multirow{2}{*}{$\begin{array}{c}\boldsymbol{p} \text {-value } \\
0.002\end{array}$} \\
\hline Model & & & & & & \\
\hline & Shot volume & 1 & 0.029201 & 0.029201 & 30.04 & 0.002 \\
\hline & Injection speed & 1 & 0.014356 & 0.014356 & 14.77 & 0.009 \\
\hline \multirow[t]{3}{*}{ Residual } & & 6 & 0.005832 & 0.000972 & & \\
\hline & Curvature & 1 & 0.000072 & 0.000072 & 0.06 & 0.812 \\
\hline & Lack of Fit & 5 & 0.005760 & 0.001152 & & \\
\hline Total & & 8 & 0.049390 & & & \\
\hline
\end{tabular}


Table B.3. Analysis of variance for cell density MD-B.

\begin{tabular}{|c|c|c|c|c|c|}
\hline Source of variation & \multirow{2}{*}{$\begin{array}{c}\begin{array}{c}\text { Degrees of } \\
\text { freedom }\end{array} \\
3\end{array}$} & \multirow{2}{*}{$\begin{array}{c}\begin{array}{c}\text { Sum of } \\
\text { Squares }\end{array} \\
6.49 \cdot 10^{13}\end{array}$} & \multirow{2}{*}{$\begin{array}{c}\begin{array}{c}\text { Mean } \\
\text { Square }\end{array} \\
2.16 \cdot 10^{13}\end{array}$} & \multirow{2}{*}{$\begin{array}{c}\boldsymbol{F} \text {-value } \\
8.14\end{array}$} & \multirow{2}{*}{$\begin{array}{c}\boldsymbol{p} \text {-value } \\
0.023\end{array}$} \\
\hline Model & & & & & \\
\hline Shot volume & 1 & $1.14 \cdot 10^{13}$ & $1.14 \cdot 10^{13}$ & 4.28 & 0.094 \\
\hline Injection speed & 1 & $3.29 \cdot 10^{13}$ & $3.29 \cdot 10^{13}$ & 12.37 & 0.017 \\
\hline Shot volume*Injection speed & 1 & $2.07 \cdot 10^{13}$ & $2.07 \cdot 10^{13}$ & 7.79 & 0.038 \\
\hline Residual & 5 & $1.33 \cdot 10^{13}$ & $2.66 \cdot 10^{12}$ & & \\
\hline Curvature & 1 & $4.76 \cdot 10^{10}$ & $4.76 \cdot 10^{10}$ & 0.01 & 0.910 \\
\hline Lack of Fit & 4 & $1.32 \cdot 10^{13}$ & $3.31 \cdot 10^{12}$ & & \\
\hline Total & 8 & $7.82 \cdot 10^{13}$ & & & \\
\hline
\end{tabular}

Table B.4. Analysis of variance for maximum cell size MD-B.

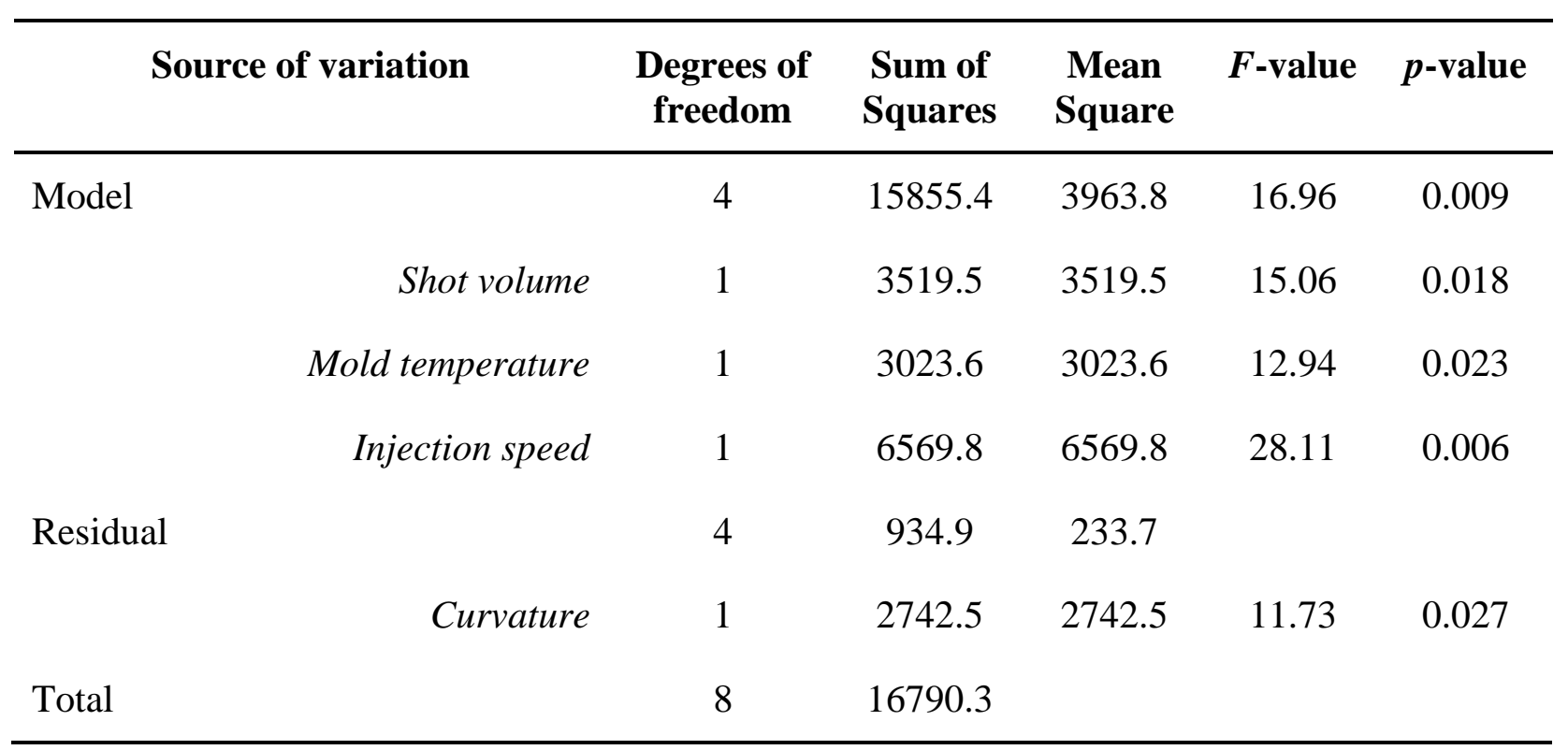


Table B.5. Analysis of variance for $C D I$ MD-B.

\begin{tabular}{|c|c|c|c|c|c|}
\hline Source of variation & $\begin{array}{l}\text { Degrees of } \\
\text { freedom }\end{array}$ & $\begin{array}{c}\text { Sum of } \\
\text { Squares }\end{array}$ & $\begin{array}{c}\text { Mean } \\
\text { Square }\end{array}$ & $F$-value & $p$-value \\
\hline Model & 6 & 0.213548 & 0.035591 & 177.24 & 0.006 \\
\hline Shot volume & 1 & 0.083084 & 0.083084 & 413.74 & 0.002 \\
\hline Mold temperature & 1 & 0.027364 & 0.027364 & 136.26 & 0.007 \\
\hline Injection speed & 1 & 0.054451 & 0.054451 & 271.15 & 0.004 \\
\hline Shot volume*Mold temperature & 1 & 0.006218 & 0.006218 & 30.97 & 0.031 \\
\hline Mold temperature *Injection speed & 1 & 0.010355 & 0.010355 & 51.57 & 0.019 \\
\hline Residual & 2 & 0.000402 & 0.000201 & & \\
\hline Curvature & 1 & 0.032076 & 0.032076 & 159.73 & 0.006 \\
\hline Total & 8 & 0.213950 & & & \\
\hline
\end{tabular}

Table B.6. Analysis of variance for skin thickness TD-B.

\begin{tabular}{|c|c|c|c|c|c|c|}
\hline \multicolumn{2}{|c|}{ Source of variation } & \multirow{2}{*}{$\begin{array}{c}\begin{array}{c}\text { Degrees of } \\
\text { freedom }\end{array} \\
2\end{array}$} & \multirow{2}{*}{$\begin{array}{c}\begin{array}{c}\text { Sum of } \\
\text { Squares }\end{array} \\
0.051358\end{array}$} & \multirow{2}{*}{$\begin{array}{c}\begin{array}{c}\text { Mean } \\
\text { Square }\end{array} \\
0.025679\end{array}$} & \multirow{2}{*}{$\begin{array}{c}\boldsymbol{F} \text {-value } \\
18.09\end{array}$} & \multirow{2}{*}{$\begin{array}{c}\boldsymbol{p} \text {-value } \\
0.003\end{array}$} \\
\hline Model & & & & & & \\
\hline & Shot volume & 1 & 0.035556 & 0.035556 & 25.04 & 0.002 \\
\hline & Injection speed & 1 & 0.015802 & 0.015802 & 11.13 & 0.016 \\
\hline \multirow[t]{3}{*}{ Residual } & & 6 & 0.008519 & 0.001420 & & \\
\hline & Curvature & 1 & 0.002608 & 0.002608 & 2.21 & 0.198 \\
\hline & Lack of Fit & 5 & 0.005910 & 0.001182 & & \\
\hline Total & & 8 & 0.059877 & & & \\
\hline
\end{tabular}


Table B.7. Analysis of variance for cell density TD-B.

\begin{tabular}{|c|c|c|c|c|c|}
\hline Source of variation & \multirow{2}{*}{$\begin{array}{c}\begin{array}{c}\text { Degrees of } \\
\text { freedom }\end{array} \\
3\end{array}$} & \multirow{2}{*}{$\begin{array}{c}\begin{array}{c}\text { Sum of } \\
\text { Squares }\end{array} \\
6.84 \cdot 10^{13}\end{array}$} & \multirow{2}{*}{$\begin{array}{c}\begin{array}{c}\text { Mean } \\
\text { Square }\end{array} \\
2.48 \cdot 10^{13}\end{array}$} & \multirow{2}{*}{$\begin{array}{c}\boldsymbol{F} \text {-value } \\
8.92\end{array}$} & \multirow{2}{*}{$\begin{array}{c}\boldsymbol{p} \text {-value } \\
0.032\end{array}$} \\
\hline Model & & & & & \\
\hline Shot volume & 1 & $1.36 \cdot 10^{13}$ & $1.36 \cdot 10^{13}$ & 4.13 & 0.093 \\
\hline Injection speed & 1 & $3.36 \cdot 10^{13}$ & $3.36 \cdot 10^{13}$ & 12.43 & 0.013 \\
\hline Shot volume*Injection speed & 1 & $2.27 \cdot 10^{13}$ & $2.27 \cdot 10^{13}$ & 7.21 & 0.037 \\
\hline Residual & 5 & $1.13 \cdot 10^{13}$ & $2.03 \cdot 10^{12}$ & & \\
\hline Curvature & 1 & $4.15 \cdot 10^{10}$ & $4.15 \cdot 10^{10}$ & 0.03 & 0.944 \\
\hline Lack of Fit & 4 & $1.21 \cdot 10^{13}$ & $3.05 \cdot 10^{12}$ & & \\
\hline Total & 8 & $7.97 \cdot 10^{13}$ & & & \\
\hline
\end{tabular}

Table B.8. Analysis of variance for maximum cell size TD-B.

\begin{tabular}{|c|c|c|c|c|c|}
\hline Source of variation & \multirow{2}{*}{$\begin{array}{c}\begin{array}{c}\text { Degrees of } \\
\text { freedom }\end{array} \\
4\end{array}$} & \multirow{2}{*}{$\begin{array}{c}\begin{array}{c}\text { Sum of } \\
\text { Squares }\end{array} \\
20961.7\end{array}$} & \multirow{2}{*}{$\begin{array}{c}\begin{array}{c}\text { Mean } \\
\text { Square }\end{array} \\
5240.4\end{array}$} & \multirow{2}{*}{$\frac{F \text {-value }}{11.64}$} & \multirow{2}{*}{$\begin{array}{r}\boldsymbol{p} \text {-value } \\
0.018\end{array}$} \\
\hline Model & & & & & \\
\hline Shot volume & 1 & 12680.6 & 12680.6 & 28.17 & 0.006 \\
\hline Mold temperature & 1 & 0.0 & 0.0 & 0.00 & 0.999 \\
\hline Injection speed & 1 & 3845.5 & 3845.5 & 8.54 & 0.043 \\
\hline Residual & 4 & 1800.8 & 450.2 & & \\
\hline Curvature & 1 & 4435.7 & 4435.7 & 9.85 & 0.035 \\
\hline Total & 8 & 22762.5 & & & \\
\hline
\end{tabular}


Table B.9. Analysis of variance for $C D I$ TD-B.

\begin{tabular}{|c|c|c|c|c|c|c|}
\hline \multicolumn{2}{|c|}{ Source of variation } & \multirow{2}{*}{$\begin{array}{c}\begin{array}{c}\text { Degrees of } \\
\text { freedom }\end{array} \\
1\end{array}$} & \multirow{2}{*}{$\begin{array}{c}\begin{array}{c}\text { Sum of } \\
\text { Squares }\end{array} \\
0.18922\end{array}$} & \multirow{2}{*}{$\begin{array}{c}\begin{array}{c}\text { Mean } \\
\text { Square }\end{array} \\
0.189223\end{array}$} & \multirow{2}{*}{$\begin{array}{c}\boldsymbol{F} \text {-value } \\
16.31\end{array}$} & \multirow{2}{*}{$\begin{array}{c}\boldsymbol{p} \text {-value } \\
0.005\end{array}$} \\
\hline Model & & & & & & \\
\hline & Shot volume & 1 & 0.18922 & 0.189223 & 16.31 & 0.005 \\
\hline \multirow[t]{3}{*}{ Residual } & & 7 & 0.08121 & 0.011602 & & \\
\hline & Curvature & 1 & 0.02935 & 0.029348 & 3.40 & 0.115 \\
\hline & Lack of Fit & 6 & 0.05186 & 0.008644 & & \\
\hline Total & & 8 & 0.27044 & & & \\
\hline
\end{tabular}

Table B.10. Analysis of variance for flexural modulus MD-A.

\begin{tabular}{|c|c|c|c|c|c|c|}
\hline \multicolumn{2}{|c|}{ Source of variation } & \multirow{2}{*}{$\begin{array}{c}\begin{array}{c}\text { Degrees of } \\
\text { freedom }\end{array} \\
1\end{array}$} & \multirow{2}{*}{$\begin{array}{c}\begin{array}{c}\text { Sum of } \\
\text { Squares }\end{array} \\
245350\end{array}$} & \multirow{2}{*}{$\begin{array}{c}\begin{array}{c}\text { Mean } \\
\text { Square }\end{array} \\
245350\end{array}$} & \multirow{2}{*}{$\begin{array}{c}\boldsymbol{F} \text {-value } \\
42.70\end{array}$} & \multirow{2}{*}{$\frac{p \text {-value }}{}$} \\
\hline Model & & & & & & \\
\hline & Shot volume & 1 & 245350 & 245350 & 42.70 & 0.000 \\
\hline \multirow[t]{3}{*}{ Residual } & & 7 & 40221 & 5746 & & \\
\hline & Curvature & 1 & 1810 & 1810 & 0.28 & 0.614 \\
\hline & Lack of Fit & 6 & 38411 & 6402 & & \\
\hline Total & & 8 & 285571 & & & \\
\hline
\end{tabular}


Table B.11. Analysis of variance for flexural modulus MD-B.

\begin{tabular}{|c|c|c|c|c|c|c|}
\hline \multicolumn{2}{|c|}{ Source of variation } & \multirow{2}{*}{$\begin{array}{c}\begin{array}{c}\text { Degrees of } \\
\text { freedom }\end{array} \\
2\end{array}$} & \multirow{2}{*}{$\begin{array}{c}\begin{array}{c}\text { Sum of } \\
\text { Squares }\end{array} \\
195281\end{array}$} & \multirow{2}{*}{$\begin{array}{c}\begin{array}{c}\text { Mean } \\
\text { Square }\end{array} \\
97640\end{array}$} & \multirow{2}{*}{$\begin{array}{c}\boldsymbol{F} \text {-value } \\
34.64\end{array}$} & \multirow{2}{*}{$\begin{array}{r}\boldsymbol{p} \text {-value } \\
0.001\end{array}$} \\
\hline Model & & & & & & \\
\hline & Shot volume & 1 & 115681 & 115681 & 41.04 & 0.001 \\
\hline & Injection speed & 1 & 79600 & 79600 & 28.24 & 0.002 \\
\hline \multirow[t]{3}{*}{ Residual } & & 6 & 16911 & 2819 & & \\
\hline & Curvature & 1 & 612 & 612 & 0.19 & 0.683 \\
\hline & Lack of Fit & 5 & 16299 & 3260 & & \\
\hline Total & & 8 & 212192 & & & \\
\hline
\end{tabular}

Table B.12. Analysis of variance for flexural modulus MD-C.

\begin{tabular}{|c|c|c|c|c|c|c|}
\hline \multicolumn{2}{|c|}{ Source of variation } & \multirow{2}{*}{$\begin{array}{c}\text { Degrees of } \\
\text { freedom }\end{array}$} & \multirow{2}{*}{$\begin{array}{c}\begin{array}{c}\text { Sum of } \\
\text { Squares }\end{array} \\
171405\end{array}$} & \multirow{2}{*}{$\begin{array}{c}\begin{array}{c}\text { Mean } \\
\text { Square }\end{array} \\
171405\end{array}$} & \multirow{2}{*}{$\begin{array}{c}\boldsymbol{F} \text {-value } \\
23.77\end{array}$} & \multirow{2}{*}{$\begin{array}{c}\boldsymbol{p} \text {-value } \\
0.002\end{array}$} \\
\hline Model & & & & & & \\
\hline & Shot volume & 1 & 171405 & 171405 & 23.77 & 0.002 \\
\hline \multirow[t]{3}{*}{ Residual } & & 7 & 50474 & 7211 & & \\
\hline & Curvature & 1 & 1 & 1 & 0.00 & 0.993 \\
\hline & Lack of Fit & 6 & 50474 & 8412 & & \\
\hline Total & & 8 & 221880 & & & \\
\hline
\end{tabular}


Table B.13. Analysis of variance for flexural strength MD-A.

\begin{tabular}{|c|c|c|c|c|c|}
\hline Source of variation & \multirow{2}{*}{$\begin{array}{c}\begin{array}{c}\text { Degrees of } \\
\text { freedom }\end{array} \\
4\end{array}$} & \multirow{2}{*}{$\begin{array}{c}\begin{array}{c}\text { Sum of } \\
\text { Squares }\end{array} \\
178.445\end{array}$} & \multirow{2}{*}{$\begin{array}{c}\begin{array}{c}\text { Mean } \\
\text { Square }\end{array} \\
44.611\end{array}$} & \multirow{2}{*}{$\begin{array}{c}\boldsymbol{F} \text {-value } \\
42.25\end{array}$} & \multirow{2}{*}{$\begin{array}{c}\boldsymbol{p} \text {-value } \\
0.002\end{array}$} \\
\hline Model & & & & & \\
\hline Shot volume & 1 & 154.001 & 154.001 & 145.84 & 0.000 \\
\hline Mold temperature & 1 & 1.201 & 1.201 & 1.14 & 0.346 \\
\hline Injection speed & 1 & 13.781 & 13.781 & 13.05 & 0.023 \\
\hline Mold temperature *Injection speed & 1 & 9.461 & 9.461 & 8.96 & 0.040 \\
\hline Residual & 4 & 4.224 & 1.056 & & \\
\hline Curvature & 1 & 2.920 & 2.920 & 6.72 & 0.081 \\
\hline Lack of Fit & 3 & 1.304 & 0.435 & & \\
\hline Total & 8 & 182.669 & & & \\
\hline
\end{tabular}

Table B.14. Analysis of variance for flexural strength MD-B.

\begin{tabular}{|c|c|c|c|c|c|c|}
\hline \multicolumn{2}{|c|}{ Source of variation } & \multirow{2}{*}{$\begin{array}{c}\begin{array}{c}\text { Degrees of } \\
\text { freedom }\end{array} \\
2\end{array}$} & \multirow{2}{*}{$\begin{array}{c}\begin{array}{c}\text { Sum of } \\
\text { Squares }\end{array} \\
104.570\end{array}$} & \multirow{2}{*}{$\begin{array}{c}\begin{array}{c}\text { Mean } \\
\text { Square }\end{array} \\
52.2850\end{array}$} & \multirow{2}{*}{$\begin{array}{c}\boldsymbol{F} \text {-value } \\
77.16\end{array}$} & \multirow{2}{*}{$\begin{array}{c}\boldsymbol{p} \text {-value } \\
0.000\end{array}$} \\
\hline Model & & & & & & \\
\hline & Shot volume & 1 & 68.445 & 68.4450 & 101.01 & 0.000 \\
\hline & Injection speed & 1 & 36.125 & 36.1250 & 53.31 & 0.000 \\
\hline \multirow[t]{3}{*}{ Residual } & & 6 & 4.066 & 0.6776 & & \\
\hline & Curvature & 1 & 0.161 & 0.1606 & 0.21 & 0.669 \\
\hline & Lack of Fit & 5 & 3.905 & 0.7810 & & \\
\hline Total & & 8 & 108.636 & & & \\
\hline
\end{tabular}


Table B.15. Analysis of variance for flexural strength MD-C.

\begin{tabular}{|c|c|c|c|c|c|c|}
\hline \multicolumn{2}{|c|}{ Source of variation } & \multirow{2}{*}{$\begin{array}{c}\begin{array}{c}\text { Degrees of } \\
\text { freedom }\end{array} \\
1\end{array}$} & \multirow{2}{*}{$\begin{array}{c}\begin{array}{c}\text { Sum of } \\
\text { Squares }\end{array} \\
114.005\end{array}$} & \multirow{2}{*}{$\begin{array}{c}\begin{array}{c}\text { Mean } \\
\text { Square }\end{array} \\
114.005\end{array}$} & \multirow{2}{*}{$\begin{array}{c}\boldsymbol{F} \text {-value } \\
28.14\end{array}$} & \multirow{2}{*}{$\begin{array}{r}\boldsymbol{p} \text {-value } \\
0.001\end{array}$} \\
\hline Model & & & & & & \\
\hline & Shot volume & 1 & 114.005 & 114.005 & 28.14 & 0.001 \\
\hline \multirow[t]{3}{*}{ Residual } & & 7 & 28.355 & 4.051 & & \\
\hline & Curvature & 1 & 1.125 & 1.125 & 0.25 & 0.636 \\
\hline & Lack of Fit & 6 & 27.230 & 4.538 & & \\
\hline Total & & 8 & 142.360 & & & \\
\hline
\end{tabular}

Table B.16. Analysis of variance for flexural modulus TD-A.

\begin{tabular}{lcccccc}
\hline \multicolumn{1}{c}{ Source of variation } & $\begin{array}{c}\text { Degrees of } \\
\text { freedom }\end{array}$ & $\begin{array}{c}\text { Sum of } \\
\text { Squares }\end{array}$ & $\begin{array}{c}\text { Mean } \\
\text { Square }\end{array}$ & F-value & $\boldsymbol{p}$-value \\
\hline Model & 1 & 376278 & 376278 & 195.48 & 0.000 \\
& Shot volume & 1 & 376278 & 376278 & 195.48 & 0.000 \\
Residual & & 7 & 13474 & 1925 & & \\
& Curvature & 1 & 475 & 475 & 0.22 & 0.656 \\
& Lack of Fit & 6 & 12999 & 2166 & & \\
Total & & 8 & 389752 & & & \\
\hline
\end{tabular}


Table B.17. Analysis of variance for flexural modulus TD-B.

\begin{tabular}{|c|c|c|c|c|c|c|}
\hline \multicolumn{2}{|c|}{ Source of variation } & \multirow{2}{*}{$\begin{array}{c}\text { Degrees of } \\
\text { freedom }\end{array}$} & \multirow{2}{*}{$\begin{array}{c}\begin{array}{c}\text { Sum of } \\
\text { Squares }\end{array} \\
210925\end{array}$} & \multirow{2}{*}{$\begin{array}{c}\begin{array}{c}\text { Mean } \\
\text { Square }\end{array} \\
210925\end{array}$} & \multirow{2}{*}{$\begin{array}{c}\boldsymbol{F} \text {-value } \\
72.67\end{array}$} & \multirow{2}{*}{$\begin{array}{r}\boldsymbol{p} \text {-value } \\
0.000\end{array}$} \\
\hline Model & & & & & & \\
\hline & Shot volume & 1 & 210925 & 210925 & 72.67 & 0.000 \\
\hline \multirow[t]{3}{*}{ Residual } & & 7 & 20319 & 2903 & & \\
\hline & Curvature & 1 & 10878 & 10878 & 6.91 & 0.039 \\
\hline & Lack of Fit & 6 & 9441 & 1573 & & \\
\hline Total & & 8 & 231244 & & & \\
\hline
\end{tabular}

Table B.18. Analysis of variance for flexural modulus TD-C.

\begin{tabular}{|c|c|c|c|c|c|c|}
\hline \multicolumn{2}{|c|}{ Source of variation } & \multirow{2}{*}{$\begin{array}{c}\text { Degrees of } \\
\text { freedom }\end{array}$} & \multirow{2}{*}{$\begin{array}{c}\begin{array}{c}\text { Sum of } \\
\text { Squares }\end{array} \\
331705\end{array}$} & \multirow{2}{*}{$\begin{array}{c}\begin{array}{c}\text { Mean } \\
\text { Square }\end{array} \\
331705\end{array}$} & \multirow{2}{*}{$\begin{array}{c}\boldsymbol{F} \text {-value } \\
120.43\end{array}$} & \multirow{2}{*}{$\begin{array}{c}\boldsymbol{p} \text {-value } \\
0.000\end{array}$} \\
\hline Model & & & & & & \\
\hline & Shot volume & 1 & 331705 & 331705 & 120.43 & 0.000 \\
\hline \multirow[t]{3}{*}{ Residual } & & 7 & 19280 & 2754 & & \\
\hline & Curvature & 1 & 584 & 584 & 0.19 & 0.680 \\
\hline & Lack of Fit & 6 & 18697 & 3116 & & \\
\hline Total & & 8 & 350986 & & & \\
\hline
\end{tabular}


Table B.19. Analysis of variance for flexural strength TD-A.

\begin{tabular}{|c|c|c|c|c|c|}
\hline Source of variation & \multirow{2}{*}{$\begin{array}{c}\begin{array}{c}\text { Degrees of } \\
\text { freedom }\end{array} \\
4\end{array}$} & \multirow{2}{*}{$\begin{array}{c}\begin{array}{c}\text { Sum of } \\
\text { Squares }\end{array} \\
423.455\end{array}$} & \multirow{2}{*}{$\begin{array}{c}\begin{array}{c}\text { Mean } \\
\text { Square }\end{array} \\
105.864\end{array}$} & \multirow{2}{*}{$\begin{array}{c}\boldsymbol{F} \text {-value } \\
80.39\end{array}$} & \multirow{2}{*}{$\begin{array}{r}\boldsymbol{p} \text {-value } \\
0.000\end{array}$} \\
\hline Model & & & & & \\
\hline Shot volume & 1 & 407.551 & 407.551 & 309.50 & 0.000 \\
\hline Mold temperature & 1 & 2.101 & 2.101 & 1.60 & 0.275 \\
\hline Injection speed & 1 & 1.051 & 1.051 & 0.80 & 0.422 \\
\hline Mold temperature*Injection speed & 1 & 12.751 & 12.751 & 9.68 & 0.036 \\
\hline Residual & 4 & 5.267 & 1.317 & & \\
\hline Curvature & 1 & 0.003 & 0.003 & 0.00 & 0.967 \\
\hline Lack of Fit & 3 & 5.264 & 1.755 & & \\
\hline Total & 8 & 428.722 & & & \\
\hline
\end{tabular}

Table B.20. Analysis of variance for flexural strength TD-B.

\begin{tabular}{|c|c|c|c|c|c|c|}
\hline \multicolumn{2}{|c|}{ Source of variation } & \multirow{2}{*}{$\begin{array}{c}\begin{array}{c}\text { Degrees of } \\
\text { freedom }\end{array} \\
1\end{array}$} & \multirow{2}{*}{$\begin{array}{c}\begin{array}{c}\text { Sum of } \\
\text { Squares }\end{array} \\
192.080\end{array}$} & \multirow{2}{*}{$\begin{array}{c}\begin{array}{c}\text { Mean } \\
\text { Square }\end{array} \\
192.080\end{array}$} & \multirow{2}{*}{$\begin{array}{c}\boldsymbol{F} \text {-value } \\
74.37\end{array}$} & \multirow{2}{*}{$\frac{p \text {-value }}{}$} \\
\hline Model & & & & & & \\
\hline & Shot volume & 1 & 192.080 & 192.080 & 74.37 & 0.000 \\
\hline \multirow[t]{3}{*}{ Residual } & & 7 & 18.080 & 2.583 & & \\
\hline & Curvature & 1 & 0.720 & 0.720 & 0.25 & 0.636 \\
\hline & Lack of Fit & 6 & 17.360 & 2.893 & & \\
\hline Total & & 8 & 210.160 & & & \\
\hline
\end{tabular}


Table B.21. Analysis of variance for flexural strength TD-C.

\begin{tabular}{|c|c|c|c|c|c|c|}
\hline \multicolumn{2}{|c|}{ Source of variation } & \multirow{2}{*}{$\begin{array}{c}\begin{array}{c}\text { Degrees of } \\
\text { freedom }\end{array} \\
2\end{array}$} & \multirow{2}{*}{$\begin{array}{c}\begin{array}{c}\text { Sum of } \\
\text { Squares }\end{array} \\
261.945\end{array}$} & \multirow{2}{*}{$\begin{array}{c}\begin{array}{c}\text { Mean } \\
\text { Square }\end{array} \\
130.973\end{array}$} & \multirow{2}{*}{$\begin{array}{c}\boldsymbol{F} \text {-value } \\
203.38\end{array}$} & \multirow{2}{*}{$\frac{p \text {-value }}{0.000}$} \\
\hline Model & & & & & & \\
\hline & Shot volume & 1 & 253.125 & 253.125 & 393.06 & 0.000 \\
\hline & Mold temperature & 1 & 8.820 & 8.820 & 13.70 & 0.010 \\
\hline \multirow[t]{3}{*}{ Residual } & & 6 & 3.864 & 0.644 & & \\
\hline & Curvature & 1 & 0.269 & 0.269 & 0.37 & 0.568 \\
\hline & Lack of Fit & 5 & 3.595 & 0.719 & & \\
\hline Total & & 8 & 265.809 & & & \\
\hline
\end{tabular}




\section{Appendix C: \\ List of publications}

\section{C.1. Publications in journals}

Influence of injection molding parameters on the morphology and mechanical properties of ABS foams

JOURNAL OF

celutuarPLASTICS

Original Article

Corresponding Author:

Javier Gómez-Monterde, Centre Catala del Plastic, Universitat Politécnica de Catalunya

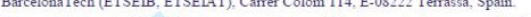
Centro Técnico de SEAT SA, Autoria A-2, lm 585. Apartado de correos 91, E-08760 Email ;avier gomez Q Qupcedu

Influence of injection molding parameters on the morphology and mechanical properties of ABS foams

Javier Gómez-Monterde ${ }^{1.2}$, Manfred Schulte ${ }^{2}$, Stefan Ilijevic ${ }^{2}$, Jörg Hain $^{3}$, Wilco MH Verbeeten ${ }^{4}$ Orlando O Santana ${ }^{1}$, Miguel Sánchez Soto $^{1}$, Maria Lluisa Maspoch

${ }^{1}$ Centre Català del Plastic, Universitat Politécnica de Catalunya-BarcelonaTech (ETSEIB ETSELAT), Terrassa, Spain.

"Centro Tecnico de SEAT SA, Martorell, Spail

${ }^{3}$ Vollkswagen AG, Wolfsburz, Germany:

${ }^{4}$ Structural Integrity Research Group, University of Burgos, Burgos, Spain.
- Journal: Journal of Cellular Plastics.

- Authors: J. Gómez-Monterde, M. Schulte, S. Ilijevic, J. Hain, W.M.H. Verbeeten, O.O. Santana, M. Sánchez-Soto and M. Ll. Maspoch.

- Status: Under review.

- Print ISSN: 0021-955X.

- Online ISSN: 1530-7999. 


\section{Effect of microcellular foaming on the fracture behavior of ABS polymer}

\section{Applied Polymer}
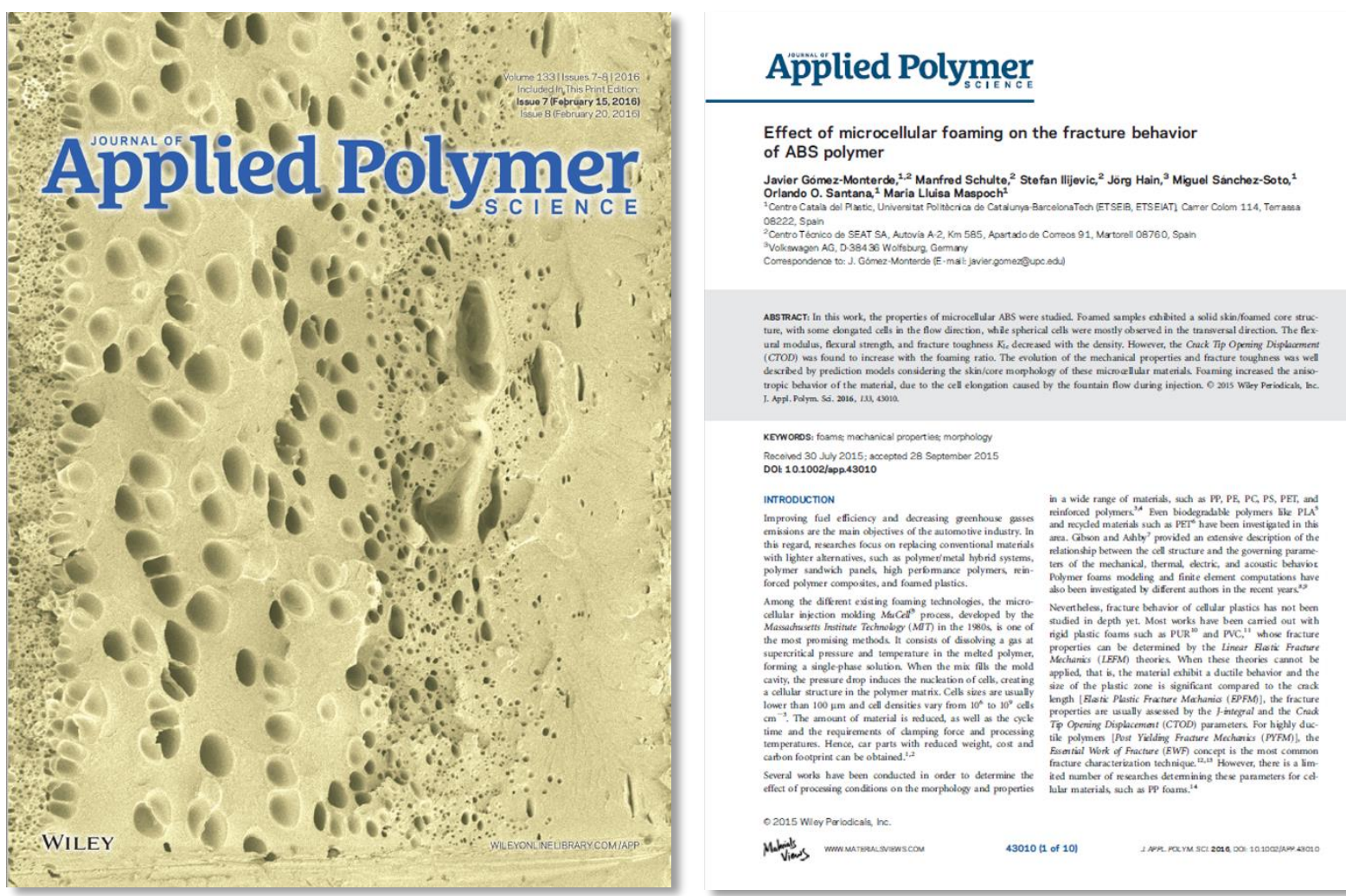

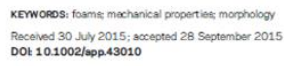

INTRODUCTion
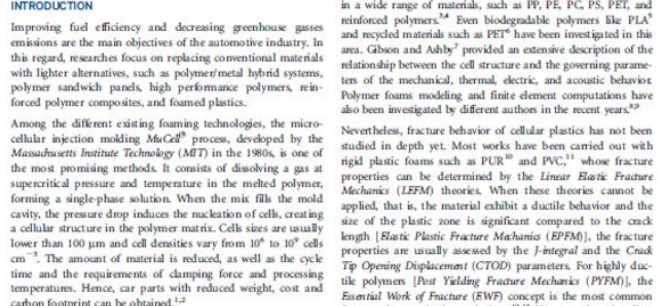

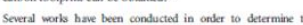
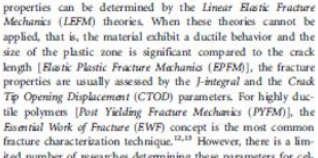

02015 Whay Periodicale he

Mutions $43010(1$ of 10$)$

- Journal: Journal of Applied Polymer Science.

- Authors: J. Gómez-Monterde, M. Schulte, S. Ilijevic, J. Hain, M. Sánchez-Soto, O.O. Santana and M. Ll. Maspoch.

- Year: 2016.

- Volume: 133.

- Issue: 7.

- Pages: 43010-43019.

- DOI: 10.1002/app.43010.

- ISSN: 1097-4628. 


\section{Morphology and mechanical characterization of ABS foamed by microcellular}

\section{injection molding}

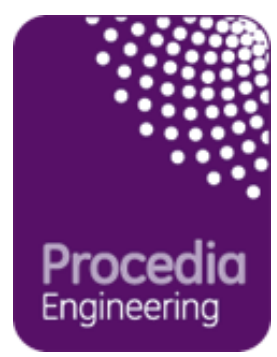

- Journal: Procedia Engineering.

- Authors: J. Gómez-Monterde, M. Schulte, S. Ilijevic, J. Hain, D. Arencón, M. Sánchez-Soto and M. Ll. Maspoch.

- Year: 2015.

- Volume: 132.

- Pages: 15-22.

- DOI: 10.1016/j.proeng.2015.12.462.

- ISSN: 1877-7058.

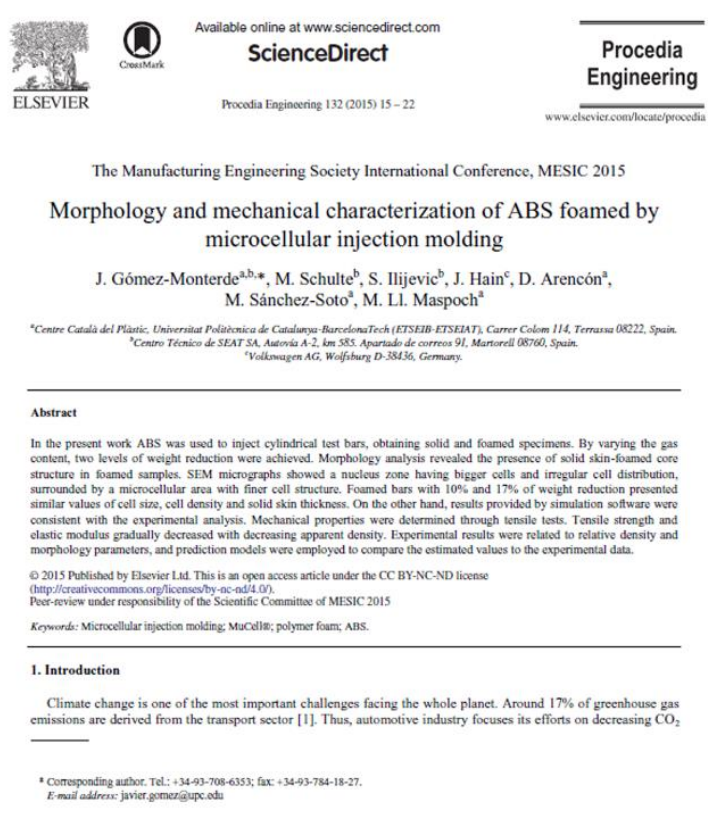




\title{
C.2. Publications derived from conferences
}

\section{Análisis morfológico y del comportamiento a fractura de polipropileno}

\author{
espumado
}
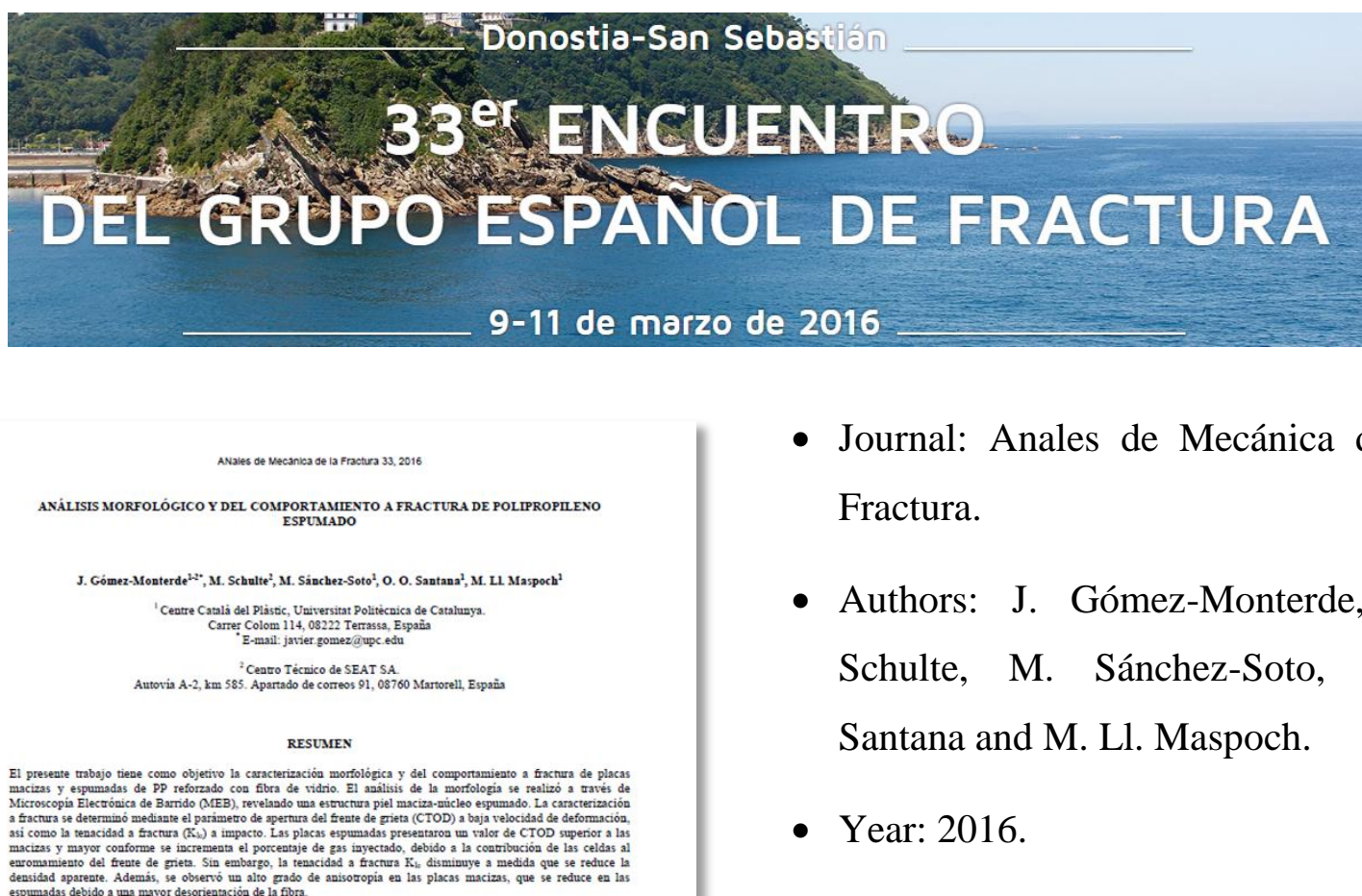

PALABRAS CLAVE: Polipropileno reforzado con fbra de vidrio (PP FV), Moldeo por inyección microcelular, Crack

ABSTRACT

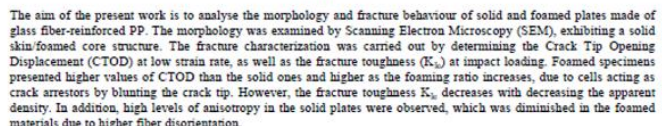

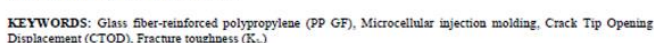

1. NTRoducciós

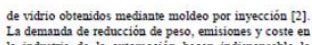

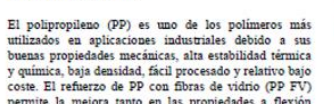

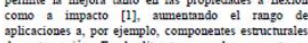

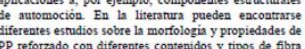

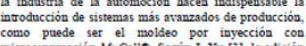

(a)

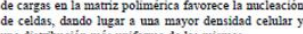

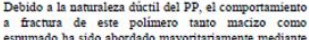

- Journal: Anales de Mecánica de la Fractura.

- Authors: J. Gómez-Monterde, M. Schulte, M. Sánchez-Soto, O.O. Santana and M. Ll. Maspoch.

- Year: 2016.

- Volume: 33.

- Pages: 337-342.

- ISSN: 0213-3727.

- Award for the best paper submitted by a non-doctor investigator 


\section{Efecto de la microespumación de ABS sobre el comportamiento a fractura}

\section{Trigésimo-Segundo Congreso Español de \\ Fractura e Integridad Estructural \\ Encuentro del Grupo Español de Fractura}

\section{CEFIE / 32 GEF}

27-29 de abril de 2015

EFECTO DE LA MICROESPUMACIÓN DE ABS SOBRE EL COMPORTAMIIENTO A FRACTURA

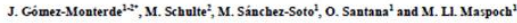

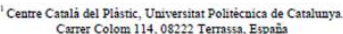

2Ceartro Técuico de Sear SA
Autoria A-2, km 585. Apartado de correos 91, 08760 Marrorell, España

RESUMEN

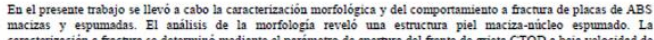

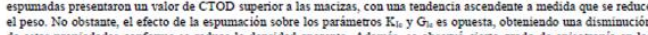

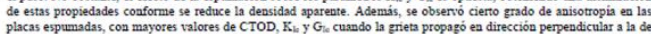
placas espumanas,

ABSTRACT

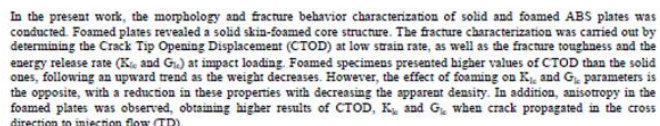

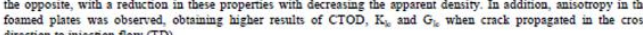

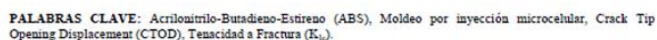

1 ENTRODUCCIÓN
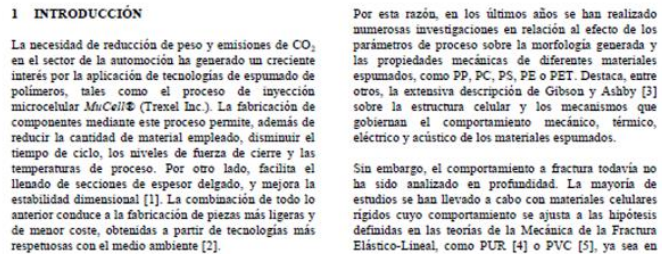

- Journal: Anales de Mecánica de la Fractura.

- Authors: J. Gómez-Monterde, M. Schulte, M. Sánchez-Soto, O.O. Santana and M. Ll. Maspoch.

- Year: 2015.

- Volume: 32.

- Pages: 261-266.

- ISSN: 0213-3727. 


\section{Caracterización del comportamiento a fractura de un polipropileno} copolímero espumado
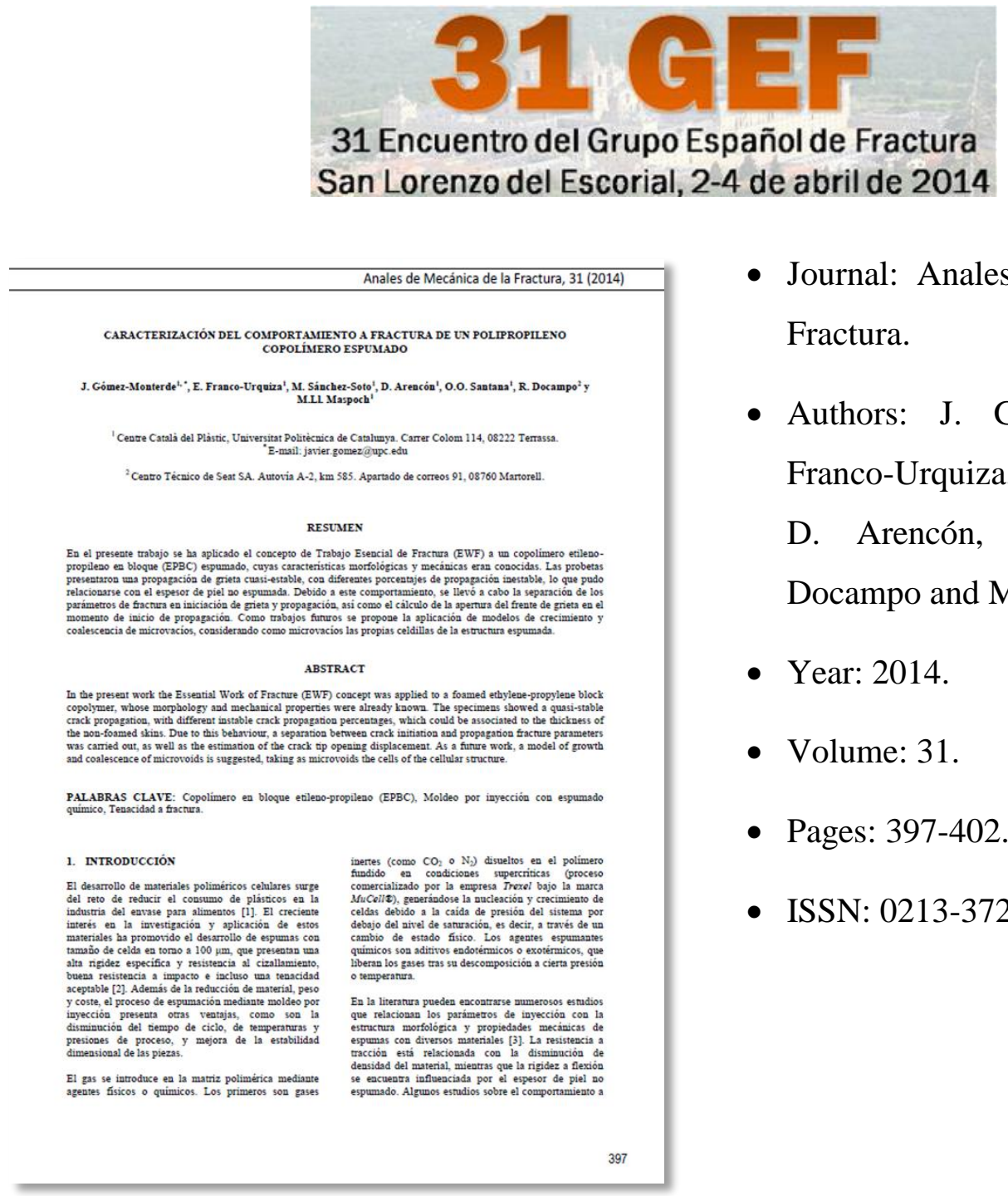

- Journal: Anales de Mecánica de la Fractura.

- Authors: J. Gómez-Monterde, E. Franco-Urquiza, M. Sánchez-Soto, D. Arencón, O.O. Santana, R. Docampo and M. Ll. Maspoch.

- Year: 2014.

- Volume: 31.

- Pages: 397-402.

- ISSN: 0213-3727. 


\section{C.3. Conferences}

Caracterización morfológica y mecánica de polipropileno microespumado y reforzado con fibra de vidrio
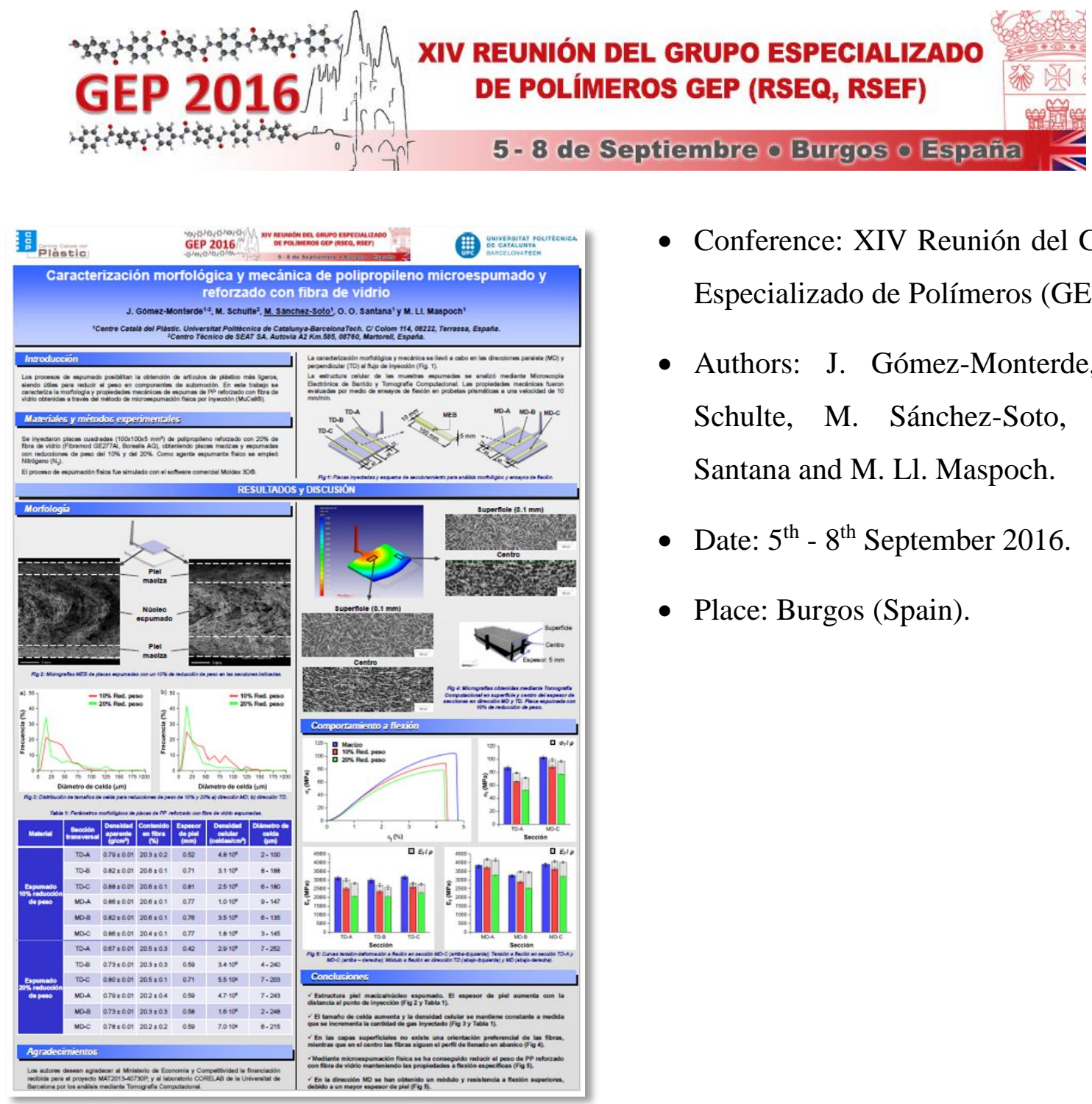

- Conference: XIV Reunión del Grupo Especializado de Polímeros (GEP).

- Authors: J. Gómez-Monterde, M. Schulte, M. Sánchez-Soto, O.O. Santana and M. Ll. Maspoch.

- Date: $5^{\text {th }}-8^{\text {th }}$ September 2016.

- Place: Burgos (Spain). 


\section{Morphology and mechanical characterization of ABS foamed by microcellular} injection molding

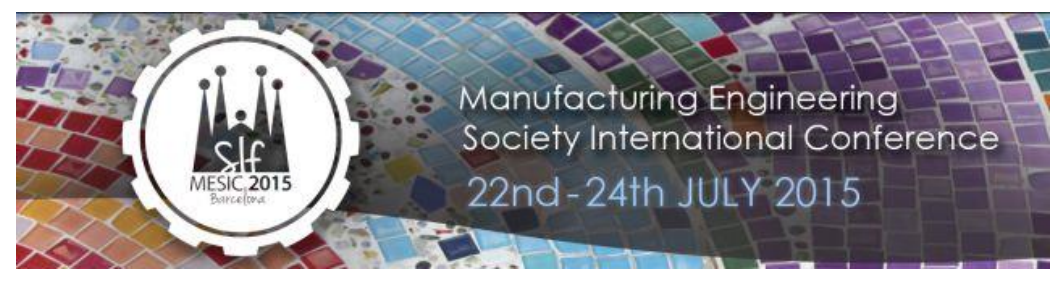

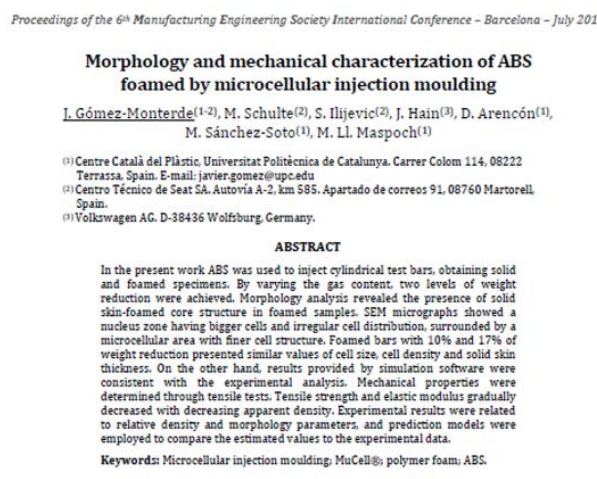

1. Introduction

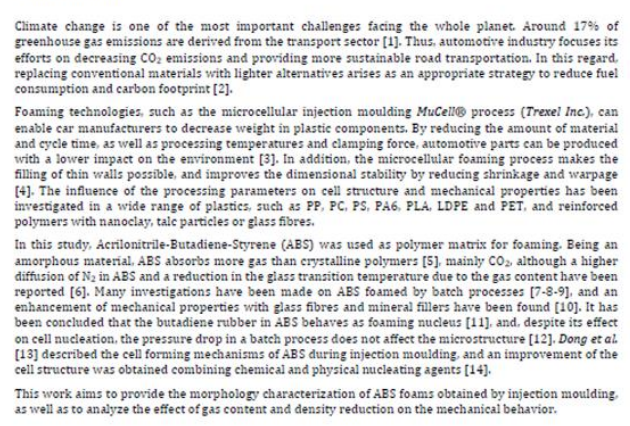

- Conference: $6^{\text {th }} \quad$ Manufacturing Engineering Society International Conference (MESIC).

- Authors: J. Gómez-Monterde, M. Schulte, S. Ilijevic, J. Hain, D. Arencón, M. Sánchez-Soto and M. Ll. Maspoch.

- Date: $22^{\text {nd }}-24^{\text {th }}$ July 2015 .

- Place: Barcelona (Spain). 